\title{
On-DNA Decarboxylative Arylation: Merging Photoredox with Nickel Catalysis in Water
}

Dominik K. Kölmel ${ }^{\star \dagger}$, Jiang Meng ${ }^{\ddagger}$, Mei-Hsuan Tsai ${ }^{\ddagger}$, Jiamin Que ${ }^{\ddagger}$, Richard P. Loach ${ }^{\dagger}$, Thomas Knauber ${ }^{\dagger}$, Jinqiao Wan ${ }^{\ddagger}$, and Mark E. Flanagan*†

†Pfizer Worldwide Research and Development, Groton, Connecticut 06340, United States

†HitGen Inc, Building 6, No. 8, Huigu first East Road, Tianfu International Bio-Town, Shuangliu District, Chengdu City, Sichuan Province, P. R. China 
Table of Contents

1) General Information

2) Synthetic Procedures

3) UPLC Traces

4) Mass Spectra

S104

5) DNA Damage Evaluation

S153 


\section{1) General Information}

All commercial reagents were used as received without further purification. The molecular structure of the DNA headpiece, which was used for the preparation of the DNA-tagged aryl halides, is depicted in Figure S1. Reactions were performed either in Eppend orf Safe-Lock microcentrifuge tubes or in sealed glass vials without stirring. Reaction mixtures were vortexed with a Fisherbrand Mini Vortex Mixer and subsequently centrifuged with a Fisherbrand Mini-Centrifuge (max. speed: 6,000 rpm). A PennOC Photoreactor $\mathrm{m} 1(\lambda=450 \mathrm{~nm})$ was used for all photoredox reactions. During the reaction, the integrated fan was used to keep the light from heating up the reaction mixtures. The light intensity was set to $100 \%$. Alternatively, photoredox reactions were carried out in 96-Well Polystyrene Round Bottom Microwell Plates (Thermo Scientific Nunc, $V=300 \mu \mathrm{L}$ ). The well paltes were placed inside a AtmosBag (Aldrich, size $\mathrm{M}, V=280 \mathrm{~L}$ ) and, after rigorous degassing, sealed with a Platemax Aluminum Sealing Film (Axygen). The well plates were irradiated with a TeleOpto 96-Well LED Array $(\lambda=450 \mathrm{~nm})$. The light intensity was set to maximum volume (13.9 V, LED Array Driver). After the final ethanol precipitation, a Fisherbrand High Speed Mini-Centrifuge (max. speed: 12,500 rpm) was used for centrifugation. UPLC analyses were performed on a Waters Acquity UPLC H-Class Bio System coupled to a Waters Acquity UPLC Tunable Ultraviolet (TUV) detector and a Waters Xevo G2-XS QTof Mass Spectrometer. The separation was performed using a Waters Acquity UPLC Oligonucleotide BEHC18 Column (130 A, 1.7 $\mu \mathrm{m}, 2.1 \times 50 \mathrm{~mm}, \mathrm{P} / \mathrm{N} 186003949$; flow rate $0.2 \mathrm{~mL} / \mathrm{min}$; column temperature $\left.60^{\circ} \mathrm{C}\right)$. Mobile phase $\mathrm{A}$ : $15 \mathrm{mM}$ triethylamine and $400 \mathrm{mM}$ hexafluoroisopropanol in water; mobile phase $\mathrm{B}: 50 \%$ mobile phase $A$ and $50 \%$ methanol. An LC gradient of $40 \%$ B to $95 \%$ B over 5 min was performed with UV detection at $260 \mathrm{~nm}$. MS data was collected from 400-3000 $\mathrm{m} / \mathrm{z}$ (negative mode). The oligonucleotide peaks were observed at their most abundant charge state (3-). Typical injection concentration was $10 \mathrm{nmol} / \mathrm{mL}$ with respect to DNA-derived compounds. Yields are reported as a \% conversion as determined from UPLC analysis by comparing the integrals of all DNA-derived compounds at $260 \mathrm{~nm}$ (low molecular weight impurities, $M<1000 \mathrm{~g} / \mathrm{mol}$, which were not DNA-derived, and impurities from previous reactions were not taken into account).

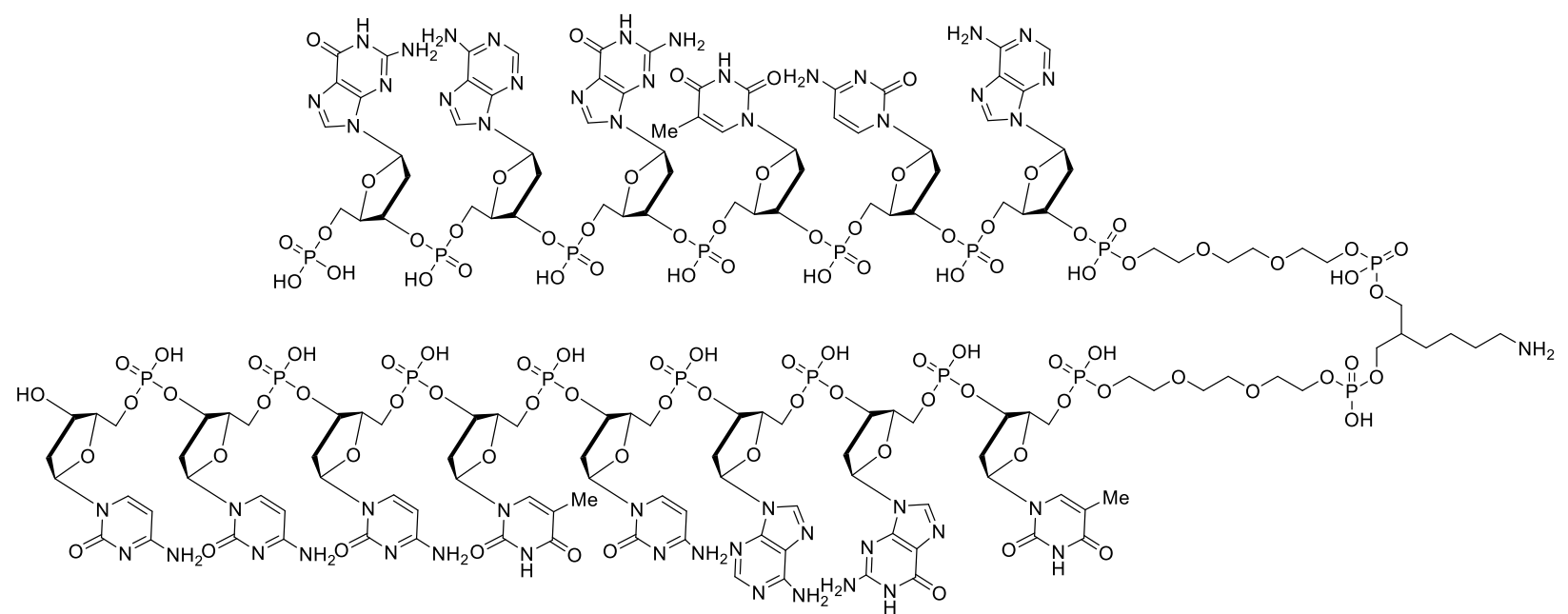

Figure S1. Molecular structure of the DNA headpiece. The DNA duplex consists of six selfcomplementary nucleotide pairs and two 3'-overhang nucleotides which could be used for DNA ligation. The nucleobase sequence is as follows: 5'-GAGTCA-linker-TGACTCCC-3'. 


\section{2) Synthetic Procedures}

General procedure I for the preparation of DNA-tagged aryl halides 12, 14, S1-S5, S9-S11, and S14-S18:

A solution of the respective carboxylic acid $(2.0 \mu \mathrm{mol})$ in DMA $(10 \mu \mathrm{L})$ and 4-(4,6-dimethoxy-1,3,5-triazin2-yl)-4-methylmorpholinium chloride (DMT-MM, $0.6 \mathrm{mg}, 2.0 \mu \mathrm{mol}$ ) in $\mathrm{H}_{2} \mathrm{O}(10 \mu \mathrm{L}$ ) was added to a solution of the DNA headpiece $(0.2 \mathrm{mg}, 40 \mathrm{nmol}$, Figure S1) in sodium borate buffer ( $250 \mathrm{mM}, \mathrm{pH} 9.5,40 \mu \mathrm{L})$. The mixture was vortexed, centrifuged, and allowed to stand at room temperature overnight. Subsequently, a solution of $\mathrm{NaCl}$ in $\mathrm{H}_{2} \mathrm{O}(5 \mathrm{M}, 6 \mu \mathrm{L})$ was added, followed by the addition of cold $\mathrm{EtOH}$ $(400 \mu \mathrm{L})$. The mixture was kept at $-20^{\circ} \mathrm{C}$ for $20 \mathrm{~min}$ and then centrifuged at 10,000 rpm for $2 \mathrm{~min}$. The supernatant was discarded and the DNA pellet was re-dissolved in $\mathrm{H}_{2} \mathrm{O}(34 \mu \mathrm{L})$. The triazine-containing side product, which forms alongside the intended productduring the previous acylation step, was cleaved by adding piperidine $(6 \mu \mathrm{L})$ to the solution. The mixture was kept at room temperature for $1 \mathrm{~h}$. Subsequently, a solution of $\mathrm{NaCl}$ in $\mathrm{H}_{2} \mathrm{O}(5 \mathrm{M}, 6 \mu \mathrm{L})$ was added, followed by the addition of cold $\mathrm{EtOH}$ $(400 \mu \mathrm{L})$. The mixture was kept at $-20^{\circ} \mathrm{C}$ for $20 \mathrm{~min}$ and then centrifuged at $10,000 \mathrm{rpm}$ for $2 \mathrm{~min}$. The supernatant was discarded and the DNA pellet was re-dissolved in $\mathrm{H}_{2} \mathrm{O}(40 \mu \mathrm{L})$. The precipitation was repeated two more times to remove residual amine base. An aliquot $(1 \mu \mathrm{L})$ was taken, diluted with $\mathrm{H}_{2} \mathrm{O}$ $(100 \mu \mathrm{L})$ and analyzed via UPLC. The title compounds were used for the following reactions without further purification.

\section{General procedure II for the preparation of DNA-tagged aryl halides S6-S8 and S19-S21:}

A solution of the respective carboxylic acid $(2.0 \mu \mathrm{mol})$ in DMA $(5 \mu \mathrm{L})$ and DIPEA $(0.3 \mu \mathrm{L}, 2.0 \mu \mathrm{mol})$ in DMA $(5 \mu \mathrm{L})$ was added to a solution of HATU $(0.8 \mathrm{mg}, 2.0 \mu \mathrm{mol})$ in DMA $(10 \mu \mathrm{L})$ and the mixture was allowed to stand at room temperature for $10 \mathrm{~min}$. Subsequenlty, this solution was added to a solution of the DNA headpiece $(0.2 \mathrm{mg}, 40 \mathrm{nmol}$, Figure S1) in sodium borate buffer (250 mM, pH 9.5, $40 \mu \mathrm{L})$. The mixture was vortexed, centrifuged, and allowed to stand at room temperature overnight. Subsequently, a solution of $\mathrm{NaCl}$ in $\mathrm{H}_{2} \mathrm{O}(5 \mathrm{M}, 6 \mu \mathrm{L})$ was added, followed by the addition of cold $\mathrm{EtOH}(400 \mu \mathrm{L})$. The mixture was kept at $-20^{\circ} \mathrm{C}$ for $20 \mathrm{~min}$ and then centrifuged at 10,000 rpm for $2 \mathrm{~min}$. The supernatant was discarded and the DNA pellet was re-dissolved in $\mathrm{H}_{2} \mathrm{O}(40 \mu \mathrm{L})$. The precipitation was repeated two more times. An aliquot $(1 \mu \mathrm{L})$ was taken, diluted with $\mathrm{H}_{2} \mathrm{O}(100 \mu \mathrm{L})$ and analyzed via UPLC. The title compounds were used for the following reactions without further purification.

\section{Synthesis of DNA-tagged aryl iodide 12:}

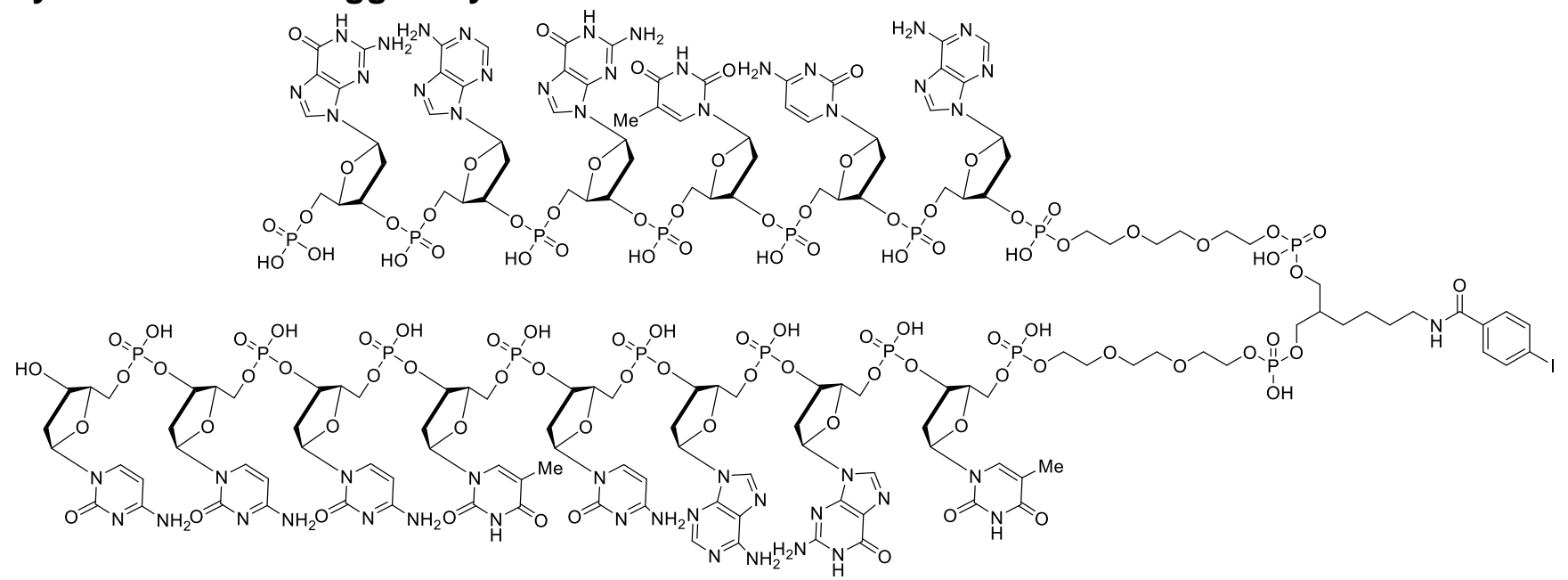

The title compound was synthesized according to the general procedure I from 4-iodobenzoic acid $(0.5 \mathrm{mg}, 2.0 \mu \mathrm{mol})$. The intended product was formed in quantitative yield.

$m / z=1721.2[\mathrm{M}-3 \mathrm{H}]^{3-}$ 


\section{Synthesis of DNA-tagged aryl bromide 14:}

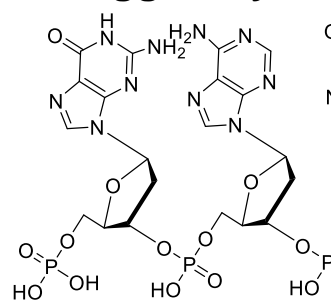<smiles></smiles><smiles>Cn1cnc2c(N)ncnc21</smiles><smiles>CCOCCOP(C)OCCOCCOC</smiles>

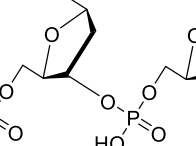<smiles>COC(=O)C1CC2CCCCC2C1</smiles>

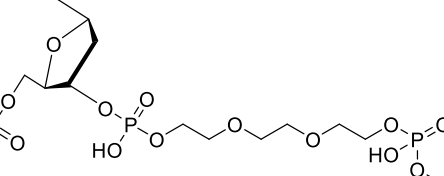

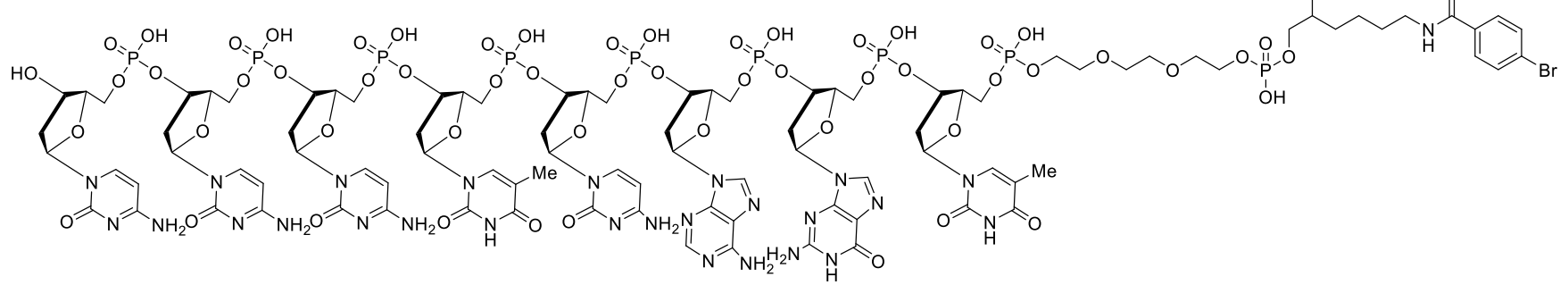

The title compound was synthesized according to the general procedure I from 4-bromobenzoic acid $(0.4 \mathrm{mg}, 2.0 \mu \mathrm{mol})$. The intended product was formed in quantitative yield.

$m / z=1705.6[\mathrm{M}-3 \mathrm{H}]^{3-}$

\section{Synthe sis of DNA-tagged aryl iodide S1:}
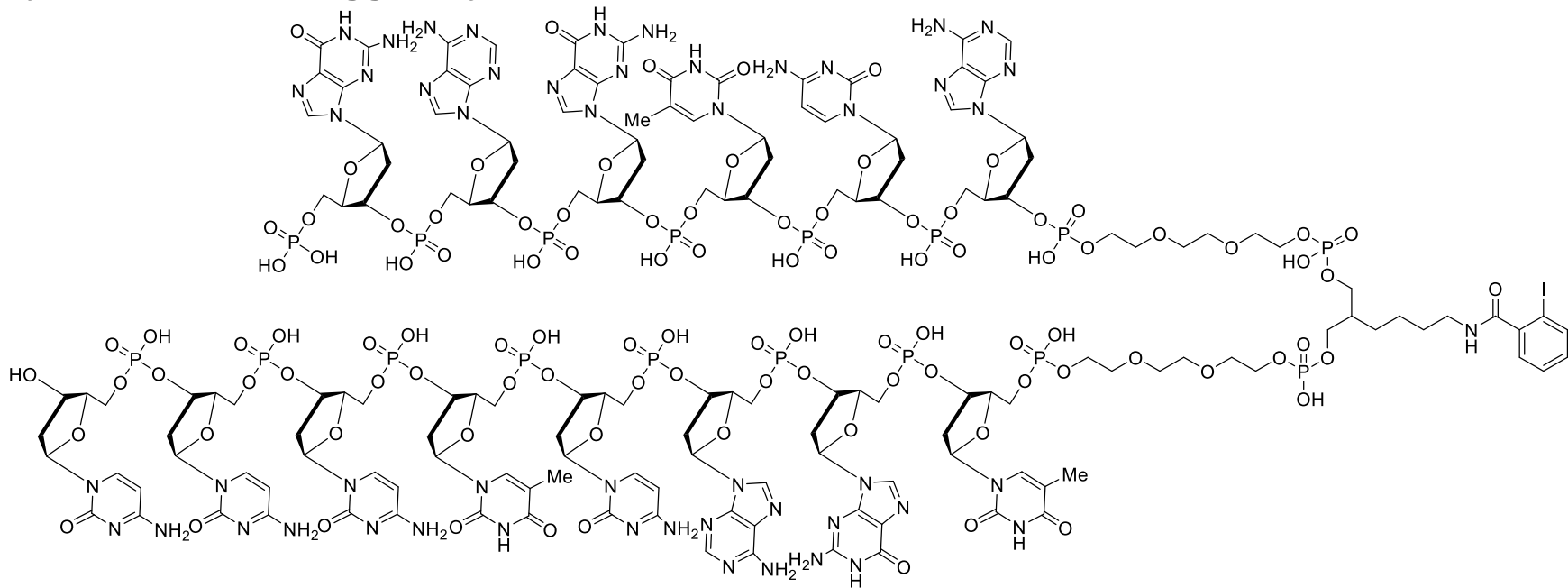

The title compound was synthesized according to the general procedure I from 2-iodobenzoic acid $(0.5 \mathrm{mg}, 2.0 \mu \mathrm{mol})$. The intended product was formed in 95\% yield.

$m / z=1720.9[\mathrm{M}-3 \mathrm{H}]^{3-}$ 


\section{Synthesis of DNA-tagged aryl iodide S2:}
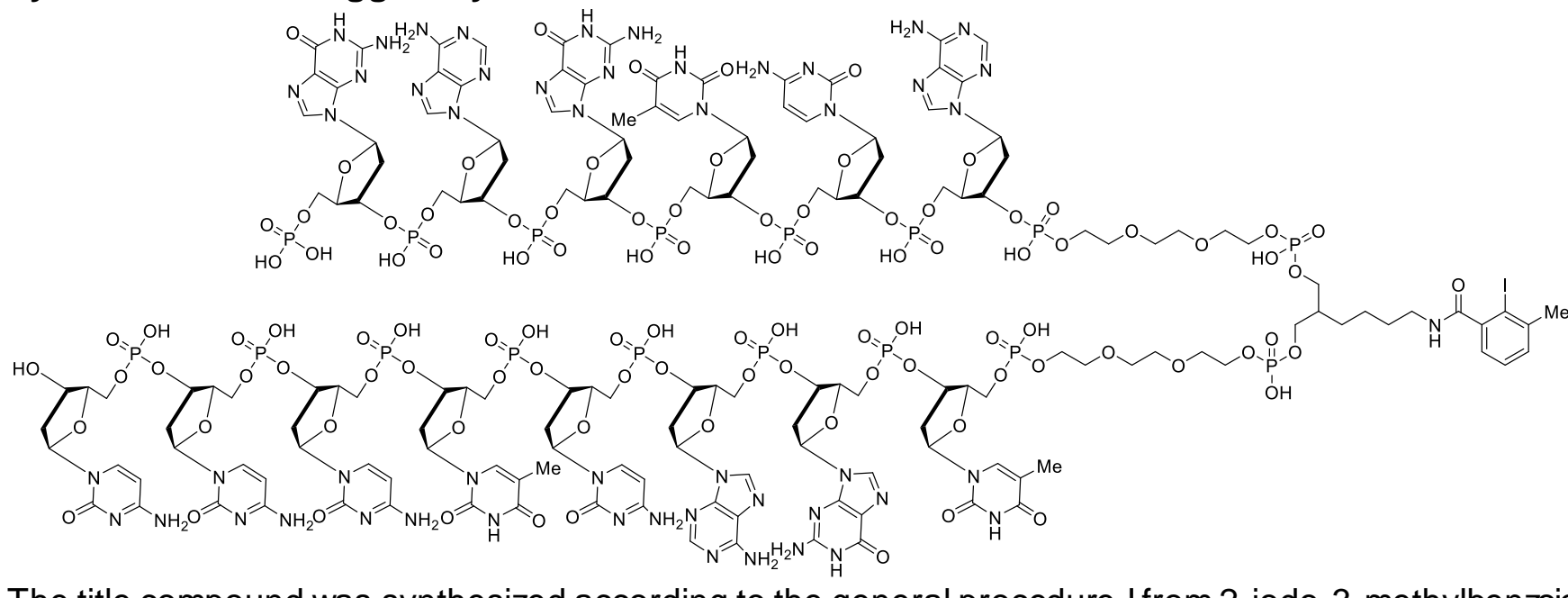

The title compound was synthesized according to the general procedure I from 2-iodo-3-methylbenzoic acid $(0.5 \mathrm{mg}, 2.0 \mu \mathrm{mol})$. The intended product was formed in $93 \%$ yield.

$m / z=1725.9[\mathrm{M}-3 \mathrm{H}]^{3-}$

\section{Synthesis of DNA-tagged aryl iodide S3:}

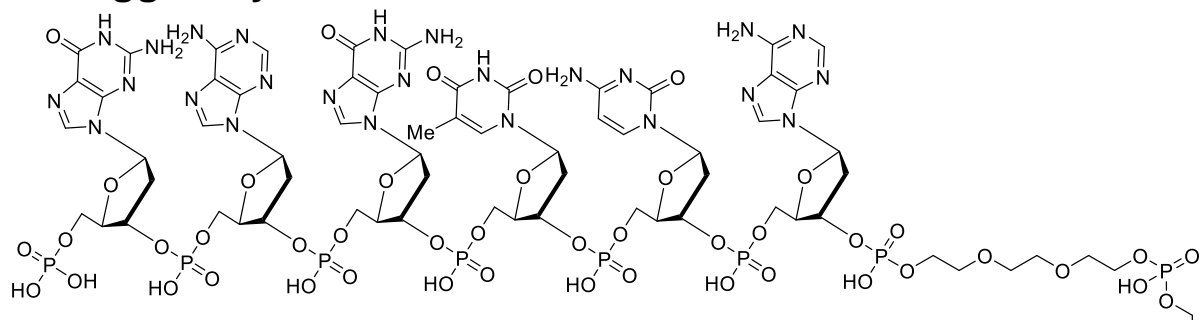<smiles>Cn1cnc2c(N)ncnc21</smiles>

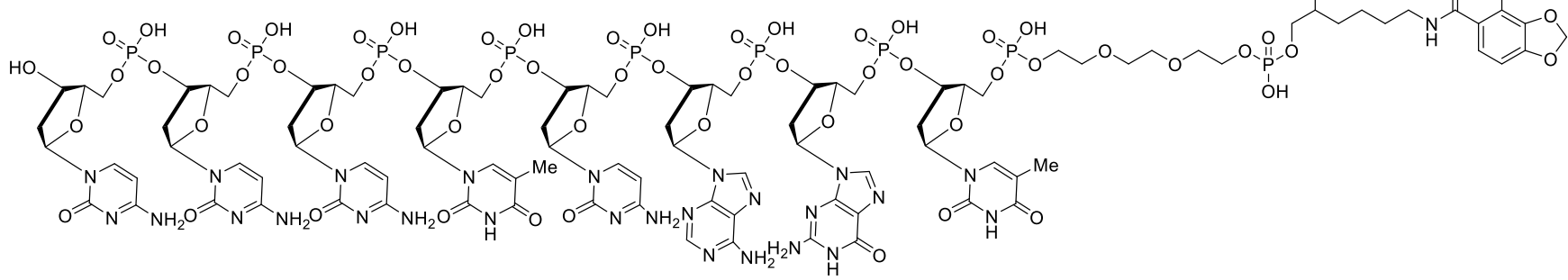

The title compound was synthesized according to the general procedure I from 4iodobenzo[ $d][1,3]$ dioxole-5-carboxylic acid $(0.6 \mathrm{mg}, 2.0 \mu \mathrm{mol})$. The intended product was formed in $83 \%$ yield.

$m / z=1735.9[\mathrm{M}-3 \mathrm{H}]^{3-}$ 


\section{Synthesis of DNA-tagged aryl iodide S4:}
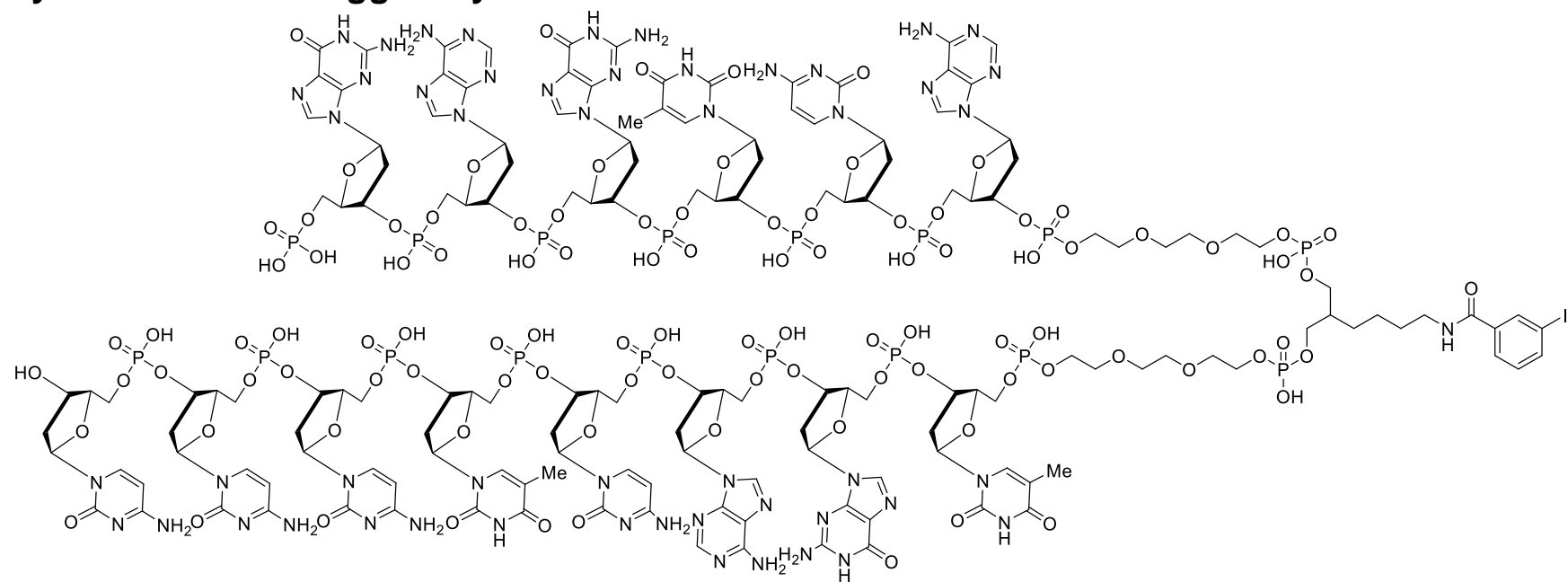

The title compound was synthesized according to the general procedure I from 3-iodobenzoic acid $(0.5 \mathrm{mg}, 2.0 \mu \mathrm{mol})$. The intended product was formed in quantitative yield.

$m / z=1720.9[\mathrm{M}-3 \mathrm{H}]^{3-}$

\section{Synthesis of DNA-tagged aryl iodide S5:}
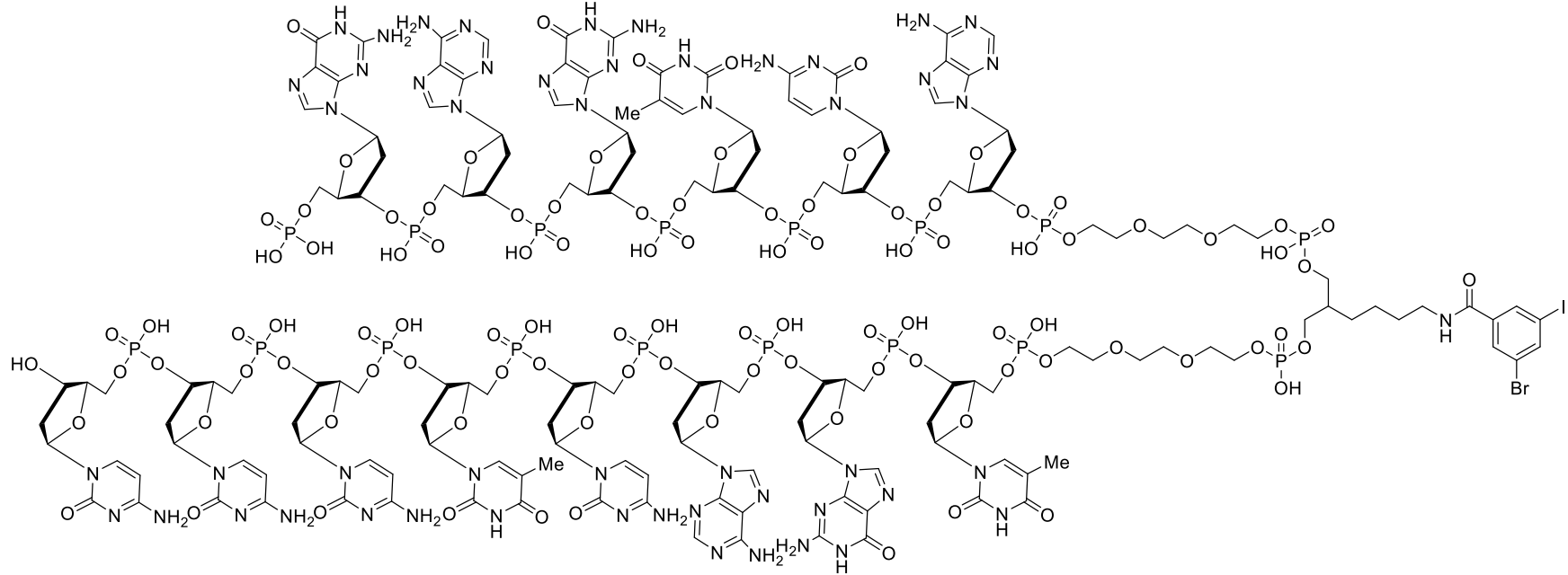

The title compound was synthesized according to the general procedure I from 5-bromo-3-iodobenzoic acid $(0.7 \mathrm{mg}, 2.0 \mu \mathrm{mol})$. The intended product was formed in $93 \%$ yield.

$m / z=1747.5[\mathrm{M}-3 \mathrm{H}]^{3-}$ 


\section{Synthesis of DNA-tagged aryl iodide S6:}
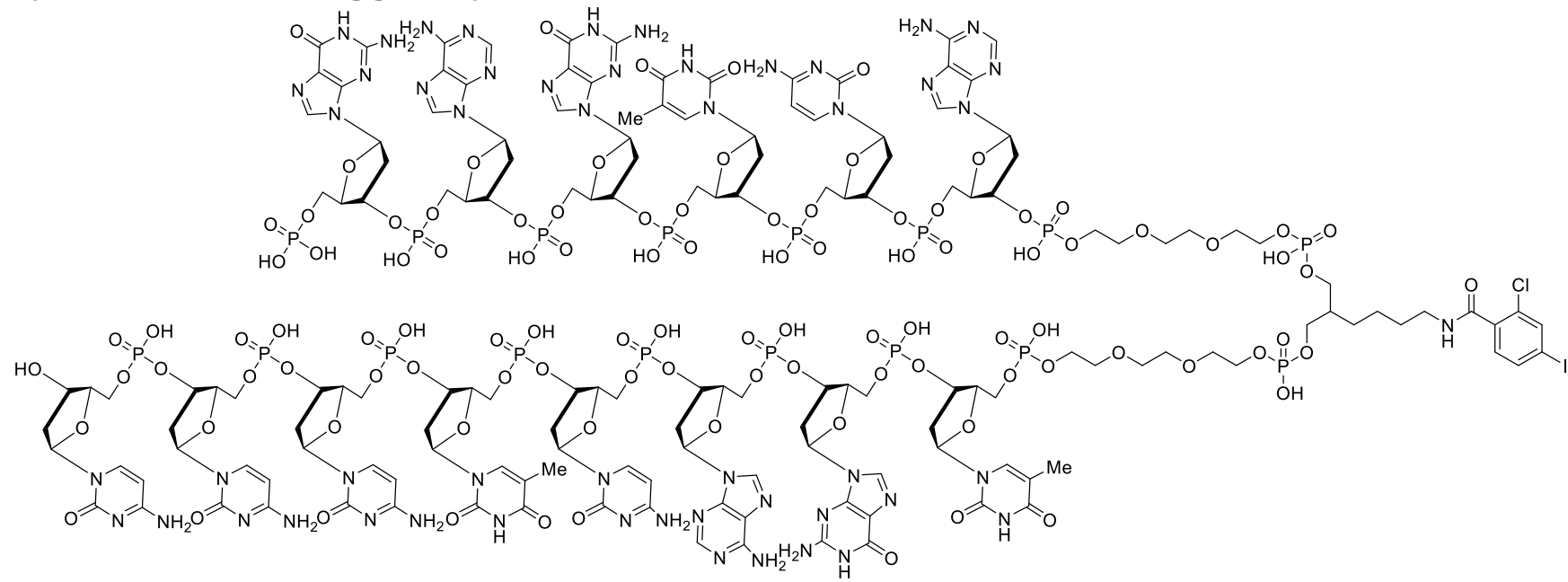

The title compound was synthesized according to the general procedure II from 2-chloro-4-iodobenzoic acid $(0.6 \mathrm{mg}, 2.0 \mu \mathrm{mol})$. The intended product was formed in $90 \%$ yield.

$m / z=1732.6[\mathrm{M}-3 \mathrm{H}]^{3-}$

\section{Synthesis of DNA-tagged aryl iodide S7:}
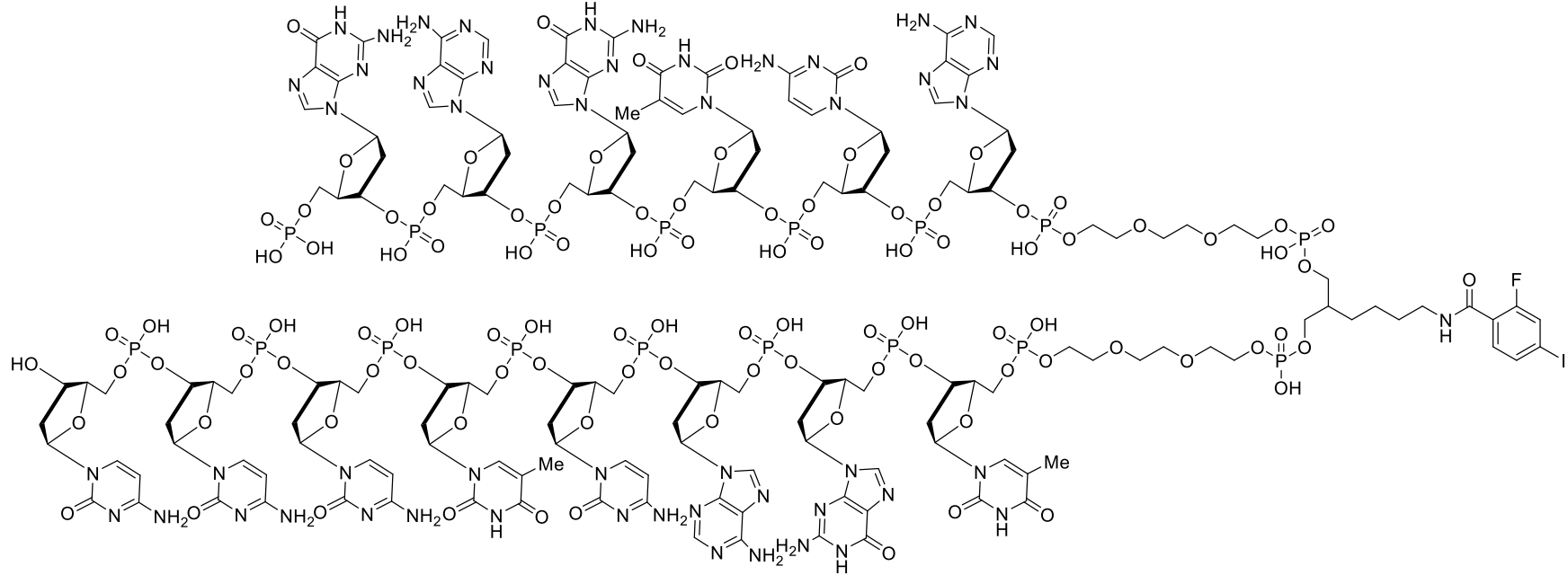

The title compound was synthesized according to the general procedure II from 2-fluoro-4-iodobenzoic acid $(0.5 \mathrm{mg}, 2.0 \mu \mathrm{mol})$. The intended product was formed in $93 \%$ yield.

$m / z=1726.9[\mathrm{M}-3 \mathrm{H}]^{3-}$ 


\section{Synthesis of DNA-tagged aryl iodide S8:}
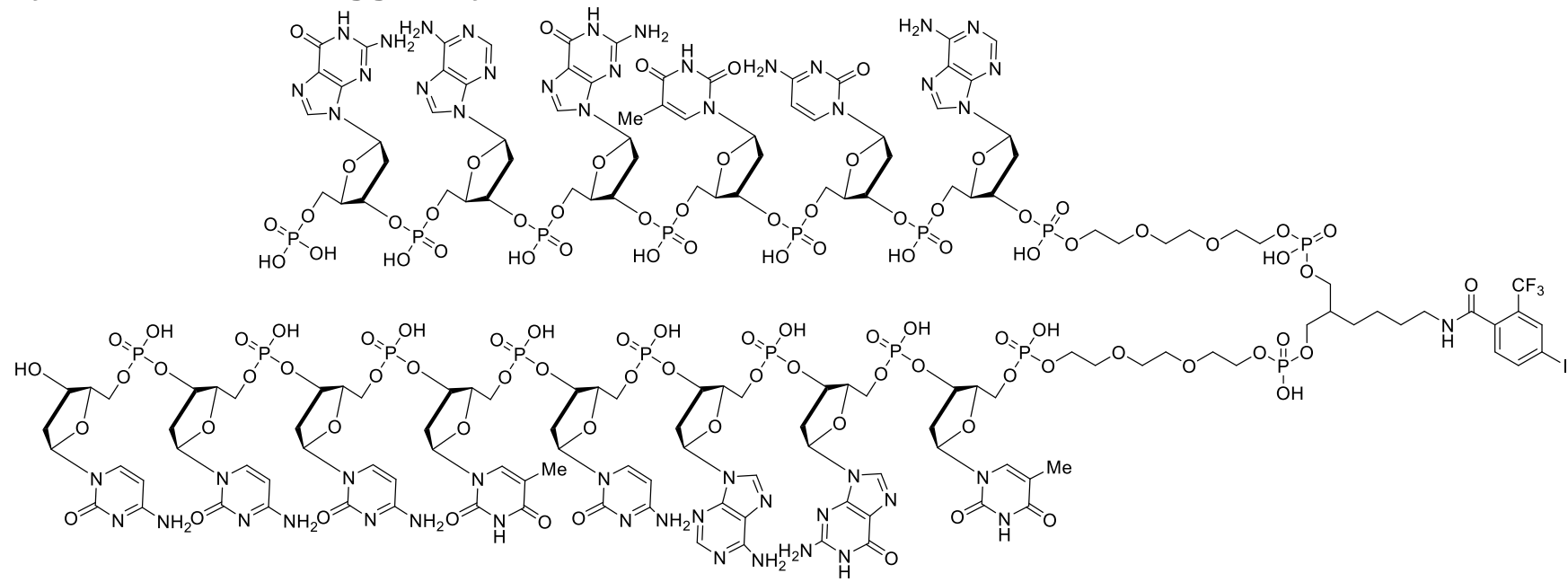

The title compound was synthesized according to the general procedure II from 4-iodo-2(trifluoromethyl)benzoic acid $(0.6 \mathrm{mg}, 2.0 \mu \mathrm{mol})$. The intended product was formed in $88 \%$ yield.

$m / z=1743.9[\mathrm{M}-3 \mathrm{H}]^{3-}$

\section{Synthesis of DNA-tagged aryl iodide S9:}
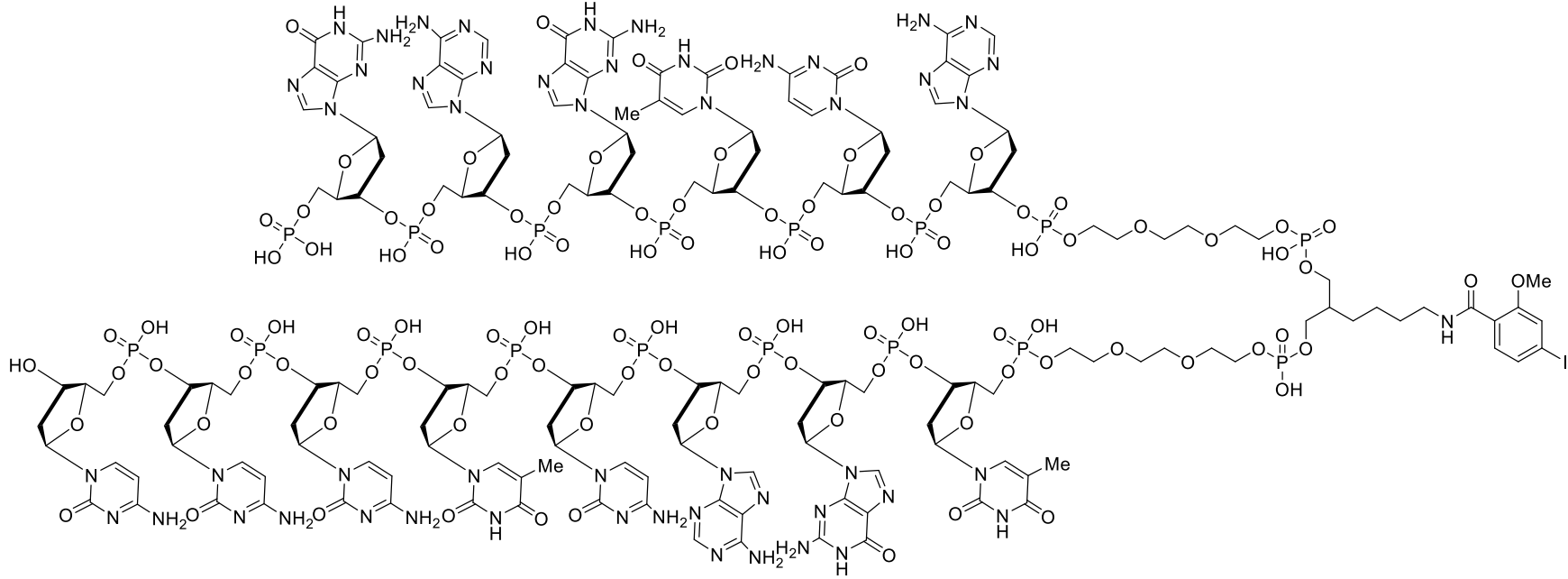

The title compound was synthesized according to the general procedure Ifrom 4-iodo-2-methoxybenzoic acid $(0.6 \mathrm{mg}, 2.0 \mu \mathrm{mol})$. The intended product was formed in $98 \%$ yield.

$m / z=1730.9[\mathrm{M}-3 \mathrm{H}]^{3-}$ 


\section{Synthe sis of DNA-tagged aryl iodide S10:}
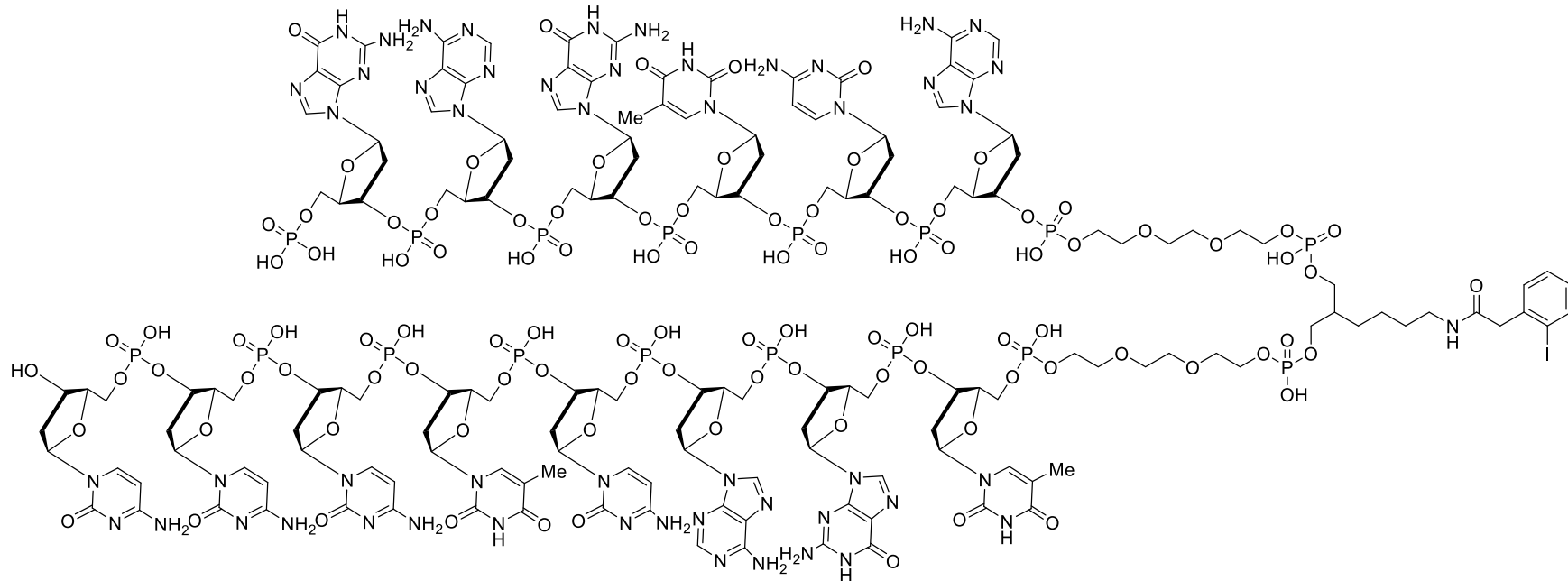

The title compound was synthesized according to the general procedure I from 2-(2-iodophenyl)acetic acid $(0.5 \mathrm{mg}, 2.0 \mu \mathrm{mol})$. The intended product was formed in $97 \%$ yield.

$m / z=1725.9[\mathrm{M}-3 \mathrm{H}]^{3-}$

\section{Synthe sis of DNA-tagged aryl iodide S11:}
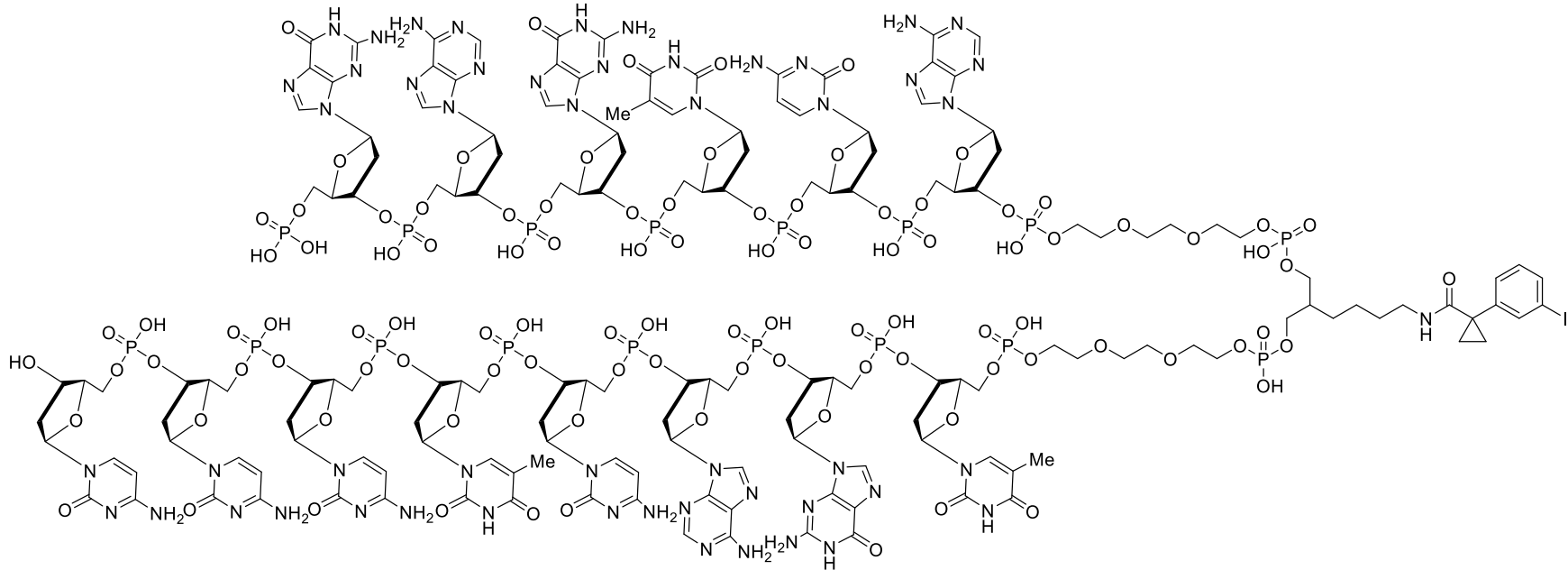

The title compound was synthesized according to the general procedure I from 1-(3iodophenyl)cyclopropane-1-carboxylic acid $(0.6 \mathrm{mg}, 2.0 \mu \mathrm{mol})$. The intended product was formed in $94 \%$ yield.

$\mathrm{m} / \mathrm{z}=1734.3[\mathrm{M}-3 \mathrm{H}]^{3-}$ 


\section{Synthesis of DNA-tagged aryl iodide S12:}
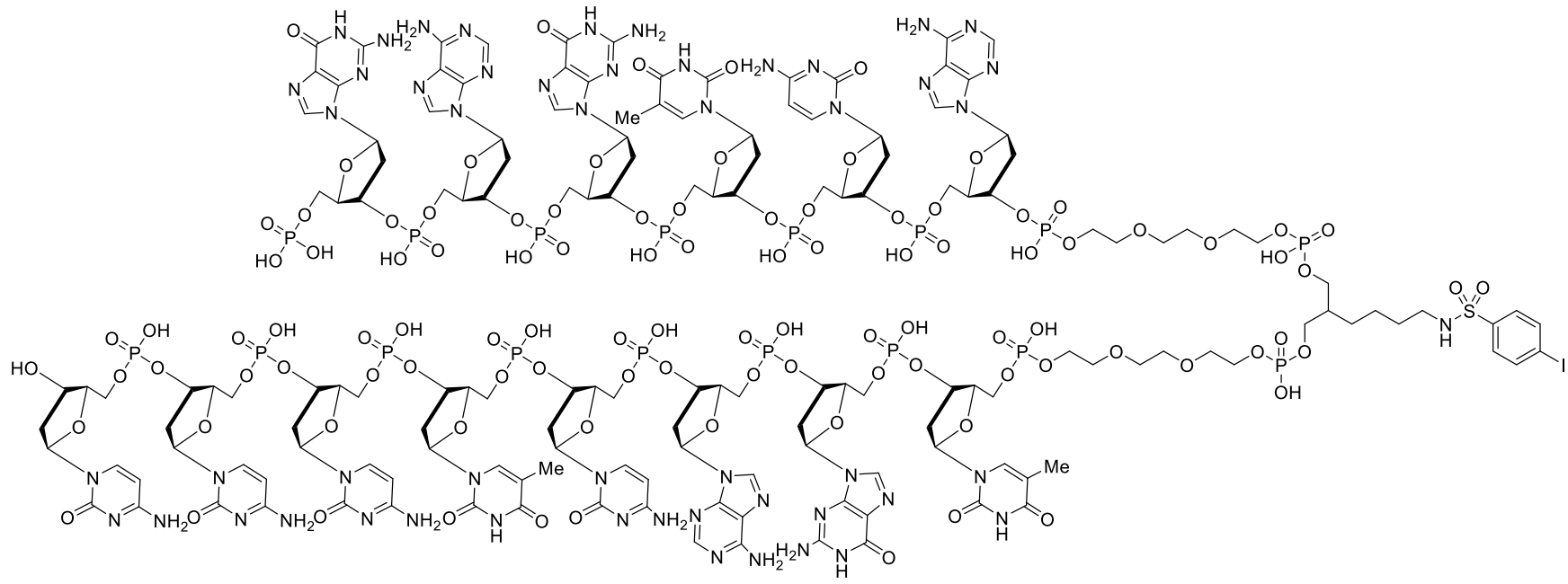

A solution of 4 -iodobenzenesulfonyl chloride $(1.2 \mathrm{mg}, 4.0 \mu \mathrm{mol})$ in acetonitrile $(10 \mu \mathrm{L})$ was added to a solution of the DNA headpiece $(0.2 \mathrm{mg}, 40 \mathrm{nmol}$, Figure $\mathrm{S} 1)$ in sodium borate buffer $(250 \mathrm{mM}, \mathrm{pH} 9.5$, $40 \mu \mathrm{L}$ ). The mixture was vortexed, centrifuged, and allowed to stand at room temperature overnight. Subsequently, a solution of $\mathrm{NaCl}$ in $\mathrm{H}_{2} \mathrm{O}(5 \mathrm{M}, 6 \mu \mathrm{L})$ was added, followed by the addition of cold $\mathrm{EtOH}$ $(400 \mu \mathrm{L})$. The mixture was kept at $-20^{\circ} \mathrm{C}$ for $20 \mathrm{~min}$ and then centrifuged at 10,000 rpm for $2 \mathrm{~min}$. The supernatant was discarded and the DNA pellet was re-dissolved in $\mathrm{H}_{2} \mathrm{O}(40 \mu \mathrm{L})$. The precipitation was repeated two more times. An aliquot $(1 \mu \mathrm{L})$ was taken, diluted with $\mathrm{H}_{2} \mathrm{O}(100 \mu \mathrm{L})$ and analyzed via UPLC. The intended product was formed in $97 \%$ yield. The title compounds were used for the following reactions without further purification.

$m / z=1733.2[\mathrm{M}-3 \mathrm{H}]^{3-}$

\section{Synthesis of DNA-tagged aryl bromide S13:}
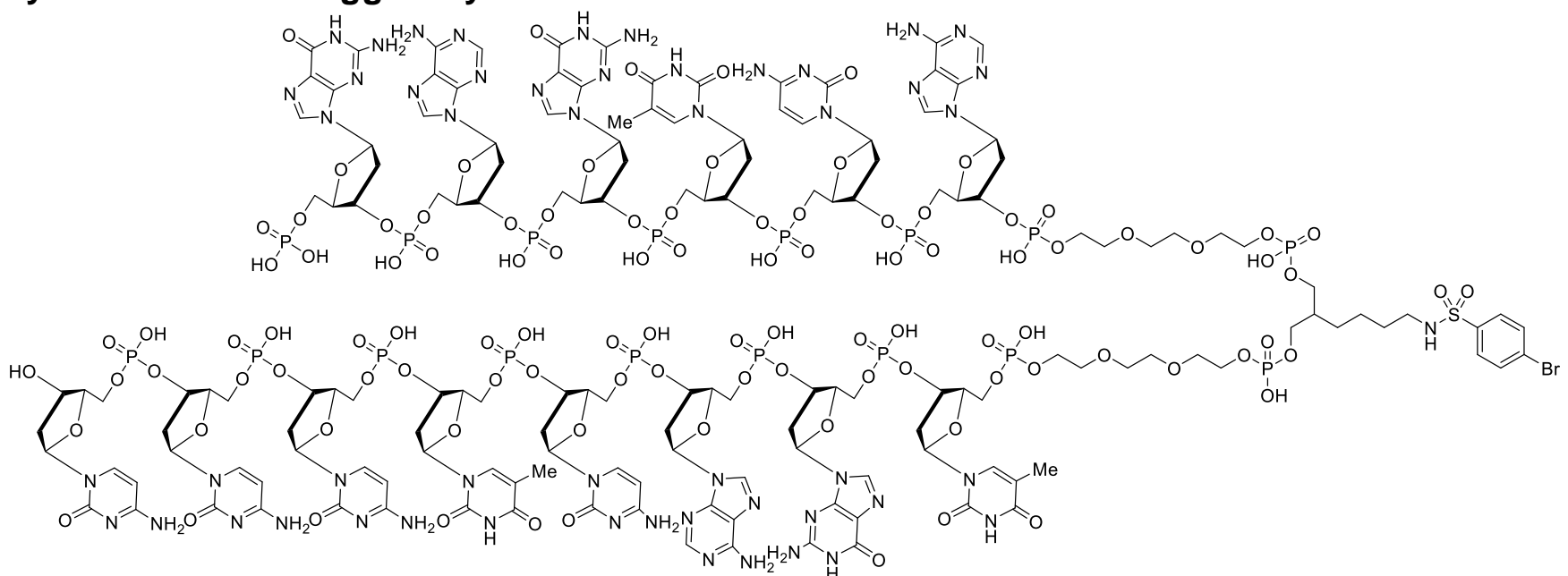

A solution of 4-bromobenzenesulfonyl chloride $(1.0 \mathrm{mg}, 4.0 \mu \mathrm{mol})$ in acetonitrile $(10 \mu \mathrm{L})$ was added to a solution of the DNA headpiece $(0.2 \mathrm{mg}, 40 \mathrm{nmol}$, Figure S1) in sodium borate buffer $(250 \mathrm{mM}, \mathrm{pH} 9.5$, $40 \mu \mathrm{L}$ ). The mixture was vortexed, centrifuged, and allowed to stand at room temperature overnight. Subsequently, a solution of $\mathrm{NaCl}$ in $\mathrm{H}_{2} \mathrm{O}(5 \mathrm{M}, 6 \mu \mathrm{L})$ was added, followed by the addition of cold $\mathrm{EtOH}$ $(400 \mu \mathrm{L})$. The mixture was kept at $-20^{\circ} \mathrm{C}$ for $20 \mathrm{~min}$ and then centrifuged at 10,000 rpm for $2 \mathrm{~min}$. The supernatant was discarded and the DNA pellet was re-dissolved in $\mathrm{H}_{2} \mathrm{O}(40 \mu \mathrm{L})$. The precipitation was repeated two more times. An aliquot $(1 \mu \mathrm{L})$ was taken, diluted with $\mathrm{H}_{2} \mathrm{O}(100 \mu \mathrm{L})$ and analyzed via UPLC. The intended product was formed in $97 \%$ yield. The title compounds were used for the following reactions without further purification.

$m / z=1717.6[\mathrm{M}-3 \mathrm{H}]^{3-}$

\section{Synthe sis of DNA-tagged aryl bromide S14:}



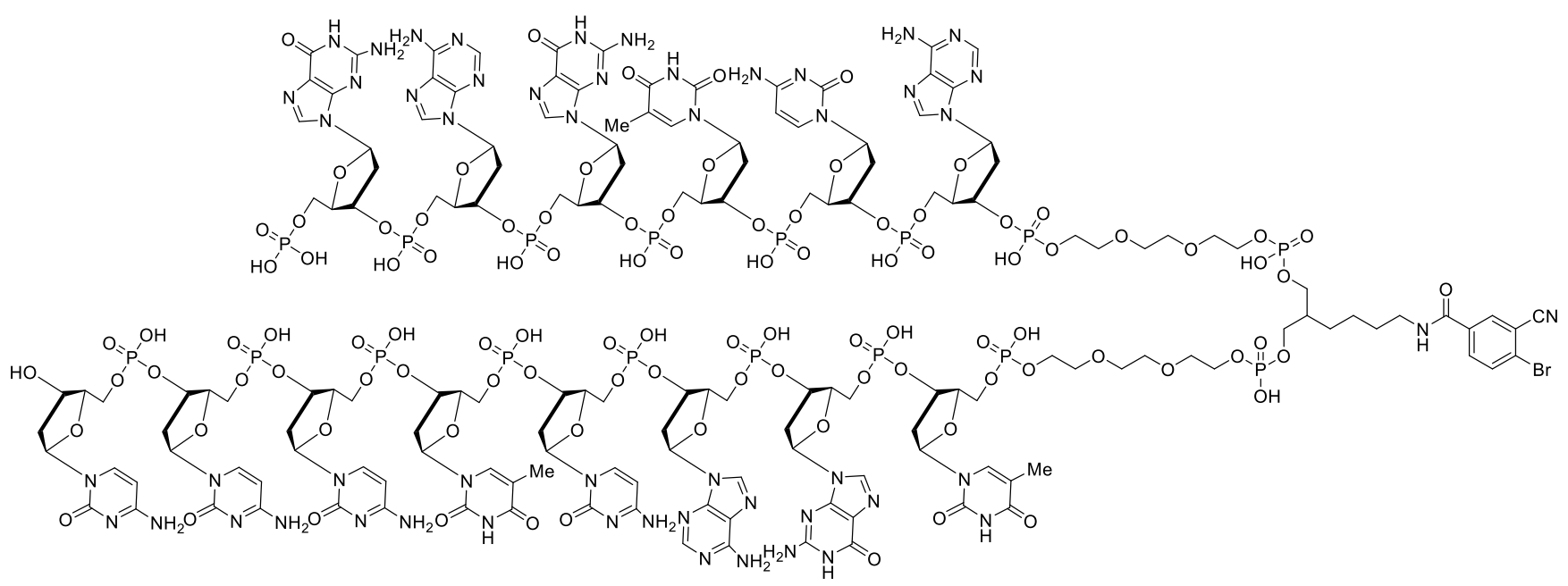

The title compound was synthesized according to the general procedure Ifrom 4-bromo-3-cyanobenzoic acid $(0.5 \mathrm{mg}, 2.0 \mu \mathrm{mol})$. The intended product was formed in $90 \%$ yield.

$m / z=1714.0[\mathrm{M}-3 \mathrm{H}]^{3-}$

\section{Synthesis of DNA-tagged aryl iodide S15:}
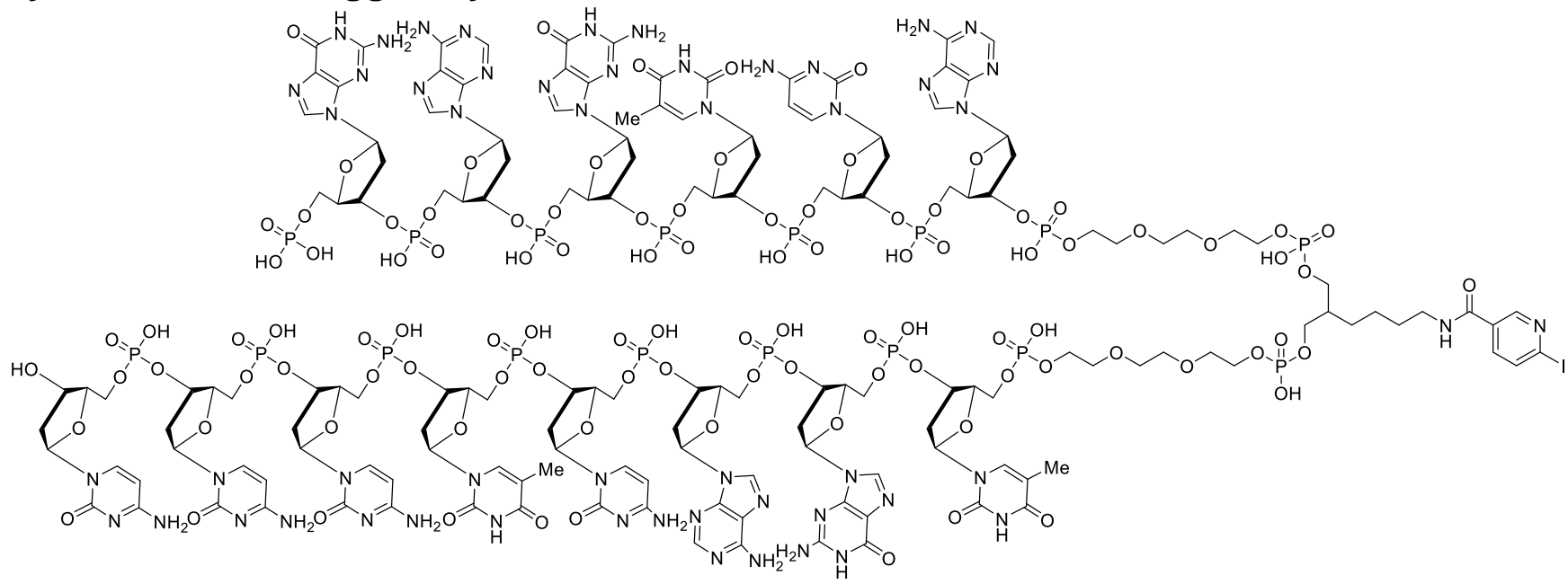

The title compound was synthesized according to the general procedure I from 6-iodonicotinic acid $(0.5 \mathrm{mg}, 2.0 \mu \mathrm{mol})$. The intended product was formed in $86 \%$ yield.

$m / z=1721.6[\mathrm{M}-3 \mathrm{H}]^{3-}$ 


\section{Synthe sis of DNA-tagged aryl bromide S16:}

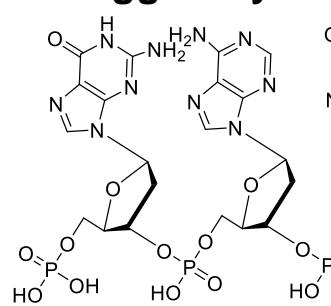<smiles>Cc1cn(C)c(=O)[nH]c1=O</smiles><smiles>Cn1cnc2c(N)ncnc21</smiles>

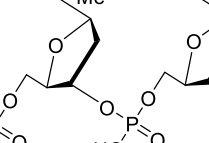<smiles>O=C(O)OC1CCCCC1COCCO</smiles><smiles>COC(=O)C1CCCCC1</smiles>

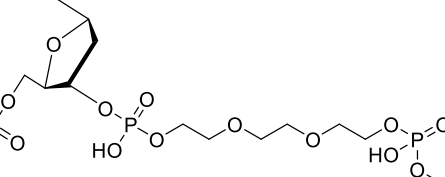

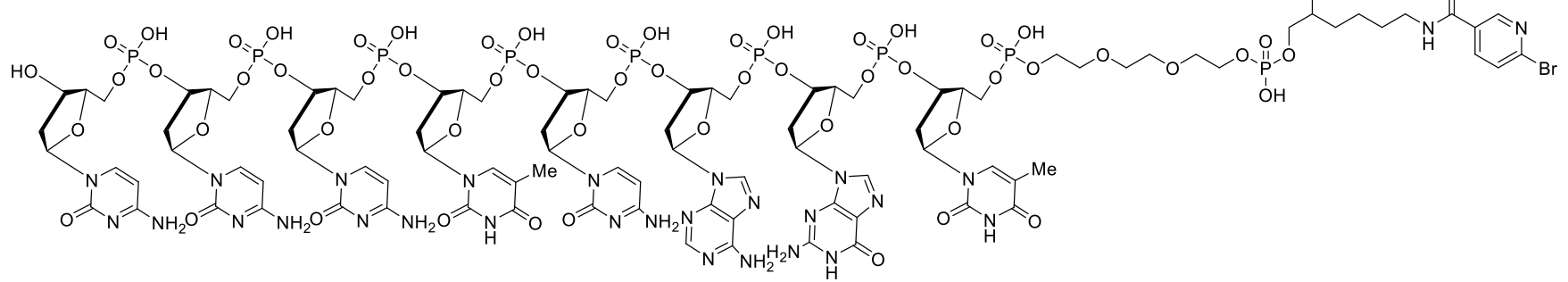

The title compound was synthesized according to the general procedure I from 6-bromonicotinic acid $(0.4 \mathrm{mg}, 2.0 \mu \mathrm{mol})$. The intended product was formed in $85 \%$ yield.

$m / z=1706.3[\mathrm{M}-3 \mathrm{H}]^{3-}$

\section{Synthesis of DNA-tagged aryl chloride S17:}
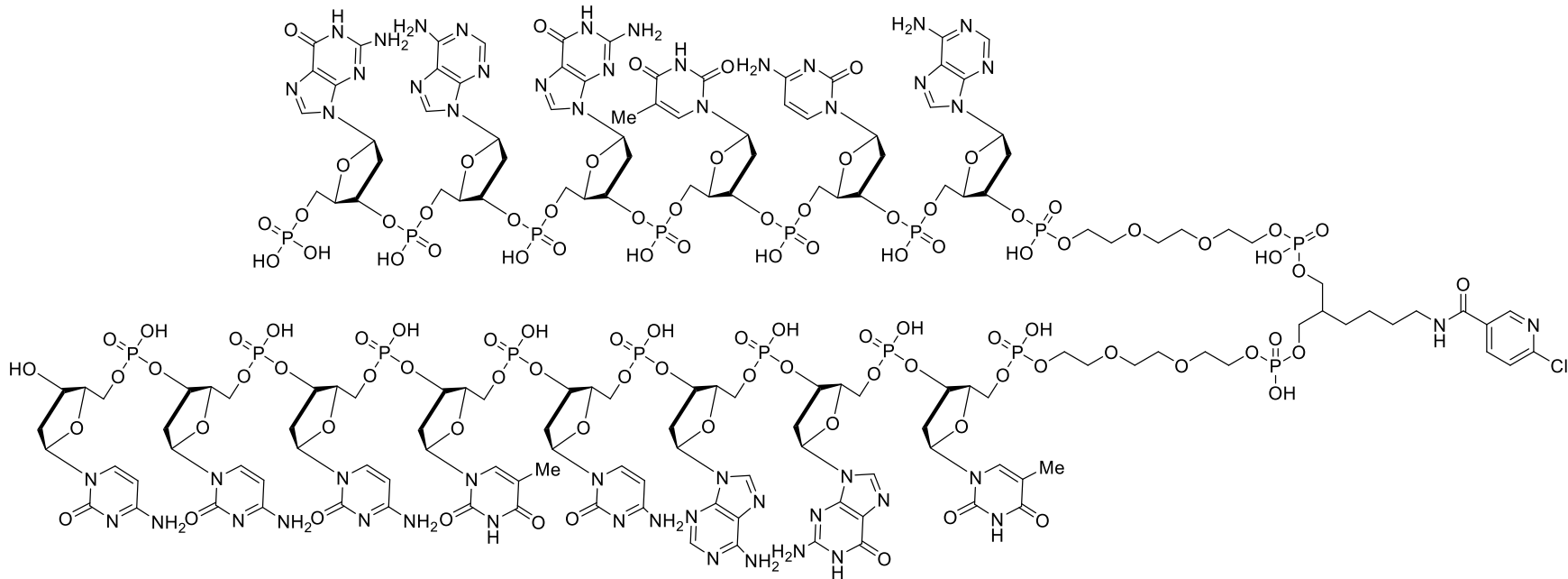

The title compound was synthesized according to the general procedure I from 6-chloronicotinic acid $(0.3 \mathrm{mg}, 2.0 \mu \mathrm{mol})$. The intended product was formed in $91 \%$ yield.

$m / z=1690.9[\mathrm{M}-3 \mathrm{H}]^{3-}$ 


\section{Synthe sis of DNA-tagged aryl bromide S18:}

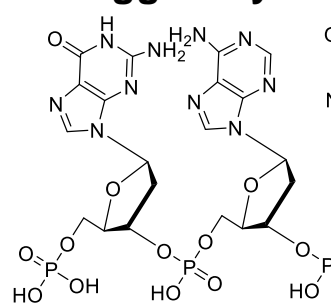<smiles>Cc1cn(C)c(=O)[nH]c1=O</smiles><smiles>Cn1cnc2c(N)ncnc21</smiles><smiles>CCOCCOP(=O)(OCCOC)OCCOC</smiles><smiles>O=C(O)OC1CCCCC1COCCO</smiles><smiles>COC(=O)C1CC2CCCCC2C1</smiles>

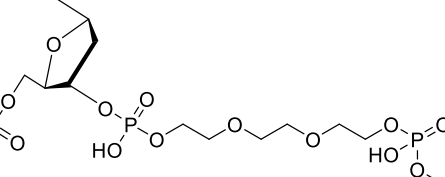

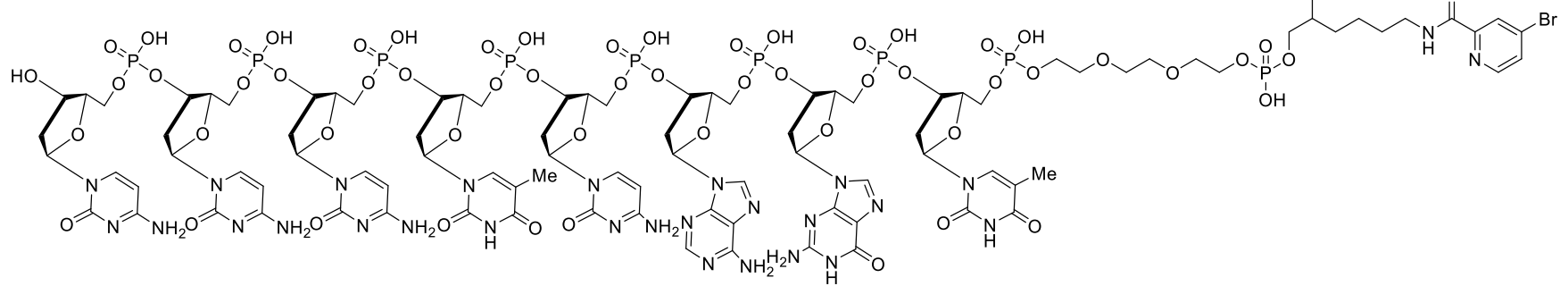

The title compound was synthesized according to the general procedure I from 4-bromopicolinic acid $(0.4 \mathrm{mg}, 2.0 \mu \mathrm{mol})$. The intended product was formed in $84 \%$ yield.

$m / z=1706.0[\mathrm{M}-3 \mathrm{H}]^{3-}$

\section{Synthesis of DNA-tagged aryl bromide S19:}
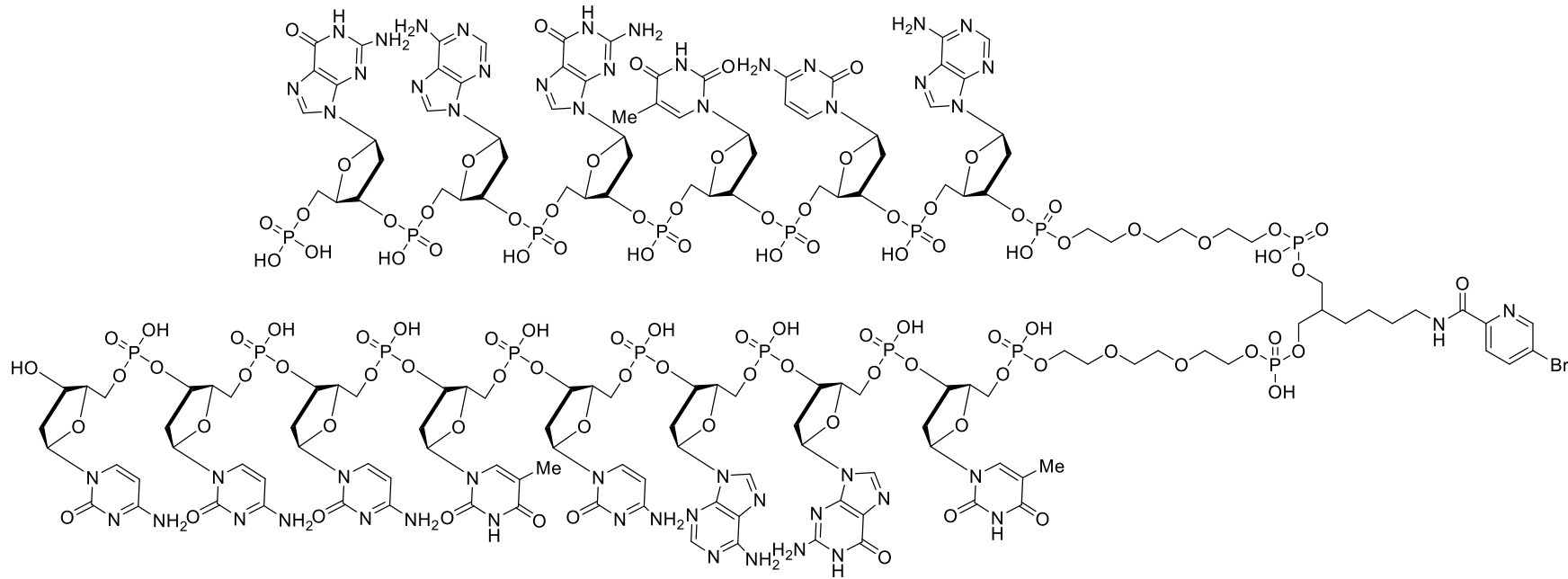

The title compound was synthesized according to the general procedure II from 5-bromopicolinic acid $(0.4 \mathrm{mg}, 2.0 \mu \mathrm{mol})$. The intended product was formed in quantitative yield.

$m / z=1706.0[\mathrm{M}-3 \mathrm{H}]^{3-}$ 


\section{Synthe sis of DNA-tagged aryl chloride S20:}
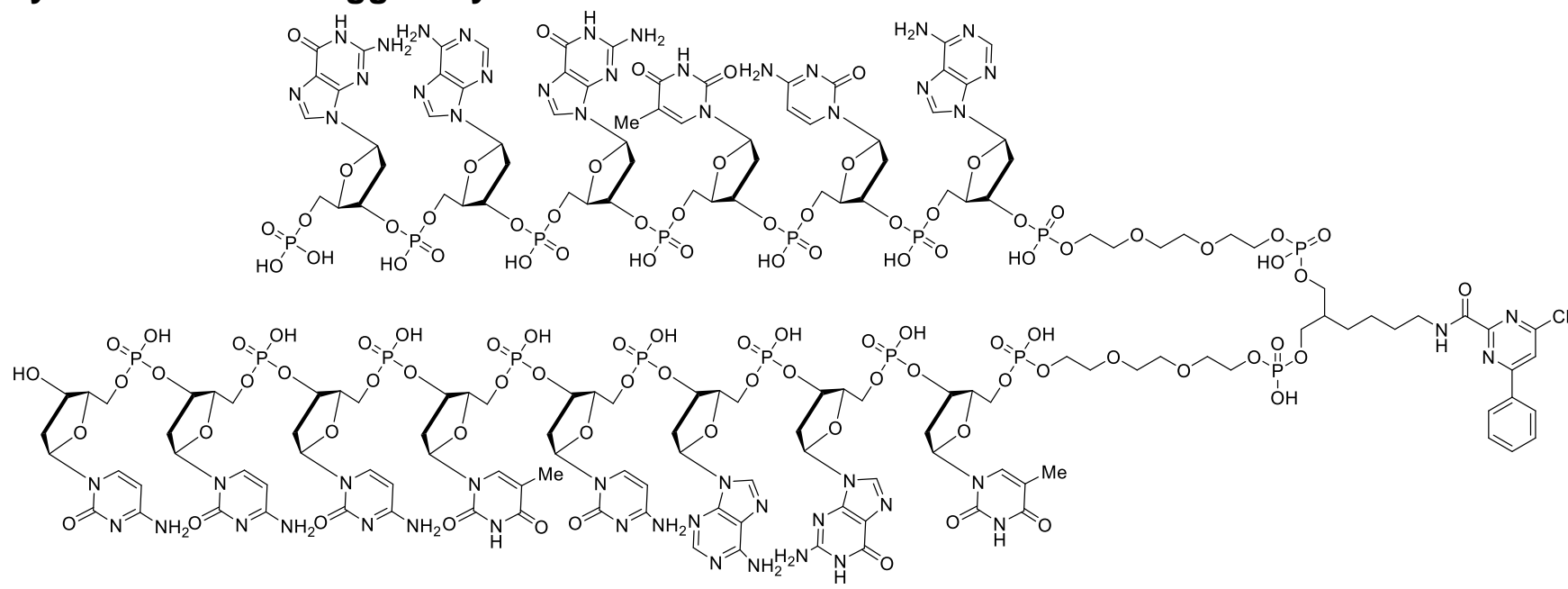

The title compound was synthesized according to the general procedure II from 4-chloro-6phenylpyrimidine-2-carboxylic acid $(0.5 \mathrm{mg}, 2.0 \mu \mathrm{mol})$. The intended product was formed in $85 \%$ yield.

$m / z=1717.0[\mathrm{M}-3 \mathrm{H}]^{3-}$

\section{Synthe sis of DNA-tagged aryl chloride S21:}
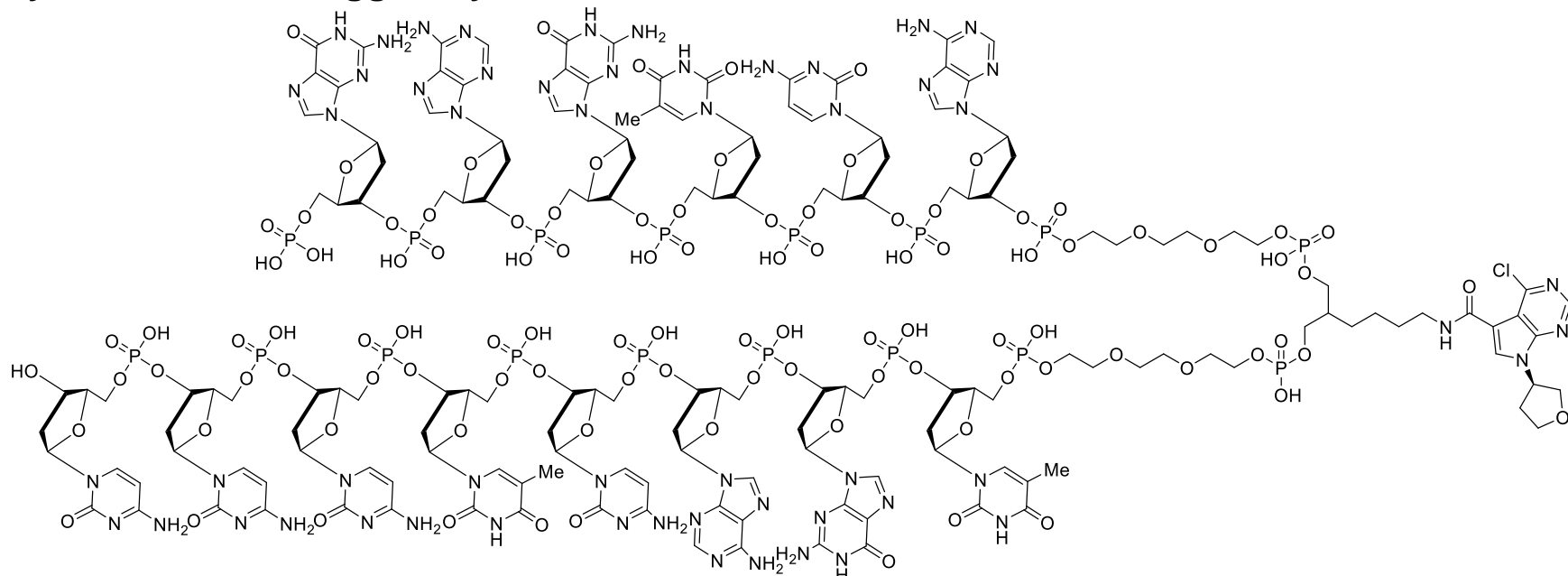

The title compound was synthesized according to the general procedure II from $(R)$-4-chloro-7(tetrahydrofuran-3-yl)-7H-pyrrolo[2,3-d]pyrimidine-5-carboxylic acid (0.5 mg, $2.0 \mu \mathrm{mol})$. The intended product was formed in $91 \%$ yield.

$m / z=1727.6[\mathrm{M}-3 \mathrm{H}]^{3-}$

\section{General procedure III for photoredox-catalyzed decarboxylative arylation:}

A solution of the respective carboxylic acid $(20 \mu \mathrm{mol}, 1000$ equiv.) in DMSO (25 $\mu \mathrm{L})$, $\operatorname{Ir}\left[\mathrm{dF}(\mathrm{F}) \mathrm{ppy}_{2}(\mathrm{dtbbpy}) \mathrm{PF}_{6}(\mathbf{1}, 80 \mu \mathrm{g}, 80 \mathrm{nmol}, \mathrm{dF}(\mathrm{F}) \mathrm{ppy}=2\right.$-(2,4-difluorophenyl)-5-fluoropyridine, dtbbpy = 4,4'-di-tert-butyl-2,2'-bipyridine) in DMSO $(1 \mu \mathrm{L})$, nickel precatalyst $16(120 \mu \mathrm{g}, 400 \mathrm{nmol})$ in DMSO (2 $\mu \mathrm{L})$, carboxamidine ligand $17(150 \mu \mathrm{g}, 800 \mathrm{nmol})$ in DMSO $(2 \mu \mathrm{L})$, and $\mathrm{K}_{2} \mathrm{HPO}_{4}(5.2 \mathrm{mg}, 30 \mu \mathrm{mol})$ in $\mathrm{H}_{2} \mathrm{O}$ $(25 \mu \mathrm{L})$ was added to a solution of the respective DNA-tagged aryl halide $(0.1 \mathrm{mg}, 20 \mathrm{nmol})$ in $\mathrm{H}_{2} \mathrm{O}(20$ $\mu \mathrm{L})$. The glass vial was then sealed and degassed by sparging with nitrogen for $5 \mathrm{~min}$. The reaction mixture was irradiated with blue light inside a photoreactor for $40 \mathrm{~min}$ at room temperature (cooling was provided via the integrated fan). Subsequently, a solution of $\mathrm{NaCl}$ in $\mathrm{H}_{2} \mathrm{O}(5 \mathrm{M}, 15 \mu \mathrm{L}$ ) was added, followed by the addition of cold EtOH $(1 \mathrm{~mL})$. The mixture was kept at $-20^{\circ} \mathrm{C}$ for 20 min and then centrifuged at 10,000 rpm for $2 \mathrm{~min}$. The supernatant was discarded and the DNA pellet was re-dissolved in $\mathrm{H}_{2} \mathrm{O}(20 \mu \mathrm{L})$. An aliquot $(1 \mu \mathrm{L})$ was taken, diluted with $\mathrm{H}_{2} \mathrm{O}(100 \mu \mathrm{L})$ and analyzed via UPLC.

\section{Decarboxylative arylation with aryl iodide 12 (Table 1, entry 1):}



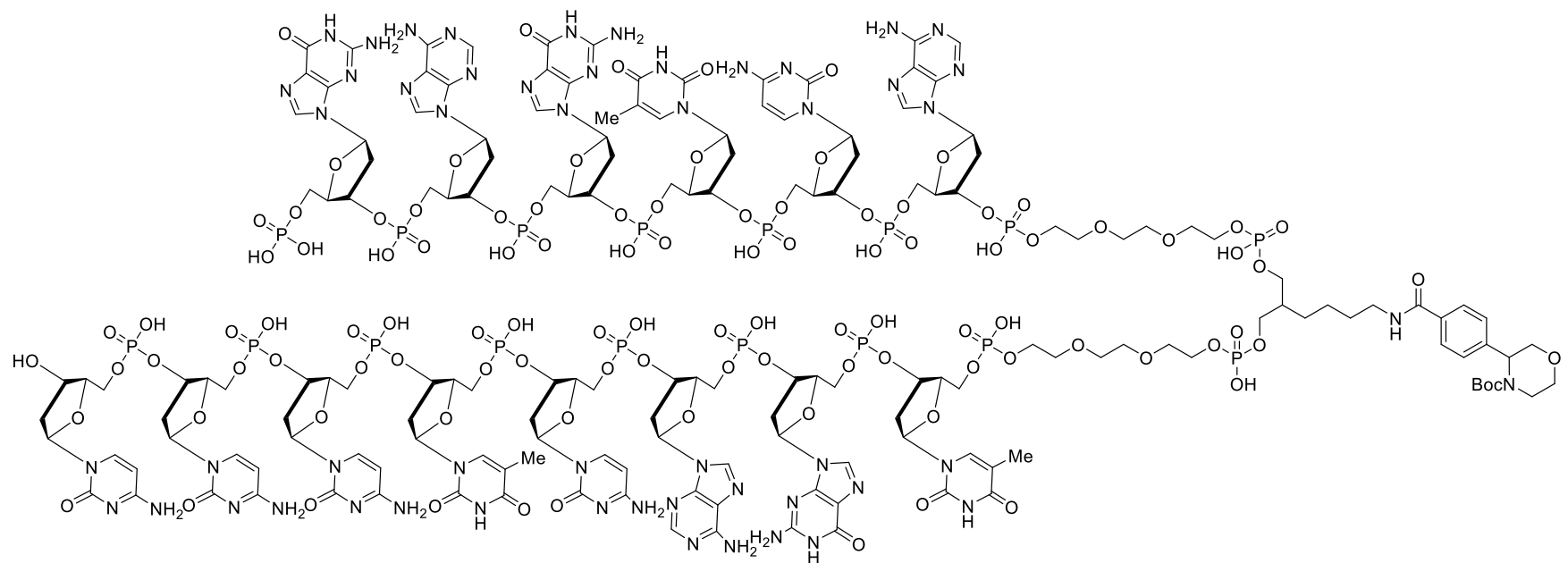

The title compound was synthesized according to the general procedure III from 4-(tertbutoxycarbonyl)morpholine-3-carboxylic acid (4.6 mg, $20 \mu \mathrm{mol})$ and the DNA-tagged aryl iodide 12. The intended product was formed in $89 \%$ yield.

$m / z=1741.1[\mathrm{M}-3 \mathrm{H}]^{3-}$

\section{Decarboxylative arylation with aryl iodide 12 (Table 1, entry 2):}
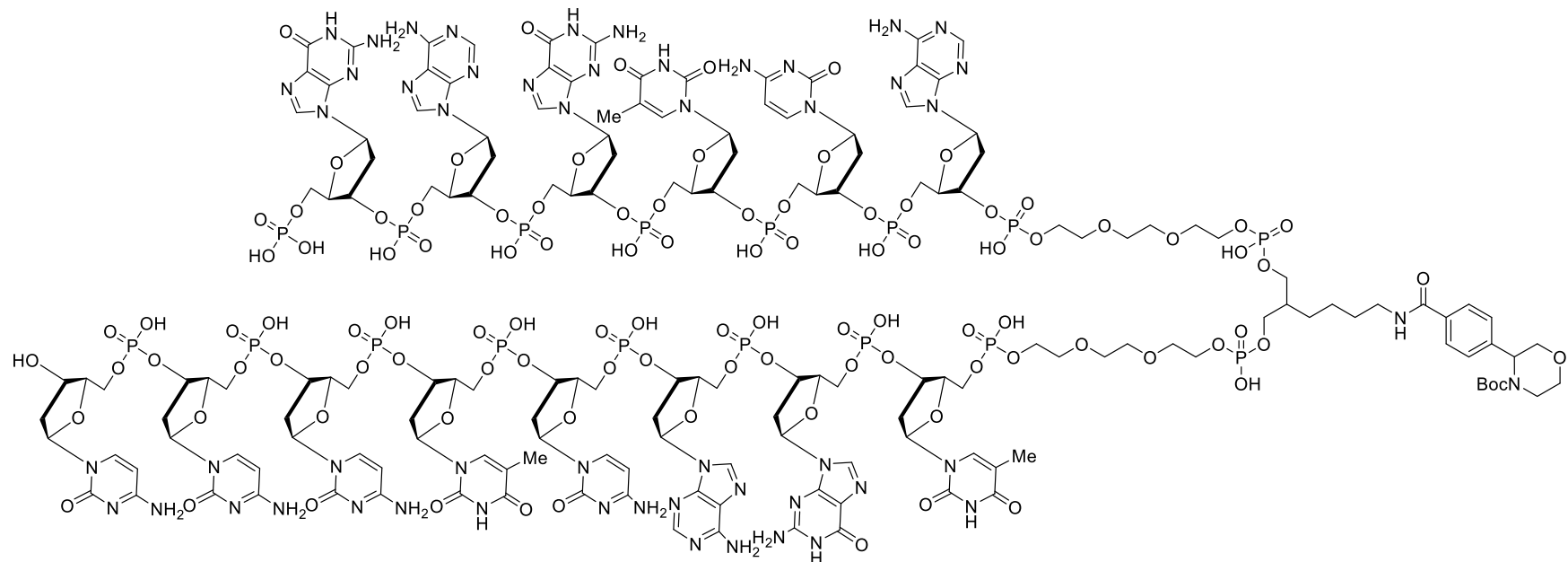

The title compound was synthesized according to the general procedure III from 4 -(tertbutoxycarbonyl)morpholine-3-carboxylic acid (4.6 mg, $20 \mu \mathrm{mol})$ and nickel(II) chloride ethylene glycol dimethyl ether complex $(90 \mu \mathrm{g}, 400 \mu \mathrm{mol})$ instead of nickel precatalyst 16 . The intended product was formed in $58 \%$ yield.

$m / z=1741.0[\mathrm{M}-3 \mathrm{H}]^{3-}$ 

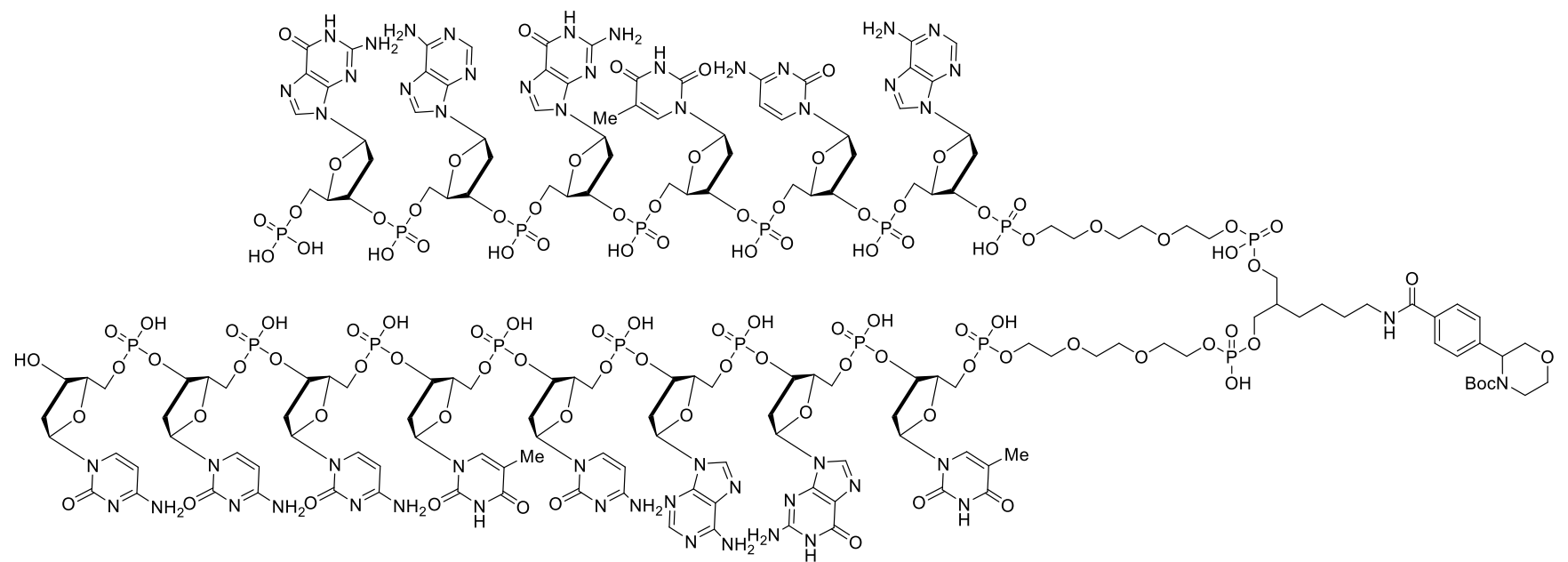

The title compound was synthesized according to the general procedure III from 4-(tertbutoxycarbonyl)morpholine-3-carboxylic acid $(4.6 \mathrm{mg}, 20 \mu \mathrm{mol})$ and bis $(1,5$-cyclooctadiene)nickel( $(0)$ $(110 \mu \mathrm{g}, 400 \mu \mathrm{mol})$ instead of nickel precatalyst 16 . The intended product was formed in $54 \%$ yield.

$m / z=1740.6[\mathrm{M}-3 \mathrm{H}]^{3-}$

\section{Decarboxylative arylation with aryl iodide 12 (Table 1, entry 4):}
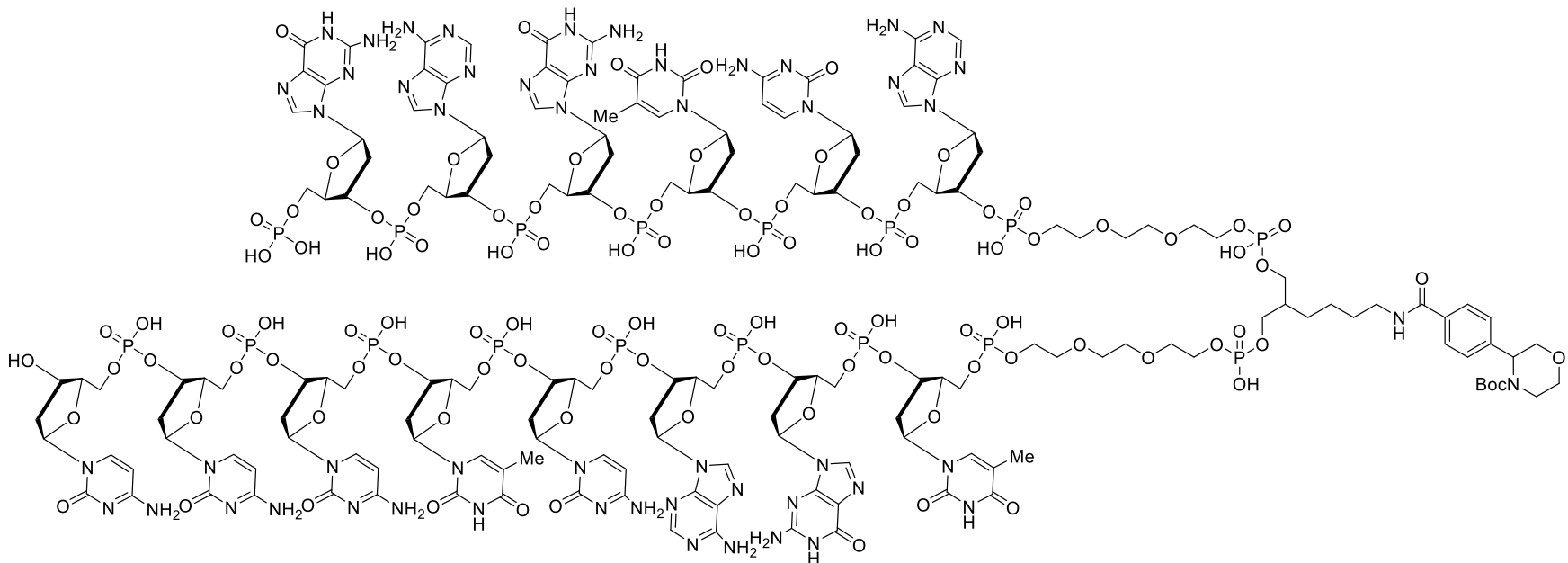

The title compound was synthesized according to the general procedure III from 4-(tertbutoxycarbonyl)morpholine-3-carboxylic acid (4.6 mg, $20 \mu \mathrm{mol}$ ) and 4,4'-di-tert-butyl-2,2'-bipyridine (220 $\mu \mathrm{g}, 800 \mu \mathrm{mol}$ ) instead of ligand $\mathbf{1 7}$. The intended product was formed in $5 \%$ yield.

$m / z=1741.0[\mathrm{M}-3 \mathrm{H}]^{3-}$ 

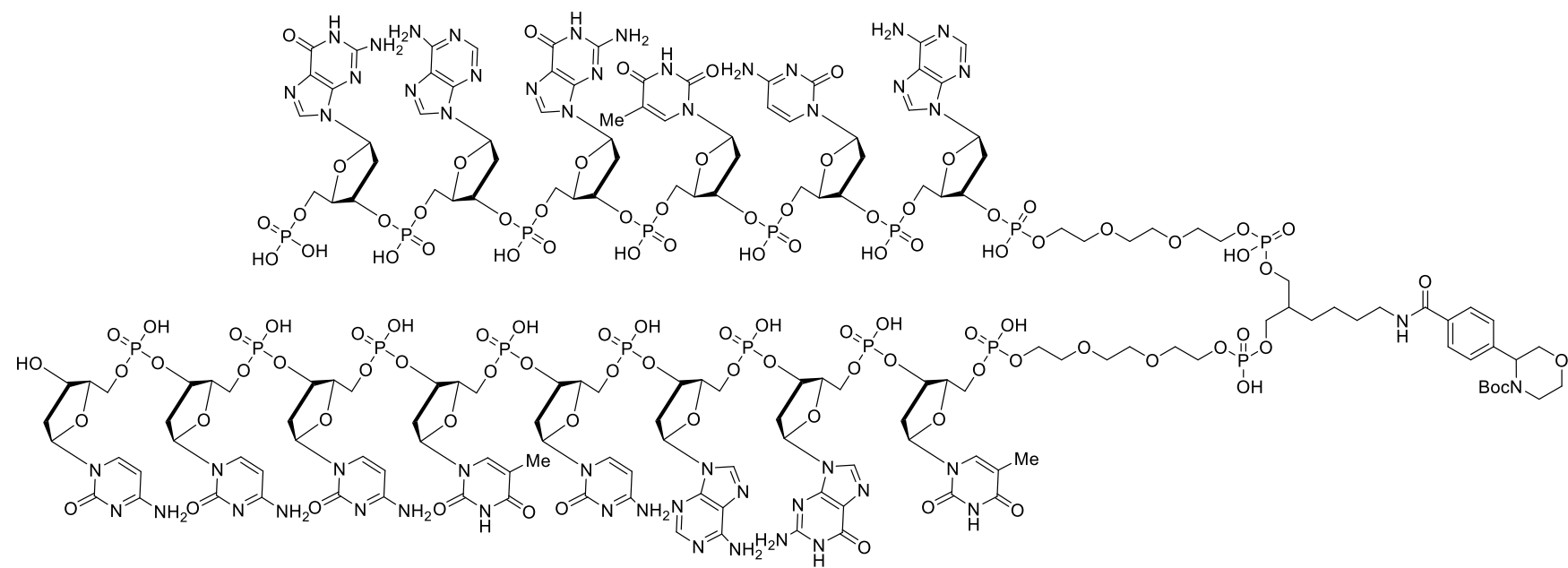

The title compound was synthesized according to the general procedure III from 4-(tertbutoxycarbonyl)morpholine-3-carboxylic acid $(4.6 \mathrm{mg}, 20 \mu \mathrm{mol})$ and $\operatorname{Ir}\left[\mathrm{dF}\left(\mathrm{CF}_{3}\right) \mathrm{ppy}\right]_{2}(\mathrm{bpy}) \mathrm{PF}_{6}(80 \mu \mathrm{g}$, $80 \mu \mathrm{mol}$ ) instead of photocatalyst 1 . The intended product was formed in $87 \%$ yield.

$m / z=1741.3[\mathrm{M}-3 \mathrm{H}]^{3-}$

\section{Decarboxylative arylation with aryl iodide 12 (Table 1, entry 6):}
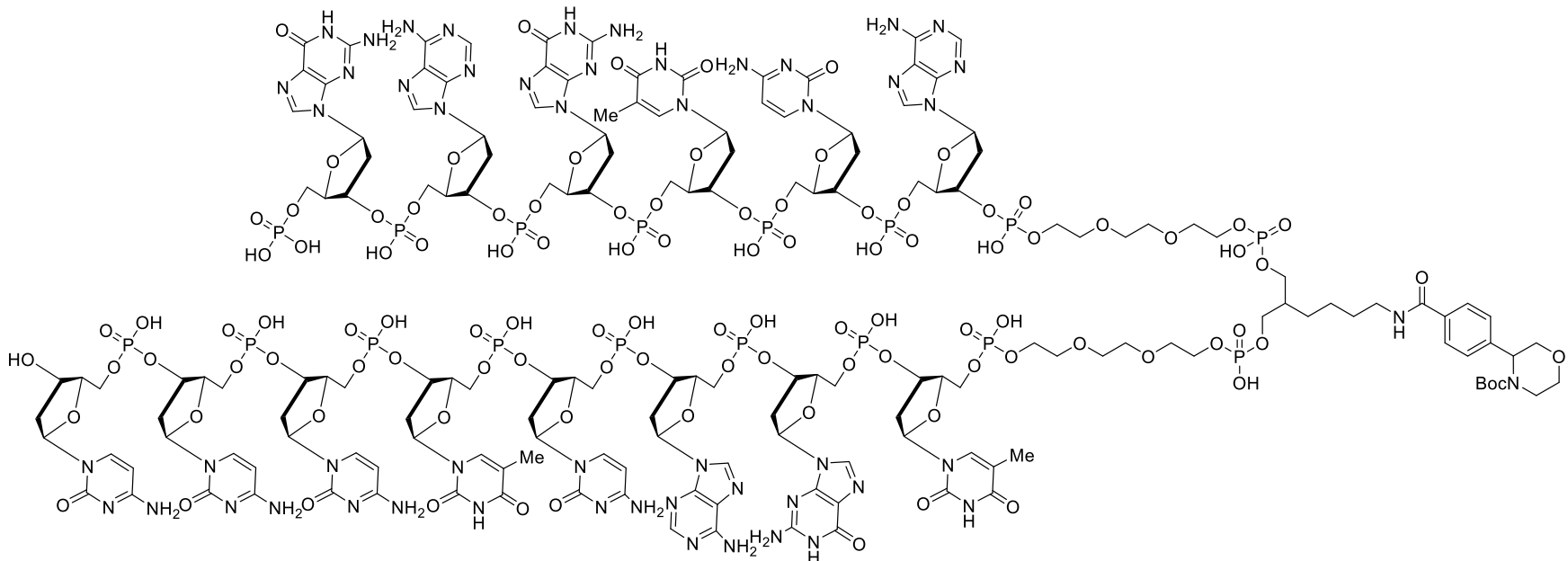

The title compound was synthesized according to the general procedure III from 4 -(tertbutoxycarbonyl)morpholine-3-carboxylic acid (4.6 mg, $20 \mu \mathrm{mol})$ and $\operatorname{Ir}\left[\mathrm{dF}\left(\mathrm{CF}_{3}\right) \mathrm{ppy}\right]_{2}(\mathrm{dtbbpy}) \mathrm{PF} 6(90 \mu \mathrm{g}$, $80 \mu \mathrm{mol})$ instead of photocatalyst 1 . The intended product was formed in $77 \%$ yield.

$m / z=1741.3[\mathrm{M}-3 \mathrm{H}]^{3-}$ 

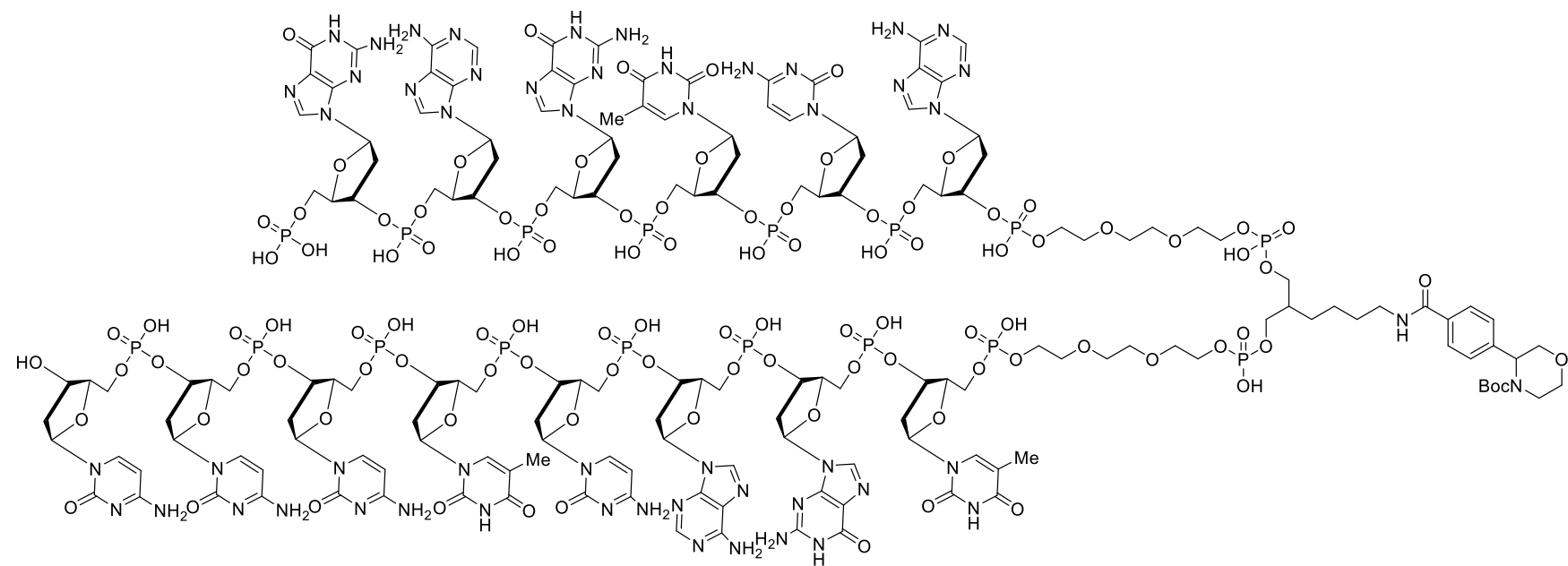

The title compound was synthesized according to the general procedure III from 4-(tertbutoxycarbonyl)morpholine-3-carboxylic acid $(4.6 \mathrm{mg}, 20 \mu \mathrm{mol})$. The degassing step was omitted. The intended product was formed in $31 \%$ yield.

$m / z=1741.0[\mathrm{M}-3 \mathrm{H}]^{3-}$

\section{Decarboxylative arylation with aryl iodide 12 (Table 1, entry 8):}
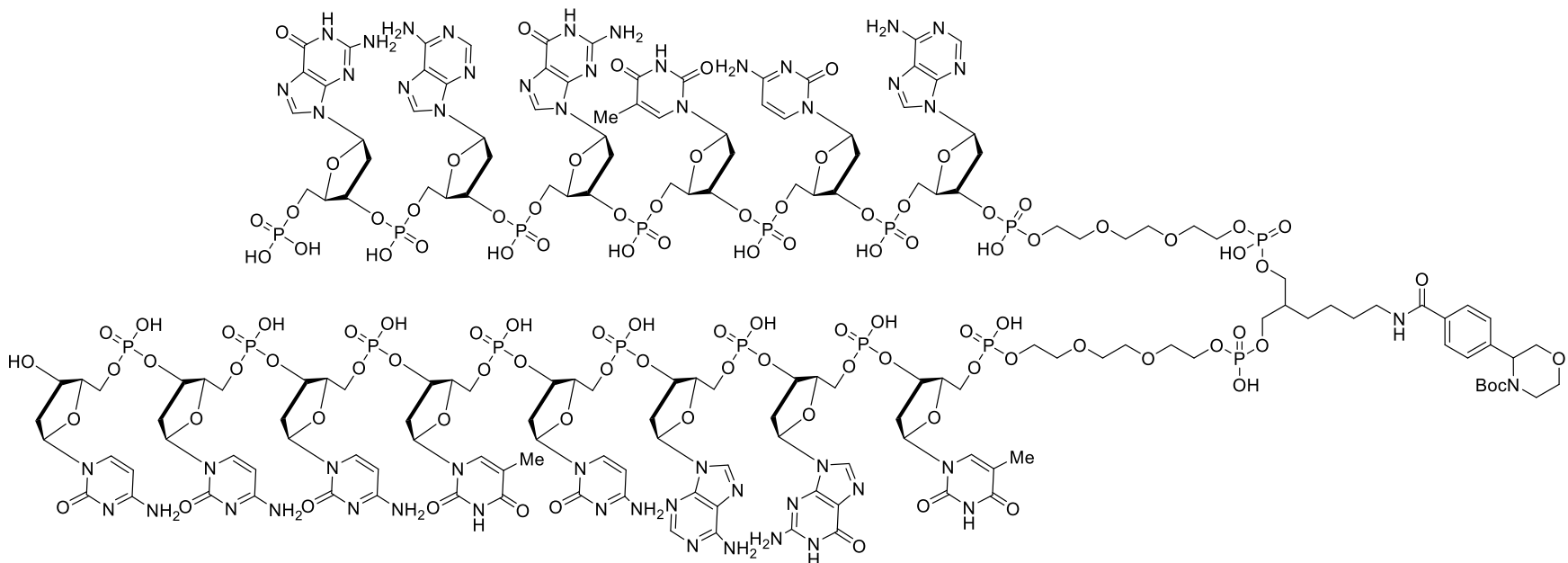

The title compound was synthesized according to the general procedure III from 4 -(tertbutoxycarbonyl)morpholine-3-carboxylic acid $(4.6 \mathrm{mg}, 20 \mu \mathrm{mol})$. No photocatalyst was added to the reaction mixture. The intended product could not be detected.

$\mathrm{m} / \mathrm{z}($ starting material $)=1721.6[\mathrm{M}-3 \mathrm{H}]^{3-}$ 

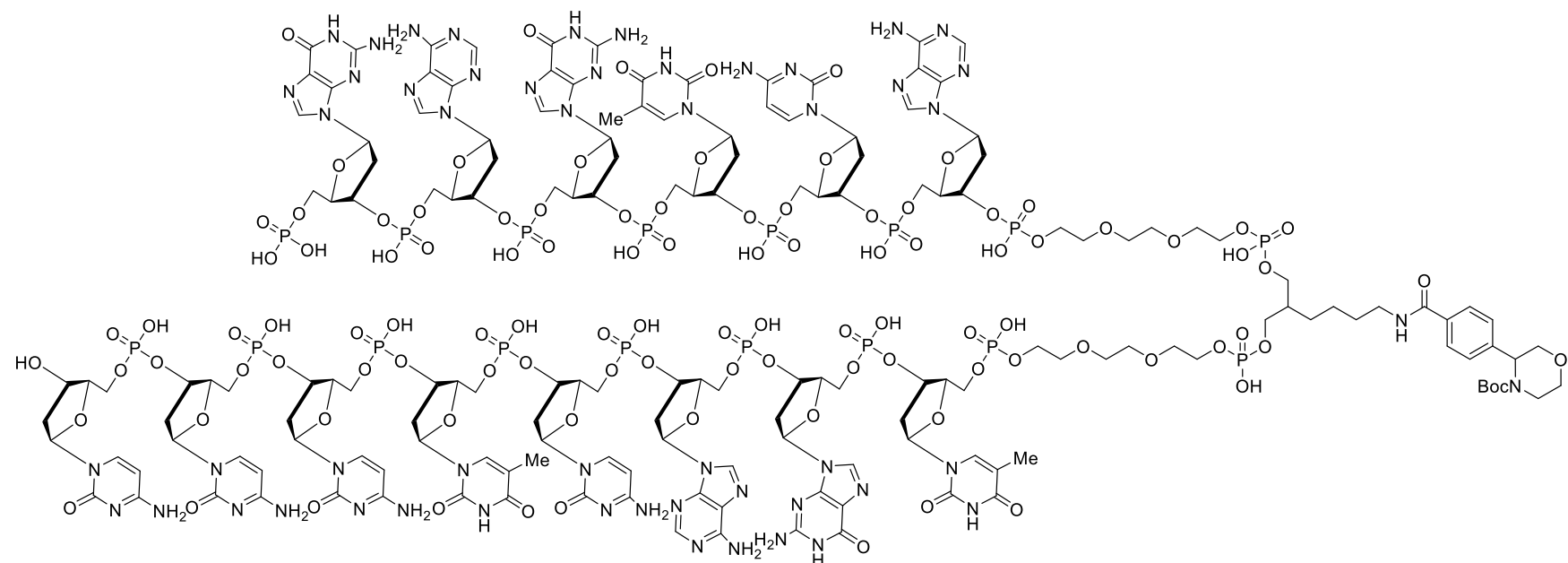

The title compound was synthesized according to the general procedure III from 4-(tertbutoxycarbonyl)morpholine-3-carboxylic acid $(4.6 \mathrm{mg}, 20 \mu \mathrm{mol})$. The reaction mixture was kept in the dark. The intended product could not be detected.

$\mathrm{m} / z($ starting material $)=1721.6[\mathrm{M}-3 \mathrm{H}]^{3-}$

\section{Decarboxylative arylation with aryl iodide 12 (Table 1, entry 10):}
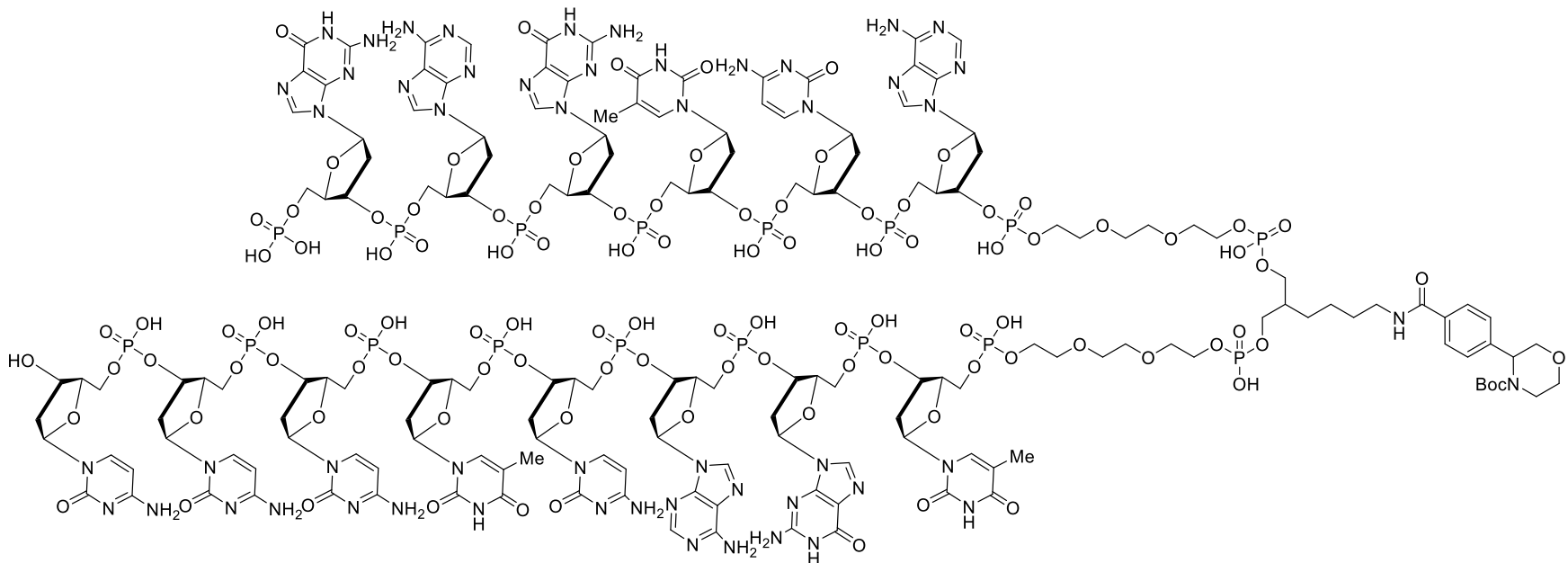

The title compound was synthesized according to the general procedure III from 4 -(tertbutoxycarbonyl)morpholine-3-carboxylic acid $(4.6 \mathrm{mg}, 20 \mu \mathrm{mol})$. No nickel catalyst was added to the reaction mixture. The intended product could not be detected.

$\mathrm{m} / \mathrm{z}($ starting material $)=1721.6[\mathrm{M}-3 \mathrm{H}]^{3-}$ 

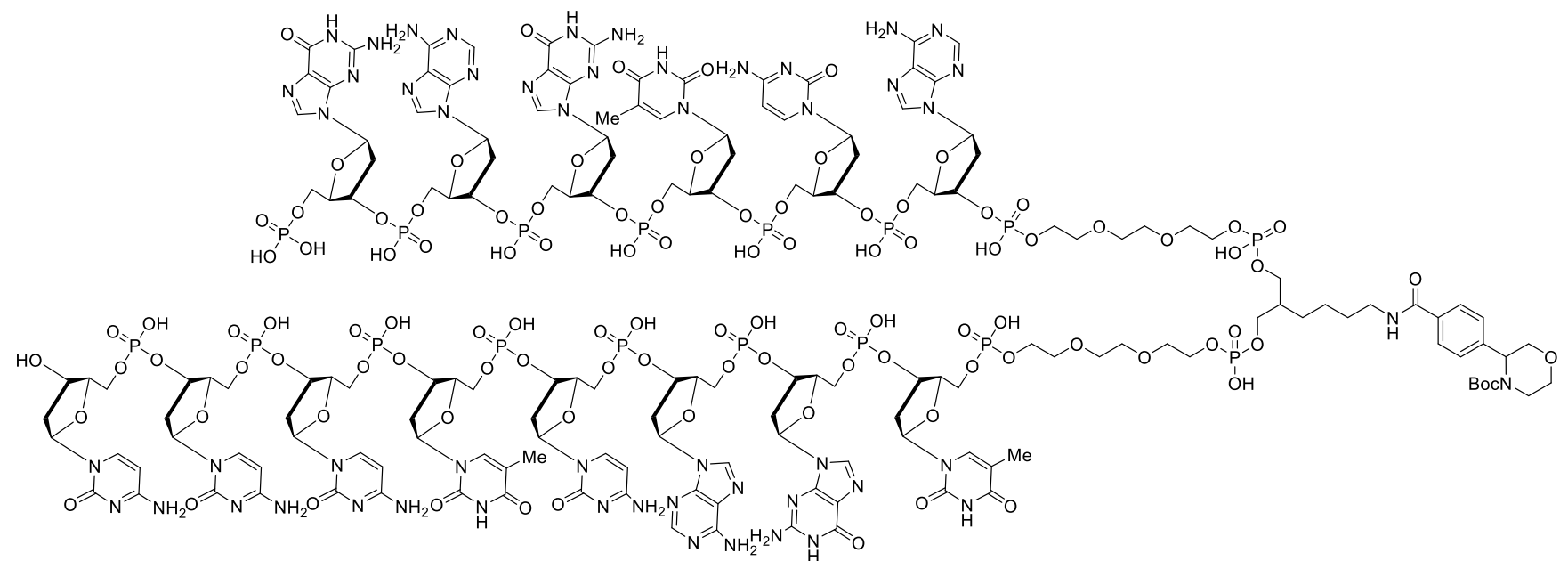

The title compound was synthesized according to the general procedure III from 4-(tertbutoxycarbonyl)morpholine-3-carboxylic acid $(4.6 \mathrm{mg}, 20 \mu \mathrm{mol})$. No ligand was added to the reaction mixture. The intended product was formed in $21 \%$ yield.

$m / z=1741.0[\mathrm{M}-3 \mathrm{H}]^{3-}$

\section{Decarboxylative arylation with aryl iodide 12 (Table 1, entry 12):}
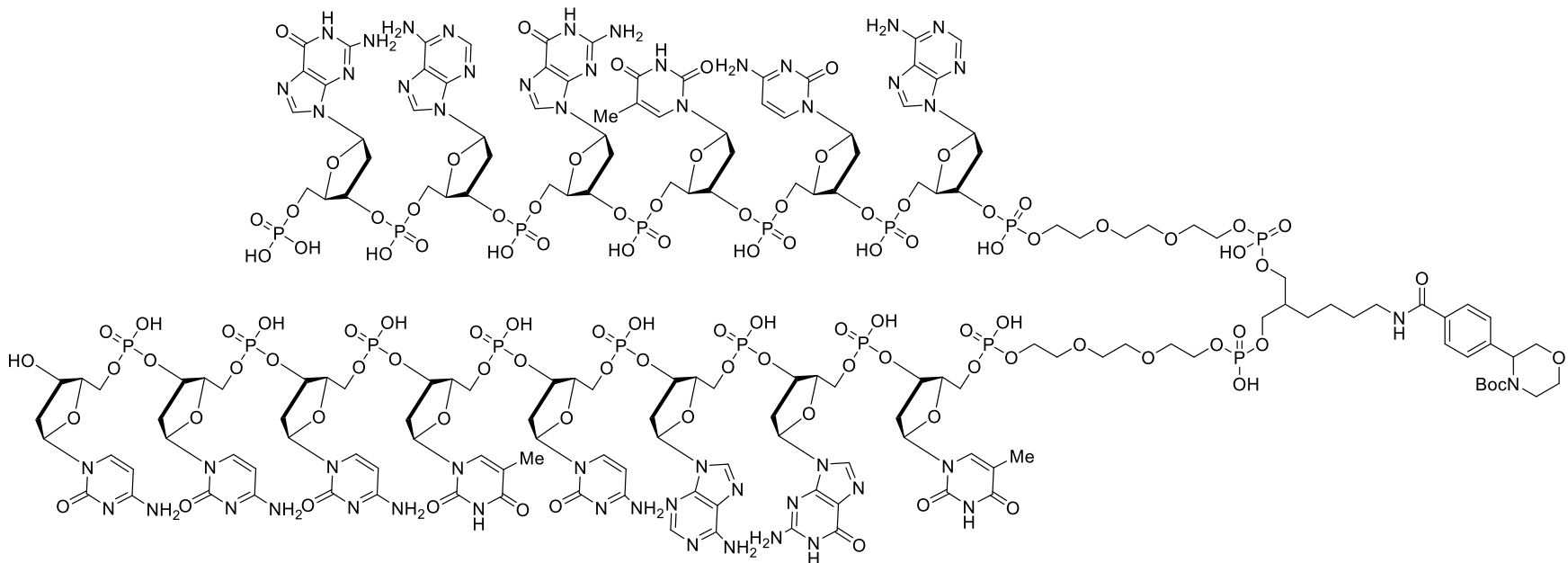

The title compound was synthesized according to the general procedure III from 4-(tertbutoxycarbonyl)morpholine-3-carboxylic acid $(4.6 \mathrm{mg}, 20 \mu \mathrm{mol})$ and aryl bromide 15 instead of aryl iodide 12. The intended product could not be detected.

$m / z($ starting material $)=1705.6\left[\mathrm{M}-3 \mathrm{H}^{3-}\right.$ 
Decarboxylative arylation with Boc-N-Me-Gly-OH (Table 2, entry 1):

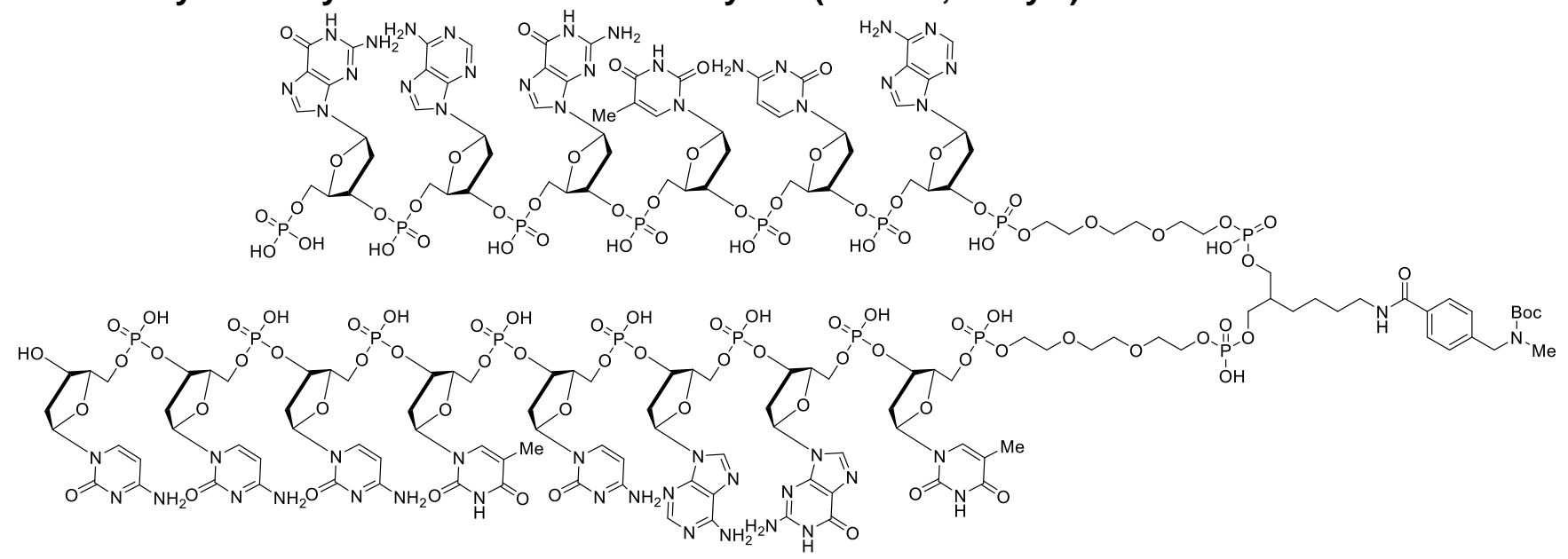

The title compound was synthesized according to the general procedure III from Boc- $\mathrm{N}-\mathrm{Me}-\mathrm{Gly}-\mathrm{OH}$ $(3.8 \mathrm{mg}, 20 \mu \mathrm{mol})$ and the DNA-tagged aryl iodide 12. The intended product was formed in $80 \%$ yield.

$m / z=1727.4[\mathrm{M}-3 \mathrm{H}]^{3-}$

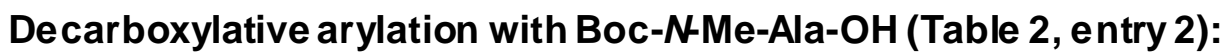

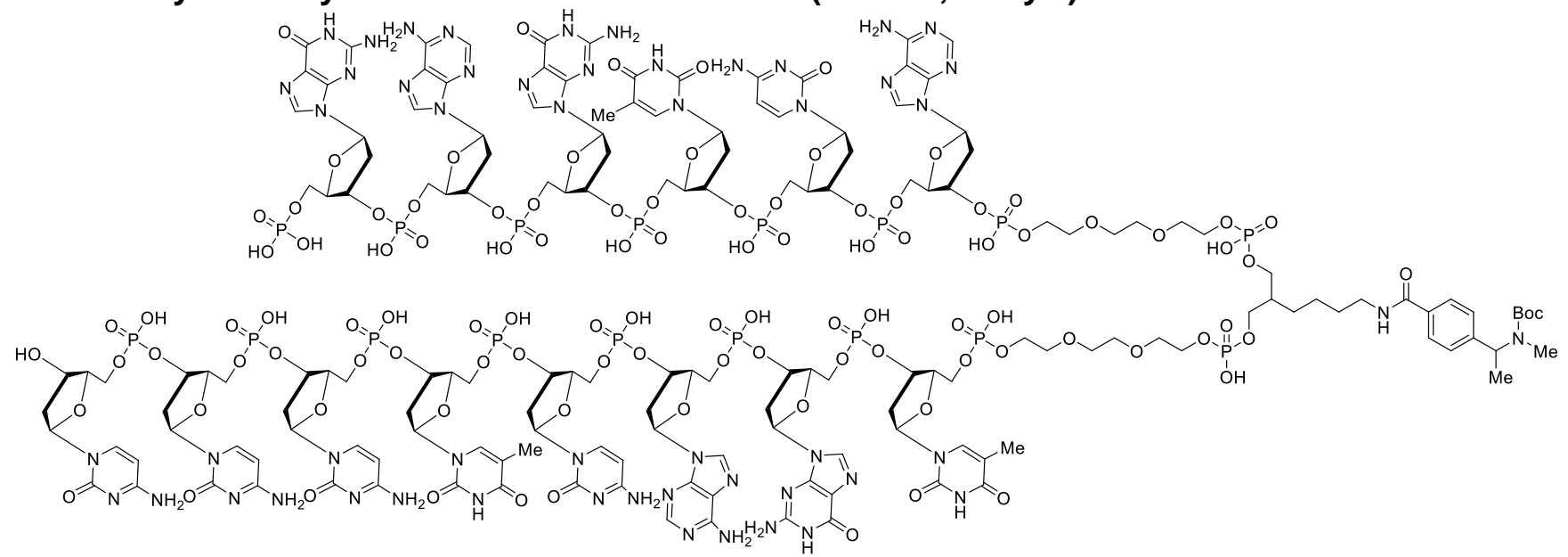

The title compound was synthesized according to the general procedure III from Boc- $\mathrm{N}-\mathrm{Me}-\mathrm{Ala}-\mathrm{OH}$ $(4.1 \mathrm{mg}, 20 \mu \mathrm{mol})$ and the DNA-tagged aryl iodide 12 . The intended product was formed in $89 \%$ yield.

$m / z=1731.8[\mathrm{M}-3 \mathrm{H}]^{3-}$

\section{Decarboxylative arylation with Boc- $\mathrm{N}-\mathrm{Me}-\mathrm{Phe}-\mathrm{OH}$ (Table 2, entry 3):}
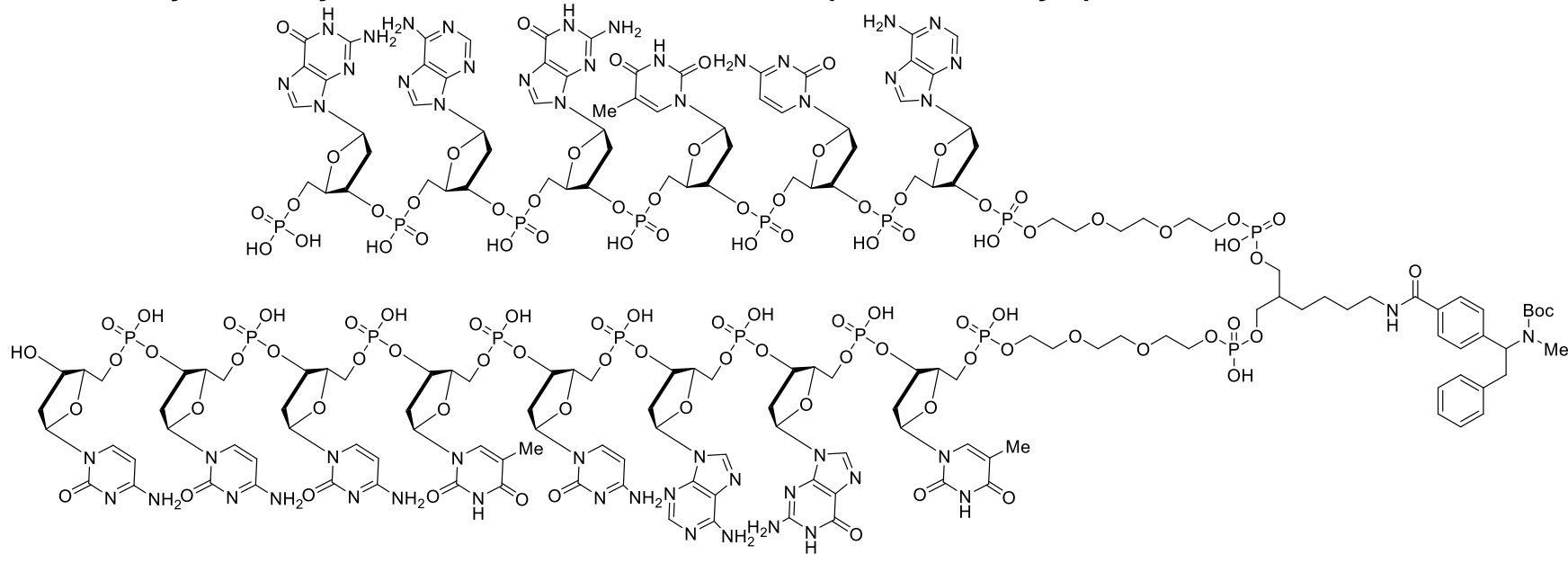
The title compound was synthesized according to the general procedure III from Boc- $\mathrm{N}-\mathrm{Me}-\mathrm{Phe}-\mathrm{OH}$ $(5.6 \mathrm{mg}, 20 \mu \mathrm{mol})$ and the DNA-tagged aryl iodide 12. The coupling was repeated one more time (double coupling). The intended product was formed in $76 \%$ yield.

$m / z=1757.4[\mathrm{M}-3 \mathrm{H}]^{3-}$

Decarboxylative arylation with Boc- $\mathrm{N}-\mathrm{Bn}-\mathrm{Ala}-\mathrm{OH}$ (Table 2, entry 4):

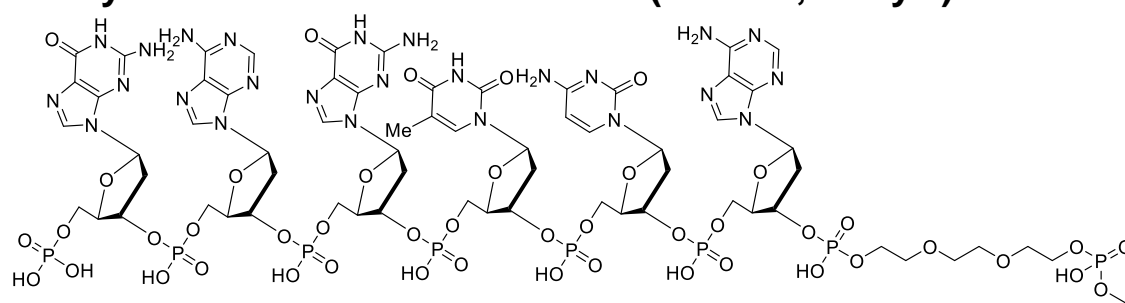

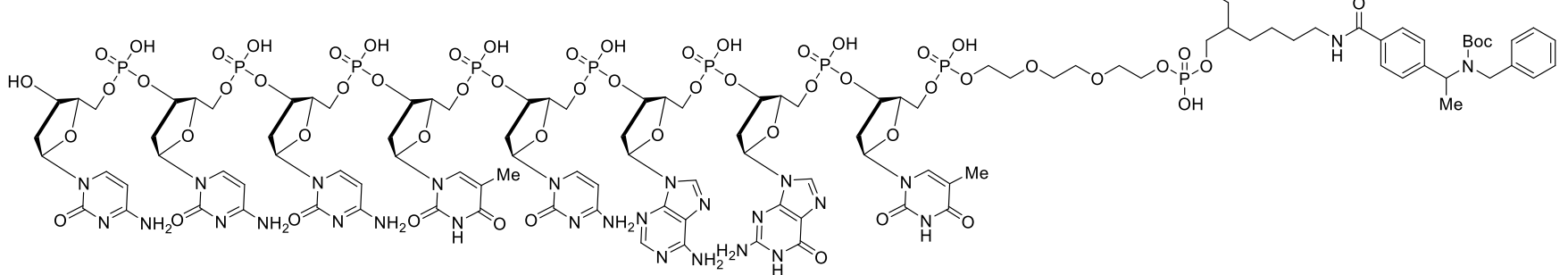

The title compound was synthesized according to the general procedure III from Boc- $N$-Bn-Ala-OH $(5.6 \mathrm{mg}, 20 \mu \mathrm{mol})$ and the DNA-tagged aryl iodide 12. The coupling was repeated one more time (double coupling). The intended product was formed in $61 \%$ yield.

$m / z=1757.3[\mathrm{M}-3 \mathrm{H}]^{3-}$

Decarboxylative arylation with $N$-(tert-butoxycarbonyl)- $N$-cyclopropylglycine (Table 2, entry 5):

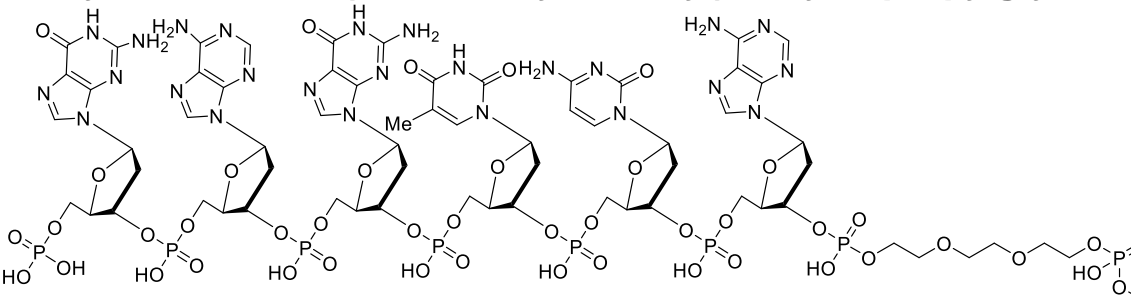

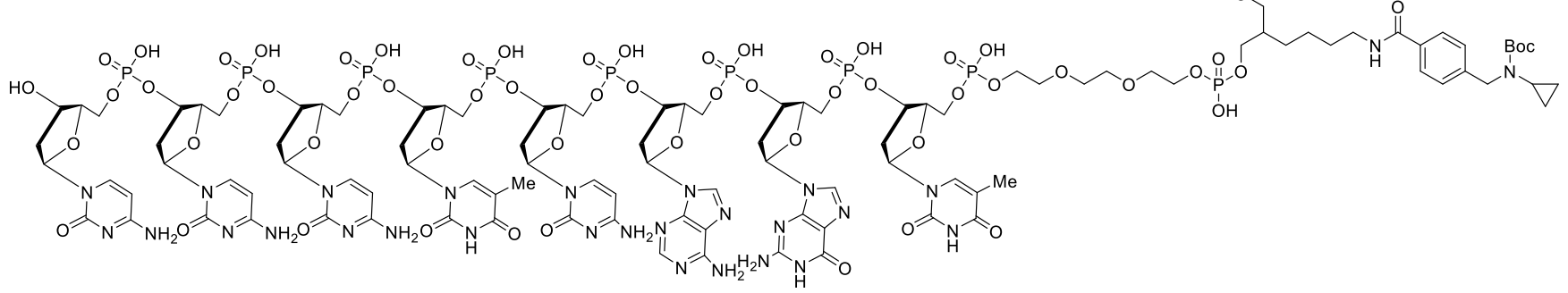

The title compound was synthesized according to the general procedure III from $\mathrm{N}$-(tert-butoxycarbonyl)$\mathrm{N}$-cyclopropylglycine $(4.3 \mathrm{mg}, 20 \mu \mathrm{mol})$ and the DNA-tagged aryl iodide 12 . The intended product was formed in $88 \%$ yield.

$m / z=1735.9[\mathrm{M}-3 \mathrm{H}]^{3-}$ 
Decarboxylative arylation with $N$-(tert-butoxycarbonyl)azetidine-2-carboxylic acid (Table 2, entry 6):
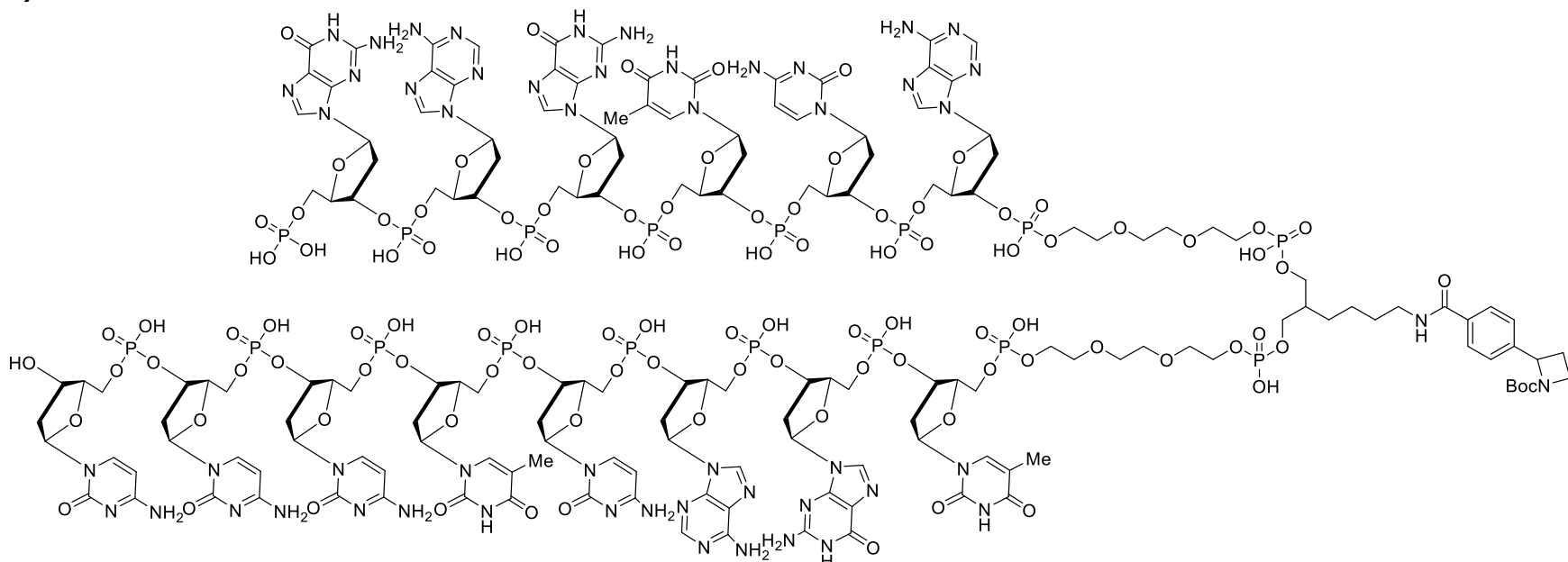

The title compound was synthesized according to the general procedure III from $\mathrm{N}$-(tertbutoxycarbonyl)azetidine-2-carboxylic acid $(4.0 \mathrm{mg}, 20 \mu \mathrm{mol})$ and the DNA-tagged aryl iodide 12. The intended product was formed in $61 \%$ yield.

$m / z=1731.1[\mathrm{M}-3 \mathrm{H}]^{3-}$

\section{Decarboxylative arylation with Boc-Pro-OH (Table 2, entry 7):}
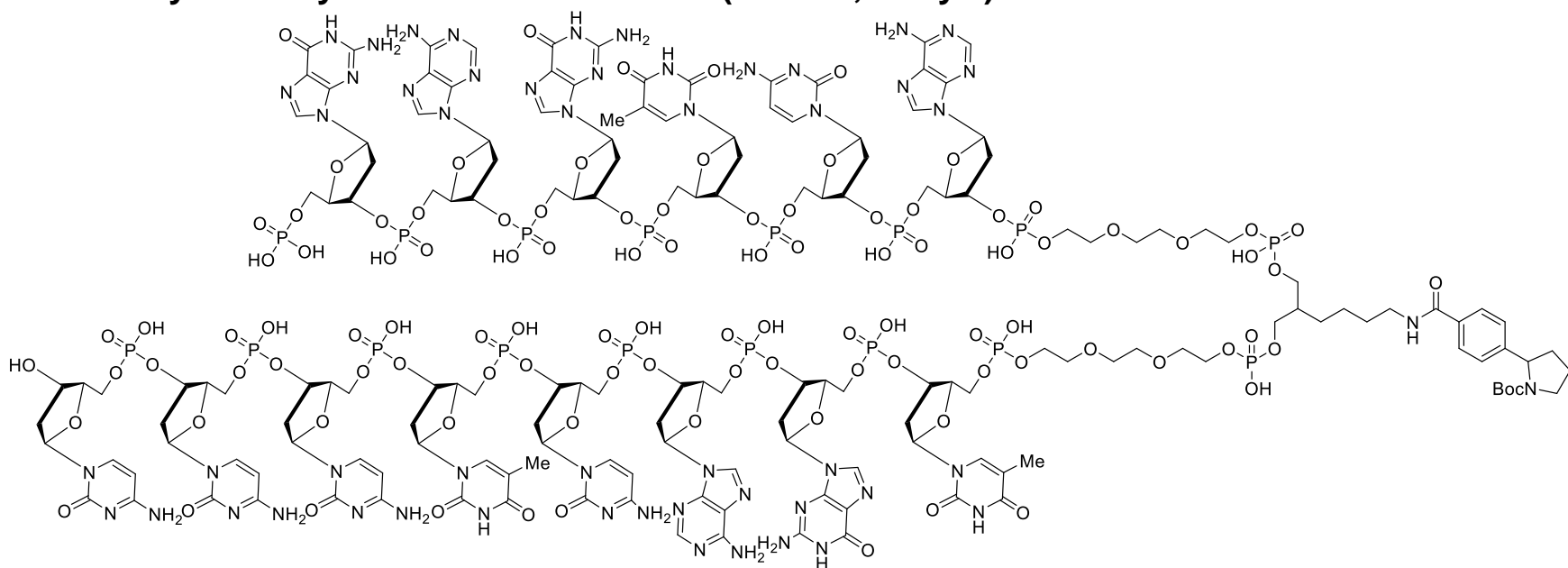

The title compound was synthesized according to the general procedure III from Boc-Pro-OH (4.3 mg, $20 \mu \mathrm{mol}$ ) and the DNA-tagged aryl iodide 12. The intended product was formed in $86 \%$ yield.

$m / z=1735.8[\mathrm{M}-3 \mathrm{H}]^{3-}$ 
Decarboxylative arylation with $N$-(tert-butoxycarbonyl)piperid ine-2-carboxylic acid (Table 2, entry 8):
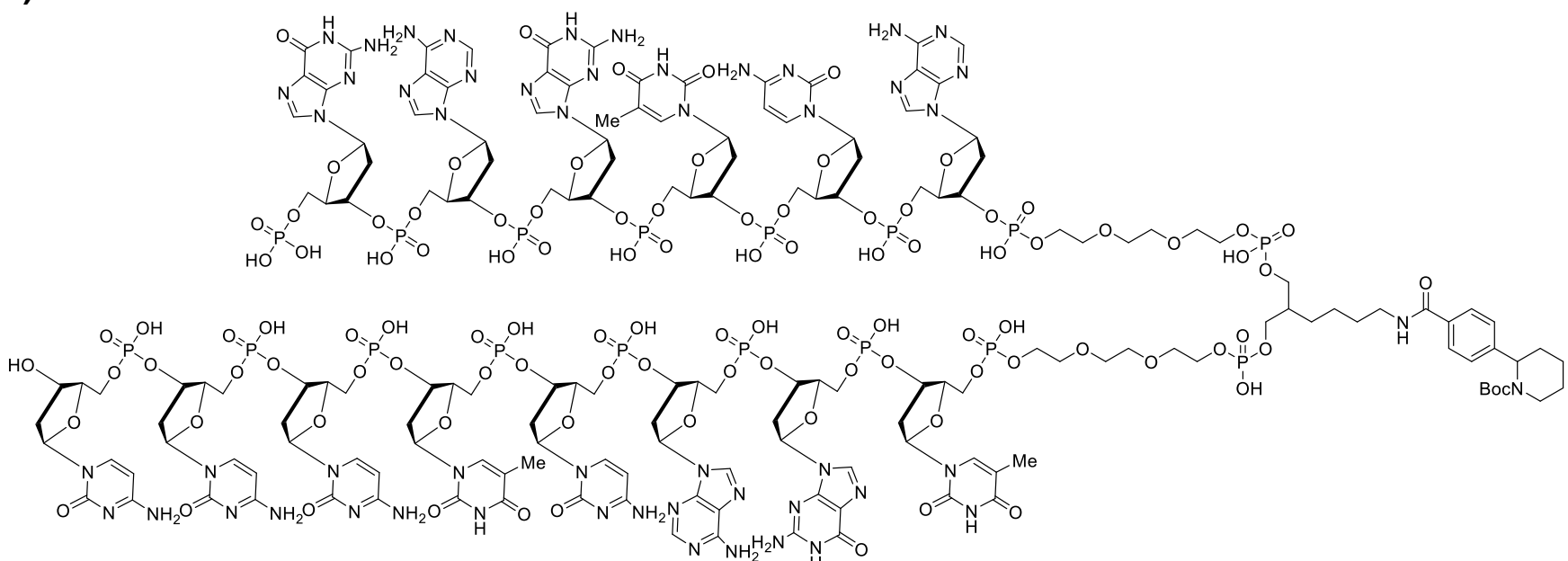

The title compound was synthesized according to the general procedure III from $\mathrm{N}$-(tertbutoxycarbonyl)piperidine-2-carboxylic acid $(4.6 \mathrm{mg}, 20 \mu \mathrm{mol})$ and the DNA-tagged aryl iodide 12. The coupling was repeated one more time (double coupling). The intended product was formed in $78 \%$ yield.

$m / z=1740.8[\mathrm{M}-3 \mathrm{H}]^{3-}$

Decarboxylative arylation with 2-(tert-butoxycarbonyl)-2-azabicyclo[2.2.1]heptane-3-carboxylic acid (Table 2, entry 9):

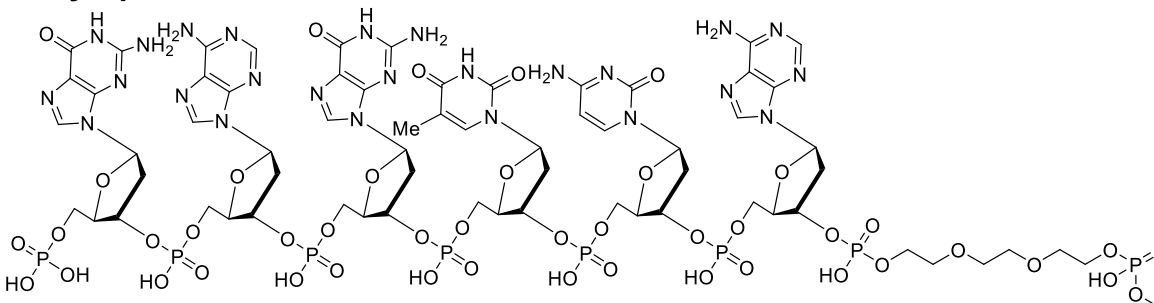

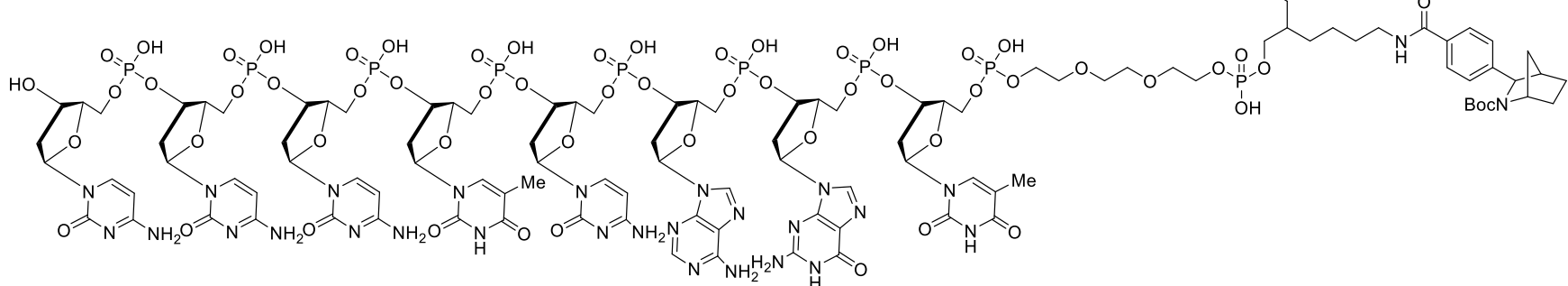

The title compound was synthesized according to the general procedure III from 2 -(tert-butoxycarbonyl)2-azabicyclo[2.2.1] heptane-3-carboxylic acid $(4.8 \mathrm{mg}, 20 \mu \mathrm{mol})$ and the DNA-tagged aryl iodide 12. The intended product was formed in $93 \%$ yield.

$m / z=1744.3[\mathrm{M}-3 \mathrm{H}]^{3-}$ 
Decarboxylative arylation with 2-(tert-butoxycarbonyl)-2-azabicyclo[2.2.2]octane-3-carboxylic acid (Table 2, entry 10):
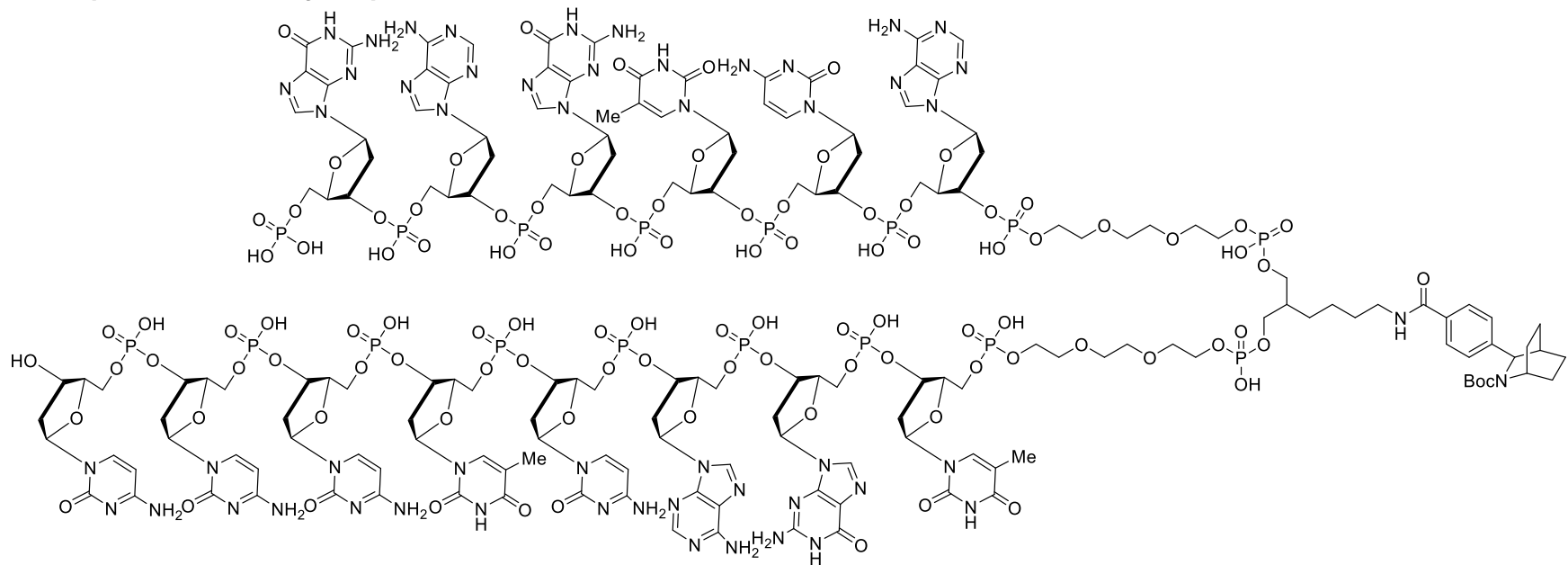

The title compound was synthesized according to the general procedure III from 2-(tert-butoxycarbonyl)2-azabicyclo[2.2.2]octane-3-carboxylic acid $(5.1 \mathrm{mg}, 20 \mu \mathrm{mol})$ and the DNA-tagged aryl iodide 12. The coupling was repeated one more time (double coupling). The intended product was formed in $75 \%$ yield.

$m / z=1749.3[\mathrm{M}-3 \mathrm{H}]^{3-}$

Decarboxylative arylation with 4-(tert-butoxycarbonyl)morpholine-3-carboxylic acid (Table 2, entry 11):
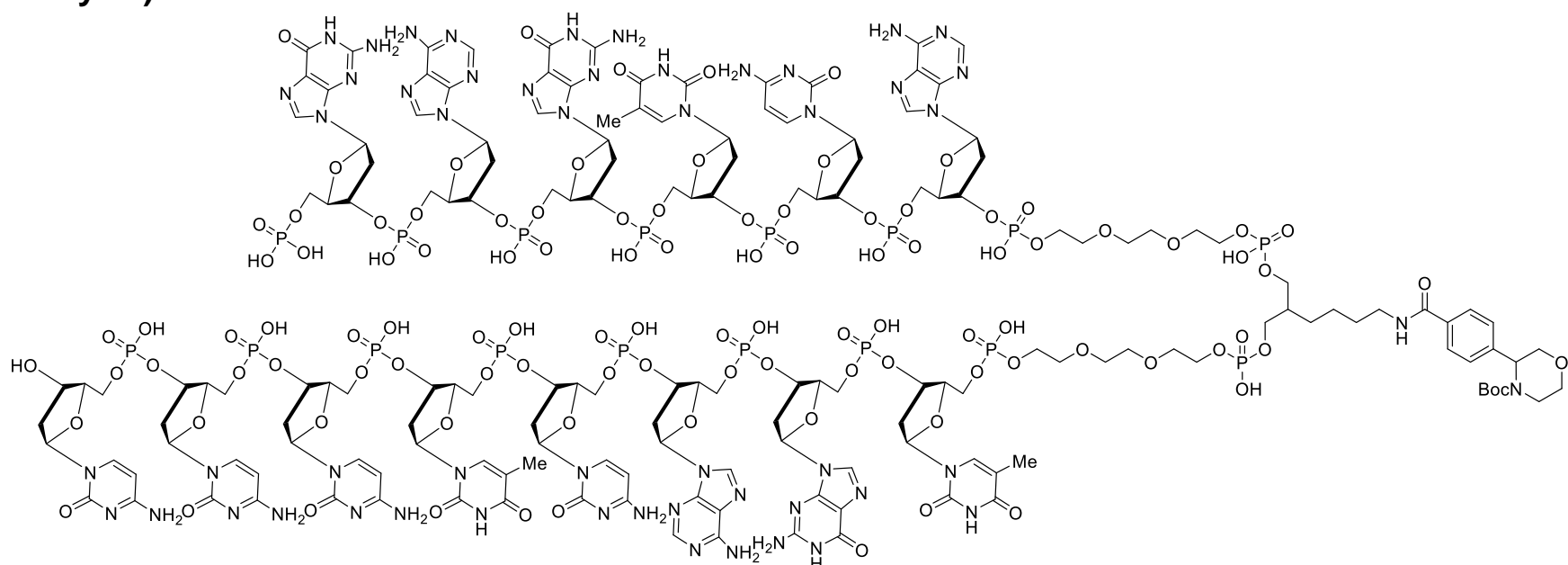

The title compound was synthesized according to the general procedure III from 4-(tertbutoxycarbonyl)morpholine-3-carboxylic acid (4.6 mg, $20 \mu \mathrm{mol})$ and the DNA-tagged aryl iodide 12. The intended product was formed in $89 \%$ yield.

$m / z=1741.1[\mathrm{M}-3 \mathrm{H}]^{3-}$ 
Decarboxylative arylation with 4-(tert-butoxycarbonyl)thiomorpholine-3-carboxylic acid (Table 2, entry 12):
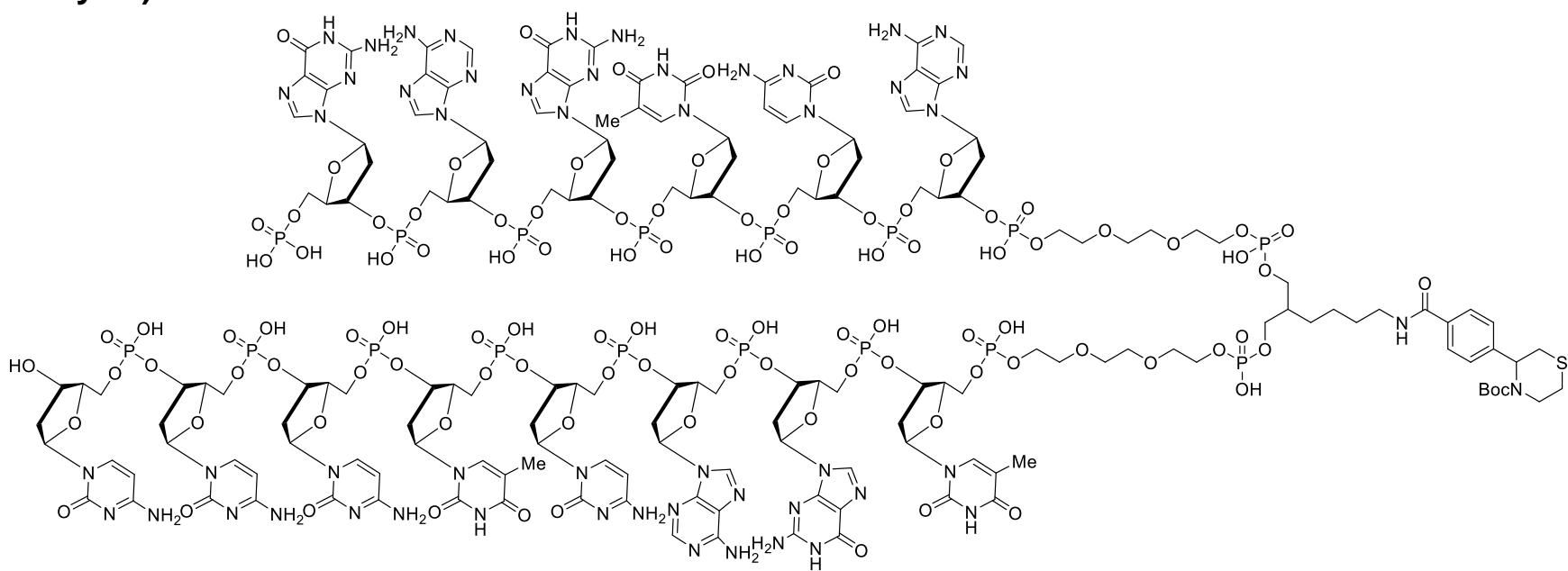

The title compound was synthesized according to the general procedure III from 4-(tertbutoxycarbonyl)thiomorpholine-3-carboxylic acid $(4.9 \mathrm{mg}, 20 \mu \mathrm{mol})$ and the DNA-tagged aryl iodide 12. The intended product was formed in $72 \%$ yield.

$m / z=1746.7[\mathrm{M}-3 \mathrm{H}]^{3-}$

Decarboxylative arylation with 1-(tert-butoxycarbonyl)-5-oxopiperazine-2-carboxylic acid (Table 2, entry 13):
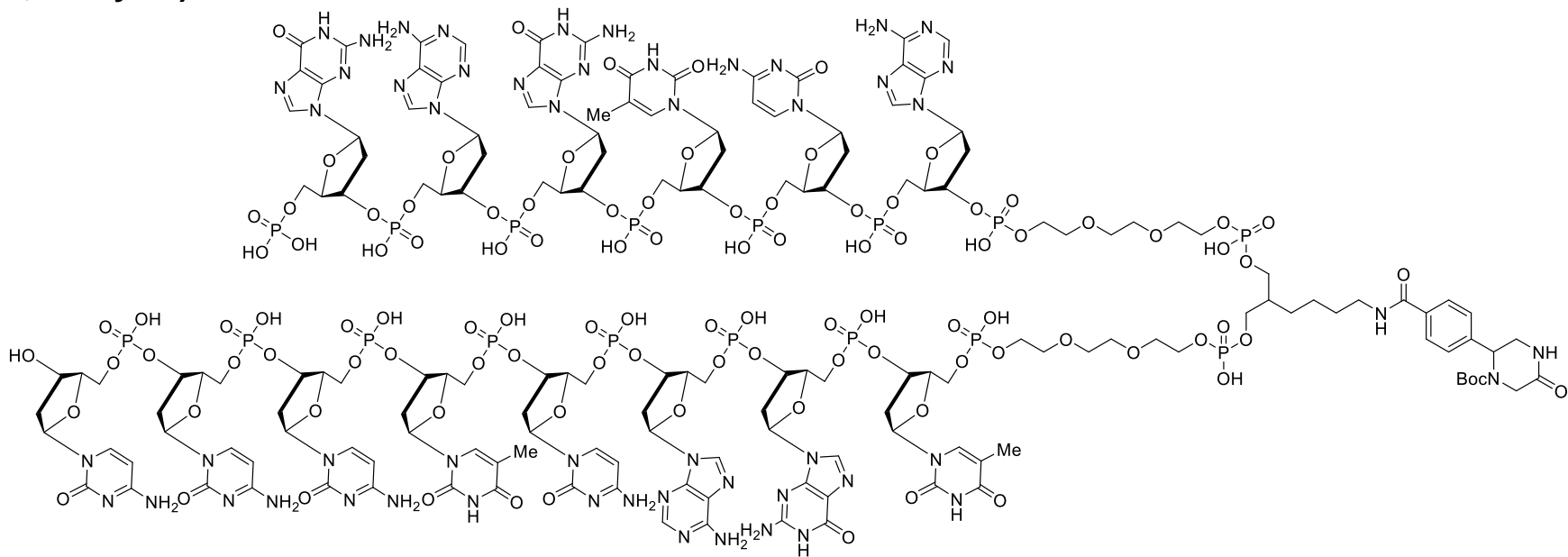

The title compound was synthesized according to the general procedure III from 1 -(tert-butoxycarbonyl)5-oxopiperazine-2-carboxylic acid $(4.9 \mathrm{mg}, 20 \mu \mathrm{mol})$ and the DNA-tagged aryl iodide 12 . The intended product was formed in $43 \%$ yield.

$m / z=1745.6[\mathrm{M}-3 \mathrm{H}]^{3-}$ 
Decarboxylative arylation with (2S,4S)-1-(tert-butoxycarbonyl)-4-fluoropyrrolidine-2-carboxylic acid (Table 2, entry 14):
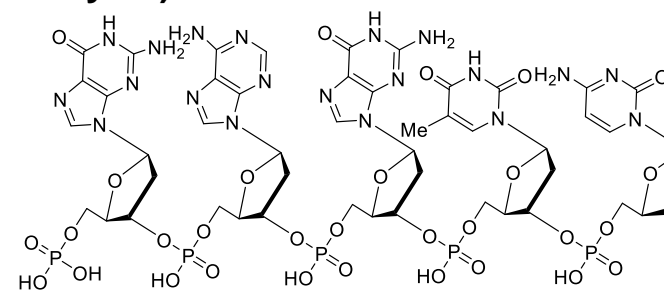<smiles></smiles>
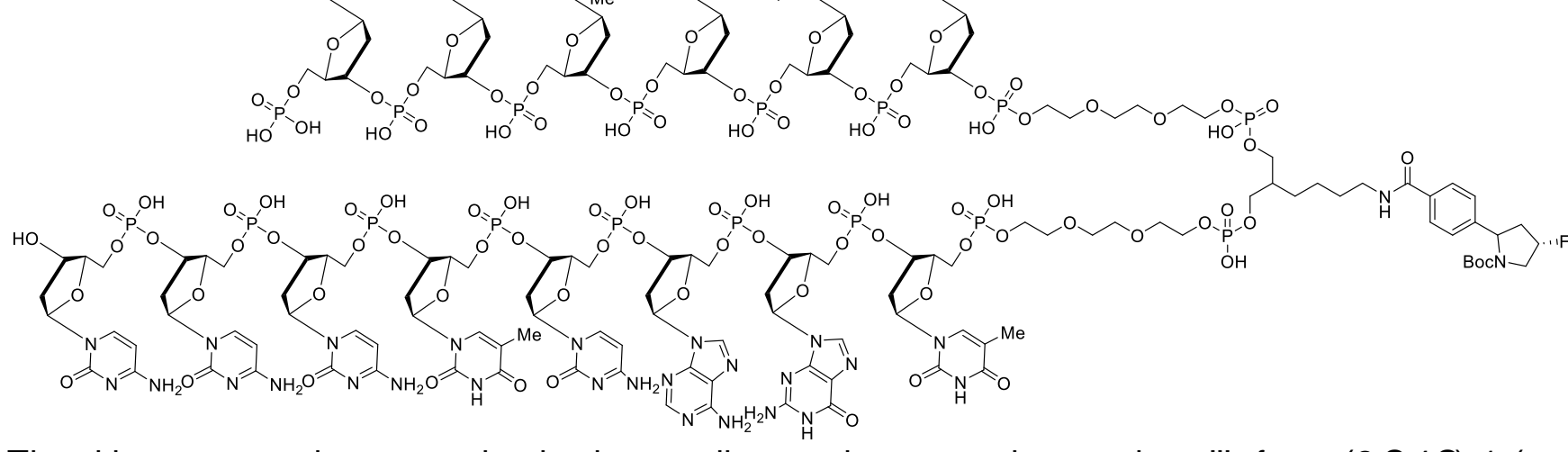

The title compound was synthesized according to the general procedure III from (2S,4S)-1-(tertbutoxycarbonyl)-4-fluoropyrrolidine-2-carboxylic acid $(4.7 \mathrm{mg}, 20 \mu \mathrm{mol})$ and the DNA-tagged aryl iodide 12. The intended product was formed in $84 \%$ yield.

$\mathrm{m} / \mathrm{z}=1742.0[\mathrm{M}-3 \mathrm{H}]^{3-}$

Decarboxylative arylation with (6S)-5-(tert-butoxycarbonyl)-1,1-difluoro-5-azaspiro[2.4]heptane6-carboxylic acid (Table 2, entry 15):

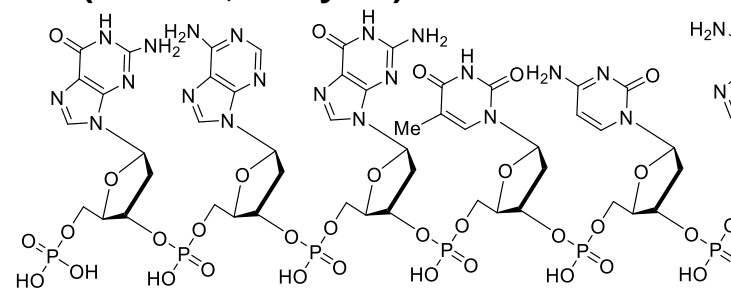<smiles>Cn1cnc2c(N)ncnc21</smiles>

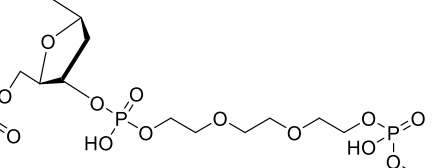

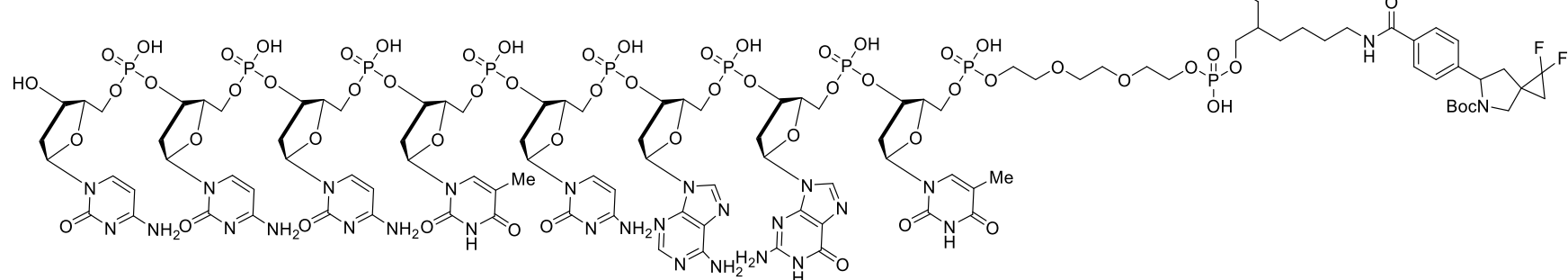

The title compound was synthesized according to the general procedure III from (6S)-5-(tertbutoxycarbonyl)-1,1-difluoro-5-azaspiro[2.4] heptane-6-carboxylic acid (5.5 mg, $20 \mu \mathrm{mol})$ and the DNAtagged aryl iodide 12 . The intended product was formed in $78 \%$ yield.

$m / z=1756.6[\mathrm{M}-3 \mathrm{H}]^{3-}$ 
Decarboxylative arylation with (2S,4R)-1-(tert-butoxycarbonyl)-4-hydroxypyrrolidine-2carboxylic acid (Table 2, entry 16):
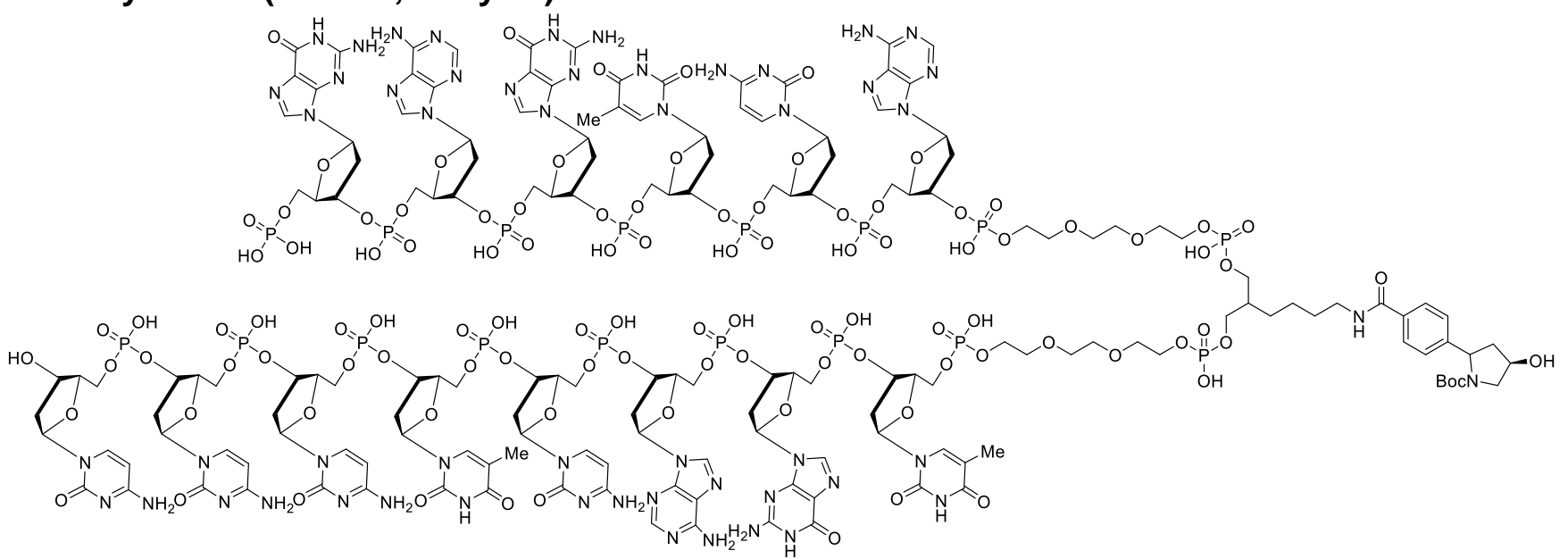

The title compound was synthesized according to the general procedure III from $(2 S, 4 R)-1-($ tertbutoxycarbonyl)-4-hydroxypyrrolidine-2-carboxylic acid $(4.6 \mathrm{mg}, 20 \mu \mathrm{mol})$ and the DNA-tagged aryl iodide 12. The intended product was formed in $57 \%$ yield.

$m / z=1741.0[\mathrm{M}-3 \mathrm{H}]^{3-}$

Decarboxylative arylation with (S)-1-(tert-butoxycarbonyl)-4-oxopyrrolidine-2-carboxylic acid (Table 2, entry 17):

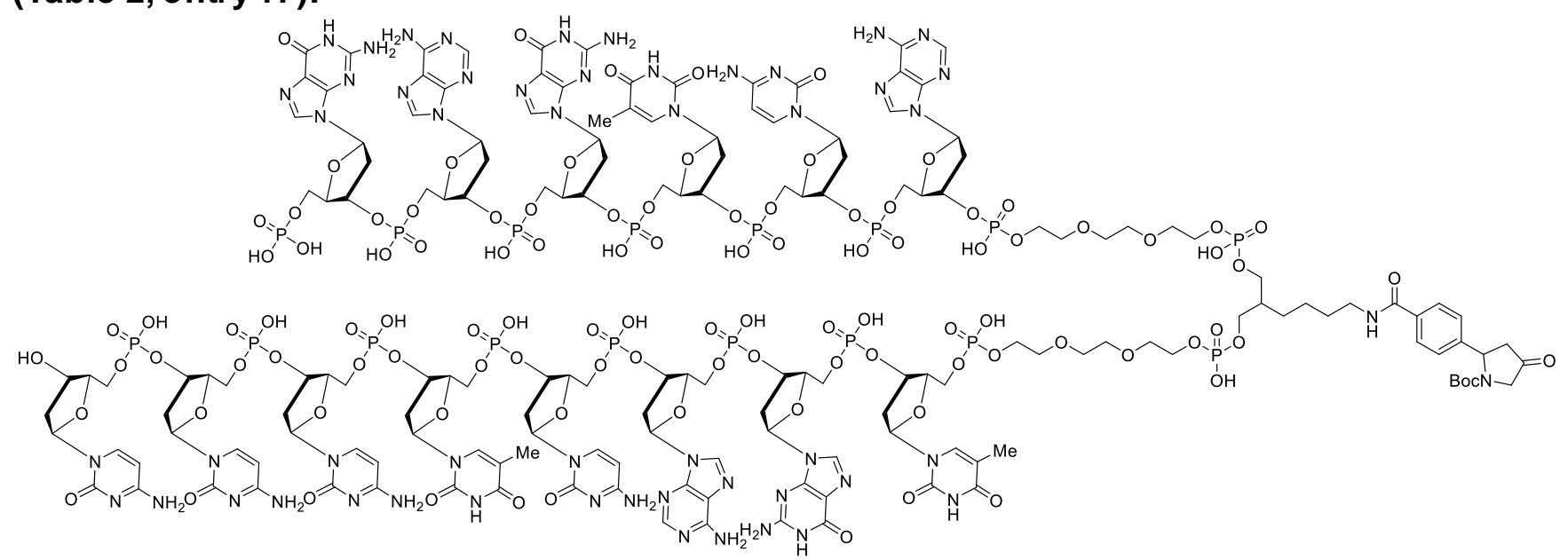

The title compound was synthesized according to the general procedure III from (S)-1-(tertbutoxycarbonyl)-4-oxopyrrolidine-2-carboxylic acid (4.6 mg, $20 \mu \mathrm{mol}$ ) and the DNA-tagged aryl iodide 12. The intended product was formed in $48 \%$ yield.

$m / z=1740.3[\mathrm{M}-3 \mathrm{H}]^{3-}$ 
Decarboxylative arylation with (2S,4S)-1-(tert-butoxycarbonyl)-4-(2,4-difluorophenoxy)pyrrolidine-2-carboxylic acid (Table 2, entry 18):

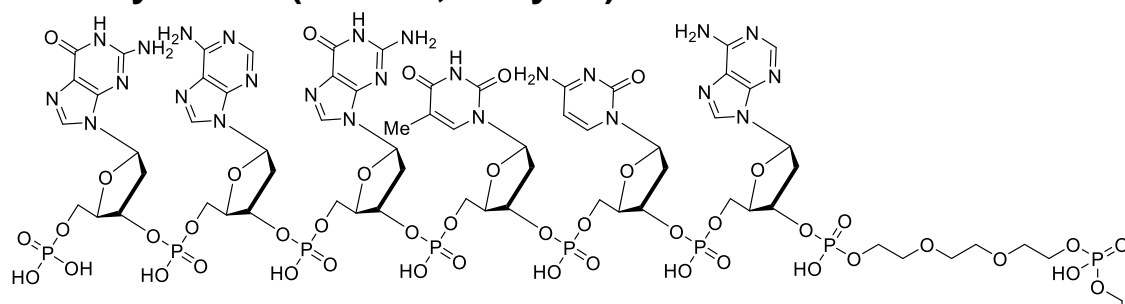

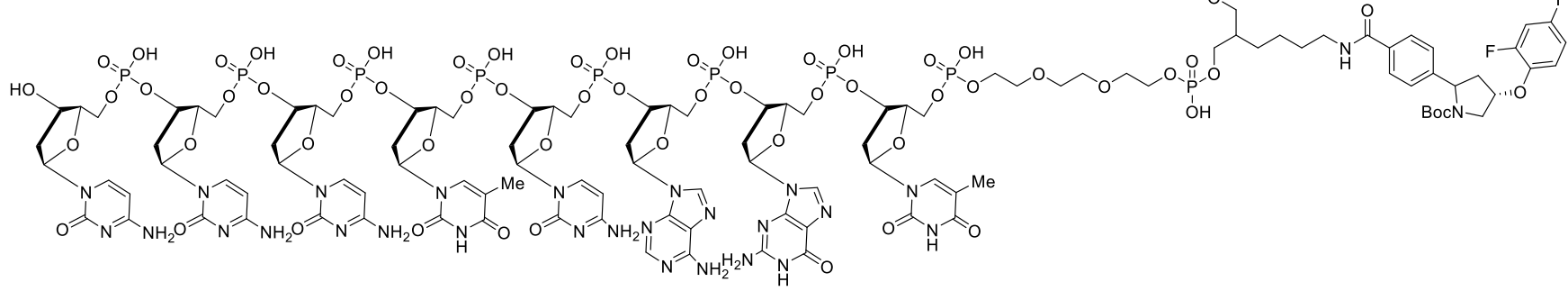

The title compound was synthesized according to the general procedure III from (2S,4S)-1-(tertbutoxycarbonyl)-4-(2,4-difluorophenoxy)pyrrolidine-2-carboxylic acid $(6.9 \mathrm{mg}, 20 \mu \mathrm{mol})$ and the DNAtagged aryl iodide 12. The coupling was repeated one more time (double coupling). The intended product was formed in $68 \%$ yield.

$m / z=1778.7[\mathrm{M}-3 \mathrm{H}]^{3-}$

Decarboxylative arylation with (3aS,7aS)-1-(tert-butoxycarbonyl)octahydro-1H-indole-2carboxylic acid (Table 2, entry 19):

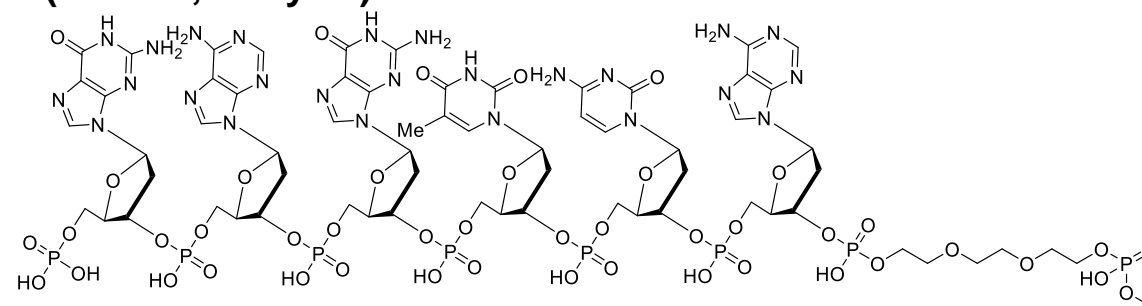

(10)

The title compound was synthesized according to the general procedure III from (3aS,7aS)-1-(tertbutoxycarbonyl)octahydro- $1 \mathrm{H}$-indole-2-carboxylic acid $(5.4 \mathrm{mg}, 20 \mu \mathrm{mol})$ and the DNA-tagged aryl iodide 12. The coupling was repeated one more time (double coupling). The intended product was formed in $56 \%$ yield.

$m / z=1753.9[\mathrm{M}-3 \mathrm{H}]^{3-}$ 
Decarboxylative arylation with 1-(tert-butoxycarbonyl)indoline-2-carboxylic acid (Table 2, entry 20):
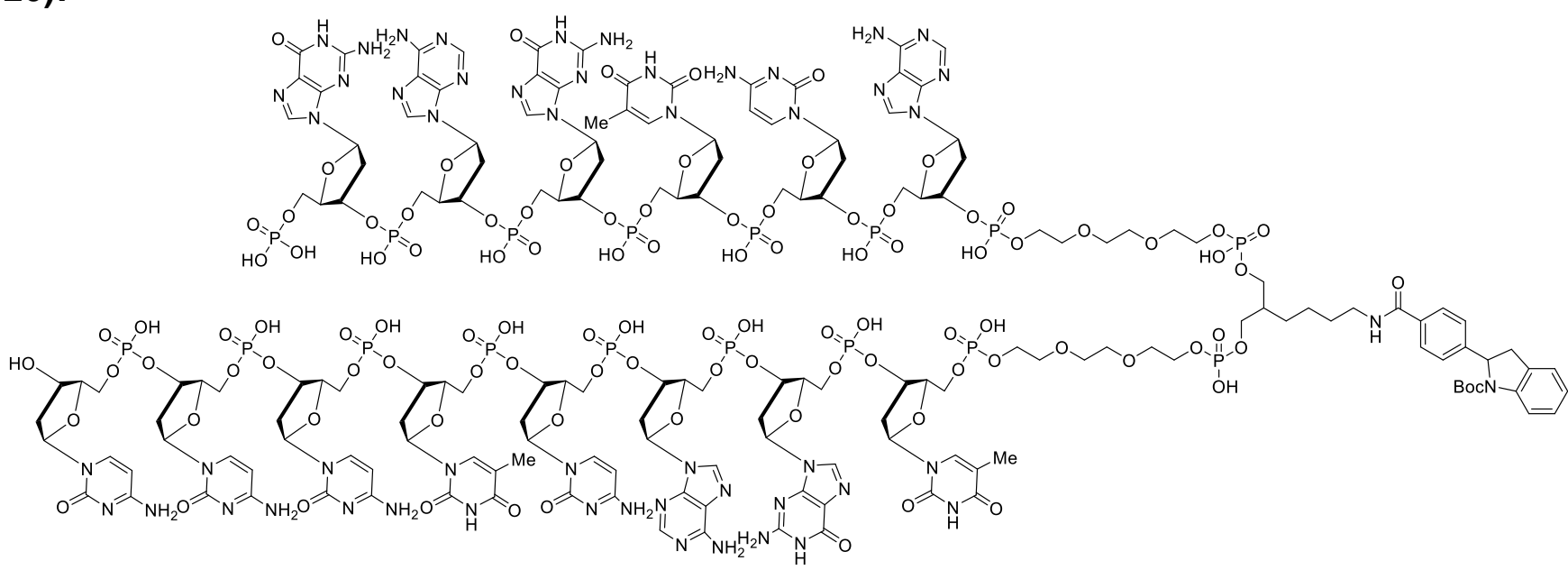

The title compound was synthesized according to the general procedure III from 1 -(tertbutoxycarbonyl) indoline-2-carboxylic acid $(5.3 \mathrm{mg}, 20 \mu \mathrm{mol})$ and the DNA-tagged aryl iodide 12. The coupling was repeated one more time (double coupling). The intended product was formed in $75 \%$ yield.

$m / z=1751.6[\mathrm{M}-3 \mathrm{H}]^{3-}$

Decarboxylative arylation with 1-(tert-butoxycarbonyl)piperidine-4-carboxylic acid (Table 2, entry 21):
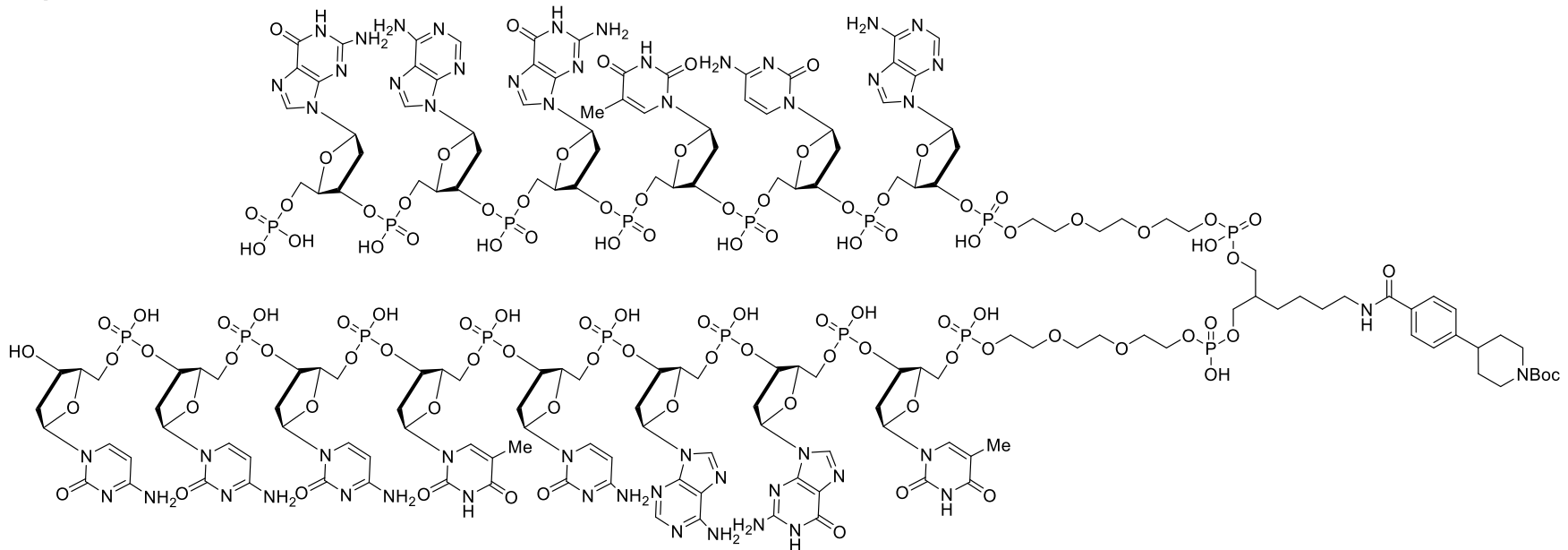

The title compound was synthesized according to the general procedure III from 1-(tertbutoxycarbonyl)piperidine-4-carboxylic acid $(4.6 \mathrm{mg}, 20 \mu \mathrm{mol})$ and the DNA-tagged aryl iodide 12. The intended product was formed in $1 \%$ yield.

$m / z=1740.5[\mathrm{M}-3 \mathrm{H}]^{3-}$ 
Decarboxylative arylation with 1-(tert-butoxycarbonyl)-2-methylpyrrolidine-2-carboxylic acid (Table 2, entry 22):
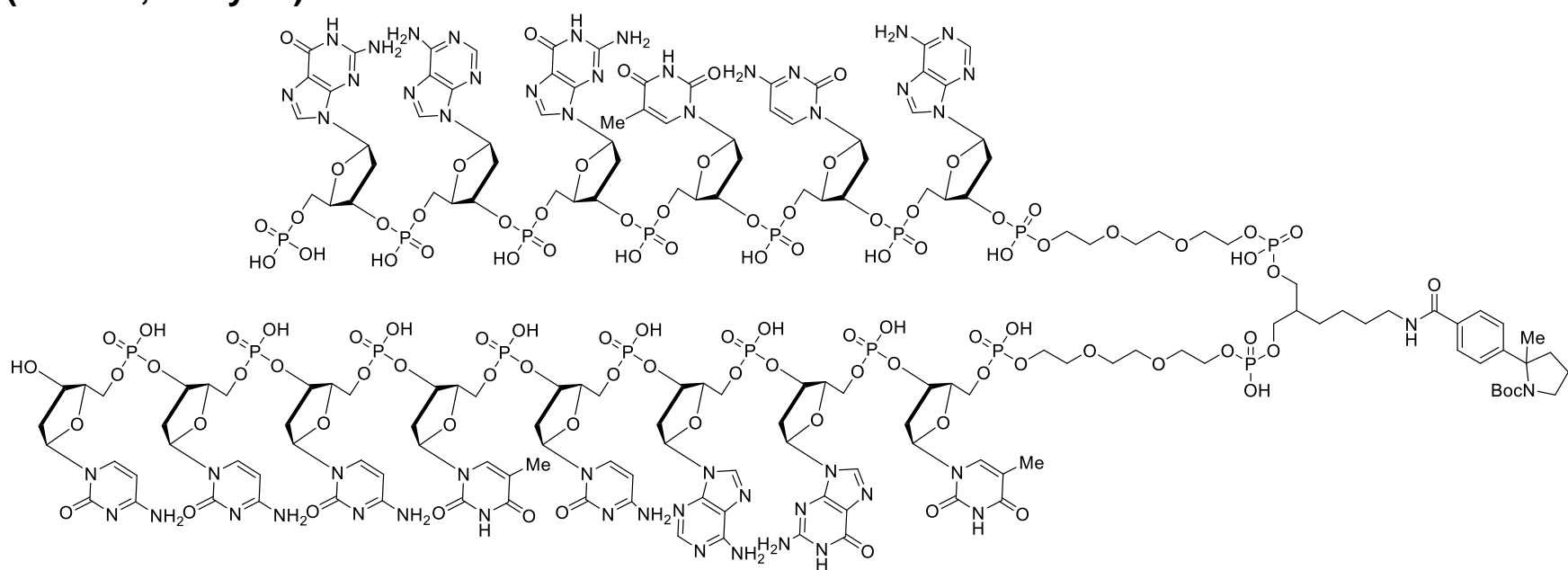

The title compound was synthesized according to the general procedure III from 1 -(tert-butoxycarbonyl)2-methylpyrrolidine-2-carboxylic acid $(4.6 \mathrm{mg}, 20 \mu \mathrm{mol})$ and the DNA-tagged aryl iodide 12. The intended product was formed in $10 \%$ yield.

$m / z=1740.5[\mathrm{M}-3 \mathrm{H}]^{3-}$

Decarboxylative arylation with Boc-Ala-OH (Table 2, entry 23):
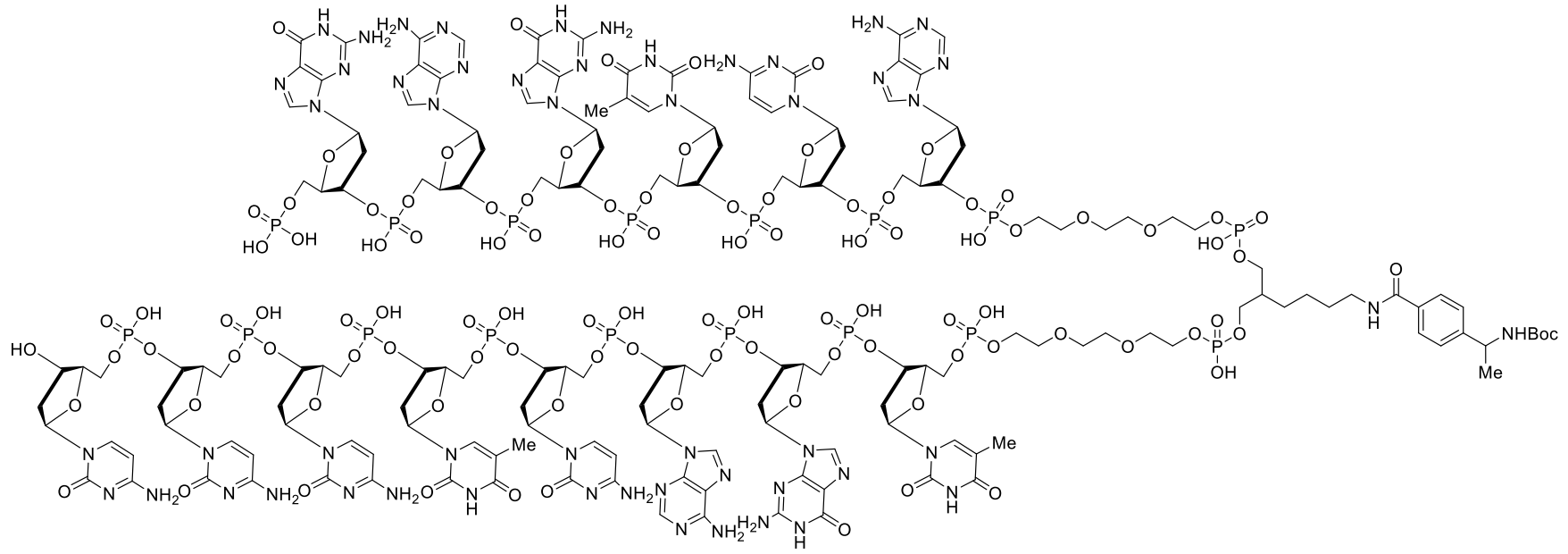

The title compound was synthesized according to the general procedure III from Boc-Ala-OH (3.8 mg, $20 \mu \mathrm{mol}$ ) and the DNA-tagged aryl iodide 12. The intended product was formed in $9 \%$ yield.

$m / z=1727.1[\mathrm{M}-3 \mathrm{H}]^{3-}$ 
Decarboxylative arylation with Boc-Phe-OH (Table 2, entry 24):
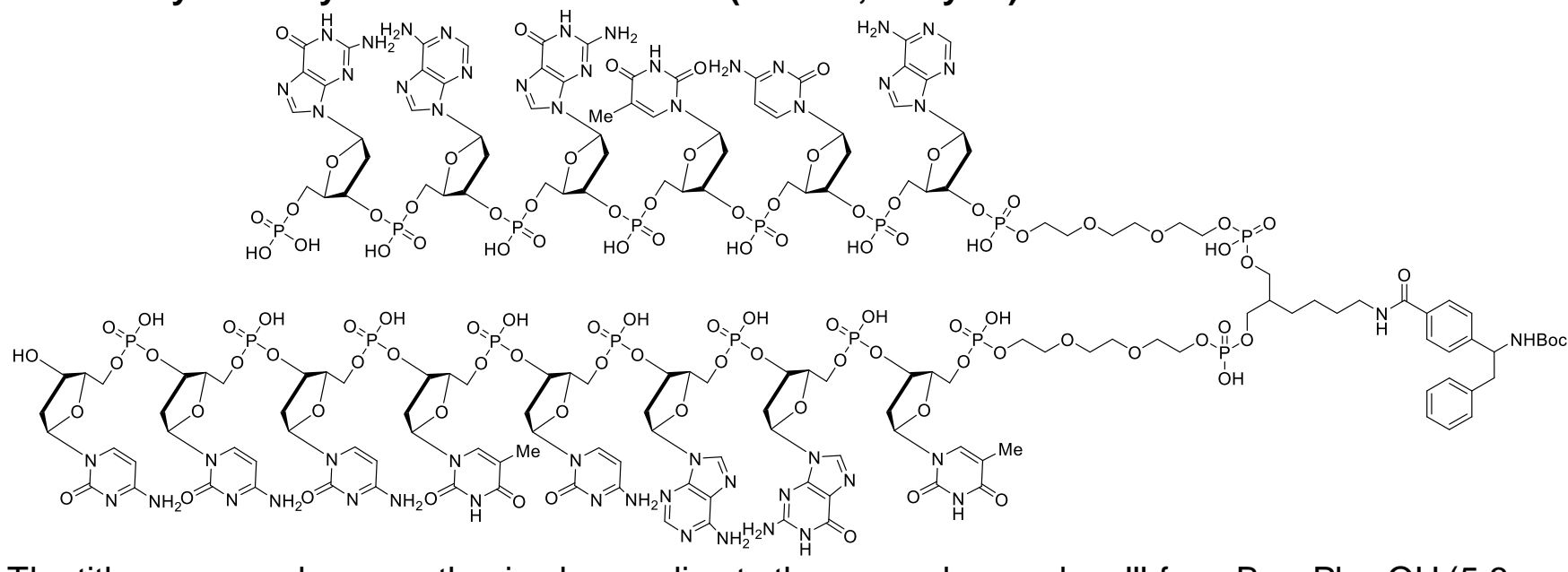

The title compound was synthesized according to the general procedure III from Boc-Phe-OH $(5.3 \mathrm{mg}$, $20 \mu \mathrm{mol}$ ) and the DNA-tagged aryl iodide 12. The intended product was formed in $40 \%$ yield.

$m / z=1752.5[\mathrm{M}-3 \mathrm{H}]^{3-}$

Decarboxylative arylation with Boc-His-OH (Table 2, entry 25):
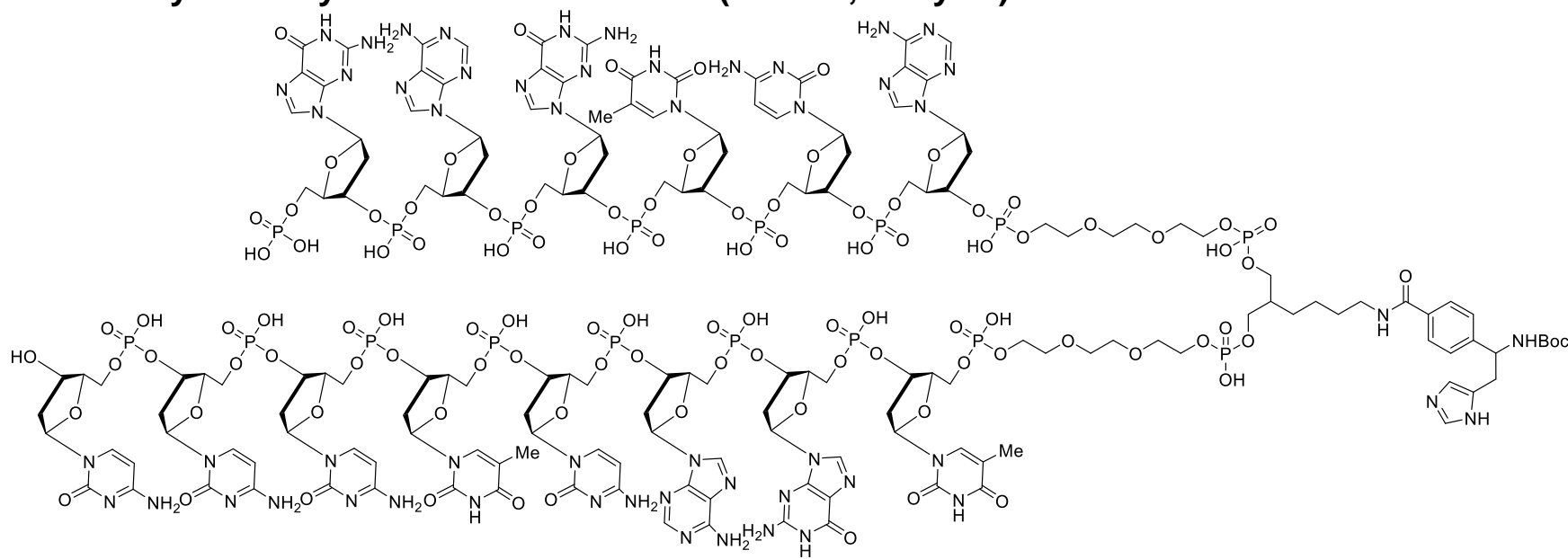

The title compound was synthesized according to the general procedure III from Boc-His-OH $(5.1 \mathrm{mg}$, $20 \mu \mathrm{mol}$ ) and the DNA-tagged aryl iodide 12. The intended product was formed in $50 \%$ yield.

$m / z=1749.0[\mathrm{M}-3 \mathrm{H}]^{3-}$ 
Decarboxylative arylation with Boc-Met-OH (Table 2, entry 26):
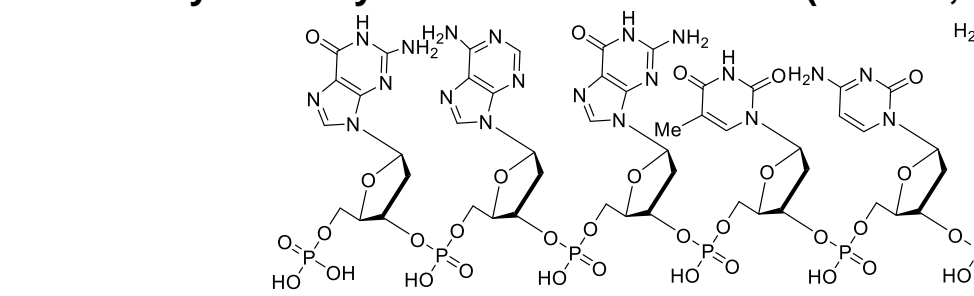<smiles>Cn1cnc2c1NC=NC2</smiles>
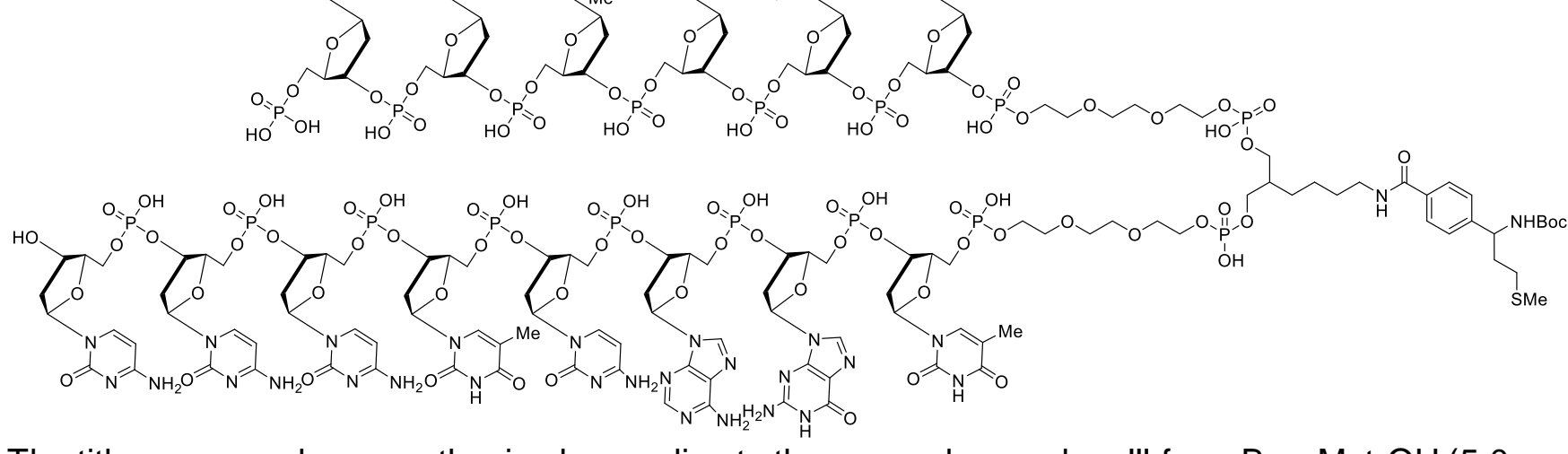

The title compound was synthesized according to the general procedure III from Boc-Met-OH (5.0 mg, $20 \mu \mathrm{mol})$ and the DNA-tagged aryl iodide 12. The intended product was formed in $72 \%$ yield.

$m / z=1747.3[\mathrm{M}-3 \mathrm{H}]^{3-}$

Decarboxylative arylation with aryl iodide S1 (Table 3, entry 1):
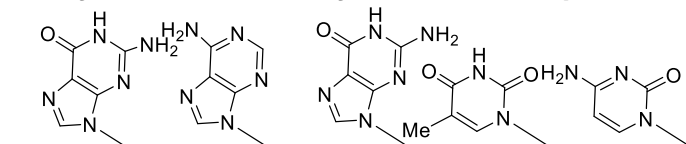<smiles>Cn1cnc2c(N)ncnc21</smiles><smiles>CCCC(COCC(C)O)OCC(C)CCO</smiles><smiles>[O]C1CCCCC1O</smiles>

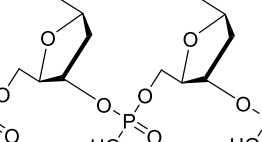<smiles>C1CC2CCCC2C1</smiles>

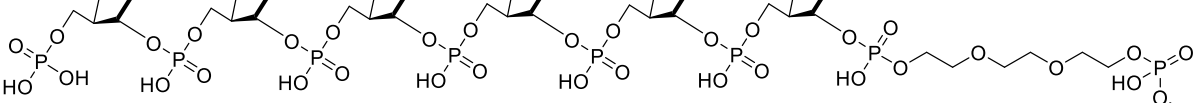

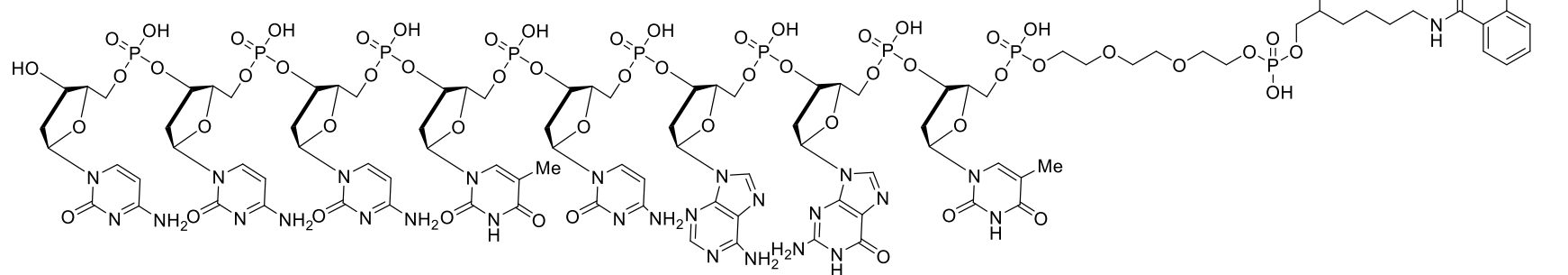

The title compound was synthesized according to the general procedure III from 4-(tertbutoxycarbonyl)morpholine-3-carboxylic acid $(4.6 \mathrm{mg}, 20 \mu \mathrm{mol})$ and the DNA-tagged aryl iodide S1. The intended product was formed in $51 \%$ yield.

$m / z=1741.0[\mathrm{M}-3 \mathrm{H}]^{3-}$ 
Decarboxylative arylation with aryl iodide S2 (Table 3, entry 2):

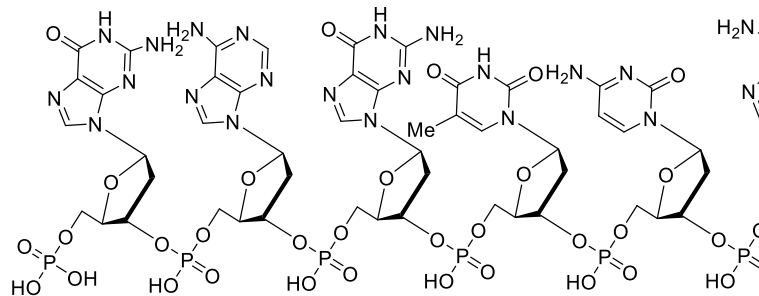<smiles>Cn1cnc2c(N)ncnc21</smiles>

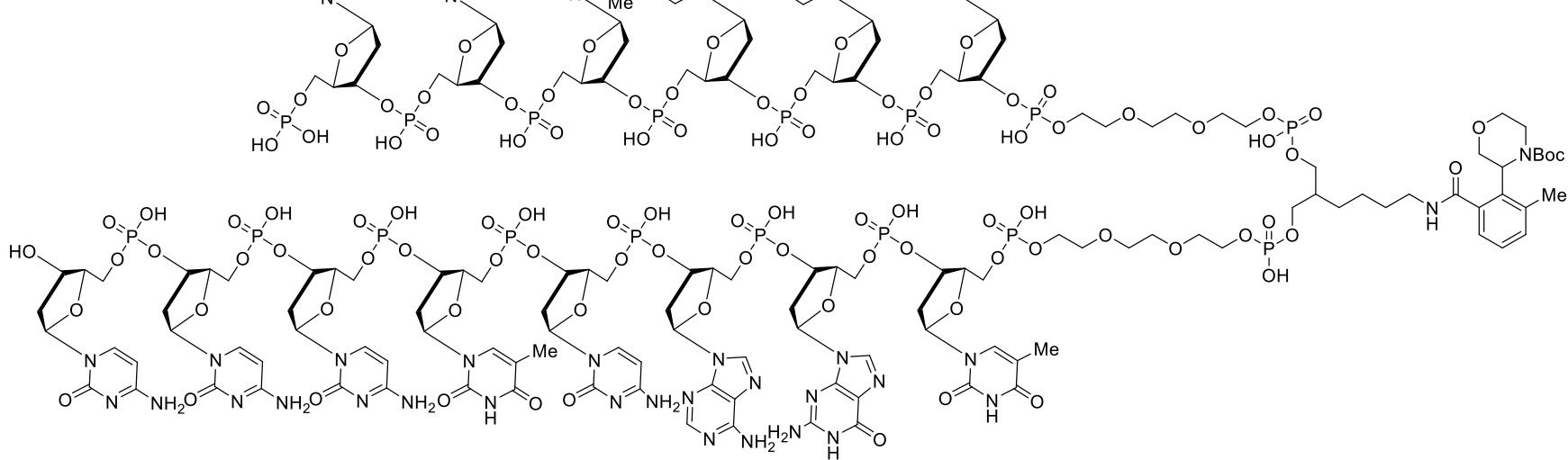

The title compound was synthesized according to the general procedure III from 4 -(tertbutoxycarbonyl)morpholine-3-carboxylic acid $(4.6 \mathrm{mg}, 20 \mu \mathrm{mol})$ and the DNA-tagged aryl iodide $\mathbf{S} 2$. The intended product was formed in $42 \%$ yield.

$m / z=1745.7[\mathrm{M}-3 \mathrm{H}]^{3-}$

Decarboxylative arylation with aryl iodide S3 (Table 3, entry 3):
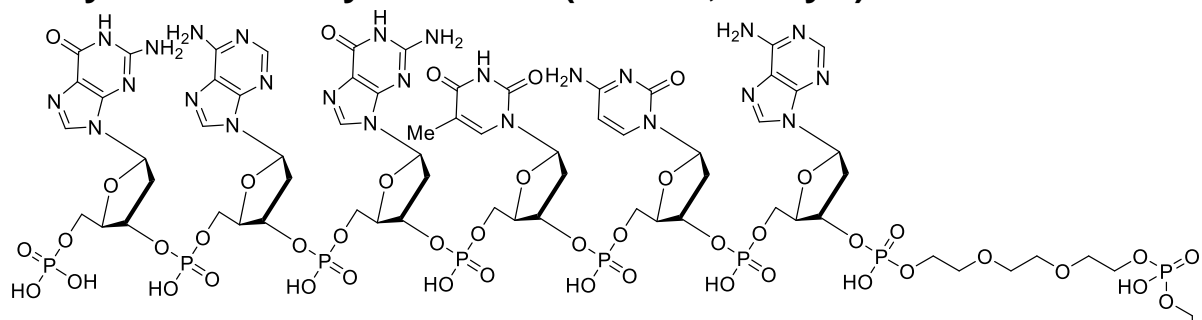

(n)

The title compound was synthesized according to the general procedure III from 4-(tertbutoxycarbonyl)morpholine-3-carboxylic acid (4.6 mg, $20 \mu \mathrm{mol})$ and the DNA-tagged aryl iodide S3. The intended product was formed in $36 \%$ yield.

$m / z=1755.7[\mathrm{M}-3 \mathrm{H}]^{3-}$ 
Decarboxylative arylation with aryl iodide S4 (Table 3, entry 4):
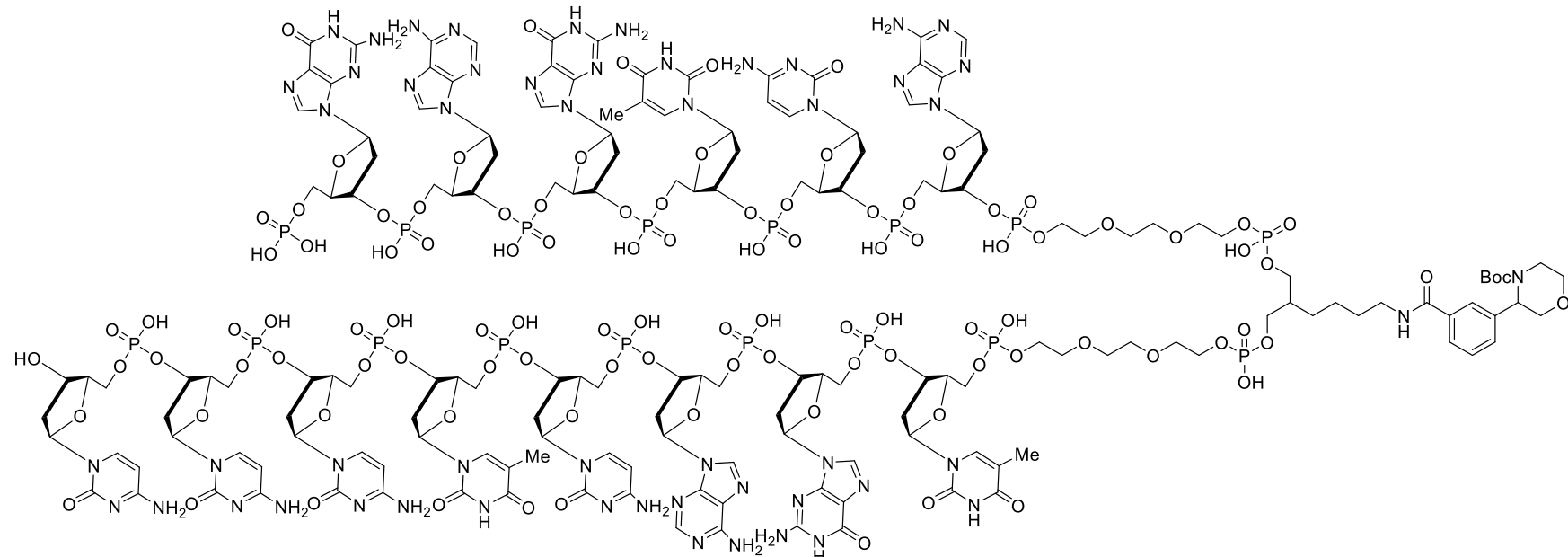

The title compound was synthesized according to the general procedure III from 4-(tertbutoxycarbonyl)morpholine-3-carboxylic acid $(4.6 \mathrm{mg}, 20 \mu \mathrm{mol})$ and the DNA-tagged aryl iodide S4. The coupling was repeated one more time (double coupling). The intended product was formed in $74 \%$ yield.

$m / z=1741.0[\mathrm{M}-3 \mathrm{H}]^{3-}$

Decarboxylative arylation with aryl iodide S5 (Table 3, entry 5):

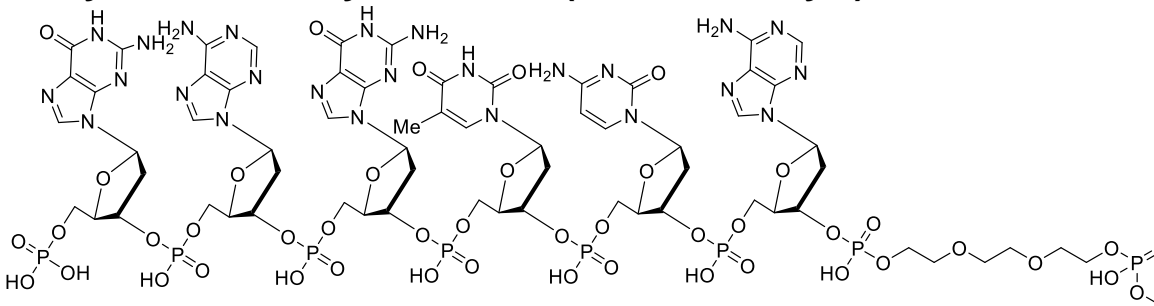

(n)

The title compound was synthesized according to the general procedure III from 4-(tertbutoxycarbonyl)morpholine-3-carboxylic acid $(4.6 \mathrm{mg}, 20 \mu \mathrm{mol})$ and the DNA-tagged aryl iodide S5. The intended product was formed in $51 \%$ yield. In addition, $14 \%$ of a dialkylated side product was observed.

$m / z$ (product) $=1767.6[\mathrm{M}-3 \mathrm{H}]^{3-}$

$\mathrm{m} / \mathrm{z}$ (dialkylated side product $)=1802.7[\mathrm{M}-3 \mathrm{H}]^{3-}$ 
Decarboxylative arylation with aryl iodide S6 (Table 3, entry 6):
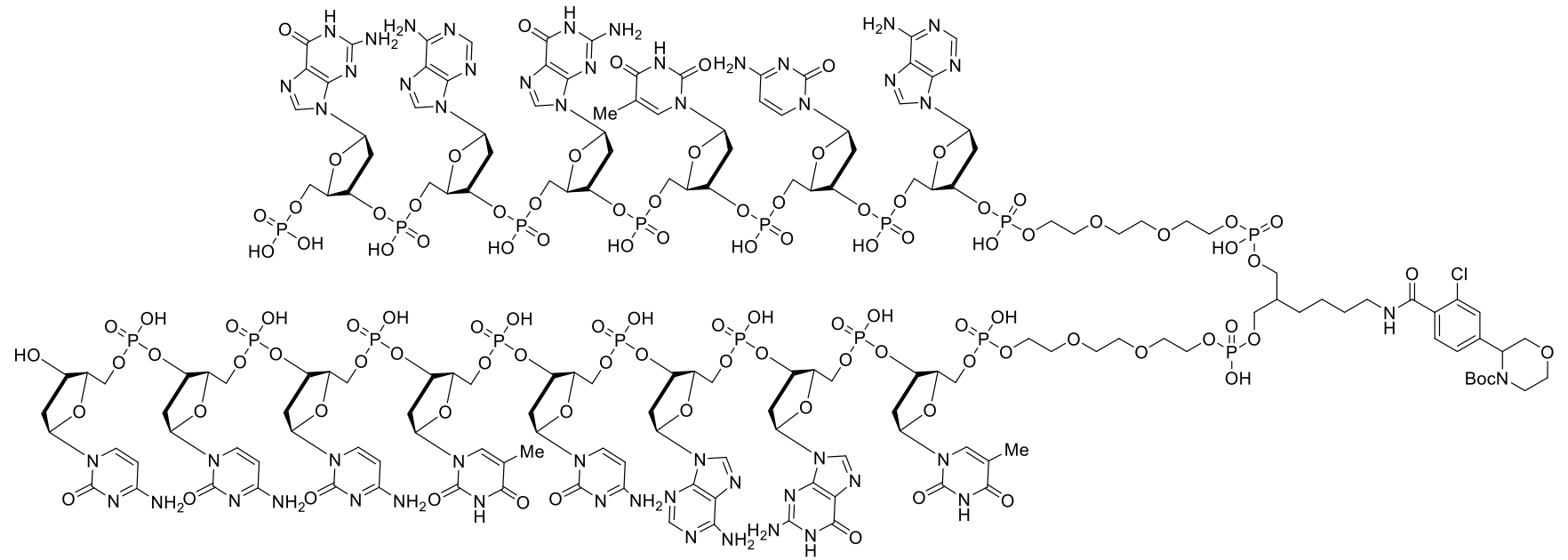

The title compound was synthesized according to the general procedure III from 4-(tertbutoxycarbonyl)morpholine-3-carboxylic acid $(4.6 \mathrm{mg}, 20 \mu \mathrm{mol})$ and the DNA-tagged aryl iodide S6. The intended product was formed in $68 \%$ yield.

$m / z=1752.6[\mathrm{M}-3 \mathrm{H}]^{3-}$

Decarboxylative arylation with aryl iodide S7 (Table 3, entry 7):

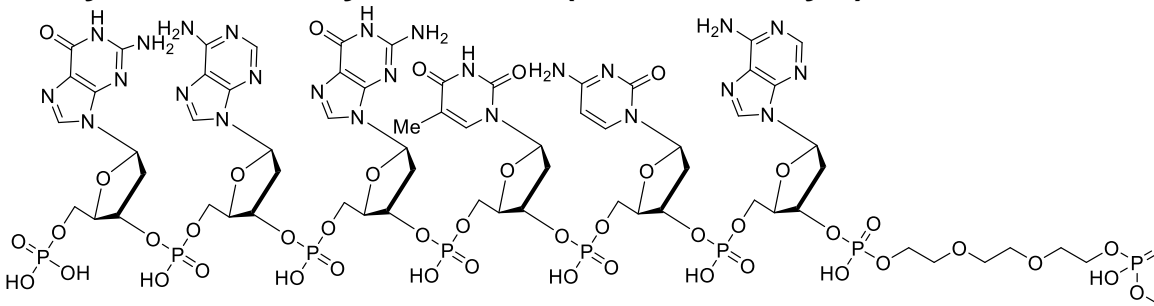

(n)

The title compound was synthesized according to the general procedure III from 4-(tertbutoxycarbonyl)morpholine-3-carboxylic acid $(4.6 \mathrm{mg}, 20 \mu \mathrm{mol})$ and the DNA-tagged aryl iodide S7. The intended product was formed in $87 \%$ yield.

$m / z=1746.9[\mathrm{M}-3 \mathrm{H}]^{3-}$ 
Decarboxylative arylation with aryl iodide S8 (Table 3, entry 8):
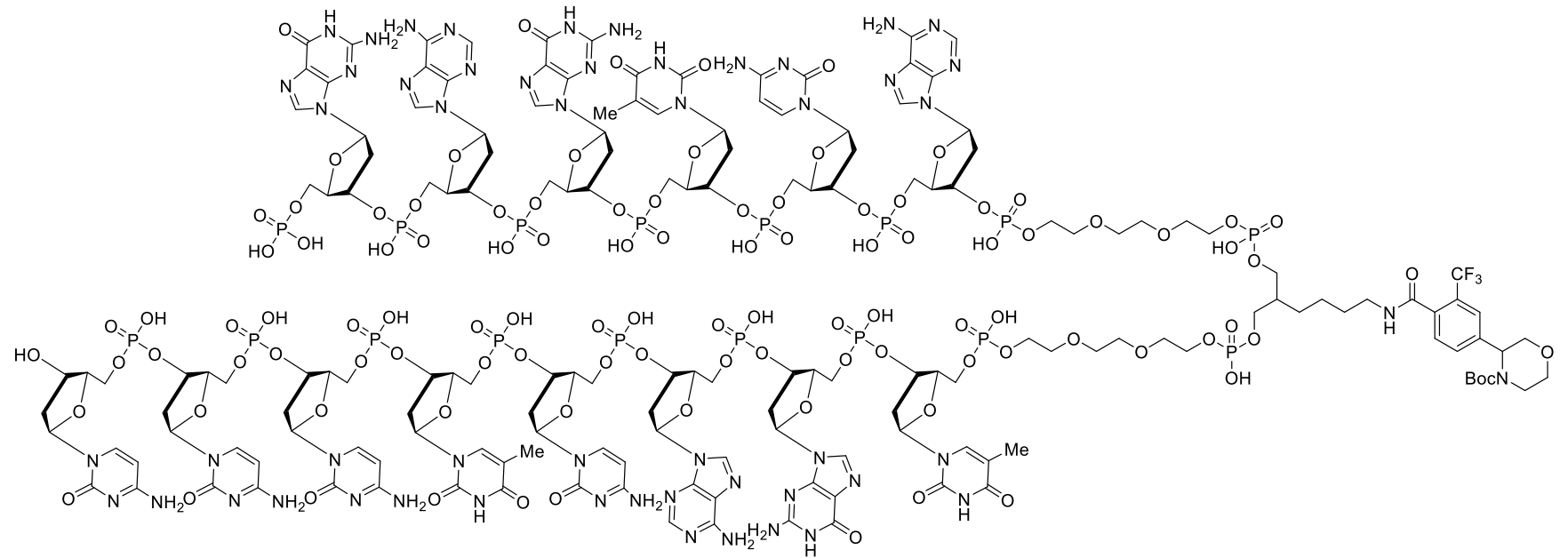

The title compound was synthesized according to the general procedure III from 4 -(tertbutoxycarbonyl)morpholine-3-carboxylic acid (4.6 mg, $20 \mu \mathrm{mol})$ and the DNA-tagged aryl iodide S8. The intended product was formed in $82 \%$ yield.

$m / z=1763.3[\mathrm{M}-3 \mathrm{H}]^{3-}$

Decarboxylative arylation with aryl iodide S9 (Table 3, entry 9):

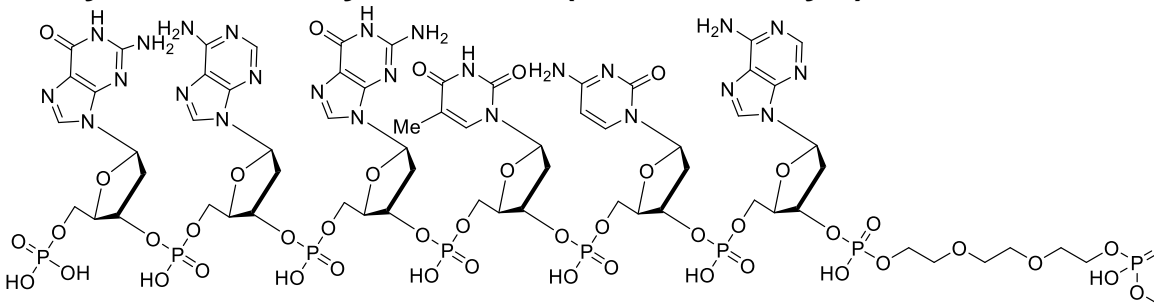

(n)

The title compound was synthesized according to the general procedure III from 4-(tertbutoxycarbonyl)morpholine-3-carboxylic acid (4.6 mg, $20 \mu \mathrm{mol})$ and the DNA-tagged aryl iodide S9. The intended product was formed in $86 \%$ yield.

$m / z=1751.0[\mathrm{M}-3 \mathrm{H}]^{3-}$ 
Decarboxylative arylation with aryl iodide S10 (Table 3, entry 10):
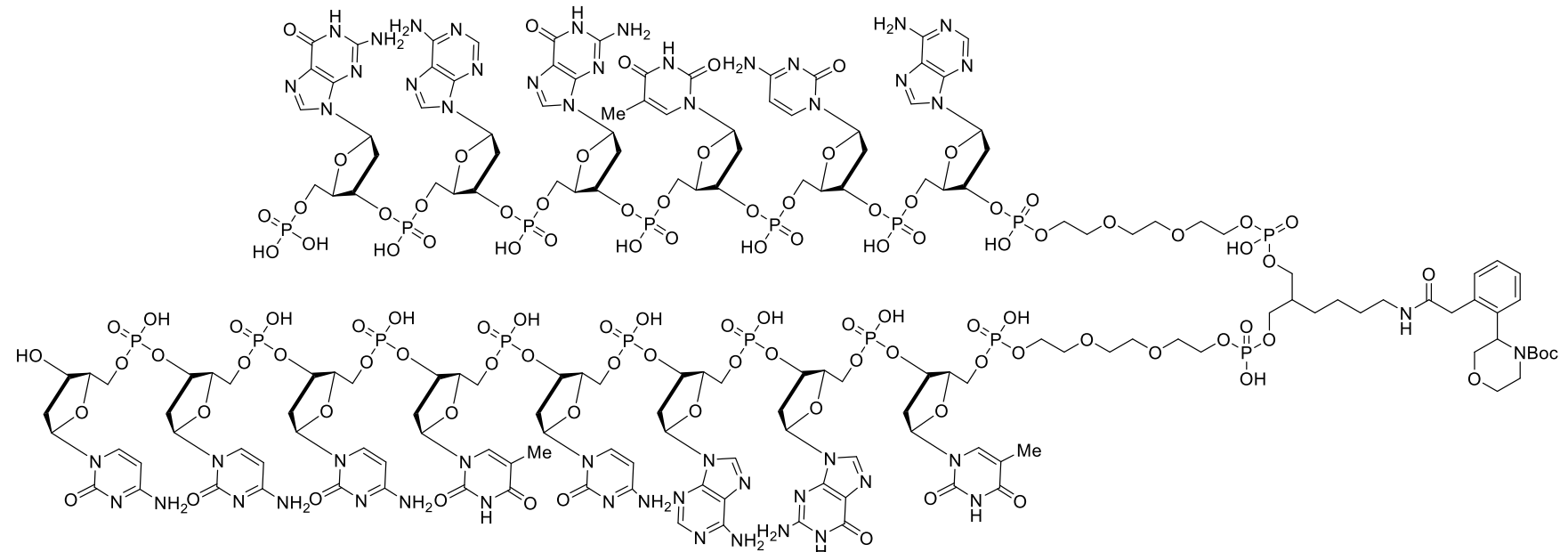

The title compound was synthesized according to the general procedure III from 4-(tertbutoxycarbonyl)morpholine-3-carboxylic acid $(4.6 \mathrm{mg}, 20 \mu \mathrm{mol})$ and the DNA-tagged aryl iodide S10. The coupling was repeated one more time (double coupling). The intended product was formed in $44 \%$ yield.

$m / z=1745.7[\mathrm{M}-3 \mathrm{H}]^{3-}$

Decarboxylative arylation with aryl iodide S11 (Table 3, entry 11):
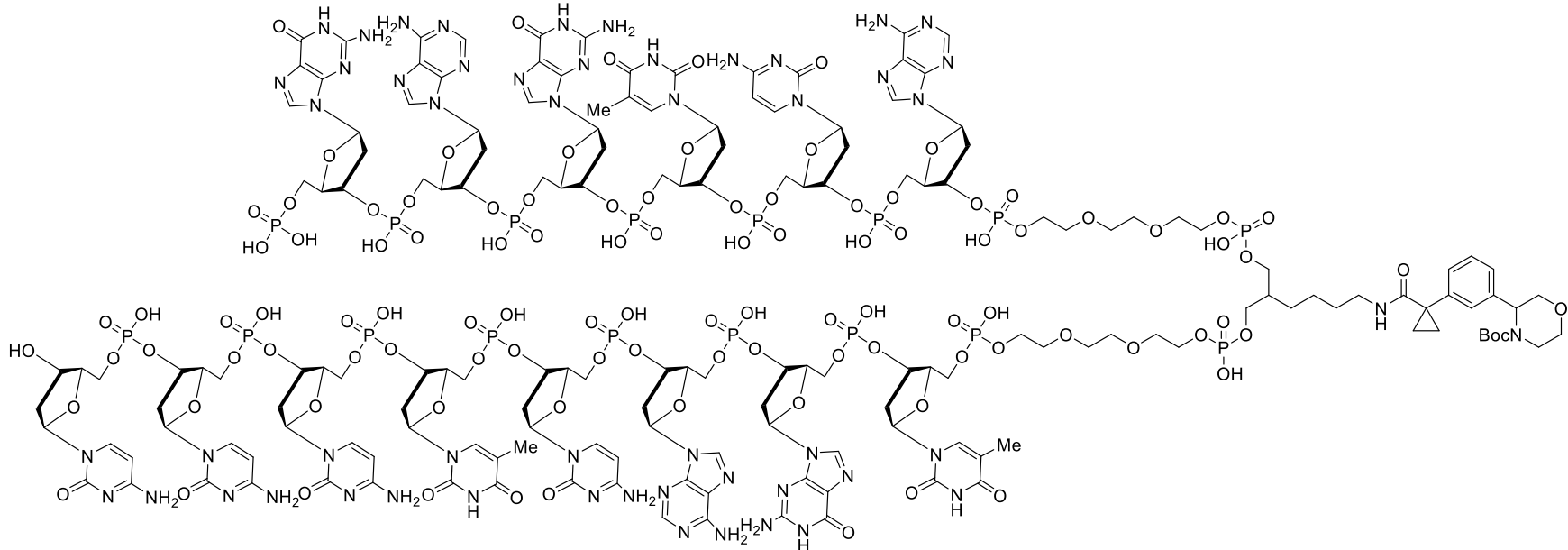

The title compound was synthesized according to the general procedure III from 4-(tertbutoxycarbonyl)morpholine-3-carboxylic acid $(4.6 \mathrm{mg}, 20 \mu \mathrm{mol})$ and the DNA-tagged aryl iodide S11. The coupling was repeated one more time (double coupling). The intended product was formed in 52\% yield.

$m / z=1754.3[\mathrm{M}-3 \mathrm{H}]^{3-}$ 
Decarboxylative arylation with aryl iodide S12 (Table 3, entry 12, $\mathrm{X}=\mathrm{I}$ ):
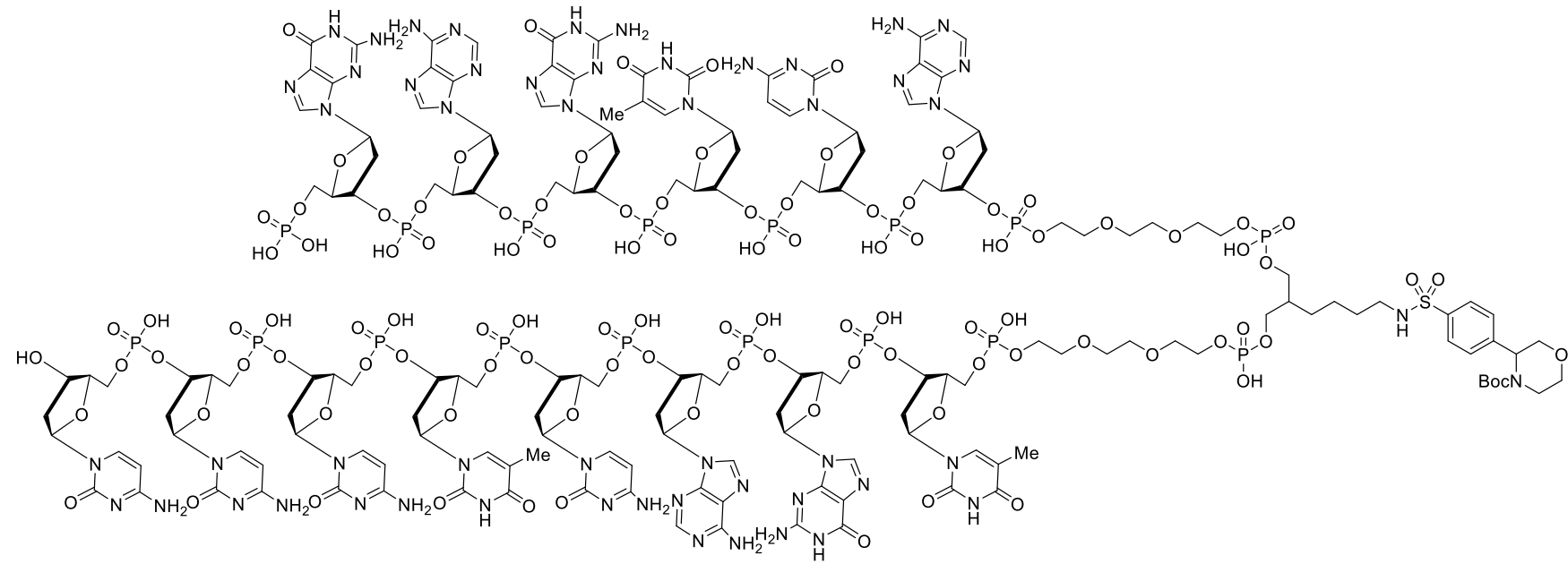

The title compound was synthesized according to the general procedure III from 4-(tertbutoxycarbonyl)morpholine-3-carboxylic acid $(4.6 \mathrm{mg}, 20 \mu \mathrm{mol})$ and the DNA-tagged aryl iodide S12. The intended product was formed in $83 \%$ yield.

$m / z=1753.0[\mathrm{M}-3 \mathrm{H}]^{3-}$

Decarboxylative arylation with aryl bromide $\mathrm{S} 13$ (Table 3, entry 12, $\mathrm{X}=\mathrm{Br}$ ):
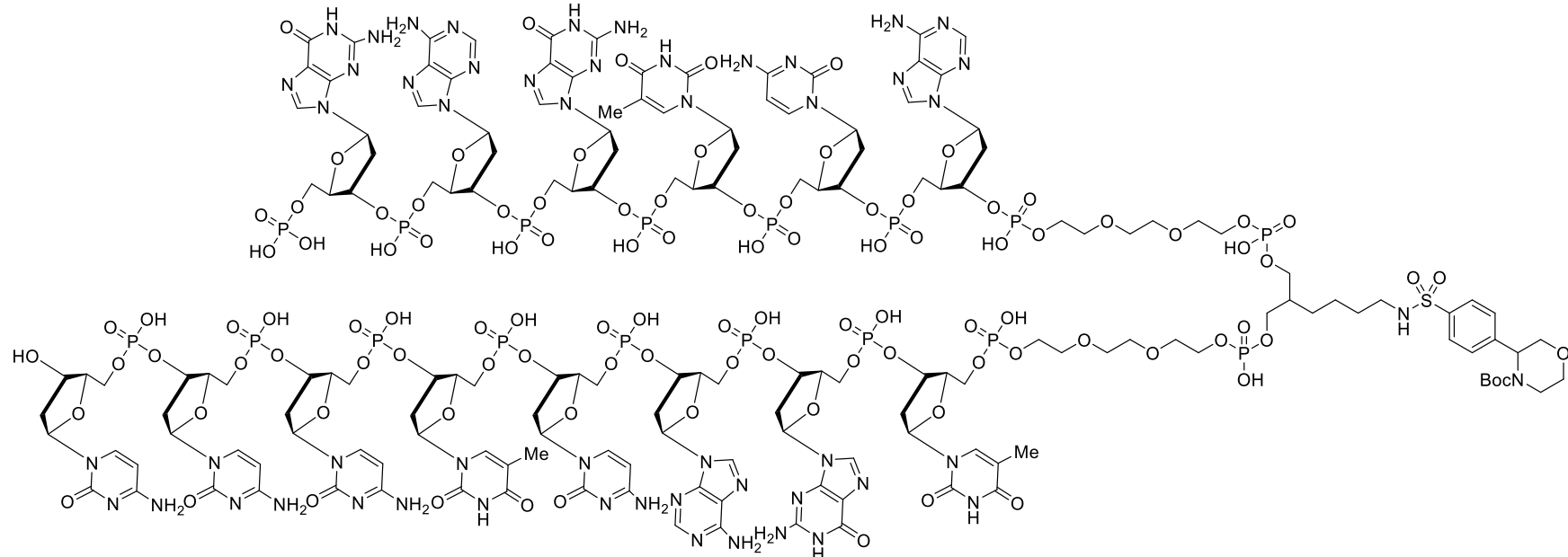

The title compound was synthesized according to the general procedure III from 4-(tertbutoxycarbonyl)morpholine-3-carboxylic acid $(4.6 \mathrm{mg}, 20 \mu \mathrm{mol})$ and the DNA-tagged aryl bromide S13. The intended product was formed in $44 \%$ yield.

$m / z=1753.0[\mathrm{M}-3 \mathrm{H}]^{3-}$ 
Decarboxylative arylation with aryl bromide S14 (Table 3, entry 13):
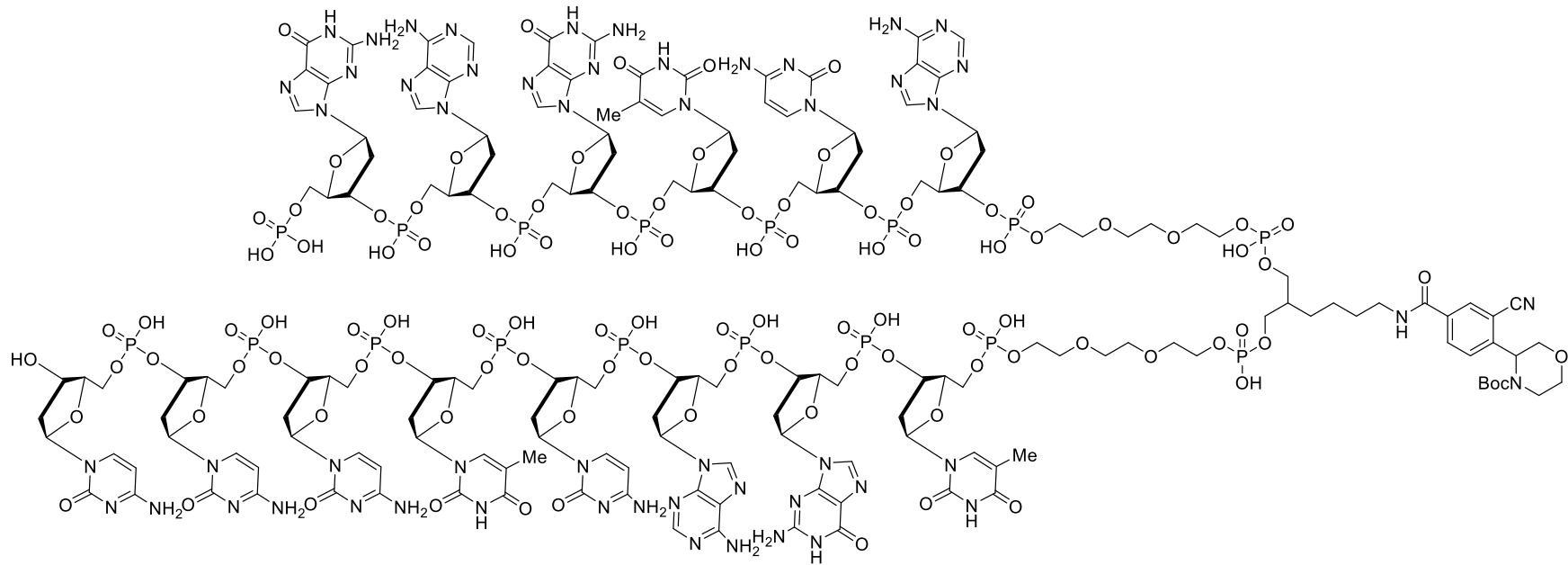

The title compound was synthesized according to the general procedure III from 4-(tertbutoxycarbonyl)morpholine-3-carboxylic acid $(4.6 \mathrm{mg}, 20 \mu \mathrm{mol})$ and the DNA-tagged aryl bromide S14. The intended product was formed in $56 \%$ yield.

$m / z=1749.4[\mathrm{M}-3 \mathrm{H}]^{3-}$

Decarboxylative arylation with aryl iodide S15 (Table 3, entry 14, X = I):
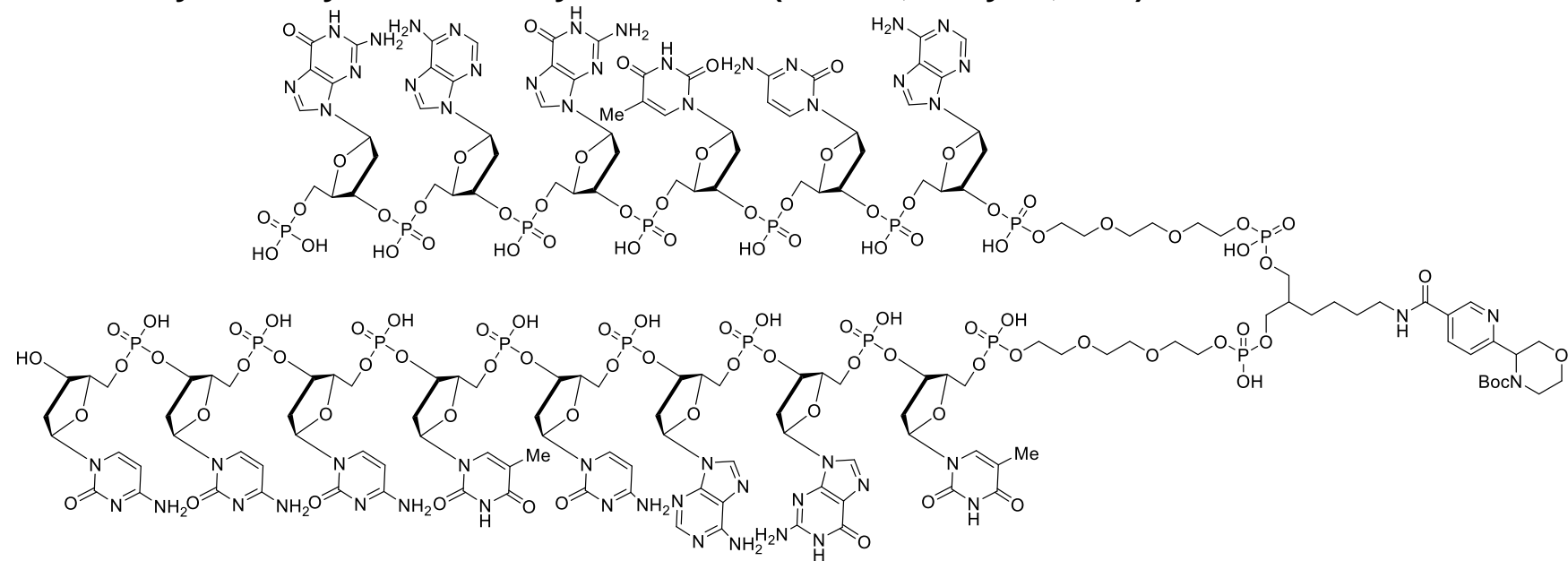

The title compound was synthesized according to the general procedure III from 4-(tertbutoxycarbonyl)morpholine-3-carboxylic acid $(4.6 \mathrm{mg}, 20 \mu \mathrm{mol})$ and the DNA-tagged aryl iodide S15. The intended product was formed in $87 \%$ yield.

$m / z=1741.3[\mathrm{M}-3 \mathrm{H}]^{3-}$ 
Decarboxylative arylation with aryl bromide S16 (Table 3, entry 14, $\mathrm{X}=\mathrm{Br}$ ):
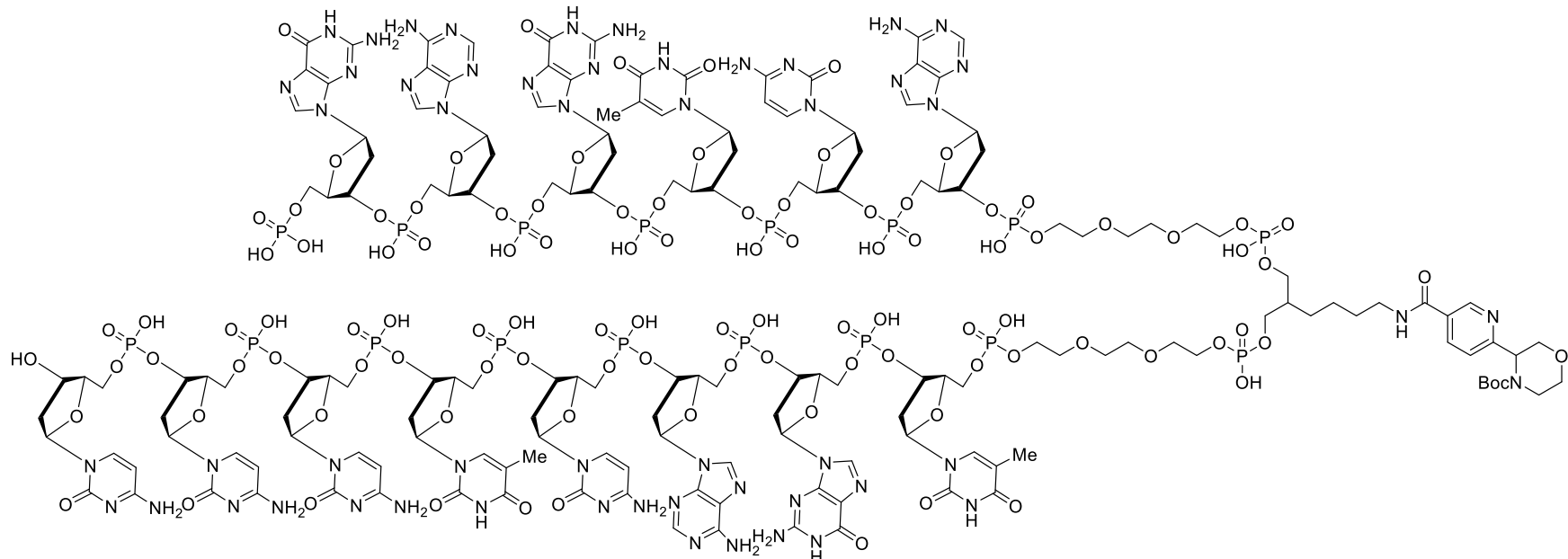

The title compound was synthesized according to the general procedure III from 4-(tertbutoxycarbonyl)morpholine-3-carboxylic acid $(4.6 \mathrm{mg}, 20 \mu \mathrm{mol})$ and the DNA-tagged aryl bromide S16. The intended product was formed in $91 \%$ yield.

$m / z=1741.3[\mathrm{M}-3 \mathrm{H}]^{3-}$

Decarboxylative arylation with aryl chloride $\mathrm{S} 17$ (Table 3, entry $14, \mathrm{X}=\mathrm{Cl}$ ):
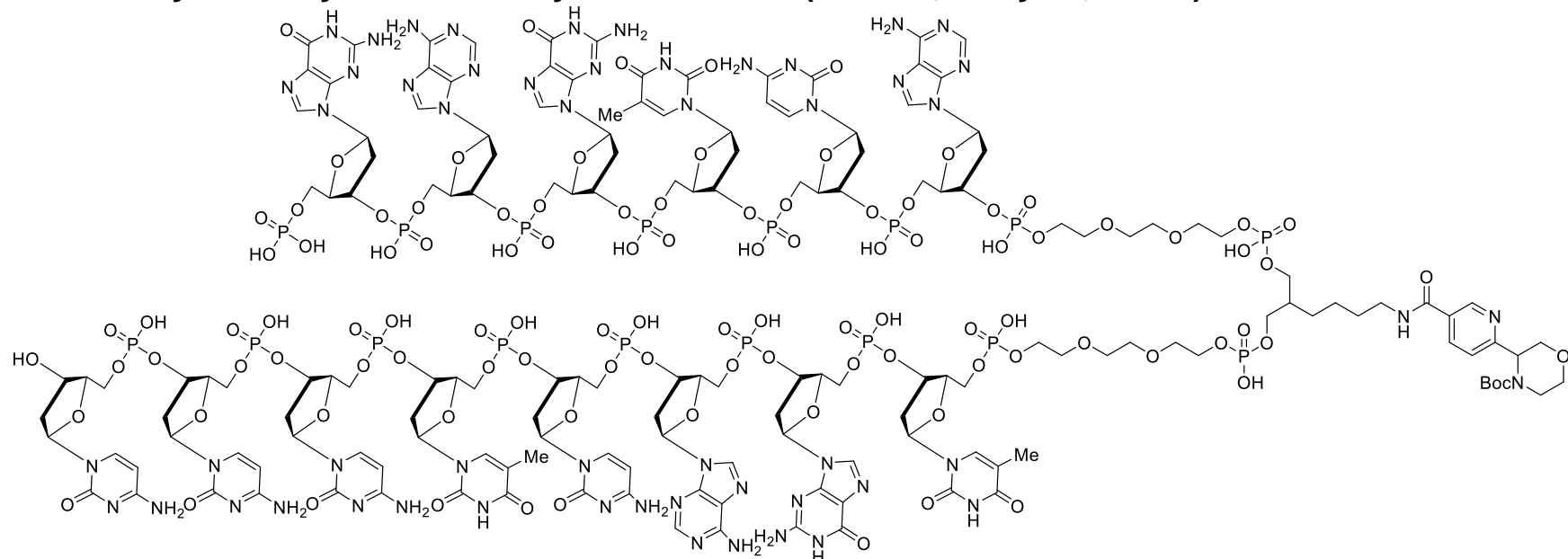

The title compound was synthesized according to the general procedure III from 4 -(tertbutoxycarbonyl)morpholine-3-carboxylic acid $(4.6 \mathrm{mg}, 20 \mu \mathrm{mol})$ and the DNA-tagged aryl chloride S17. The intended product was formed in $30 \%$ yield.

$m / z=1741.4[\mathrm{M}-3 \mathrm{H}]^{3-}$ 
Decarboxylative arylation with aryl bromide S18 (Table 3, entry 15):
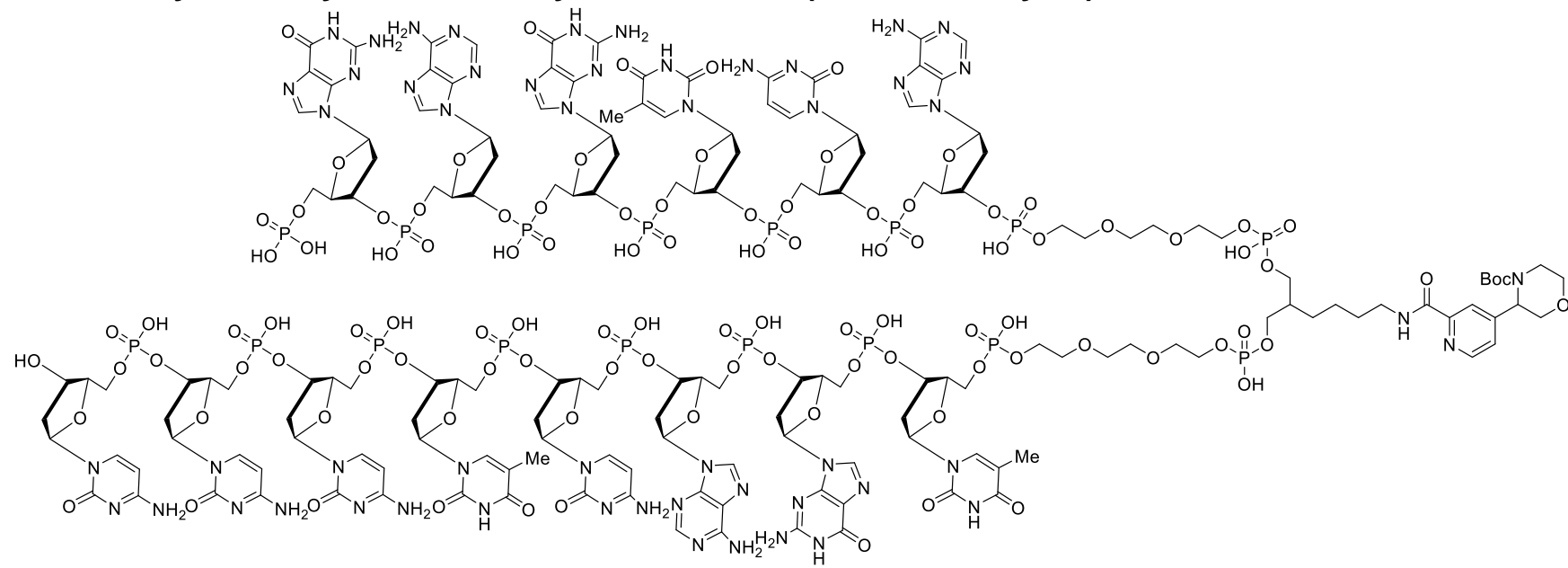

The title compound was synthesized according to the general procedure III from 4-(tertbutoxycarbonyl)morpholine-3-carboxylic acid (4.6 mg, $20 \mu \mathrm{mol})$ and the DNA-tagged aryl bromide S18. The coupling was repeated one more time (double coupling). The intended product was formed in $72 \%$ yield.

$m / z=1741.0[\mathrm{M}-3 \mathrm{H}]^{3-}$

Decarboxylative arylation with aryl bromide S19 (Table 3, entry 16):
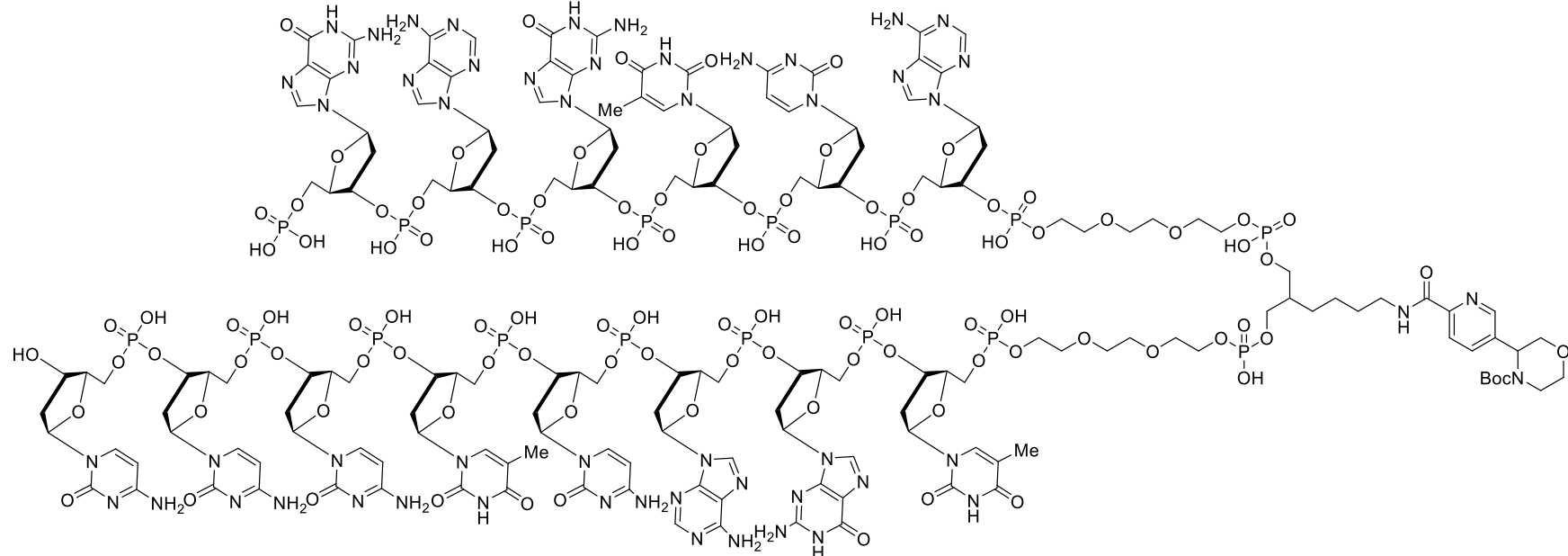

The title compound was synthesized according to the general procedure III from 4-(tertbutoxycarbonyl)morpholine-3-carboxylic acid (4.6 mg, $20 \mu \mathrm{mol})$ and the DNA-tagged aryl bromide S19. The coupling was repeated one more time (double coupling). The intended product was formed in $54 \%$ yield.

$m / z=1741.0[\mathrm{M}-3 \mathrm{H}]^{3-}$ 


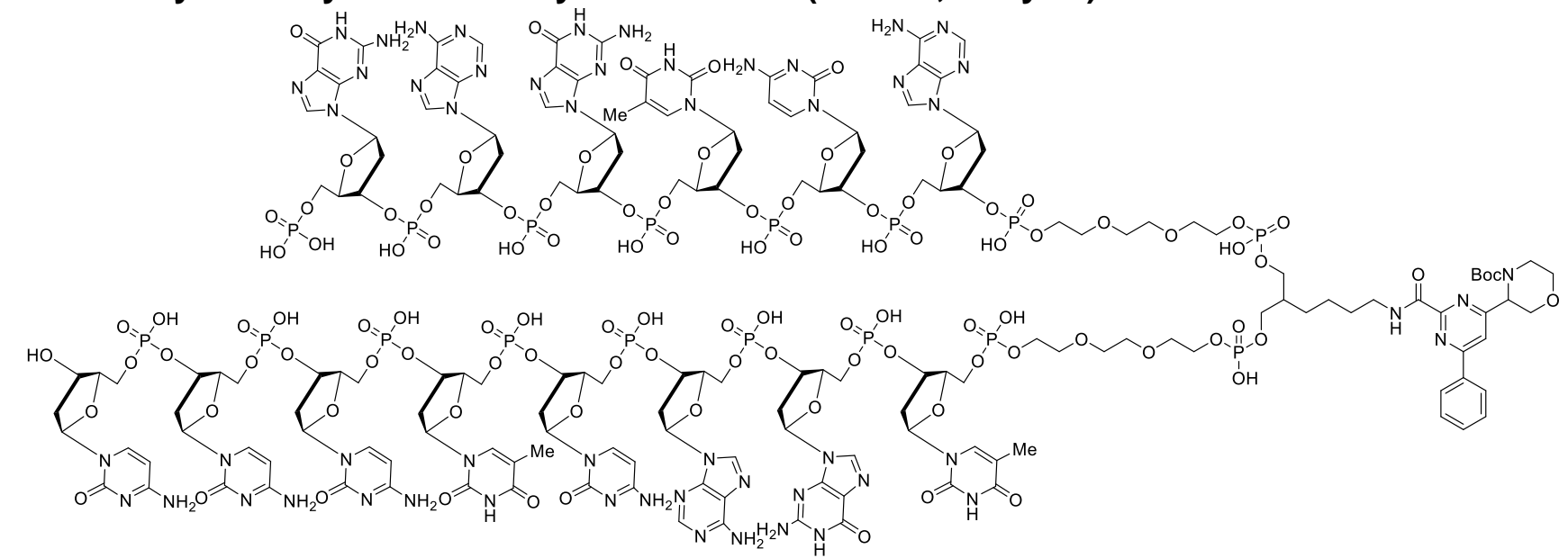

The title compound was synthesized according to the general procedure III from 4-(tertbutoxycarbonyl)morpholine-3-carboxylic acid (4.6 mg, 20 umol) and the DNA-tagged aryl bromide S20. The intended product was formed in $42 \%$ yield.

$m / z=1767.1[\mathrm{M}-3 \mathrm{H}]^{3-}$

Decarboxylative arylation with aryl chloride S21 (Table 3, entry 18):

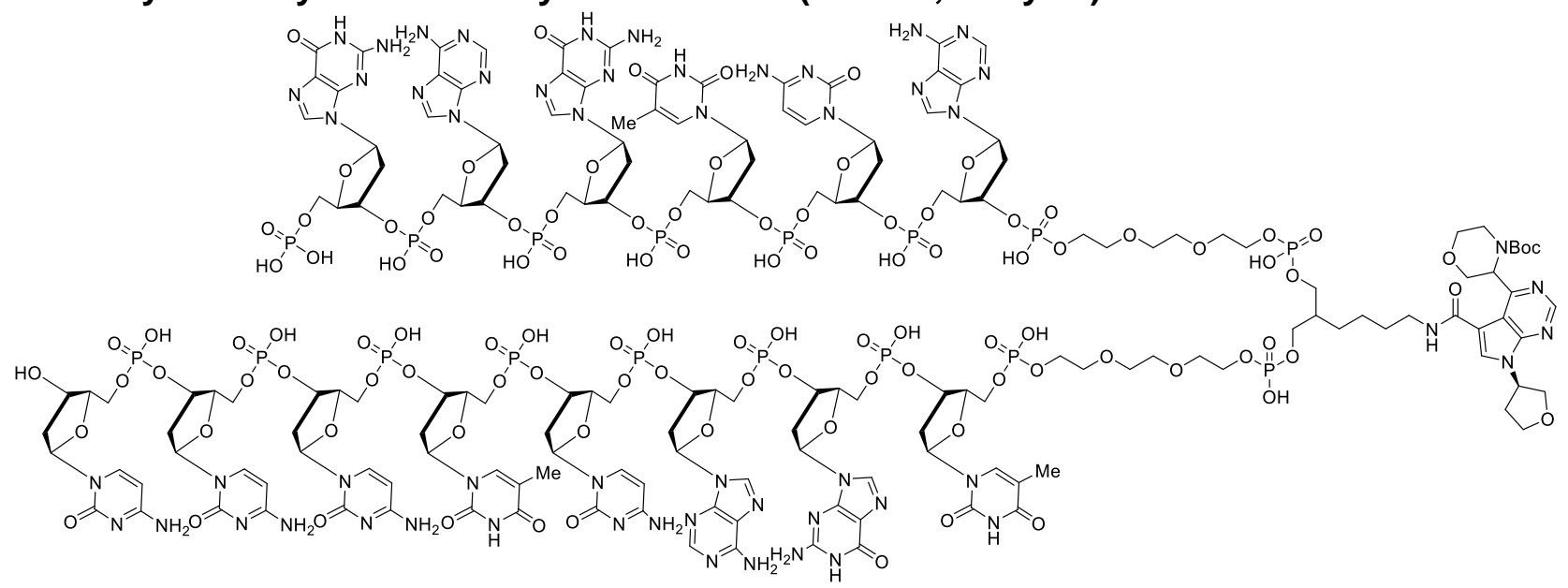

The title compound was synthesized according to the general procedure III from 4-(tertbutoxycarbonyl)morpholine-3-carboxylic acid $(4.6 \mathrm{mg}, 20 \mu \mathrm{mol})$ and the DNA-tagged aryl bromide $\mathbf{S 2 1}$. The intended product was formed in $86 \%$ yield.

$m / z=1778.4[\mathrm{M}-3 \mathrm{H}]^{3-}$

General procedure IV for photoredox-catalyzed decarboxylative arylation in 96-well plate:

A solution of the respective carboxylic acid $(20 \mu \mathrm{mol}, 1000$ equiv.) in DMSO (25 $\mu \mathrm{L})$, $\operatorname{Ir}\left[\mathrm{dF}(\mathrm{F}) \mathrm{ppy}_{2}(\mathrm{dtbbpy}) \mathrm{PF}_{6}(\mathbf{1}, 80 \mu \mathrm{g}, 80 \mathrm{nmol}, \mathrm{dF}(\mathrm{F}) \mathrm{ppy}=2\right.$-(2,4-difluorophenyl)-5-fluoropyridine, dtbbpy = 4,4'-di-tert-butyl-2,2'-bipyridine) in DMSO $(1 \mu \mathrm{L})$, nickel precatalyst $16(120 \mu \mathrm{g}, 400 \mathrm{nmol})$ in DMSO (2 $\mu \mathrm{L})$, carboxamidine ligand $17(150 \mu \mathrm{g}, 800 \mathrm{nmol})$ in DMSO $(2 \mu \mathrm{L})$, and $\mathrm{K}_{2} \mathrm{HPO}_{4}(5.2 \mathrm{mg}, 30 \mu \mathrm{mol})$ in $\mathrm{H}_{2} \mathrm{O}$ $(25 \mu \mathrm{L})$, and a solution of the DNA-tagged aryl iodide $12(0.1 \mathrm{mg}, 20 \mathrm{nmol})$ in $\mathrm{H}_{2} \mathrm{O}(20 \mu \mathrm{L})$ were added to a well. The well plate and the LED array were placed inside a glove bag and the glove bage was rigorously purged with a steady stream of nitrogen for $2 \mathrm{~h}$. The glove bag was sealed and the well plate was sealed with an aluminum sealing film. The sealed well plate was placed on top of the LED array and irradiated with blue light for $3 \mathrm{~h}$ (no active cooling). Subsequently, a solution of $\mathrm{NaCl}$ in $\mathrm{H}_{2} \mathrm{O}(5 \mathrm{M}, 15 \mu \mathrm{L}$ ) was added and the mixture was transferred to an Eppendorf tube. Cold $\mathrm{EtOH}(1 \mathrm{~mL})$ was added and the mixture was kept at $-20^{\circ} \mathrm{C}$ for $20 \mathrm{~min}$ and then centrifuged at $10,000 \mathrm{rpm}$ for $2 \mathrm{~min}$. The supernatant was discarded and the DNA pellet was re-dissolved in $\mathrm{H}_{2} \mathrm{O}(20 \mu \mathrm{L})$. An aliquot $(1 \mu \mathrm{L})$ was taken, diluted with $\mathrm{H}_{2} \mathrm{O}(100 \mu \mathrm{L})$ and analyzed via UPLC. 
Table S1. Comparison between photoredox reactions performed in 96-well plates and in glass vials. Entry Products Reference Yield (well plate) Yield (glass vial)

1<smiles>CC(=O)N(C)Cc1ccc(C(=O)Nc2ccccc2)cc1</smiles>

2

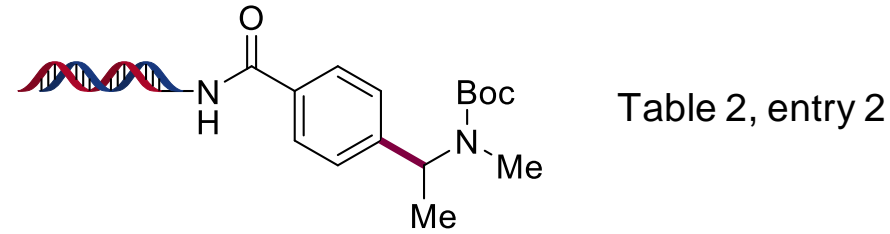

3<smiles>CC(=O)OC(=O)N(C)C(Cc1ccccc1)c1ccc(C(=O)Nc2ccccc2)cc1</smiles>

4<smiles>CC(C)(C)OC(=O)N(Cc1ccc(C(=O)NC(=O)OCc2ccccc2)cc1)C1CC1</smiles>

5<smiles>O=C(Nc1ccccc1)c1ccc(C2CCCN2C(=O)OCc2ccccc2)cc1</smiles>

6<smiles>O=C(Nc1ccccc1)c1ccc(C2CCCCN2C(=O)OCc2ccccc2)cc1</smiles>

Table 2, entry 8

$60 \%$

$61 \%$

Table 2, entry 9

$83 \%$

Table 2, entry 11

$68 \%$

$78 \%$

9<smiles>O=C(Nc1ccccc1)c1ccc(C2CC3(CN2C(=O)OCc2ccccc2)CC3(F)F)cc1</smiles>

Table 2, entry 15<smiles>CCCC(NC(C)(C)C)c1ccc(C(=O)Nc2ccccc2OCCOC(C)(C)C)cc1</smiles>

Table 2, entry 1

Table 2 , entry $3 \quad 69 \%$

$76 \%$

$88 \%$

Table 2, entry $7 \quad 82 \%$

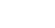




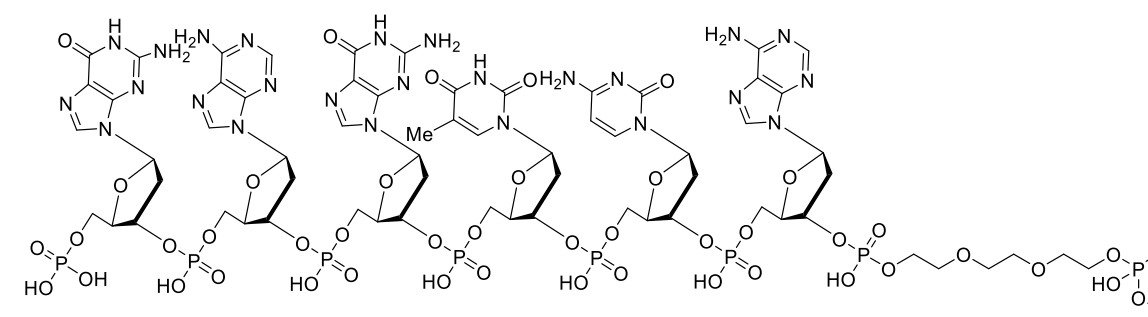

(n)

A solution of sodium 1-((benzoyloxy)carbonyl)piperidine-4-sulfinate $(6.1 \mathrm{mg}, 20 \mu \mathrm{mol})$ in DMSO $(25 \mu \mathrm{L})$, tris (2,2'-bipyridyl) ruthenium(II) chloride hexahydrate $(50 \mu \mathrm{g}, 80 \mathrm{nmol})$ in DMSO $(1 \mu \mathrm{L})$, nickel precatalyst $16(120 \mu \mathrm{g}, 400 \mathrm{nmol})$ in DMSO $(2 \mu \mathrm{L})$, carboxamidine ligand $17(150 \mu \mathrm{g}, 800 \mathrm{nmol})$ in DMSO $(2 \mu \mathrm{L})$, and $\mathrm{K}_{2} \mathrm{HPO}_{4}(5.2 \mathrm{mg}, 30 \mu \mathrm{mol})$ in $\mathrm{H}_{2} \mathrm{O}(25 \mu \mathrm{L})$ was added to a solution of the DNA-tagged aryl iodide 12 $(0.1 \mathrm{mg}, 20 \mathrm{nmol})$ in $\mathrm{H}_{2} \mathrm{O}(20 \mu \mathrm{L})$. The glass vial was then sealed and degassed by sparging with nitrogen for $5 \mathrm{~min}$. The reaction mixture was irradiated with blue light inside a photoreactor for $40 \mathrm{~min}$ at room temperature (cooling was provided via the integrated fan). Subsequently, a solution of $\mathrm{NaCl}$ in $\mathrm{H}_{2} \mathrm{O}(5 \mathrm{M}$, $15 \mu \mathrm{L})$ was added, followed by the addition of cold $\mathrm{EtOH}(1 \mathrm{~mL})$. The mixture was kept at $-20{ }^{\circ} \mathrm{C}$ for 20 min and then centrifuged at 10,000 rpm for $2 \mathrm{~min}$. The supernatant was discarded and the DNA pellet was re-dissolved in $\mathrm{H}_{2} \mathrm{O}(20 \mu \mathrm{L})$. An aliquot $(1 \mu \mathrm{L})$ was taken, diluted with $\mathrm{H}_{2} \mathrm{O}(100 \mu \mathrm{L})$ and analyzed via UPLC. The intended product was formed in $55 \%$ yield.

$m / z=1751.8[\mathrm{M}-3 \mathrm{H}]^{3-}$

\section{Synthesis of DNA-tagged conjugate 27 via deborylative coupling:}
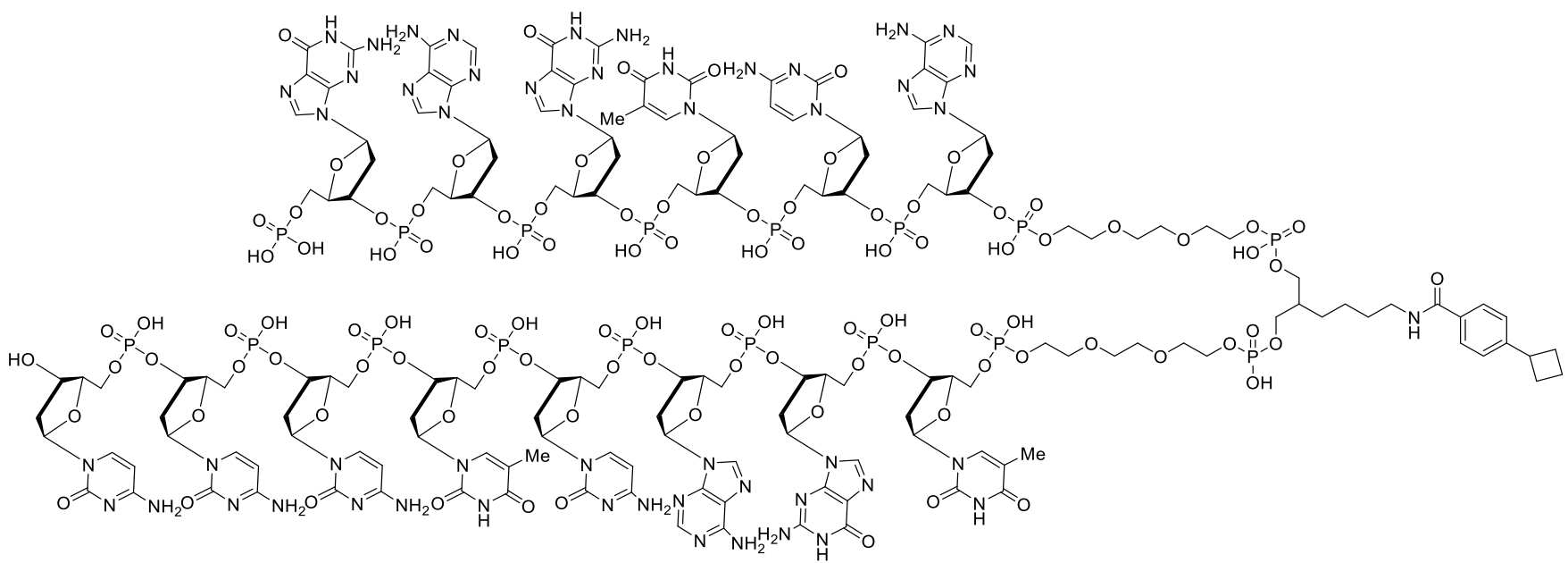

A solution of potassium cyclobutyltrifluoroborate $(3.2 \mathrm{mg}, 20 \mu \mathrm{mol})$ in DMSO $(25 \mu \mathrm{L})$, $\operatorname{Ir}\left[\mathrm{dF}(\mathrm{F})\right.$ ppy $_{2}(\mathrm{dtbbpy}) \mathrm{PF}_{6}(\mathbf{1}, 80 \mu \mathrm{g}, 80 \mathrm{nmol}, \mathrm{dF}(\mathrm{F}) \mathrm{ppy}=2$-(2,4-difluorophenyl)-5-fluoropyridine, dtbbpy = 4,4'-di-tert-butyl-2,2'-bipyridine) in DMSO $(1 \mu \mathrm{L})$, nickel precatalyst $16(120 \mu \mathrm{g}, 400 \mathrm{nmol})$ in DMSO (2 $\mu \mathrm{L})$, carboxamidine ligand $17(150 \mu \mathrm{g}, 800 \mathrm{nmol})$ in DMSO $(2 \mu \mathrm{L})$, and $\mathrm{K}_{2} \mathrm{HPO}_{4}(5.2 \mathrm{mg}, 30 \mu \mathrm{mol})$ in $\mathrm{H}_{2} \mathrm{O}$ $(25 \mu \mathrm{L})$ was added to a solution of the DNA-tagged aryl iodide $12(0.1 \mathrm{mg}, 20 \mathrm{nmol})$ in $\mathrm{H}_{2} \mathrm{O}(20 \mu \mathrm{L})$. The glass vial was then sealed and degassed by sparging with nitrogen for $5 \mathrm{~min}$. The reaction mixture was irradiated with blue light inside a photoreactor for $40 \mathrm{~min}$ at room temperature (cooling was provided via the integrated fan). Subsequently, a solution of $\mathrm{NaCl}$ in $\mathrm{H}_{2} \mathrm{O}(5 \mathrm{M}, 15 \mu \mathrm{L})$ was added, followed by the addition of cold $\mathrm{EtOH}(1 \mathrm{~mL})$. The mixture was kept at $-20{ }^{\circ} \mathrm{C}$ for 20 min and then centrifuged at $10,000 \mathrm{rpm}$ for $2 \mathrm{~min}$. The supernatant was discarded and the DNA pellet was re-dissolved in $\mathrm{H}_{2} \mathrm{O}$ 
$(20 \mu \mathrm{L})$. An aliquot $(1 \mu \mathrm{L})$ was taken, diluted with $\mathrm{H}_{2} \mathrm{O}(100 \mu \mathrm{L})$ and analyzed via UPLC. The intended product was formed in $49 \%$ yield.

$\mathrm{m} / \mathrm{z}=1697.3[\mathrm{M}-3 \mathrm{H}]^{3-}$

Synthesis of DNA-tagged conjugate 28 via cross-electrophile coupling:
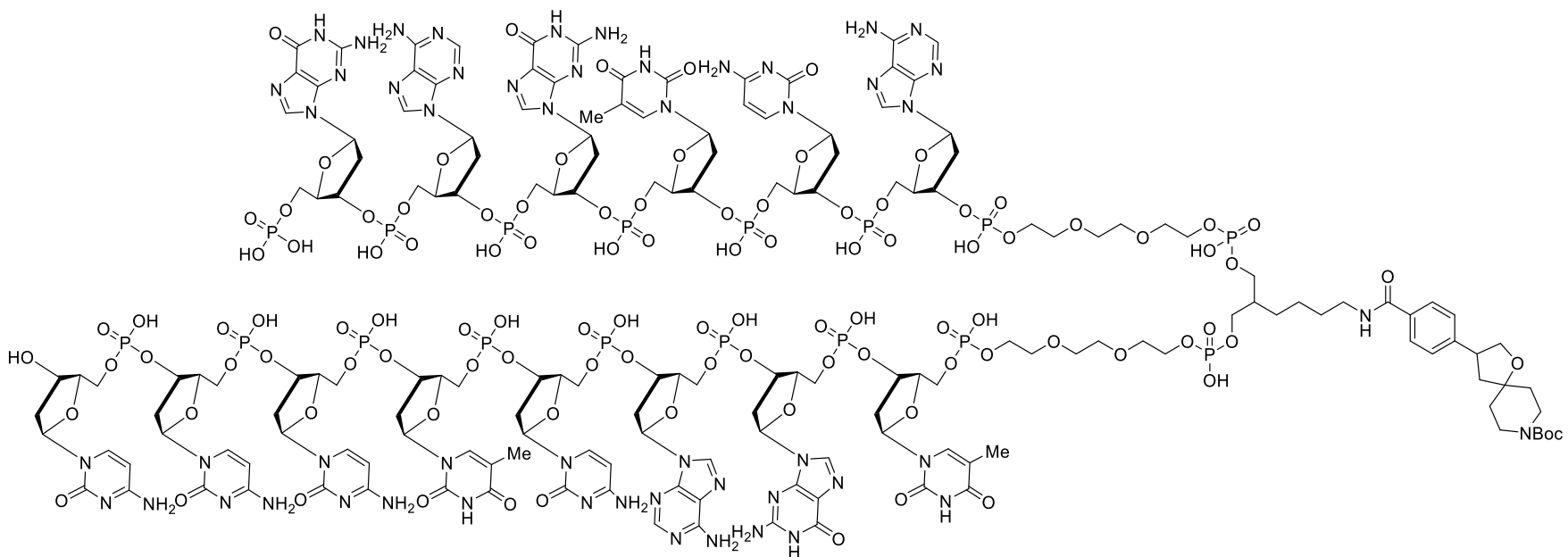

A solution of tert-butyl (R)-3-bromo-1-oxa-8-azaspiro[4.5]decane-8-carboxylate $(6.4 \mathrm{mg}, 20 \mu \mathrm{mol})$ in DMSO $(25 \mu \mathrm{L})$, tris(trimethylsilyl)silanol (6.6 mg, $20 \mu \mathrm{mol})$, Ir[dF(F)ppy $]_{2}(\mathrm{dtbbpy}) \mathrm{PF}_{6}(\mathbf{1}, 80 \mu \mathrm{g}, 80 \mathrm{nmol}$, $\mathrm{dF}(\mathrm{F}) \mathrm{ppy}=2$-(2,4-difluorophenyl)-5-fluoropyridine, dtbbpy =4,4'-di-tert-butyl-2,2'-bipyridine) in DMSO (1 $\mu \mathrm{L})$, nickel precatalyst $16(120 \mu \mathrm{g}, 400 \mathrm{nmol})$ in DMSO $(2 \mu \mathrm{L})$, carboxamidine ligand $17(150 \mu \mathrm{g}$, $800 \mathrm{nmol})$ in DMSO $(2 \mu \mathrm{L})$, and $\mathrm{K}_{2} \mathrm{HPO}_{4}(5.2 \mathrm{mg}, 30 \mu \mathrm{mol})$ in $\mathrm{H}_{2} \mathrm{O}(25 \mu \mathrm{L})$ was added to a solution of the DNA-tagged aryl iodide $12(0.1 \mathrm{mg}, 20 \mathrm{nmol})$ in $\mathrm{H}_{2} \mathrm{O}(20 \mu \mathrm{L})$. The glass vial was then sealed and degassed by sparging with nitrogen for $5 \mathrm{~min}$. The reaction mixture was irradiated with blue light inside a photoreactor for $40 \mathrm{~min}$ at room temperature (cooling was provided via the integrated fan). Subsequently, a solution of $\mathrm{NaCl}$ in $\mathrm{H}_{2} \mathrm{O}(5 \mathrm{M}, 15 \mu \mathrm{L})$ was added, followed by the addition of cold EtOH $(1 \mathrm{~mL})$. The mixture was kept at $-20^{\circ} \mathrm{C}$ for $20 \mathrm{~min}$ and then centrifuged at $10,000 \mathrm{rpm}$ for $2 \mathrm{~min}$. The supernatant was discarded and the DNA pellet was re-dissolved in $\mathrm{H}_{2} \mathrm{O}(20 \mu \mathrm{L})$. An aliquot $(1 \mu \mathrm{L})$ was taken, diluted with $\mathrm{H}_{2} \mathrm{O}(100 \mu \mathrm{L})$ and analyzed via UPLC. The intended product was formed in $56 \%$ yield.

$m / z=1759.0[\mathrm{M}-3 \mathrm{H}]^{3-}$

\section{General procedure V for the thermal deprotection of Boc-protected amines:}

A solution of the respective DNA substrate $(20 \mathrm{nmol})$ in sodium borate buffer $(250 \mathrm{mM}, \mathrm{pH} 9.5,80 \mu \mathrm{L})$ was heated to $90{ }^{\circ} \mathrm{C}$ for $16 \mathrm{~h}$. Subsequently, a solution of $\mathrm{NaCl}$ in $\mathrm{H}_{2} \mathrm{O}(5 \mathrm{M}, 3 \mu \mathrm{L})$ was added, followed by the addition of cold $\mathrm{EtOH}(200 \mu \mathrm{L})$. The mixture was kept at $-20^{\circ} \mathrm{C}$ for 20 min and then centrifuged at 10,000 rpm for 2 min. The supernatant was discarded and the DNA pellet was re-dissolved in $\mathrm{H}_{2} \mathrm{O}$ $(20 \mu \mathrm{L})$. An aliquot $(1 \mu \mathrm{L})$ was taken, diluted with $\mathrm{H}_{2} \mathrm{O}(100 \mu \mathrm{L})$ and analyzed via UPLC. 
Synthesis of DNA-tagged benzylic amine S22 via thermal Boc deprotection:
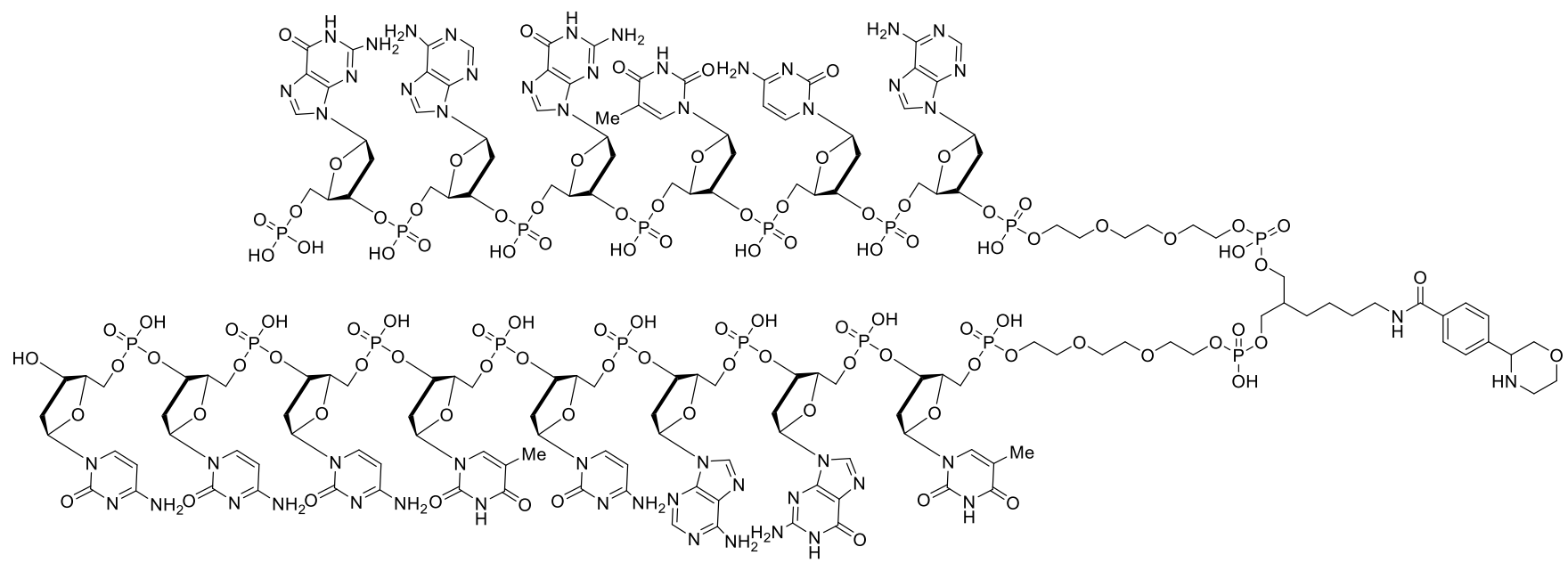

The title compound was synthesized according to the general procedure $\mathrm{V}$ from the DNA-tagged Bocprotected amine 13. The intended product was formed in $97 \%$ yield.

$m / z=1707.6[\mathrm{M}-3 \mathrm{H}]^{3-}$ 


\title{
3) UPLC Traces
}

\section{6-0894-0011:21}

DKoelmel405-1

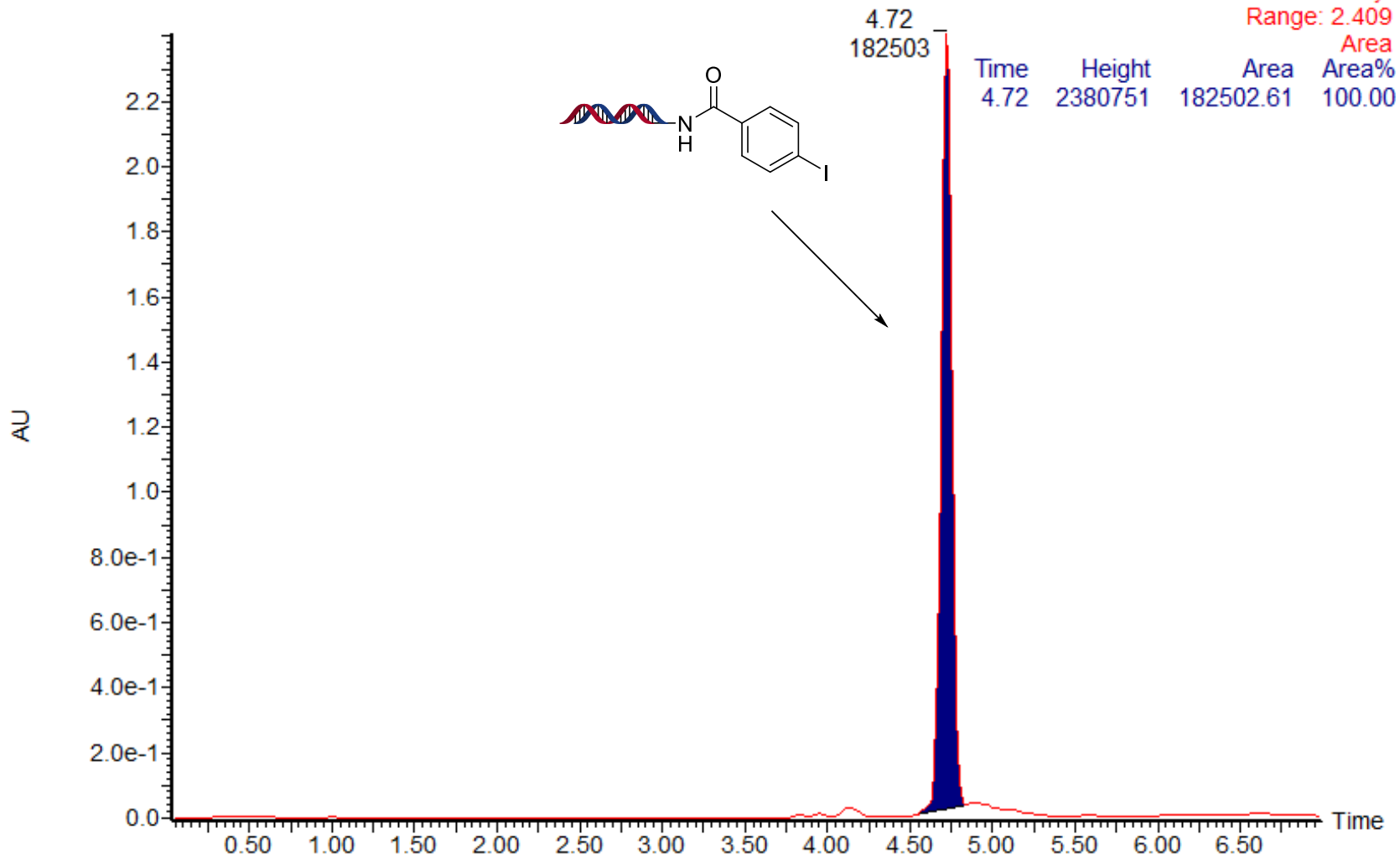

Figure S2. UPLC trace of aryl iodide 12.

1:4000712256-0358-001-Piperidine

DKoelmel155-ism (Mn, 1x1)

8

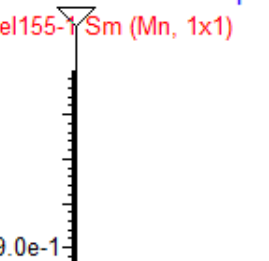

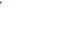


DKoelmel362-06

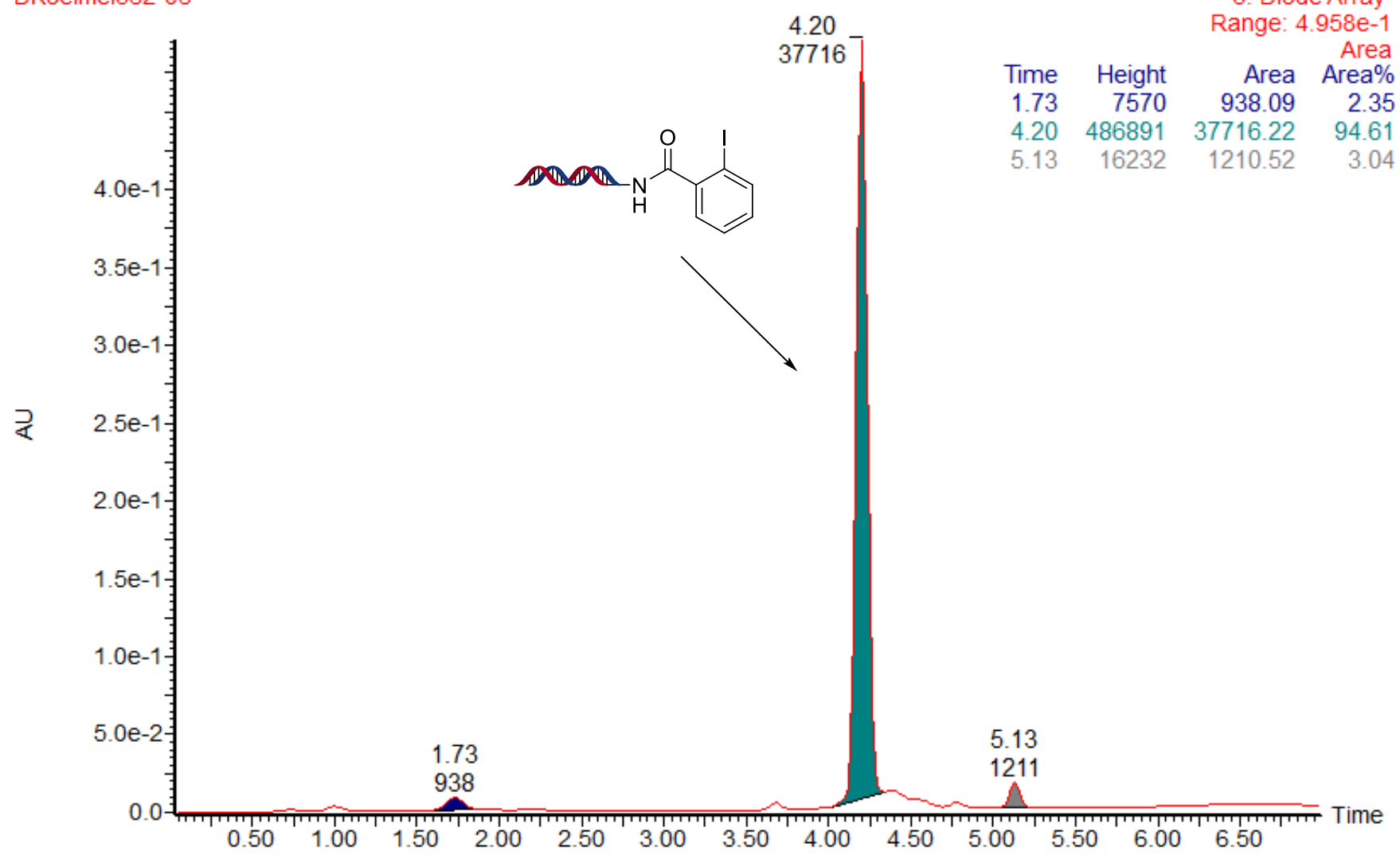

Figure S4. UPLC trace of aryl iodide S1.

00712256-0812-0011:36

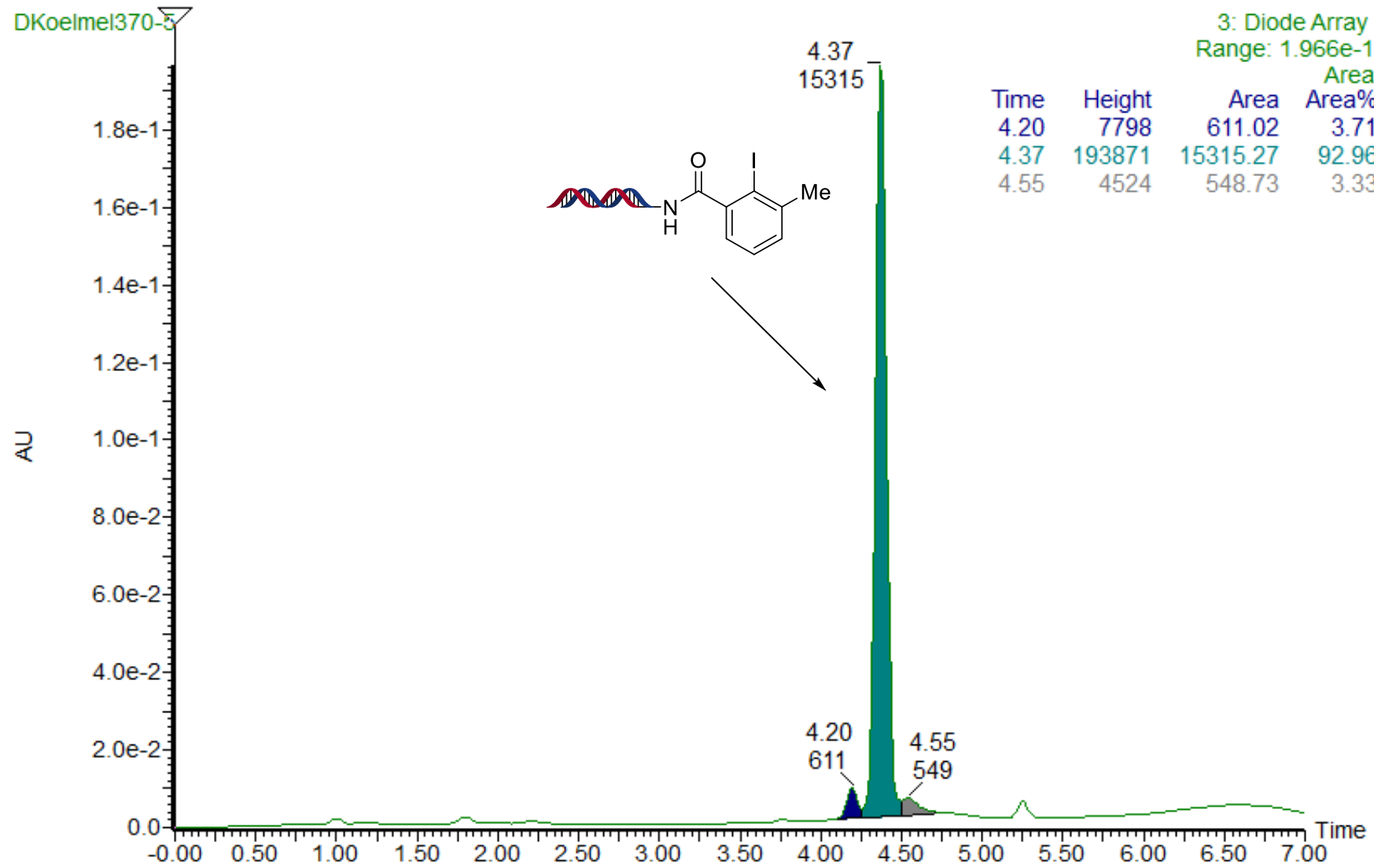

Figure S5. UPLC trace of aryl iodide S2. 


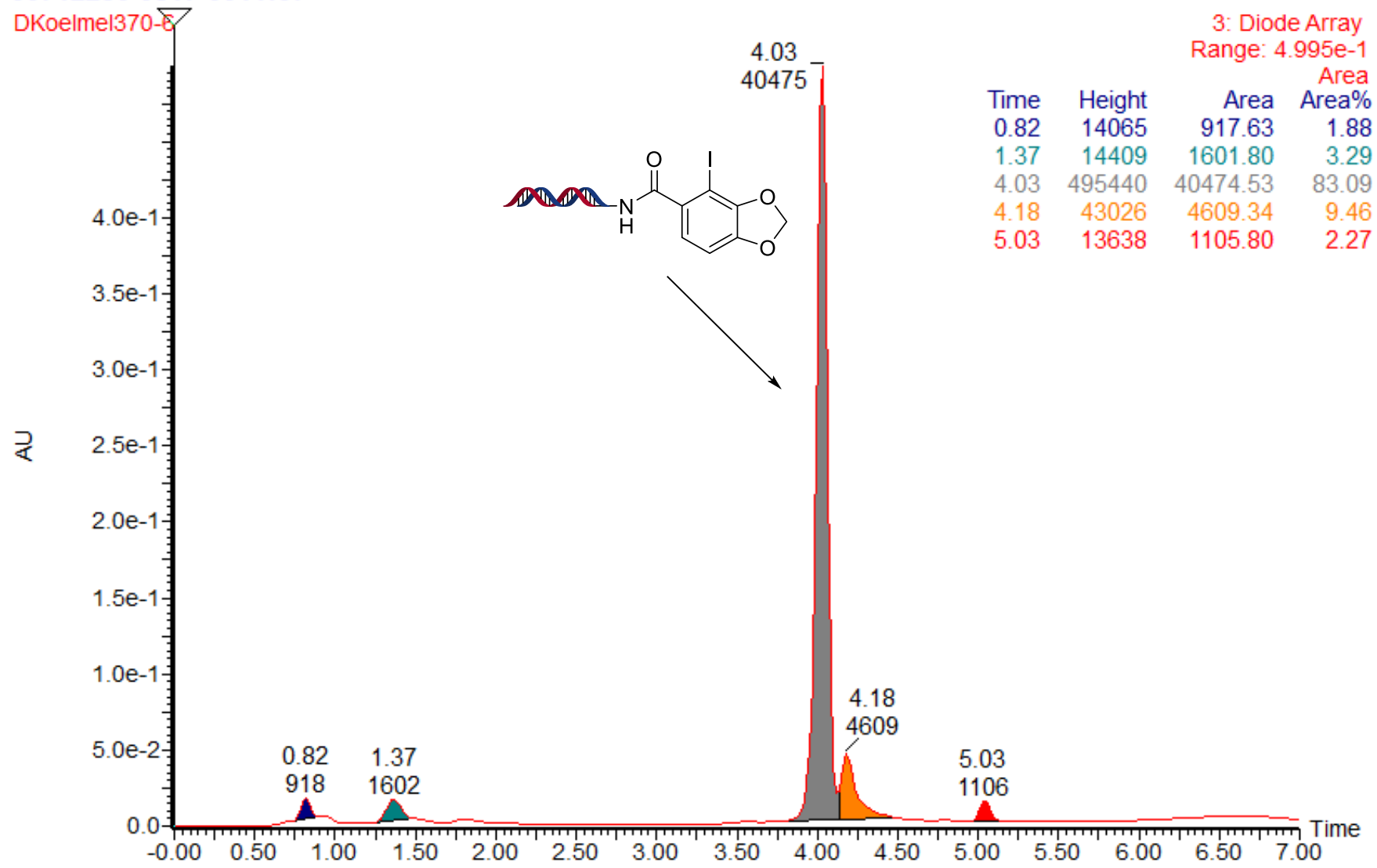

Figure S6. UPLC trace of aryl iodide S3.

00712256-0807-0011:6

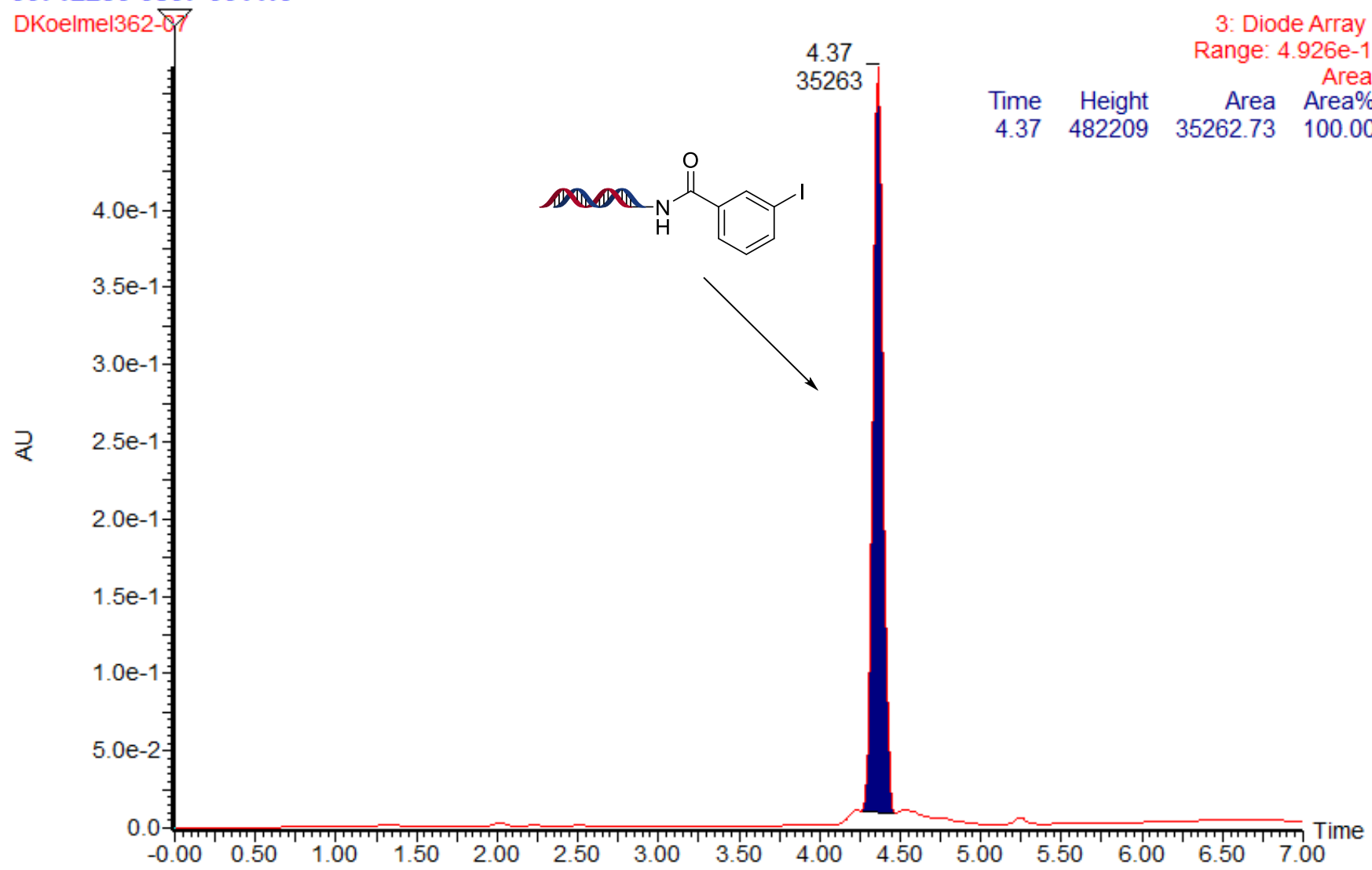

Figure S7. UPLC trace of aryl iodide S4. 


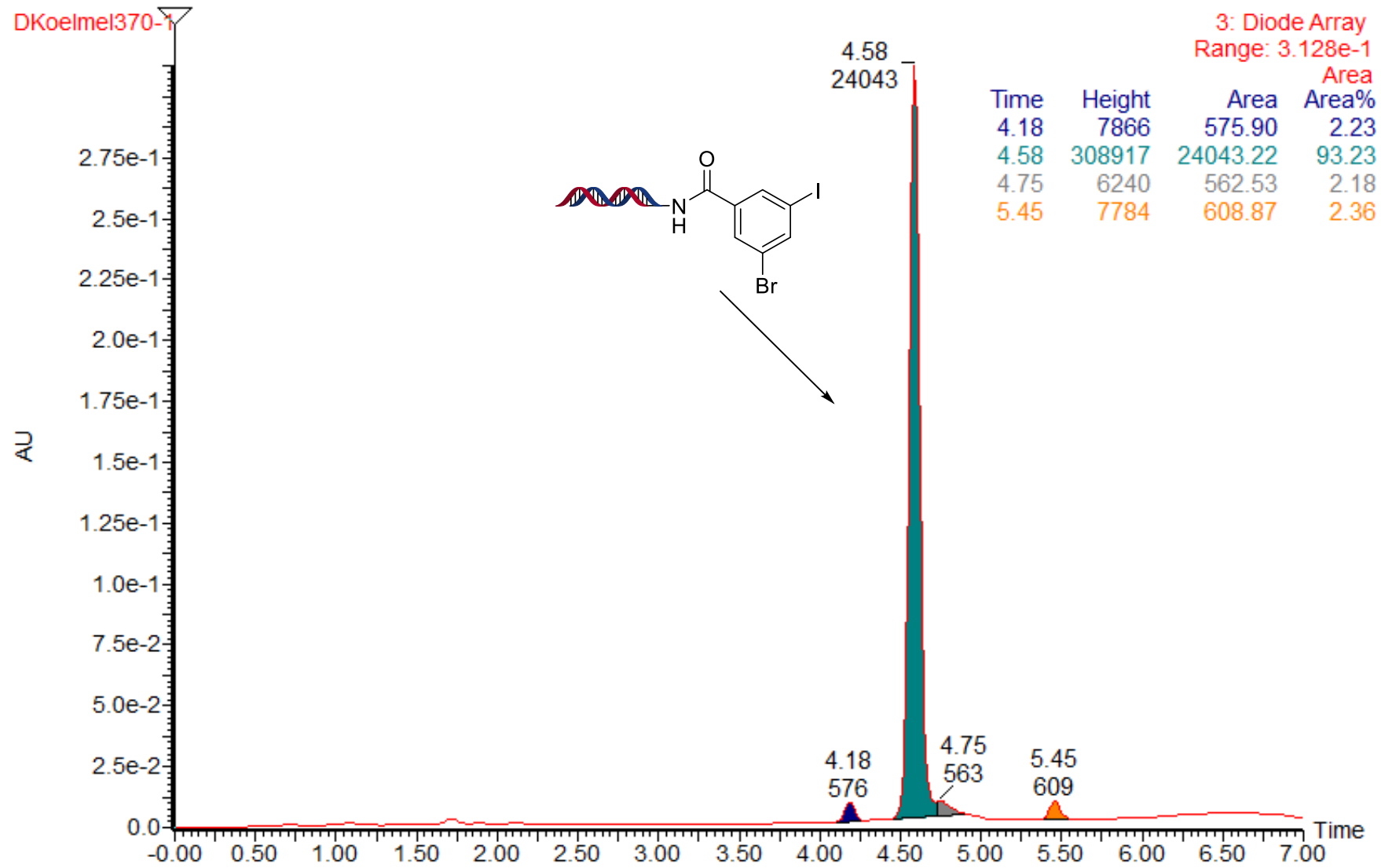

Figure S8. UPLC trace of aryl iodide S5.

00712256-0873-0011:36

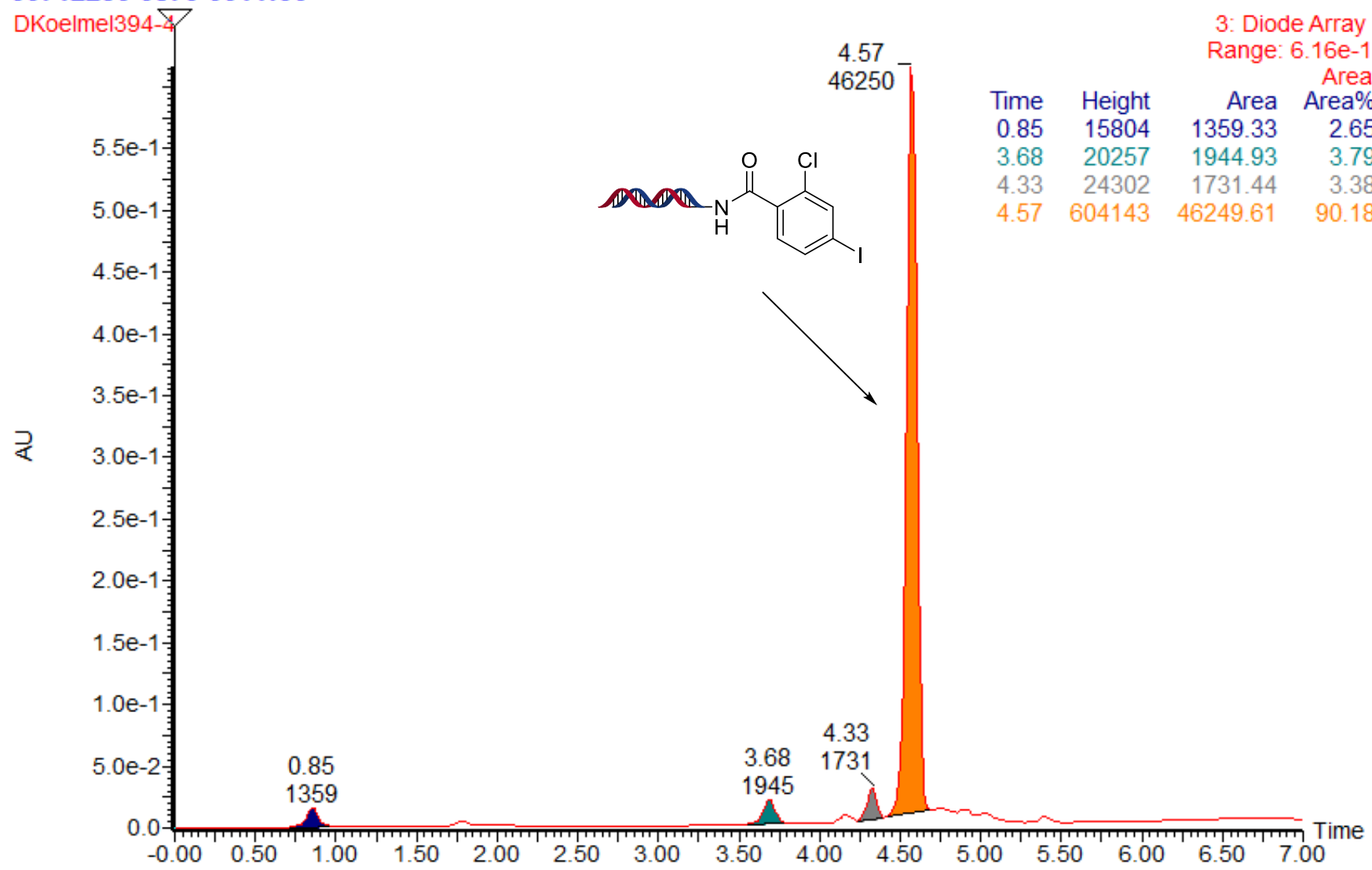

Figure S9. UPLC trace of aryl iodide S6. 


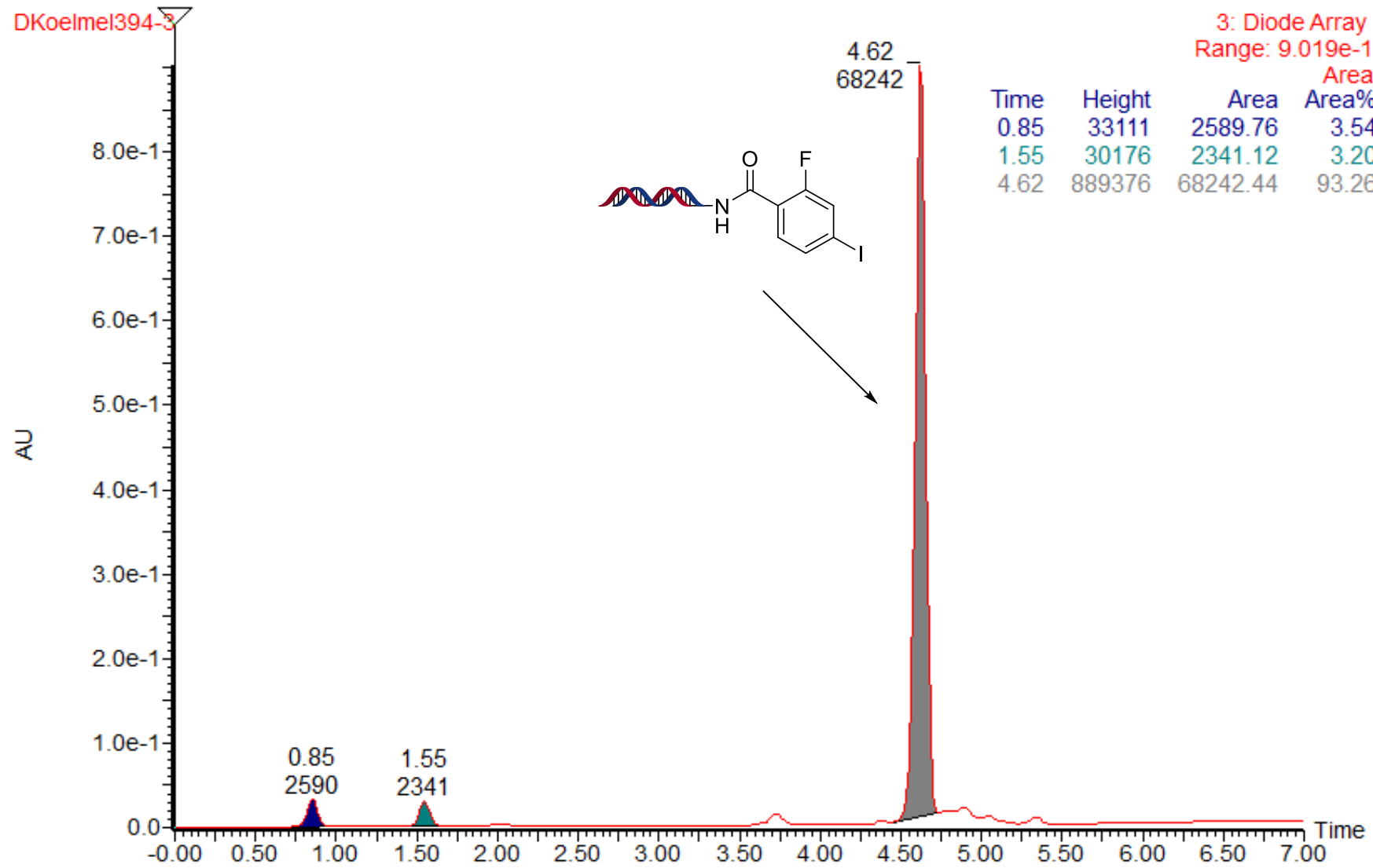

Figure S10. UPLC trace of aryl iodide S7.

00712256-0871-0011:34

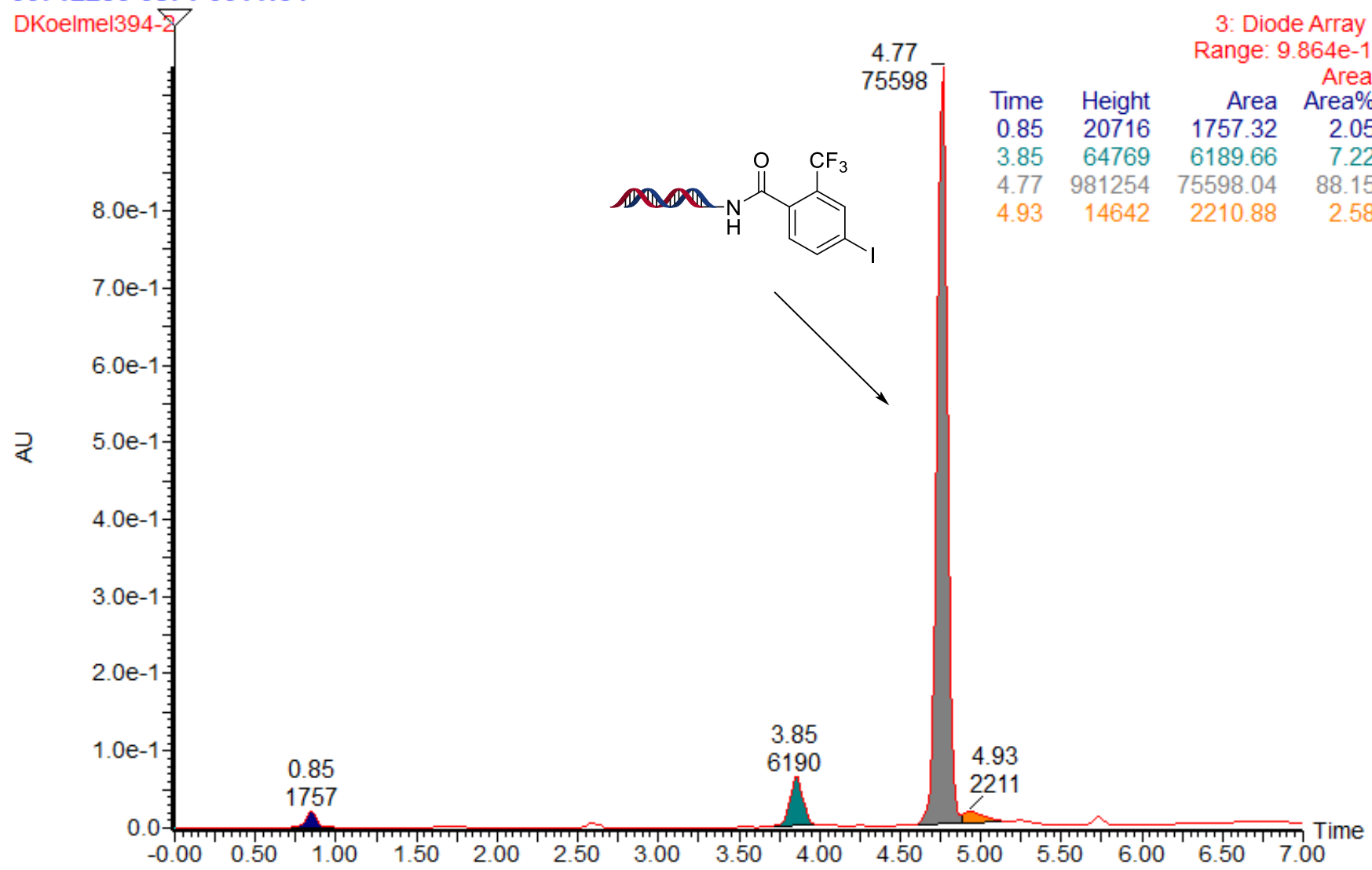

Figure S11. UPLC trace of aryl iodide S8. 


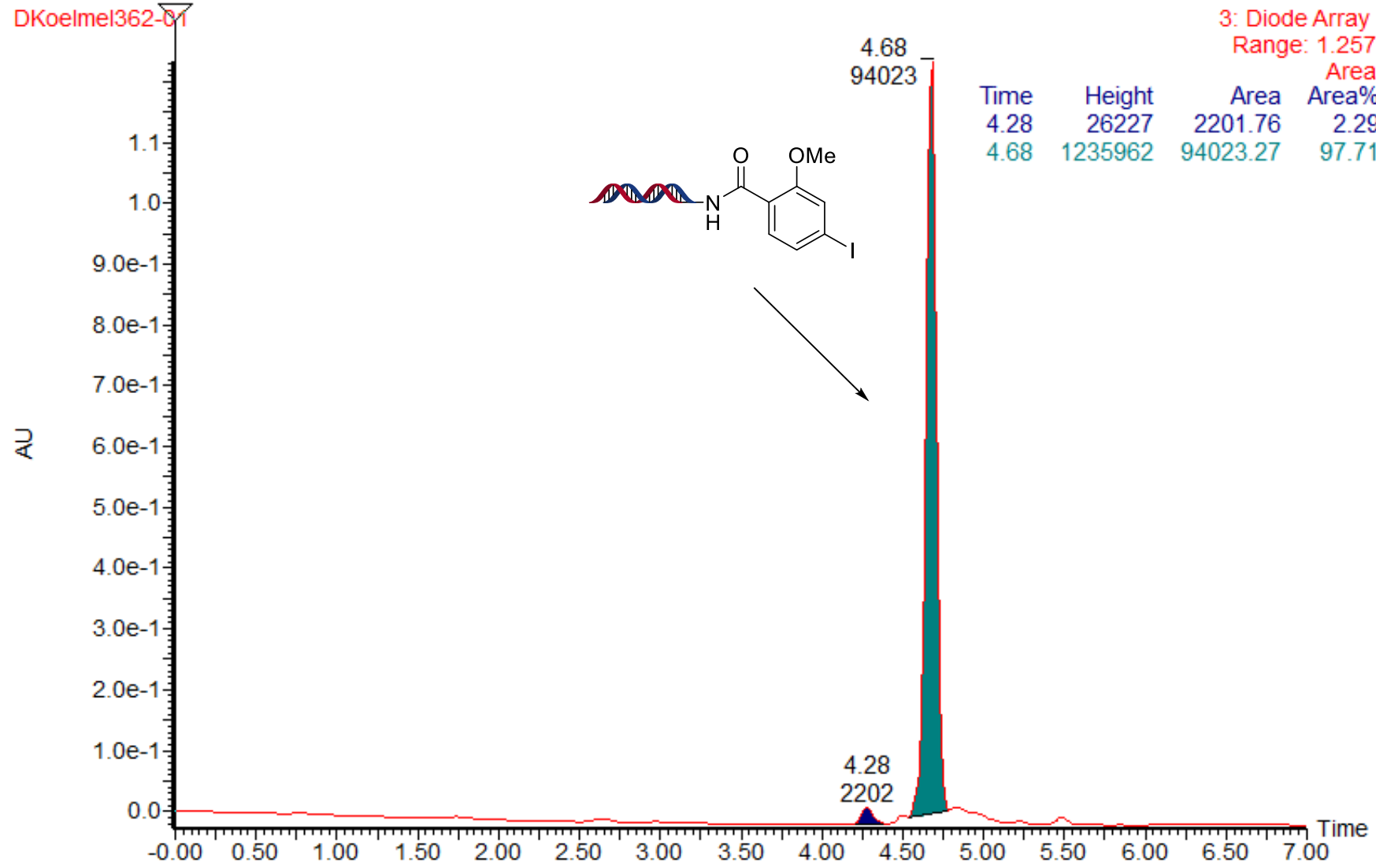

Figure S12. UPLC trace of aryl iodide S9.

00712256-0804-0011:30

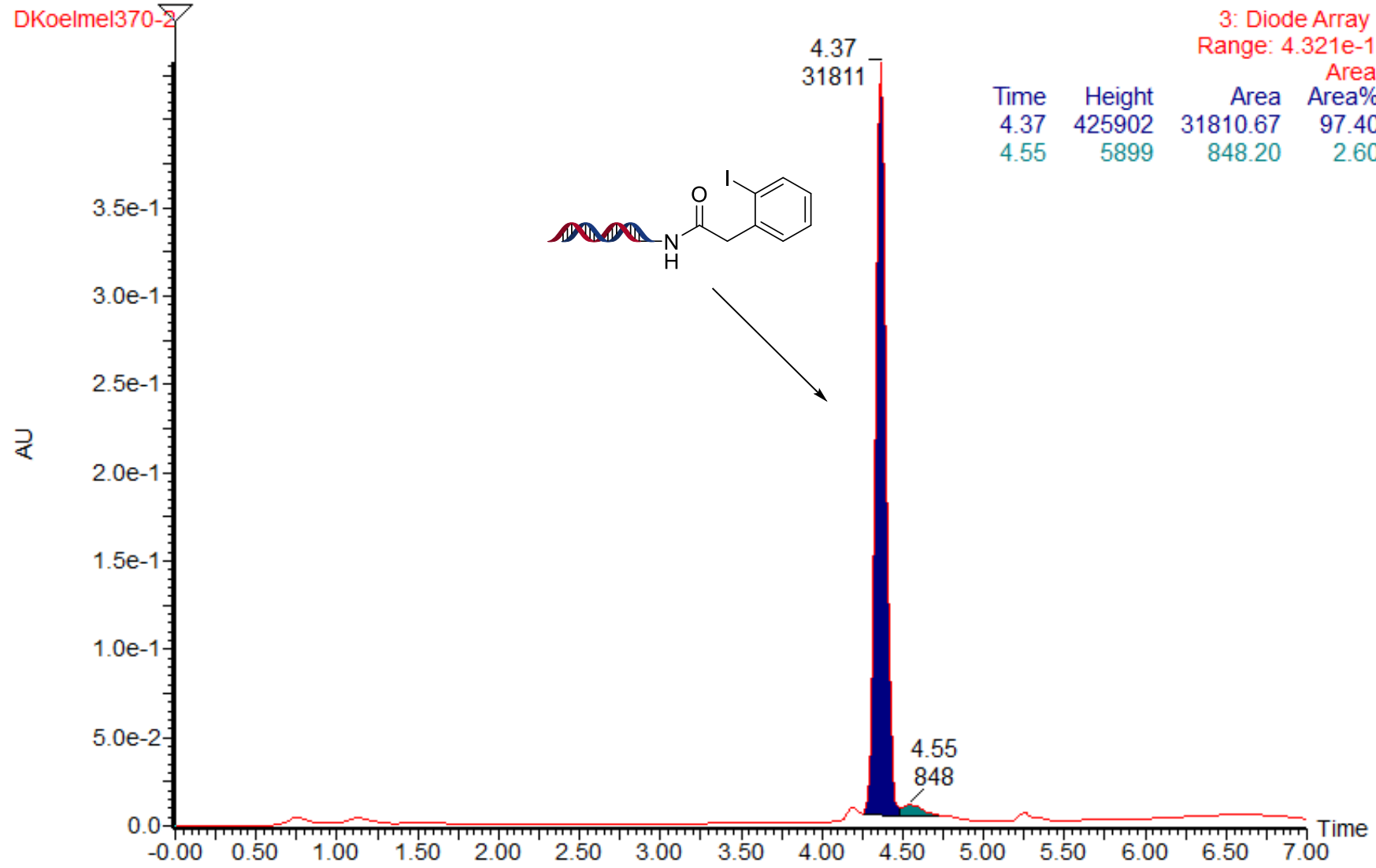

Figure S13. UPLC trace of aryl iodide S10. 


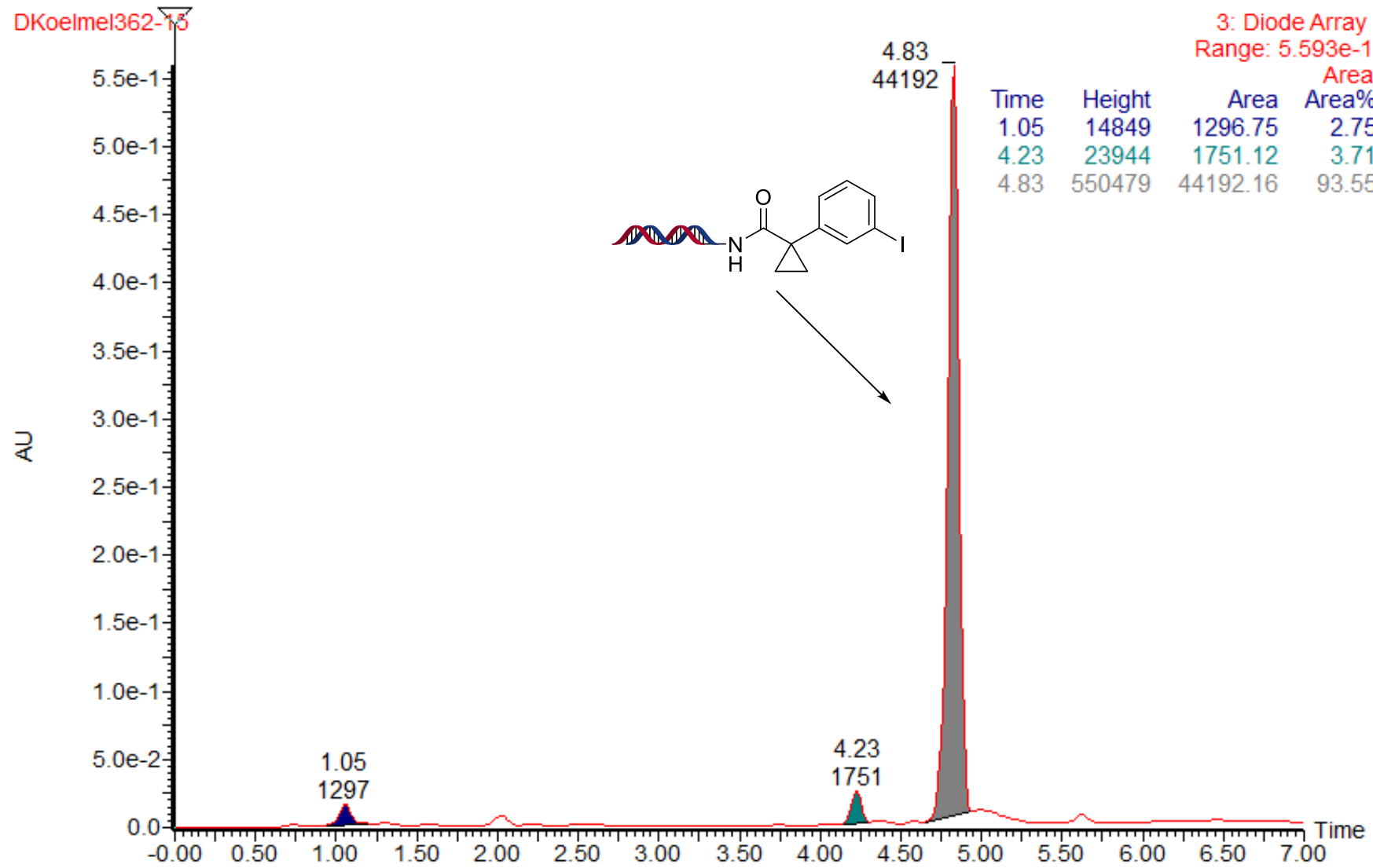

Figure S14. UPLC trace of aryl iodide S11.

00712256-0850-0011:1

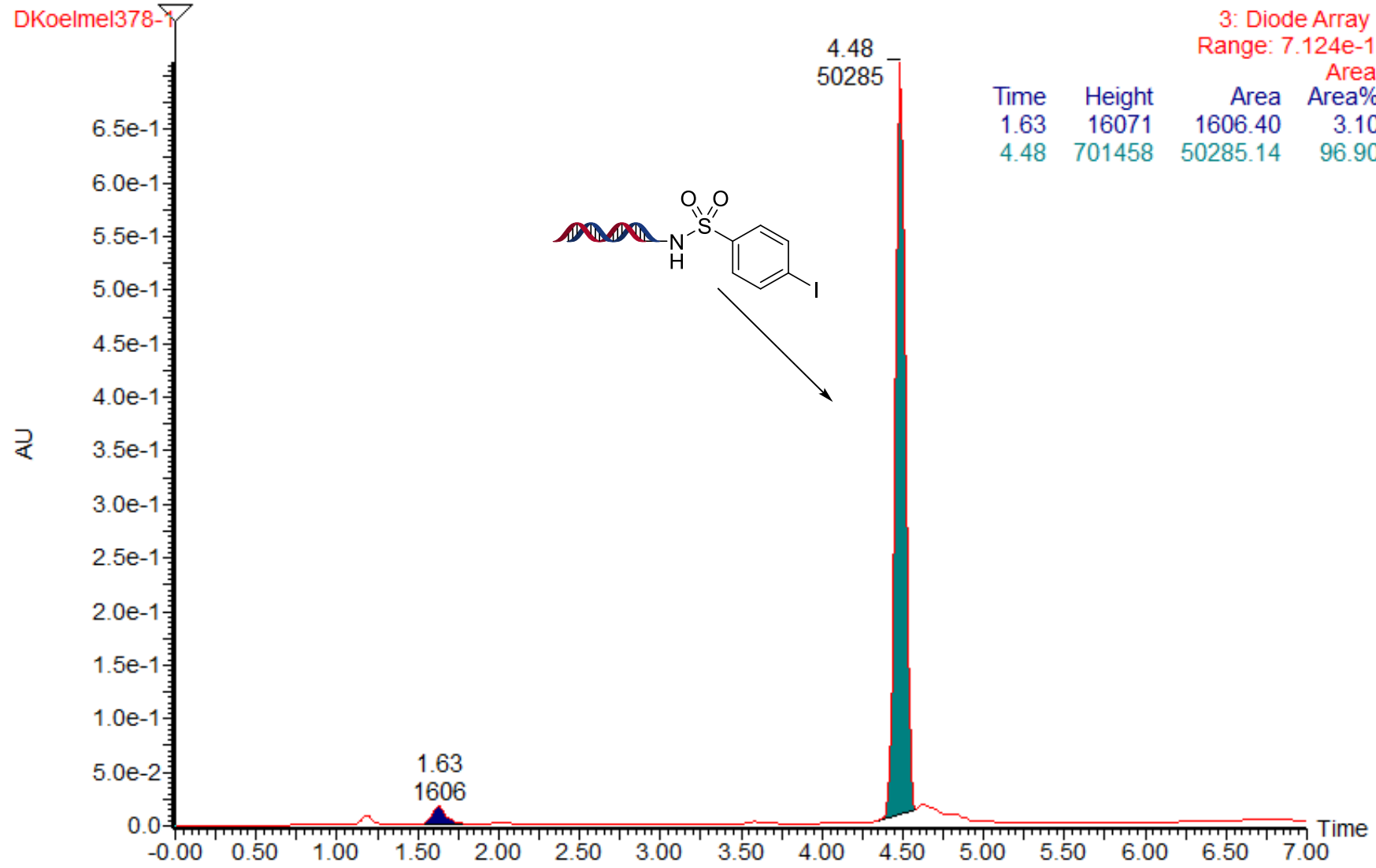

Figure S15. UPLC trace of aryl iodide S12. 


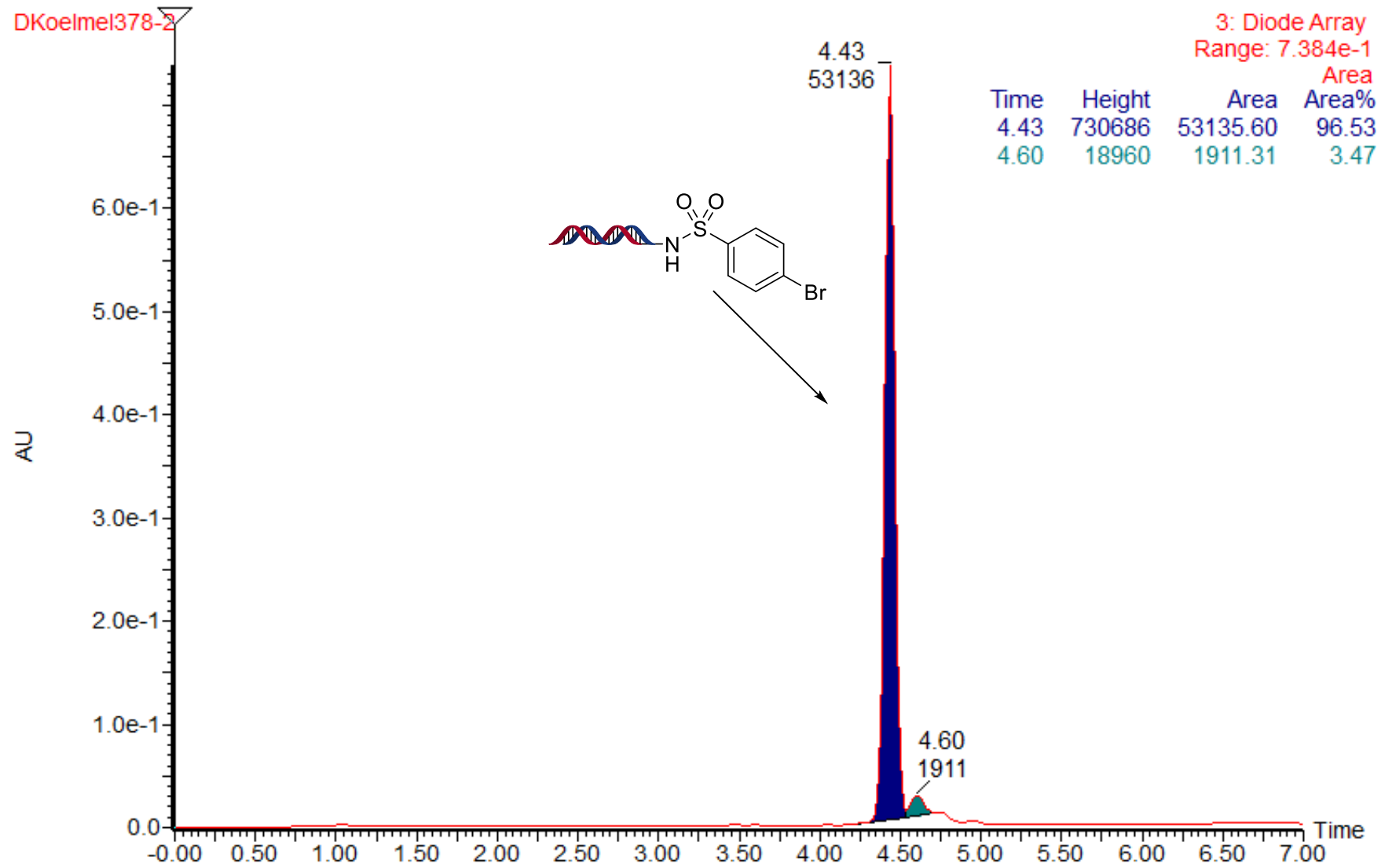

Figure S16. UPLC trace of aryl bromide S13.

00712256-0843-0011:5

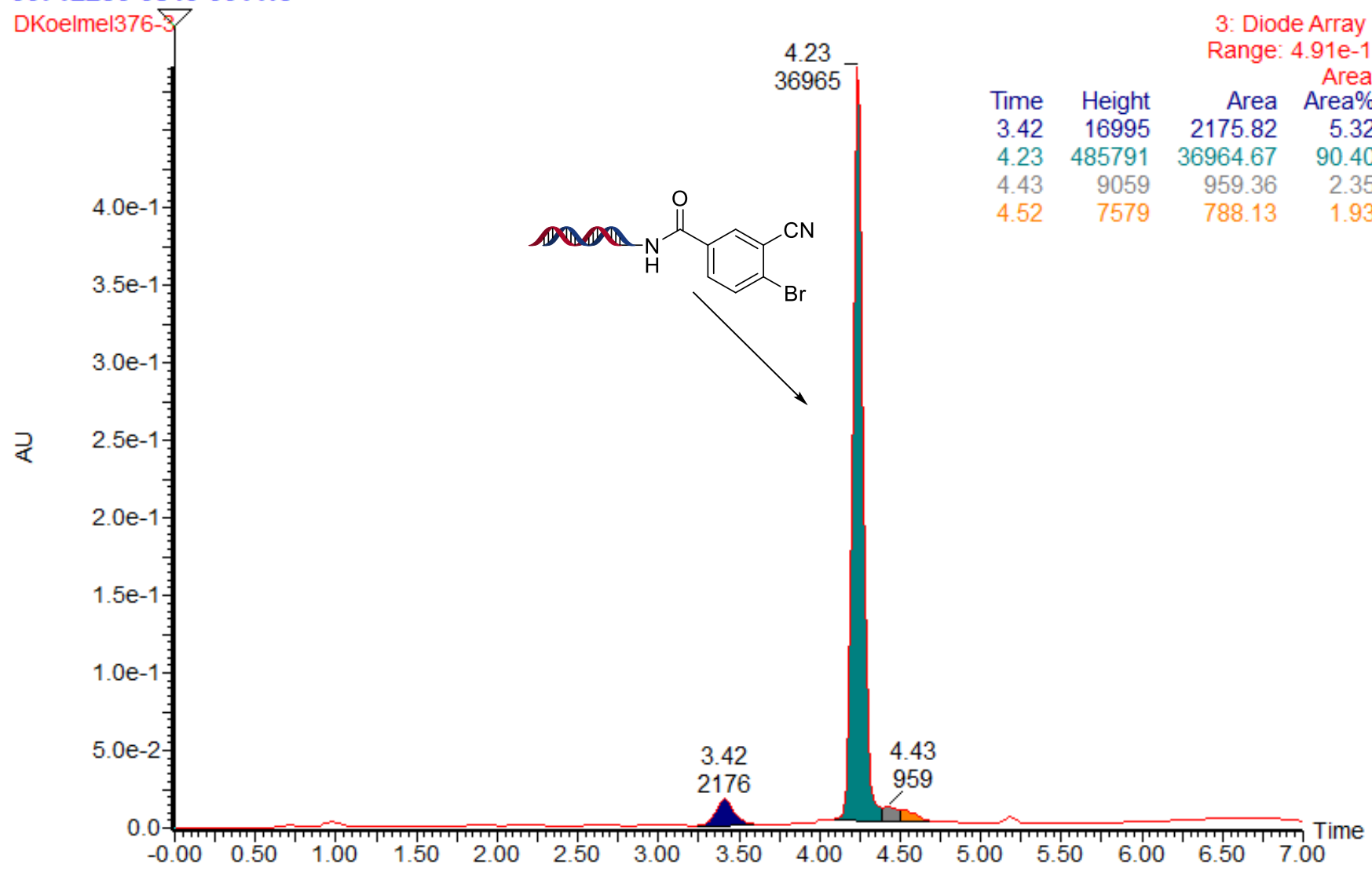

Figure S17. UPLC trace of aryl bromide S14. 


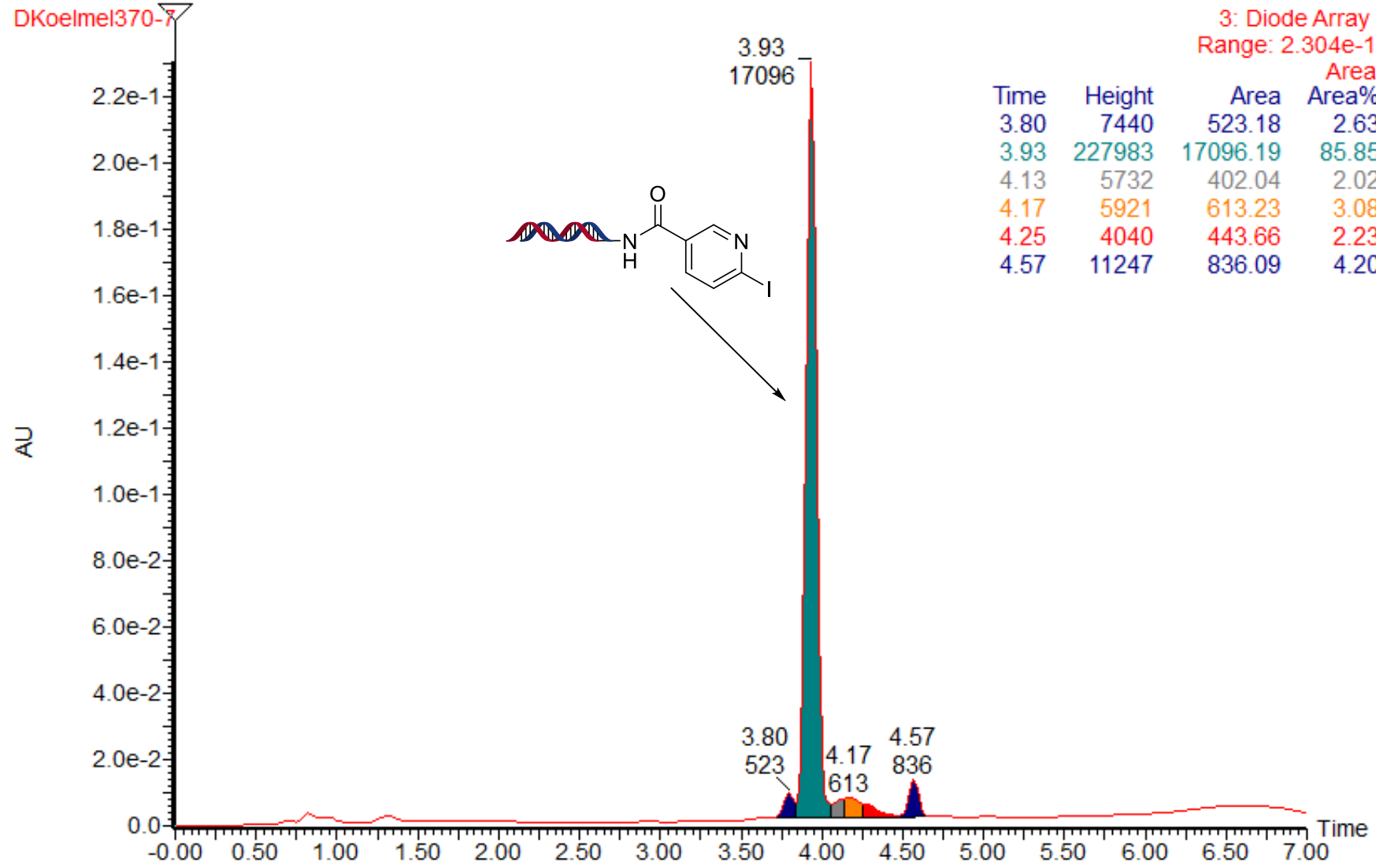

Figure S18. UPLC trace of aryl iodide S15.

00712256-0818-0011:17

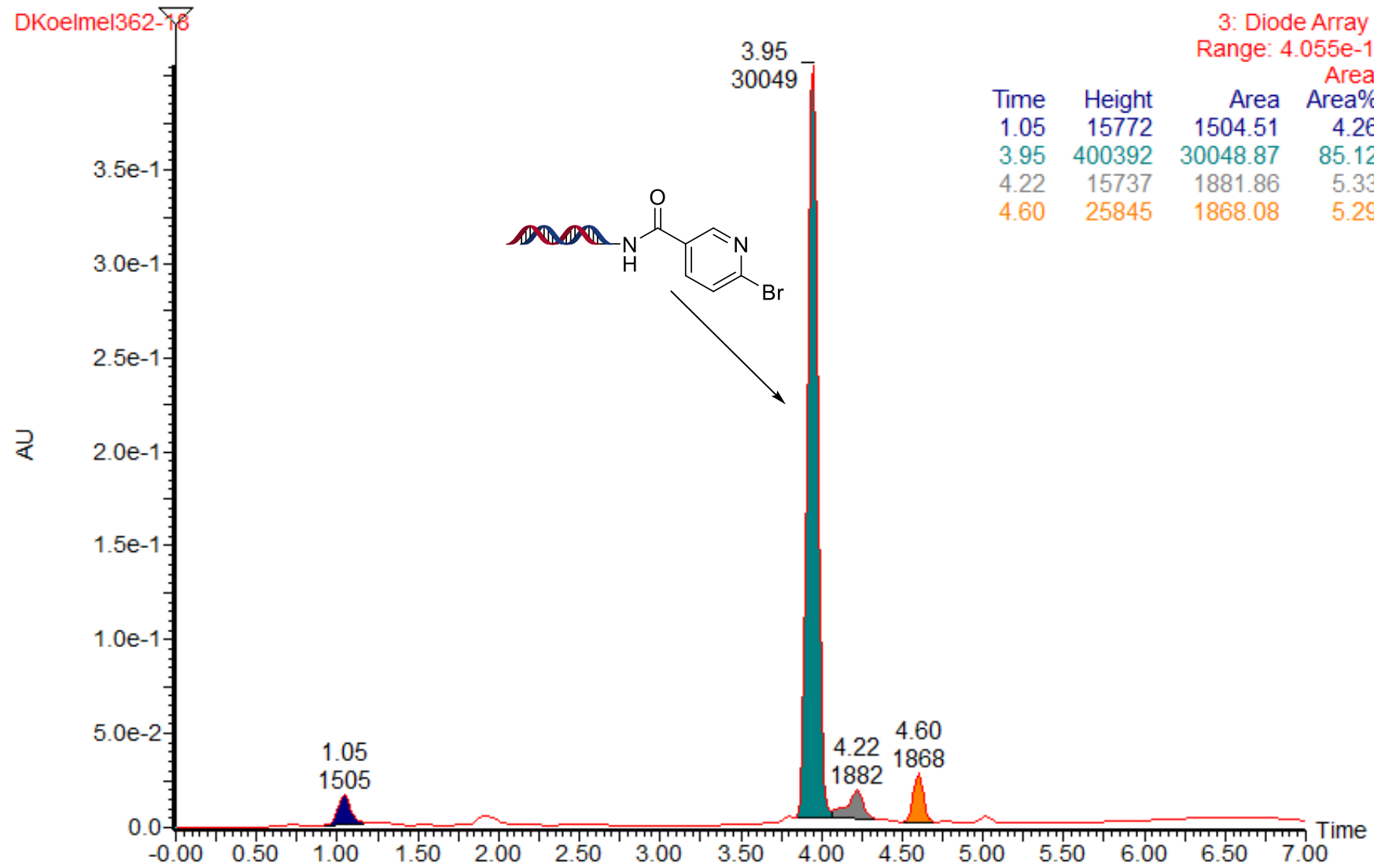

Figure S19. UPLC trace of aryl bromide S16. 


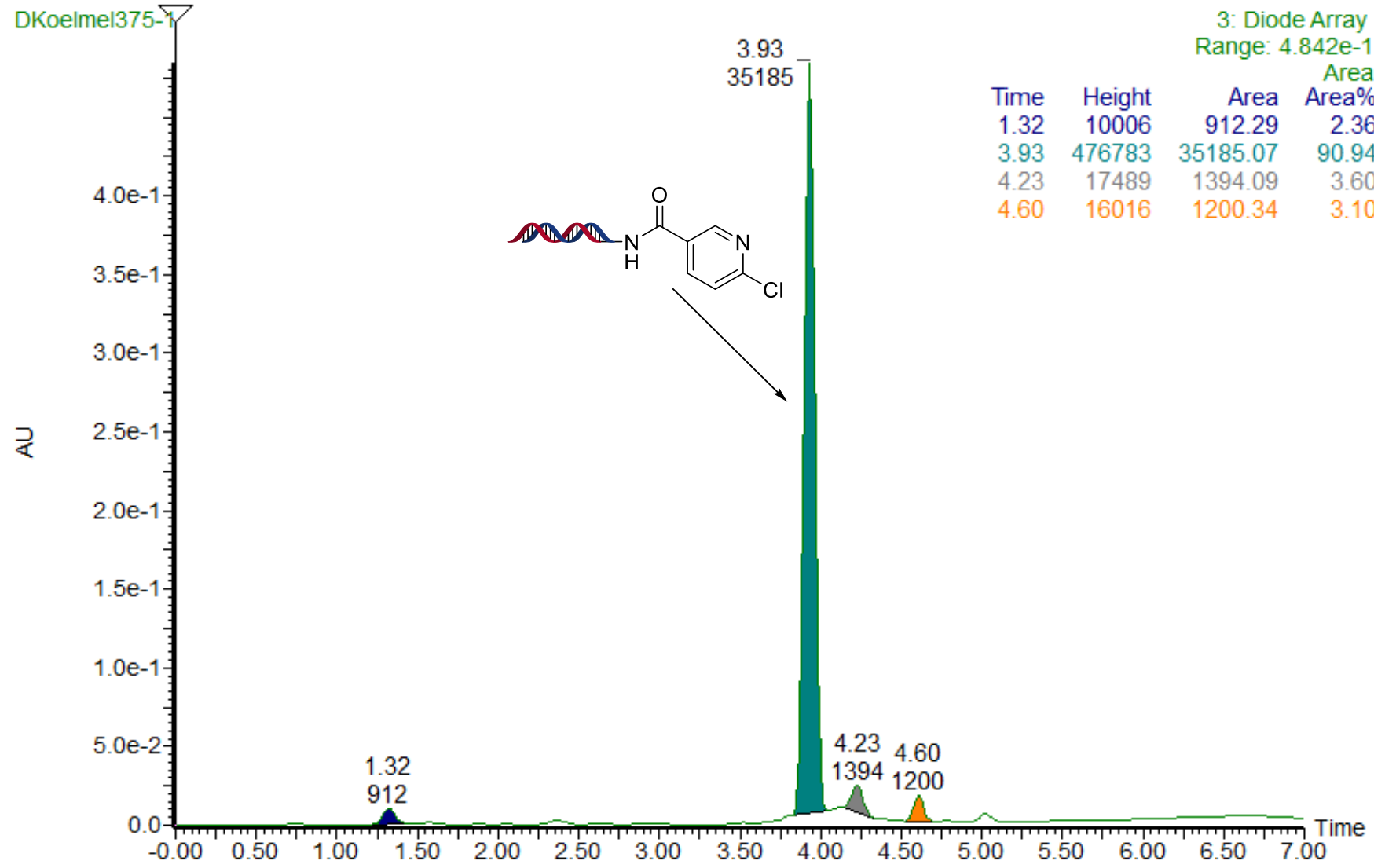

Figure S20. UPLC trace of aryl chloride S17.

00712256-0845-0011:7

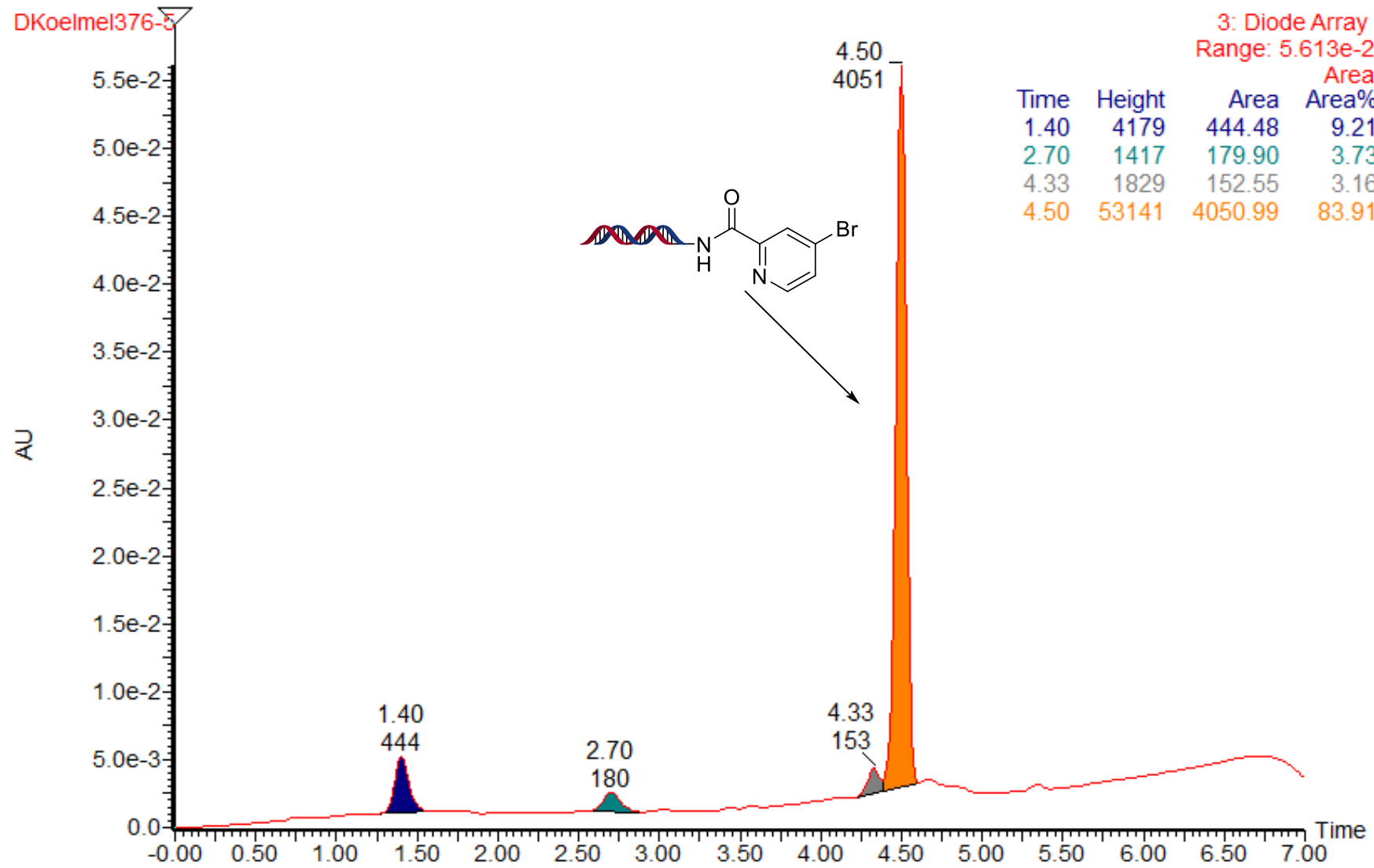

Figure S21. UPLC trace of aryl bromide S18. 


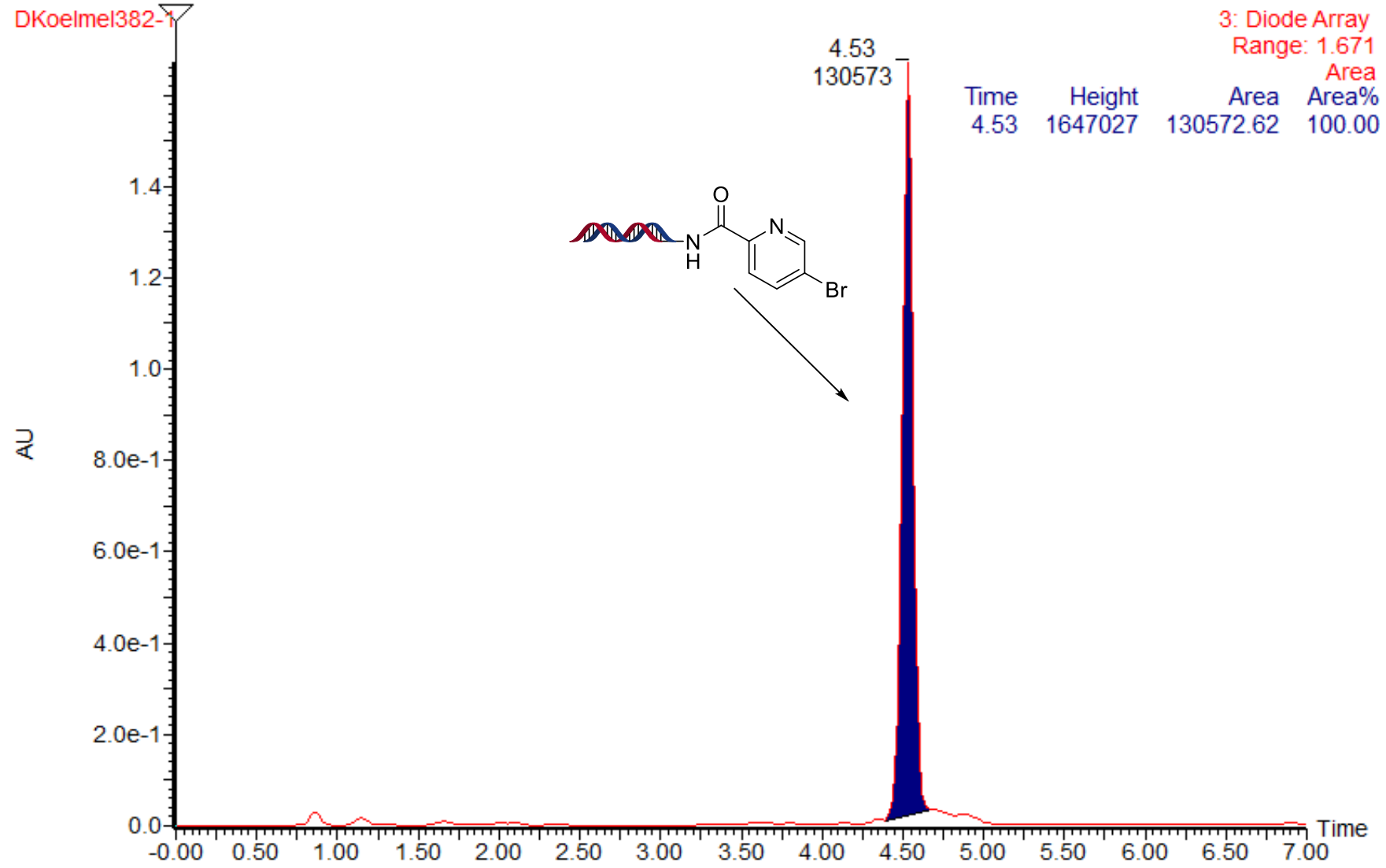

Figure S22. UPLC trace of aryl bromide S19.

00712256-0853-0011:4

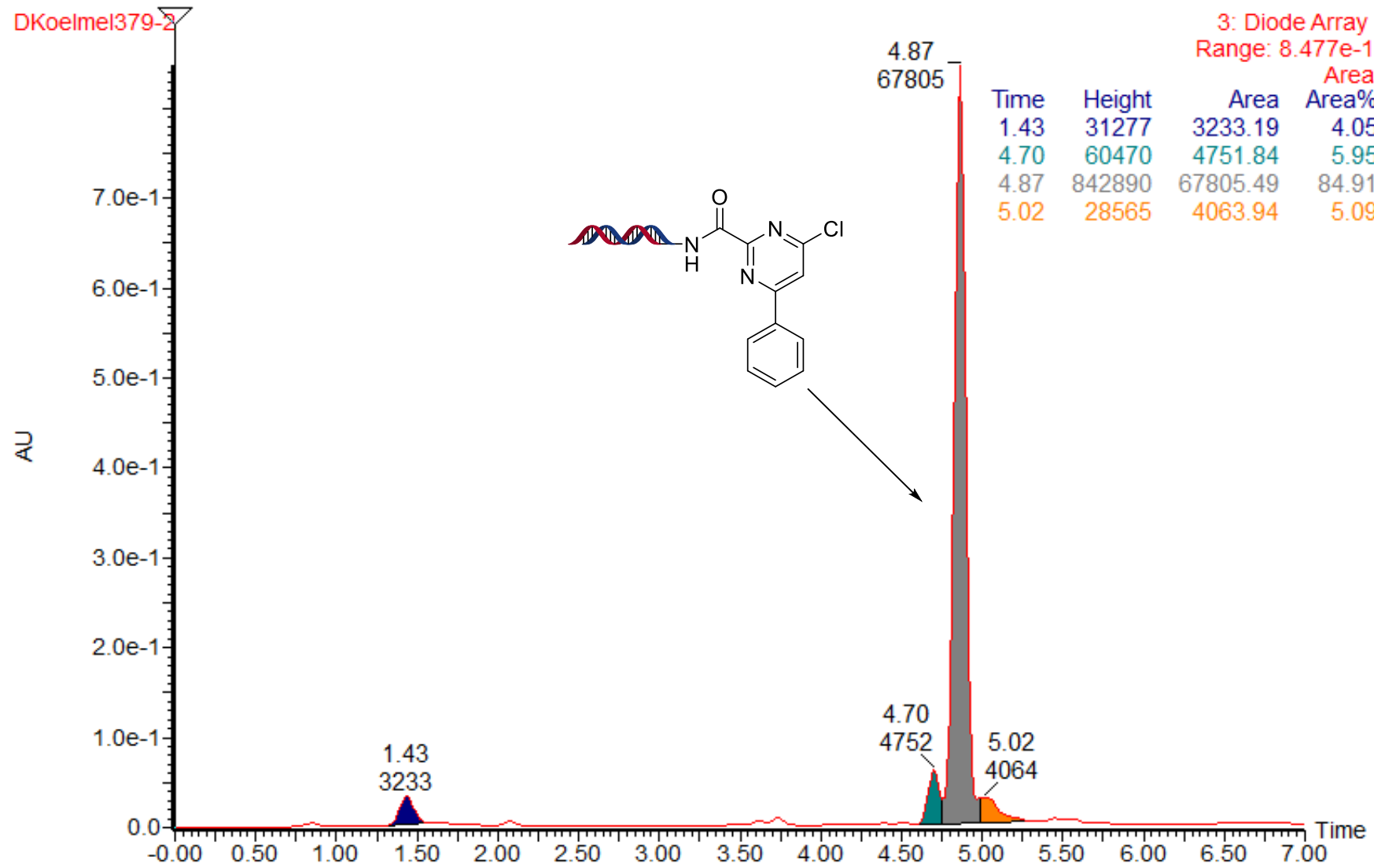

Figure S23. UPLC trace of aryl bromide S20. 


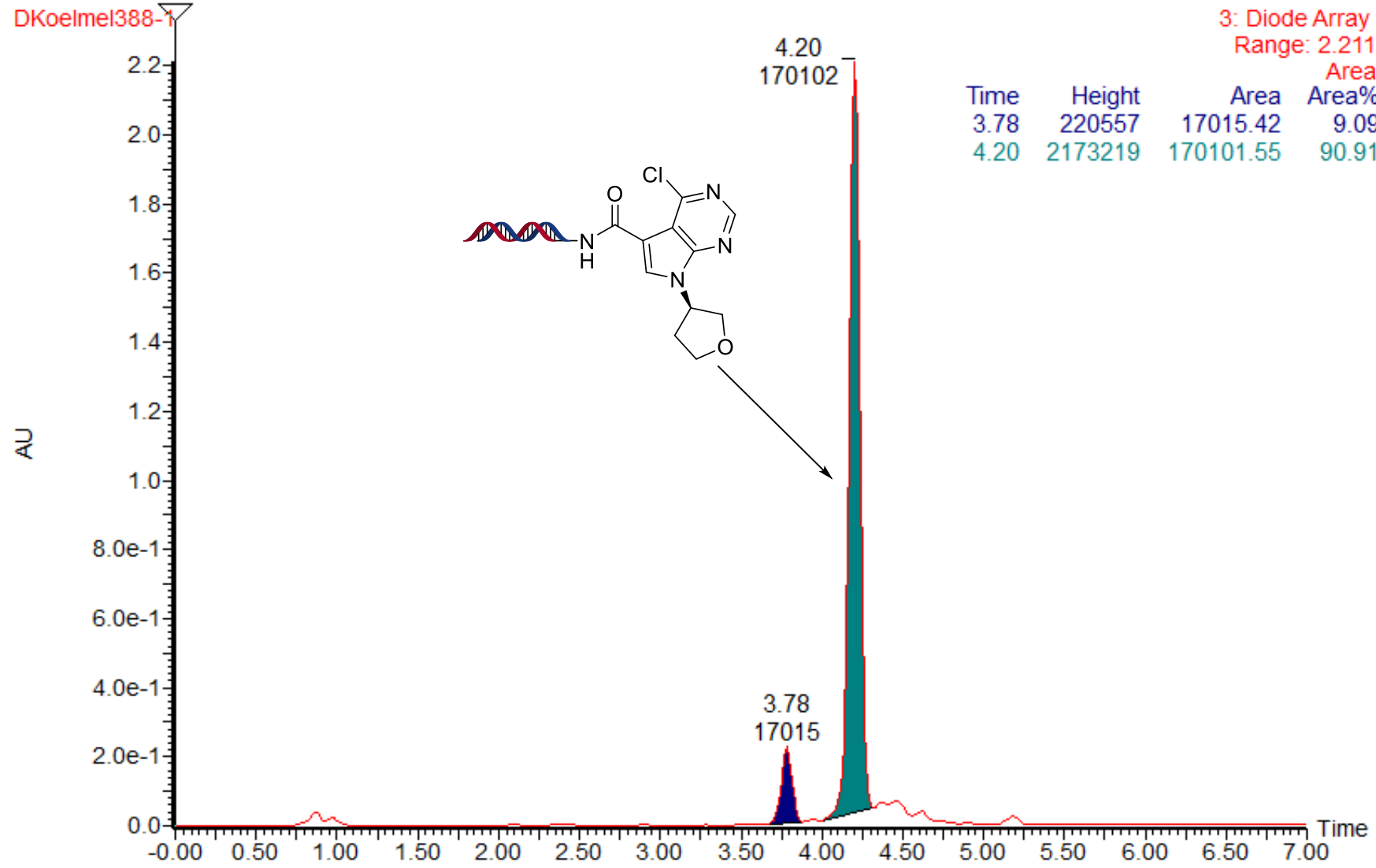

Figure S24. UPLC trace of aryl bromide S21.

1:1200712256-0629-001

DKoelmel250-2y Sm (Mn, 1x1)

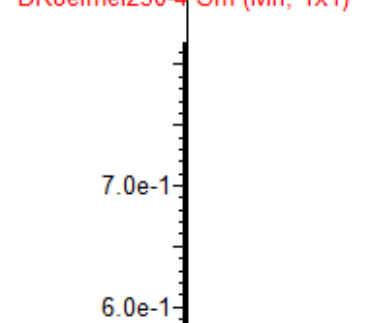

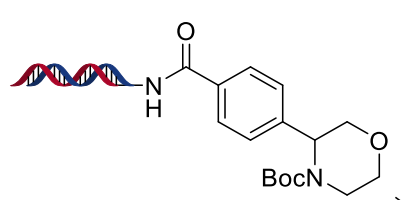

4.82 66835
789688
15-May-2018 14:23:09

3: Diode Array Range: 8.181e-1 Area, Heiaht Area Area\% $\begin{array}{lllr}4.08 & 36661 & 3138.19 & 4.17 \\ 4.33 & 49403 & 5274.72 & 7.01\end{array}$ $\begin{array}{rrrr}4.08 & 36661 & 3138.19 & 4.17 \\ 4.33 & 49403 & 5274.72 & 7.01\end{array}$ $\begin{array}{llll}4.82 & 789688 & 66834.70 & 88.82\end{array}$

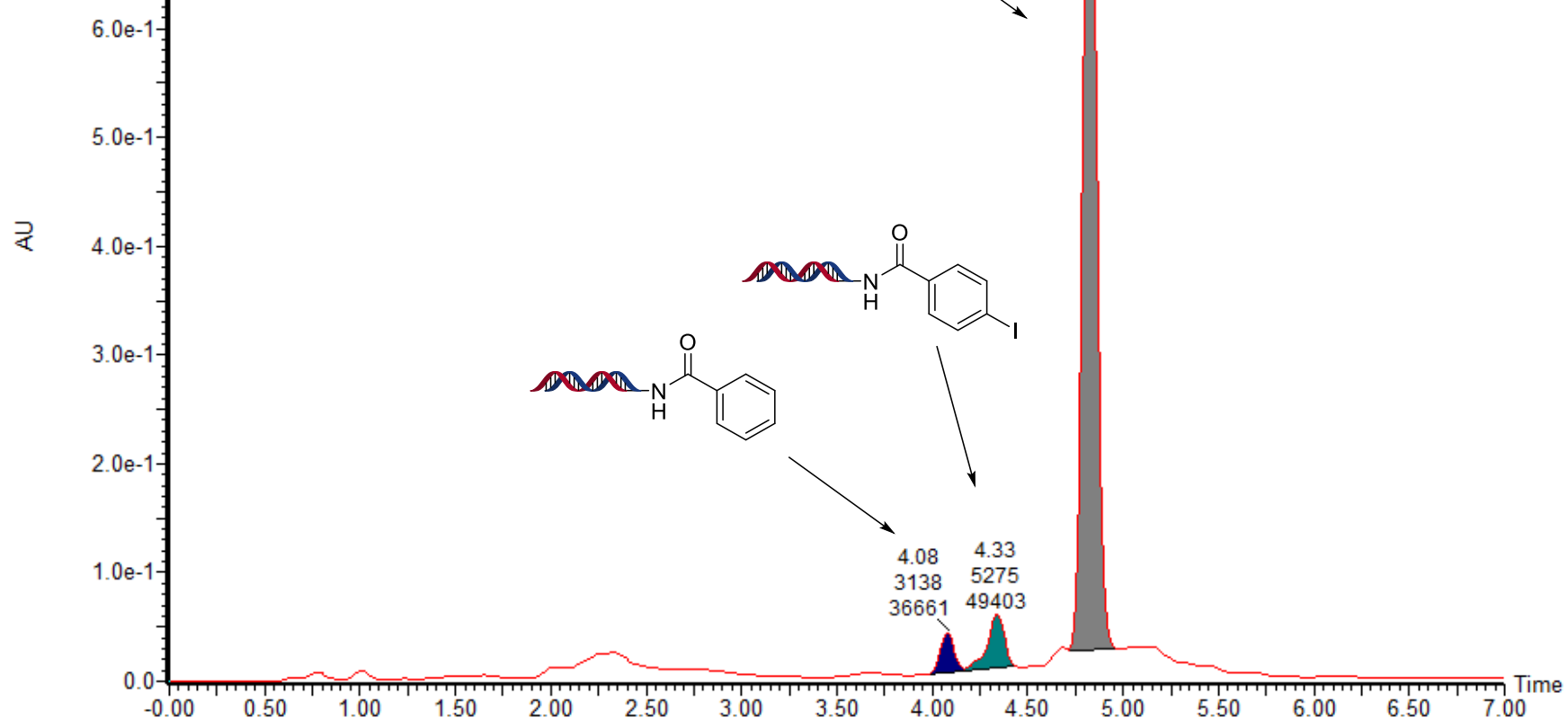

Figure S25. UPLC trace of Table 1, entry 1. 


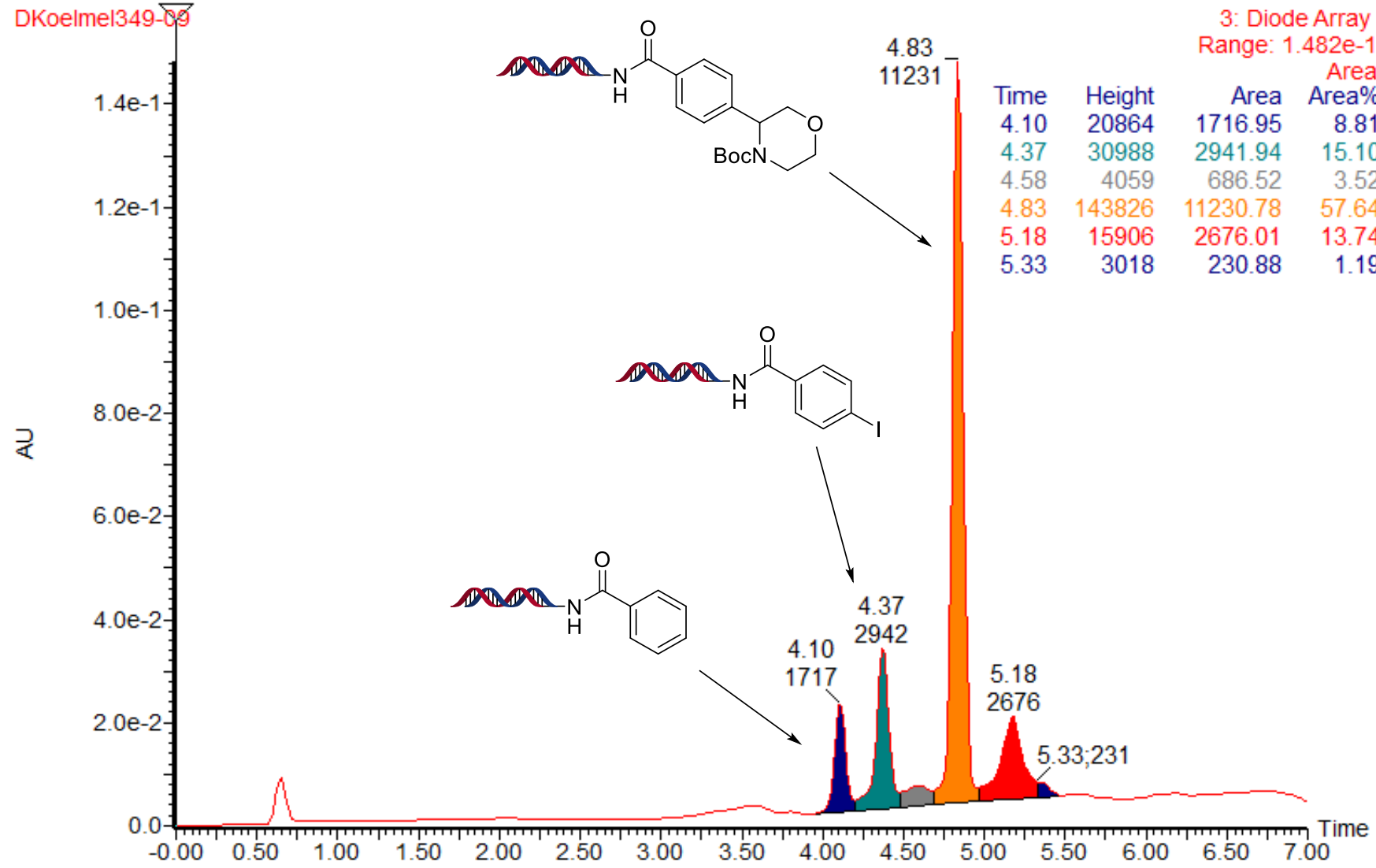

Figure S26. UPLC trace of Table 1, entry 2.

00712256-0801-001-Repeat1:48

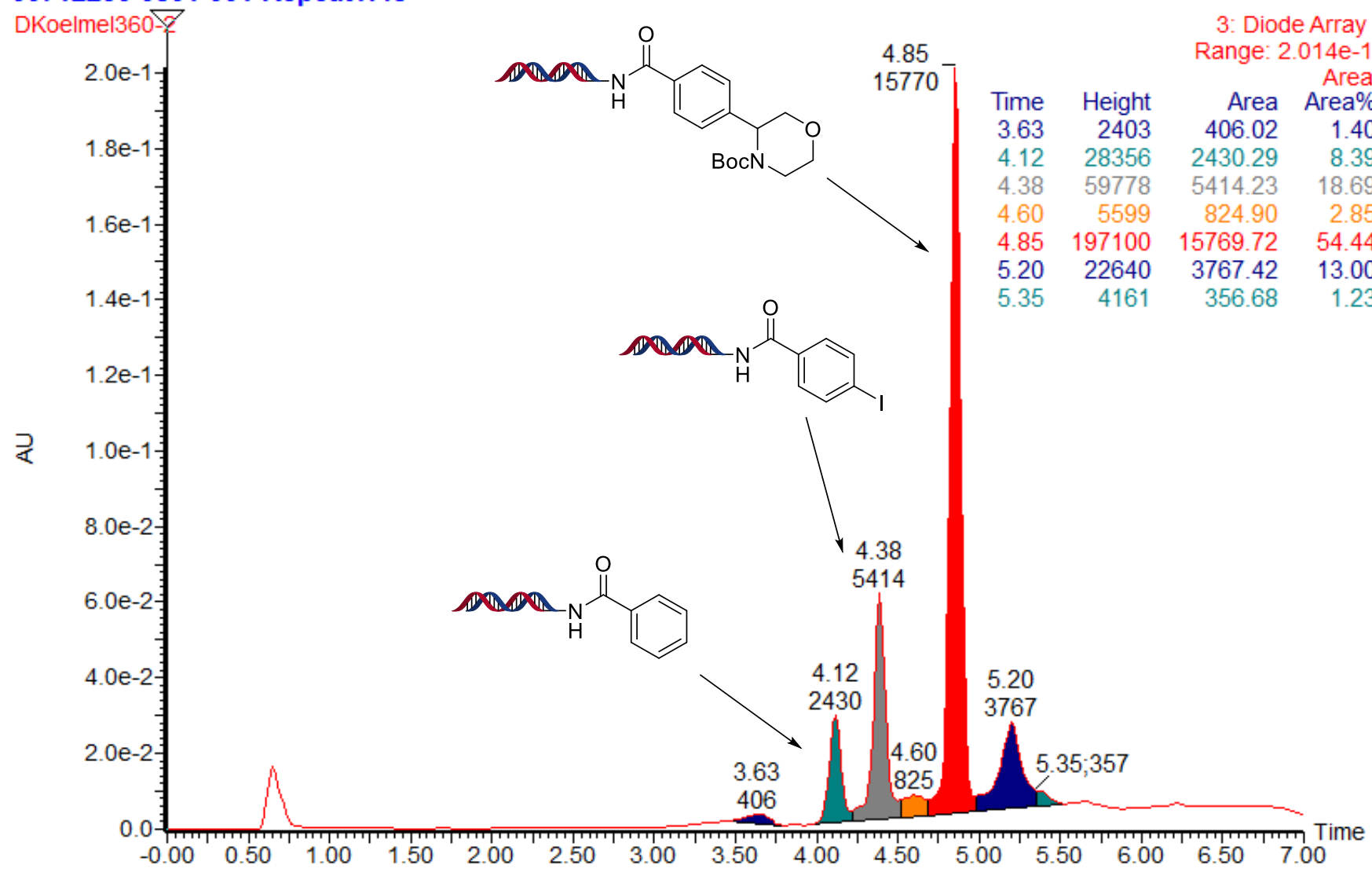

Figure S27. UPLC trace of Table 1, entry 3. 


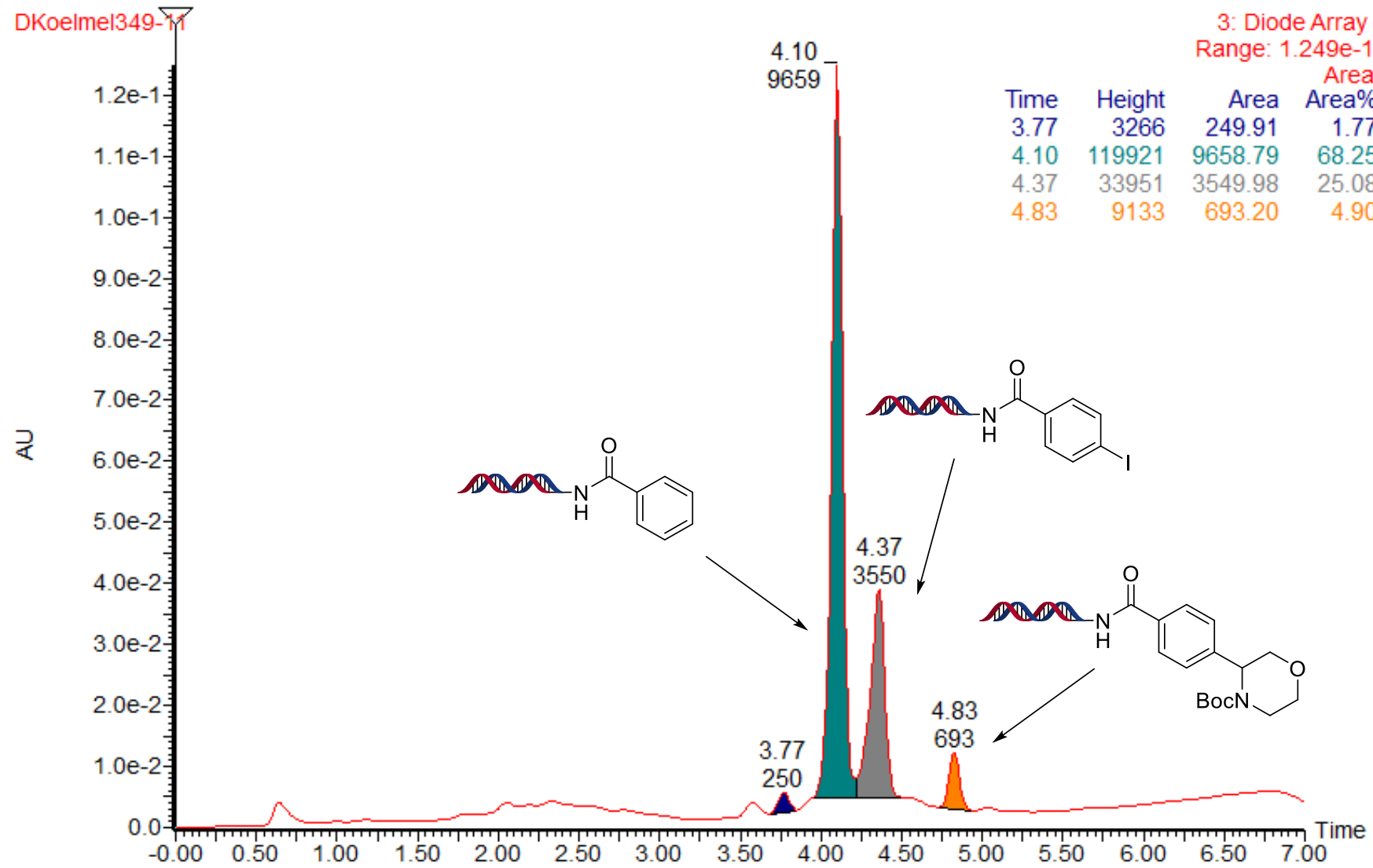

Figure S28. UPLC trace of Table 1, entry 4.

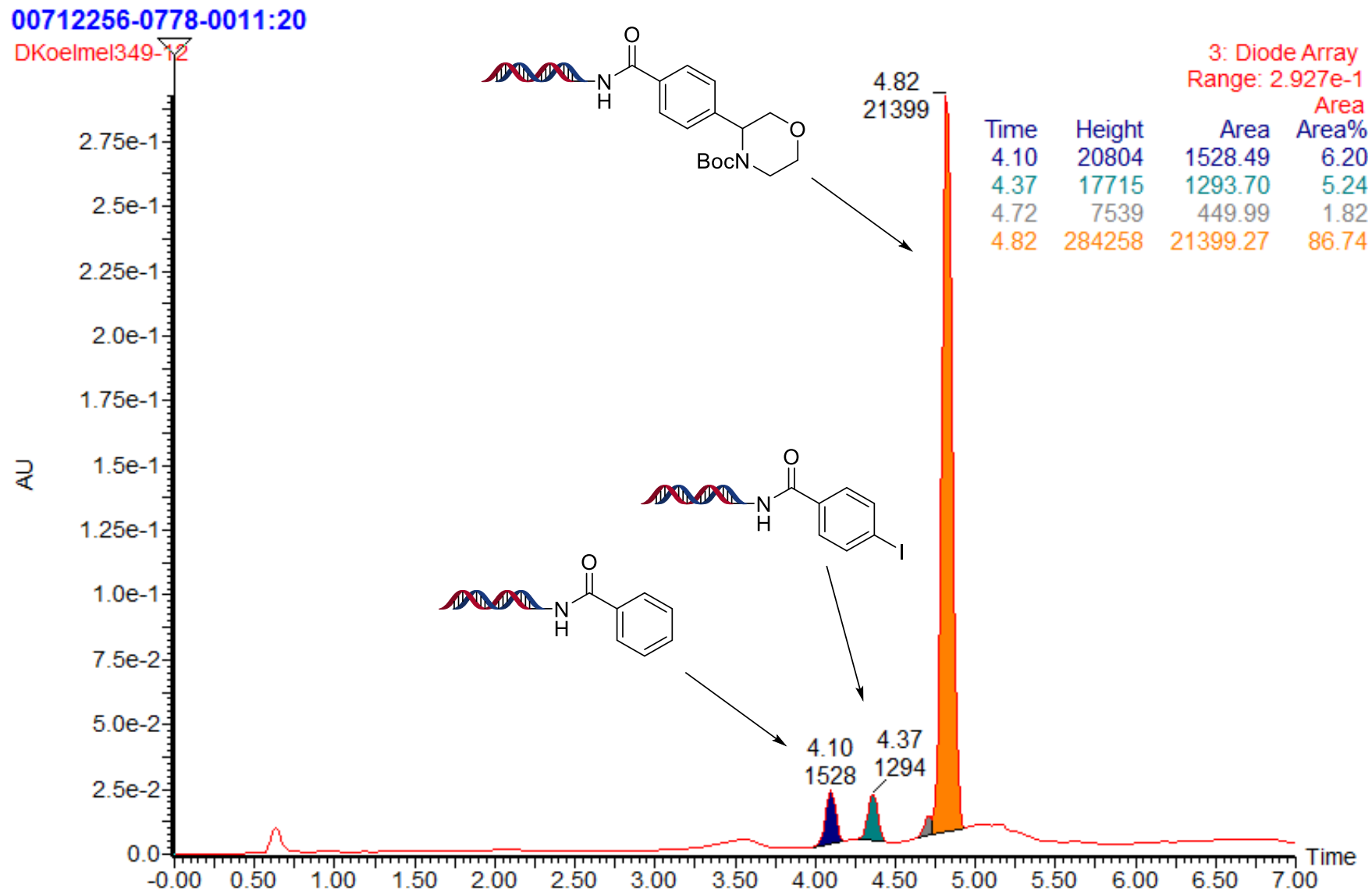

Figure S29. UPLC trace of Table 1, entry 5. 


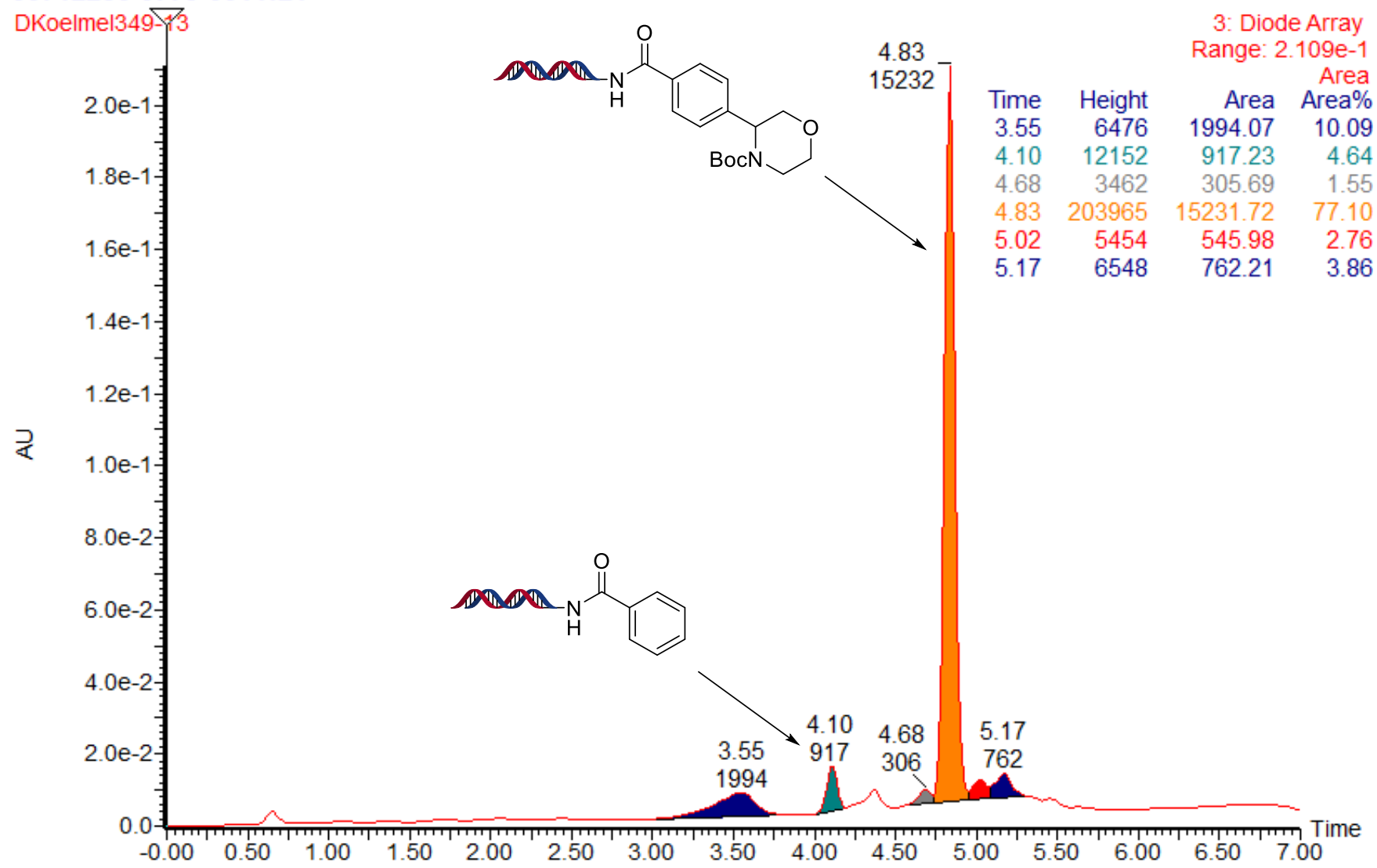

Figure S30. UPLC trace of Table 1, entry 6.

\section{6-0767-0011:9}

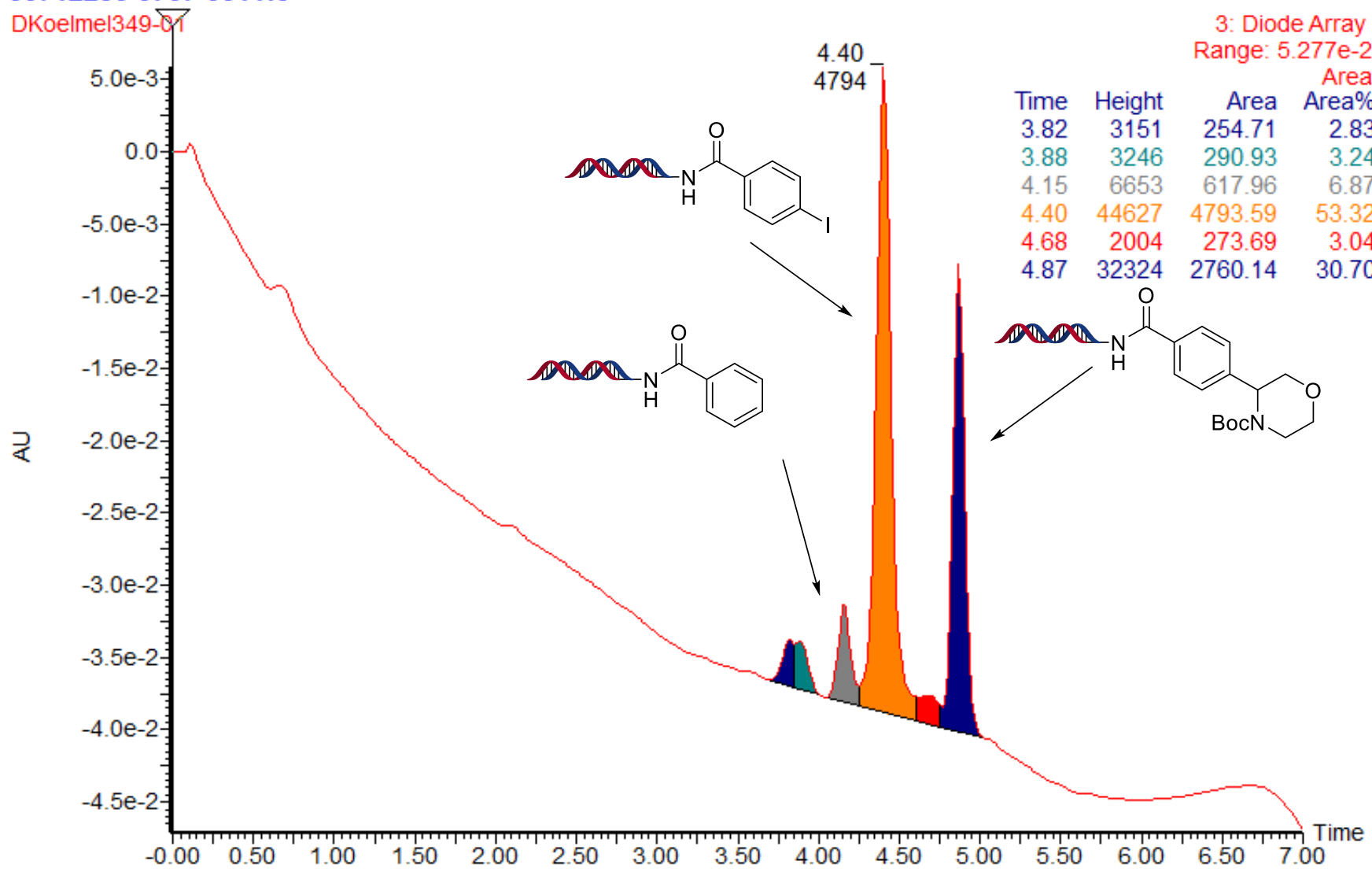

Figure S31. UPLC trace of Table 1, entry 7. 


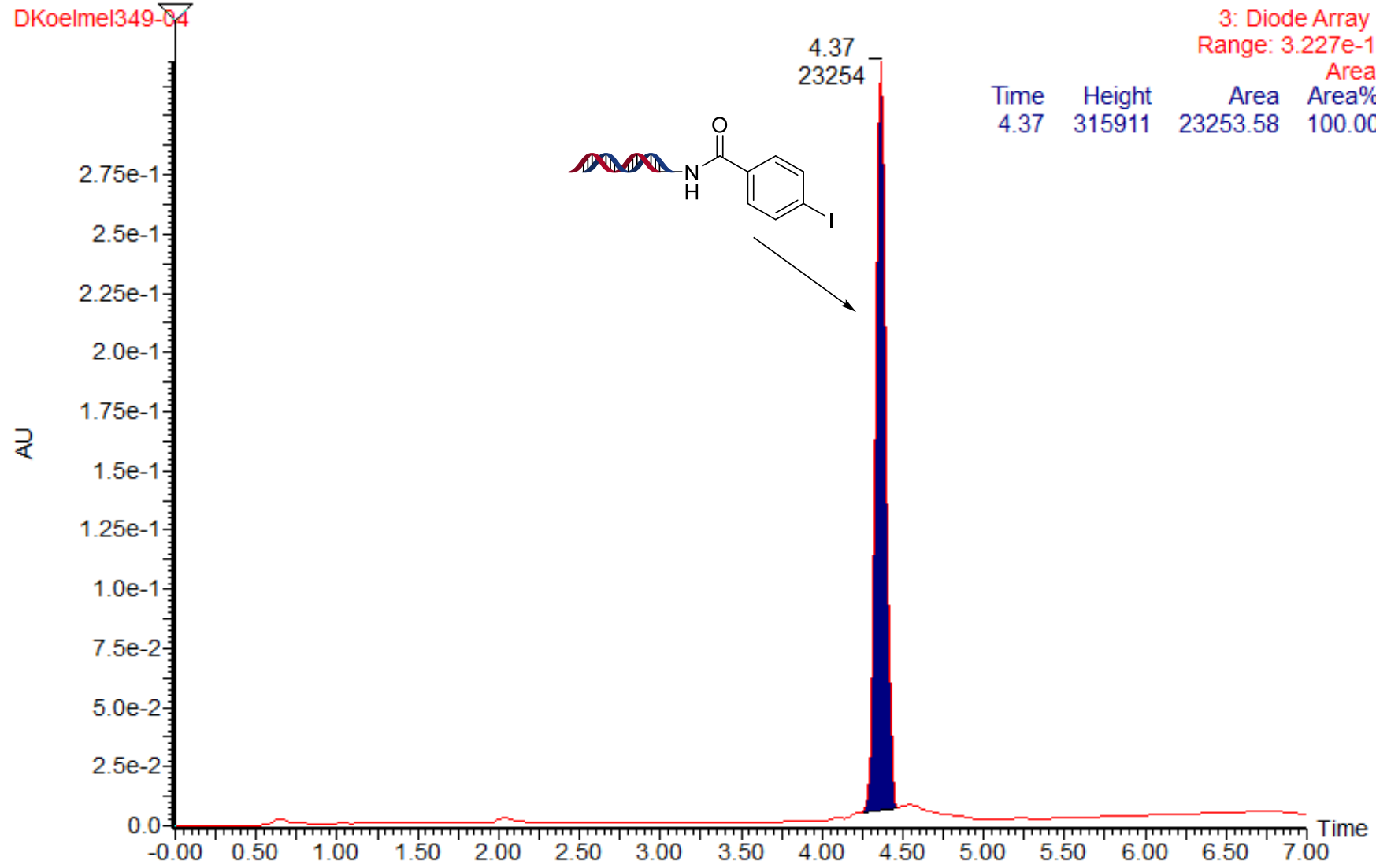

Figure S32. UPLC trace of Table 1, entry 8.

00712256-0769-0011:11

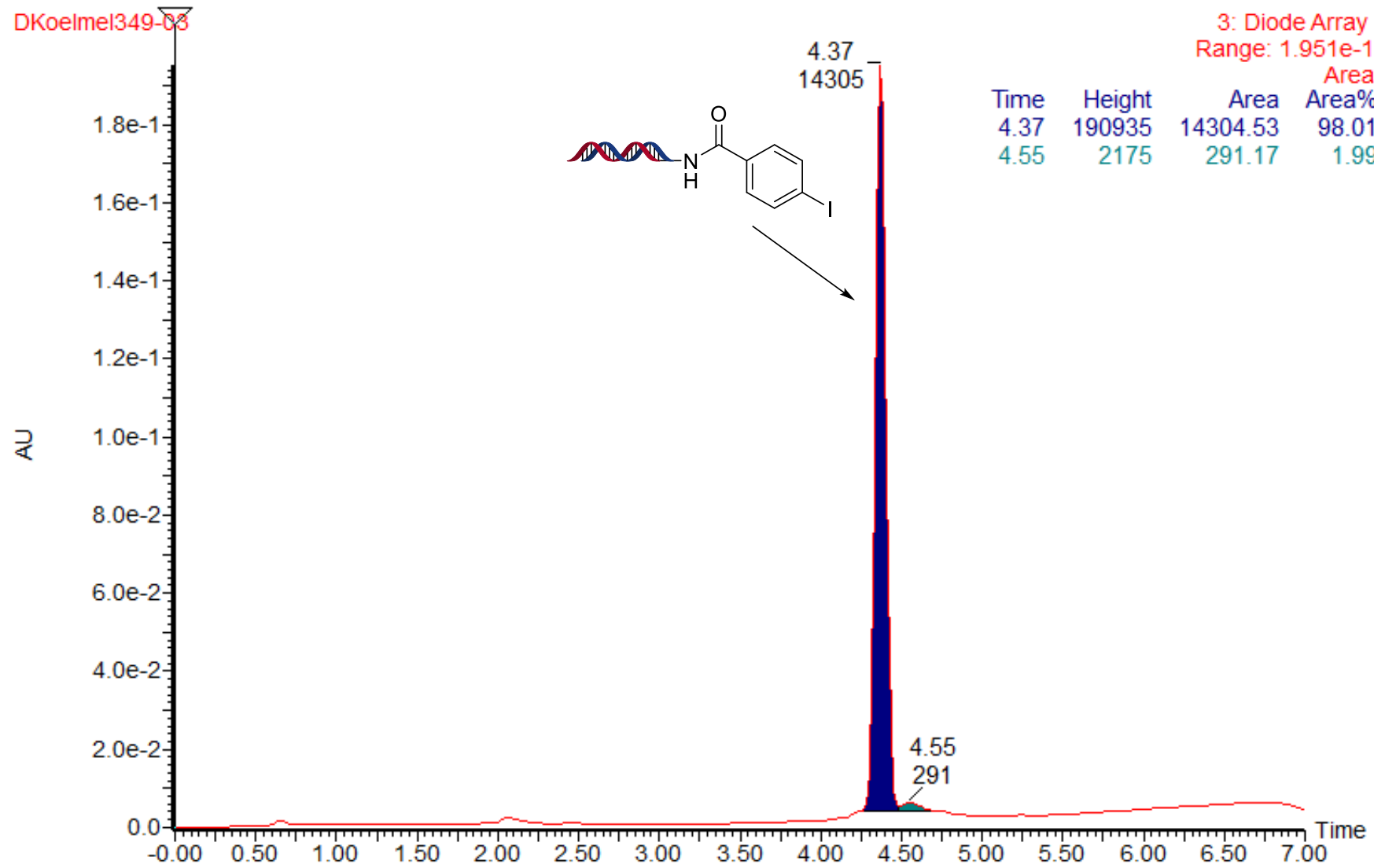

Figure S33. UPLC trace of Table 1, entry 9. 


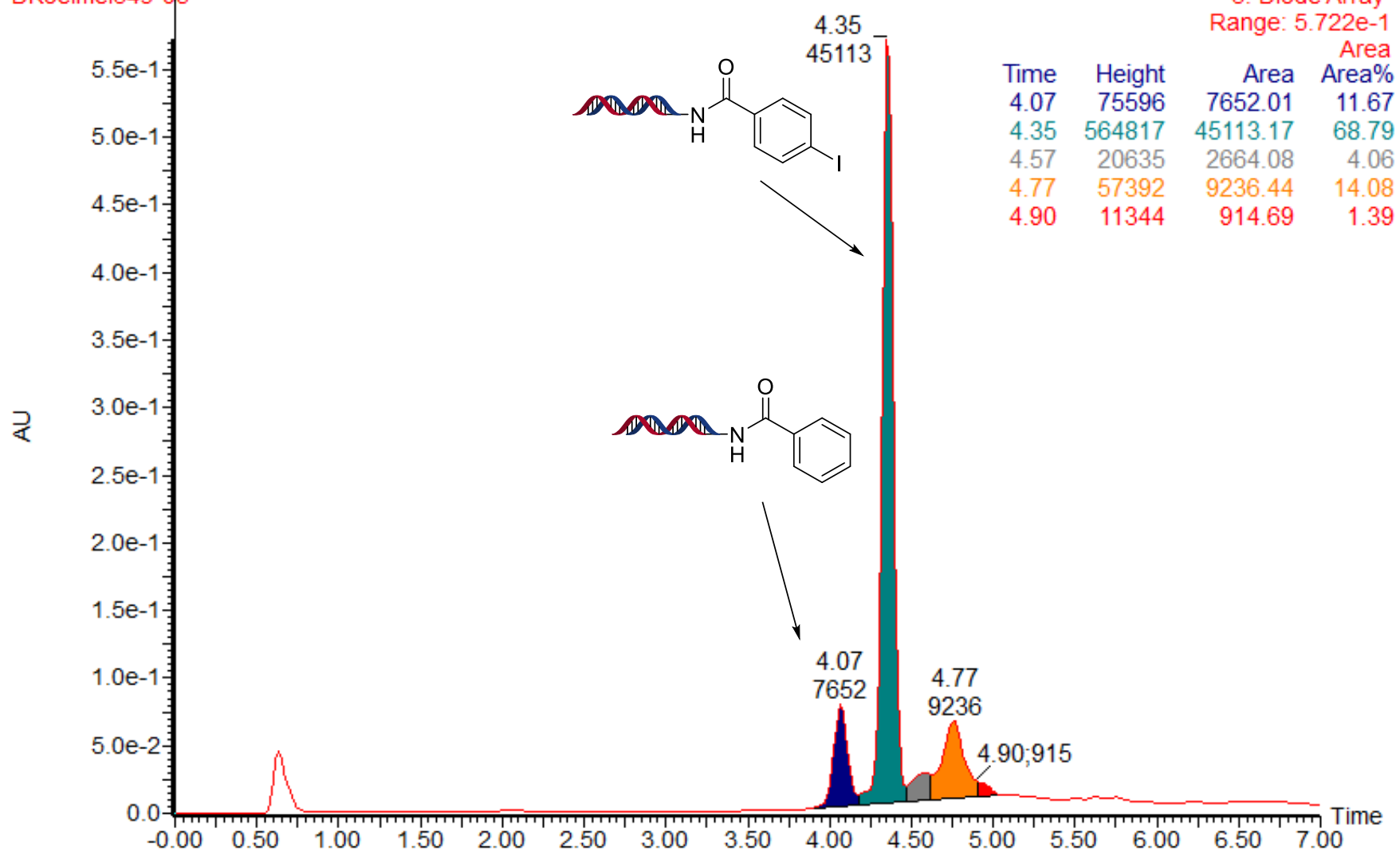

Figure S34. UPLC trace of Table 1, entry 10.

00712256-0774-0011:16

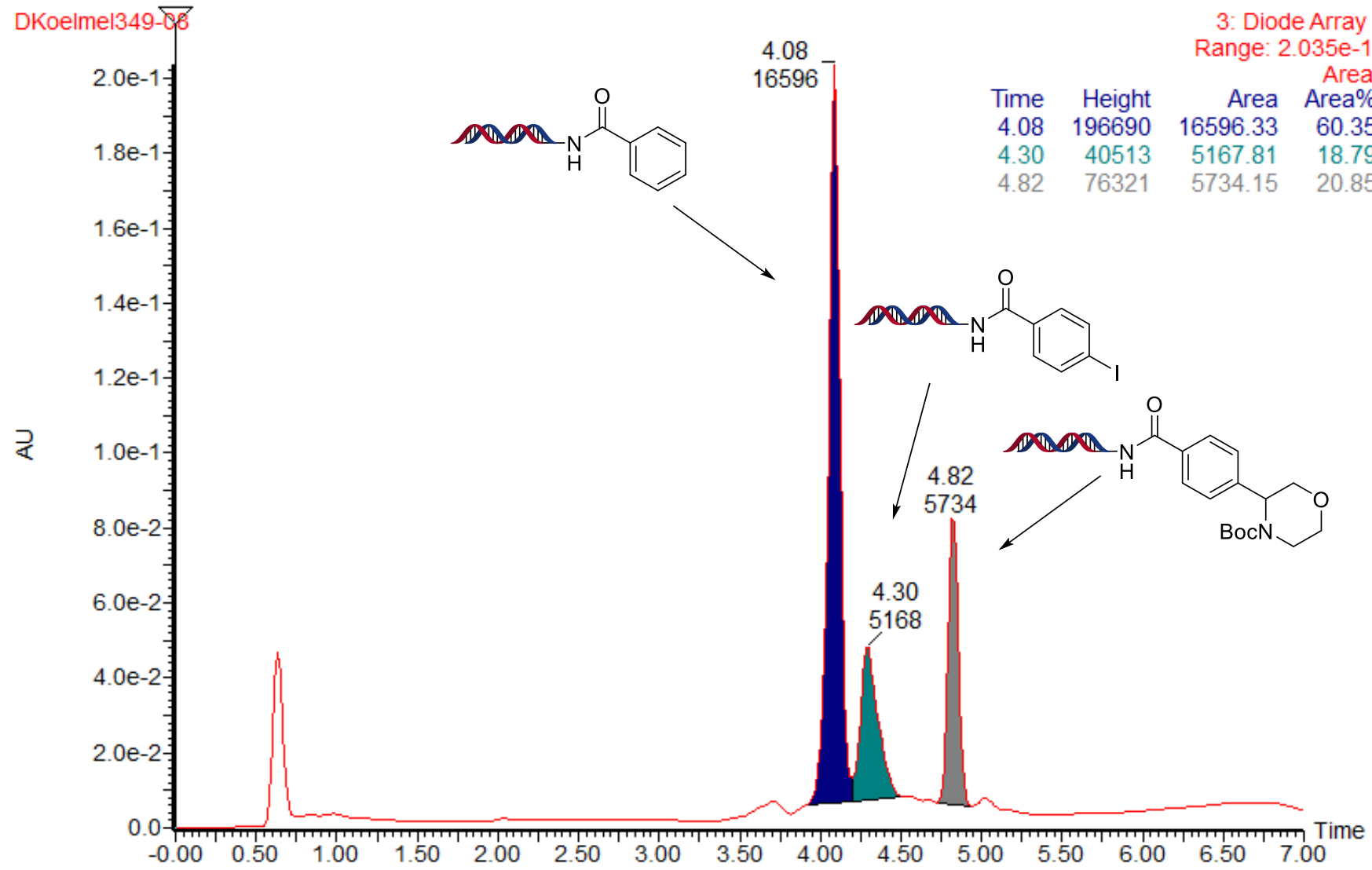

Figure S35. UPLC trace of Table 1, entry 11. 


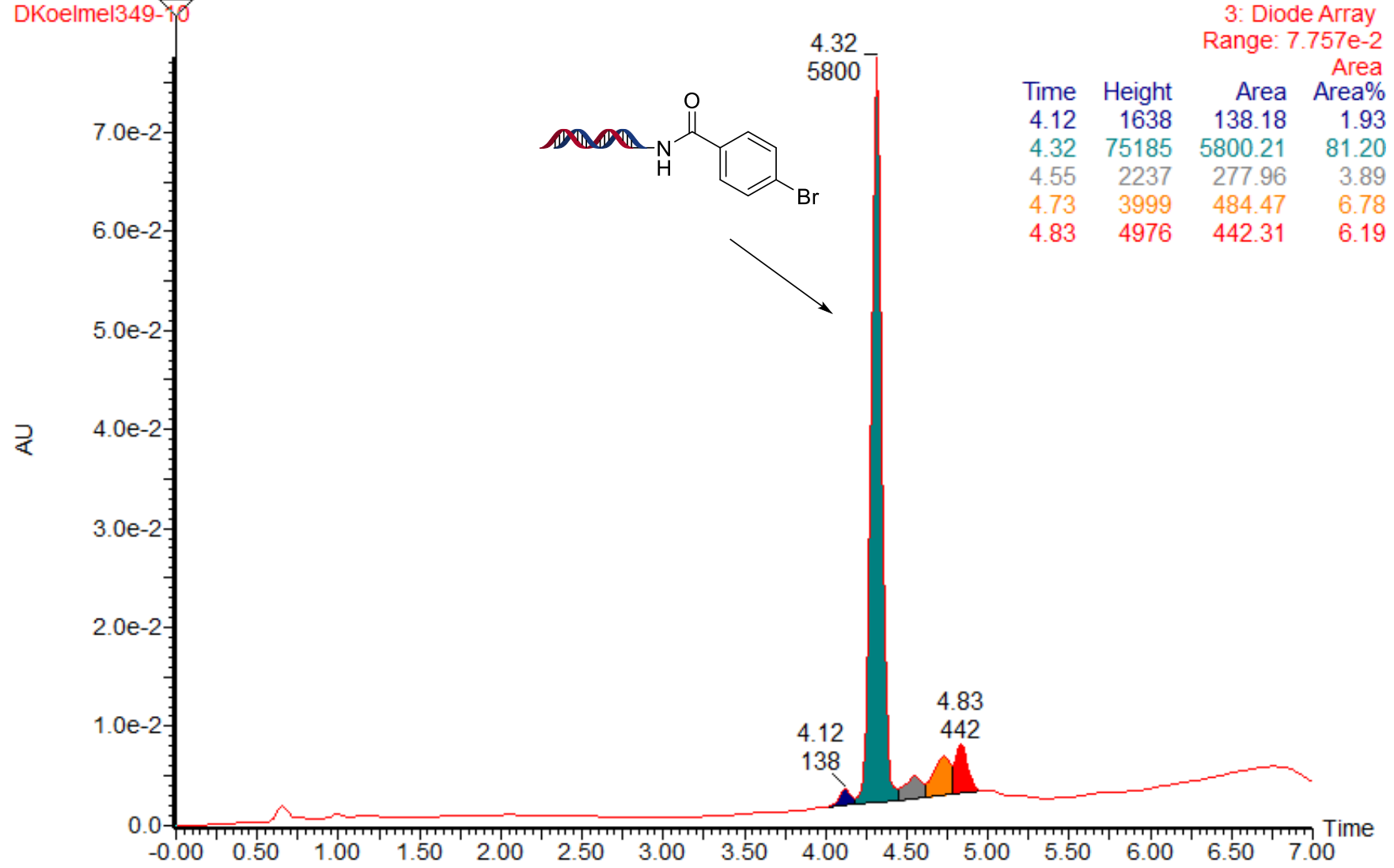

Figure S36. UPLC trace of Table 1, entry 12.

00712256-0733-001-11:10

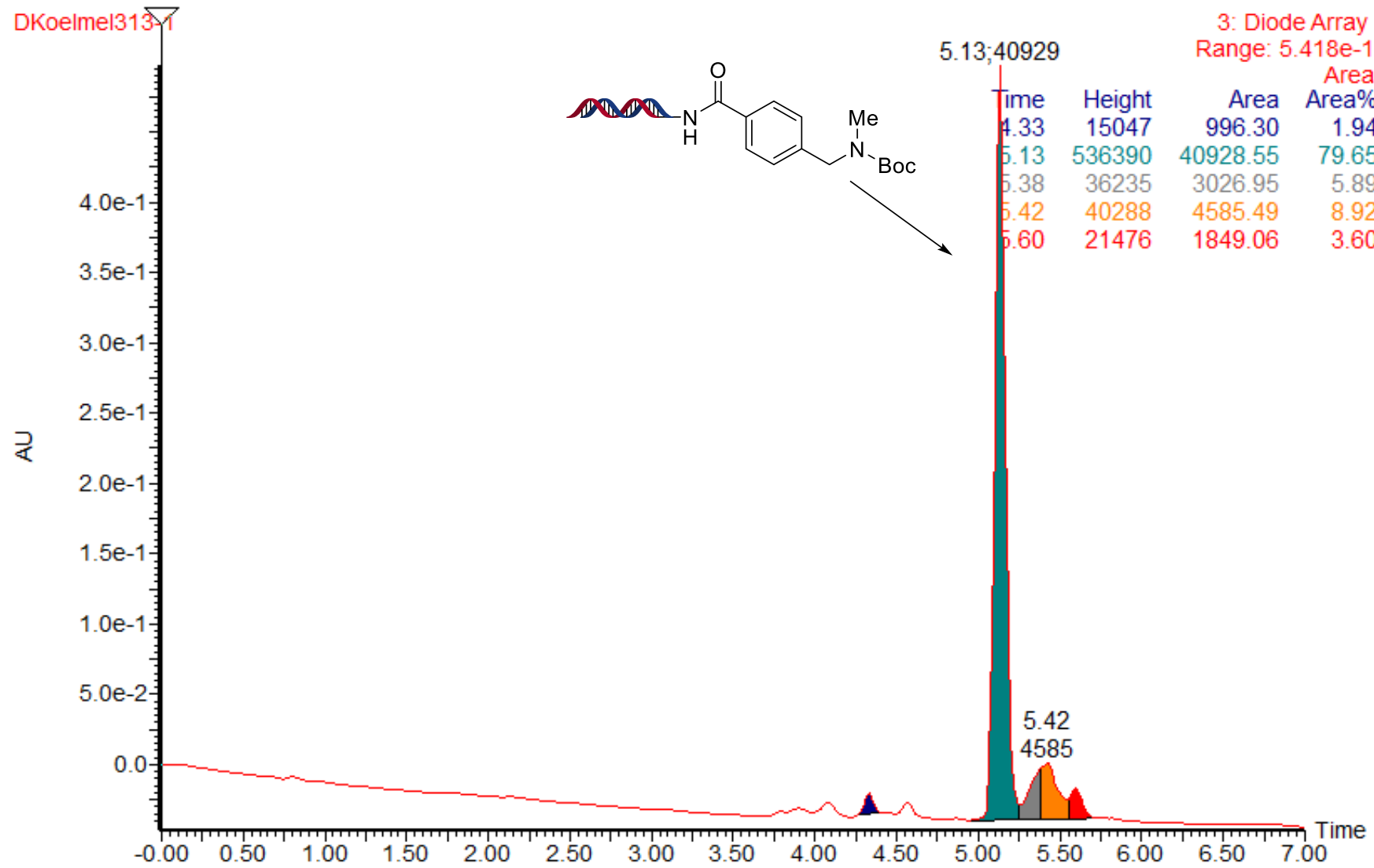

Figure S37. UPLC trace of Table 2, entry 1. 


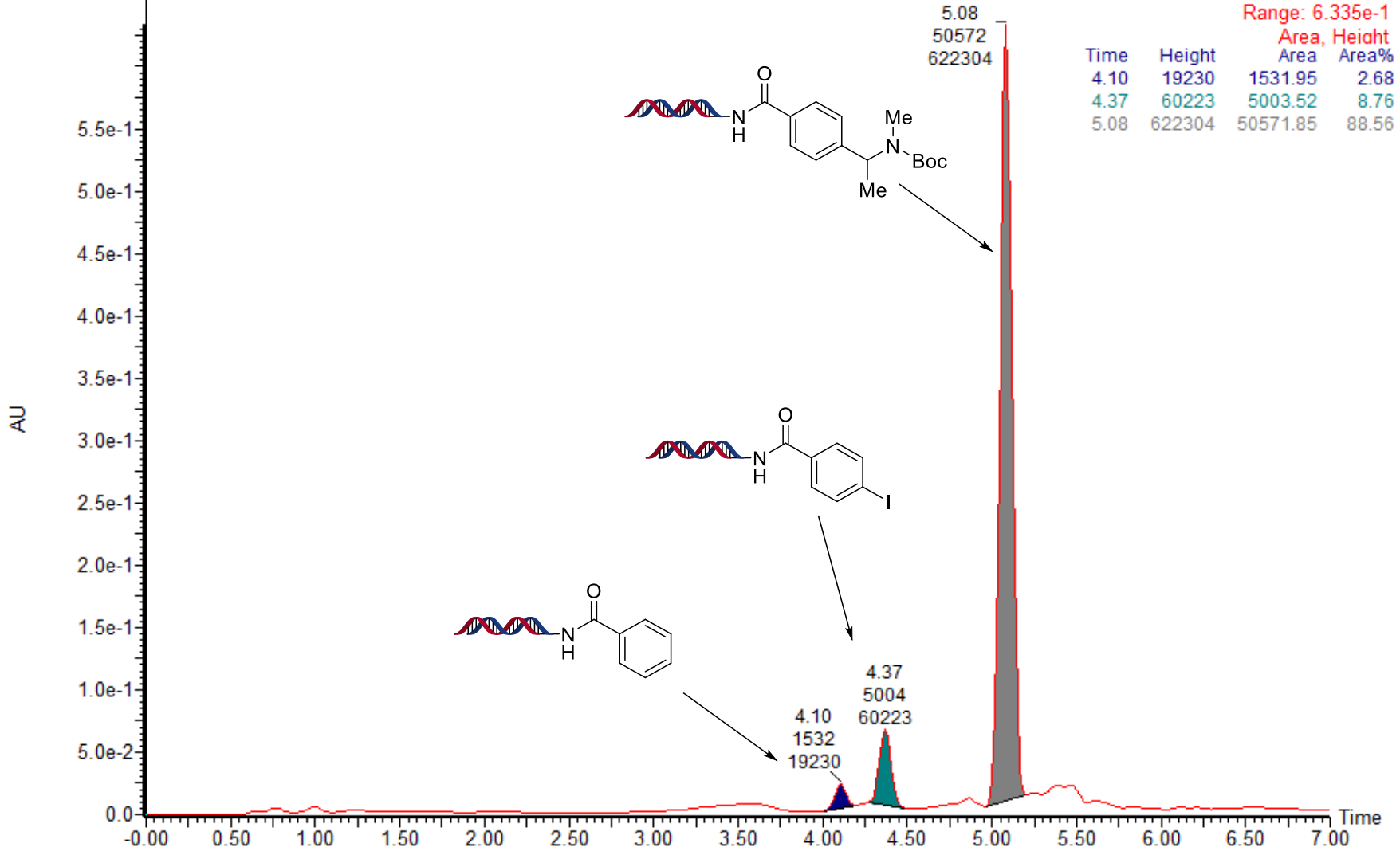

Figure S38. UPLC trace of Table 2, entry 2.

\section{6-0729-001-11:9}

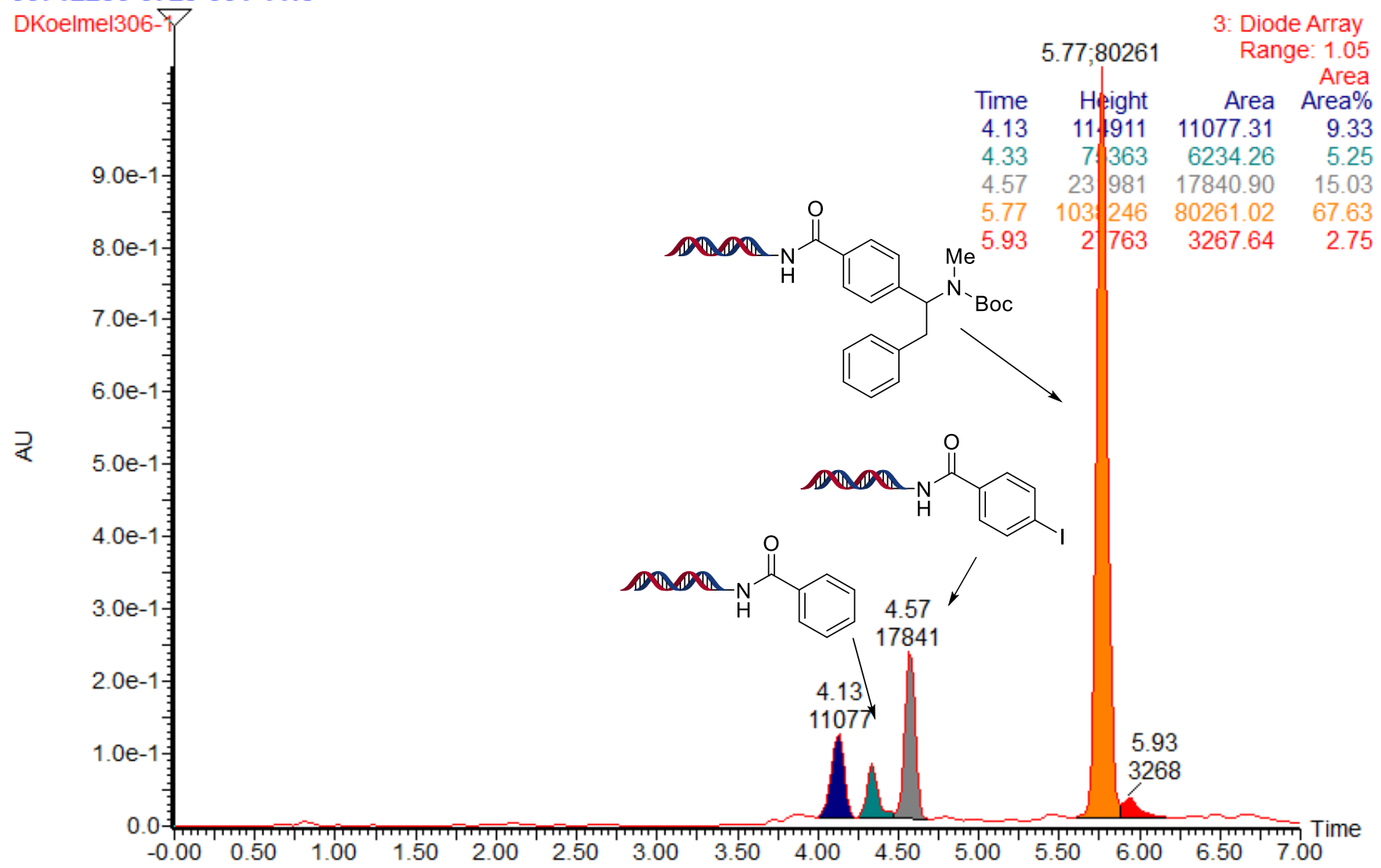

Figure S39. UPLC trace of Table 2, entry 3 , after first coupling. 


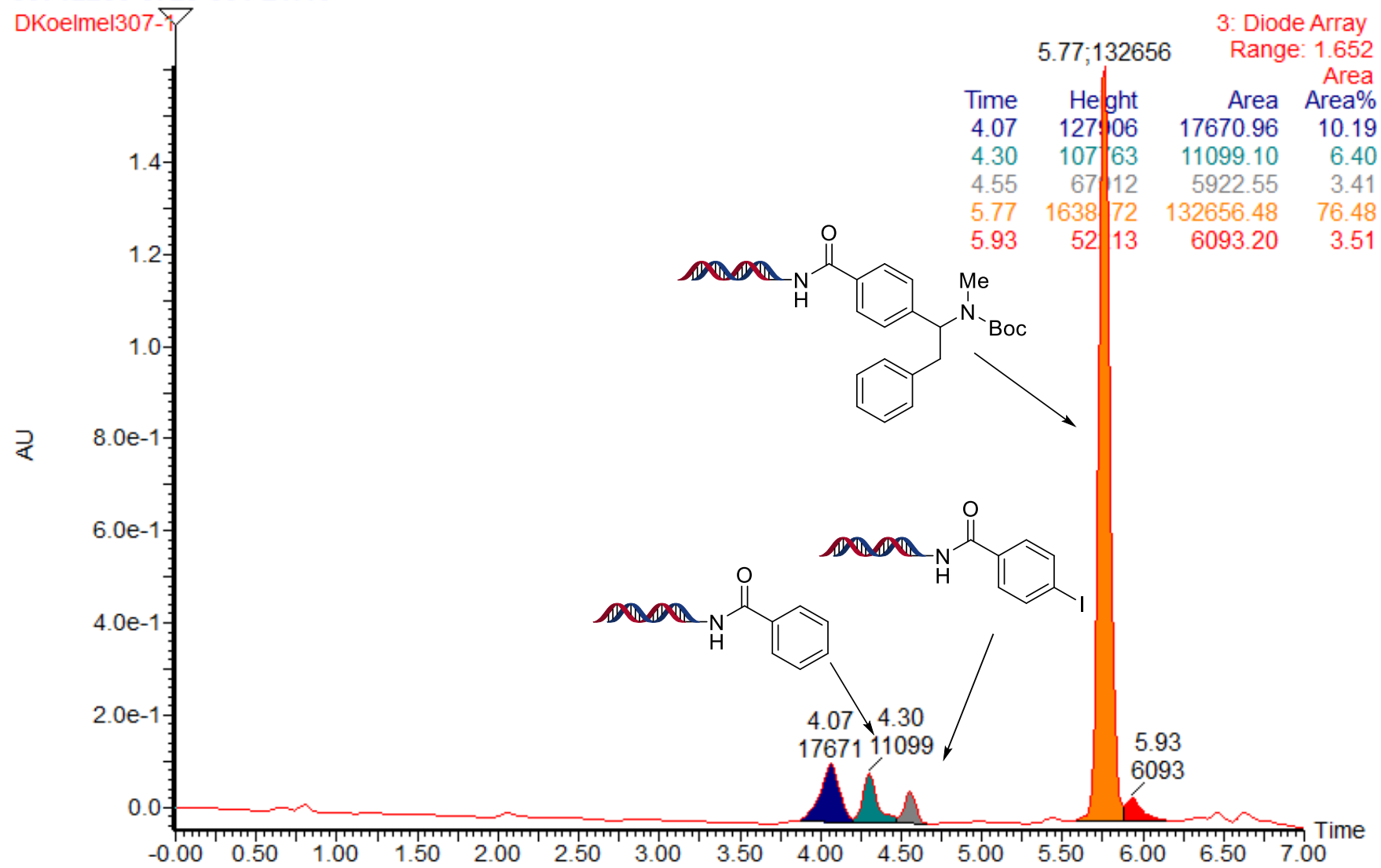

Figure S40. UPLC trace of Table 2, entry 3, after second coupling.

00712256-0754-001-blue1:10

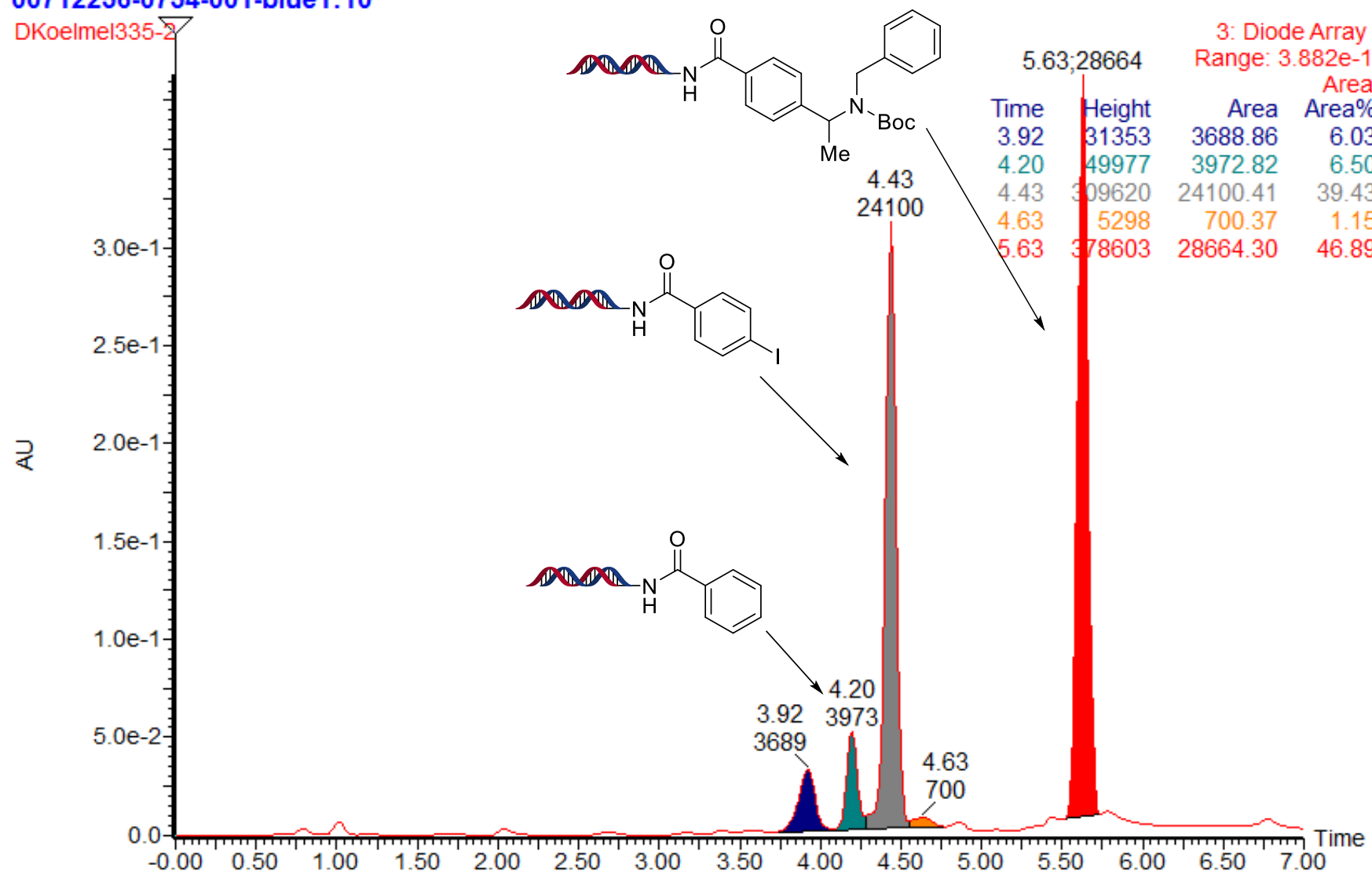

Figure S41. UPLC trace of Table 2, entry 4, after first coupling. 


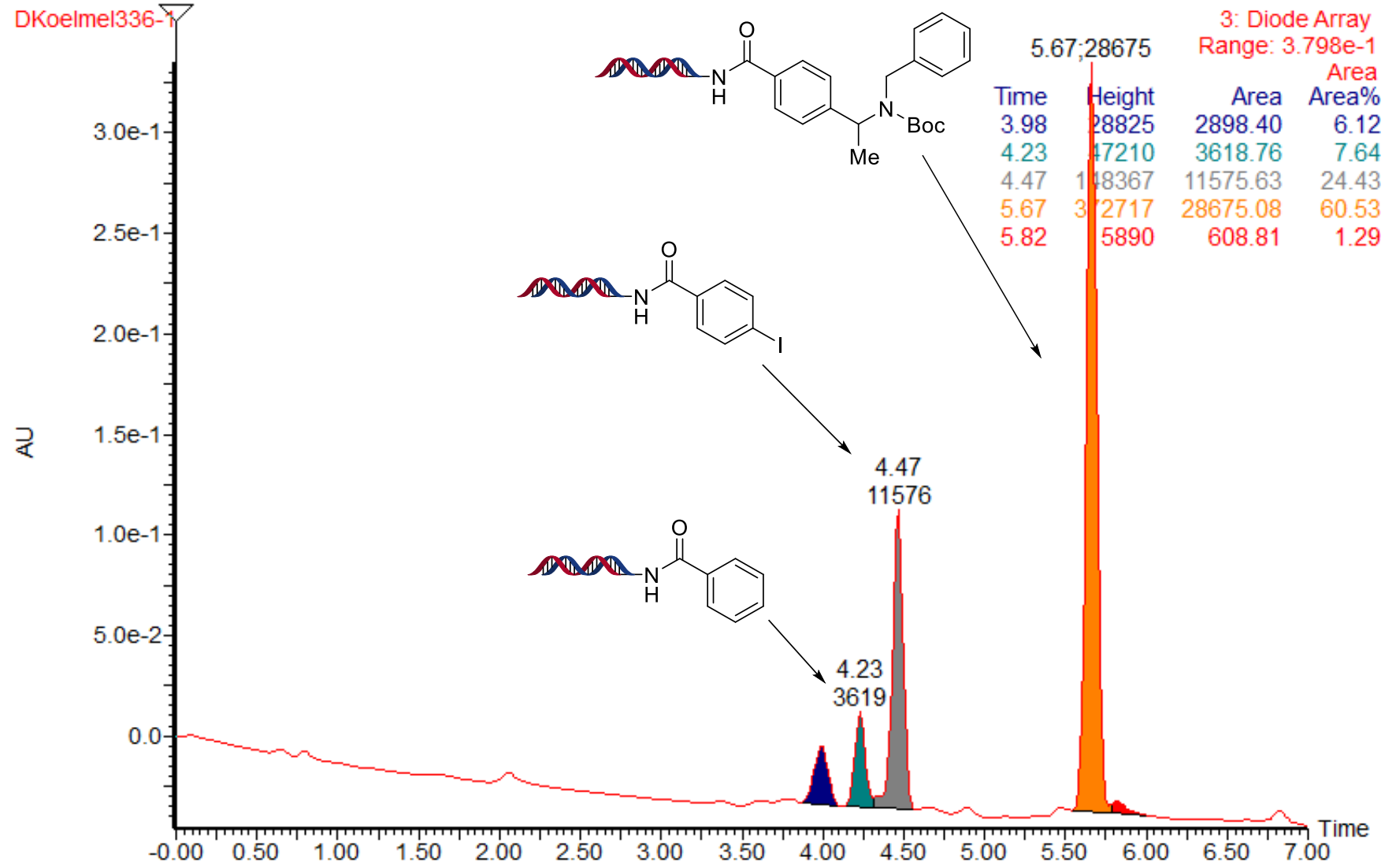

Figure S42. UPLC trace of Table 2, entry 4, after second coupling.

\section{6-0758-0011:9}

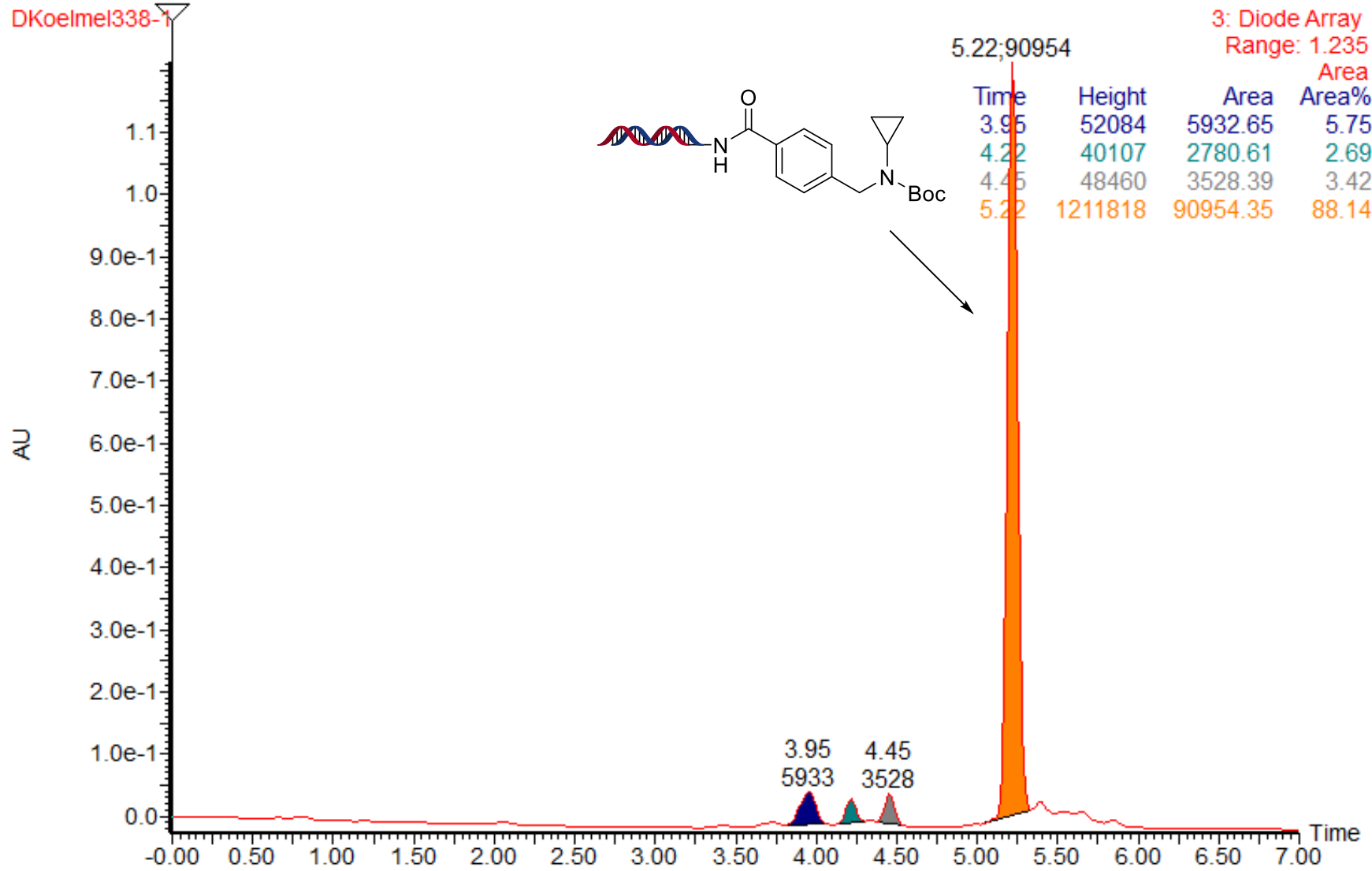

Figure S43. UPLC trace of Table 2, entry 5. 
1:2600712256-0614-001

DKoelmel239-1Sm (Mn, 1x1)

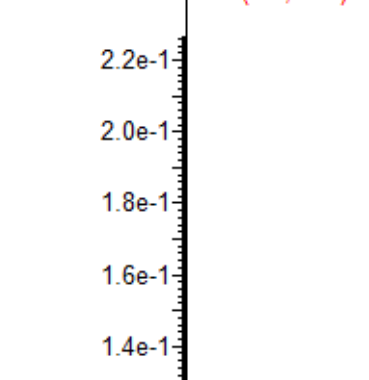

11-May-2018 10:41:24

3: Diode Array

Range: $2.8 \mathrm{e}-1$

Area, Heiaht

Area Area\%

$778.23 \quad 4.62$
701.00

$701.00 \quad 1.82$

$627.44 \quad 1.63$

$043.28 \quad 5.31$

$4163.15 \quad 10.81$

$23342.68 \quad 60.64$

$\begin{array}{rr}23342.68 & 60.64 \\ 2781.47 & 7.23\end{array}$

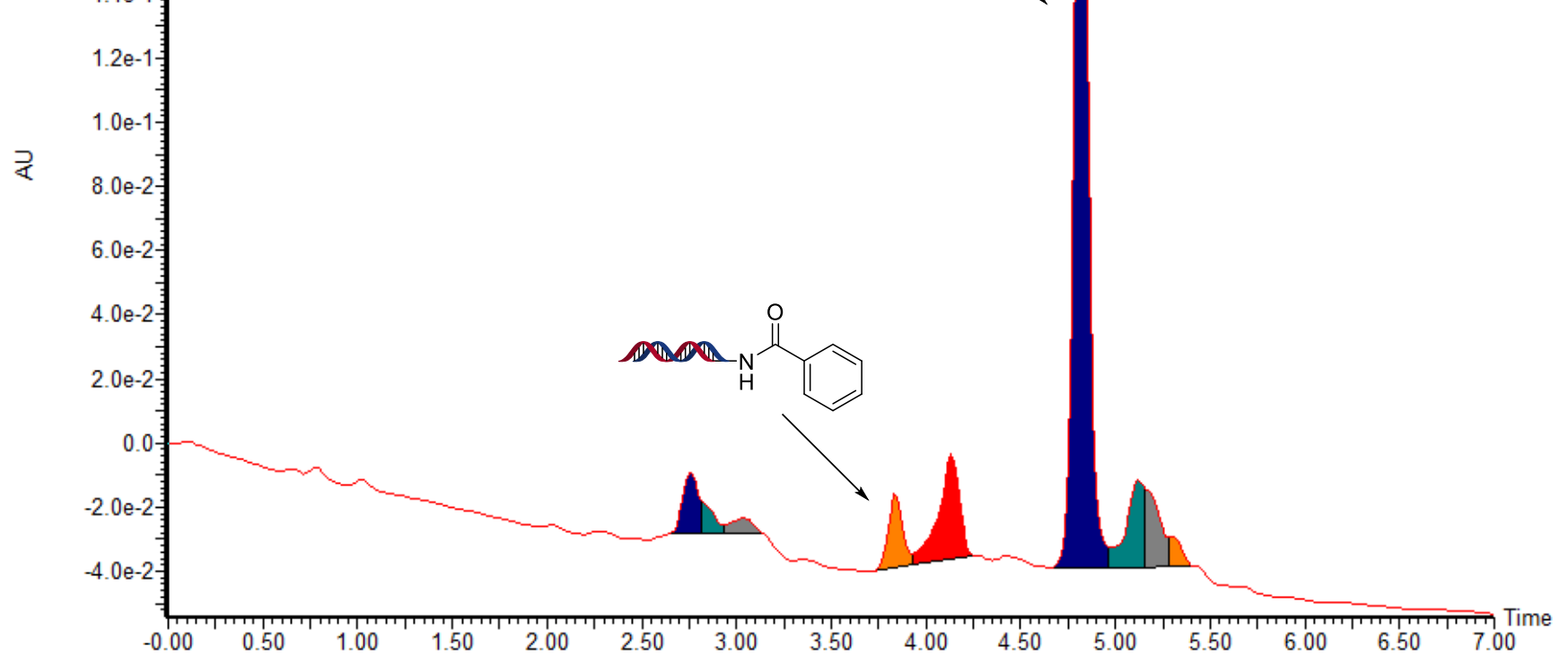

Figure S44. UPLC trace of Table 2, entry 6.

1:1000712256-0627-001

DKoelmel250-2/Sm (Mn, 1x1)

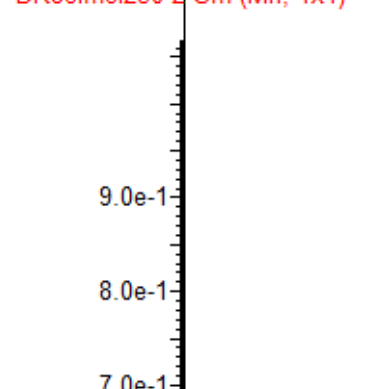

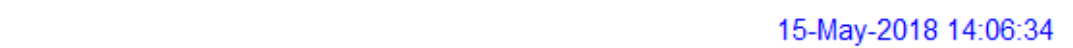

15-May-2018 14:06:34

3: Diode Array

Range: 1.067

Area, Heiaht

Area Area\%

$\begin{array}{llll}4.07 & 49548 & 5707.17 & 5.52 \\ 4.33 & 65268 & 8295.55 & 8.02\end{array}$

$\begin{array}{rrrr}4.33 & 65268 & 8295.55 & 8.02 \\ 5.07 & 1044848 & 89449.84 & 86.46\end{array}$

२
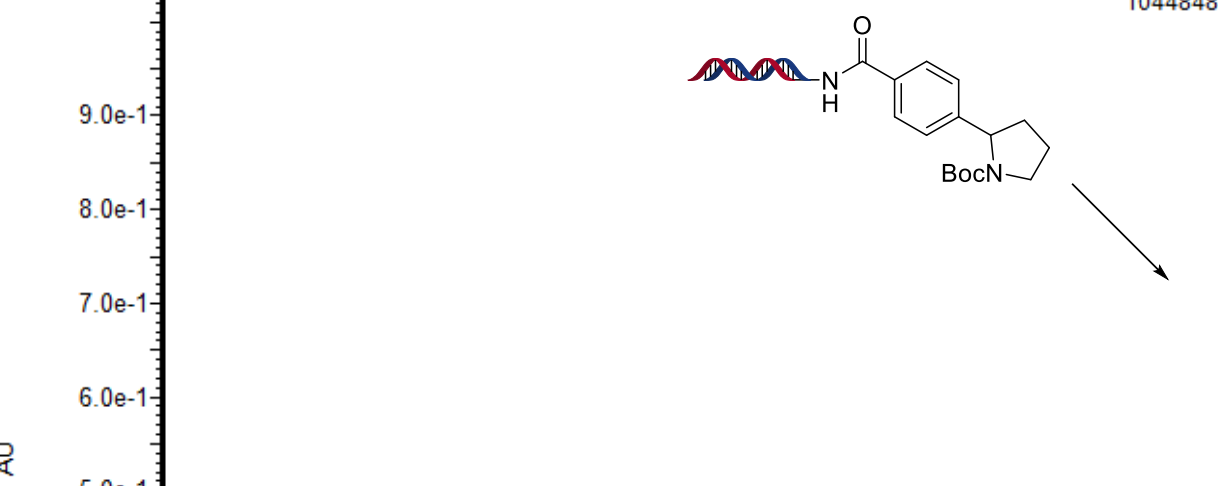

5. $0 \mathrm{e}-1$

4.0e-1

3.0e-1

2.0e-1

$1.0 \mathrm{e}-1$

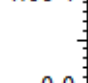

$\begin{array}{lll}0.0 & 0.50 & 1.00\end{array}$

Figure S45. UPLC trace of Table 2, entry 7. 


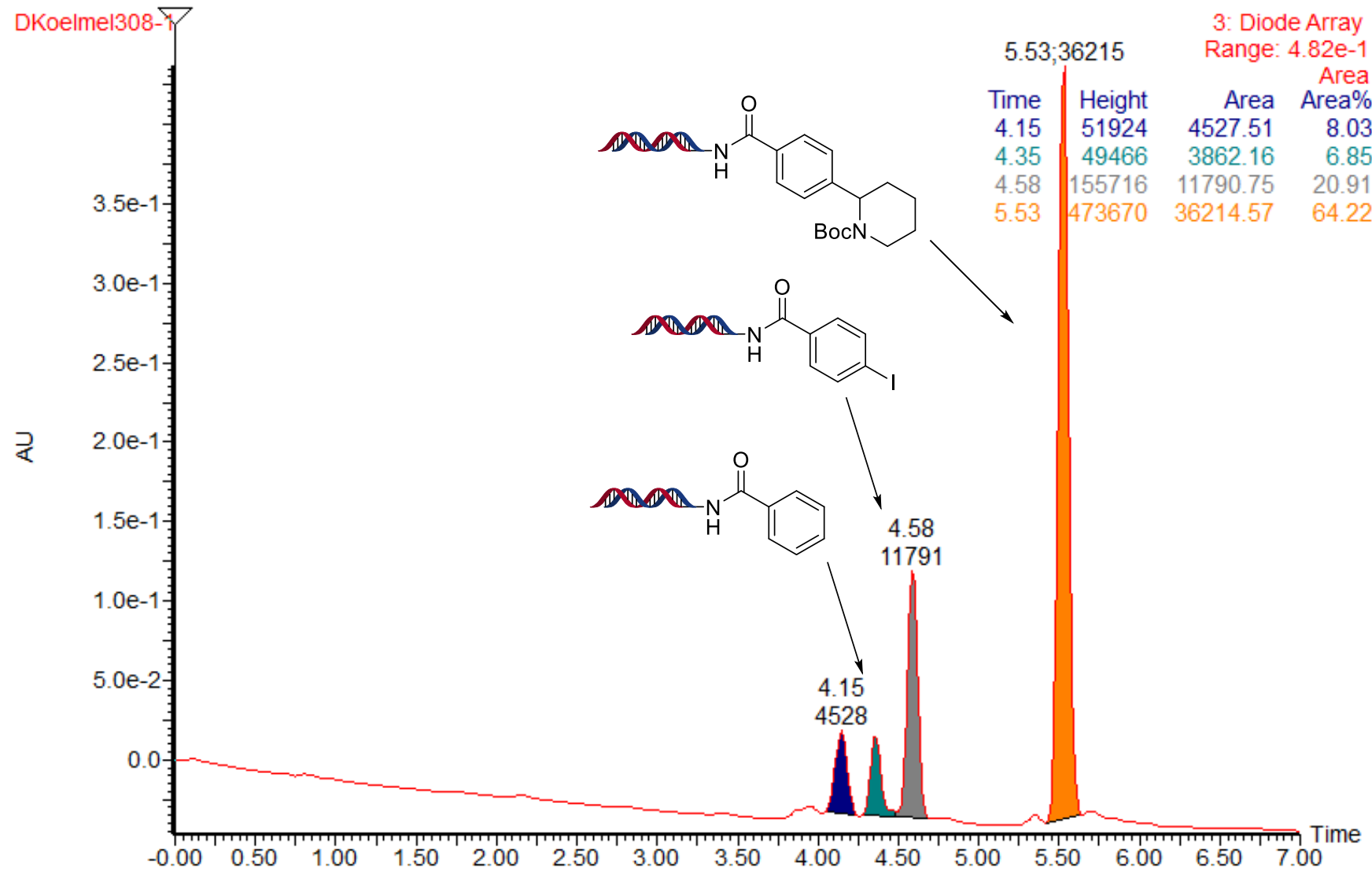

Figure S46. UPLC trace of Table 2, entry 8, after first coupling.
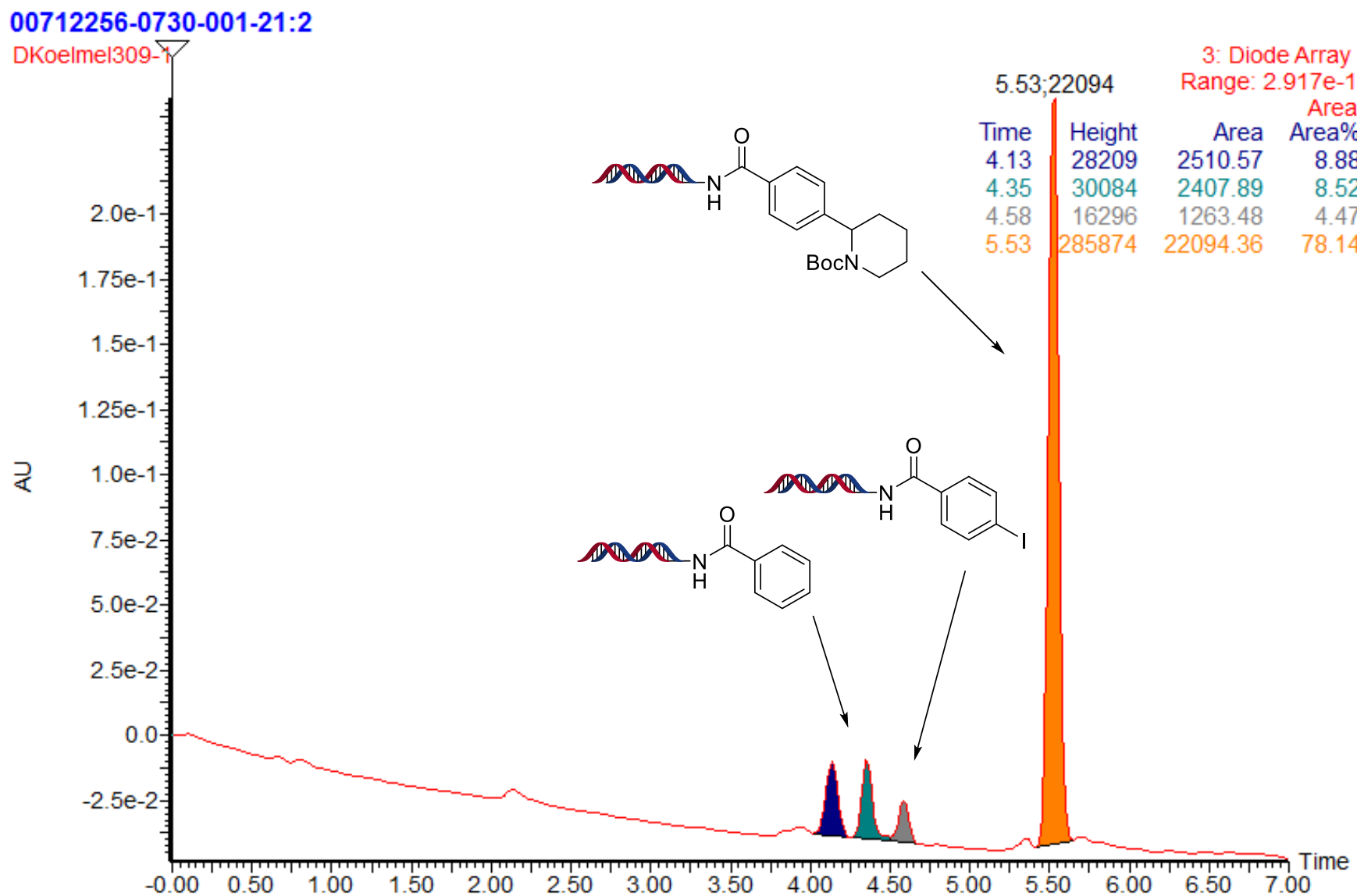

Figure S47. UPLC trace of Table 2, entry 8, after second coupling. 


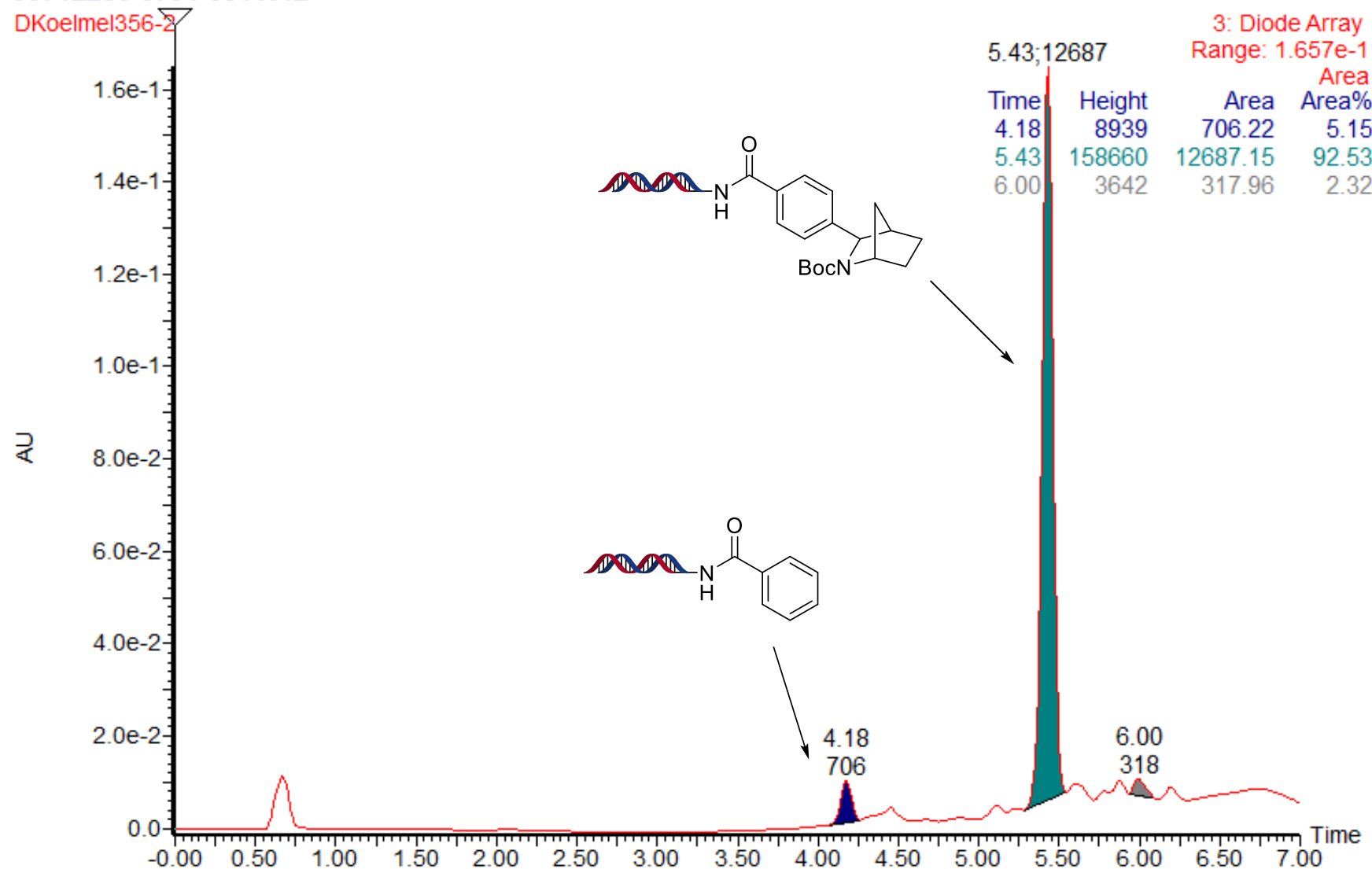

Figure S48. UPLC trace of Table 2, entry 9.

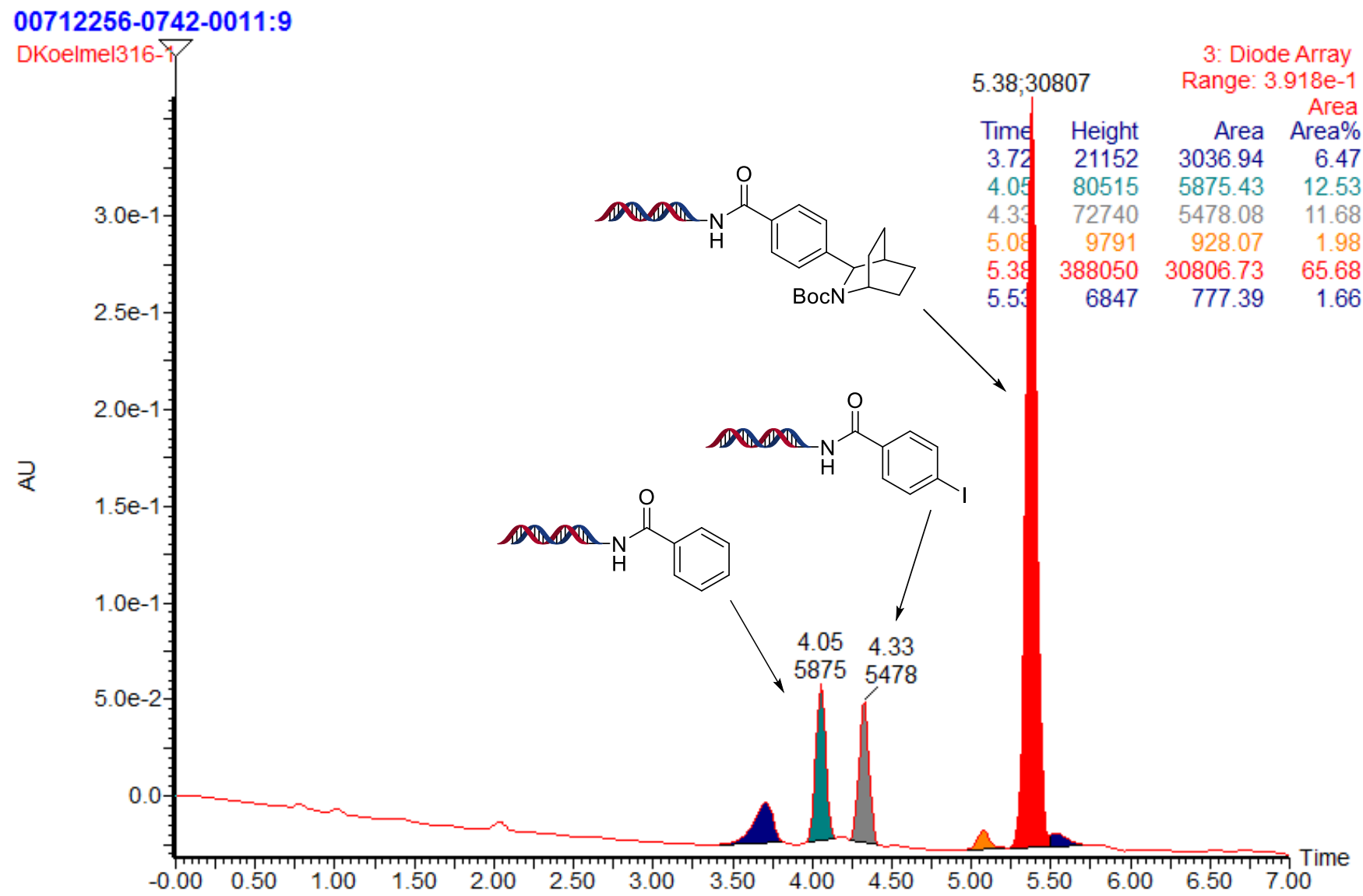

Figure S49. UPLC trace of Table 2, entry 10, after first coupling. 


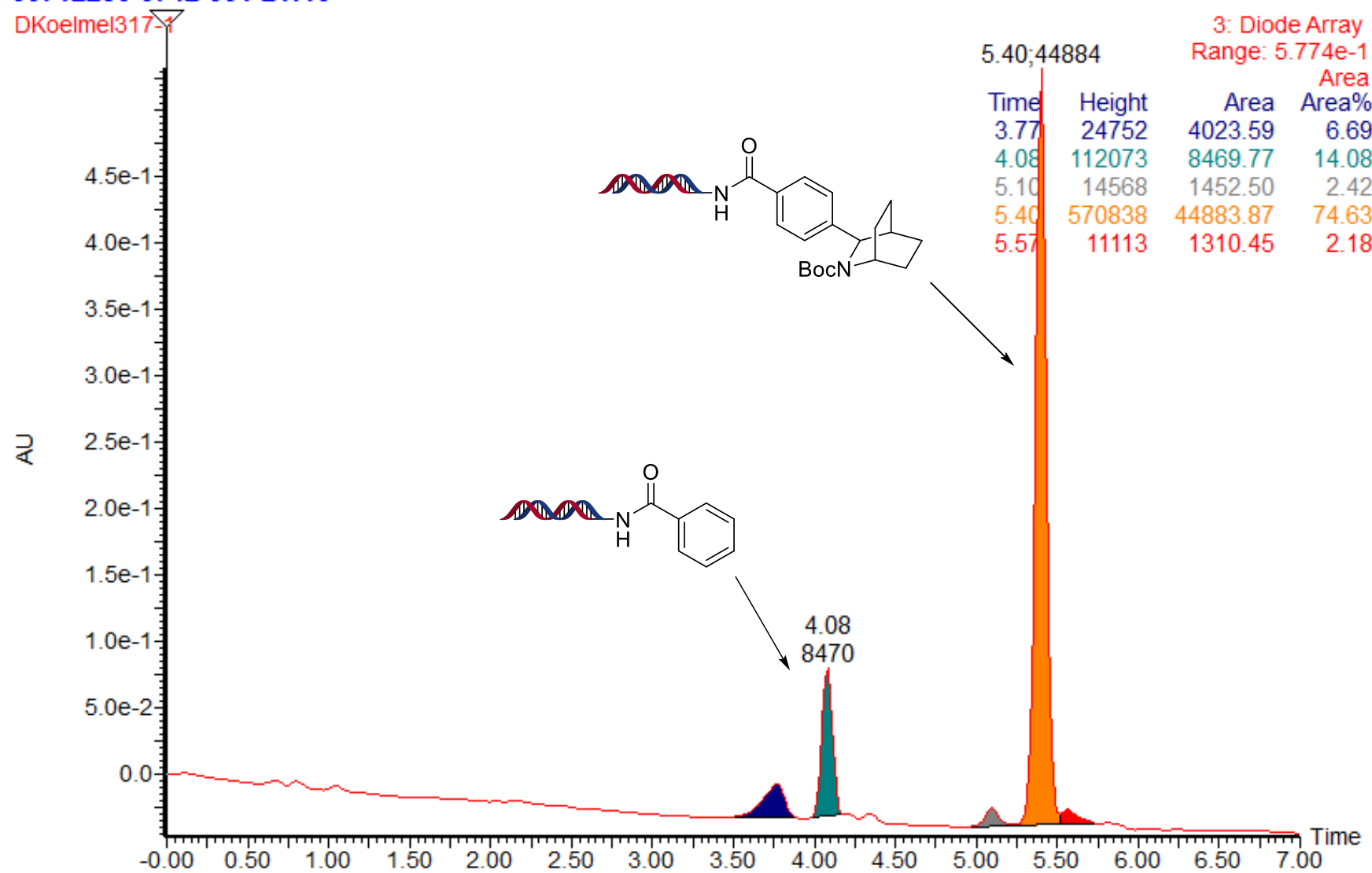

Figure S50. UPLC trace of Table 2, entry 10, after second coupling.

1:1200712256-0629-001

DKoelmel250-4/Sm (Mn, 1x1)

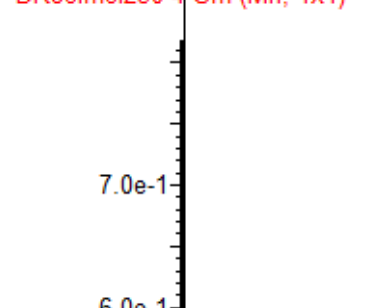

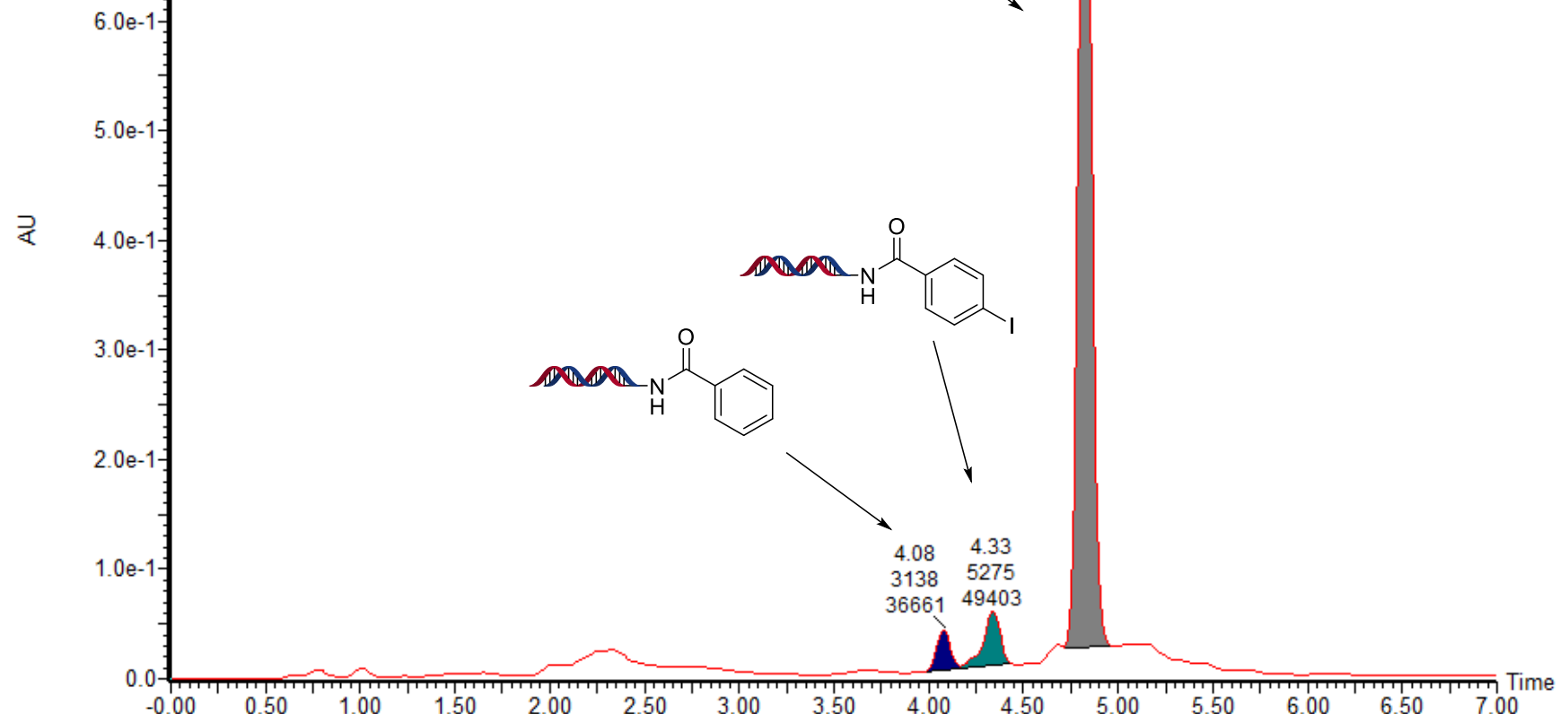

Figure S51. UPLC trace of Table 2, entry 11. 


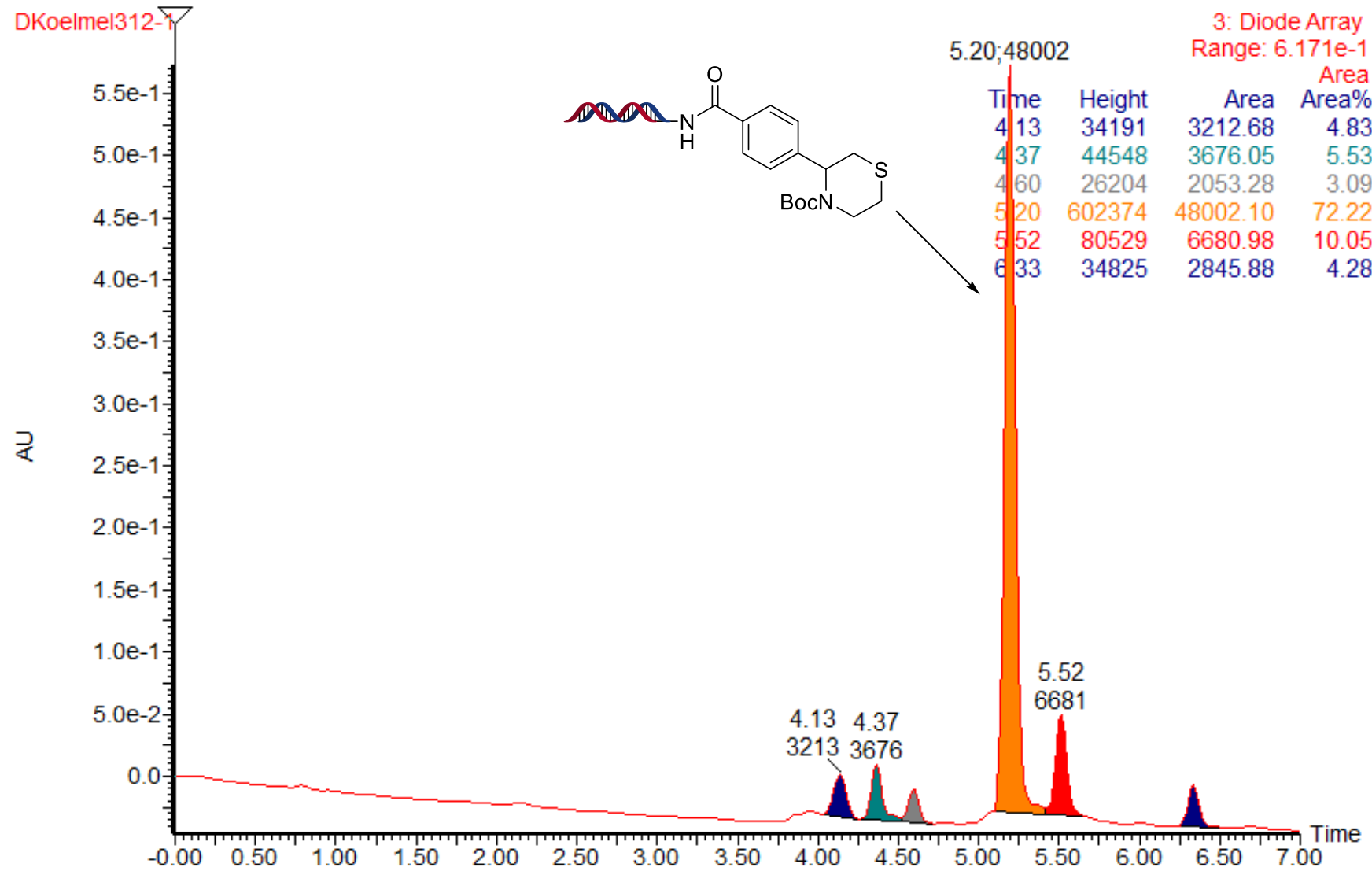

Figure S52. UPLC trace of Table 2, entry 12.

00712256-0762-0011:14

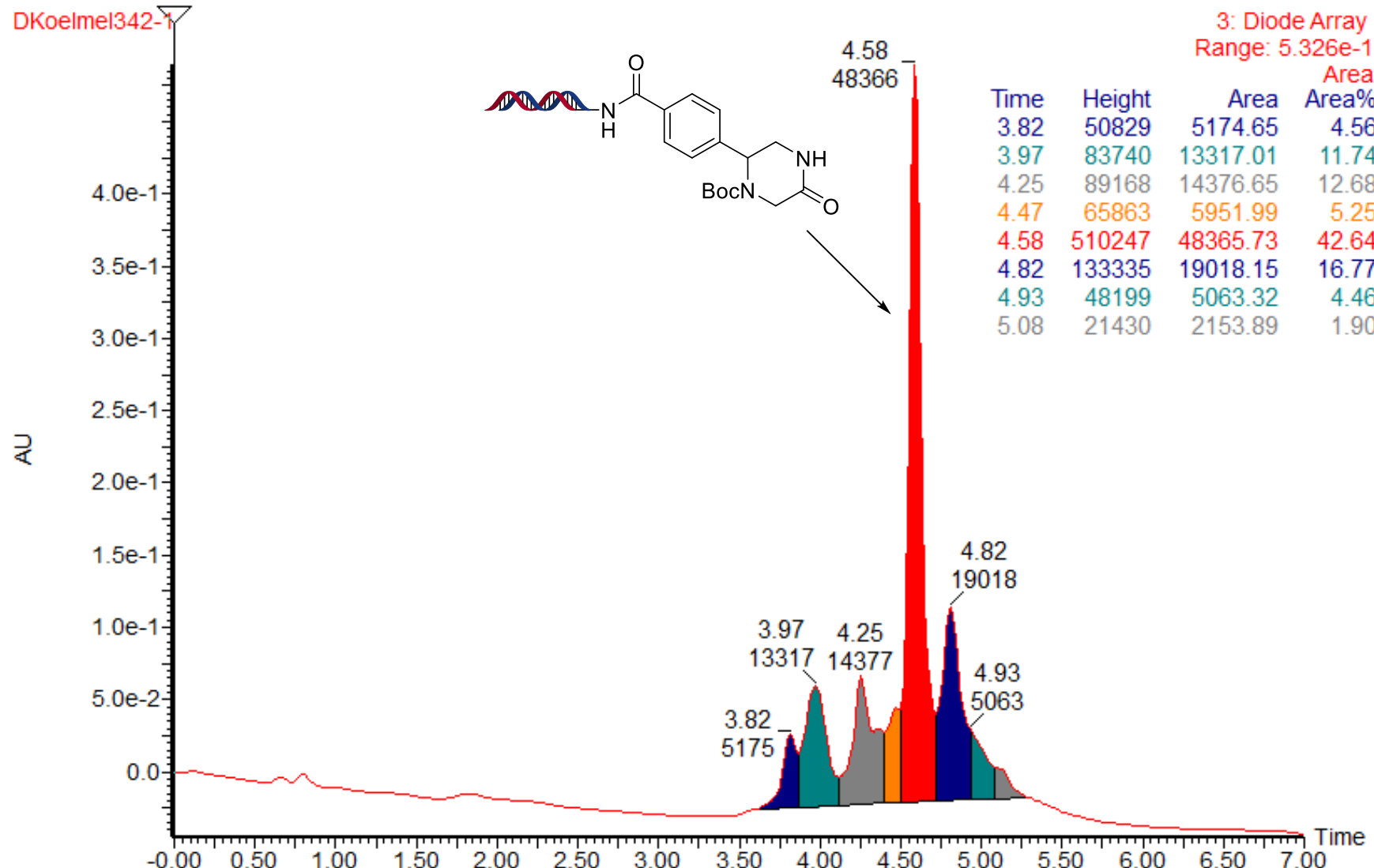

Figure S53. UPLC trace of Table 2, entry 13. 


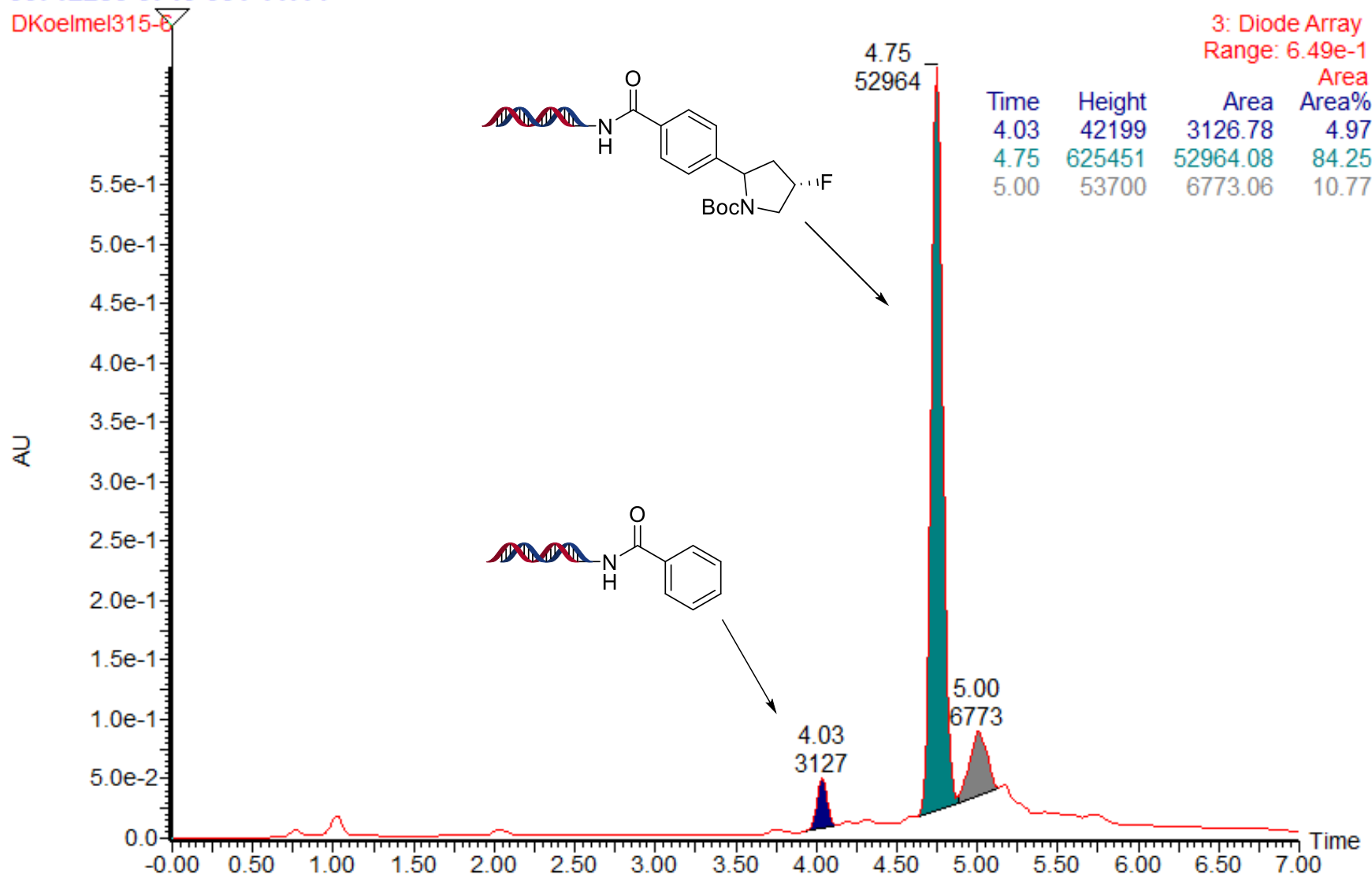

Figure S54. UPLC trace of Table 2, entry 14.

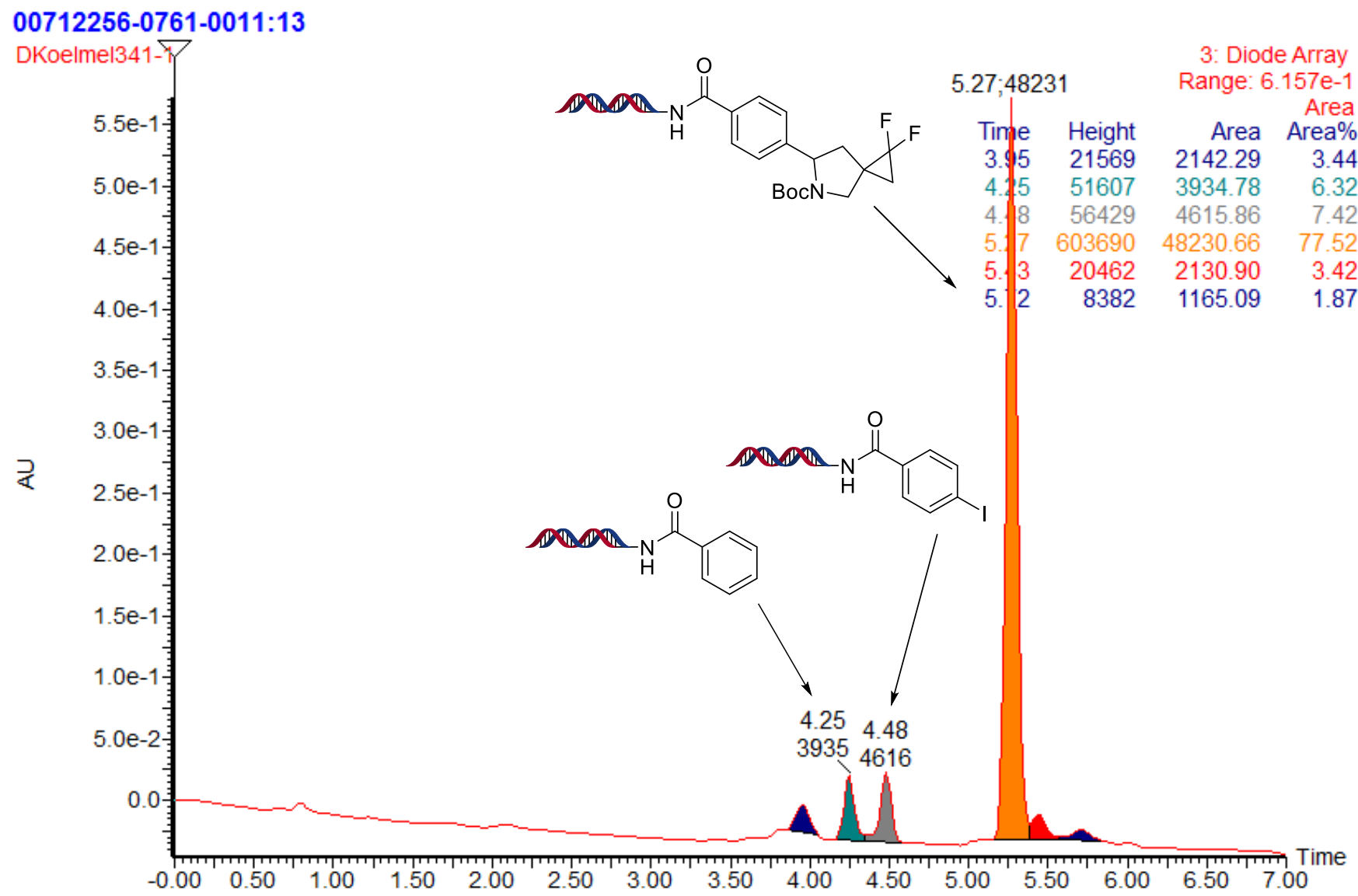

Figure S55. UPLC trace of Table 2, entry 15. 


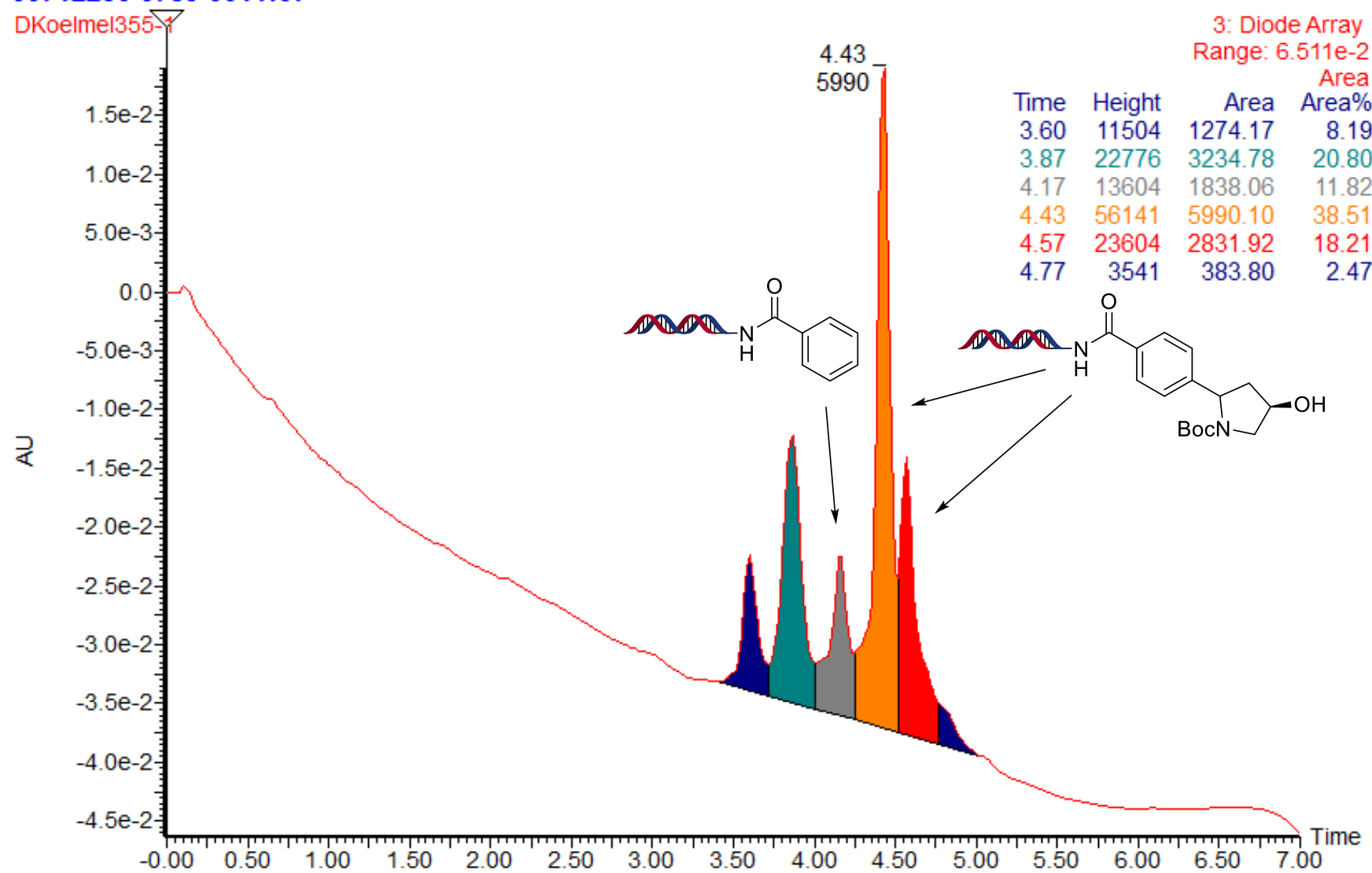

Figure S56. UPLC trace of Table 2, entry 16.

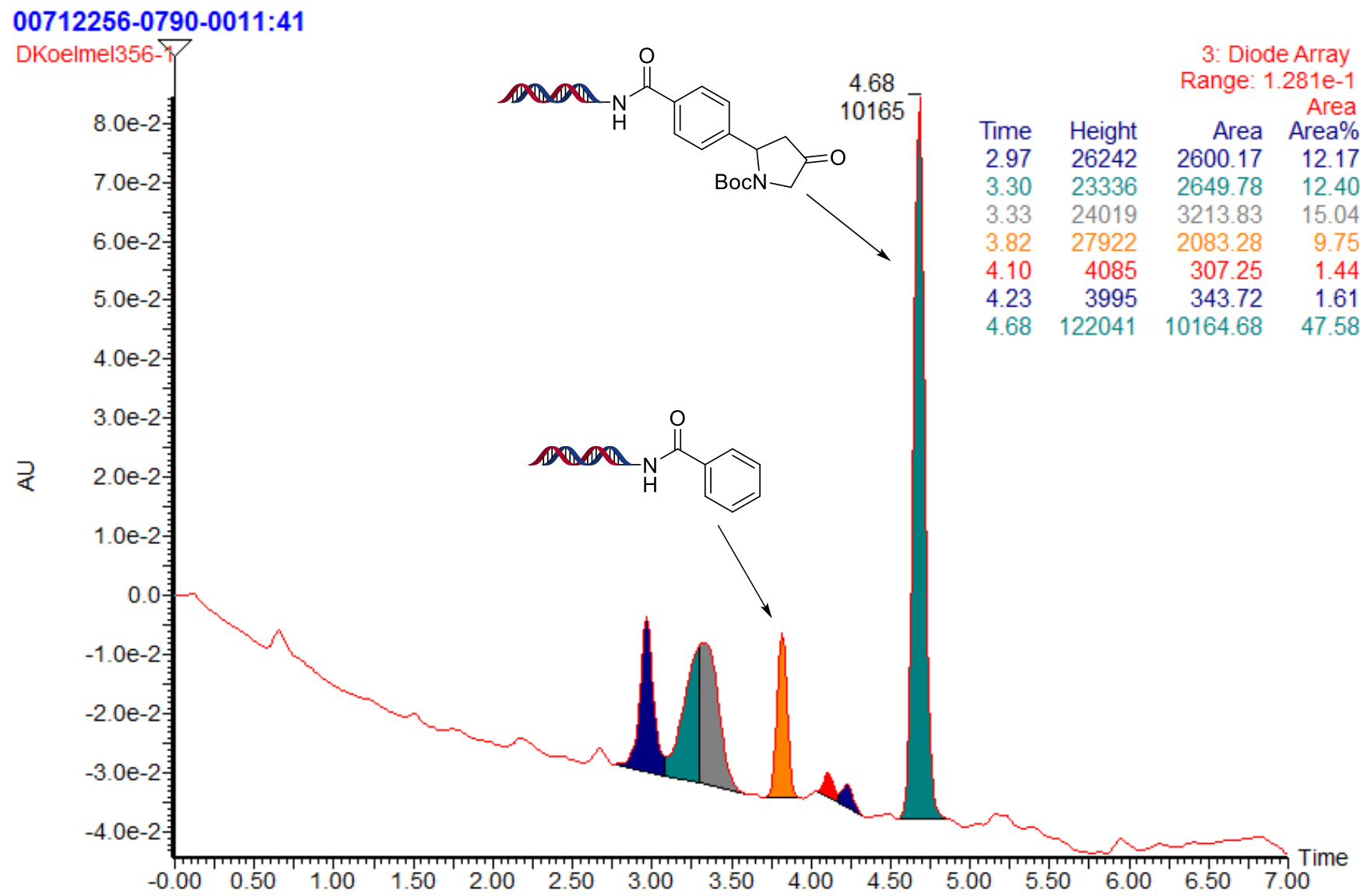

Figure S57. UPLC trace of Table 2, entry 17. 


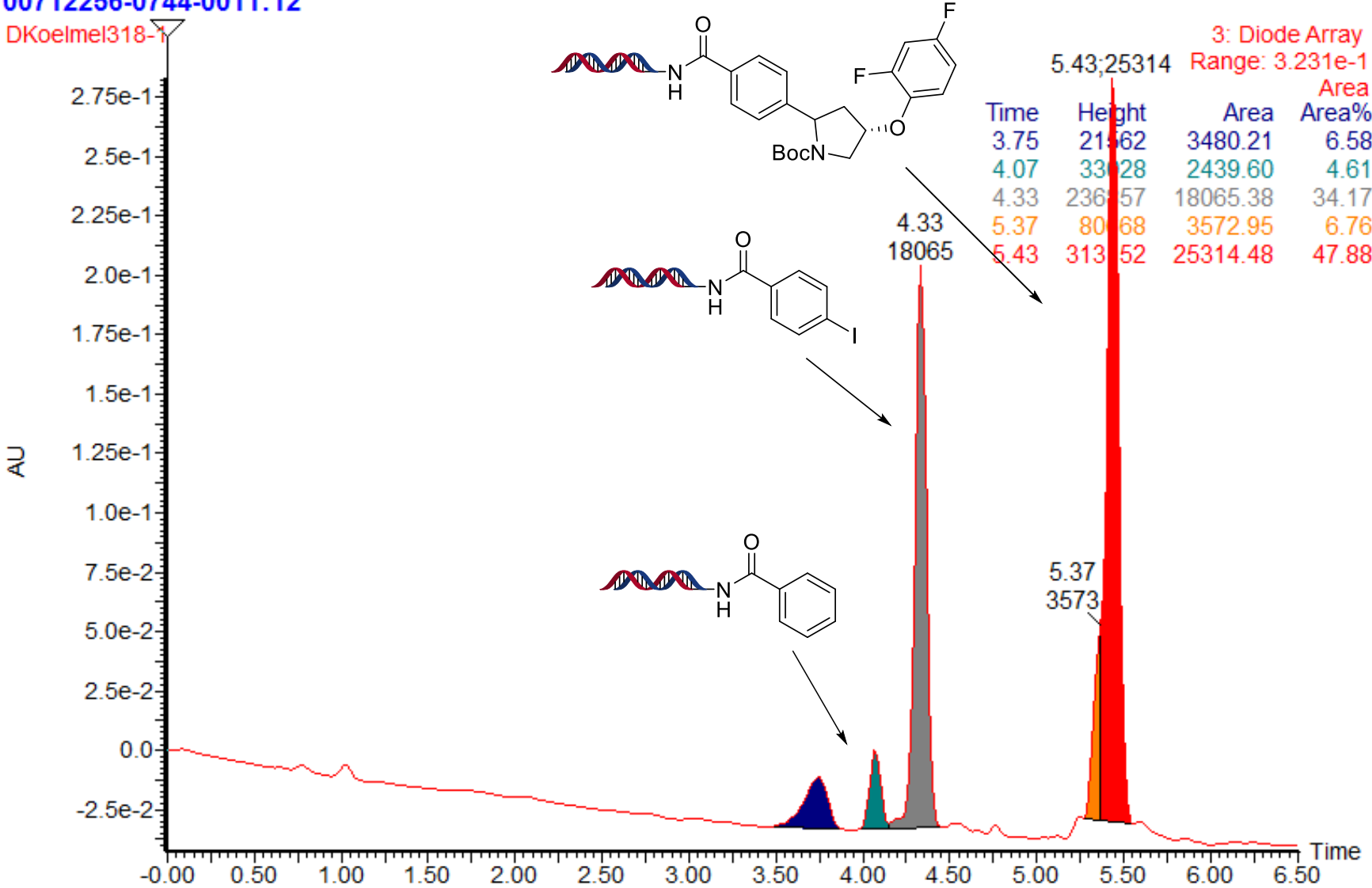

Figure S58. UPLC trace of Table 2, entry 18, after first coupling.

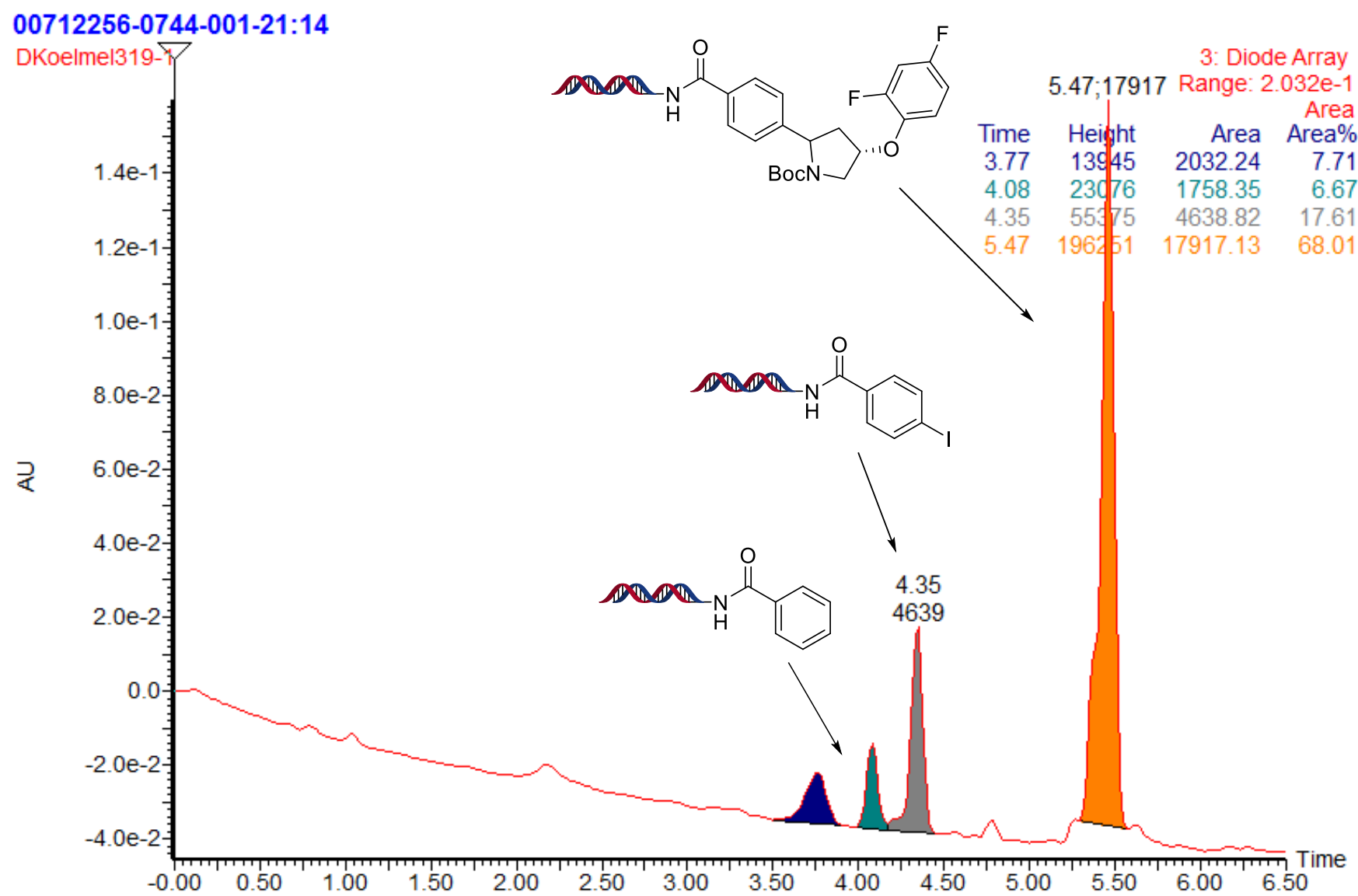

Figure S59. UPLC trace of Table 2, entry 18, after second coupling. 


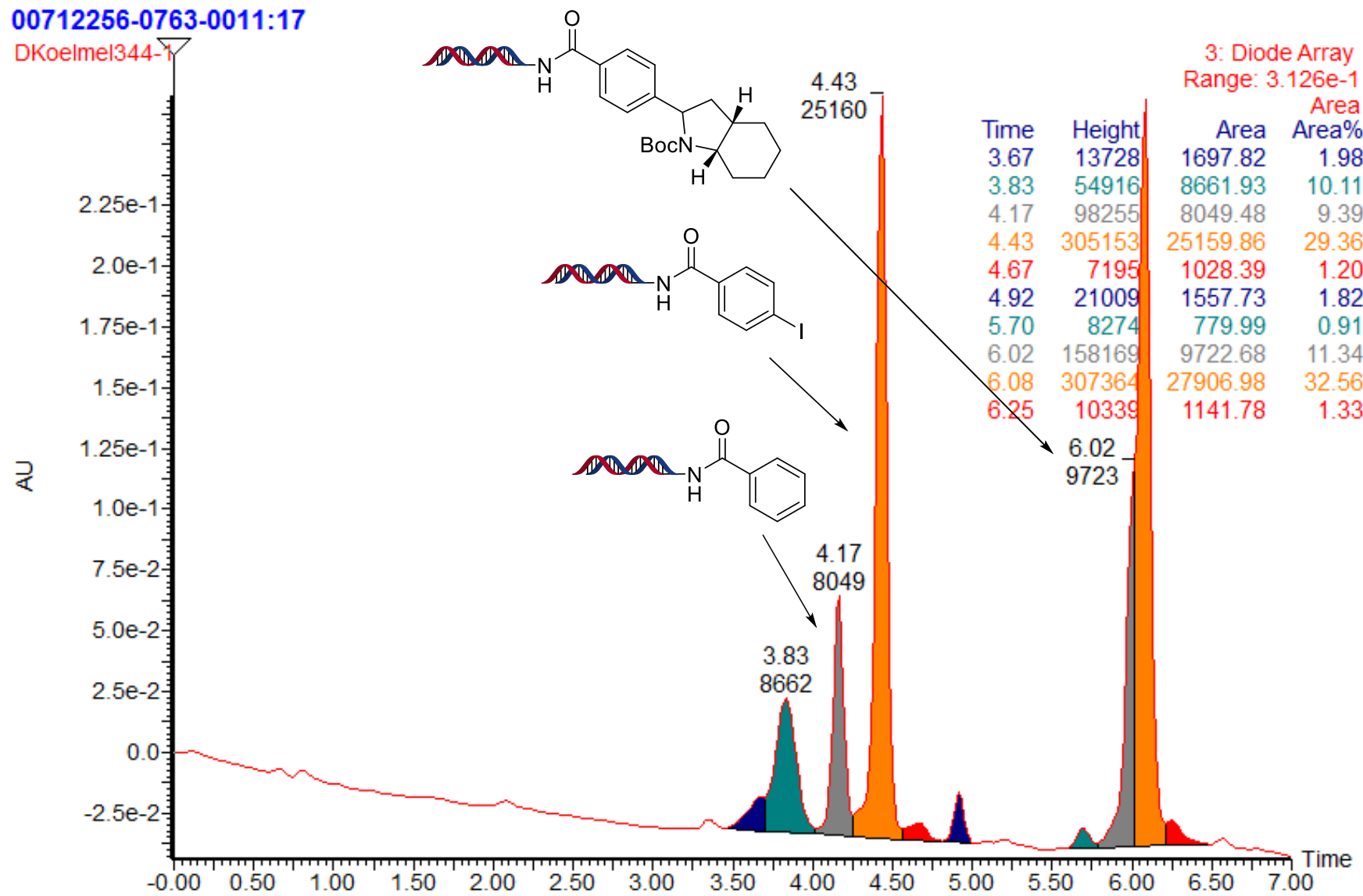

Figure S60. UPLC trace of Table 2, entry 19, after first coupling.

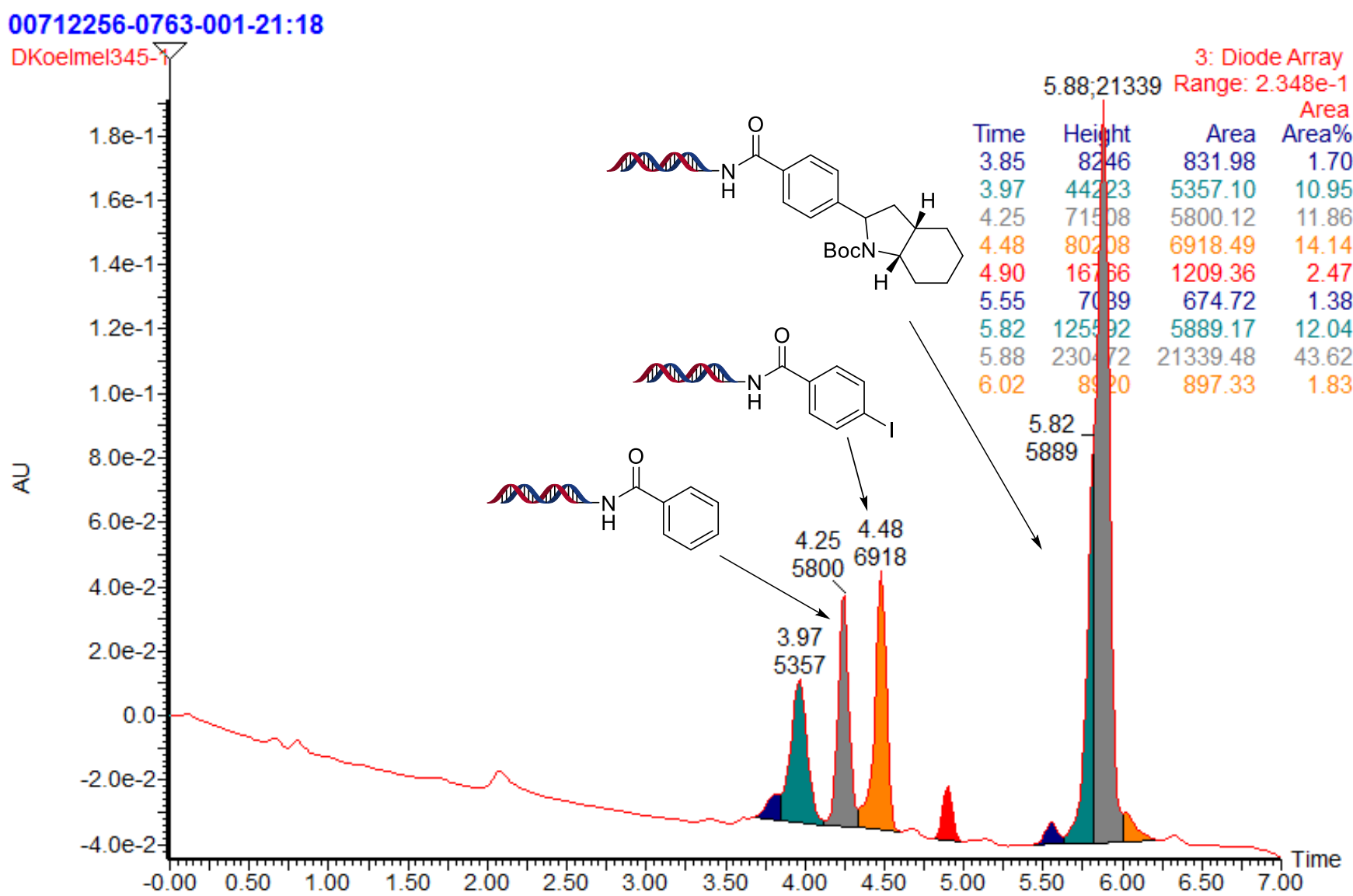

Figure S61. UPLC trace of Table 2, entry 19, after second coupling. 


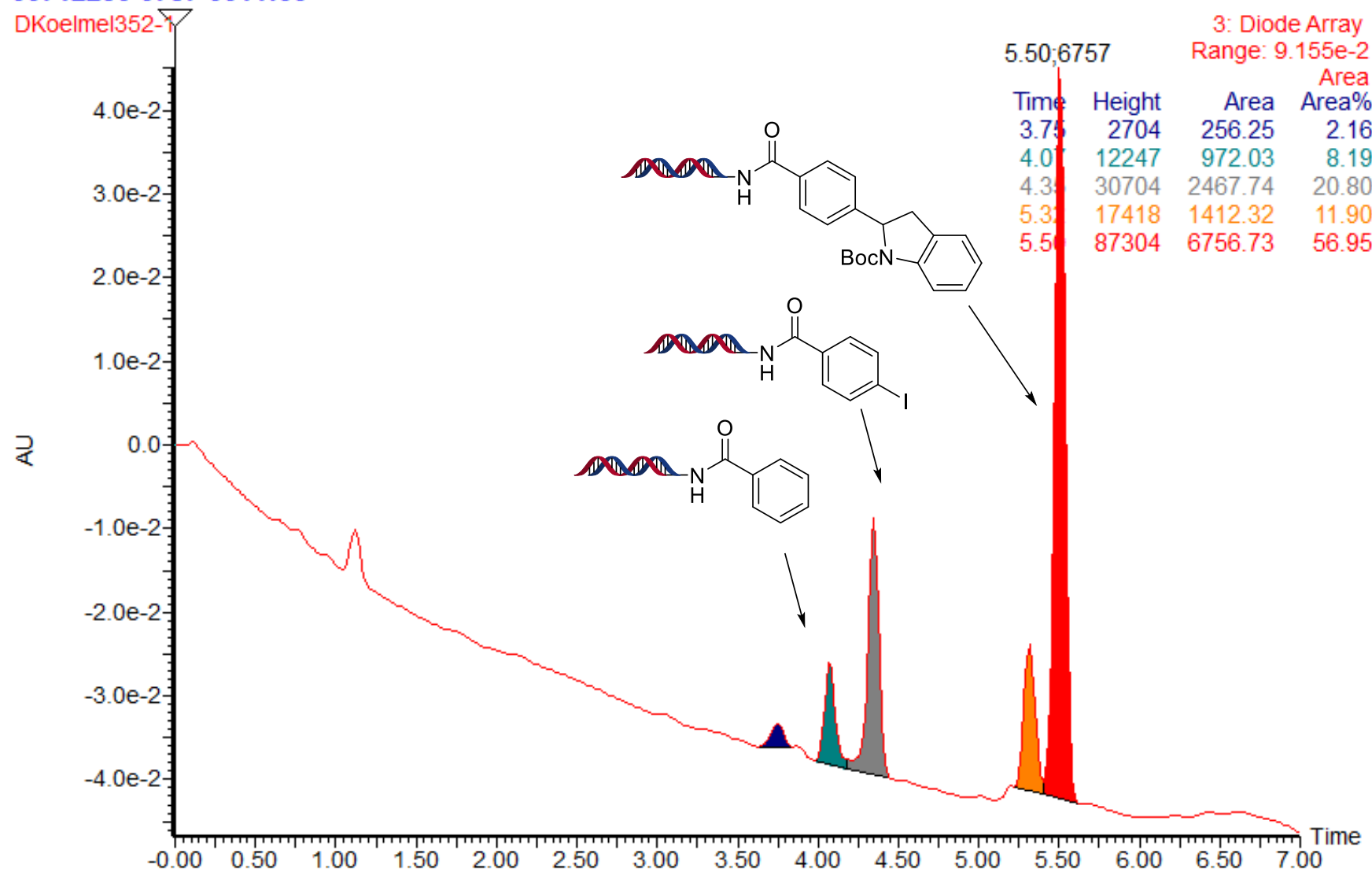

Figure S62. UPLC trace of Table 2, entry 20, after first coupling.

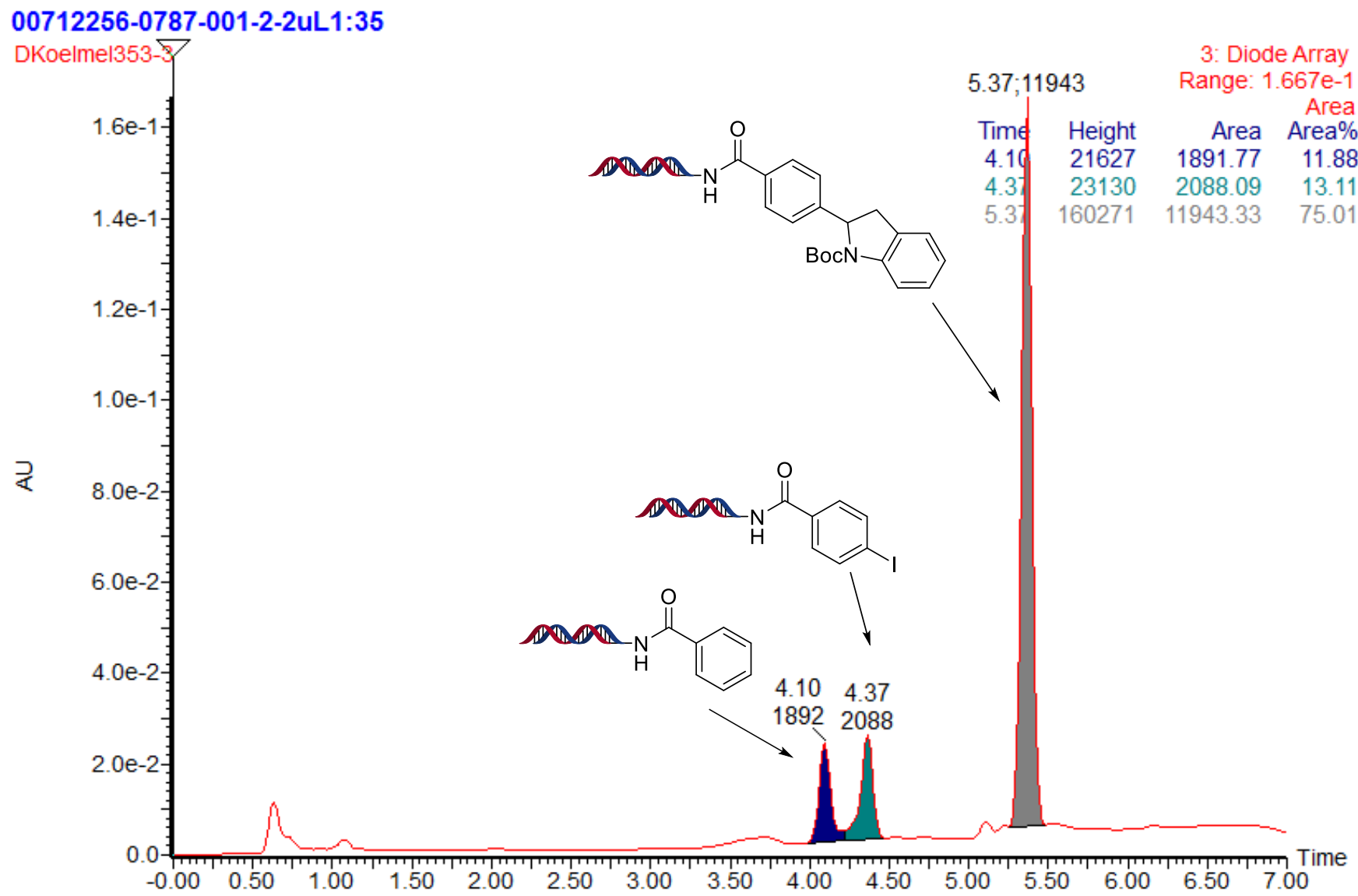

Figure S63. UPLC trace of Table 2, entry 20, after second coupling. 
1:4600712256-0633-001

DKoelmel25 $\uparrow 3 \mathrm{Sm}(\mathrm{Mn}, 1 \mathrm{x} 1)$

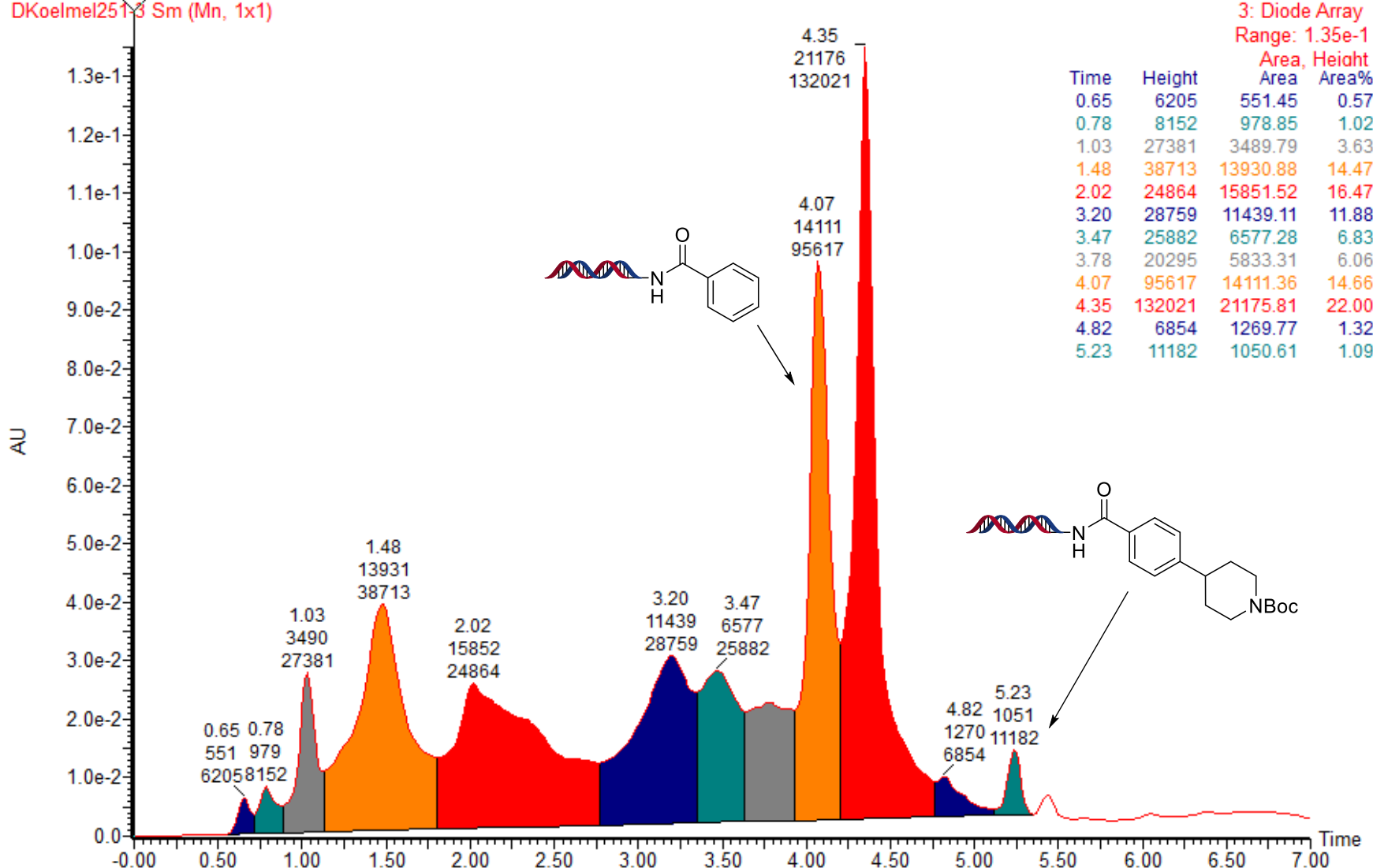

Figure S64. UPLC trace of Table 2, entry 21.

1:4400712256-0631-001

DKoelmel251-ism (Mn, 1x1)

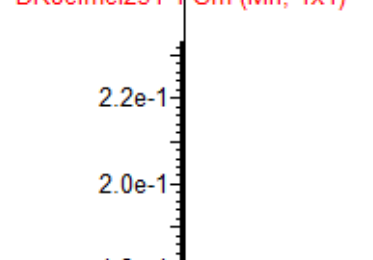

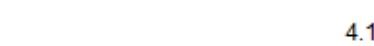

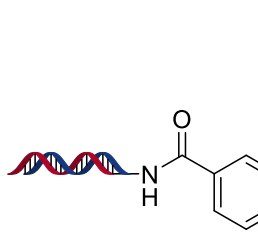

15-May-2018 18:50:13

3: Diode Array Range: $2.331 \mathrm{e}-1$ Time Height Area, Heiaht $\begin{array}{rrrr}2.53 & 6273 & 964.20 & 1.30\end{array}$ $\begin{array}{rrrr}2.53 & 6273 & 964.20 & 1.30 \\ 3.57 & 35743 & 7418.11 & 10.01\end{array}$ $\begin{array}{llll}3.80 & 120991 & 26509.68 & 35.76\end{array}$ $\begin{array}{llll}4.13 & 224934 & 21695.40 & 29.27\end{array}$ $\begin{array}{llll}4.37 & 45867 & 5638.37 & 7.61\end{array}$ $\begin{array}{llll}5.08 & 17964 & 1805.10 & 2.44\end{array}$ $\begin{array}{llll}5.18 & 69271 & 7602.67 & 10.26\end{array}$

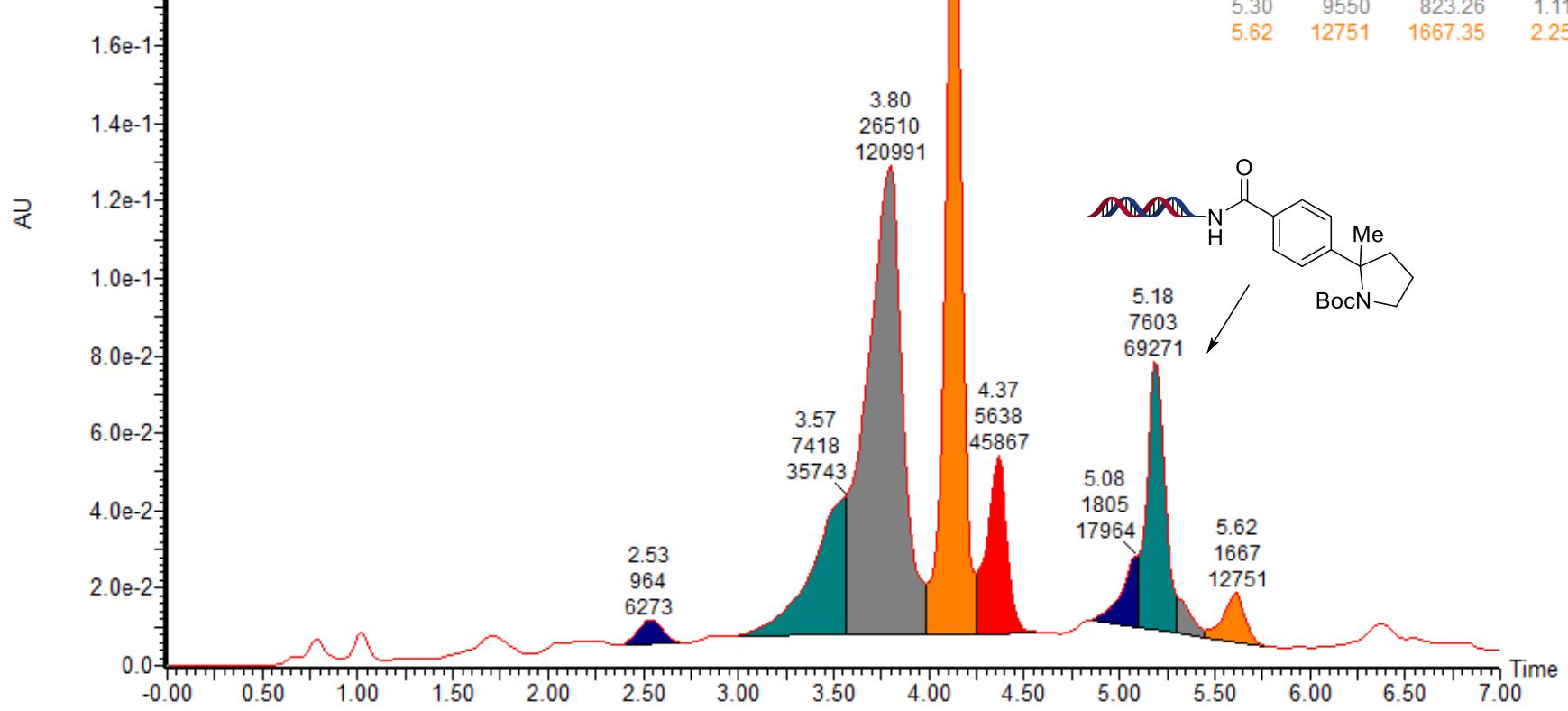

Figure S65. UPLC trace of Table 2, entry 22. 
1:1700712256-0635-001

DKoelmel252-ism (Mn, 1x1)

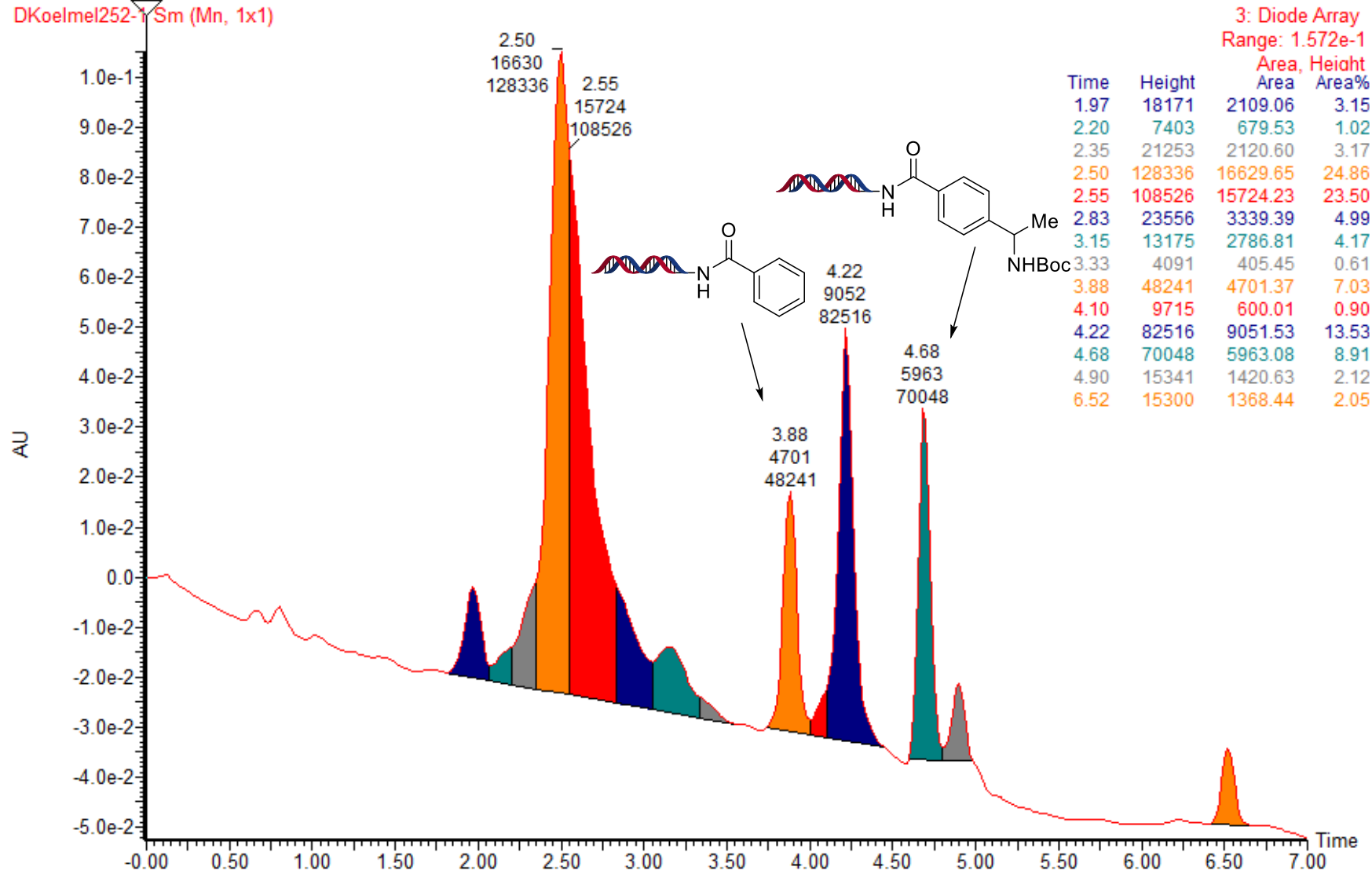

Figure S66. UPLC trace of Table 2, entry 23.

1:1900712256-0637-001

DKoelmel252-fS Sm (Mn, 1x1)

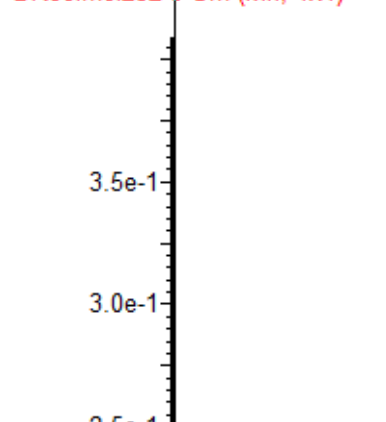

16-May-2018 12:25:25

3: Diode Array

Range: $4.088 \mathrm{e}-1$

Area, Heiaht

$\begin{array}{rrrr}\text { Time } & \text { Height } & \text { Area } & \text { Area\% } \\ 1.88 & 17844 & 2399.68 & 2.80\end{array}$

$\begin{array}{llll}1.88 & 17844 & 2399.68 & 2.80 \\ 2.00 & 24381 & 4026.59 & 4.69\end{array}$

$\begin{array}{llll}3.32 & 40107 & 10600.43 & 12.35\end{array}$

$\begin{array}{llll}3.45 & 16977 & 1948.07 & 2.27\end{array}$

$\begin{array}{llll}4.10 & 82453 & 7804.91 & 9.09\end{array}$

$\begin{array}{rrrr}4.35 & 159487 & 17518.09 & 20.41\end{array}$

$\begin{array}{llll}4.82 & 19072 & 1681.09 & 1.96\end{array}$

$\begin{array}{llll}5.18 & 399946 & 34587.06 & 40.29\end{array}$

$\begin{array}{llll}5.37 & 21766 & 2050.58 & 2.39\end{array}$

$\begin{array}{llll}5.47 & 22689 & 2046.95 & 2.38\end{array}$

$\begin{array}{llll}5.57 & 11902 & 1178.63 & 1.37\end{array}$

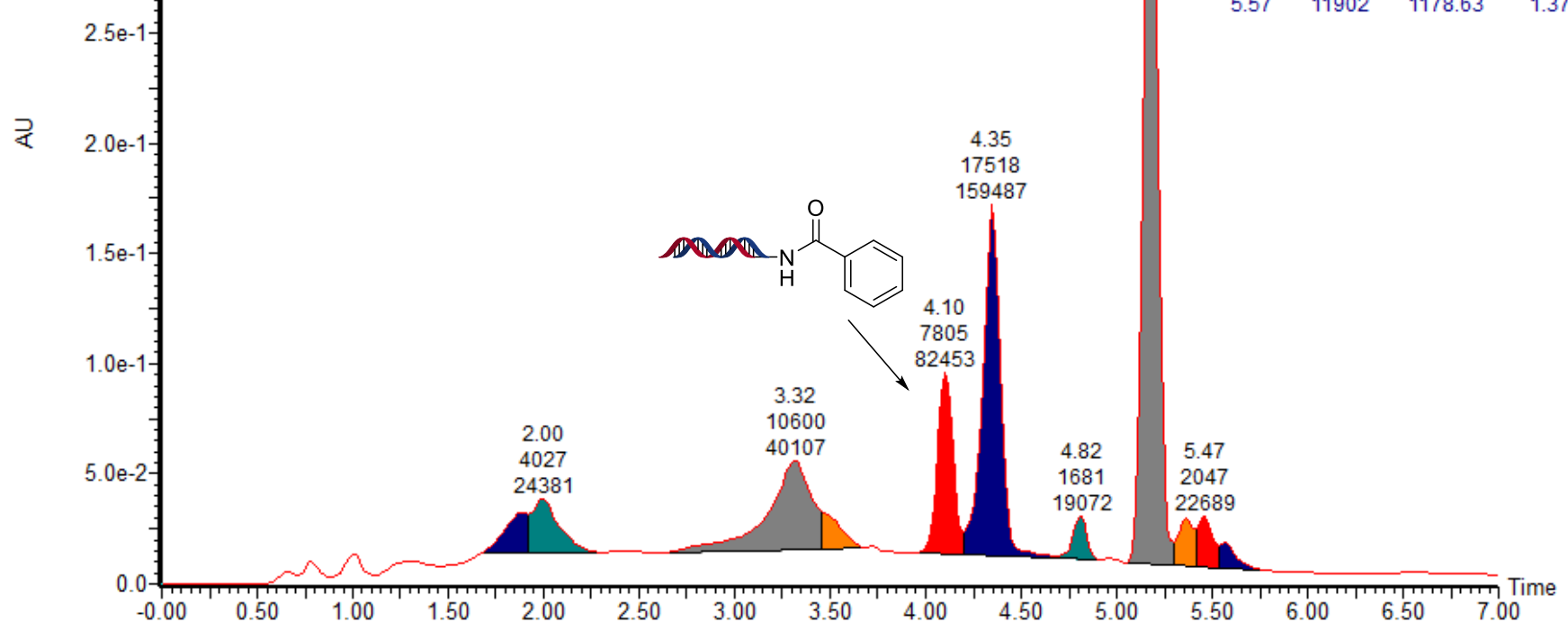

Figure S67. UPLC trace of Table 2, entry 24. 


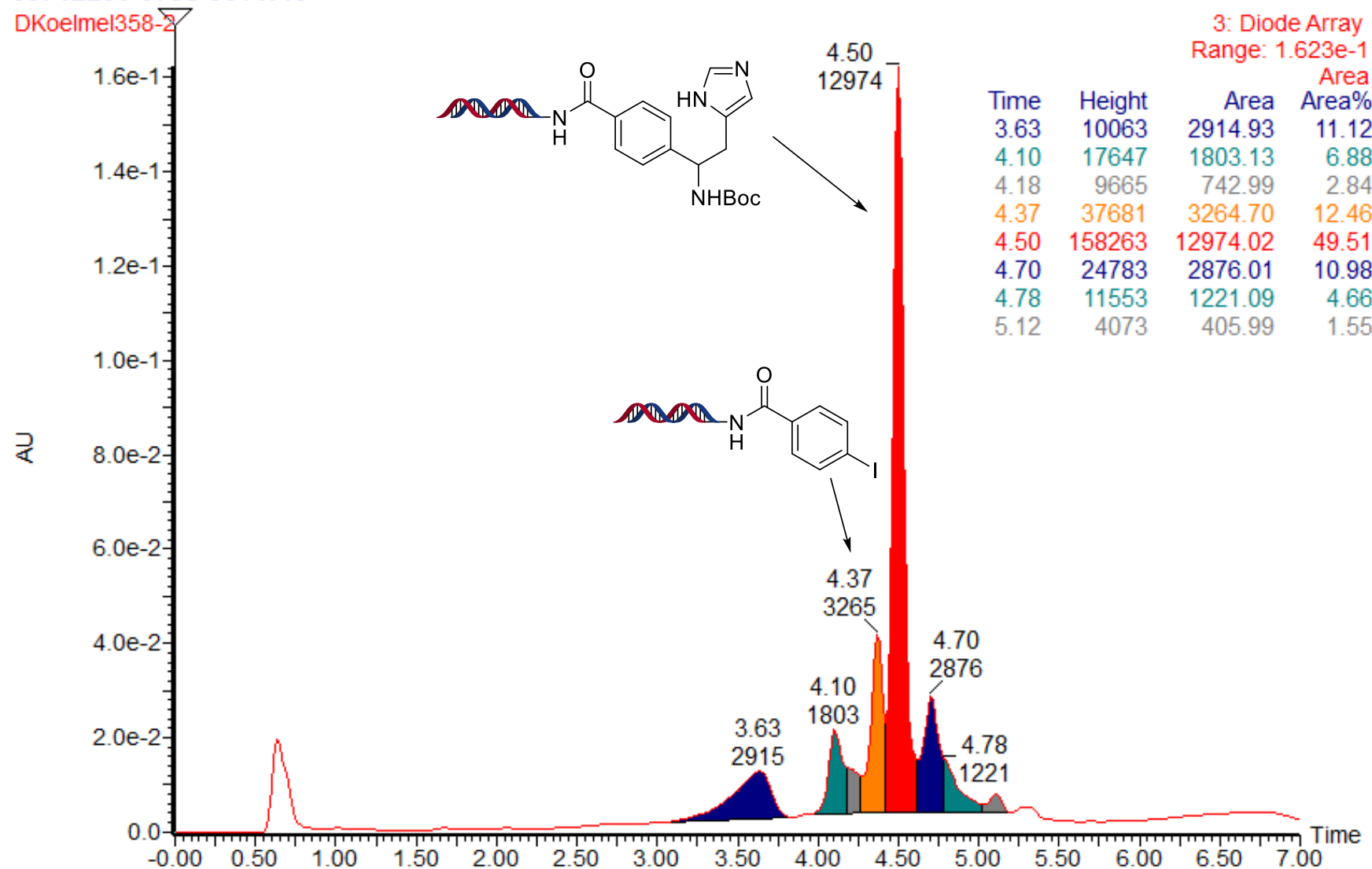

Figure S68. UPLC trace of Table 2, entry 25.

\section{6-0794-001-Reapeat1:45}

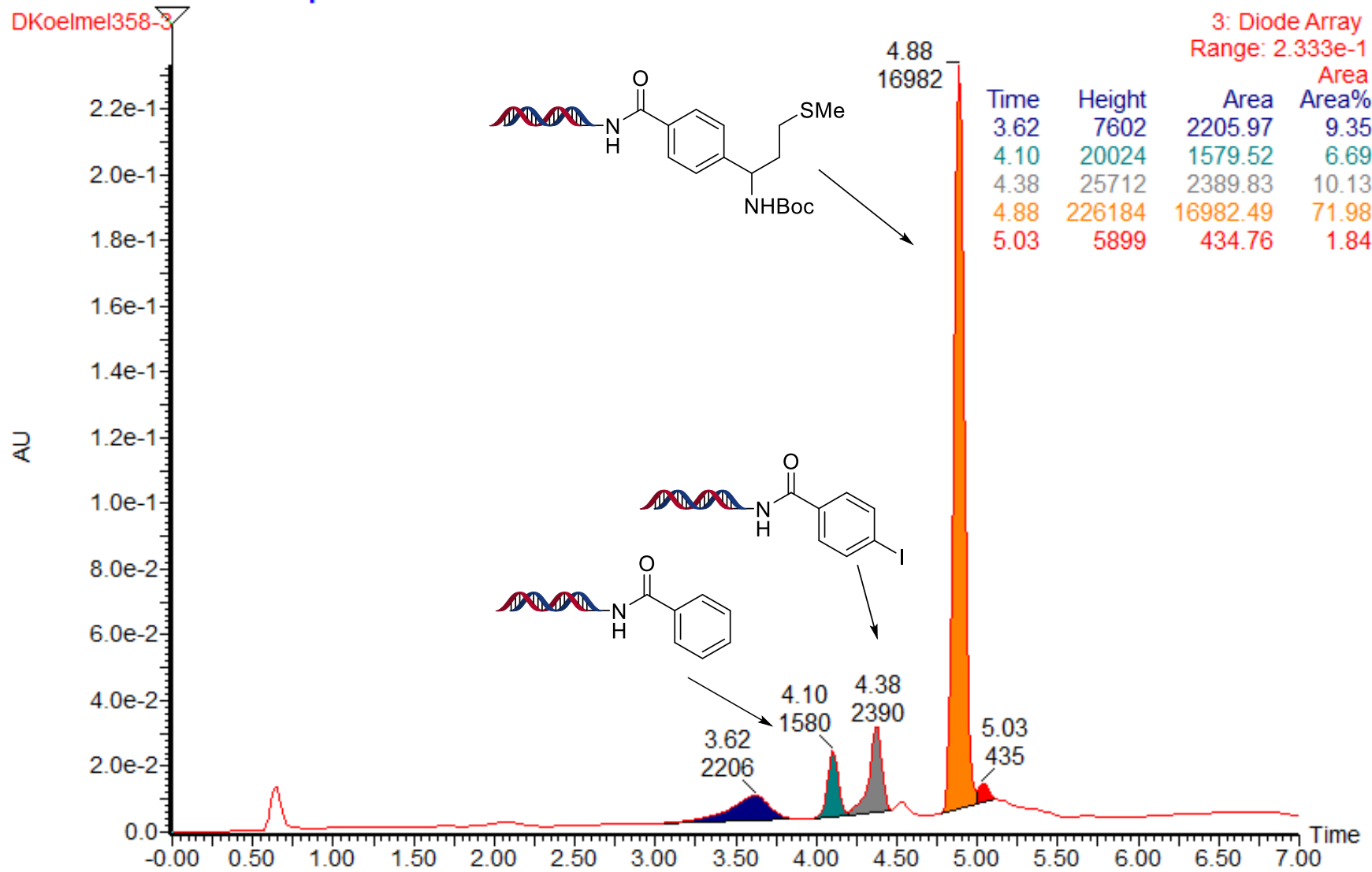

Figure S69. UPLC trace of Table 2, entry 26. 


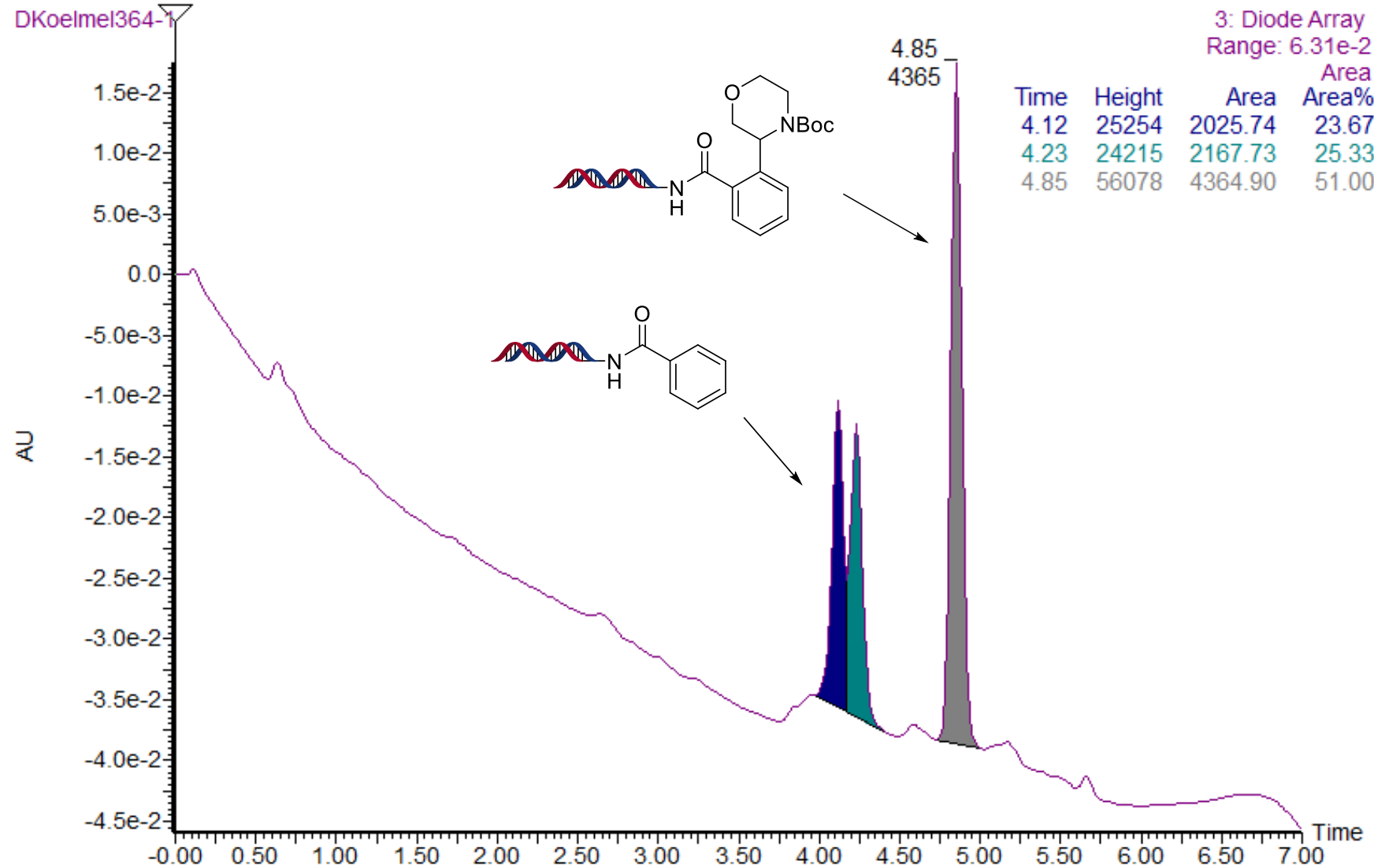

Figure S70. UPLC trace of Table 3, entry 1.

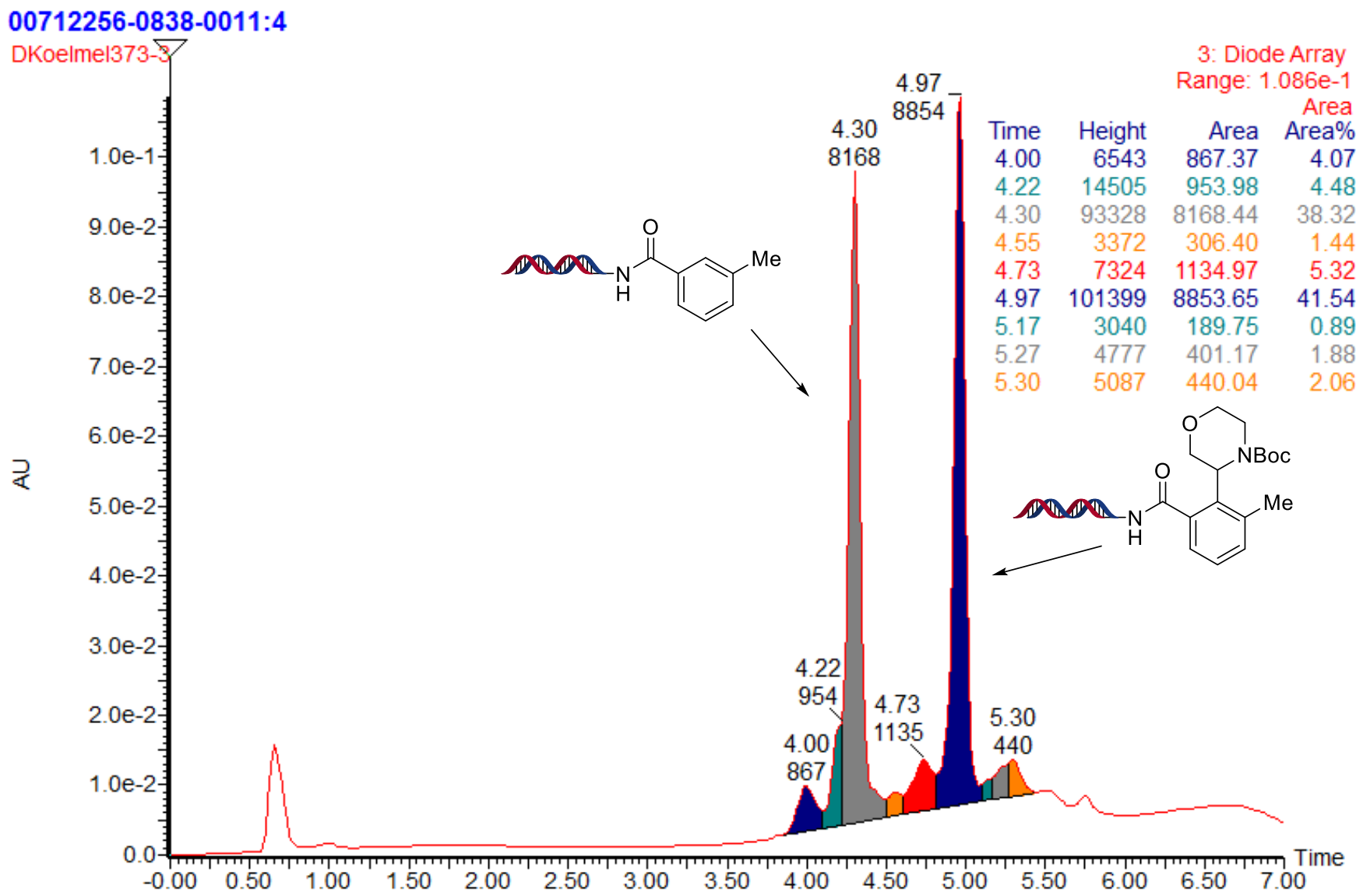

Figure S71. UPLC trace of Table 3, entry 2. 
00712256-0835-0011:1

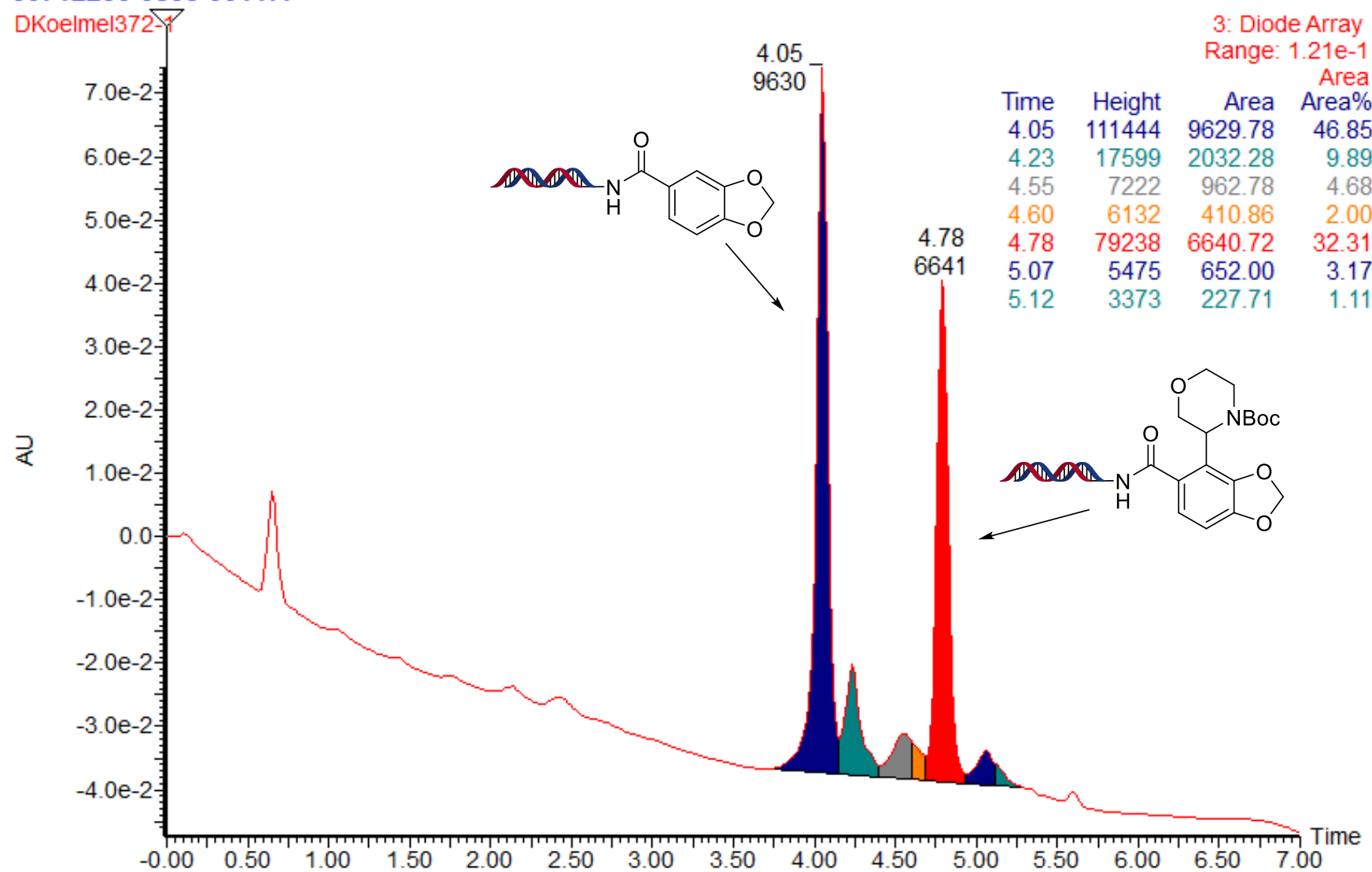

Figure S72. UPLC trace of Table 3, entry 3.

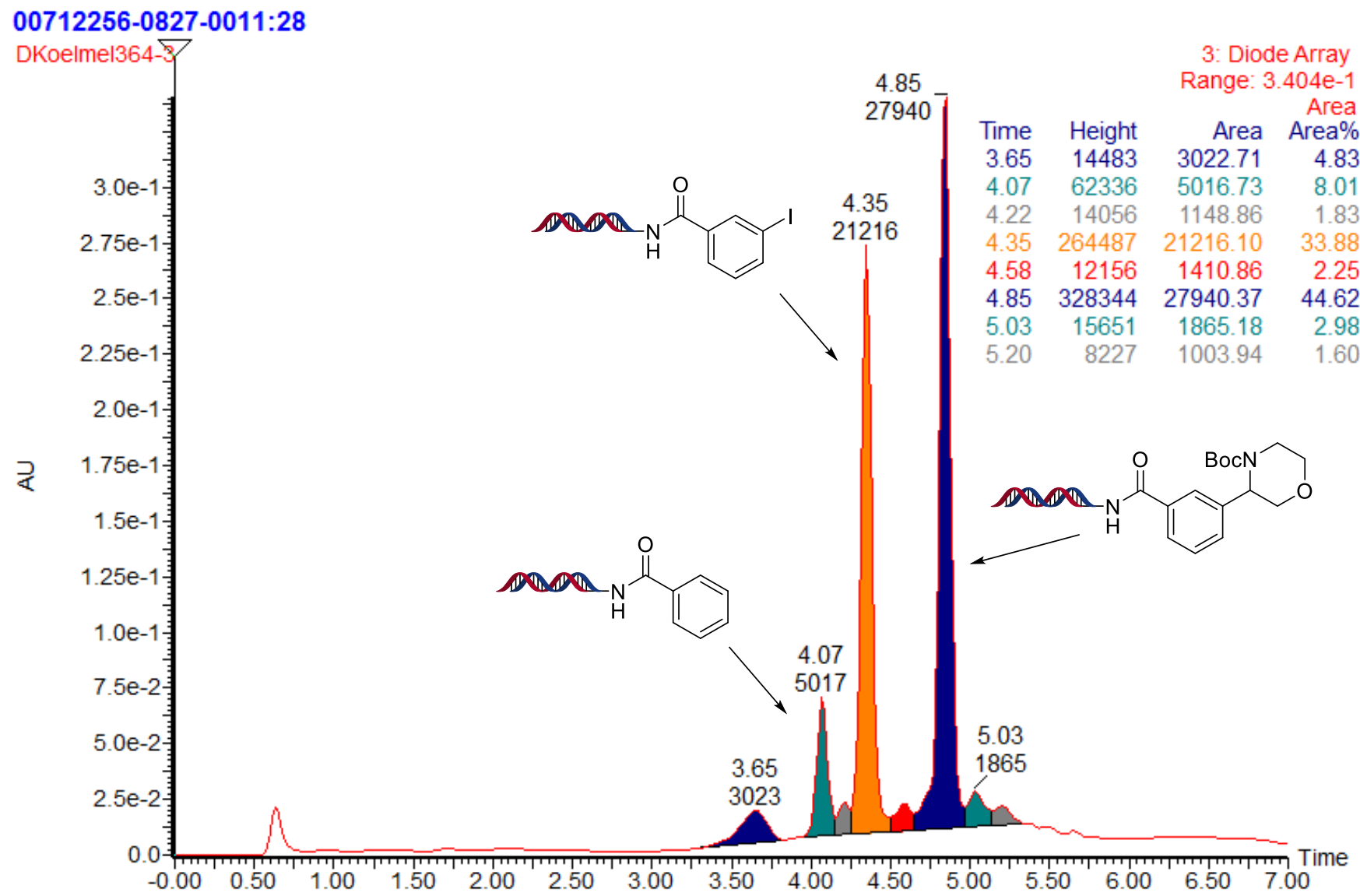

Figure S73. UPLC trace of Table 3, entry 4, after first coupling. 


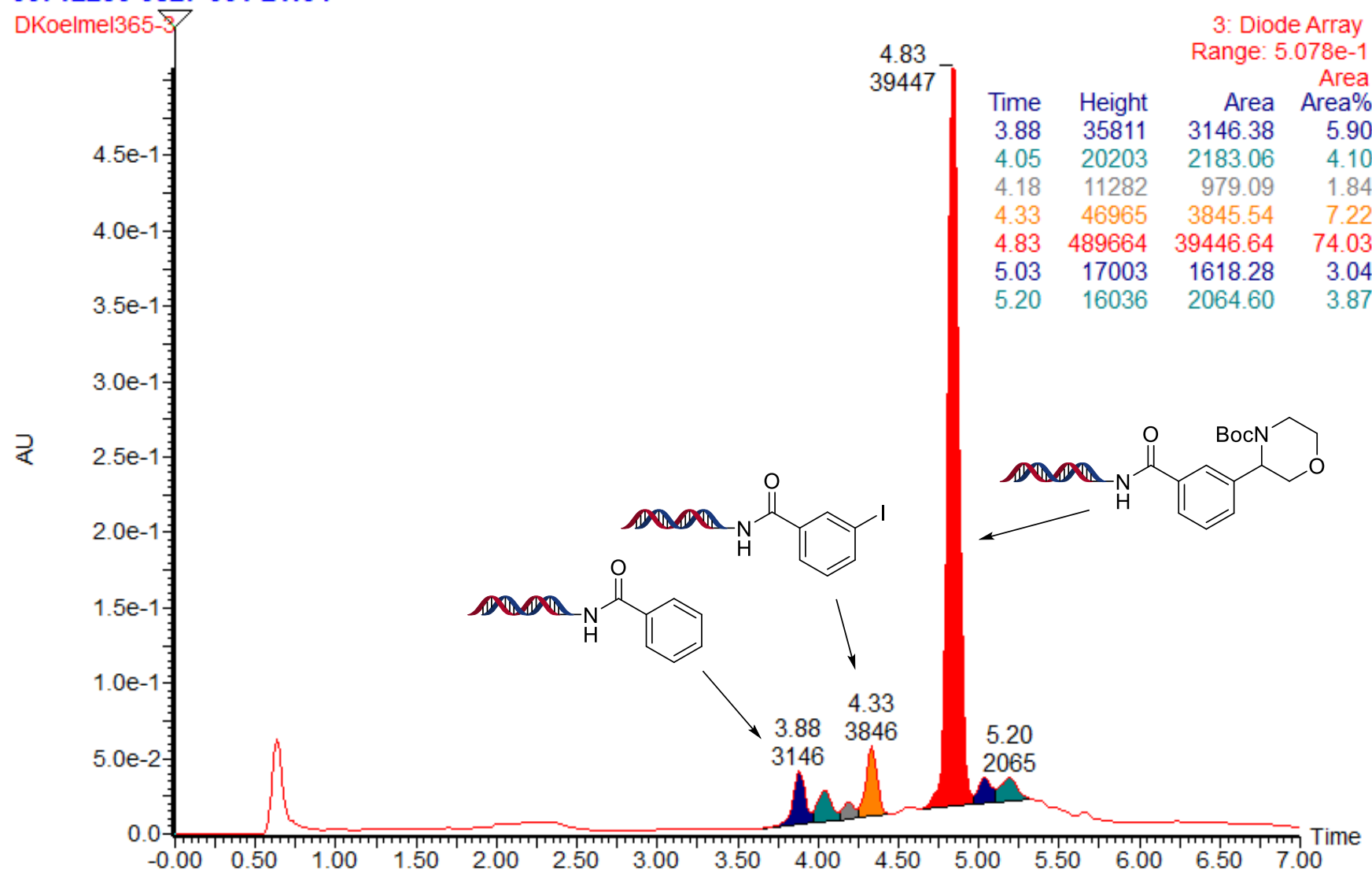

Figure S74. UPLC trace of Table 3, entry 4, after second coupling.

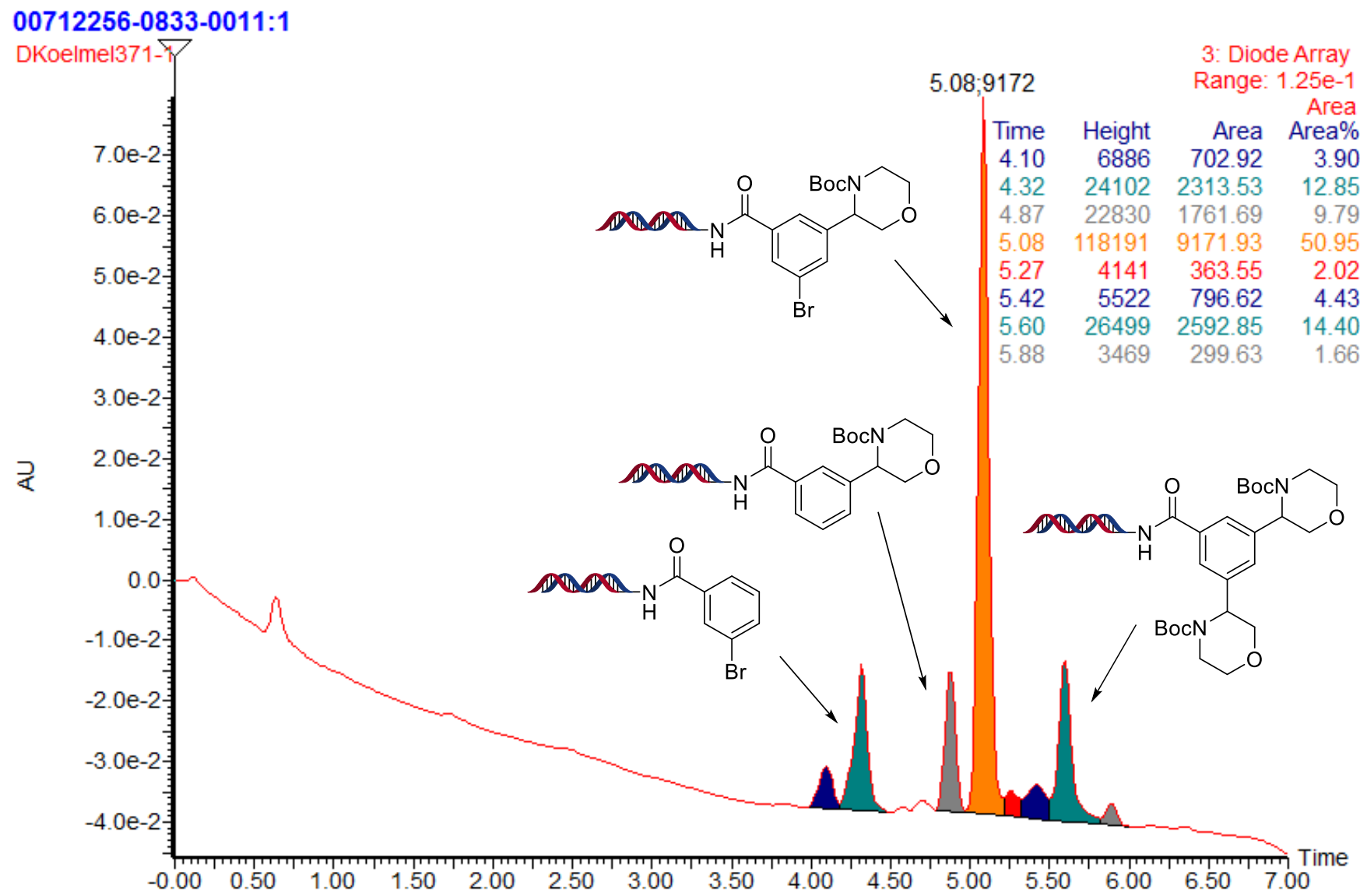

Figure S75. UPLC trace of Table 3, entry 5. 


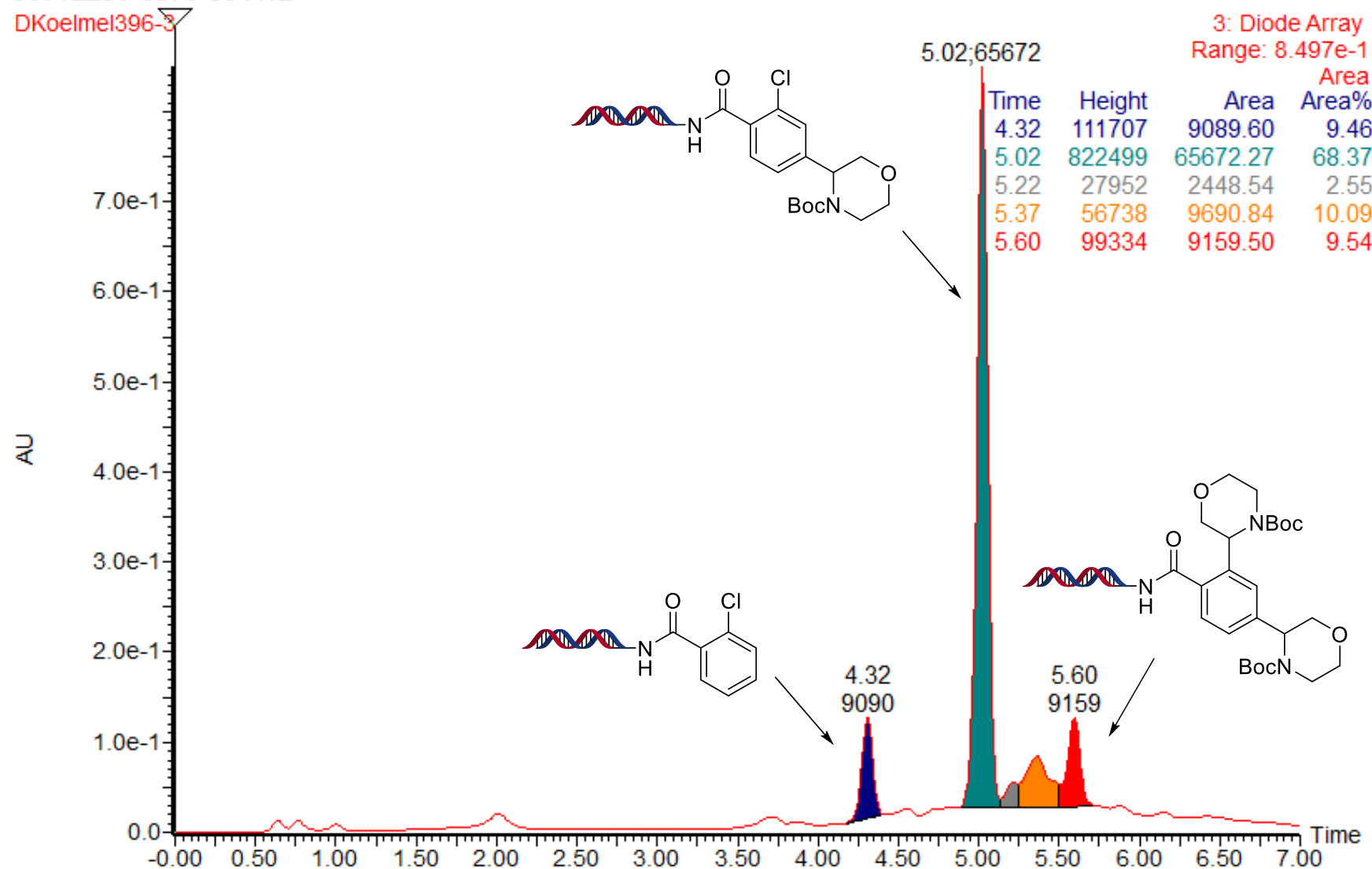

Figure S76. UPLC trace of Table 3, entry 6.

00712256-0878-0011:1

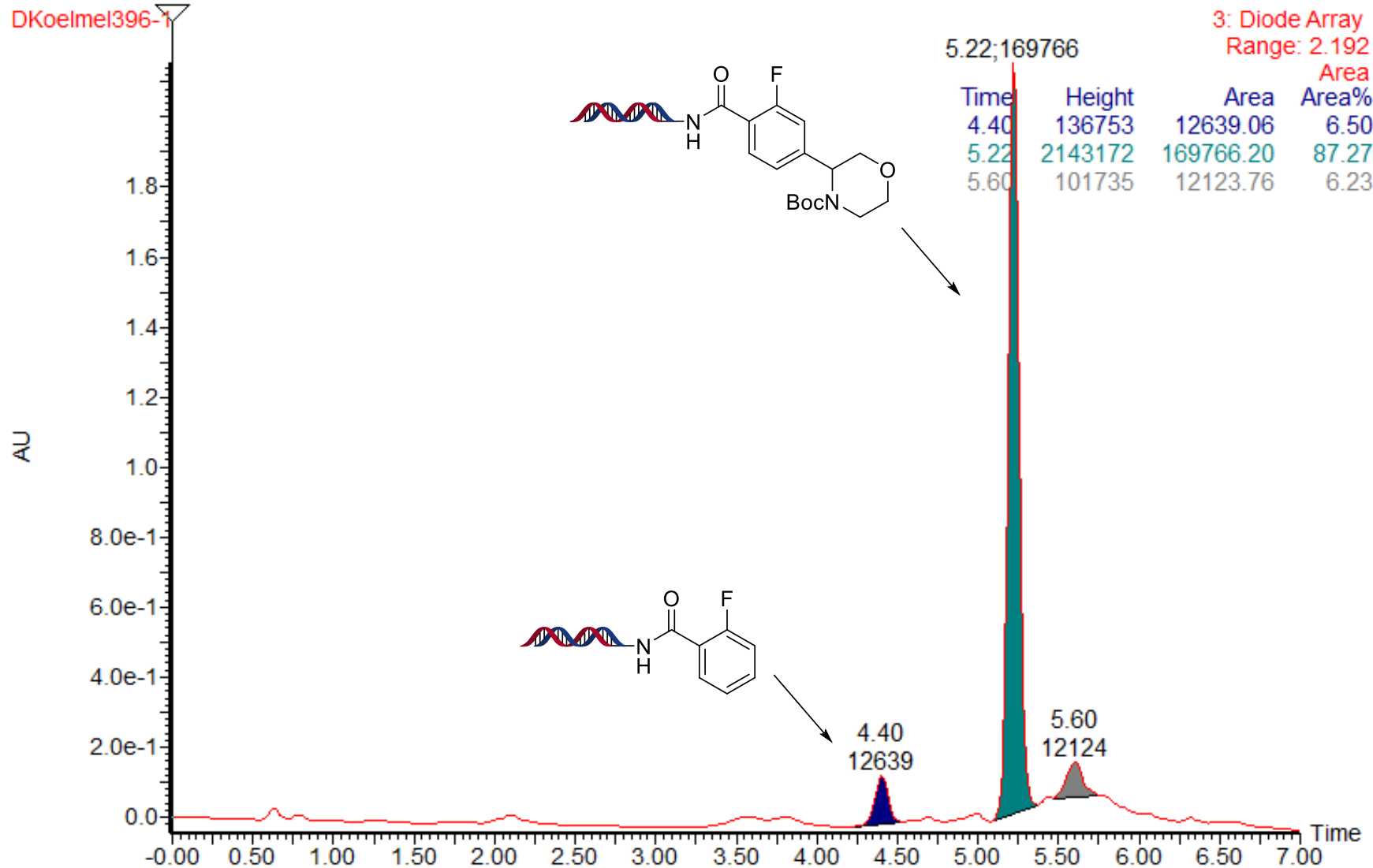

Figure S77. UPLC trace of Table 3, entry 7. 


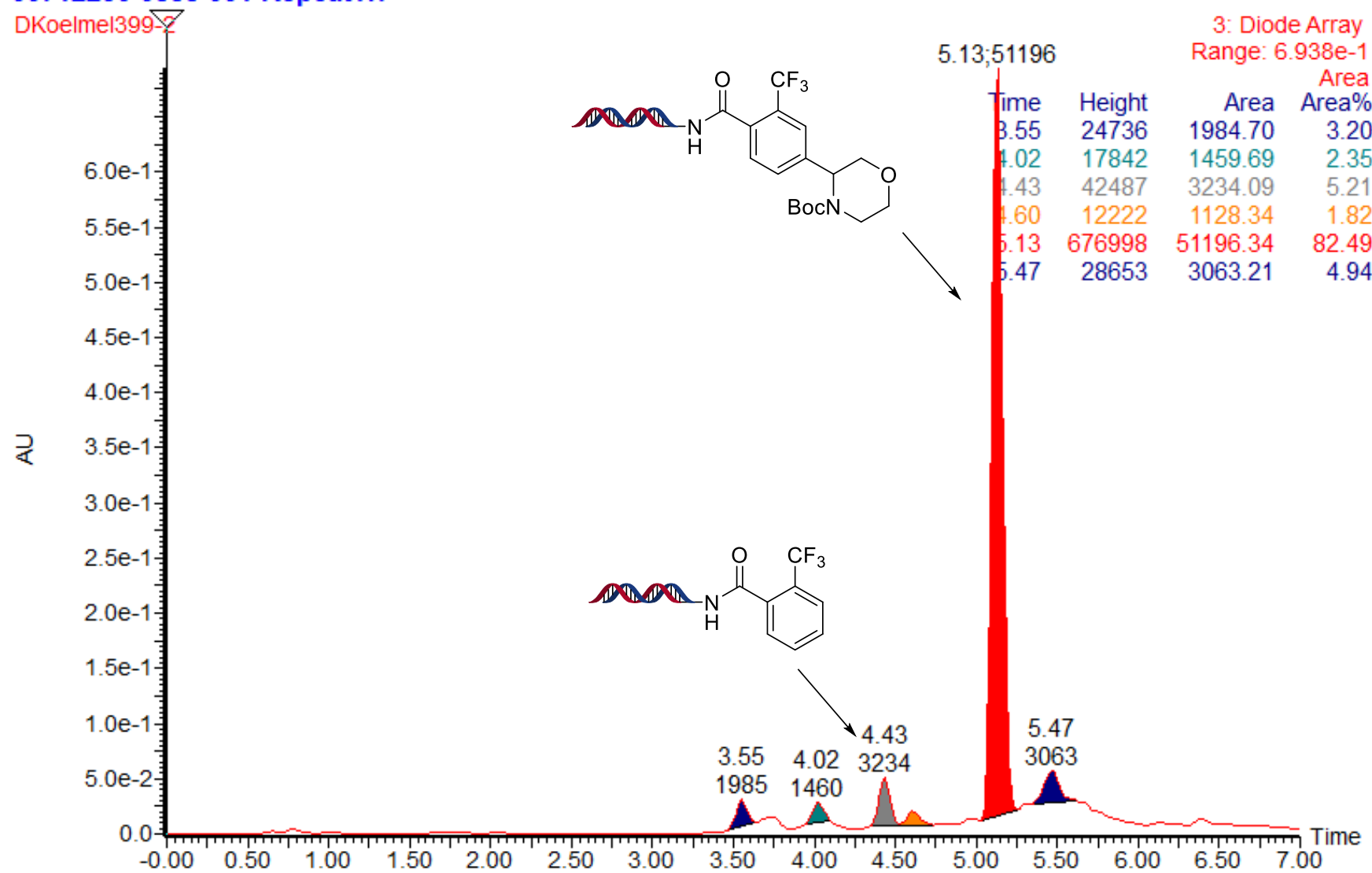

Figure S78. UPLC trace of Table 3, entry 8.

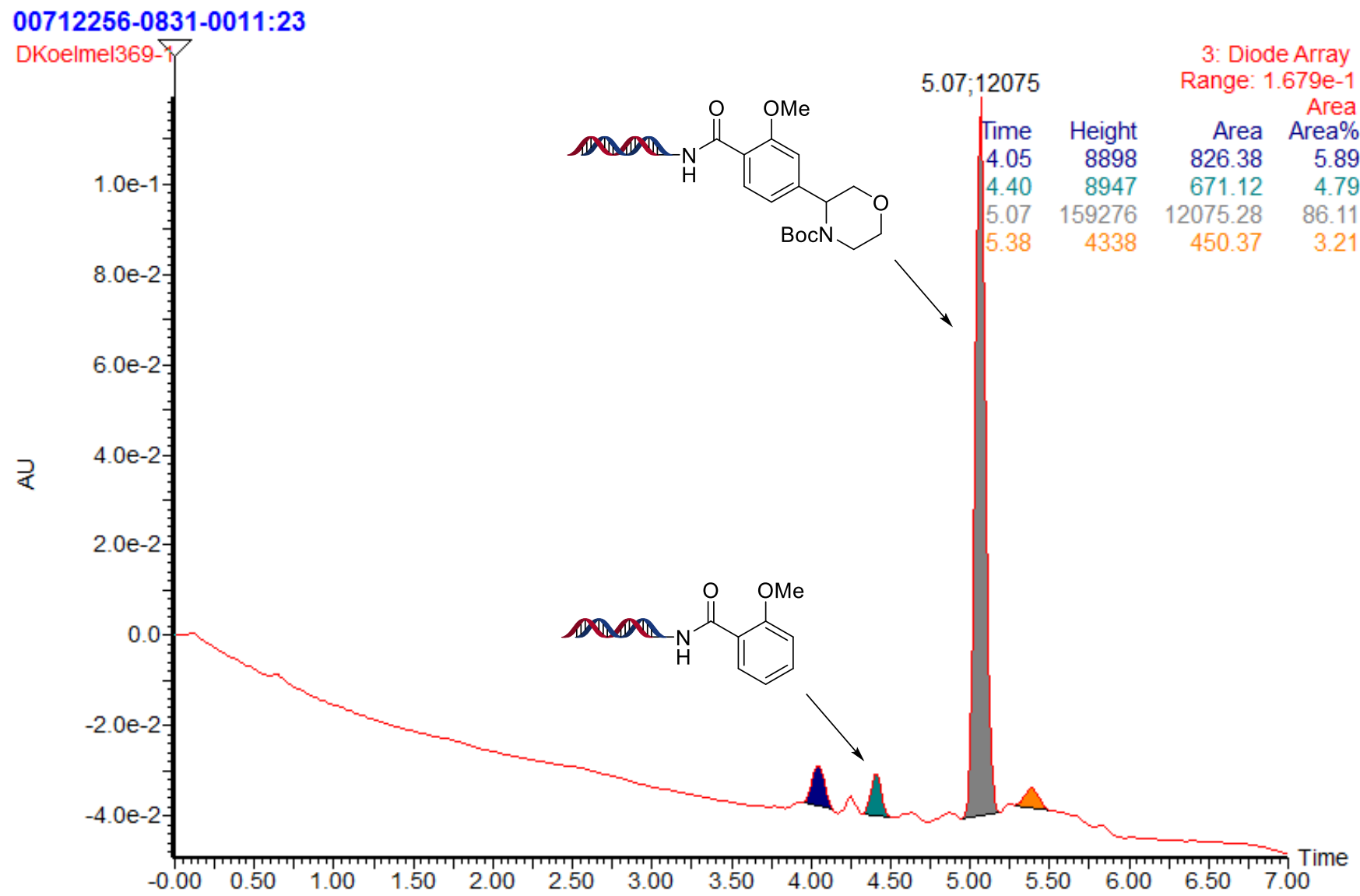

Figure S79. UPLC trace of Table 3, entry 9. 
00712256-0837-0011:3

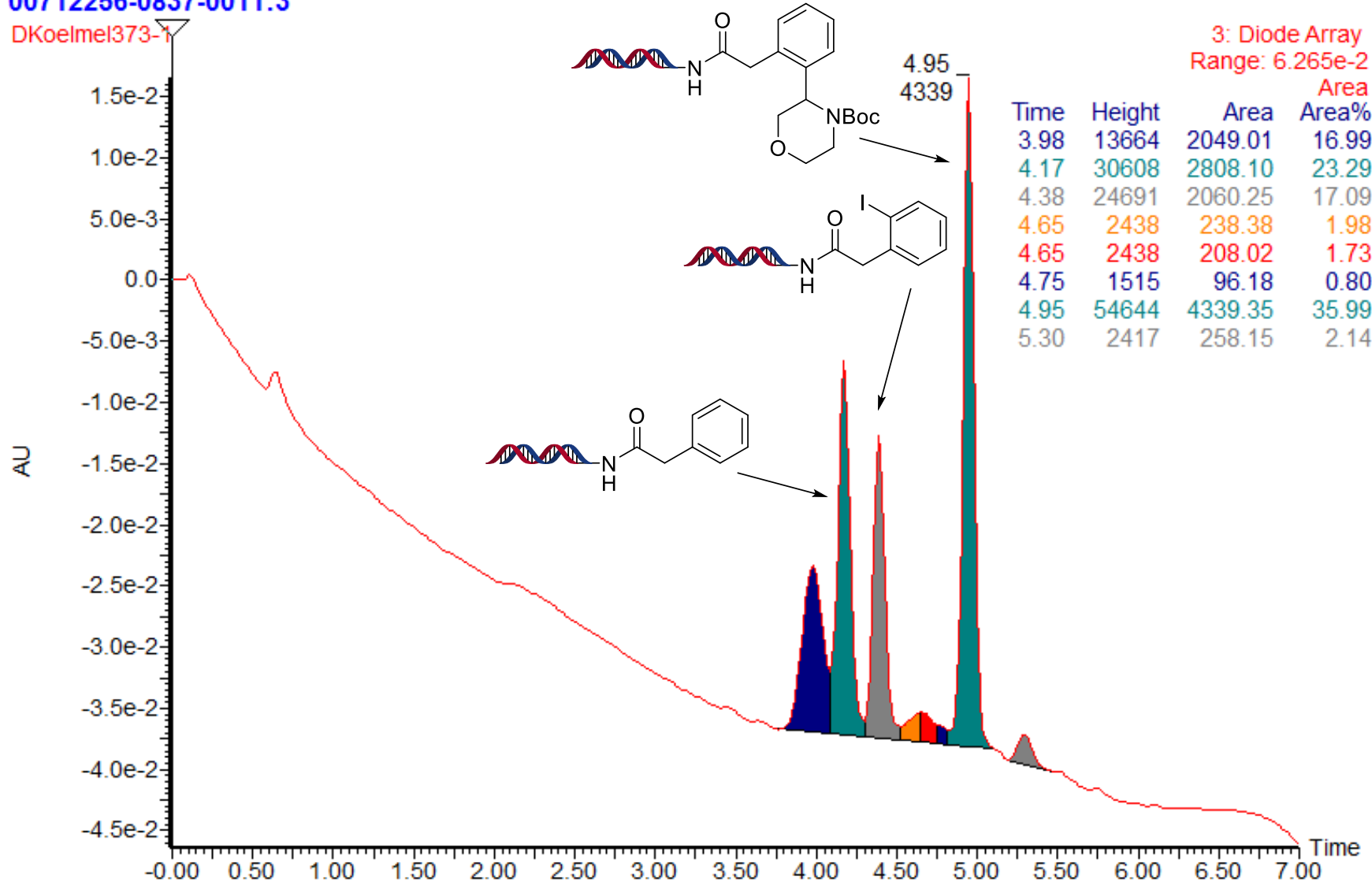

Figure S80. UPLC trace of Table 3, entry 10, after first coupling.
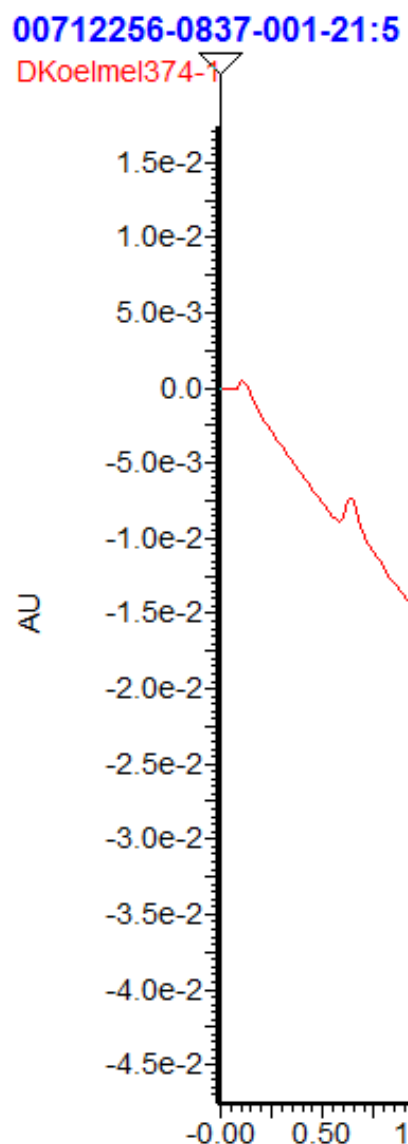

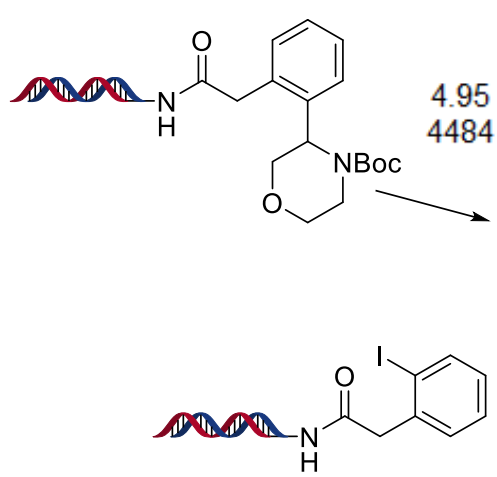

3: Diode Array Range: 6.471e-2

Time Height Area Area\%

$\begin{array}{llll}3.93 & 13049 & 1772.96 & 17.51\end{array}$

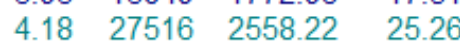

$4.40 \quad 5862 \quad 574.25 \quad 5.67$

$\begin{array}{llll}4.67 & 2134 & 402.94 & 3.98\end{array}$

$\begin{array}{llll}4.95 & 56772 & 4483.73 & 44.27\end{array}$

$\begin{array}{llll}5.30 & 3026 & 335.88 & 3.32\end{array}$

Figure S81. UPLC trace of Table 3, entry 10, after second coupling. 
00712256-0830-0011:45

D $\cos$<smiles>NC(=O)C1(c2cccc(C3COCCN3C(=O)c3ccccc3)c2)CC1</smiles>

$5.18 ; 8131$<smiles>COCCOC(=O)NC(=O)C1(c2cccc(I)c2)CC1</smiles>

Time

4 .22 Height

14824

3497

64866

59449
8450

93285

6935

2242
3: Diode Array Range: $9.942 \mathrm{e}-2$

Area Area\%

$1318.64 \quad 5.22$

$235.10 \quad 0.93$

$5672.19 \quad 22.47$

$6668.54 \quad 26.42$

$1151.85 \quad 4.56$

$8131.21 \quad 32.22$

$\begin{array}{ll}1854.68 & 7.35\end{array}$

Figure S82. UPLC trace of Table 3, entry 11, after first coupling.

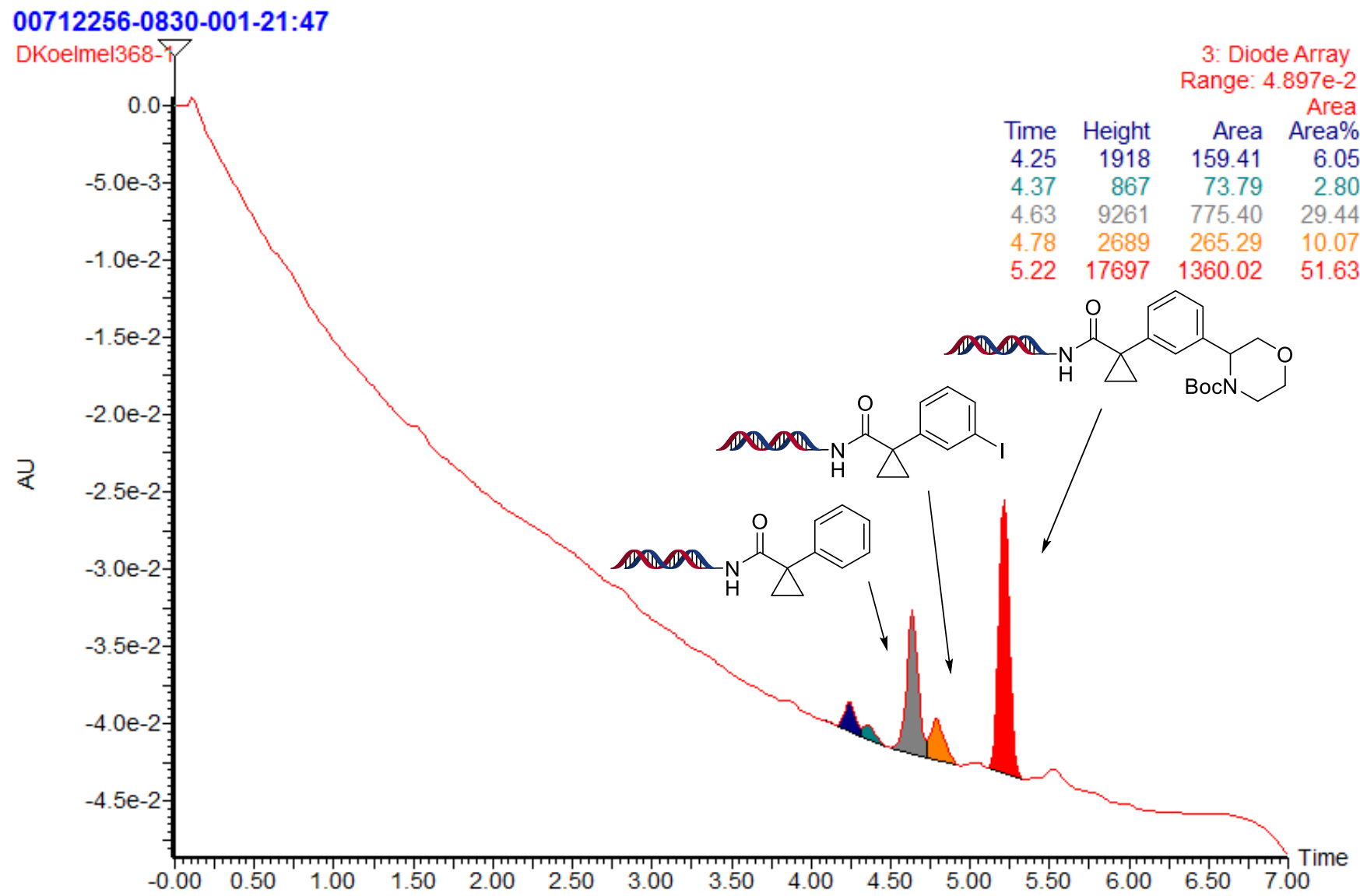

Figure S83. UPLC trace of Table 3, entry 11, after second coupling. 


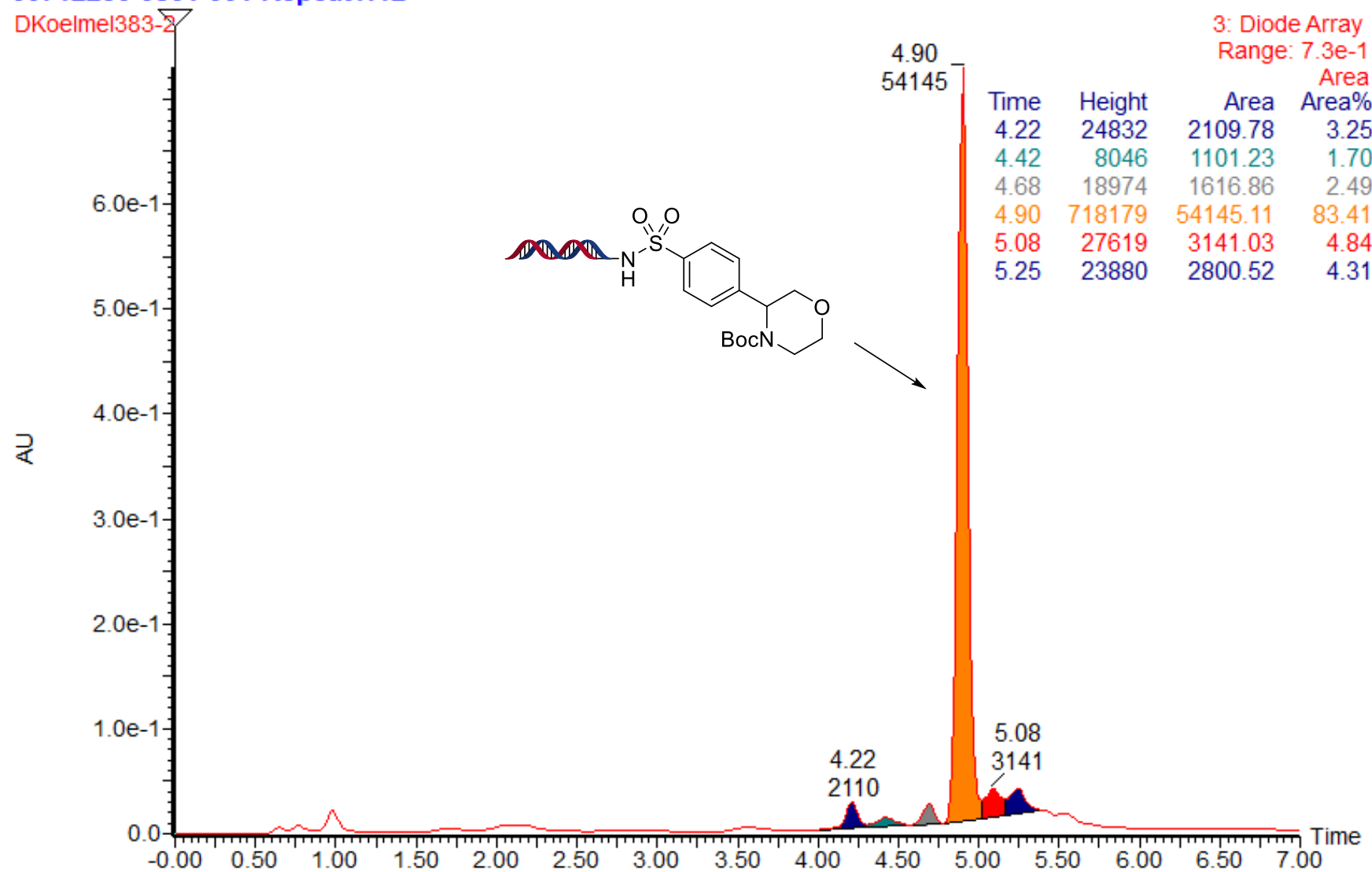

Figure S84. UPLC trace of Table 3, entry 12 (from aryl iodide S12).

00712256-0862-0011:13

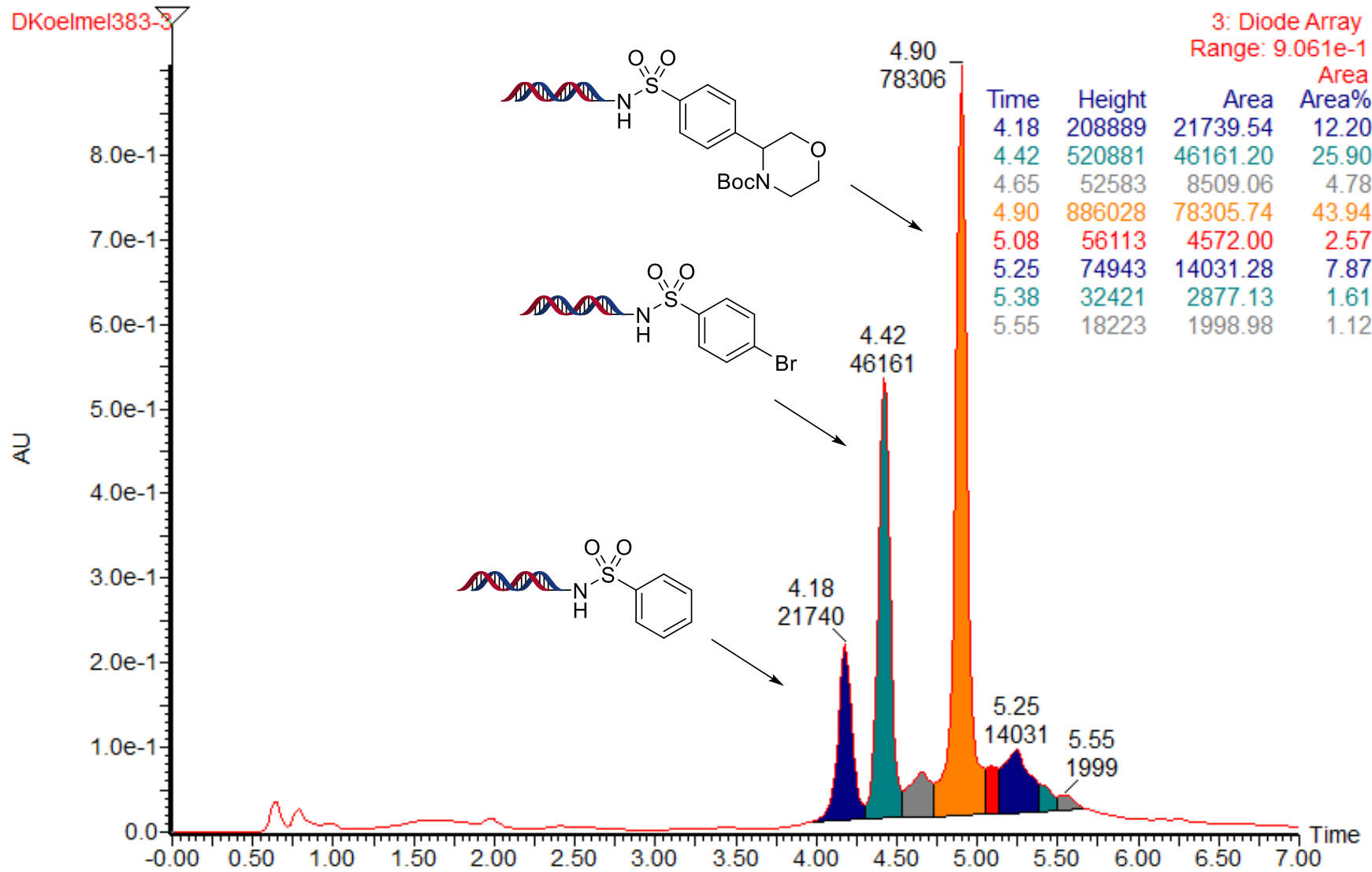

Figure S85. UPLC trace of Table 3, entry 12 (from aryl bromide S13), after first coupling. 


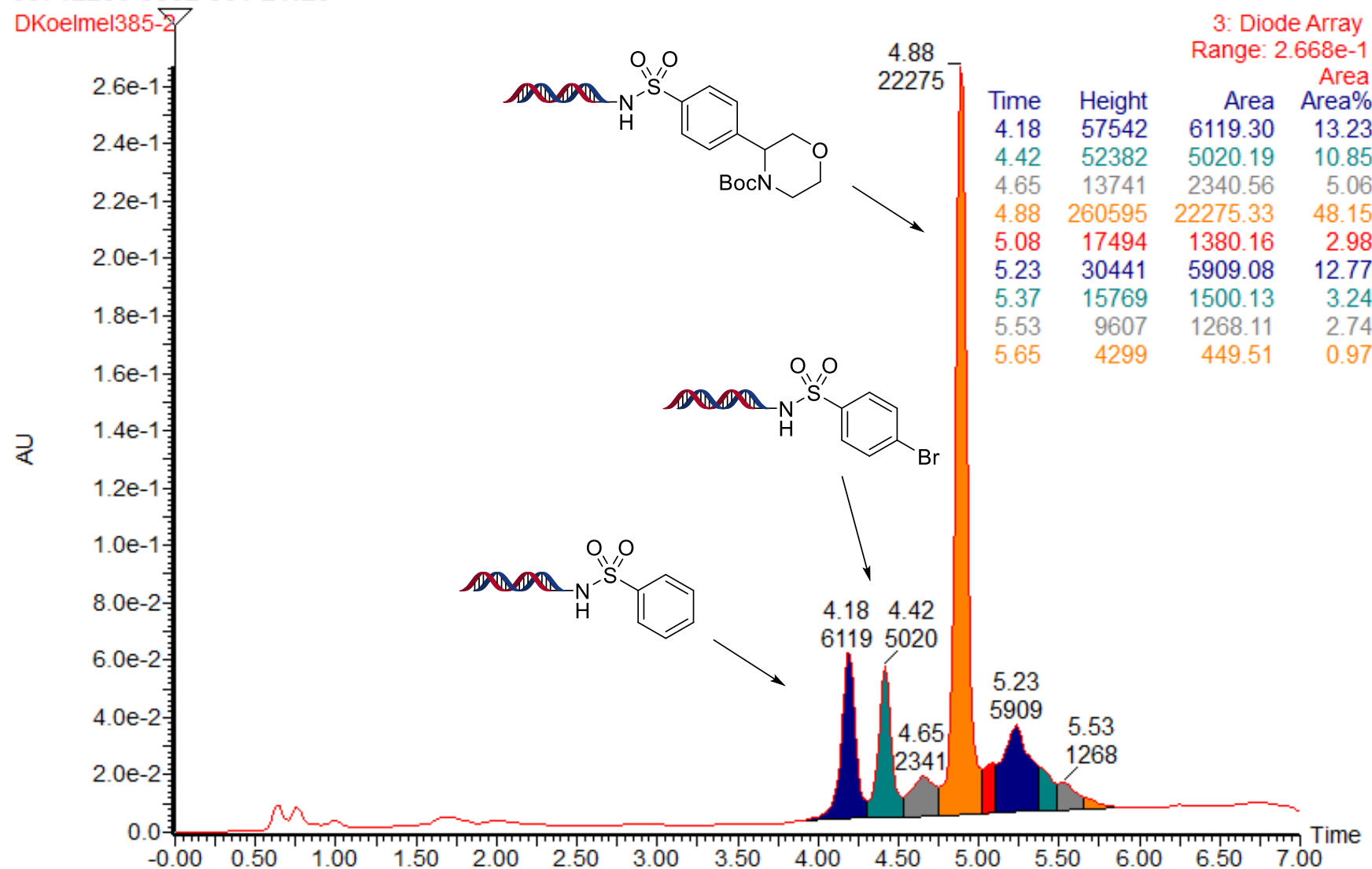

Figure S86. UPLC trace of Table 3, entry 12 (from aryl bromide S13), after second coupling.

00712256-0849-0011:2

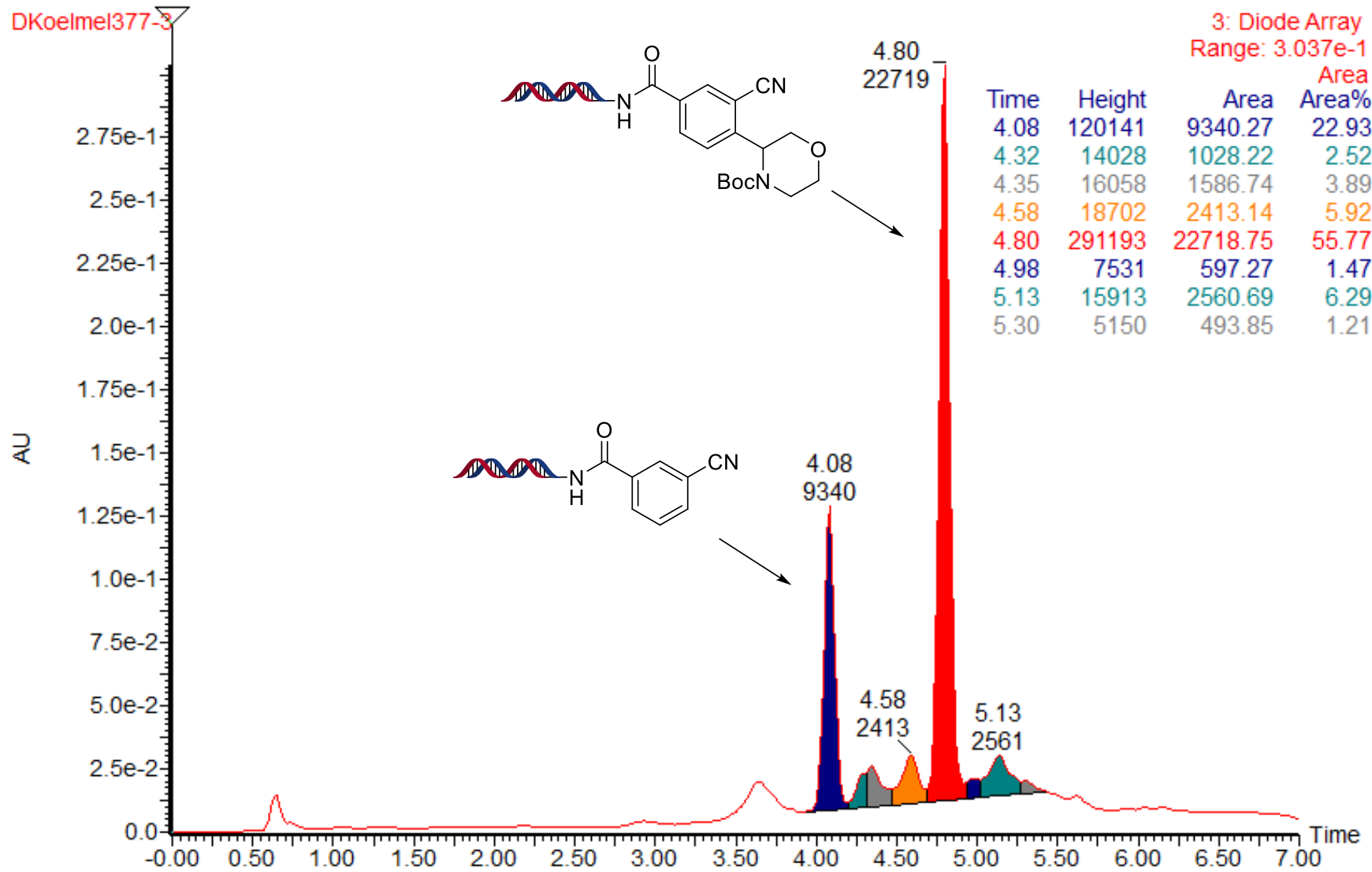

Figure S87. UPLC trace of Table 3, entry 13. 


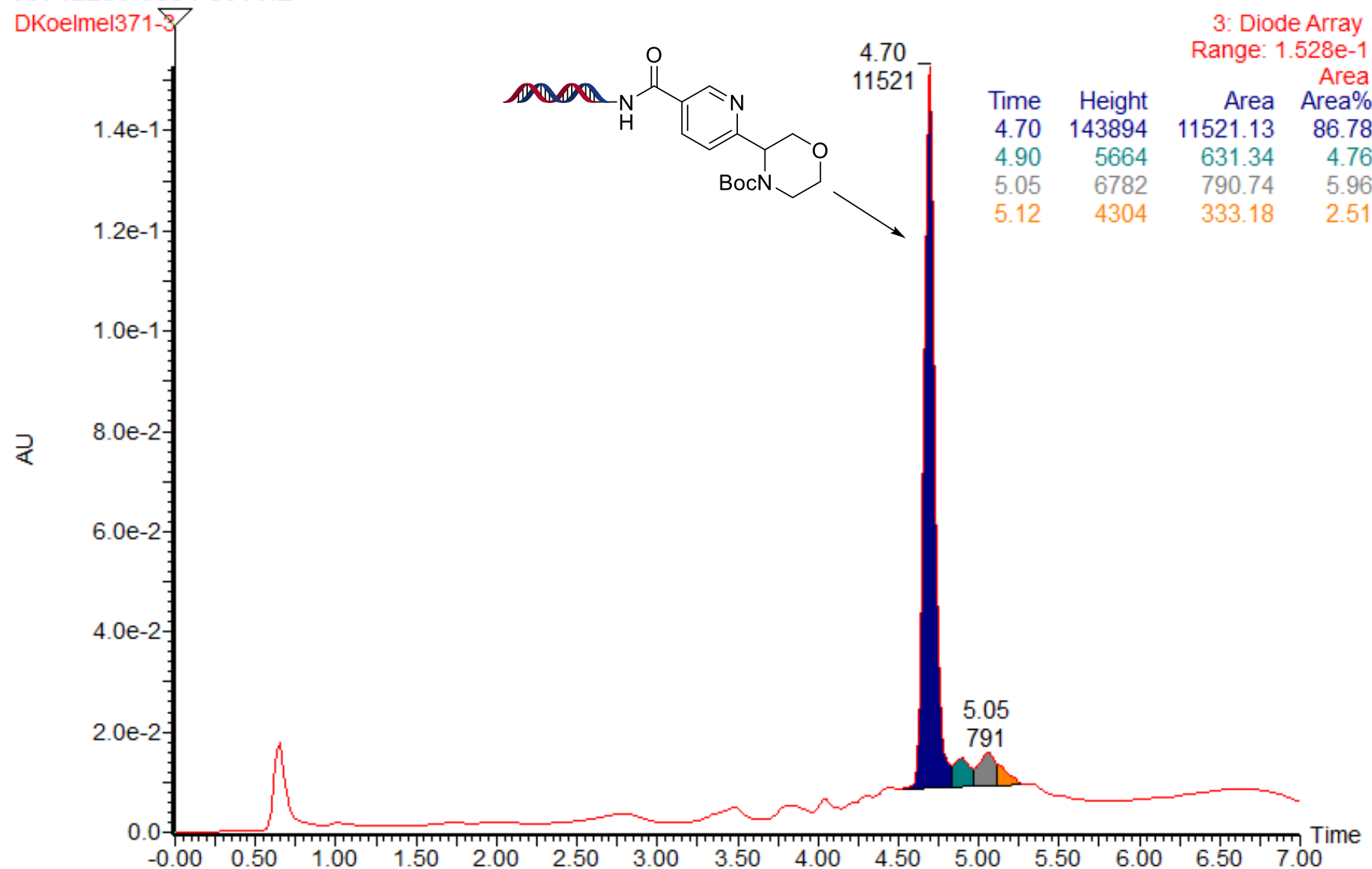

Figure S88. UPLC trace of Table 3, entry 14 (from aryl iodide S15).

\section{6-0824-001-Repeat1:25}

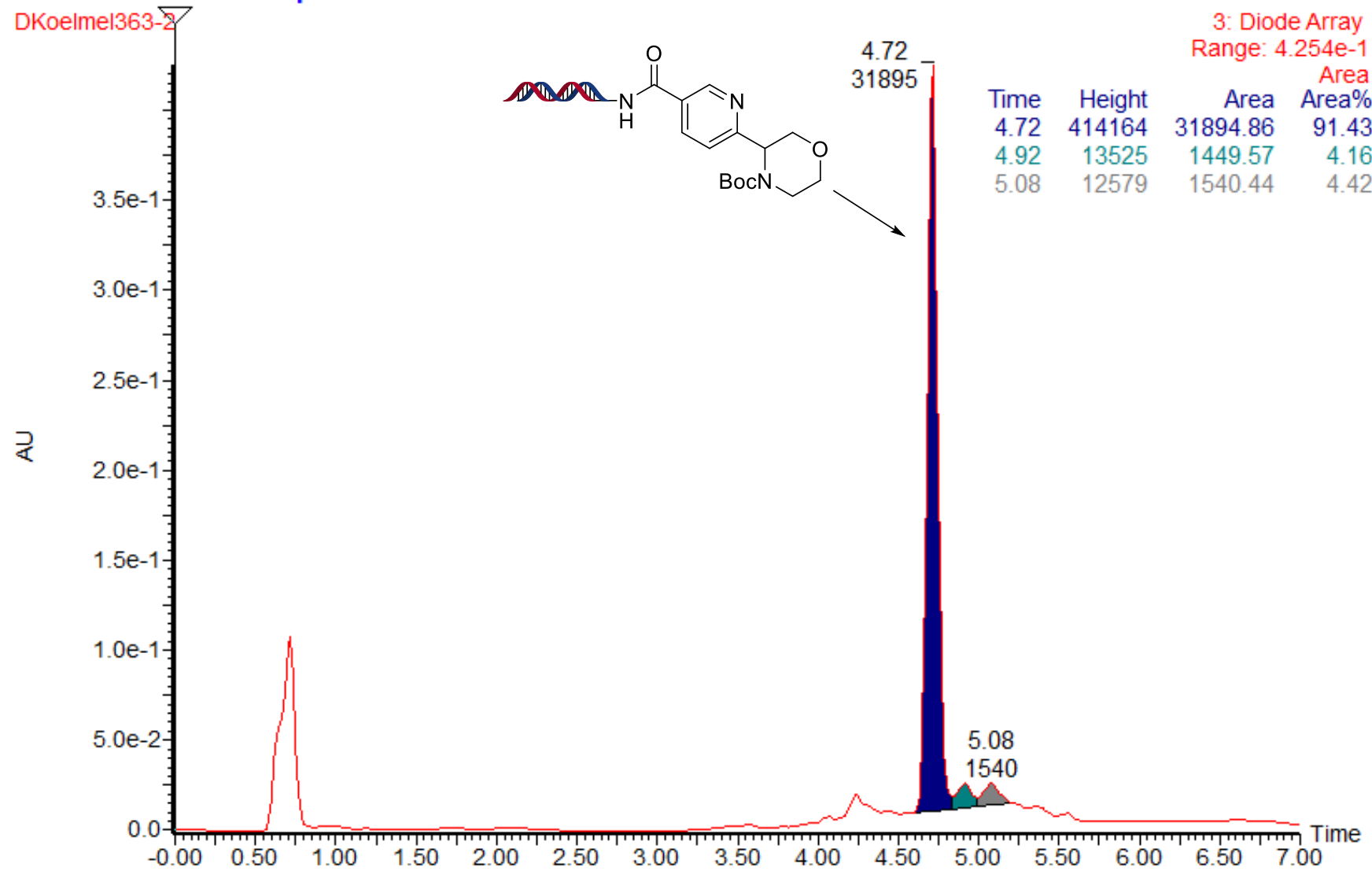

Figure S89. UPLC trace of Table 3, entry 14 (from aryl bromide S16). 


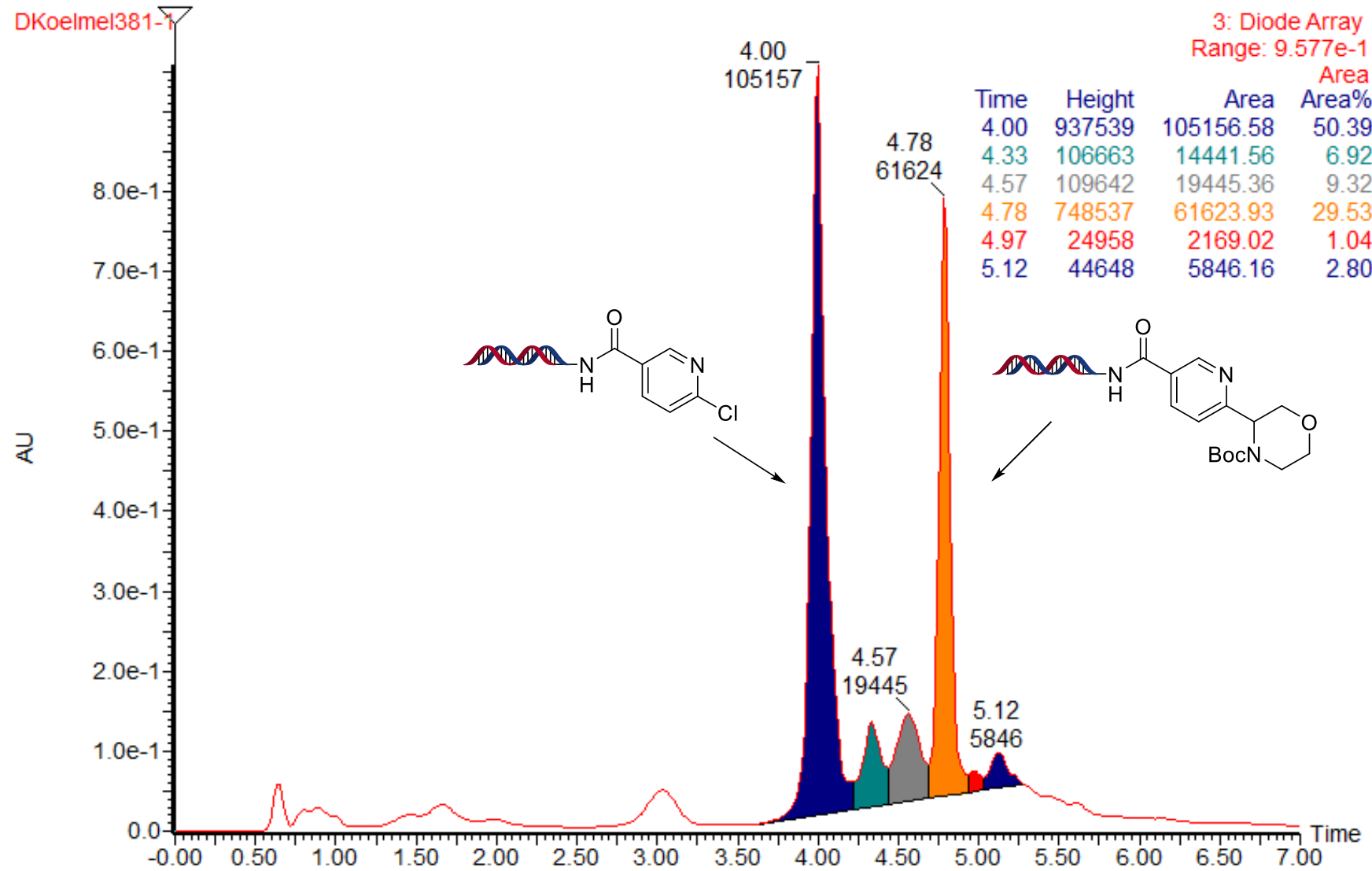

Figure S90. UPLC trace of Table 3, entry 14 (from aryl chloride S17).

\section{6-0860-0011:8}

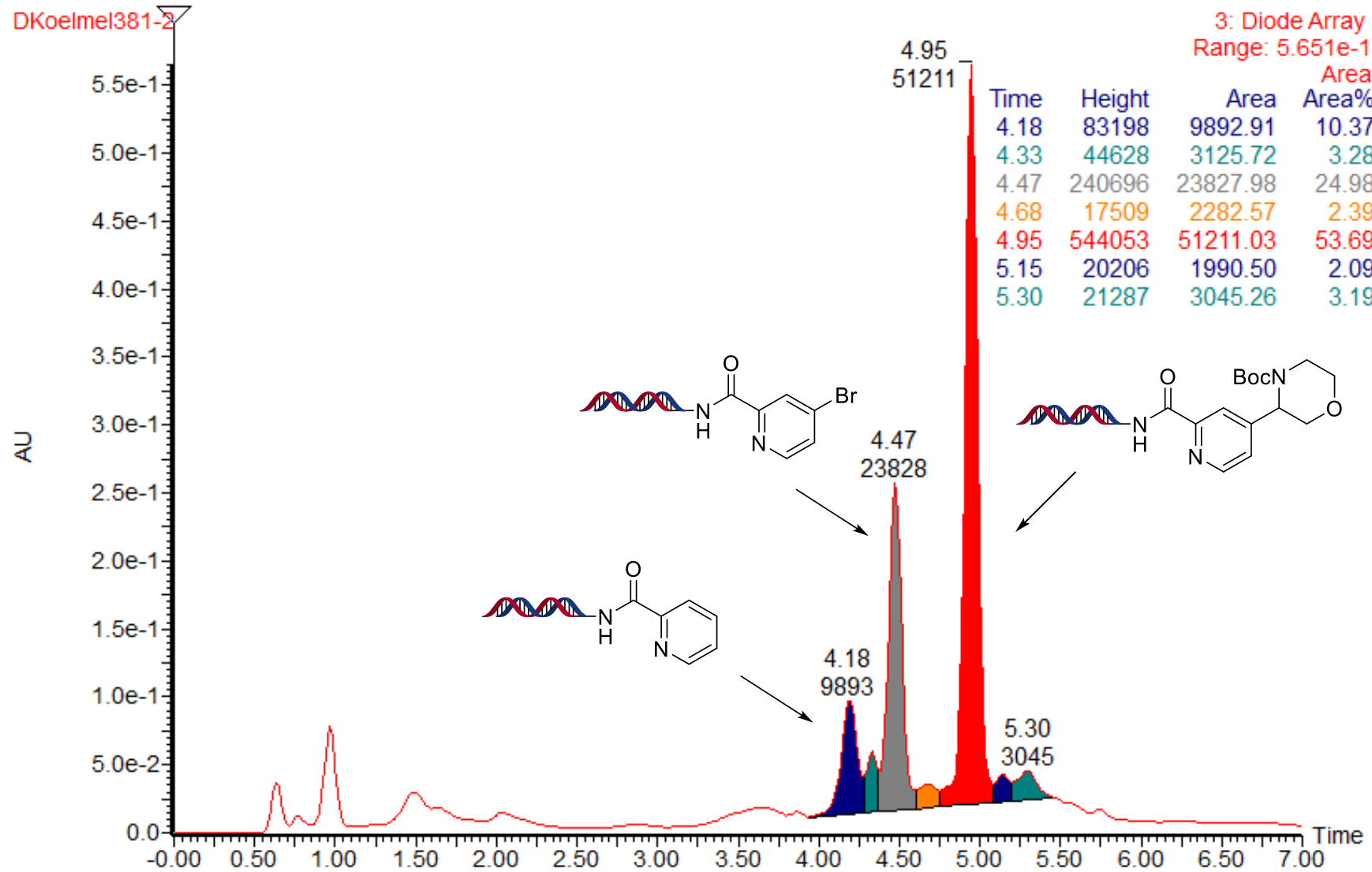

Figure S91. UPLC trace of Table 3, entry 15, after first coupling. 


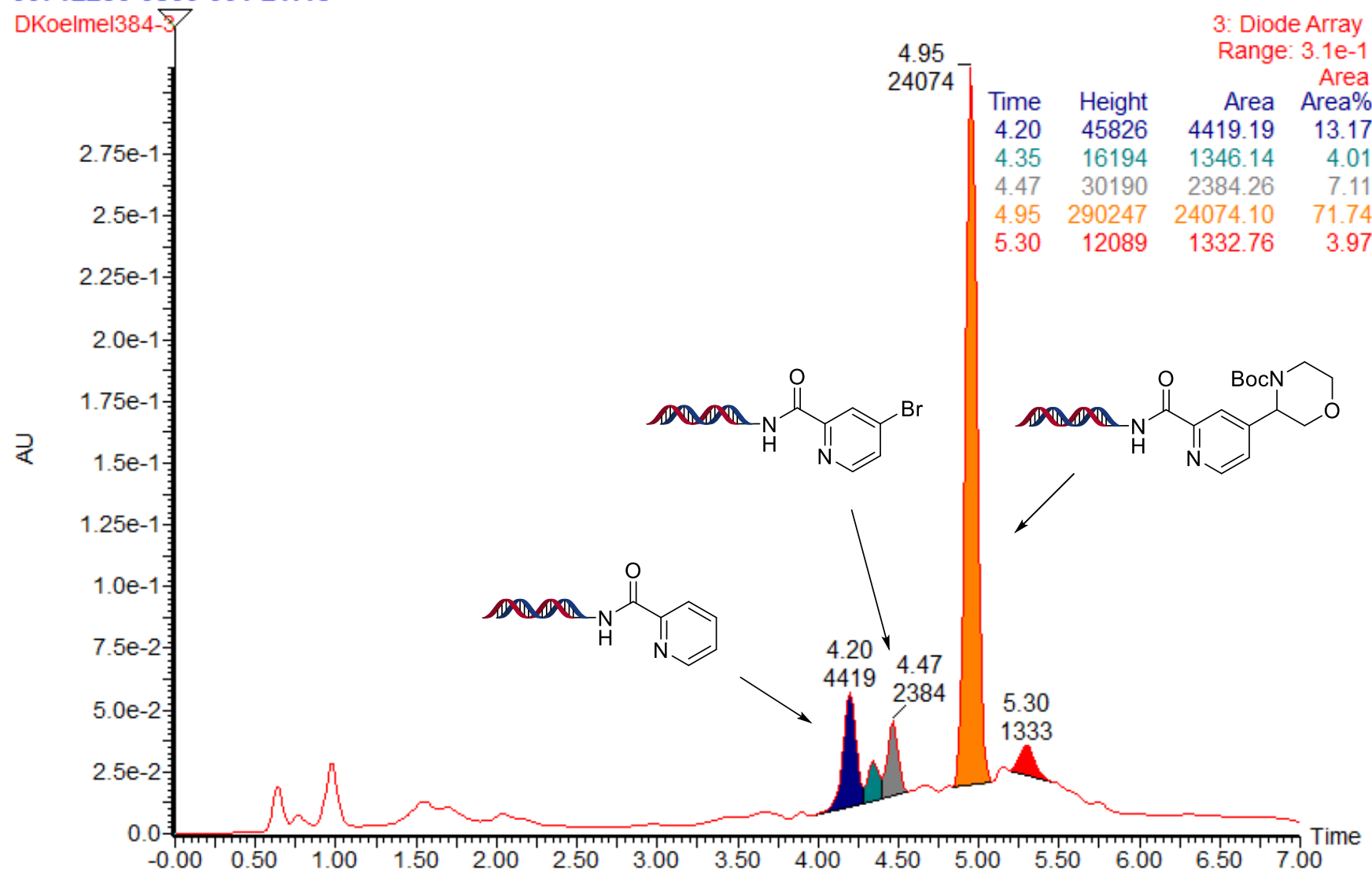

Figure S92. UPLC trace of Table 3, entry 15, after second coupling.

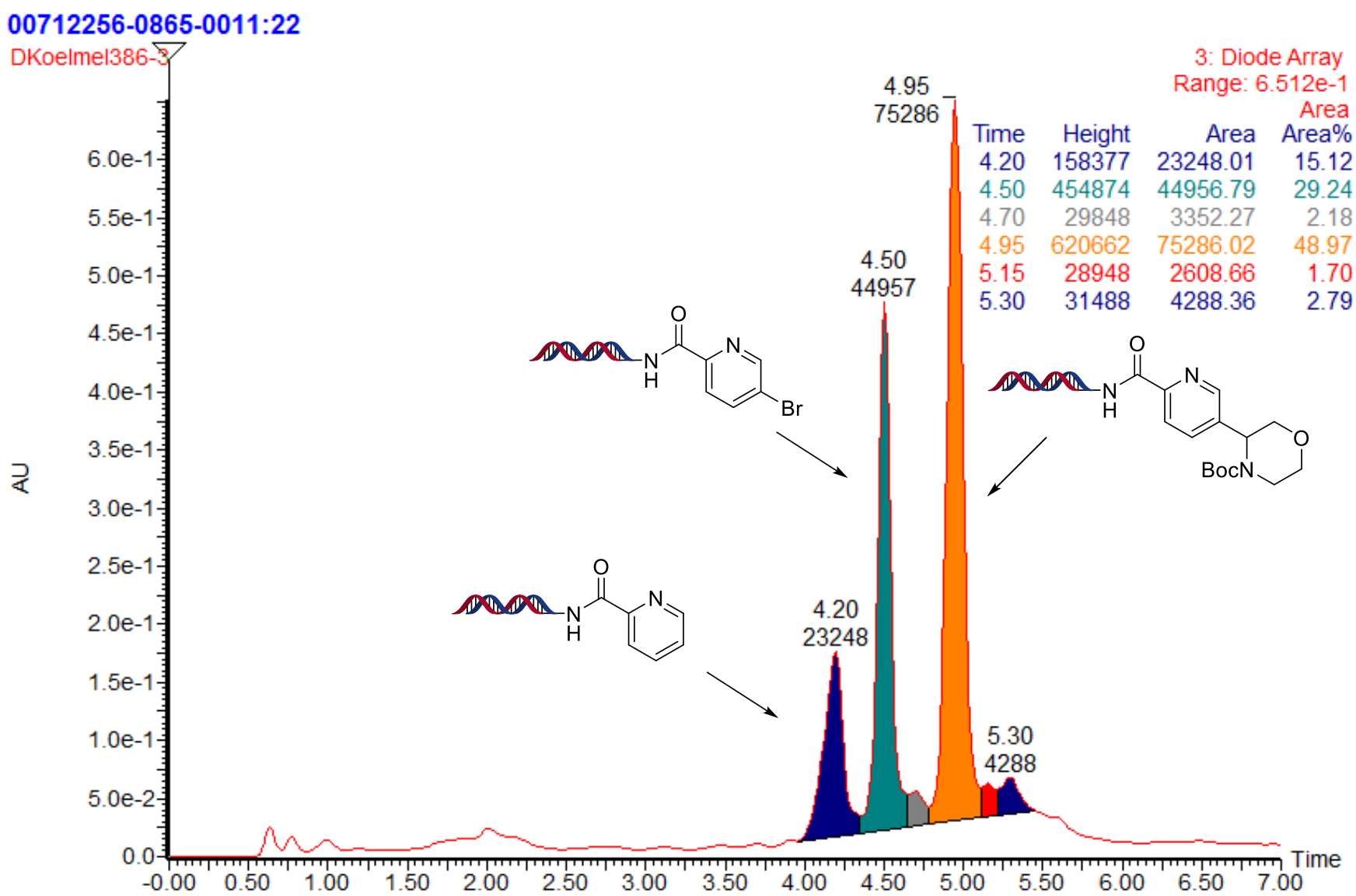

Figure S93. UPLC trace of Table 3, entry 16, after first coupling. 


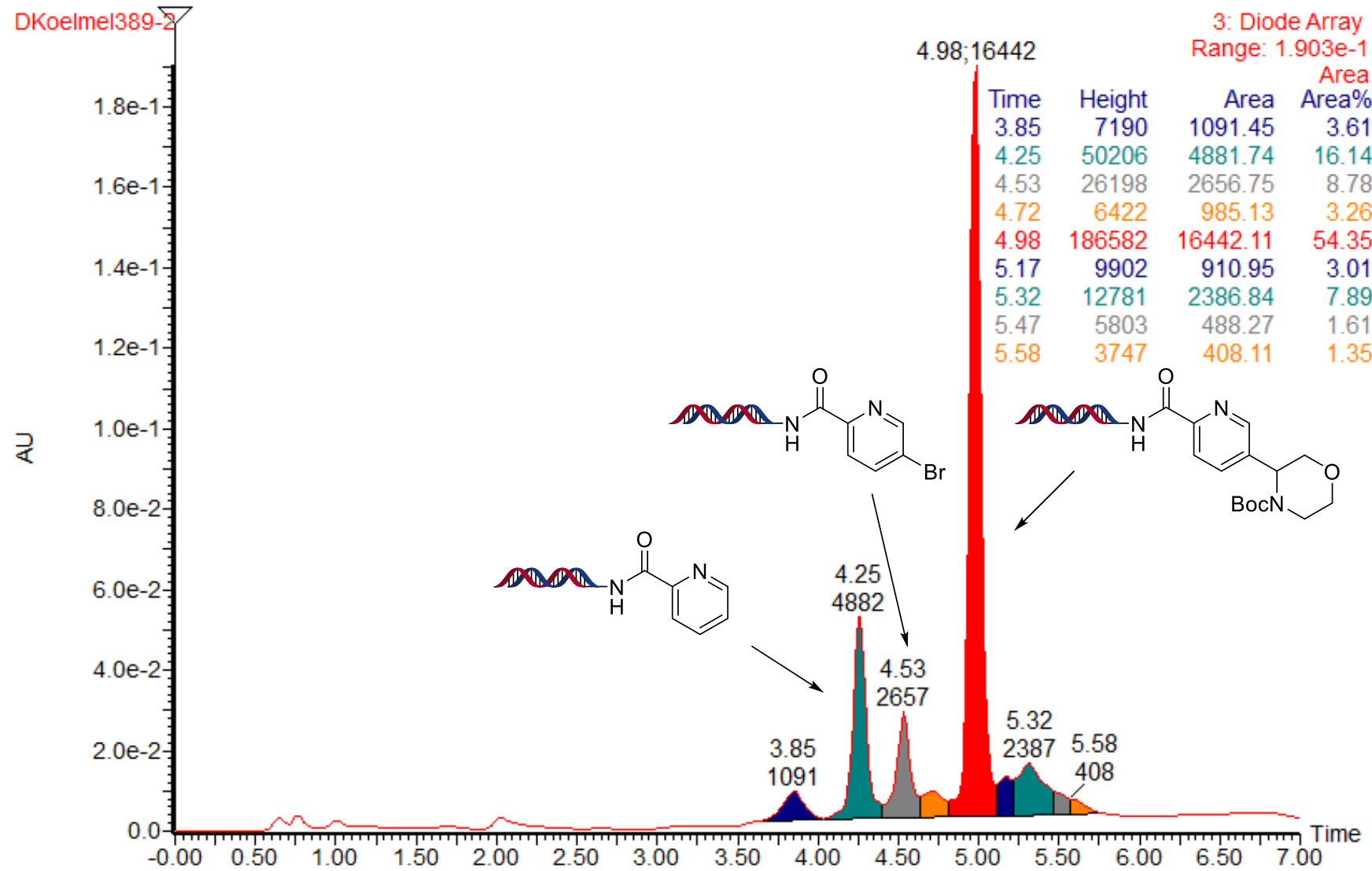

Figure S94. UPLC trace of Table 3, entry 16, after first second.

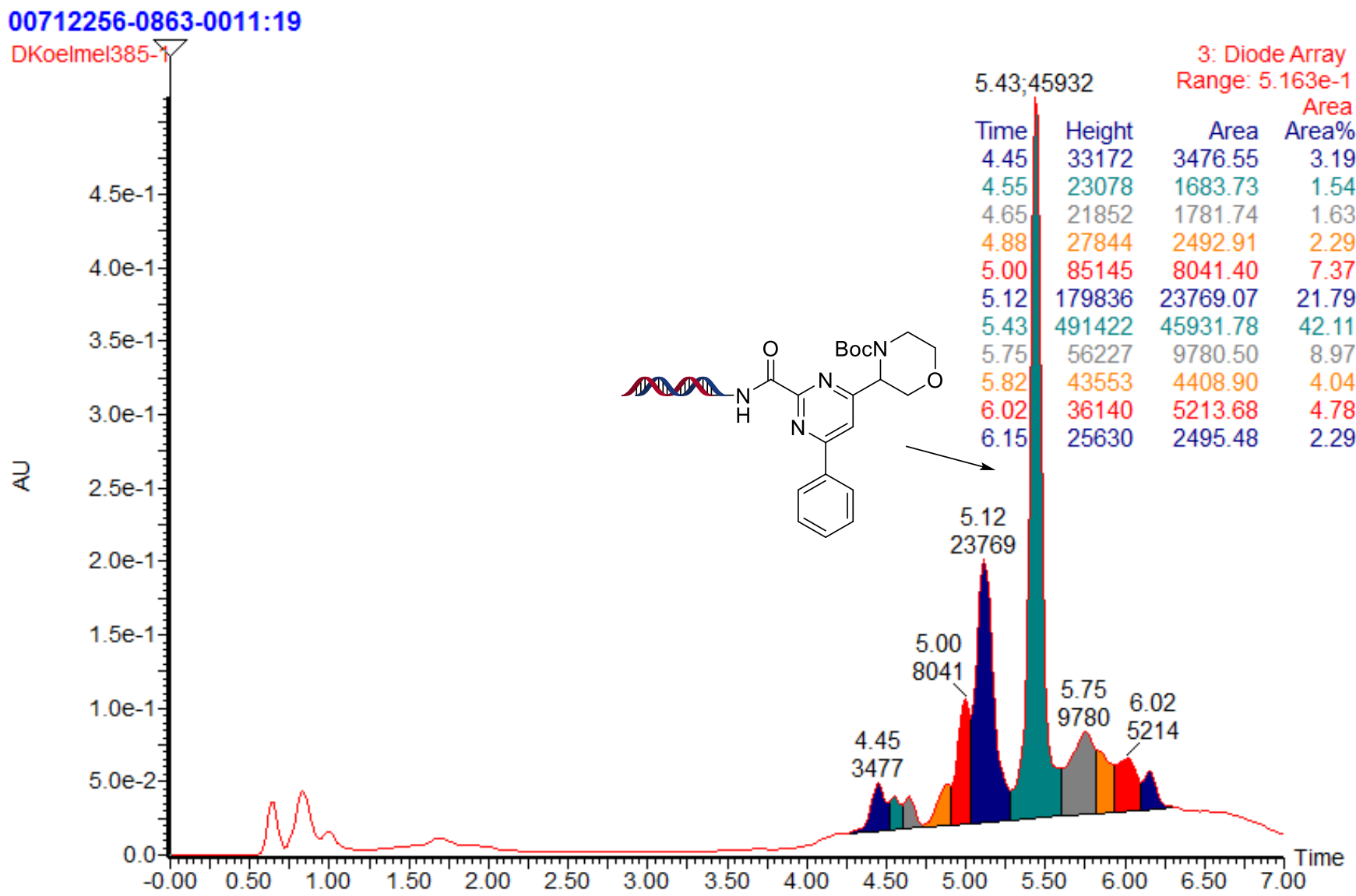

Figure S95. UPLC trace of Table 3, entry 17. 


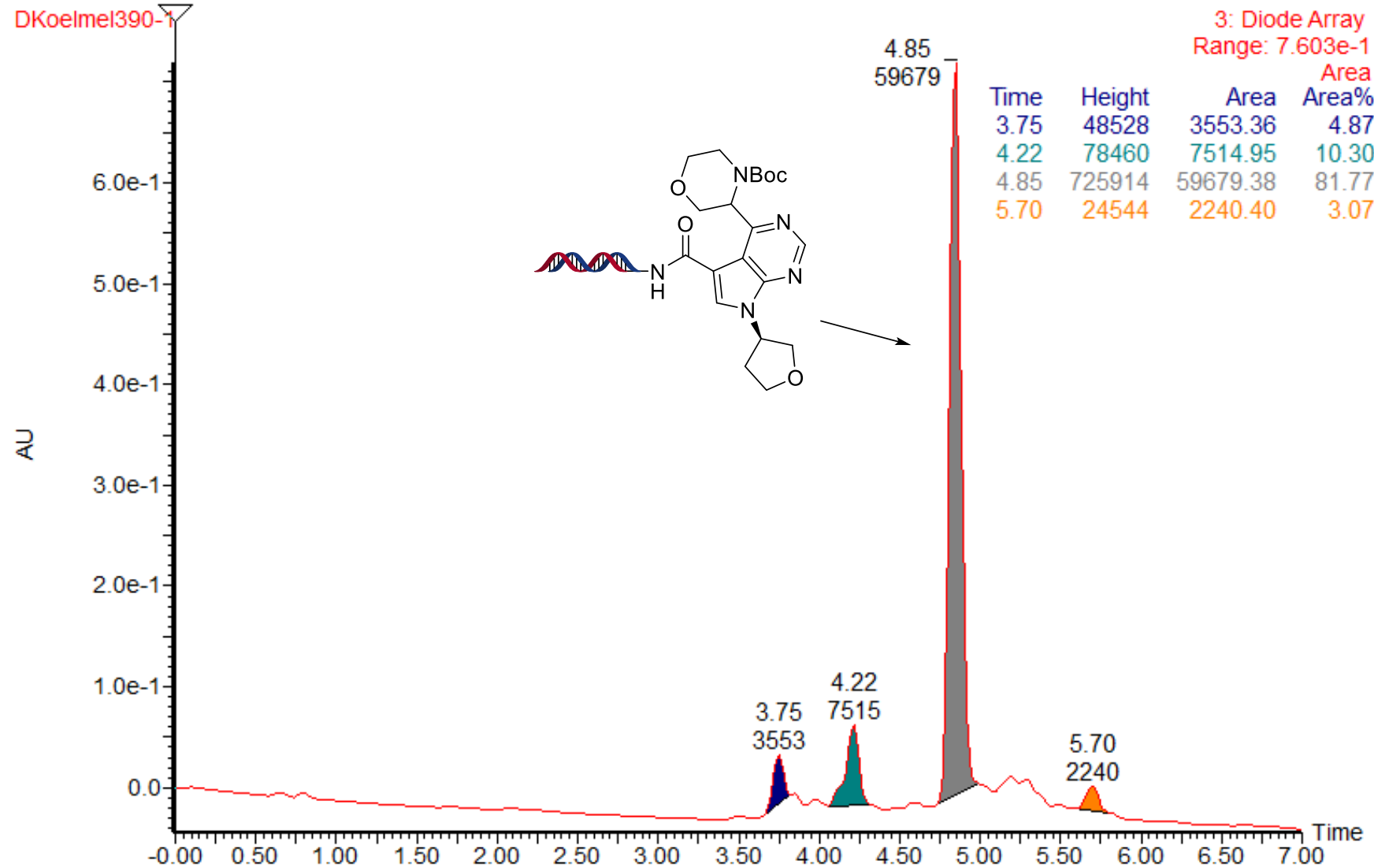

Figure S96. UPLC trace of Table 3, entry 18.

00712256-0896-001-C3-Repeat1:23

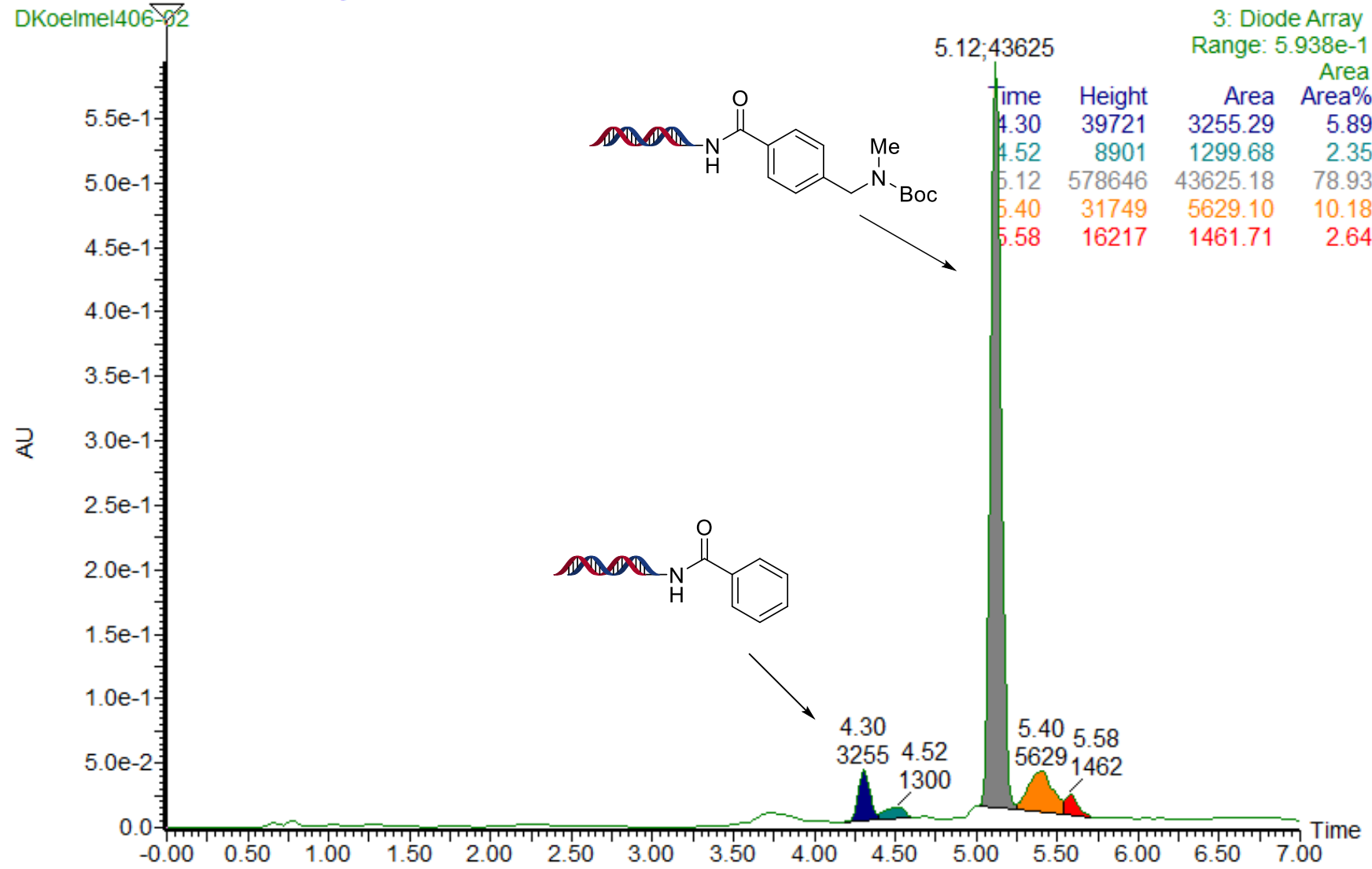

Figure S97. UPLC trace of Table S1, entry 1 (96-well plate). 


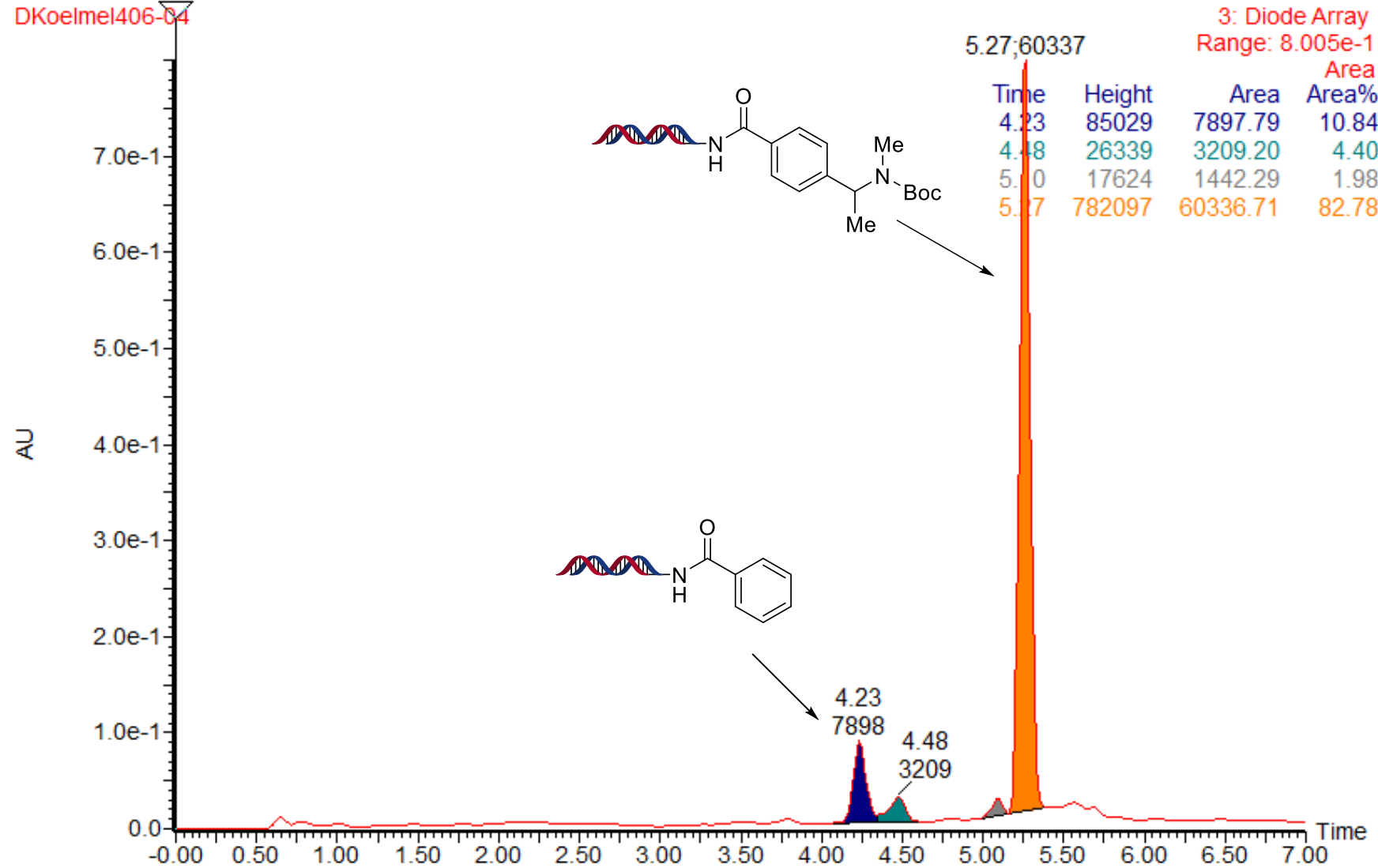

Figure S98. UPLC trace of Table S1, entry 2 (96-well plate).

00712256-0896-001-C101:26

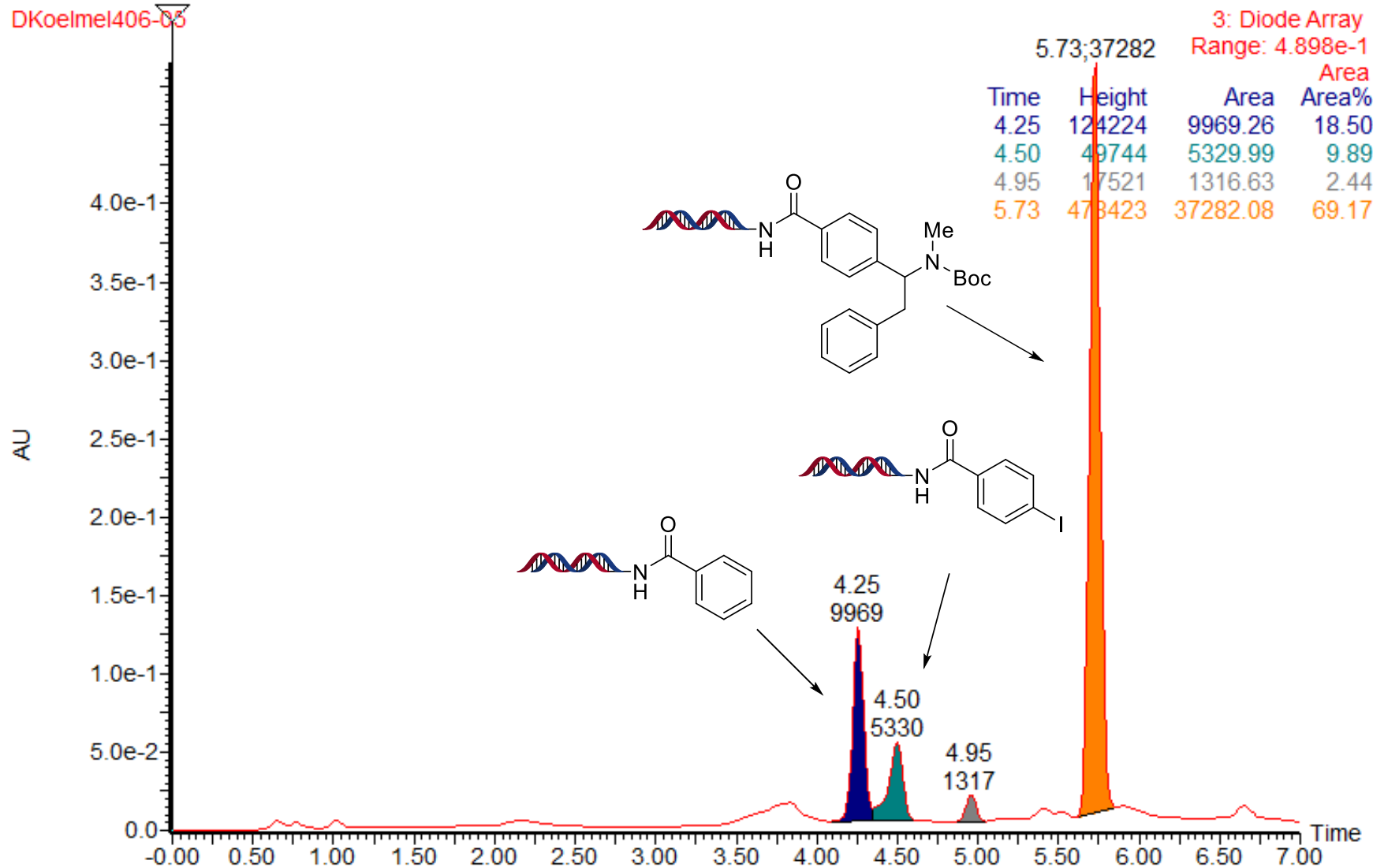

Figure S99. UPLC trace of Table S1, entry 3 (96-well plate). 


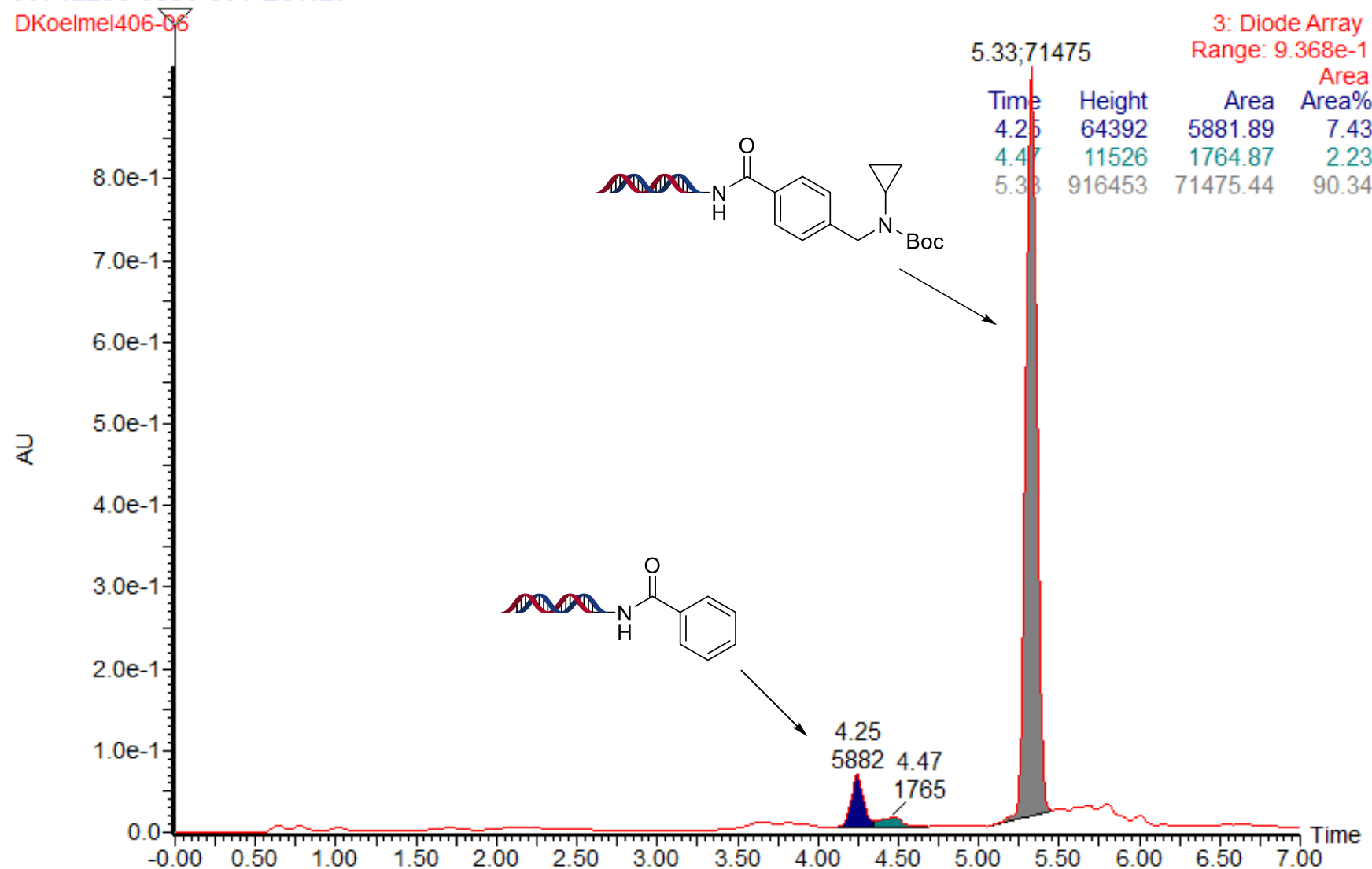

Figure S100. UPLC trace of Table S1, entry 4 (96-well plate).

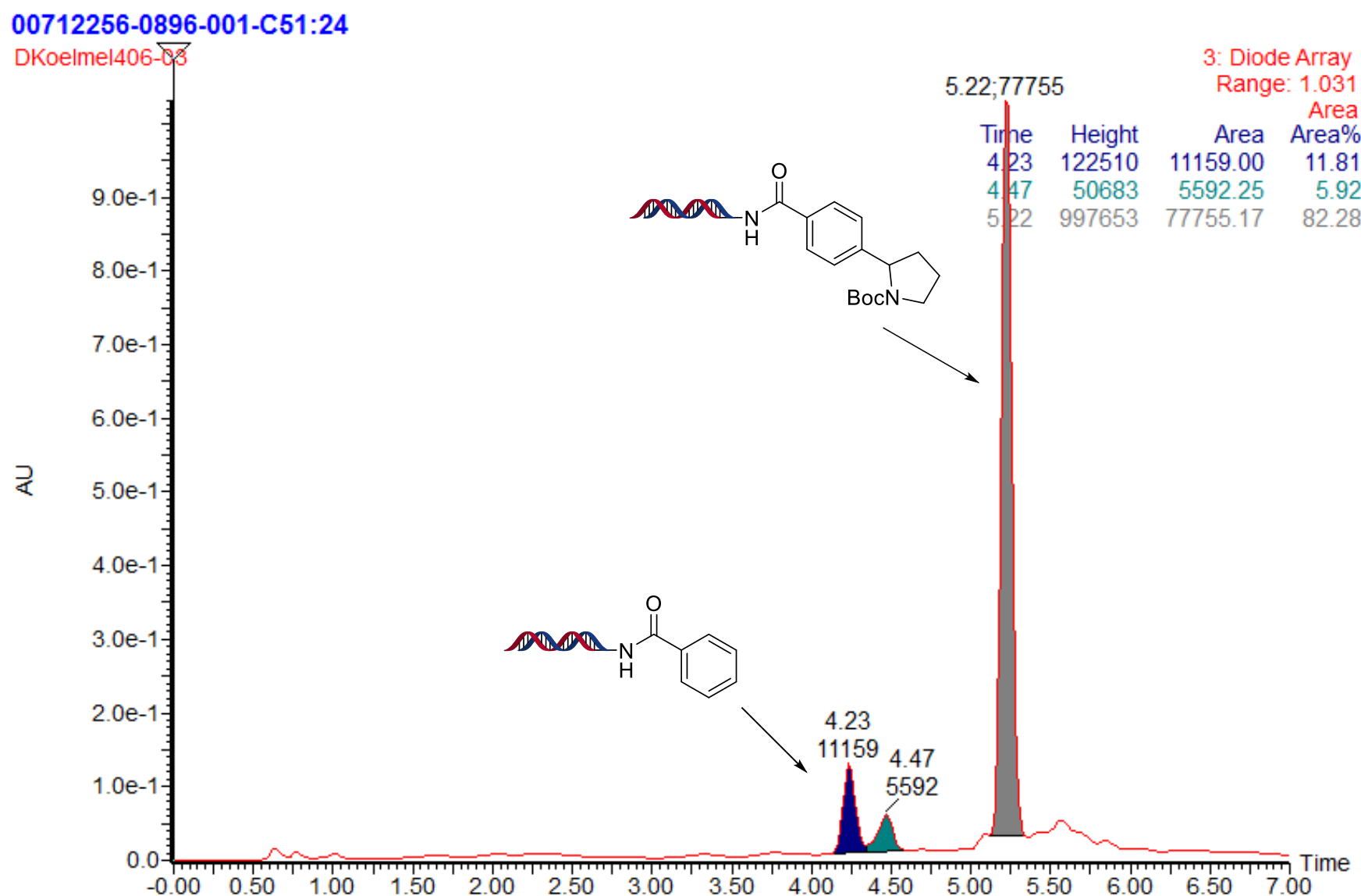

Figure S101. UPLC trace of Table S1, entry 5 (96-well plate). 


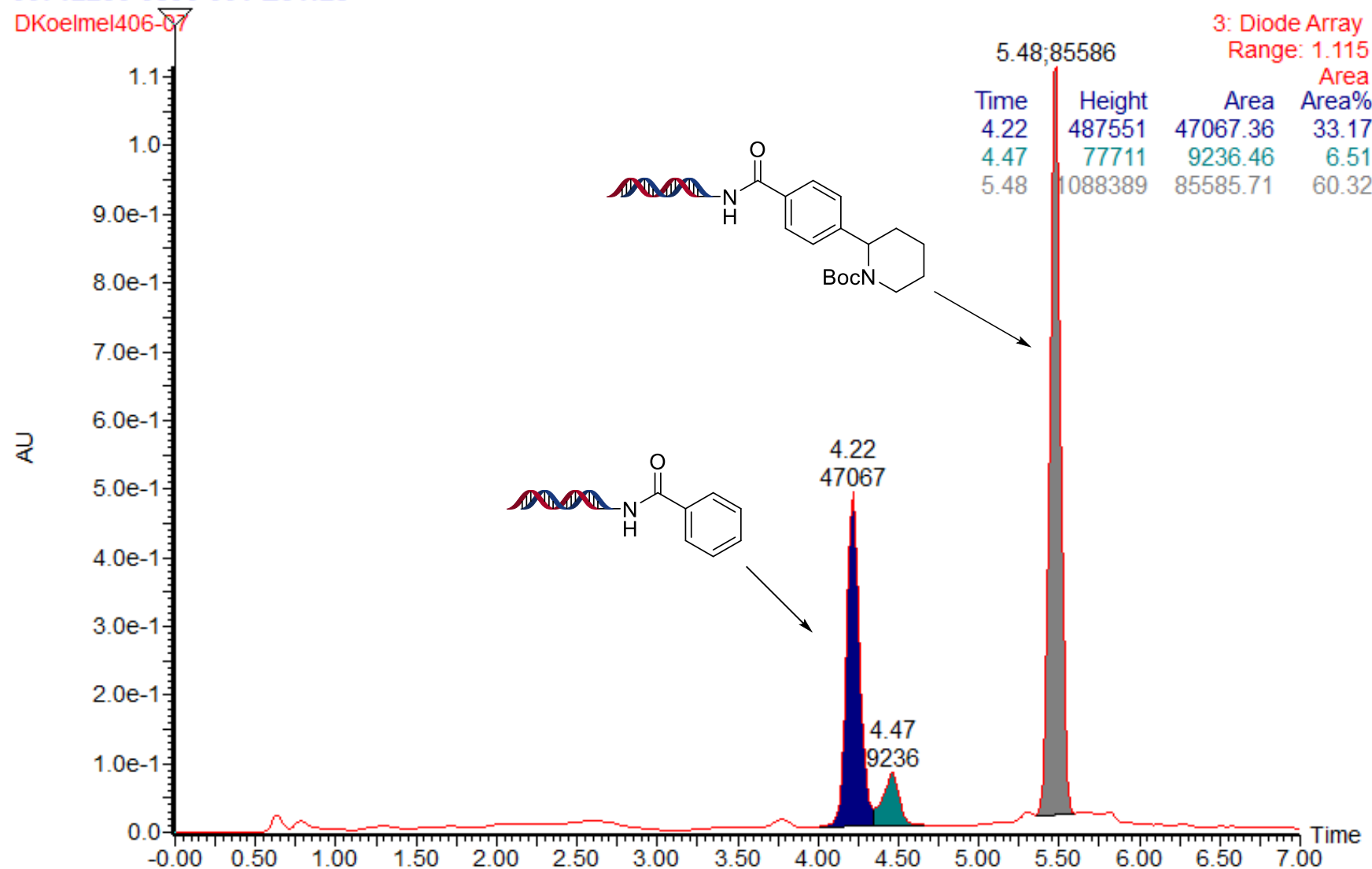

Figure S102. UPLC trace of Table S1, entry 6 (96-well plate).

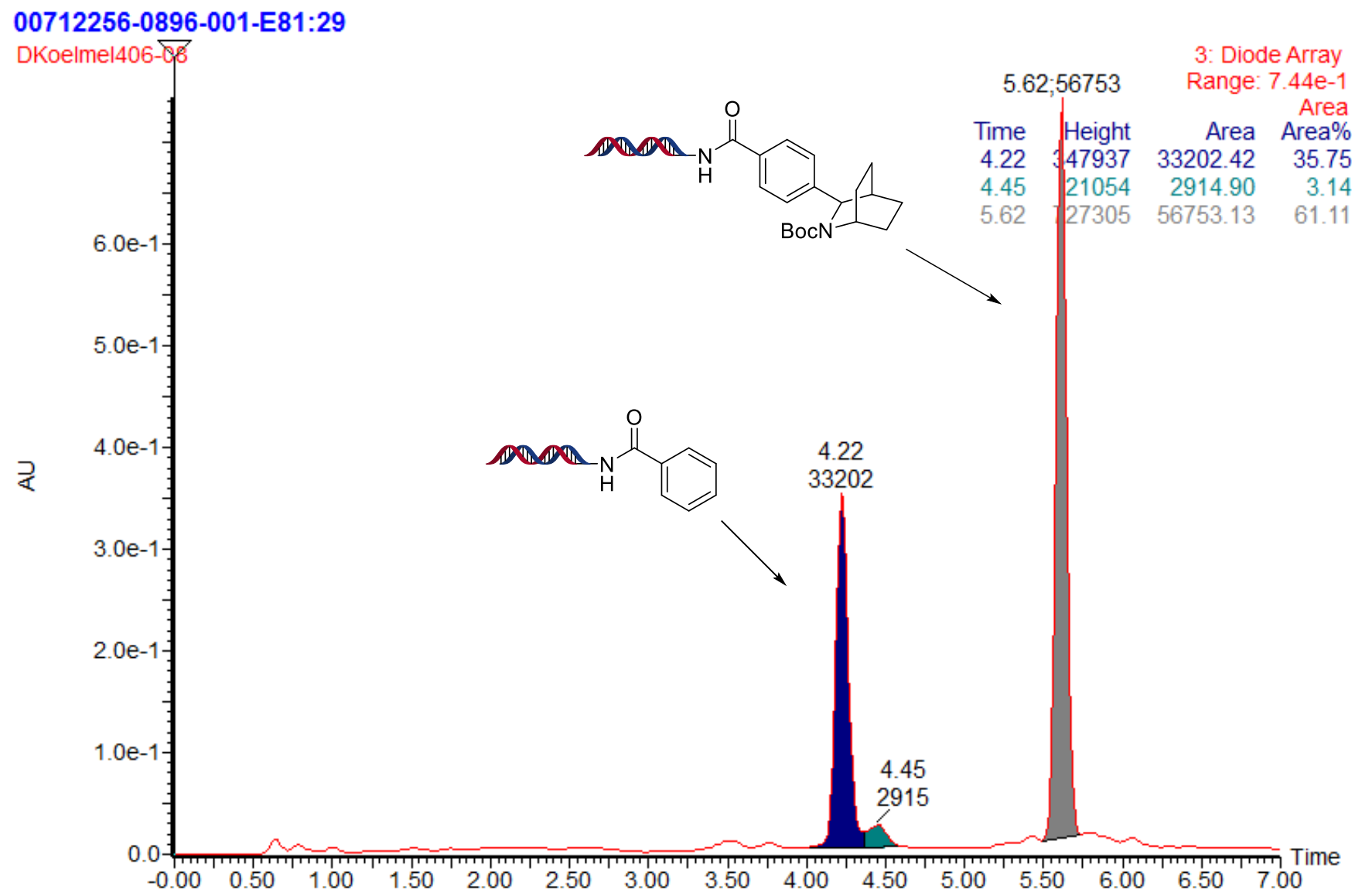

Figure S103. UPLC trace of Table S1, entry 7 (96-well plate). 


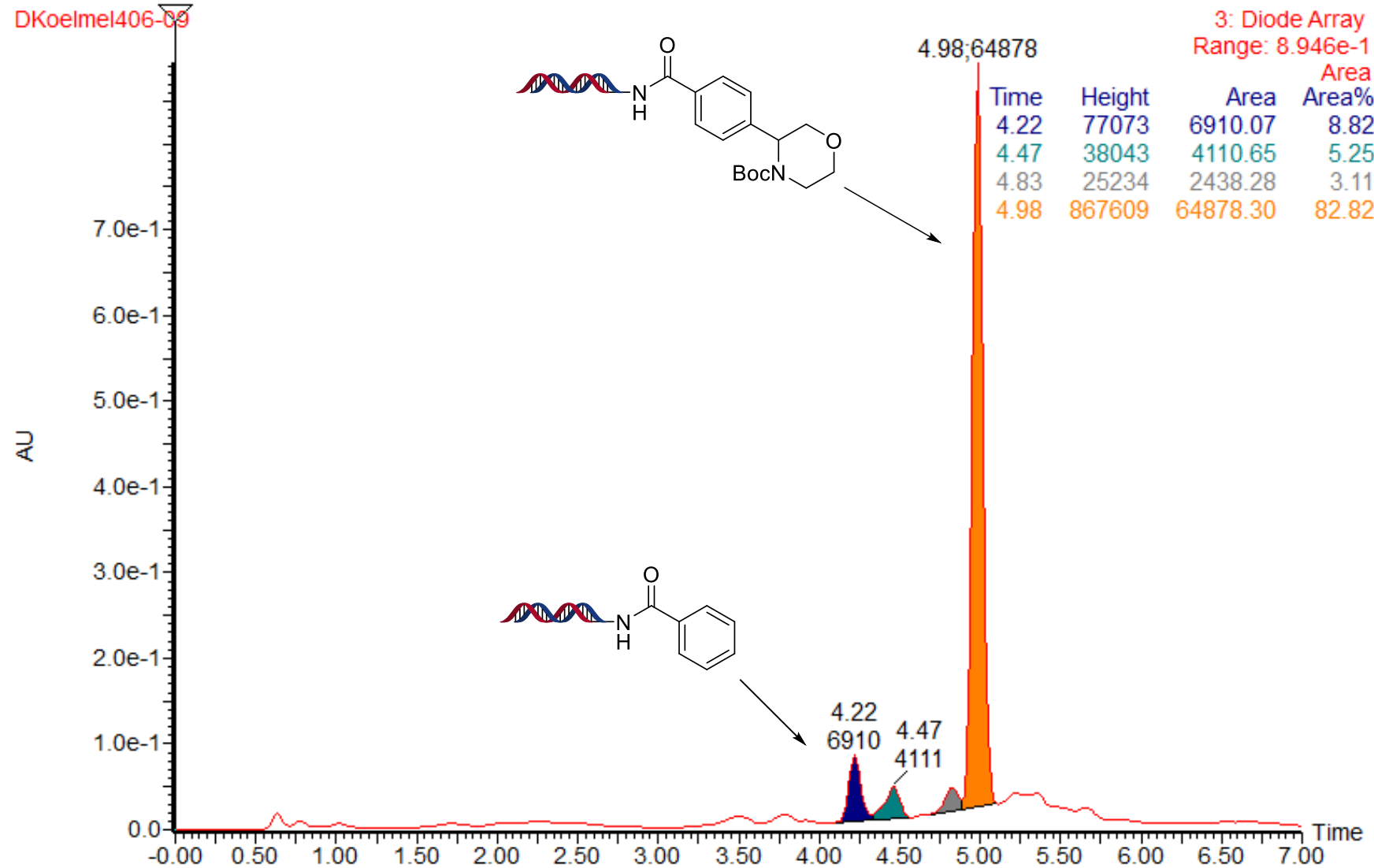

Figure S104. UPLC trace of Table S1, entry 8 (96-well plate).

00712256-0896-001-G51:32

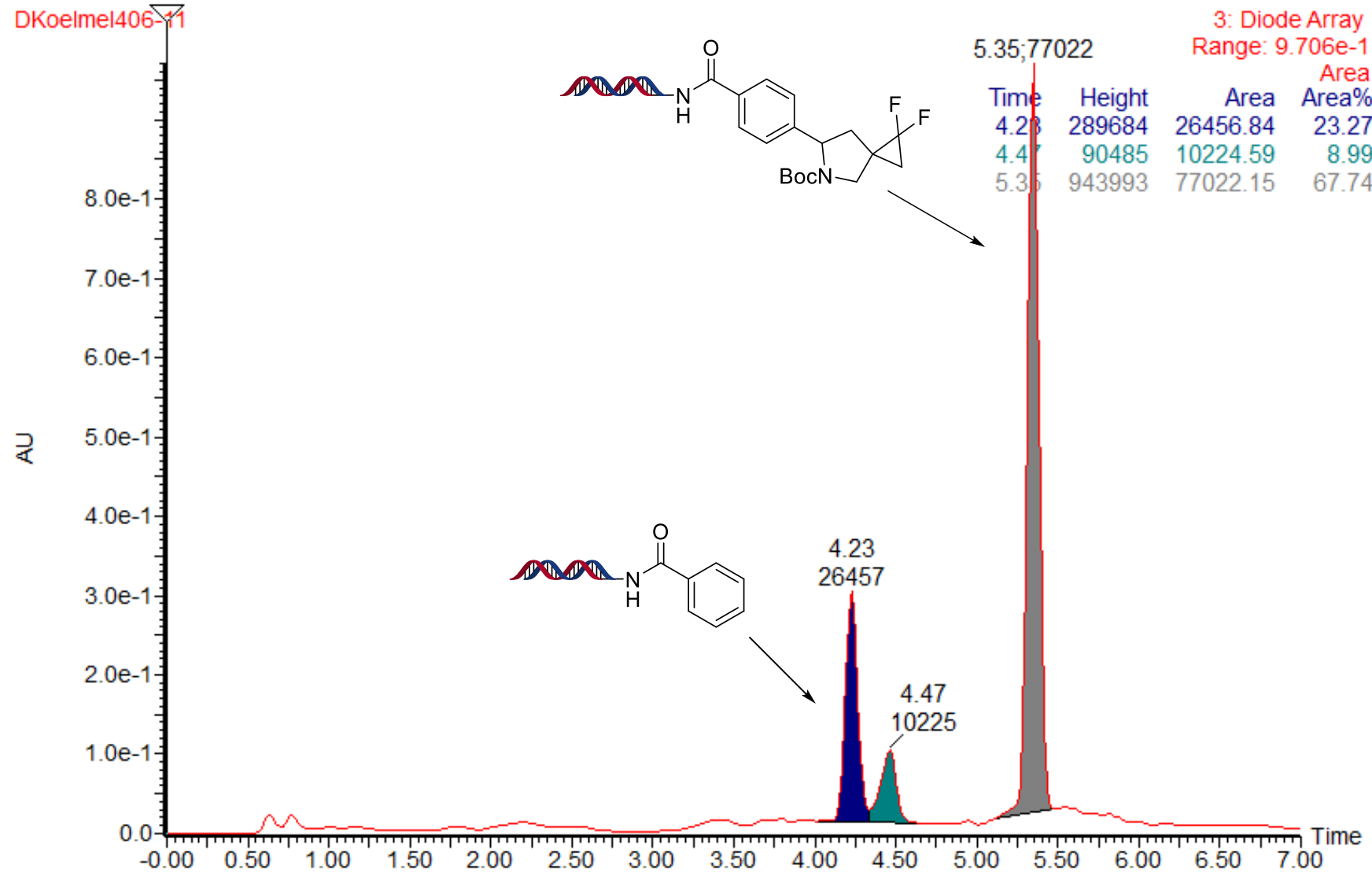

Figure S105. UPLC trace of Table S1, entry 9 (96-well plate). 


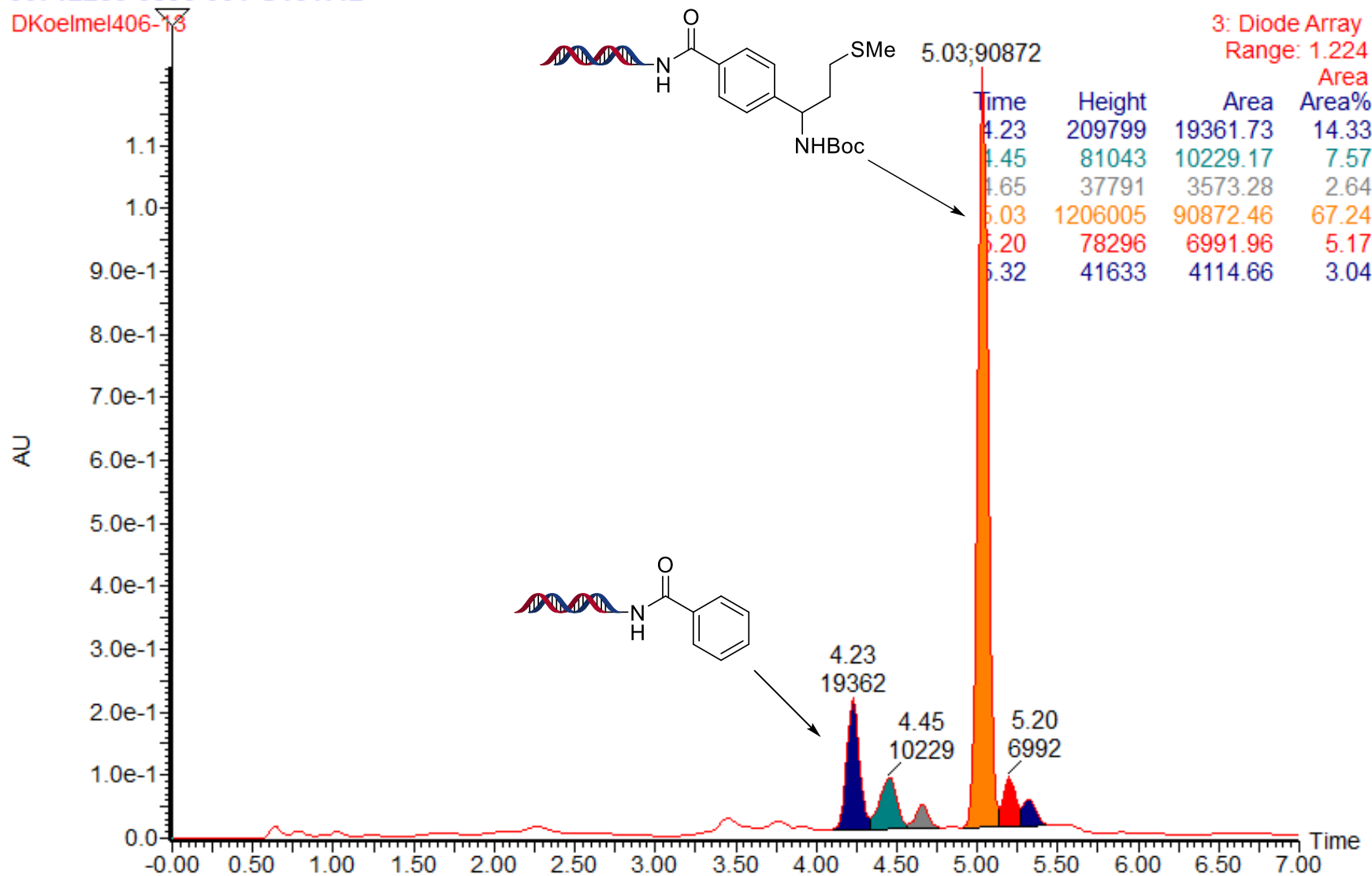

Figure S106. UPLC trace of Table S1, entry 10 (96-well plate).

1:900712256-0655-001

DKoelmel261-1 sm $(\mathrm{Mn}, 1 \mathrm{x} 1)$

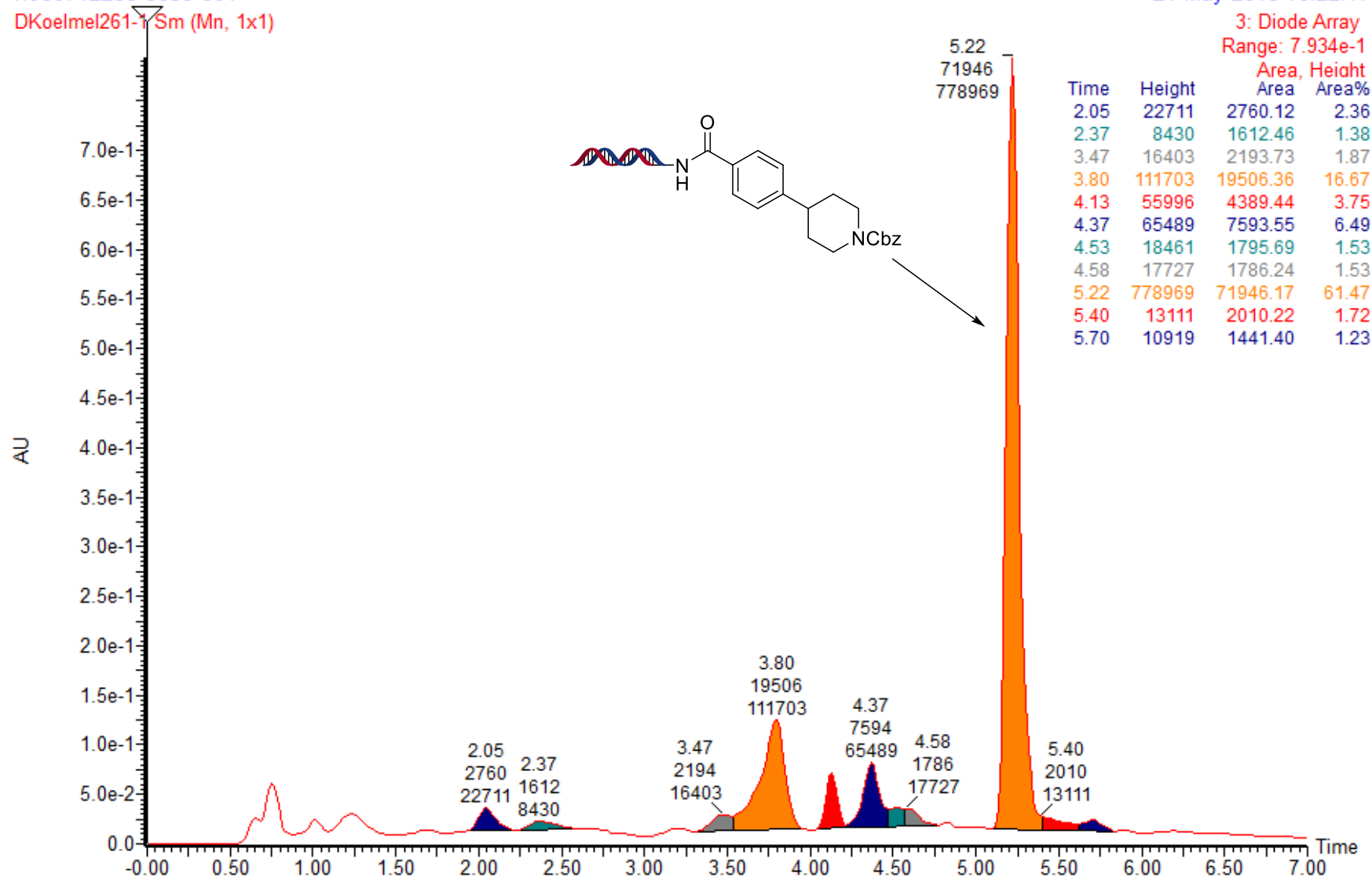

Figure S107. UPLC trace of compound 26. 


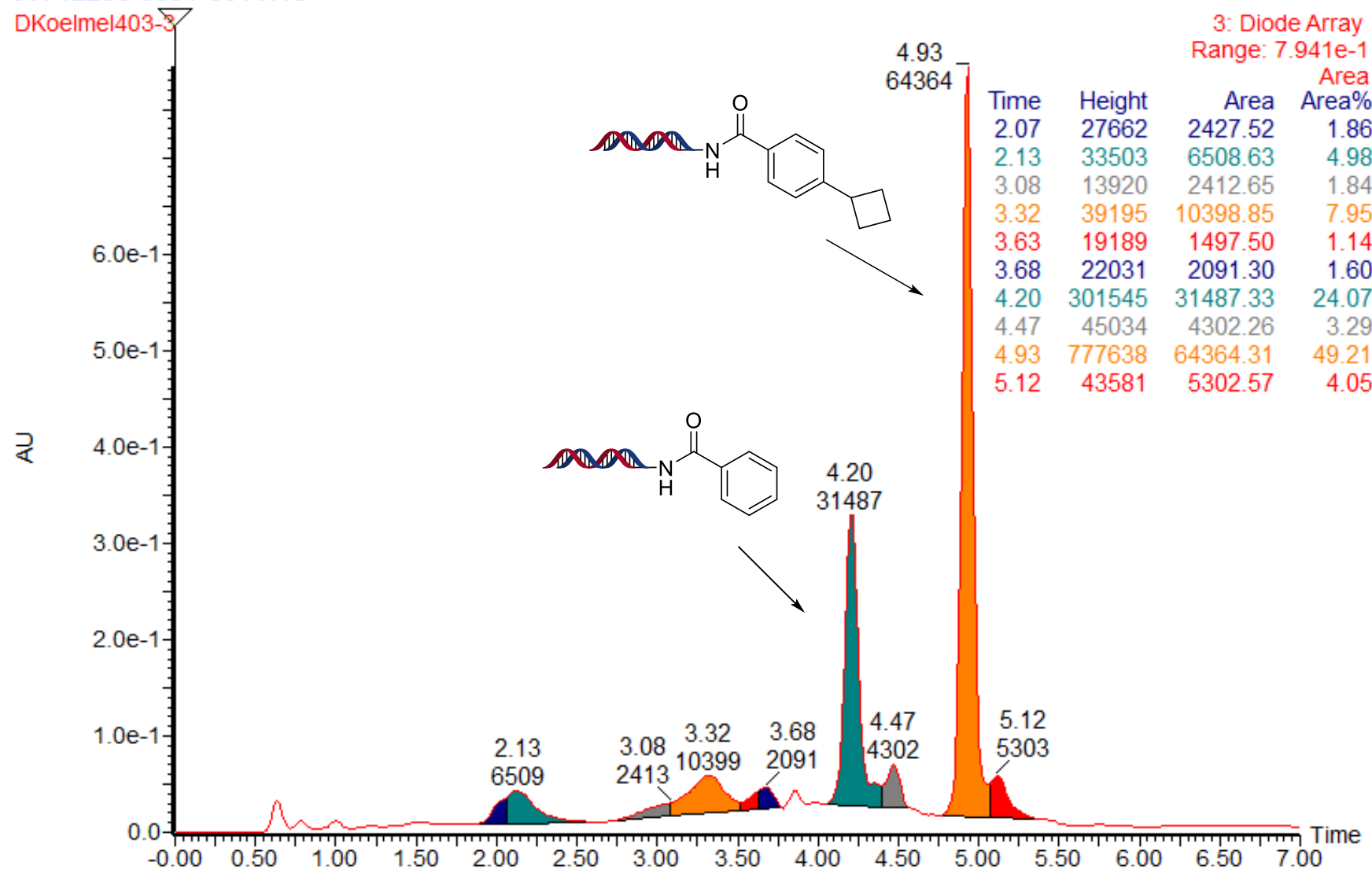

Figure S108. UPLC trace of compound 27.

00712256-0893-0011:20

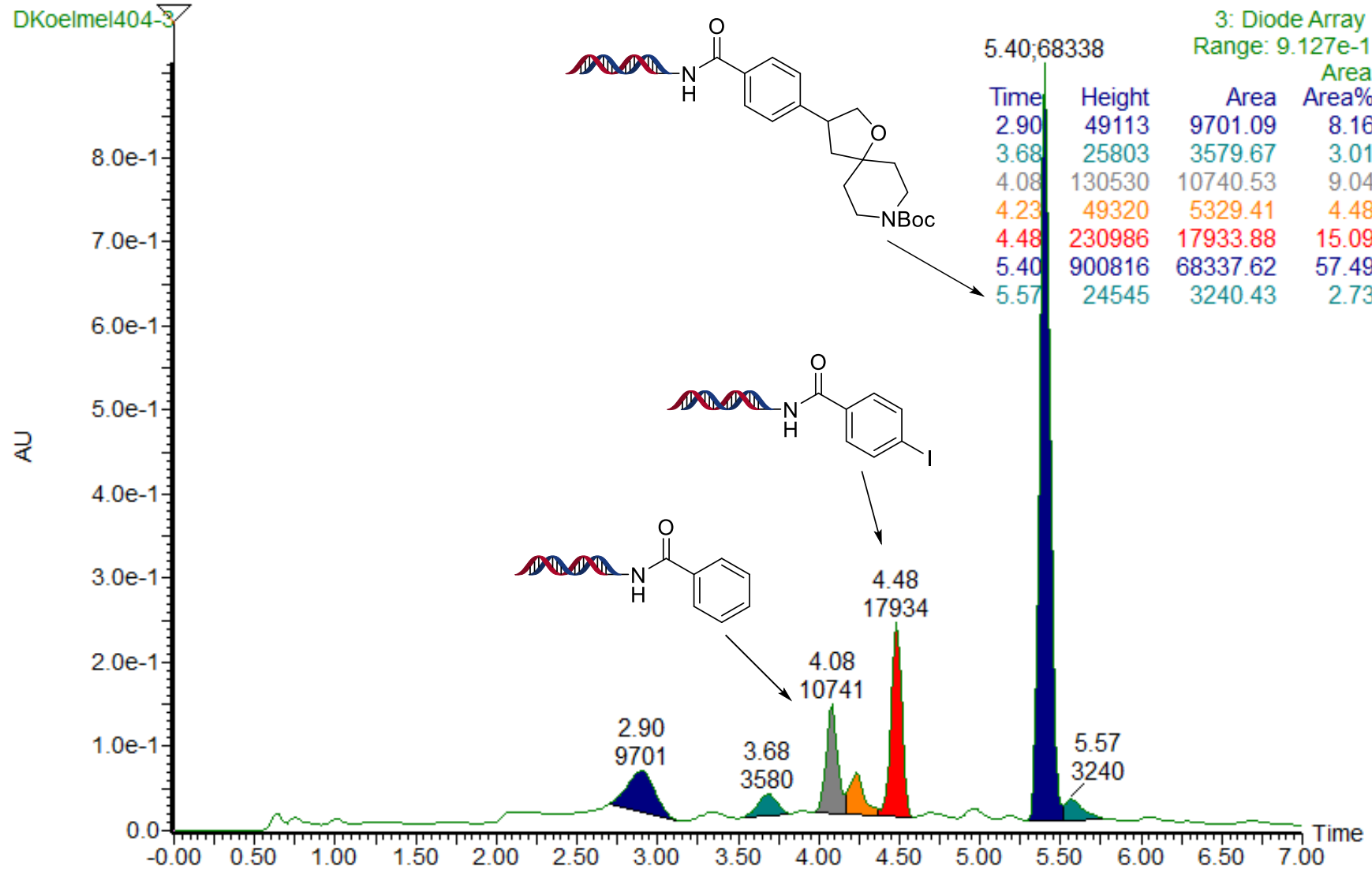

Figure S109. UPLC trace of compound 28. 
00712256-1194-001-21:7

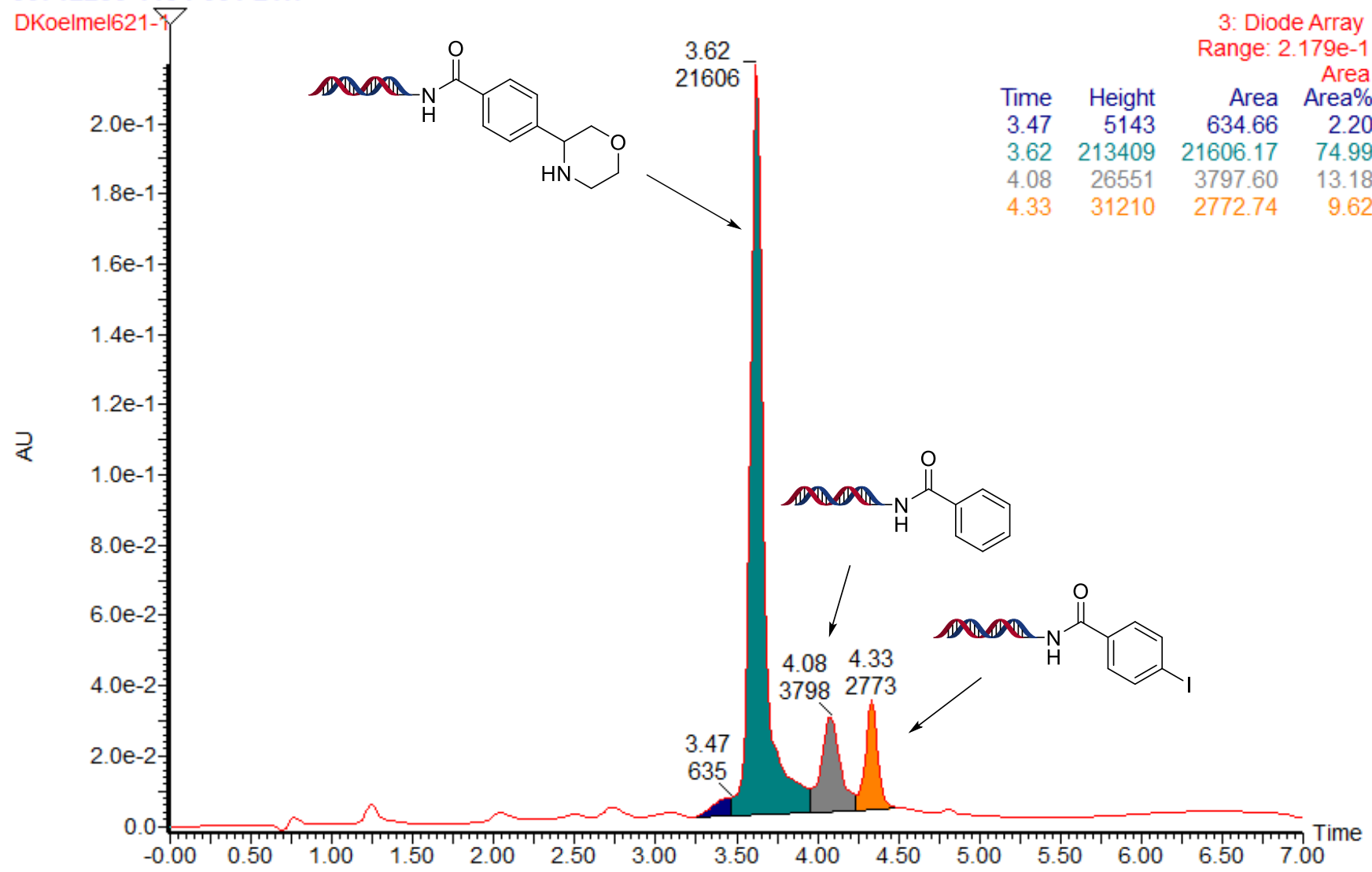

Figure S110. UPLC trace of compound $\mathbf{S 2 2}$. 


\section{4) Mass Spectra}

\section{6-0894-0011:21}

DKoelmel405-1 669 (4.737)

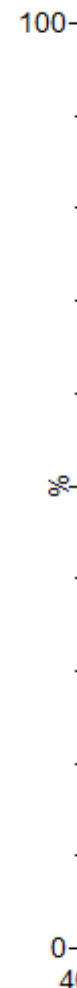

100

60.12

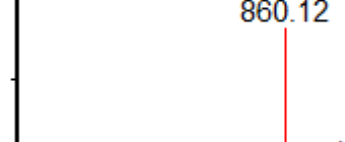

032.33

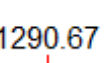

1290.42

1032.53

1290.92

1721.22

1721.54

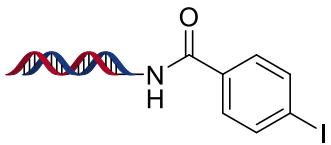

1: TOF MS ES-

$6.60 \mathrm{e} 6$

Figure S111. Mass spectrum of aryl iodide 12

00712256-0358-001-Piperidine00712256-0358-001-Piperidine DKoelmel155-1 610 (4.329)<smiles>O=C(Nc1ccccc1)c1ccc(Br)cc1</smiles>

20-Mar-2018 19:35:55 1: TOF MS ES$1.99 \mathrm{e} 6$ 


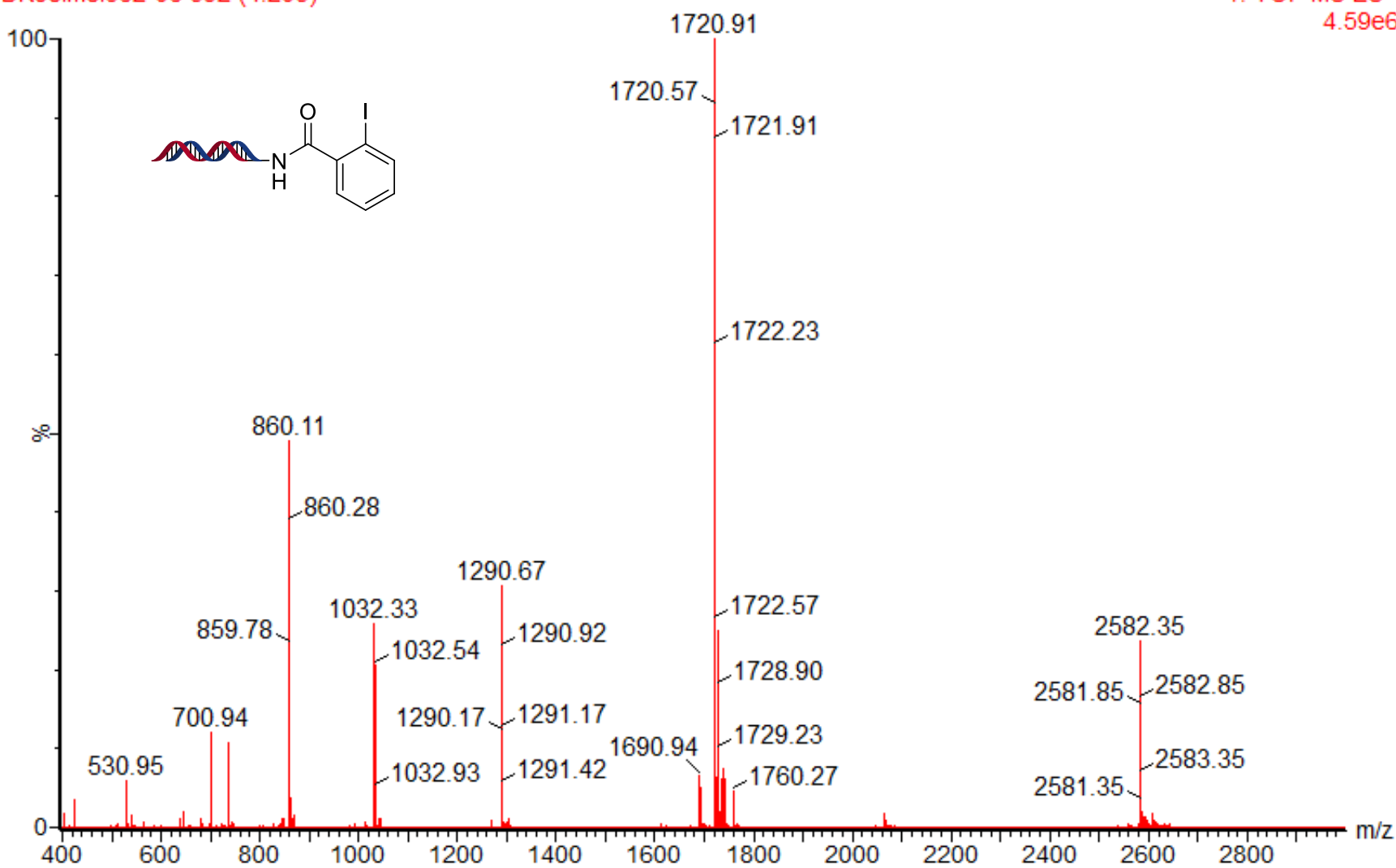

Figure S113. Mass spectrum of aryl iodide S1.

\section{6-0812-0011:36}

DKoelmel370-5 617 (4.378)

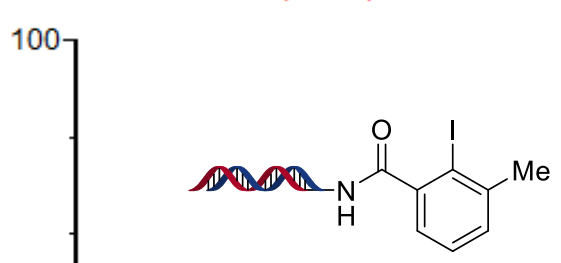

1: TOF MS ES-

$4.14 \mathrm{e} 6$

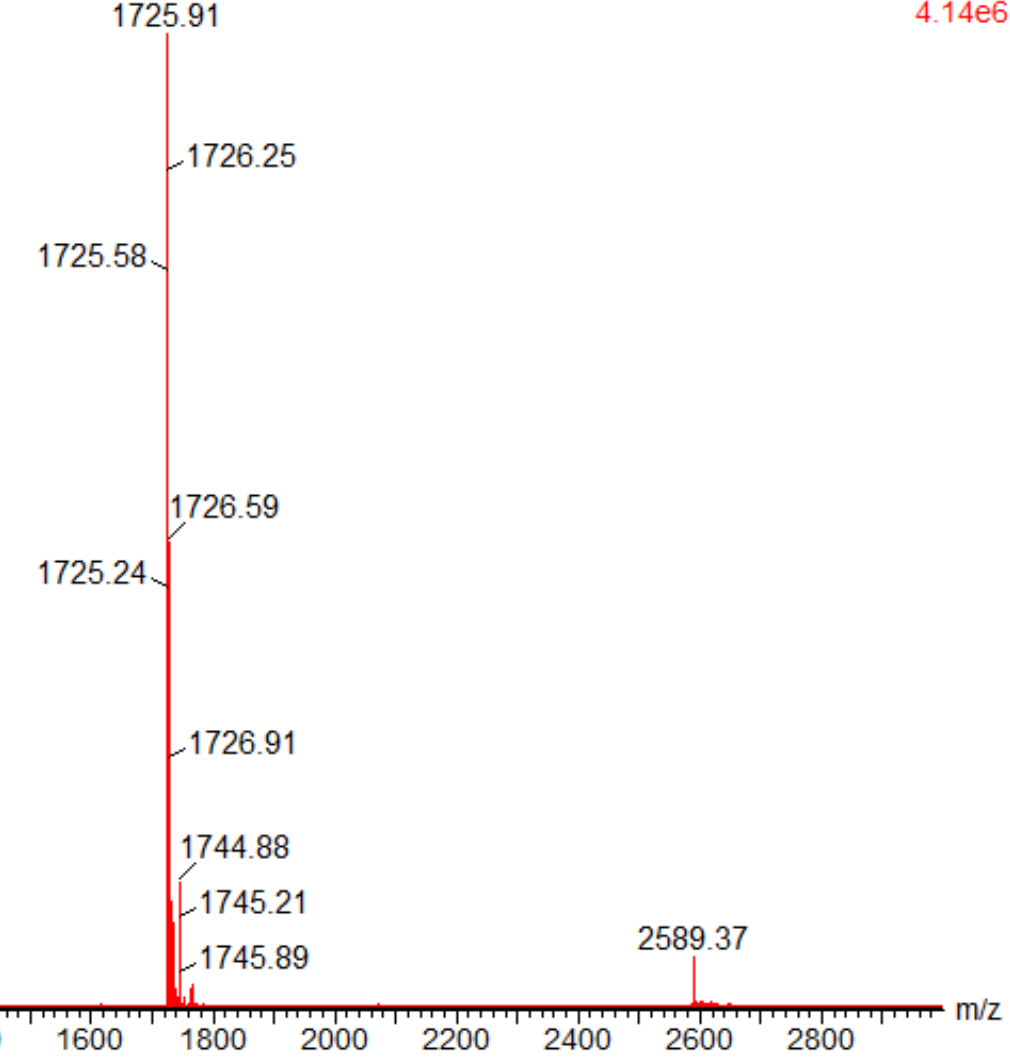

Figure S114. Mass spectrum of aryl iodide S2. 


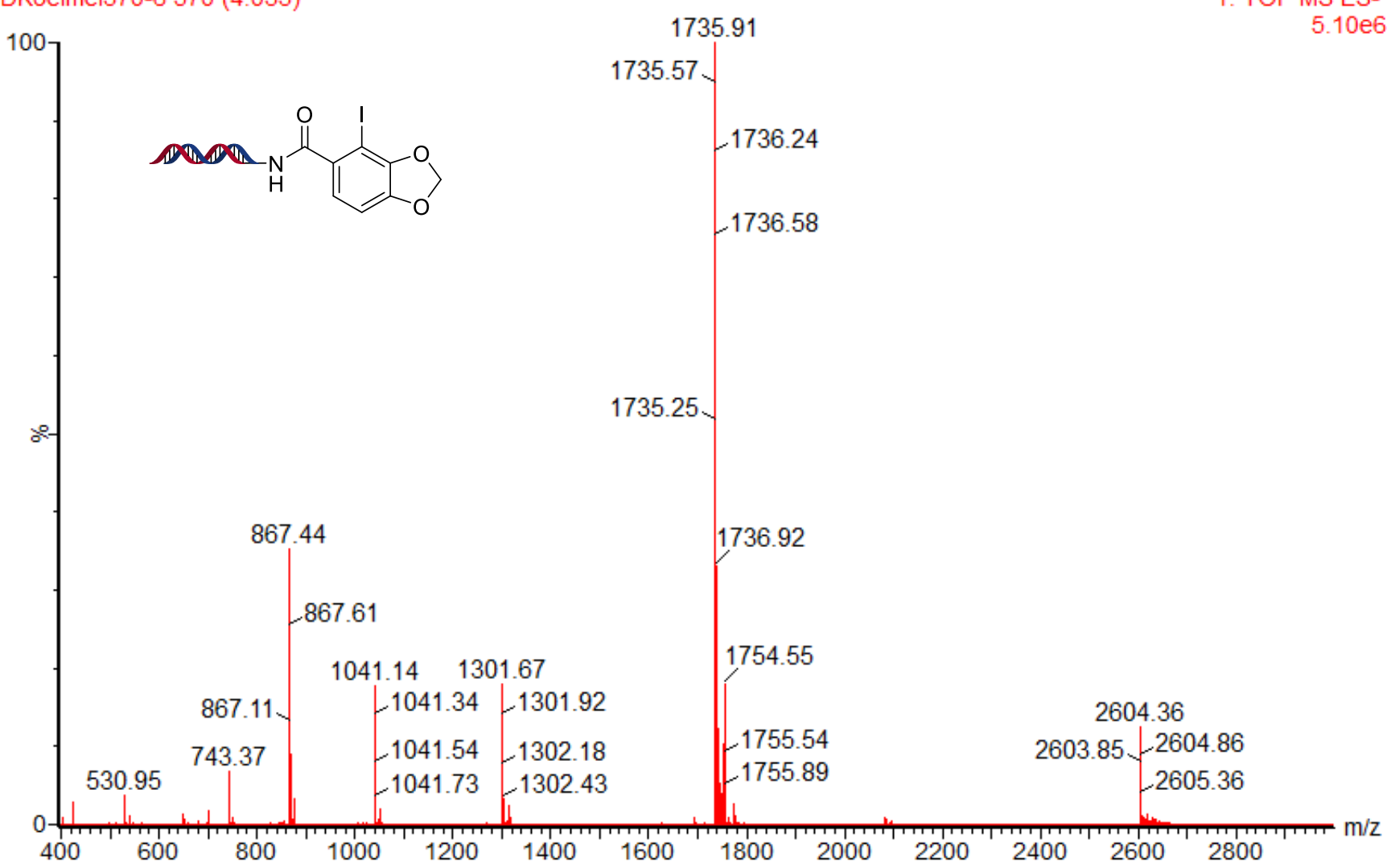

Figure S115. Mass spectrum of aryl iodide S3.

\section{6-0807-0011:6}

DKoelmel362-07 618 (4.384)

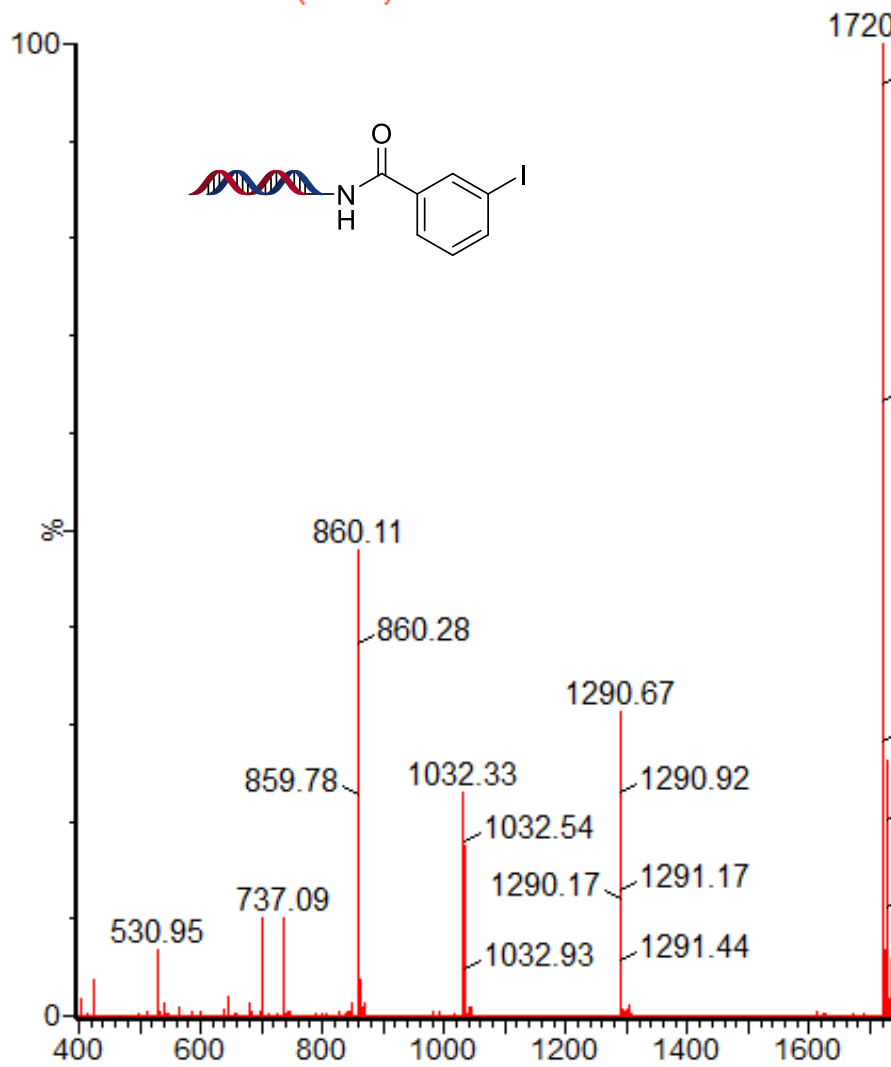

1: TOF MS ES$4.33 \mathrm{e} 6$

Figure S116. Mass spectrum of aryl iodide S4. 


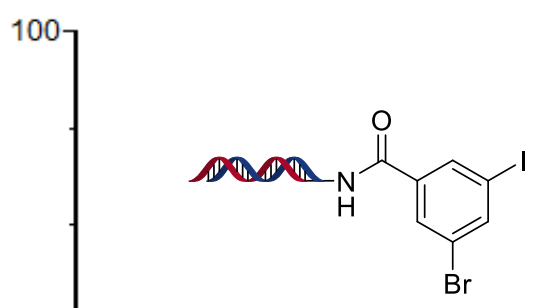

\subsection{7}

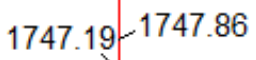

1746.54
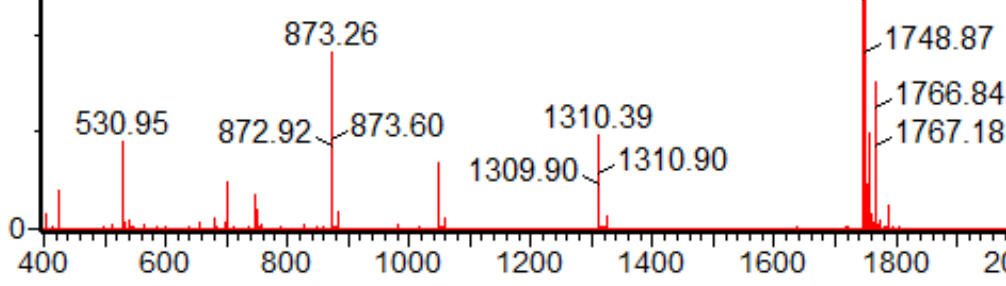

Figure S117. Mass spectrum of aryl iodide S5.

\section{6-0873-0011:36}

DKoelmel394-4 647 (4.585)

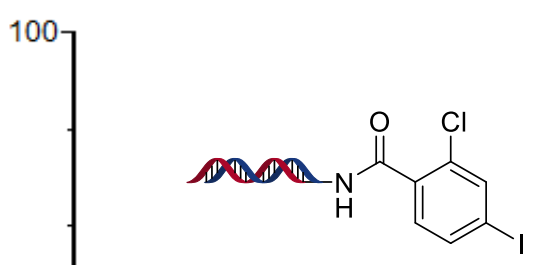

65.78

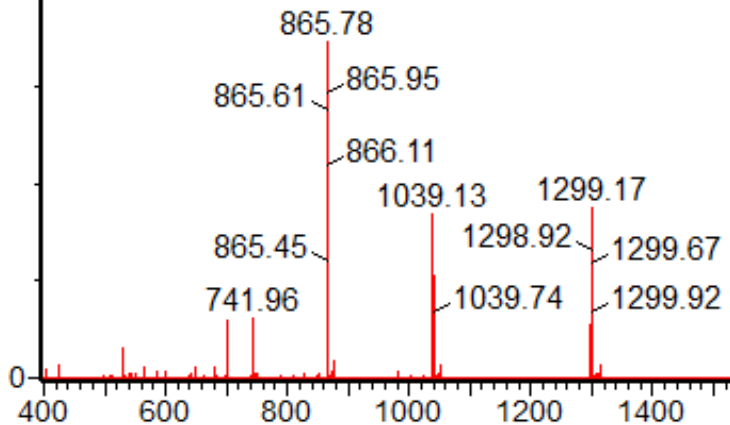

1732.57

1: TOF MS ES-

$4.56 \mathrm{e} 6$

1732.92

1733.24

1732.23

1733.56

1731.91

1733.90

1739.90

$-1752.20$
2599.86 2598.86 


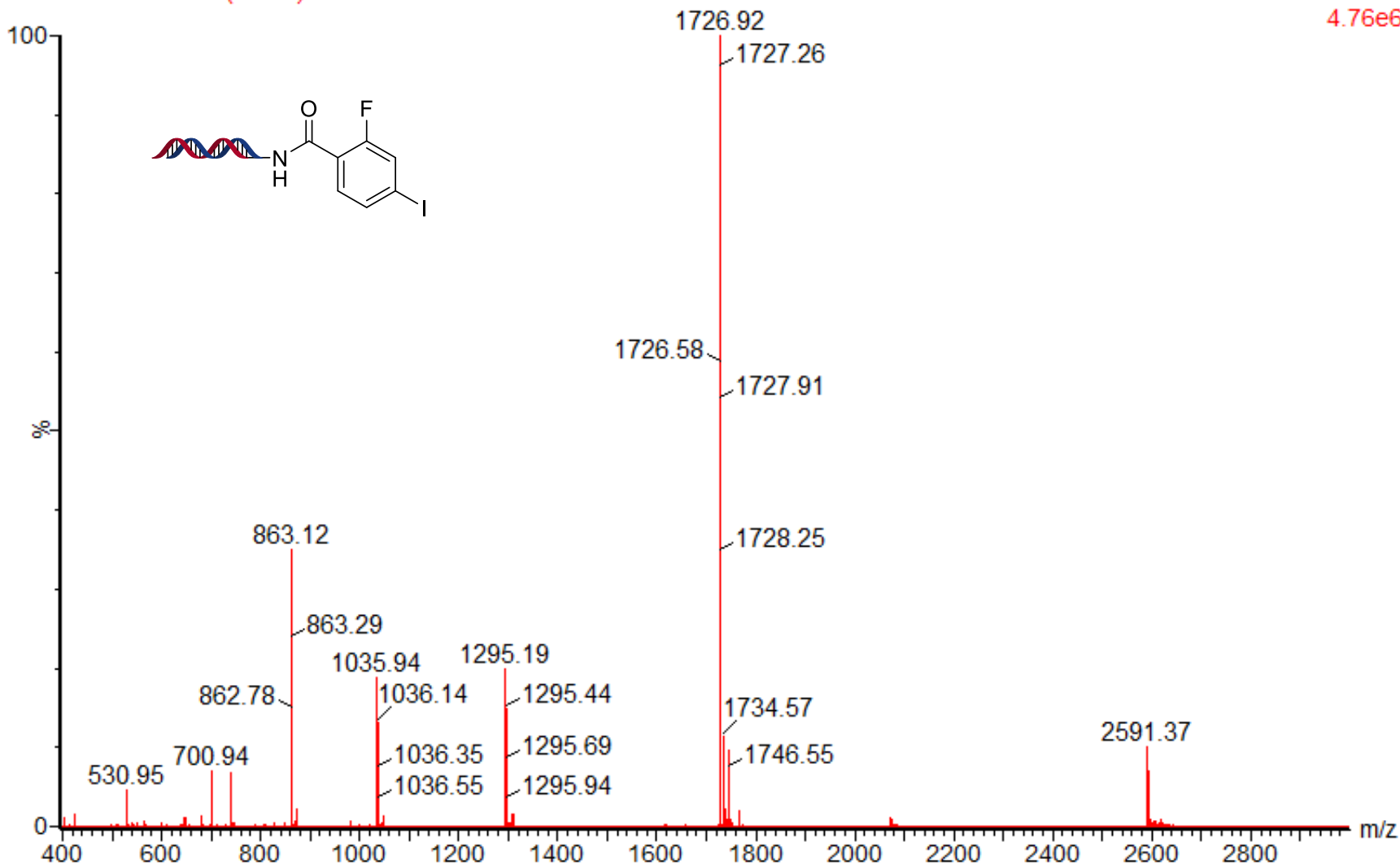

Figure S119. Mass spectrum of aryl iodide S7.

\section{6-0871-0011:34}

DKoelmel394-2 676 (4.785)

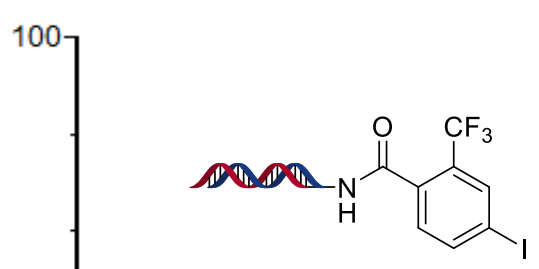

530.95

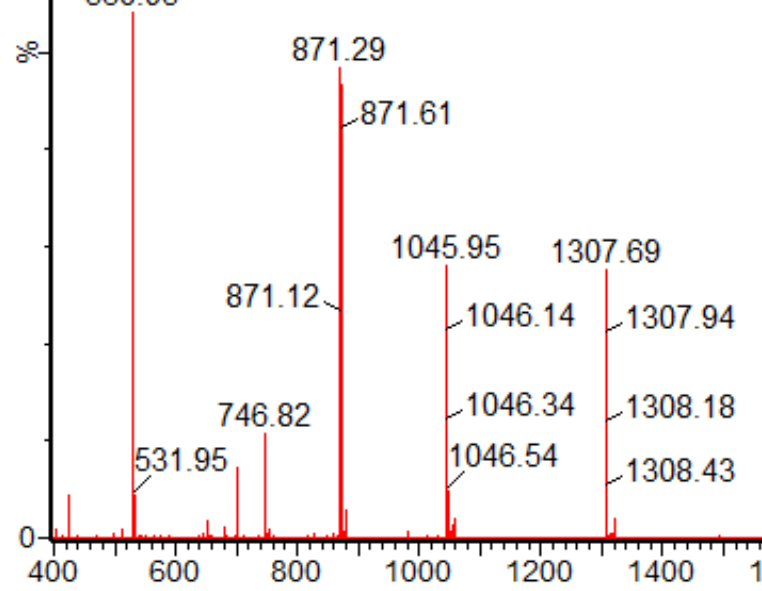

\subsection{1}

1: TOF MS ES-

4. $43 \mathrm{e} 6$

Figure S120. Mass spectrum of aryl iodide S8.

1744.26

1744.58

1743.25

1744.91
2616.36 


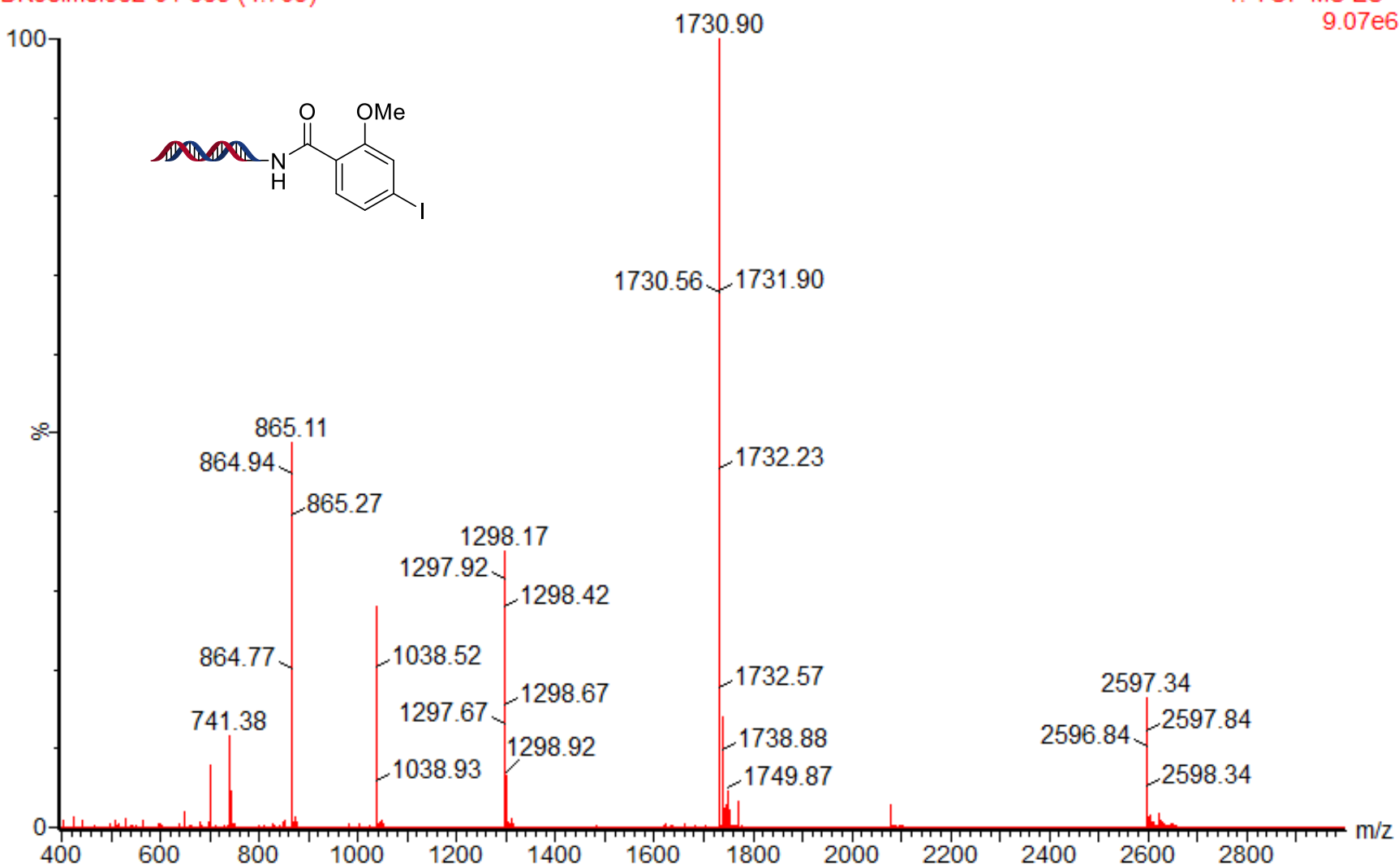

Figure S121. Mass spectrum of aryl iodide S9.

\section{6-0804-0011:30}

DKoelmel370-2 618 (4.384)

$$
100
$$<smiles>COCCOC(=O)NC(=O)Cc1ccccc1I</smiles>

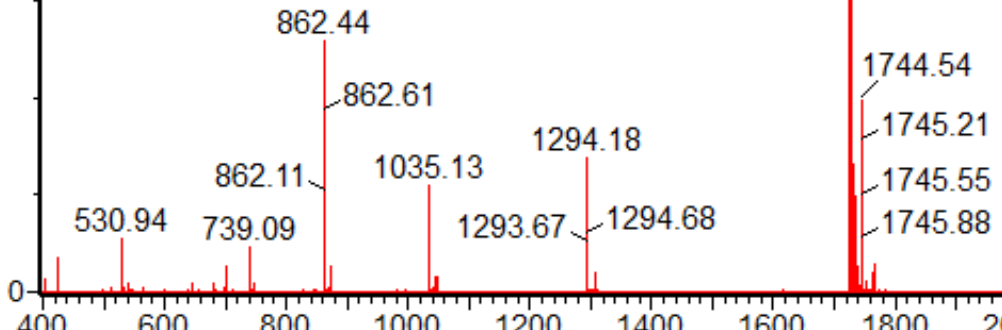

Figure S122. Mass spectrum of aryl iodide S10.
1: TOF MS ES-

$5.02 \mathrm{e} 6$

1725.57

1725.91

1726.25

1726.91

744.54

745.2

745.88
2589.37 


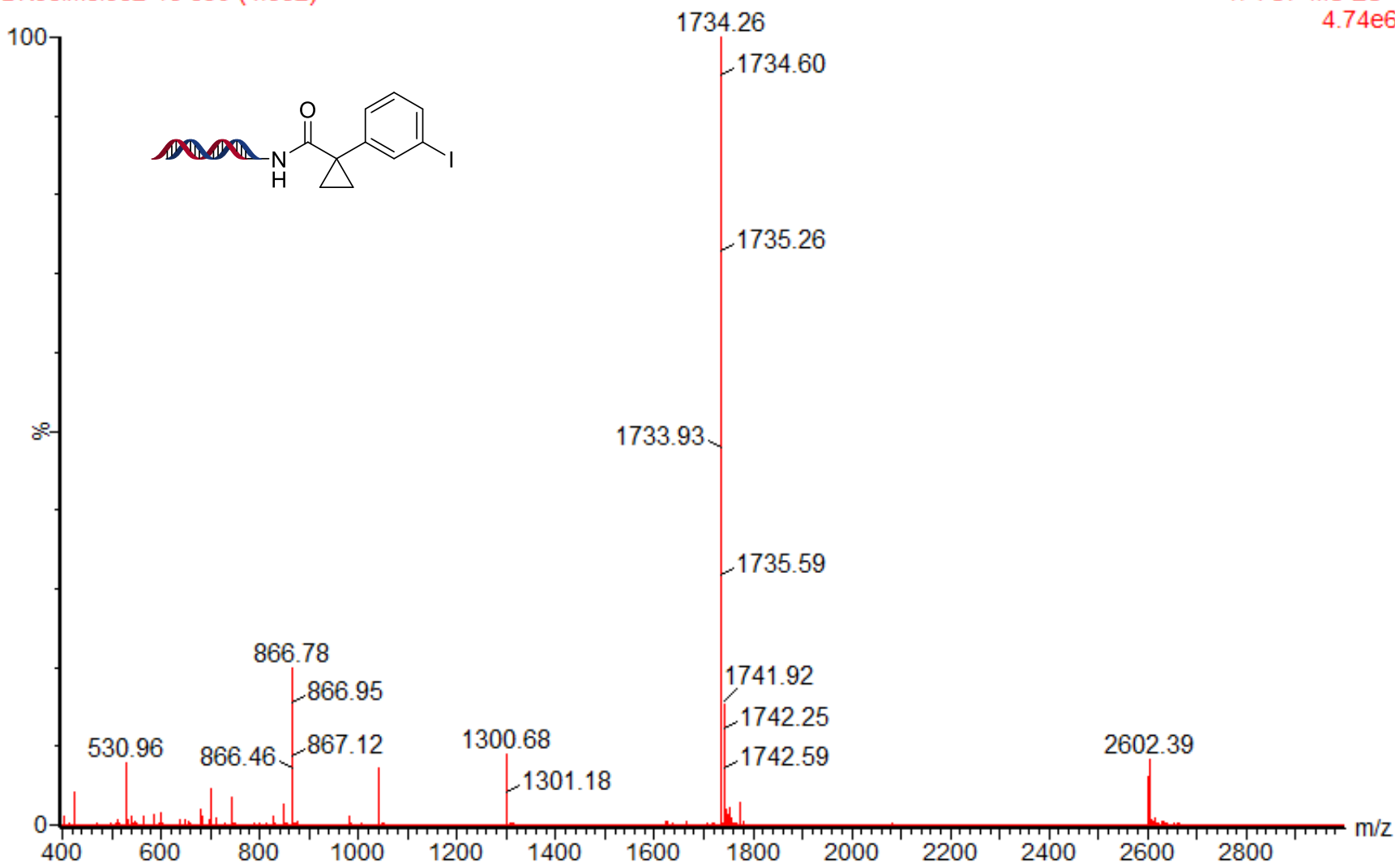

Figure S123. Mass spectrum of aryl iodide S11.

\section{6-0850-0011:1}

DKoelmel378-1 640 (4.536)

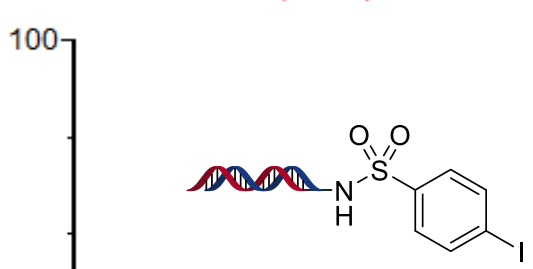

-

700.94

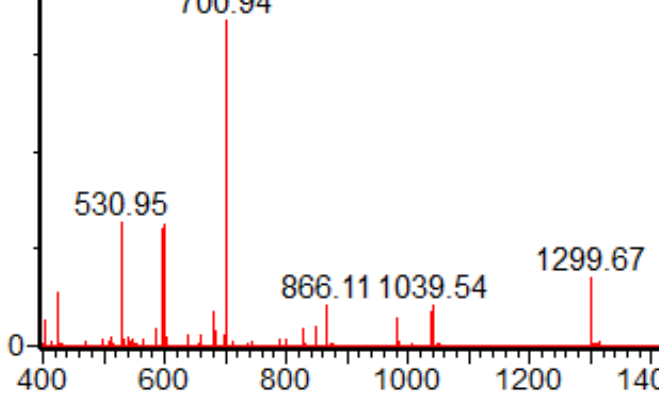

Figure S124. Mass spectrum of aryl iodide S12.
1: TOF MS ES-

$2.80 \mathrm{e} 6$

1733.58

1732.92

1733.90

1732.57

1734.25

1740.56

1741.25

2600.36 


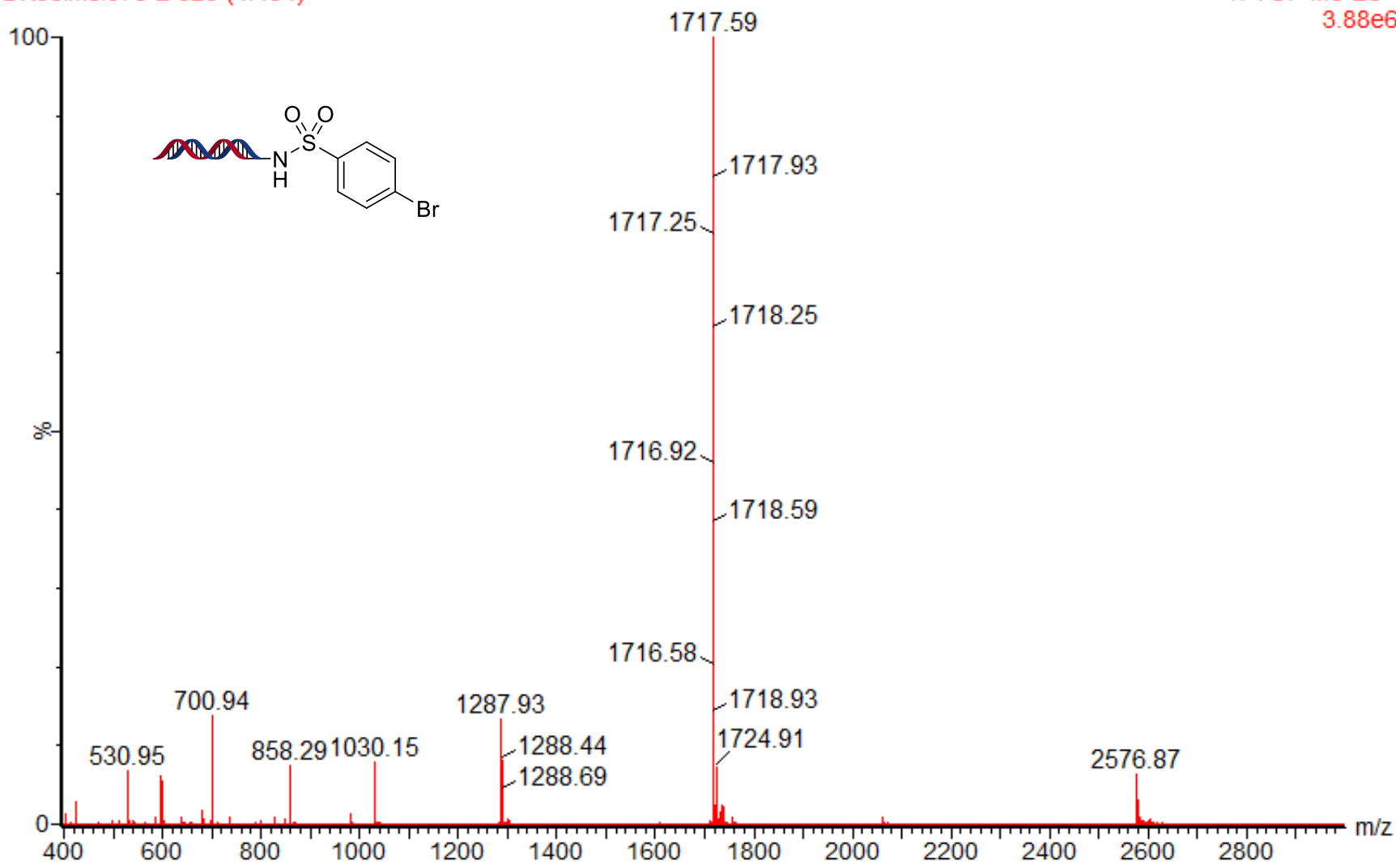

Figure S125. Mass spectrum of aryl bromide S13.

\section{6-0843-0011:5}

DKoelmel376-3 600 (4.260)<smiles>O=C(Nc1ccc(Br)c(Cl)c1)c1ccc(Br)cc1</smiles>

856.46

$856.30 \downarrow 856.63$

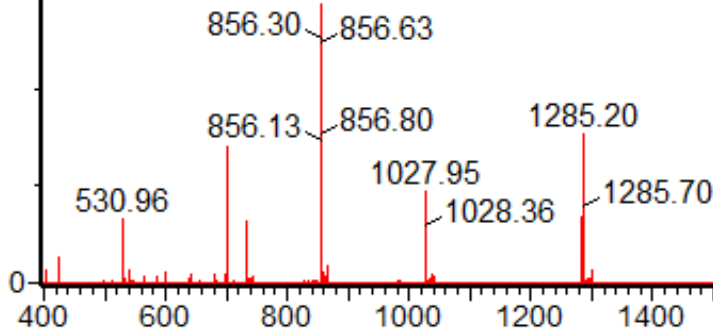

1713.95

1713.61

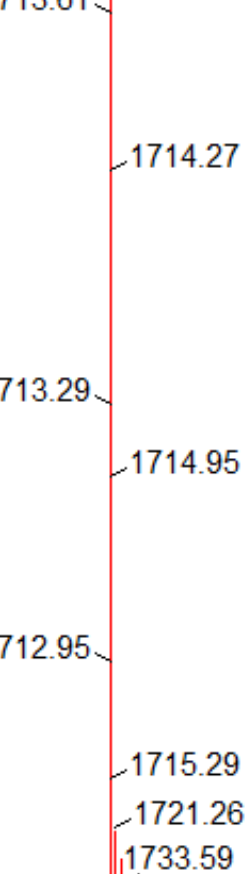

1: TOF MS ES$4.58 \mathrm{e} 6$

Figure S126. Mass spectrum of aryl bromide S14. 


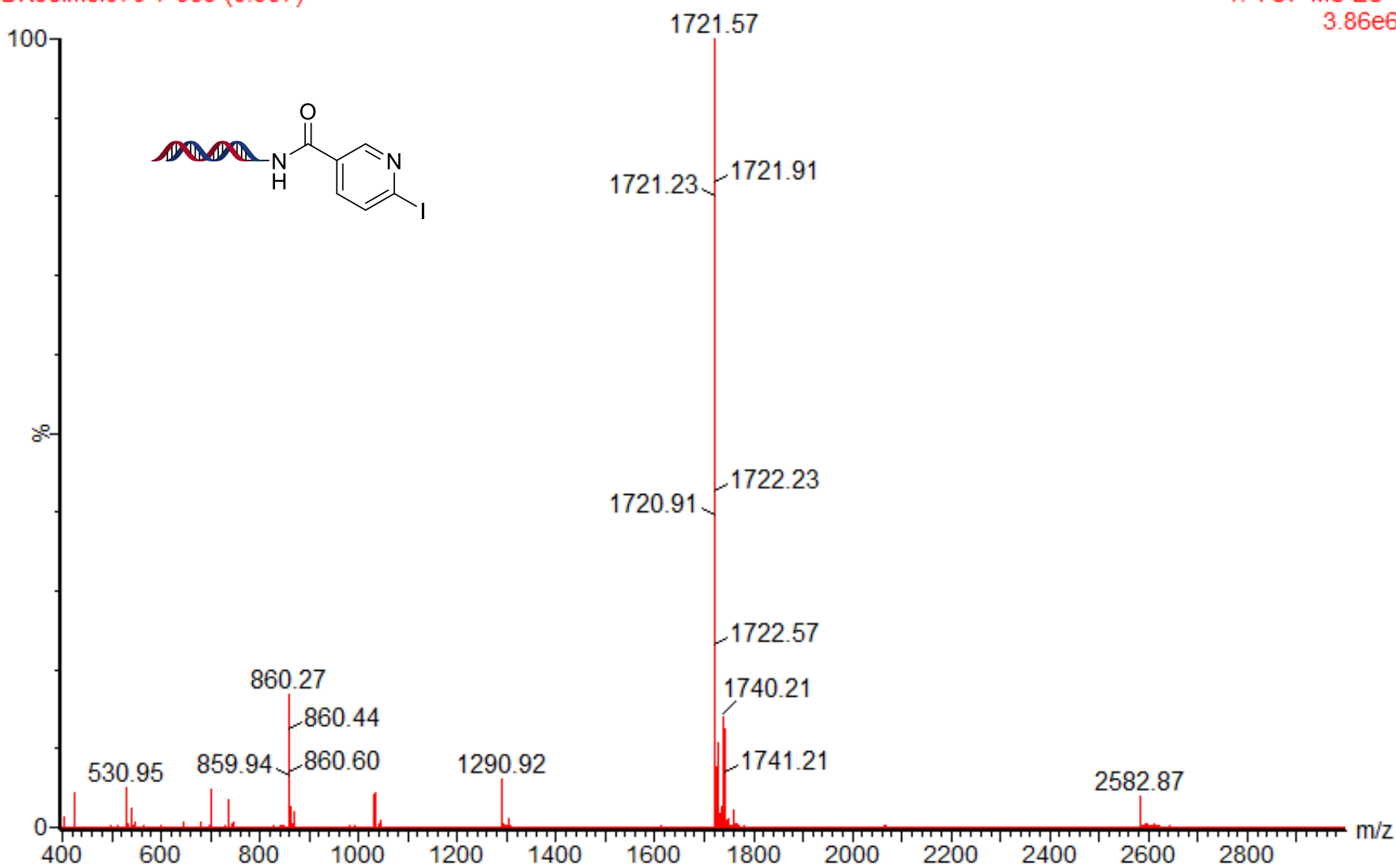

Figure S127. Mass spectrum of aryl iodide S15.

\section{6-0818-0011:17}

DKoelmel362-18 560 (3.964)

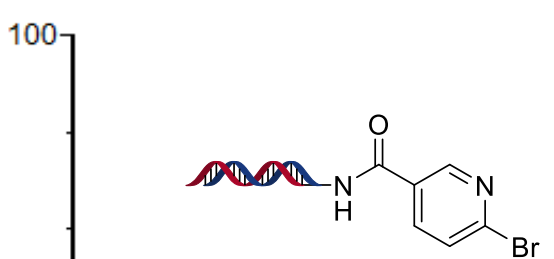

1: TOF MS ES-

$4.72 \mathrm{e} 6$

\subsection{6}

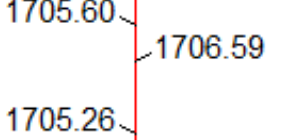

1706.93

1704.92

1707.25

1713.25

1713.91

$-1713.91$

2559.40

2560.39

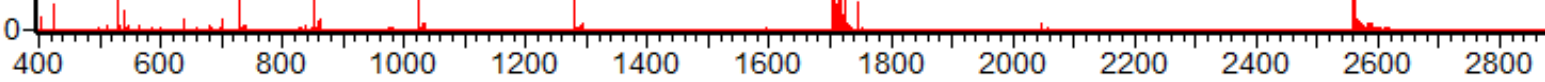

Figure S128. Mass spectrum of aryl bromide S16. 


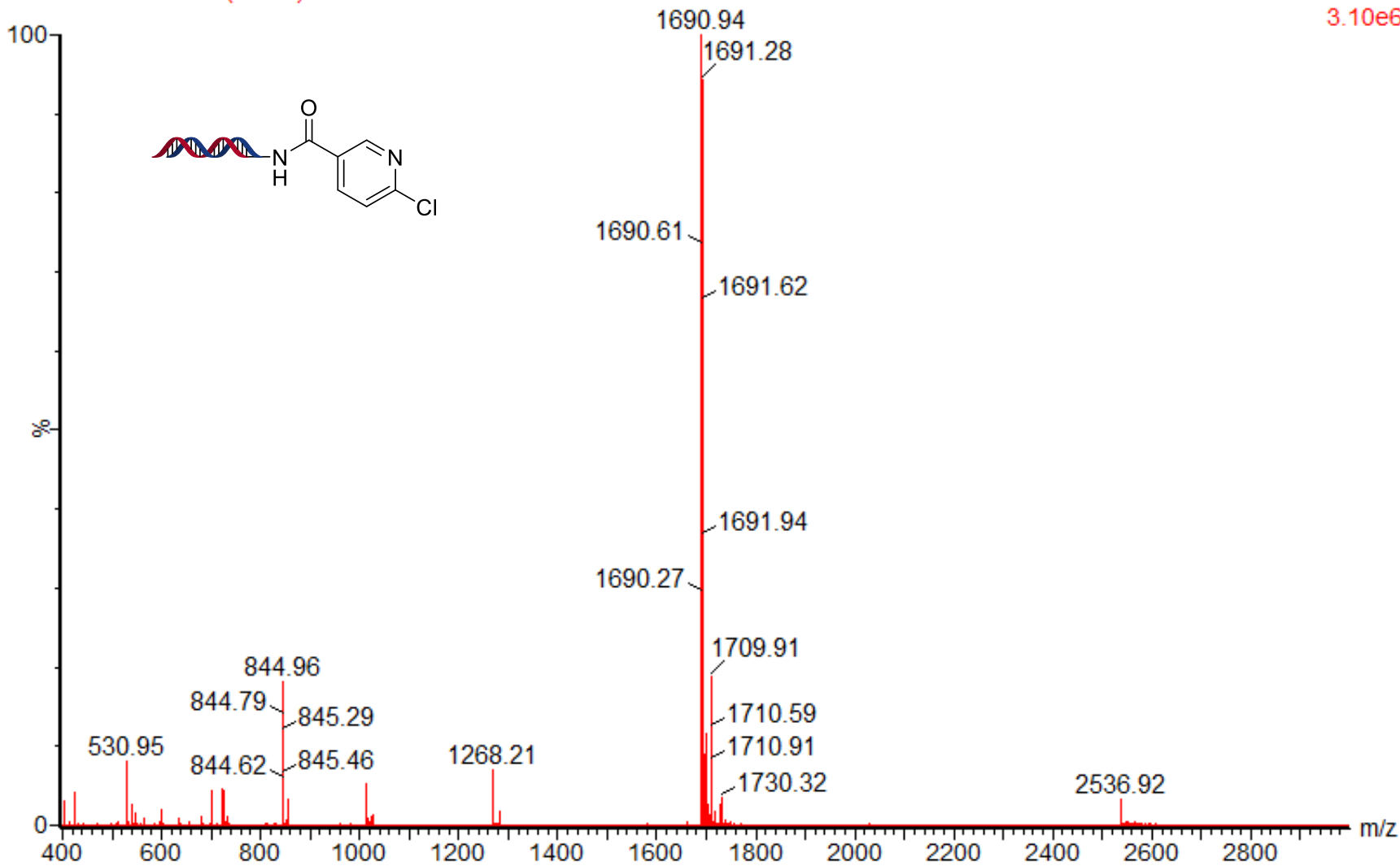

Figure S129. Mass spectrum of aryl chloride S17.

\section{6-0845-0011:7}

DKoelmel376-5 639 (4.530)<smiles>O=C(OCCCO)ONC(=O)c1cc(Br)ccn1</smiles>

700.96

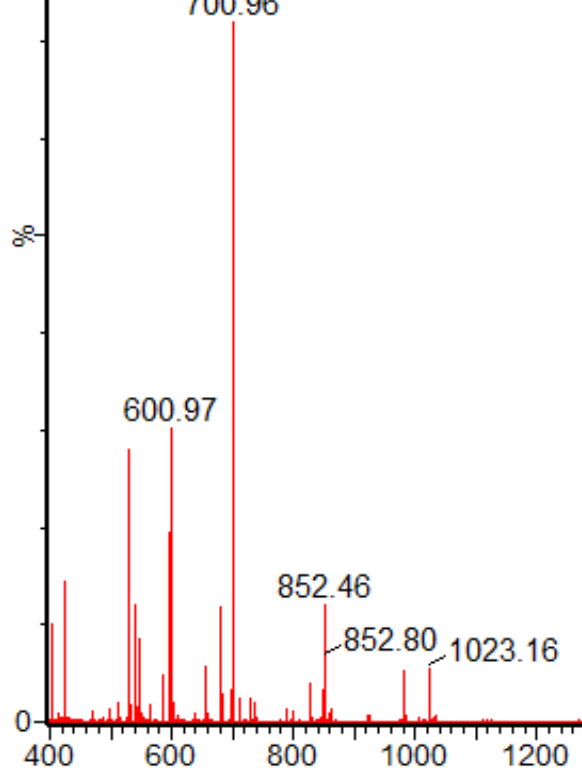

1705.95

1: TOF MS ES-

$6.09 \mathrm{e} 5$

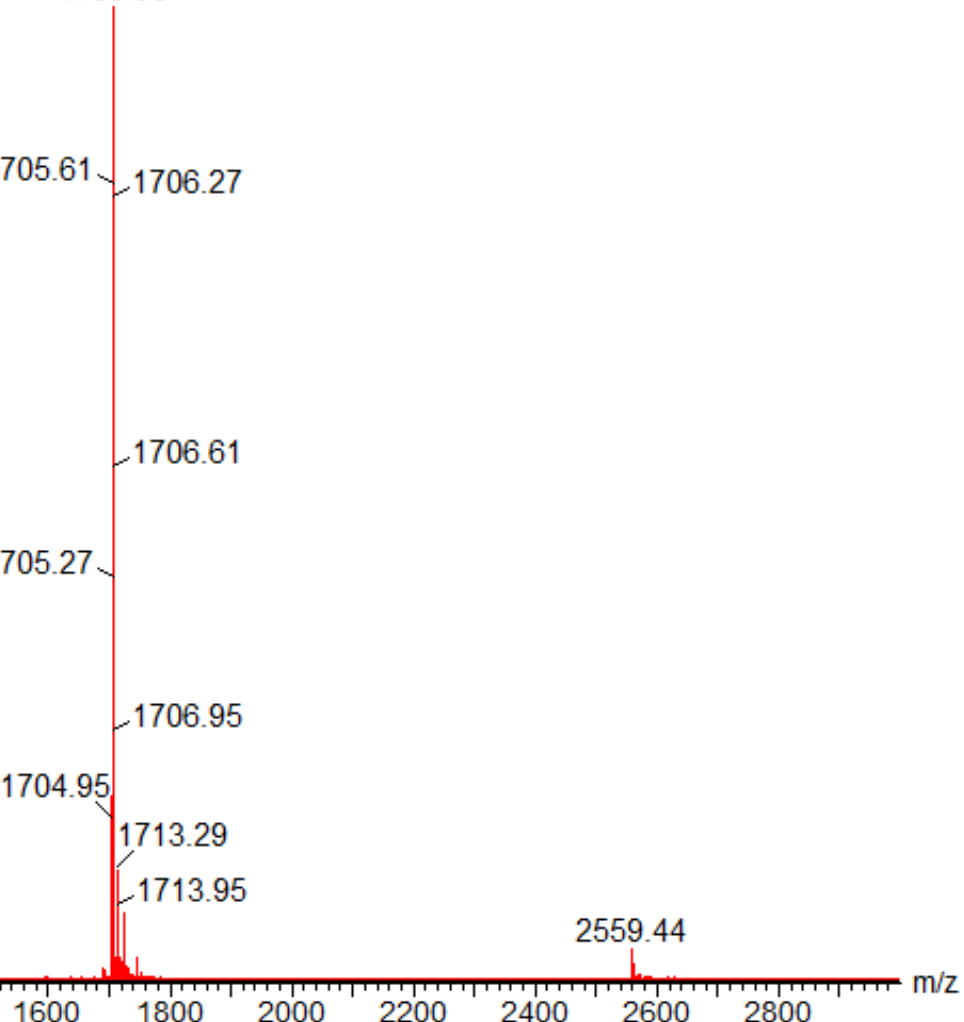

Figure S130. Mass spectrum of aryl bromide S18. 


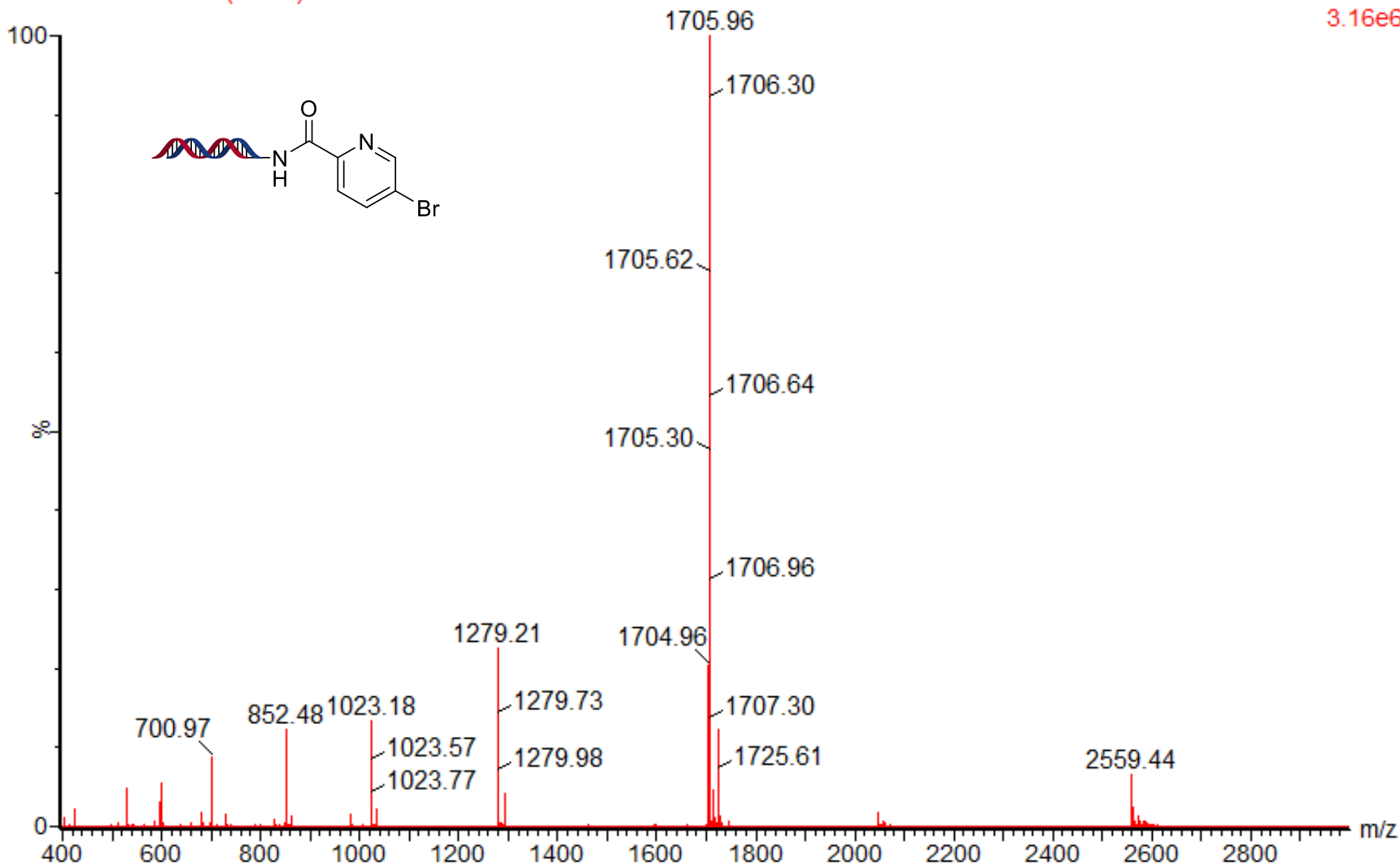

Figure S131. Mass spectrum of aryl bromide S19.

\section{6-0853-0011:4}

DKoelmel379-2 691 (4.889)<smiles>O=C(NCc1ccccc1)c1nc(Cl)cc(-c2ccccc2)n1</smiles>

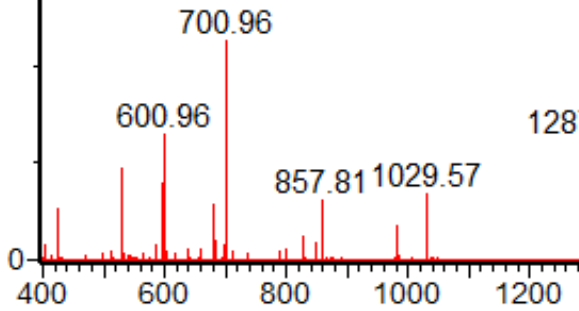

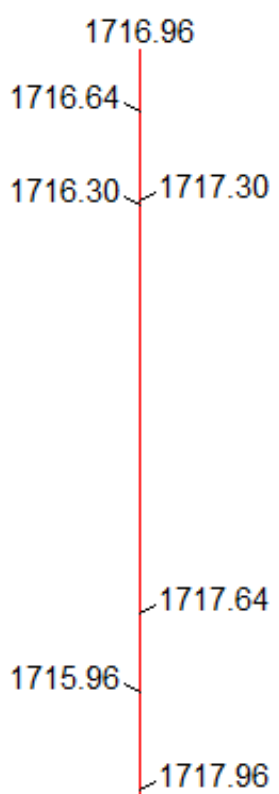

1: TOF MS ES$3.08 \mathrm{e} 6$

Figure S132. Mass spectrum of aryl chloride S20. 

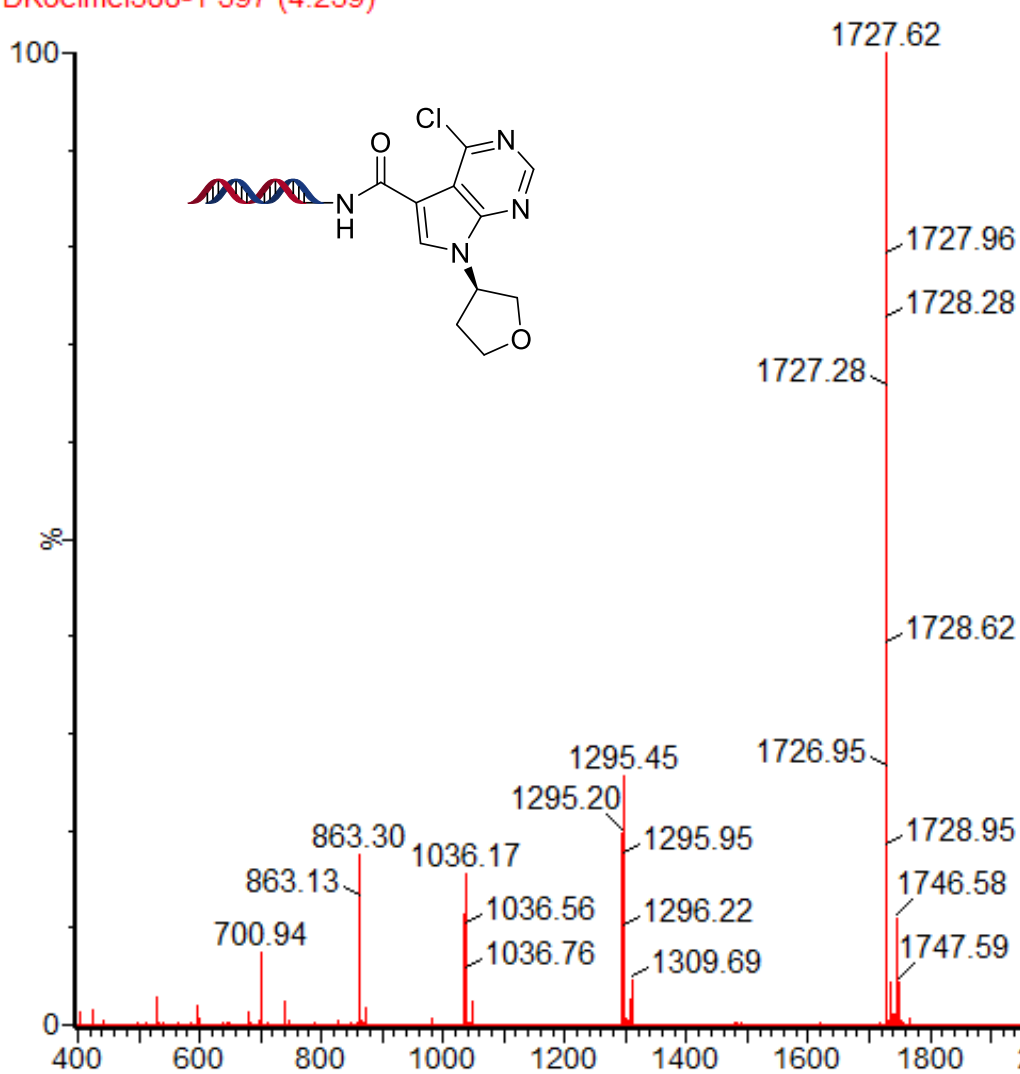

Figure S133. Mass spectrum of aryl chloride S21.

00712256-0629-00100712256-0629-001

DKoelmel250-4 686 (4.854)

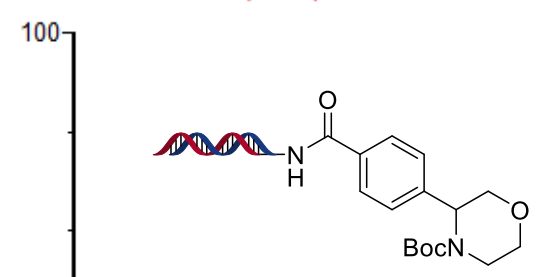

15-May-2018 14:23:09 1: TOF MS ES$1.52 \mathrm{e} 6$ 
00712256-0775-0011:17

DKoelmel349-09 685 (4.847)

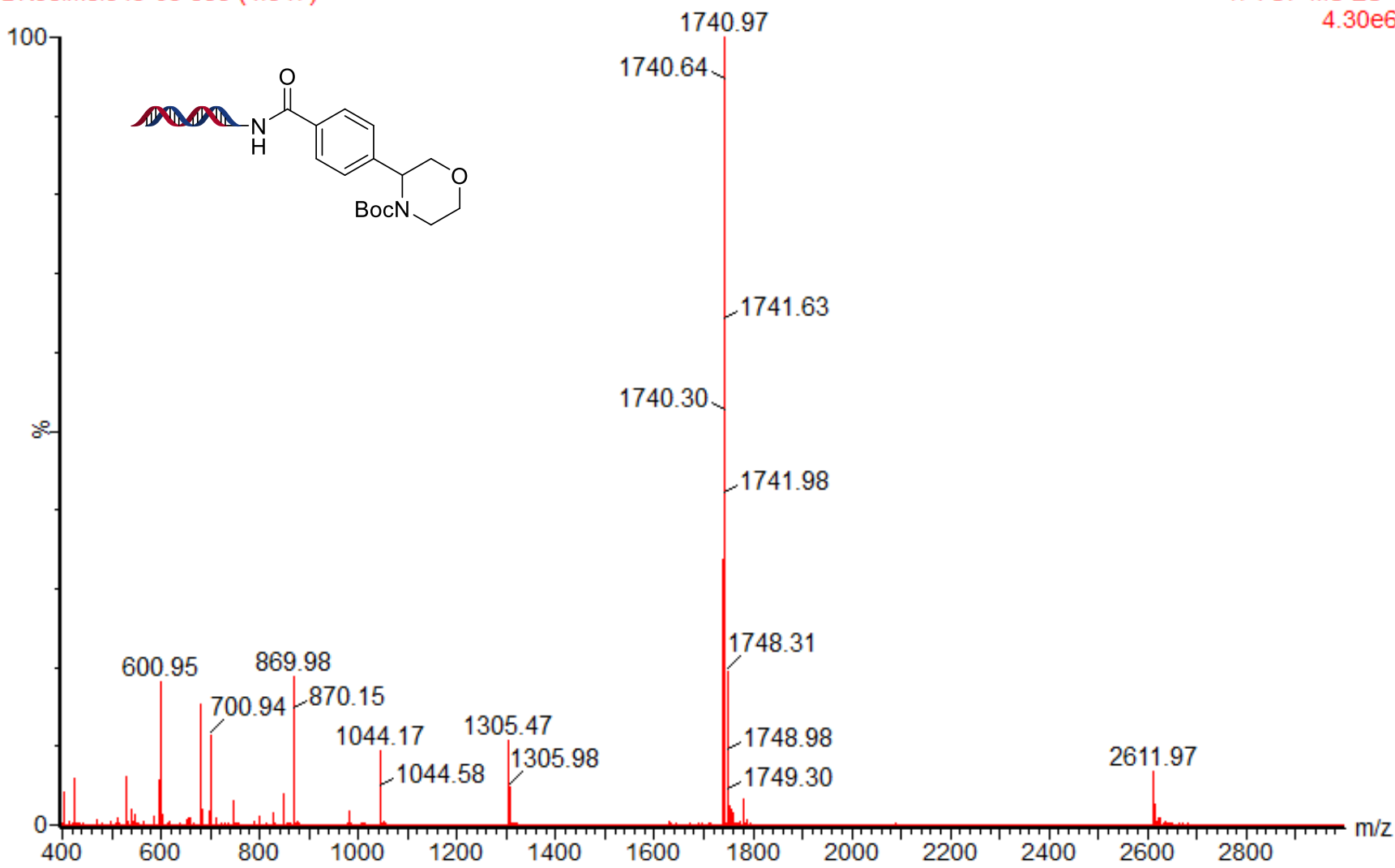

Figure S135. Mass spectrum of Table 1, entry 2.

\section{6-0801-001-Repeat1:48}

DKoelmel360-2 690 (4.882)<smiles>O=C(Nc1ccccc1)c1ccc(C2COCCN2C(=O)O)cc1</smiles>

700.94

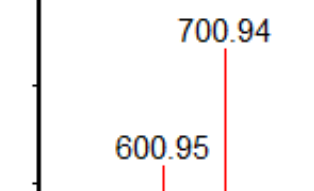

870.14

$1044.17 \quad 1305.46$ $1044.57 \quad 1305.96$
1740.63

1 : TOF MS ES-

$3.80 \mathrm{e} 6$

1741.63

1740.30

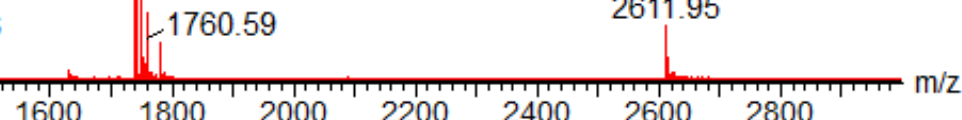




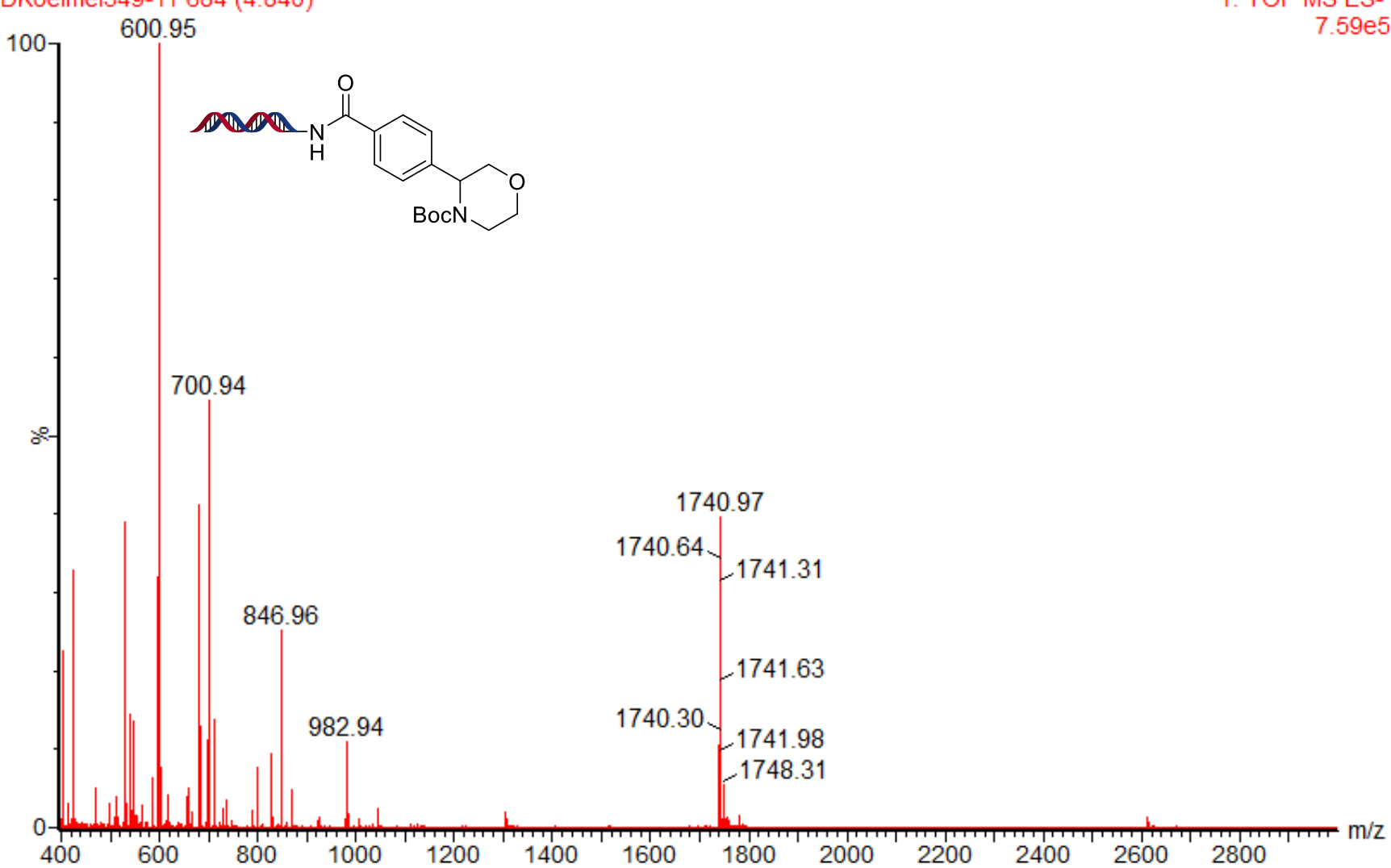

Figure S137. Mass spectrum of Table 1, entry 4.

\section{6-0778-0011:20}

DKoelmel349-12 687 (4.861)

$$
{ }^{100}
$$$$
\overbrace{\text { BocN }}
$$

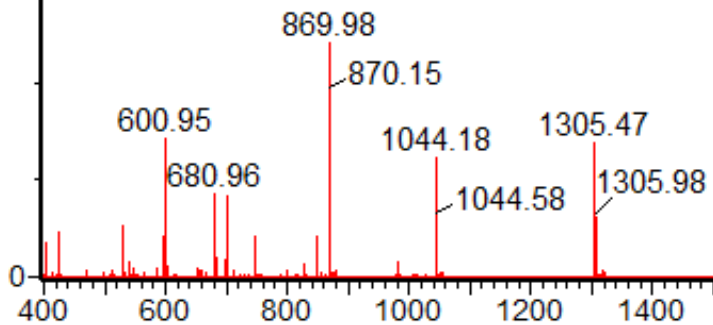

1741.31

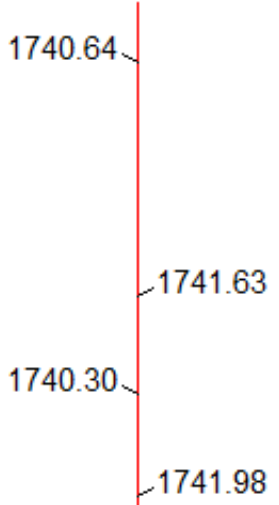

1748.31

1748.98

2612.96
1: TOF MS ES-

$4.67 \mathrm{e} 6$

Figure S138. Mass spectrum of Table 1, entry 5. 


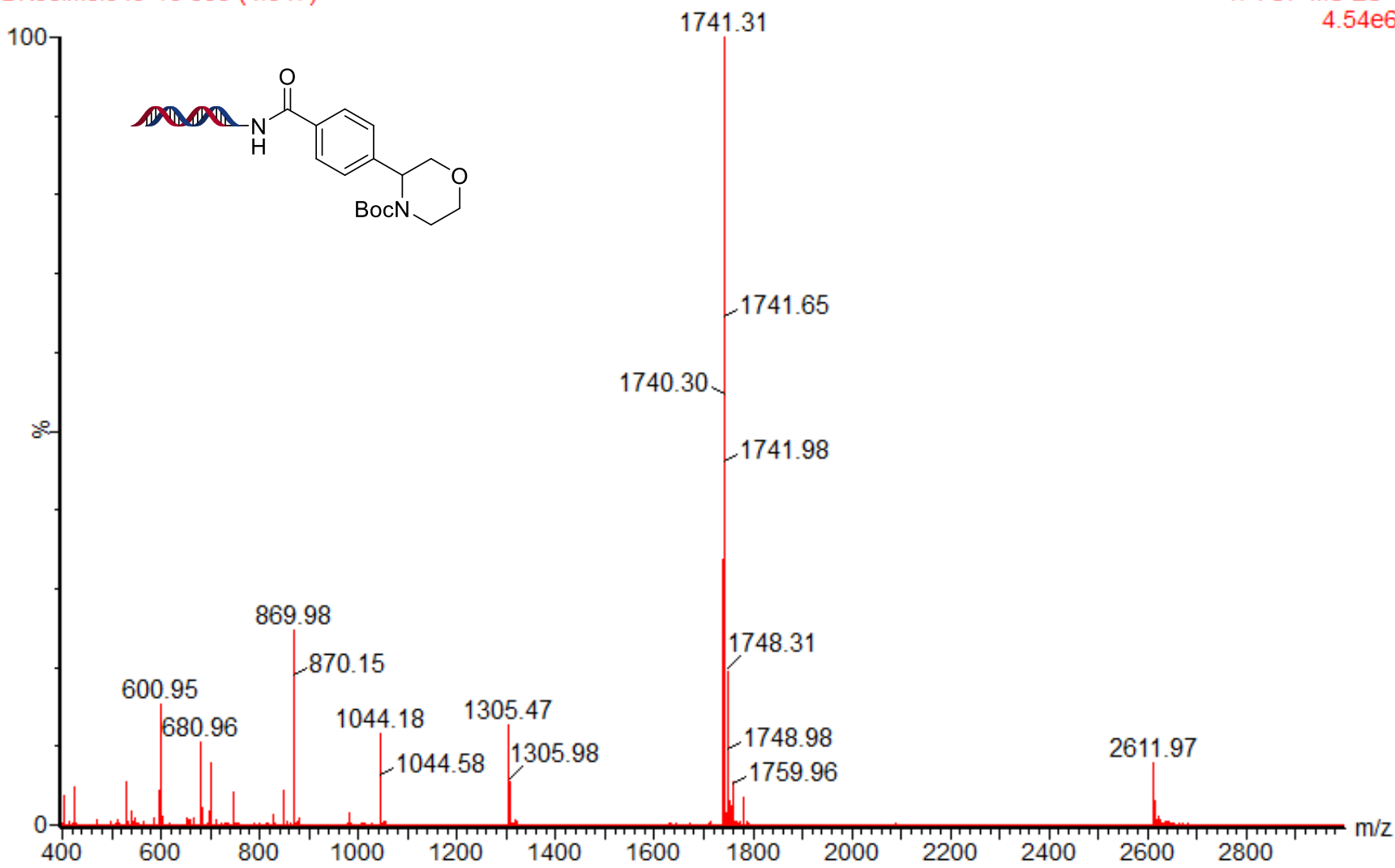

Figure S139. Mass spectrum of Table 1, entry 6.

\section{6-0767-0011:9}

DKoelmel349-01 691 (4.889)

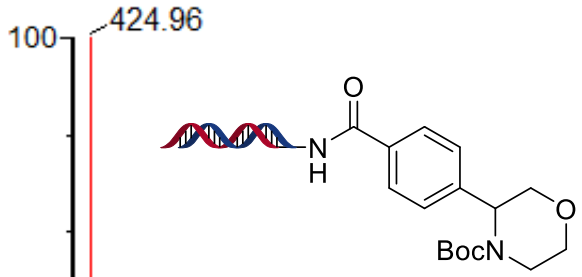

\subsection{0 .94}

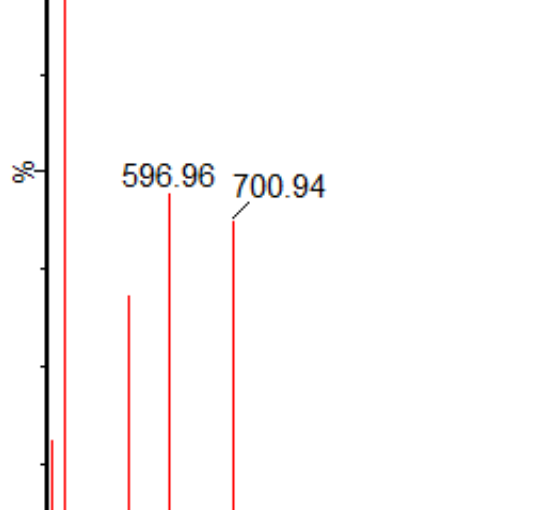

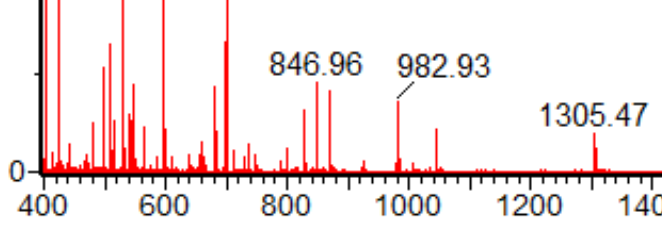

Figure S140. Mass spectrum of Table 1, entry 7.

1: TOF MS ES-

$1.34 \mathrm{e} 6$ 


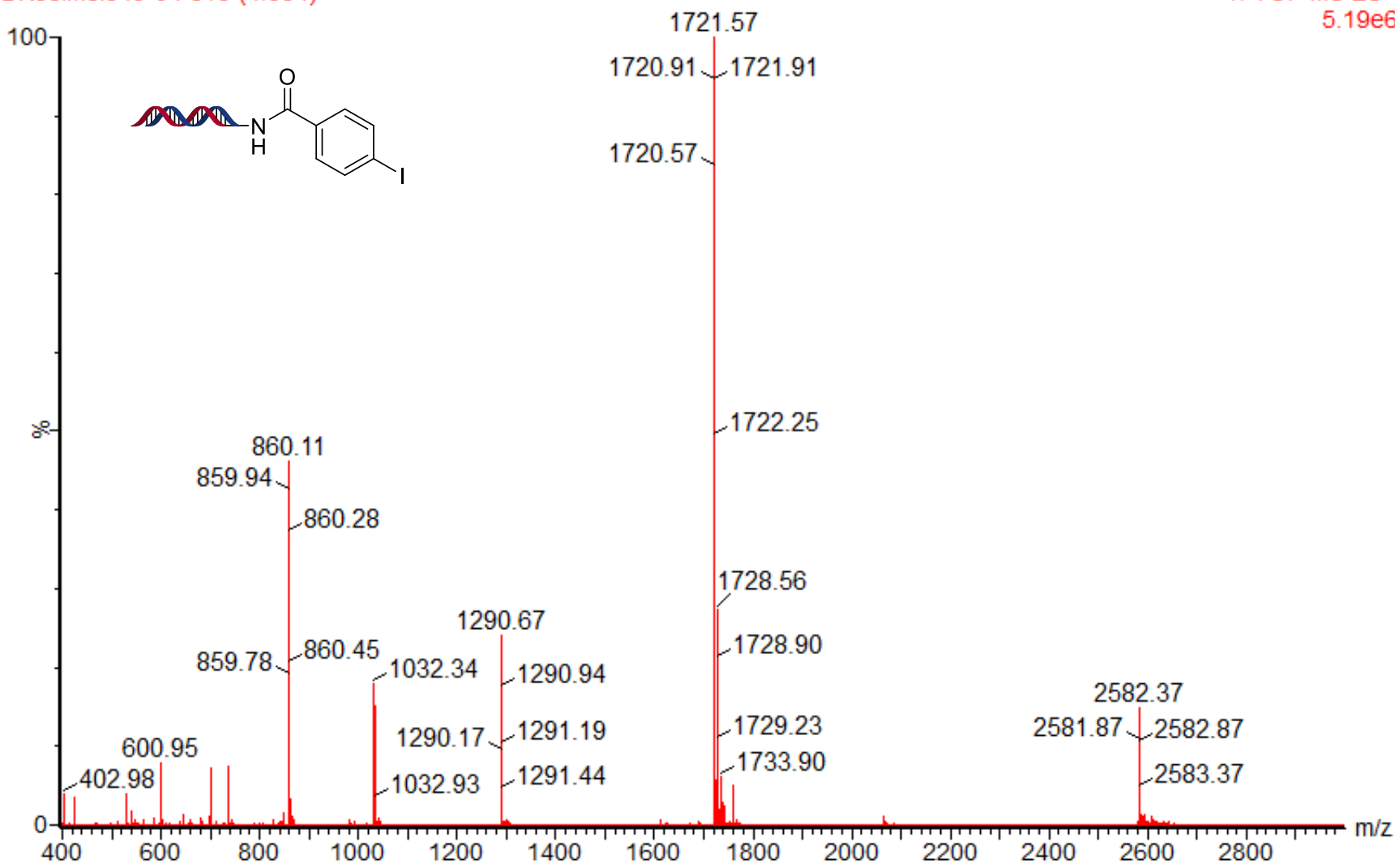

Figure S141. Mass spectrum of Table 1, entry 8.

\section{6-0769-0011:11}

DKoelmel349-03 618 (4.384)

$$
100
$$$$
\operatorname{son}^{n}
$$

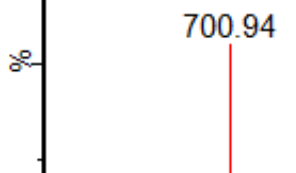

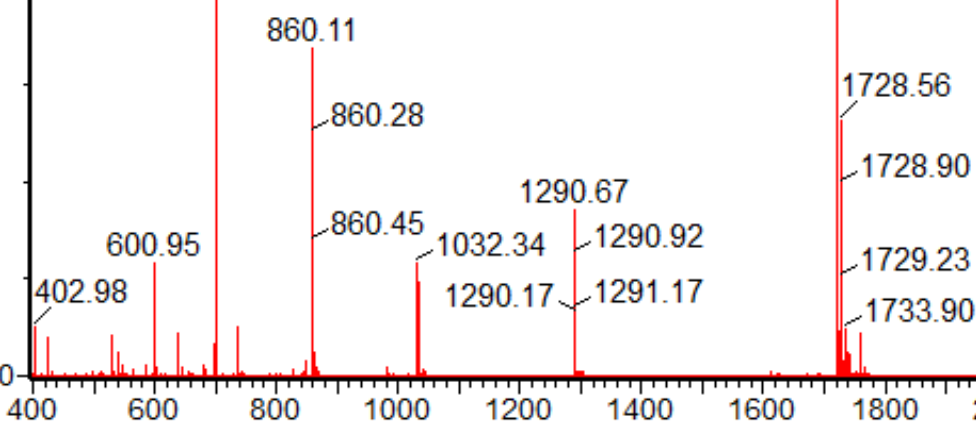

1721.57

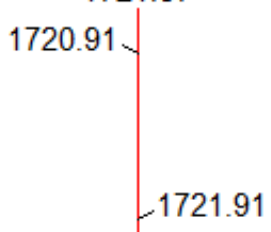

1720.57

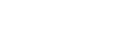

Figure S142. Mass spectrum of Table 1, entry 9. 


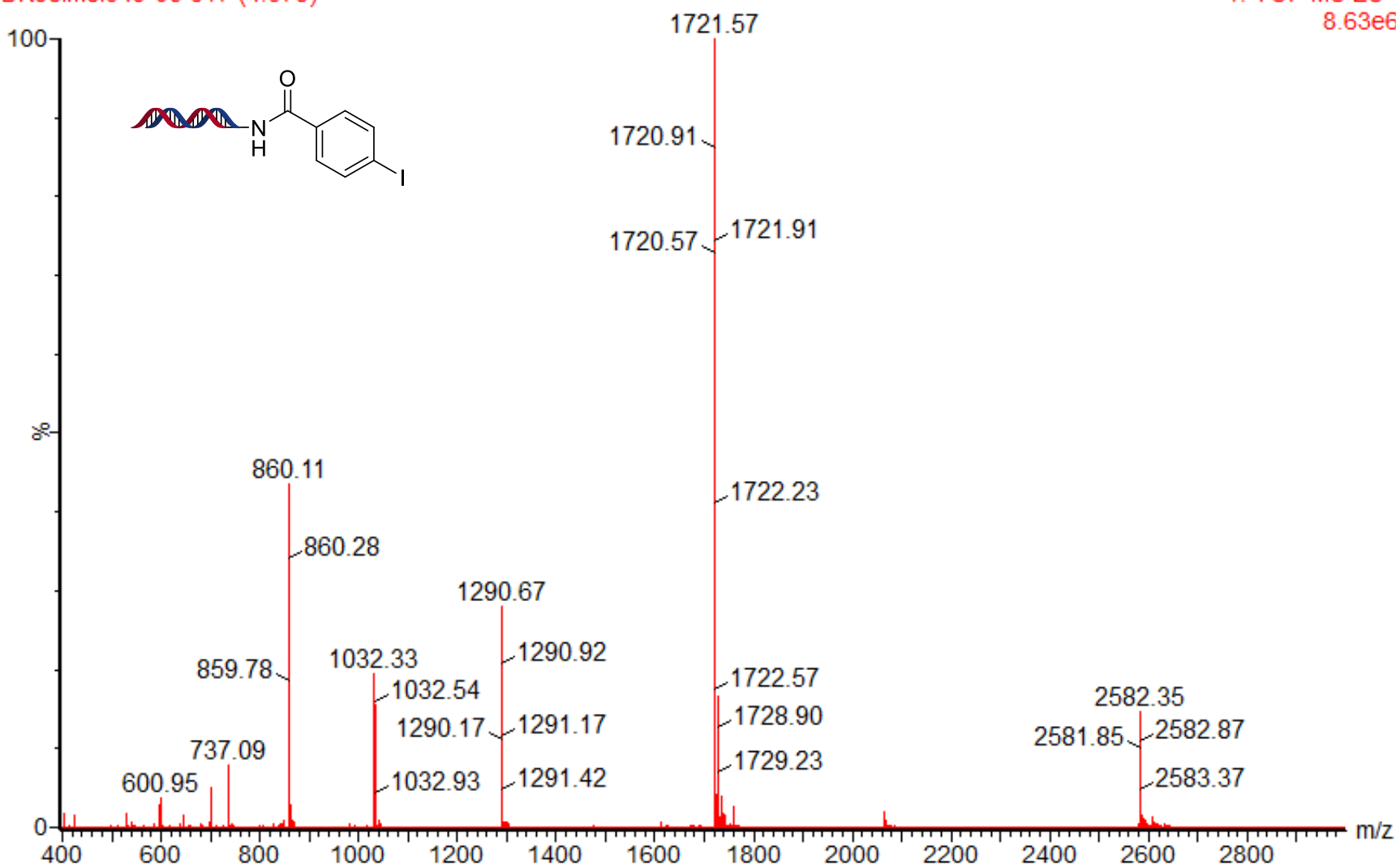

Figure S143. Mass spectrum of Table 1, entry 10.

\section{6-0774-0011:16}

DKoelmel349-08 684 (4.840)

100

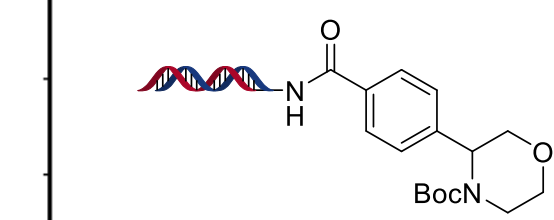

00.95

700.94869 .98

1740.30

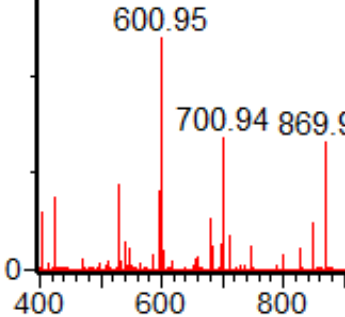

$1044.18 \quad 1305.47$

1740.64

1741.98

Figure S144. Mass spectrum of Table 1, entry 11. 


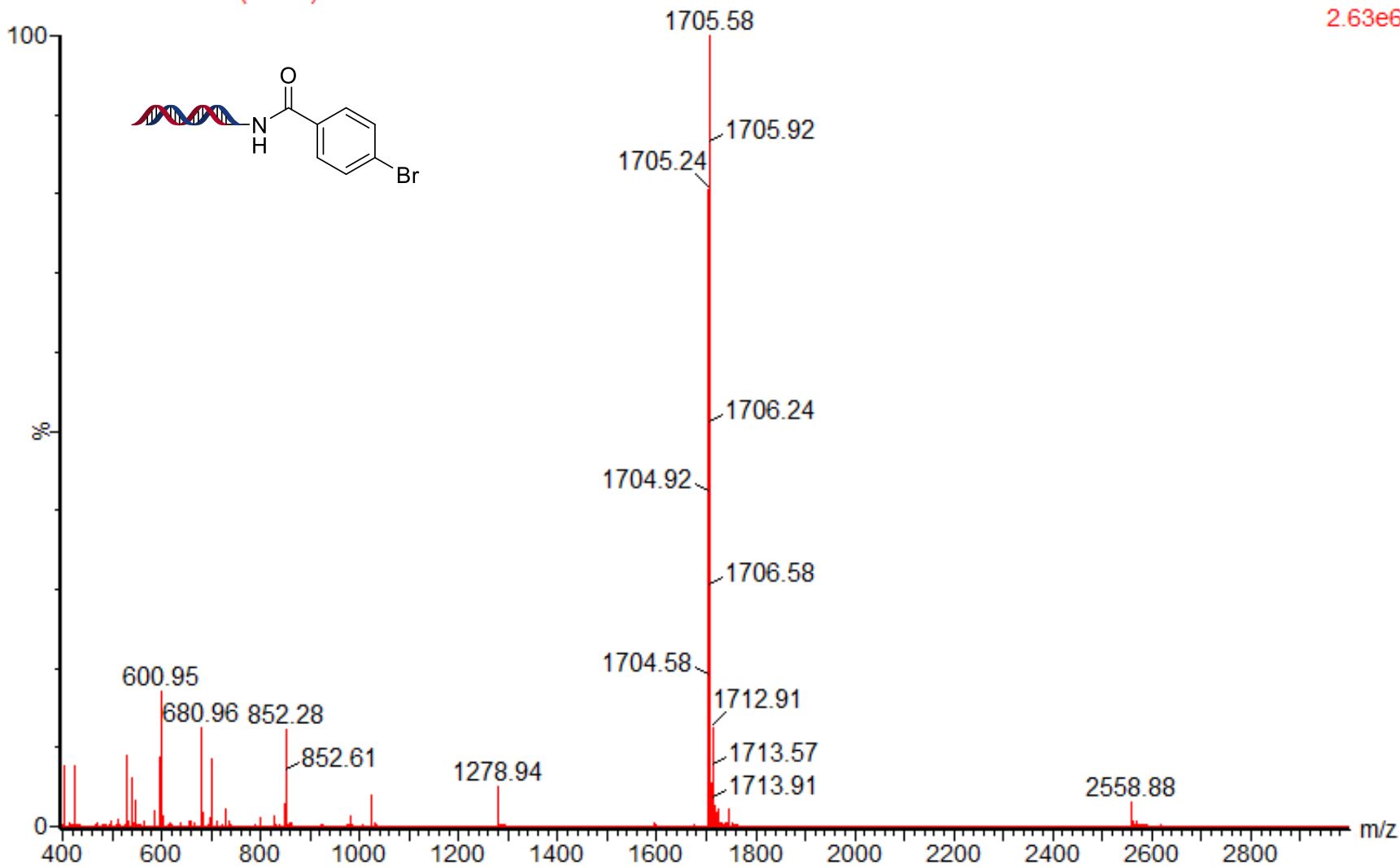

Figure S145. Mass spectrum of Table 1, entry 12.

\section{6-0733-001-11:10}

DKoelmel313-1 727 (5.157)

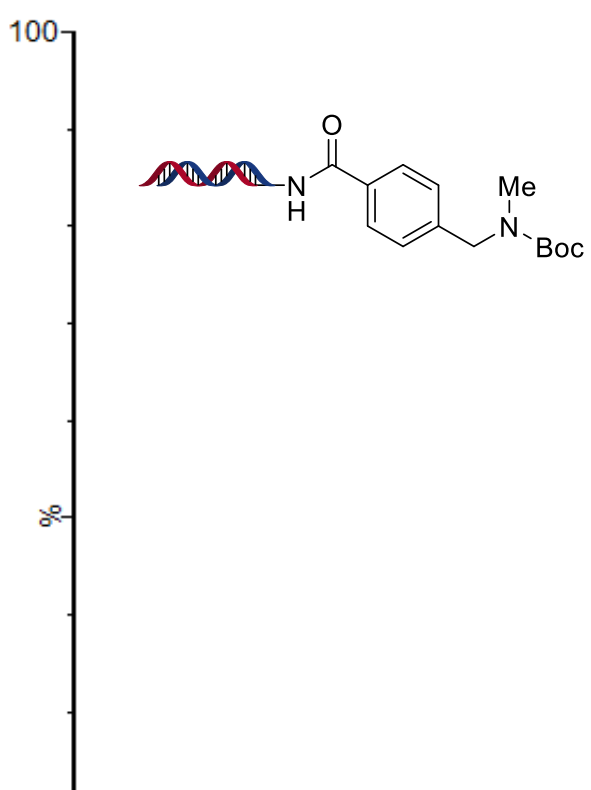

1: TOF MS ES$2.67 e 6$

1726.73

1728.39

1734.73

1295.32

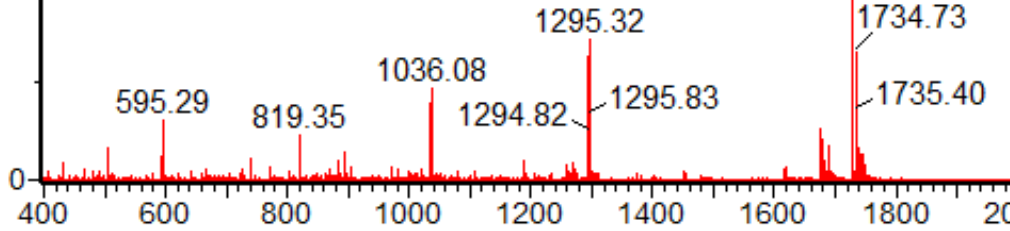

Figure S146. Mass spectrum of Table 2, entry 1. 

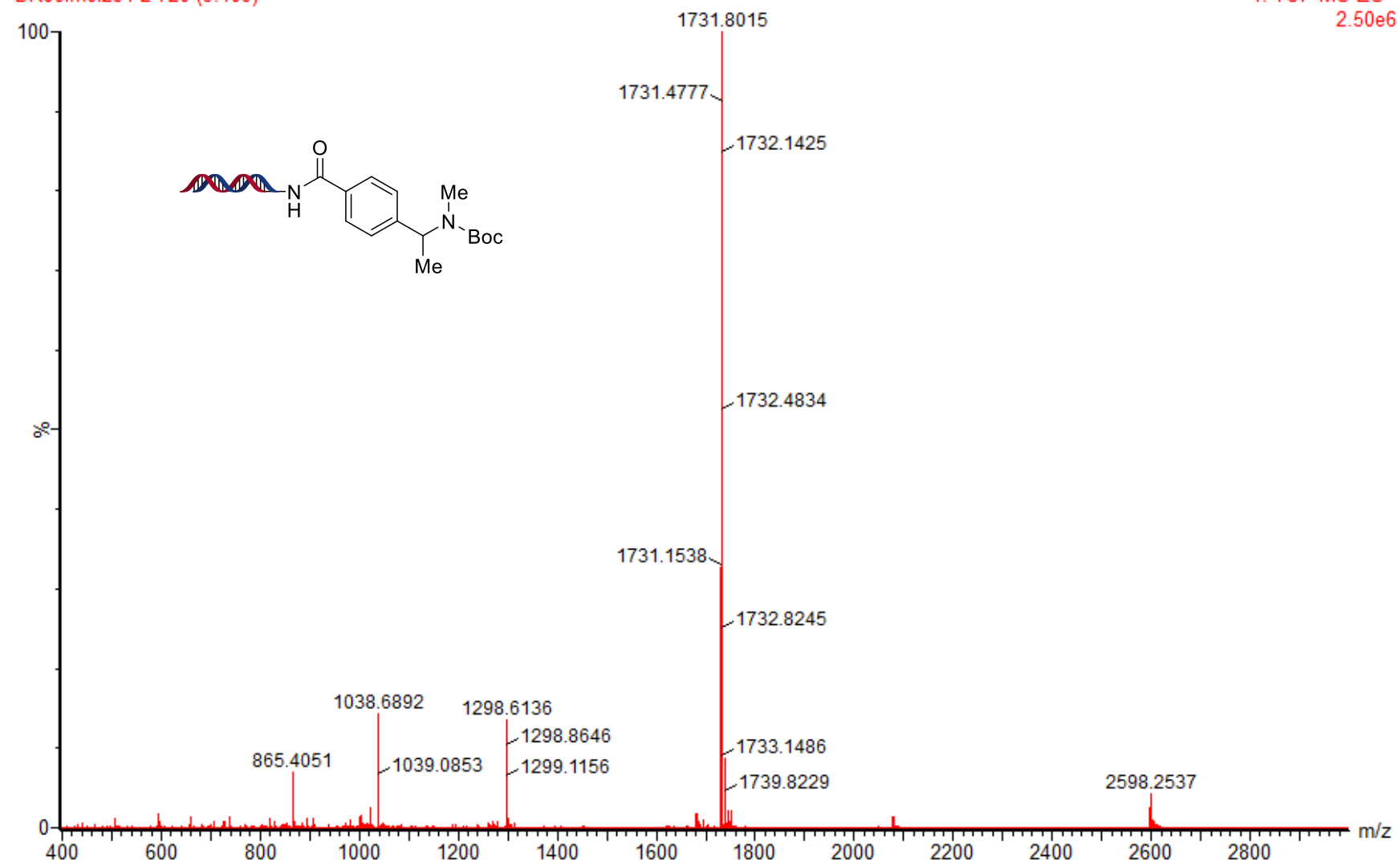

Figure S147. Mass spectrum of Table 2, entry 2.

\section{6-0729-001-11:9}

DKoelmel306-1 818 (5.786)

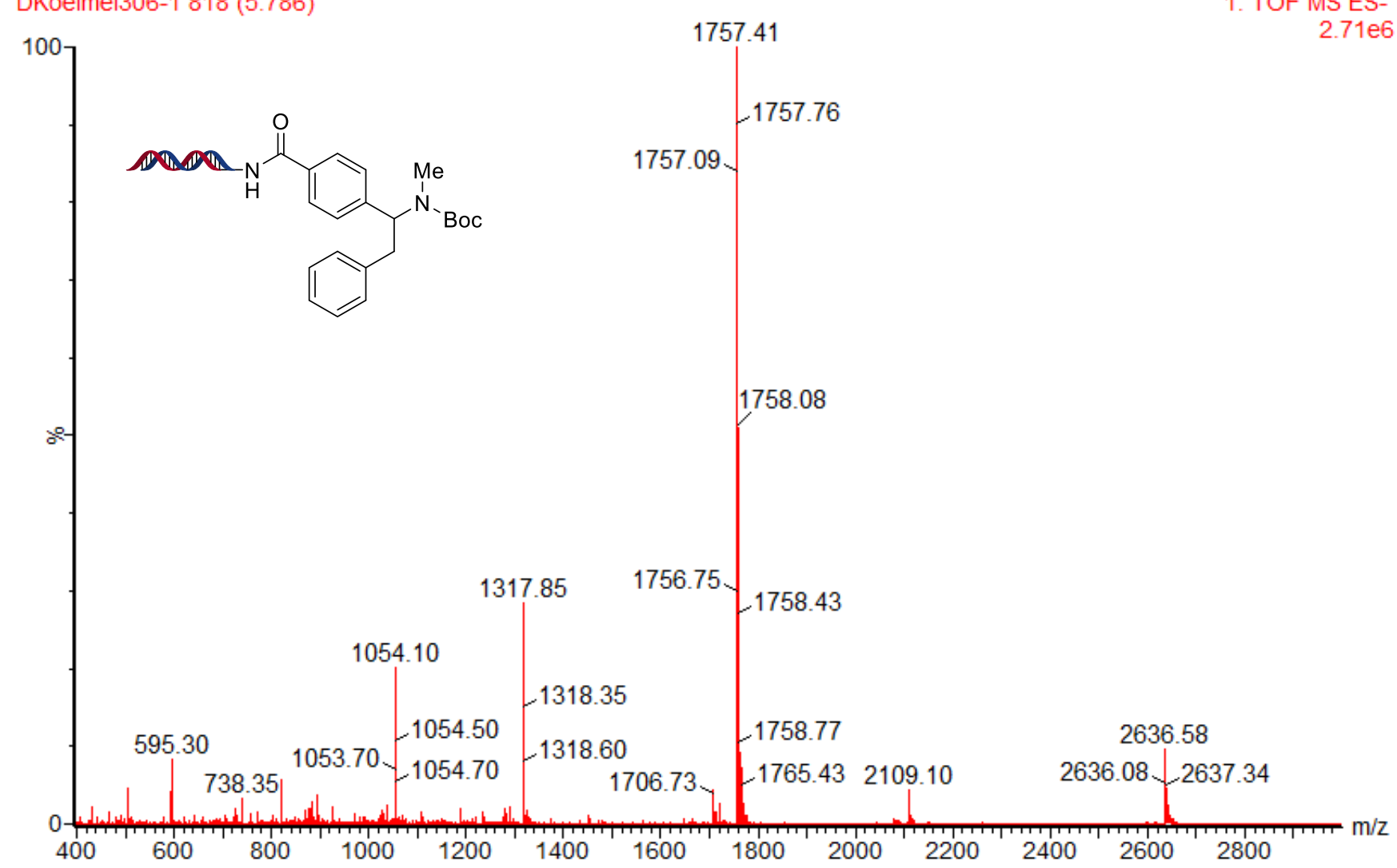

Figure S148. Mass spectrum of Table 2, entry 3. 


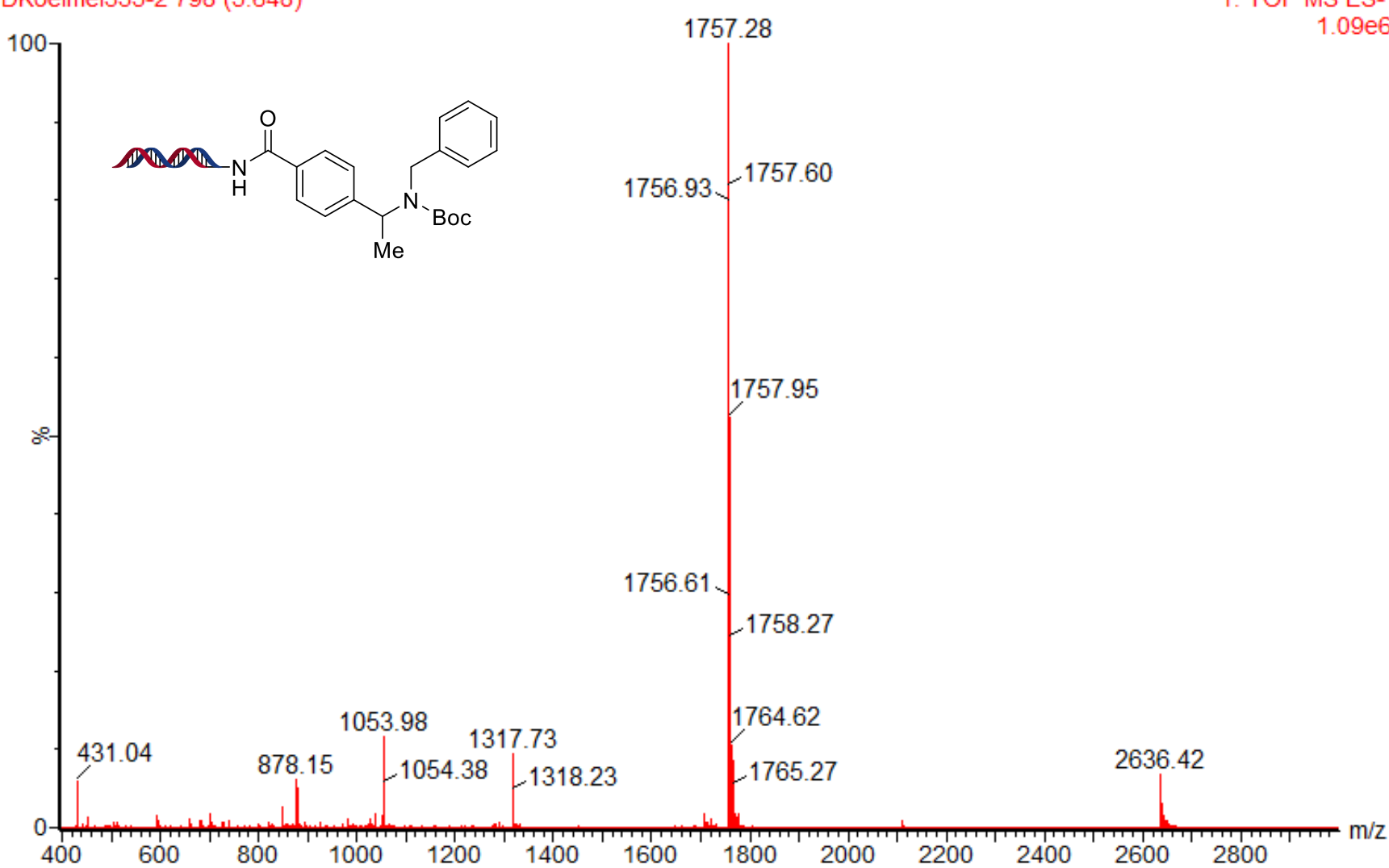

Figure S149. Mass spectrum of Table 2, entry 4.

\section{6-0758-0011:9}

DKoelmel338-1 740 (5.247)

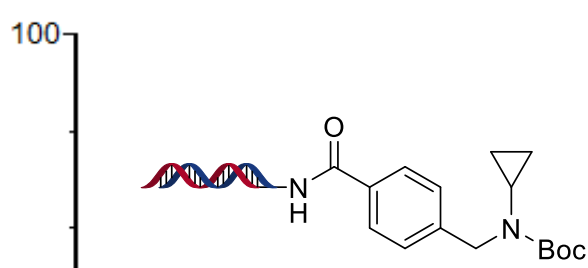

1: TOF MS ES-

$1.84 \mathrm{e} 6$

1735.21

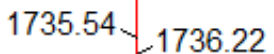

1736.54

2604.33 2603.83

\footnotetext{
Figure S150. Mass spectrum of Table 2, entry 5.
} 

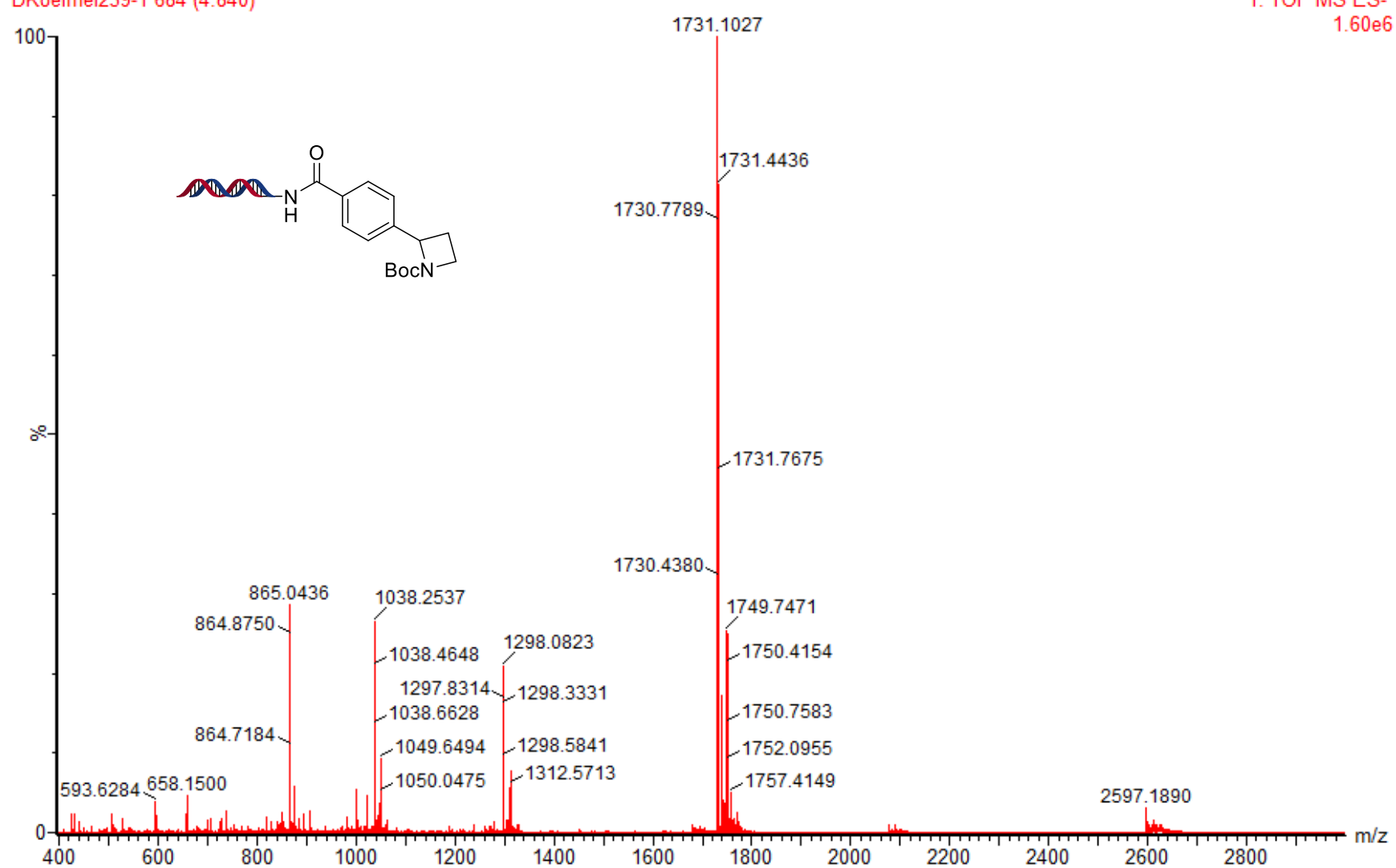

Figure S151. Mass spectrum of Table 2, entry 6.

00712256-0627-00100712256-0627-001

DKoelmel250-2 717 (5.088)

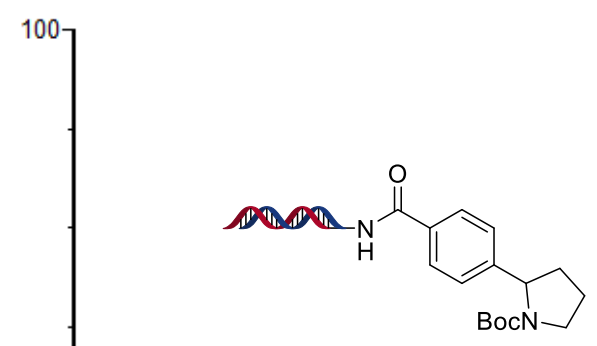

15-May-2018 14:06:34 1: TOF MS ES-

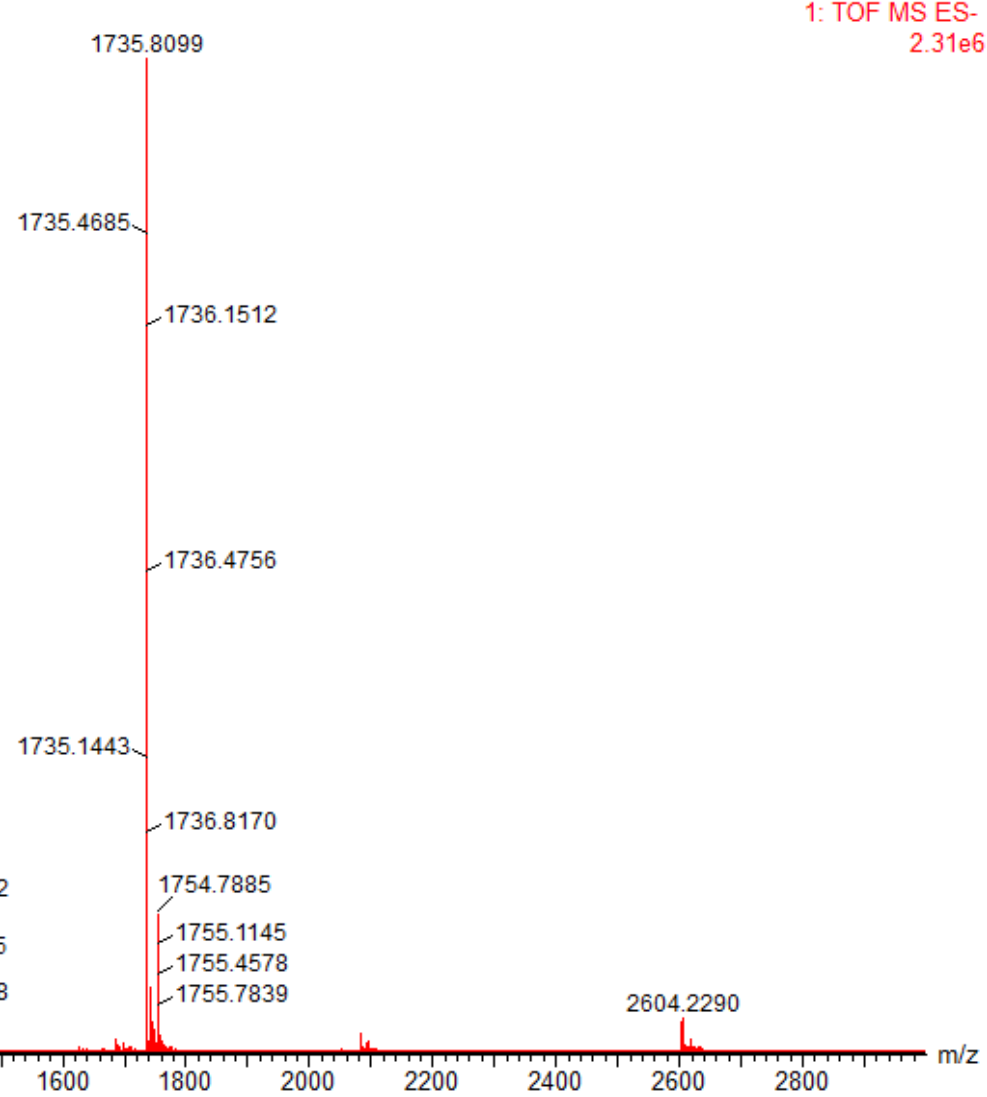

Figure S152. Mass spectrum of Table 2, entry 7. 


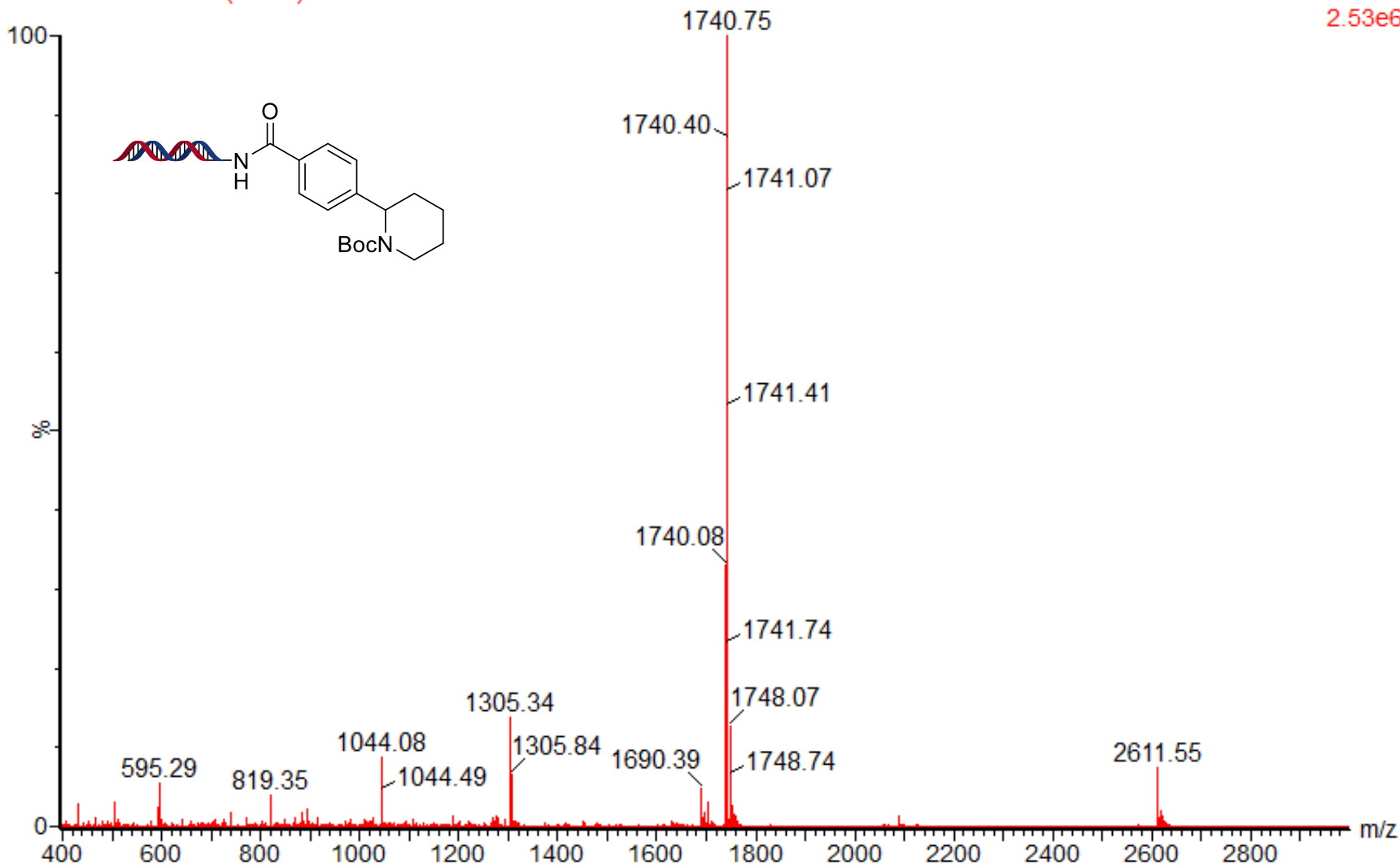

Figure S153. Mass spectrum of Table 2, entry 8.

\section{6-0791-0011:42}

DKoelmel356-2 769 (5.447)
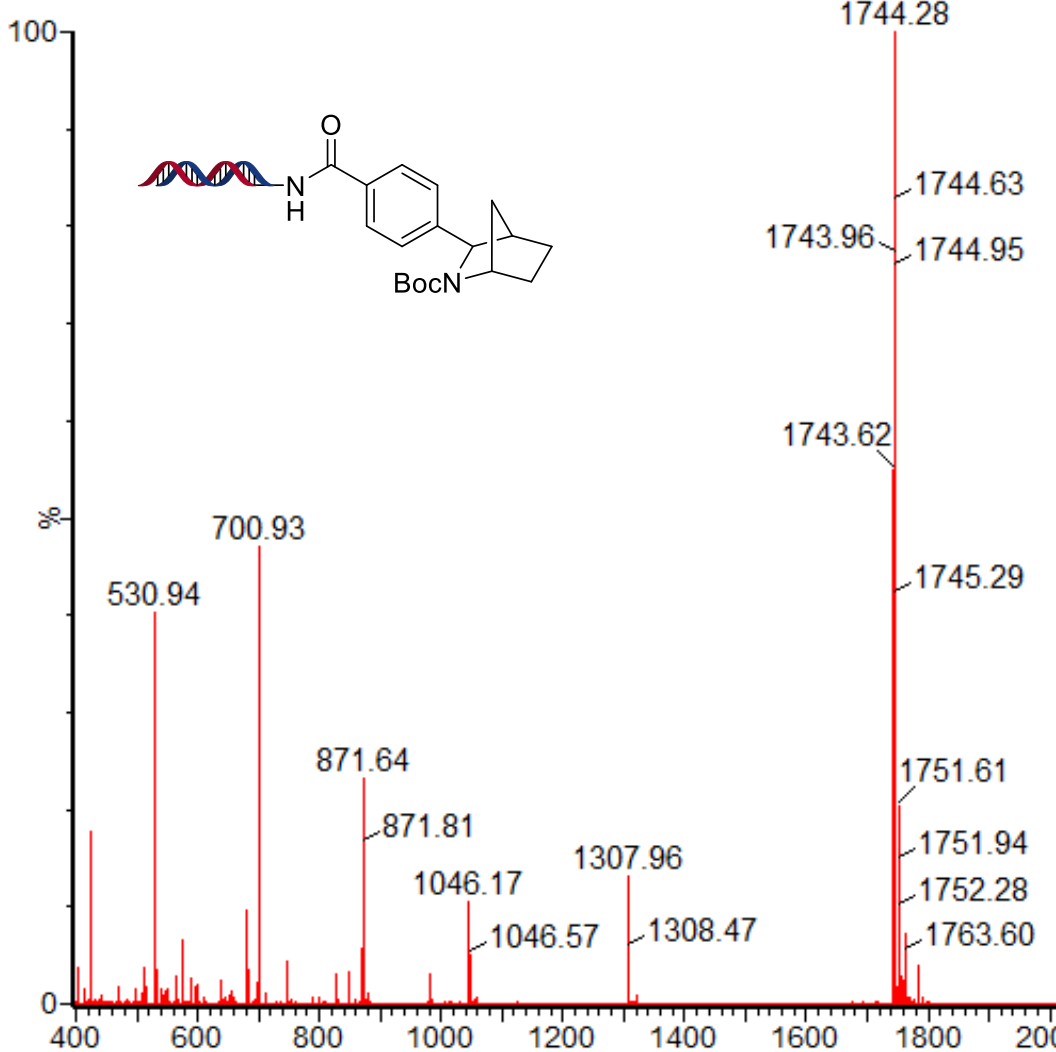

Figure S154. Mass spectrum of Table 2, entry 9.
1: TOF MS ES$4.58 \mathrm{e} 6$ 


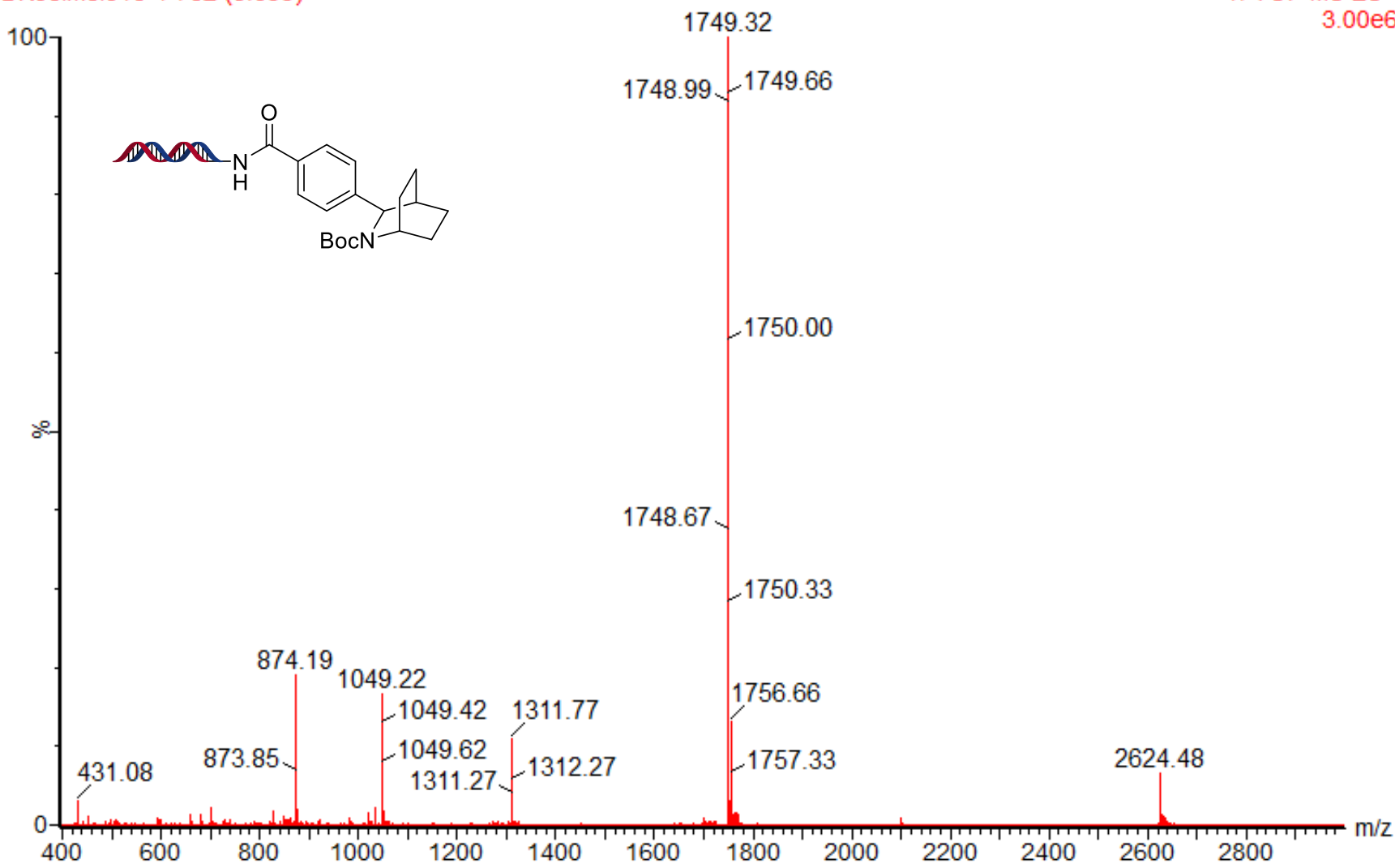

Figure S155. Mass spectrum of Table 2, entry 10.

00712256-0629-00100712256-0629-001

DKoelmel250-4 686 (4.854)

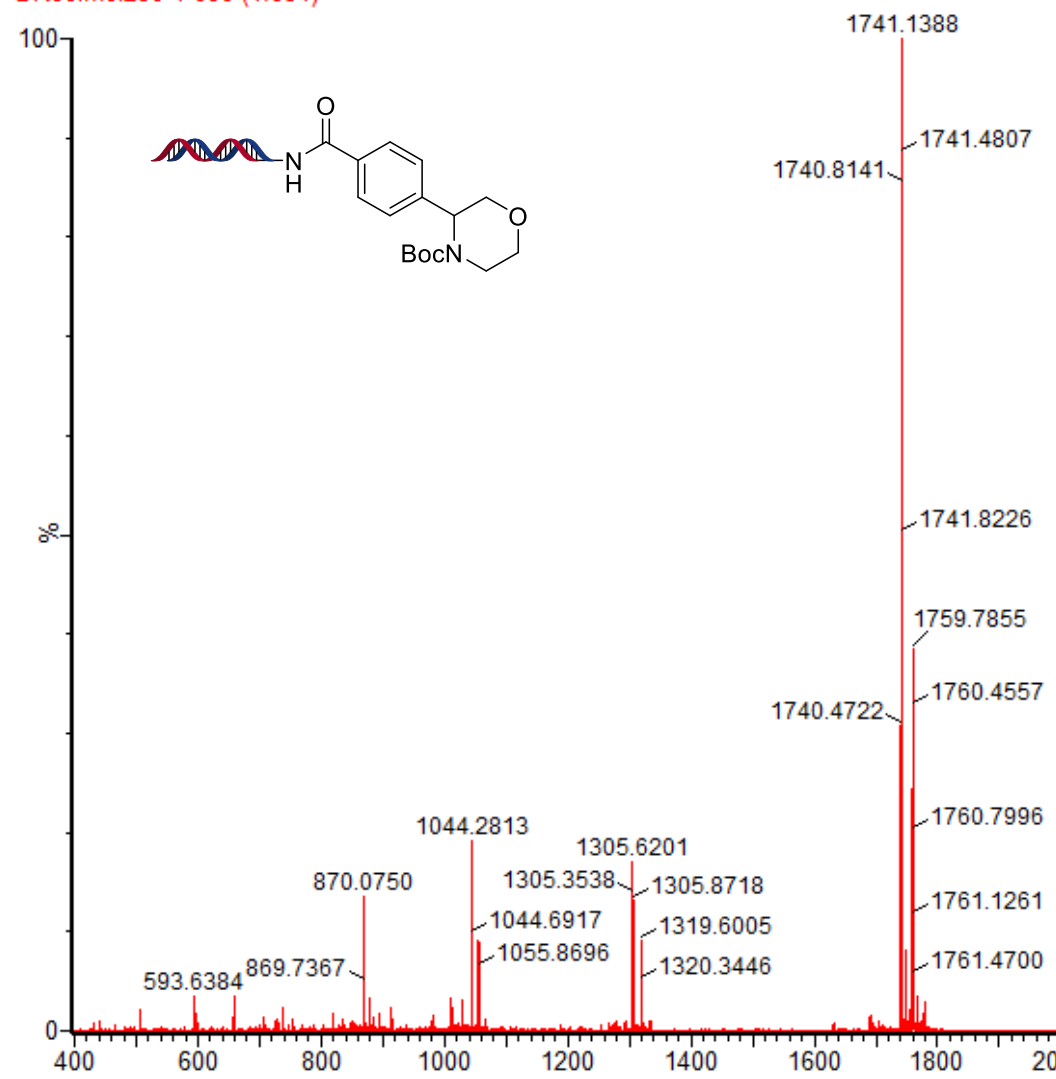

15-May-2018 14:23:09 1. TOF MS ES. $1.52 \mathrm{e} 6$

Figure S156. Mass spectrum of Table 2, entry 11. 


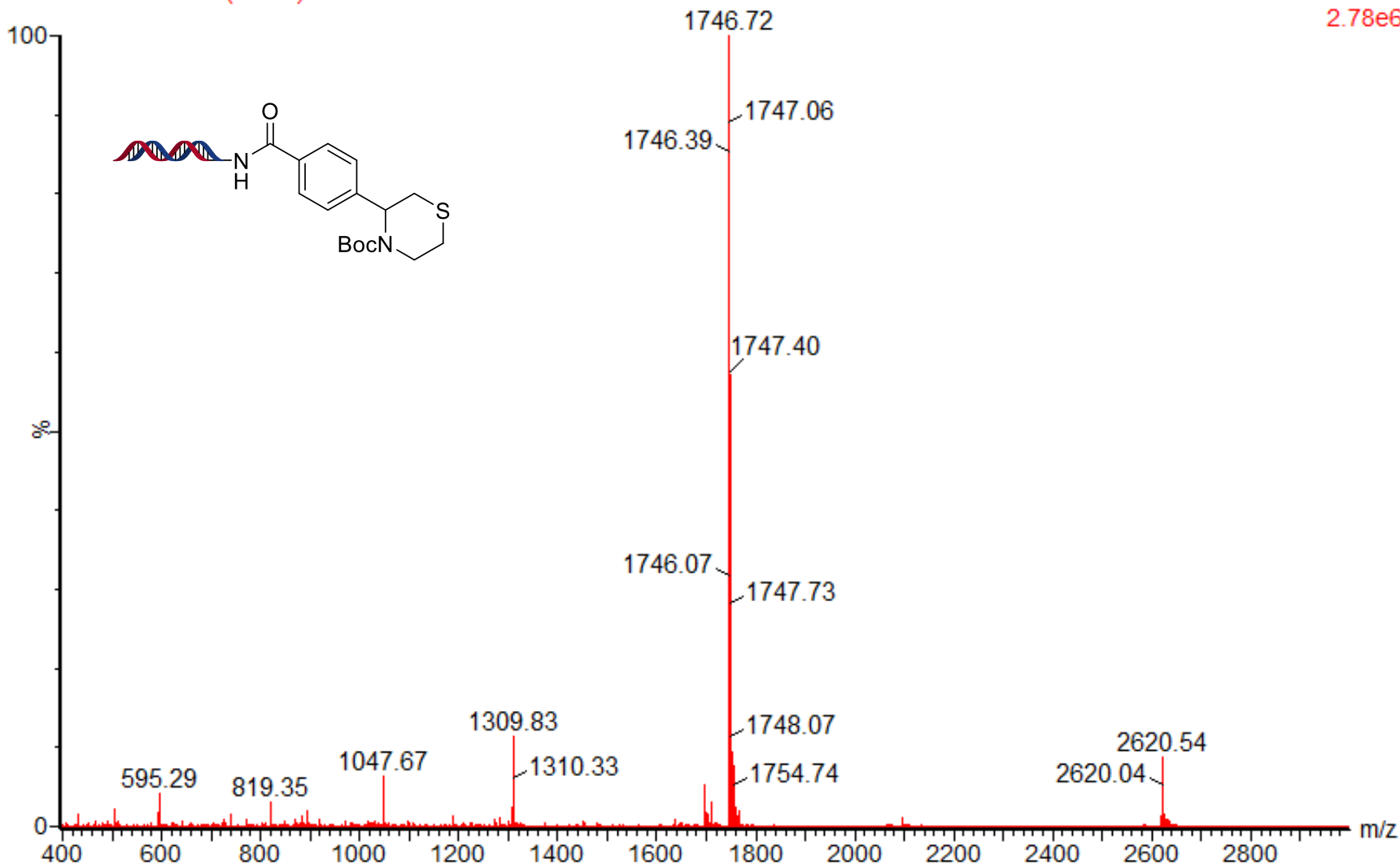

Figure S157. Mass spectrum of Table 2, entry 12.

\section{6-0762-0011:14}

DKoelmel342-1 648 (4.592)
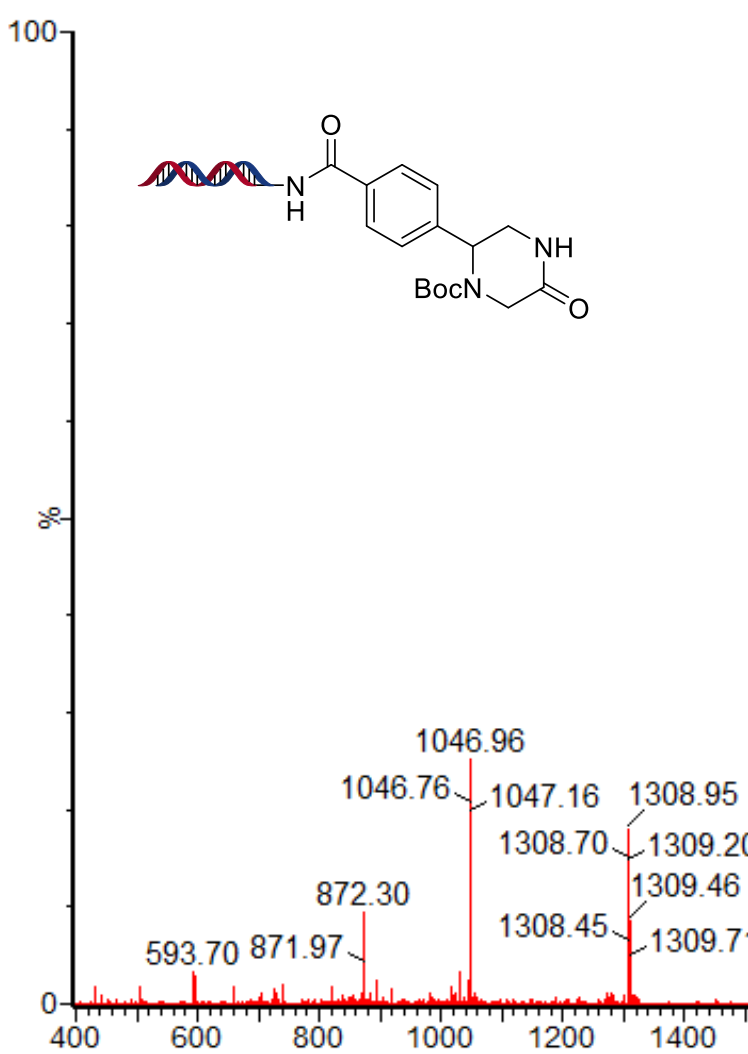

1745.59

1745.24

1745.91

1744.92
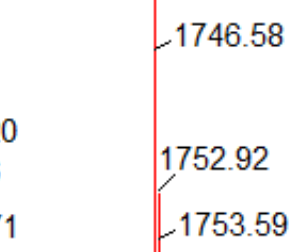

Figure S158. Mass spectrum of Table 2, entry 13. 


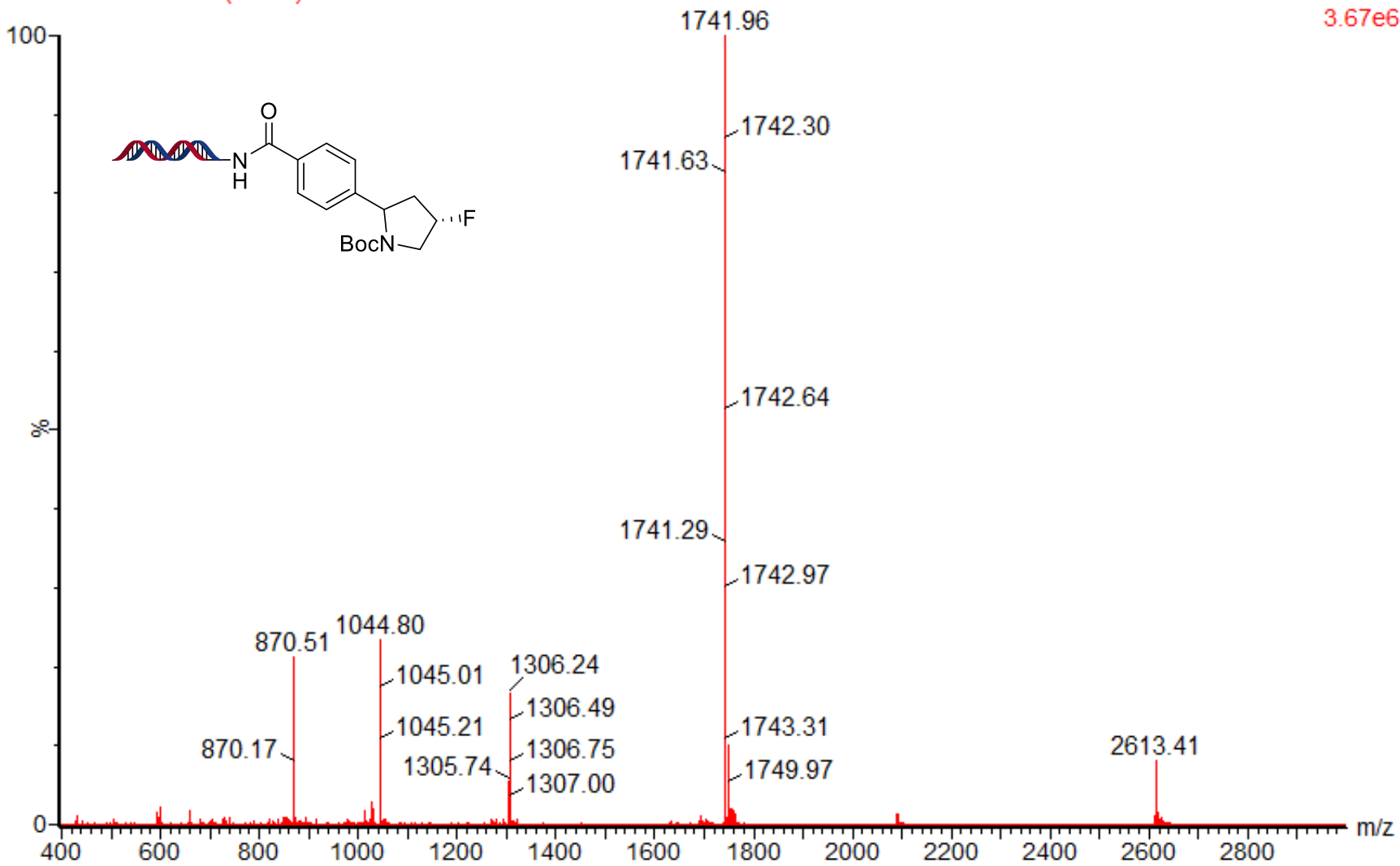

Figure S159. Mass spectrum of Table 2, entry 14.

\section{6-0761-0011:13}

DKoelmel341-1 747 (5.295)

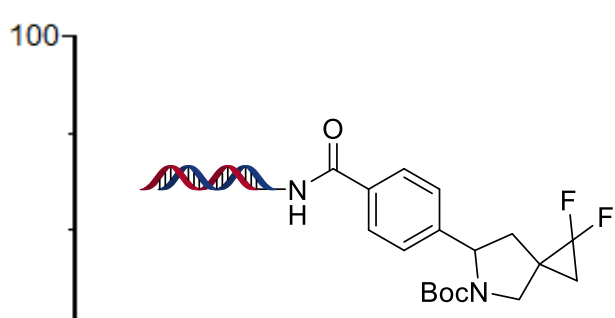

1: TOF MS ES-

$1.37 \mathrm{e} 6$

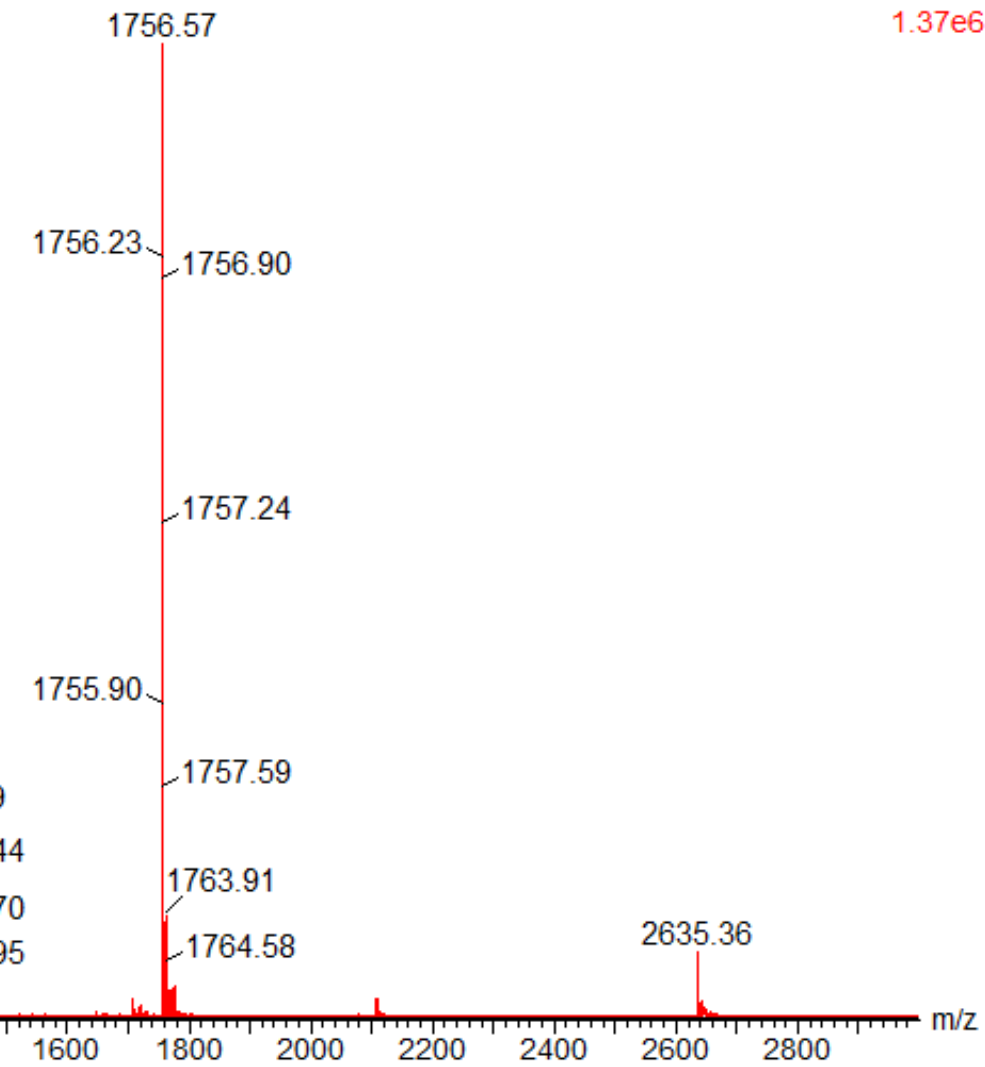

Figure S160. Mass spectrum of Table 2, entry 15. 


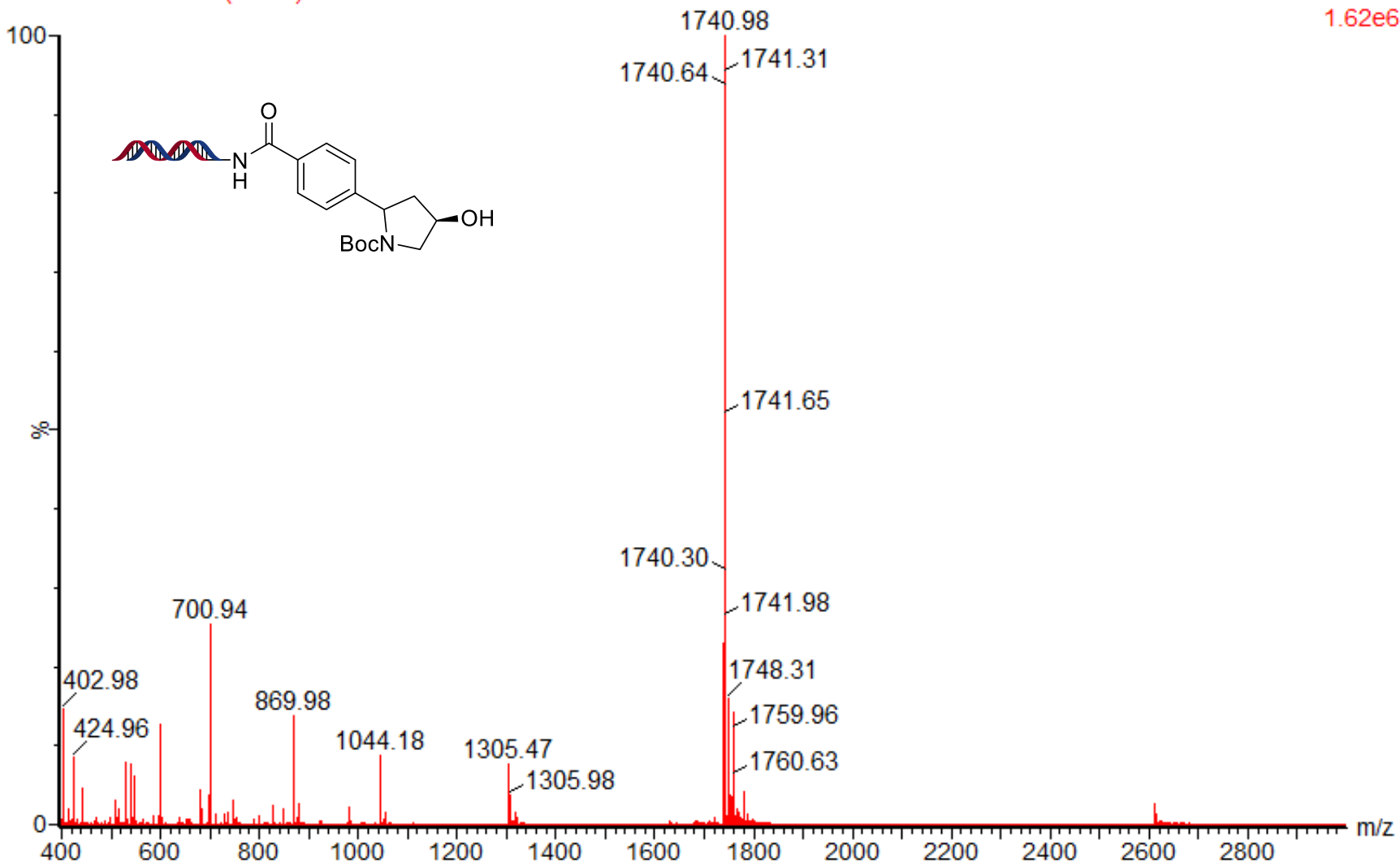

Figure S161. Mass spectrum of Table 2, entry 16.

\section{6-0790-0011:41}

DKoelmel356-1 662 (4.688)

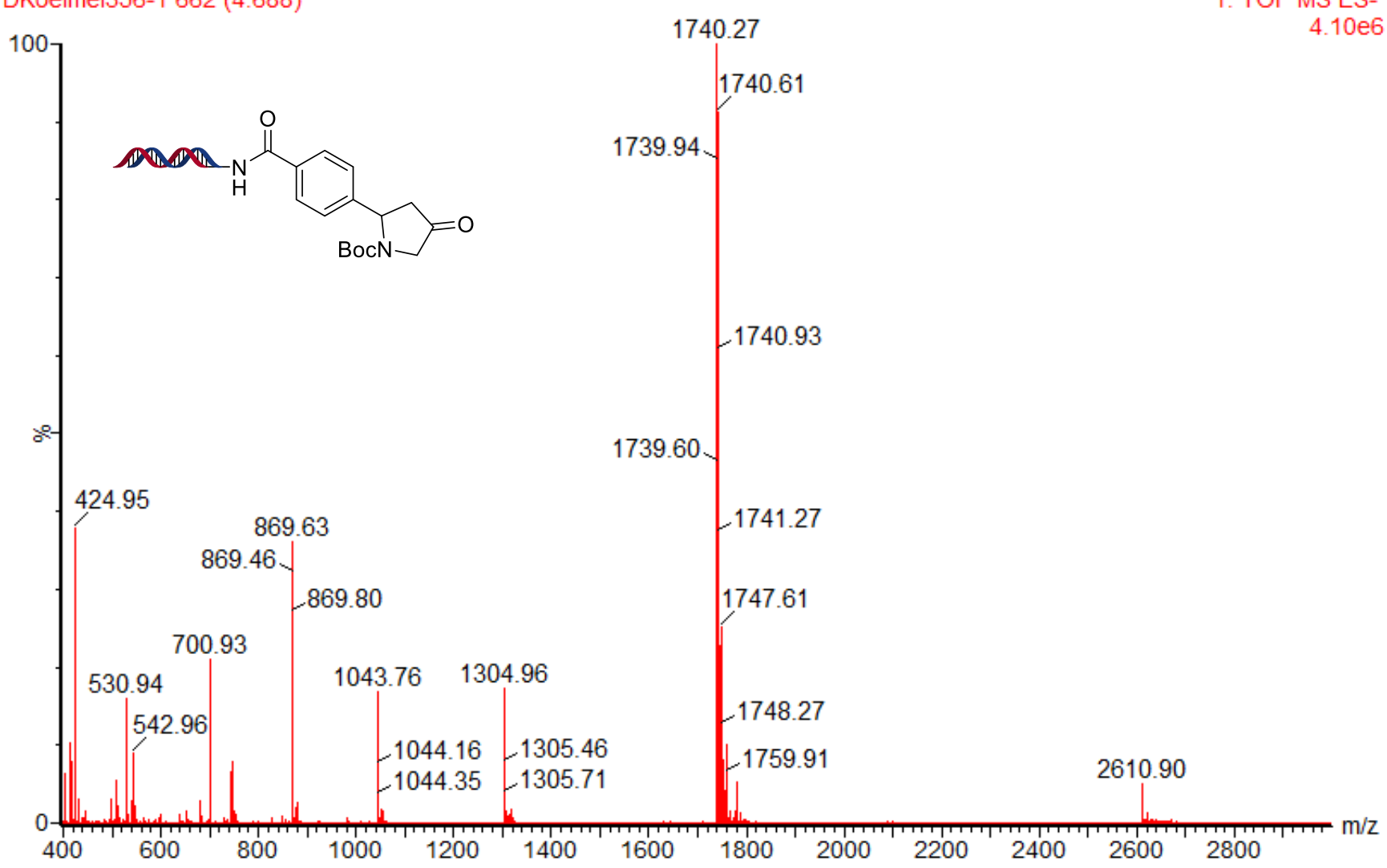

Figure S162. Mass spectrum of Table 2, entry 17. 


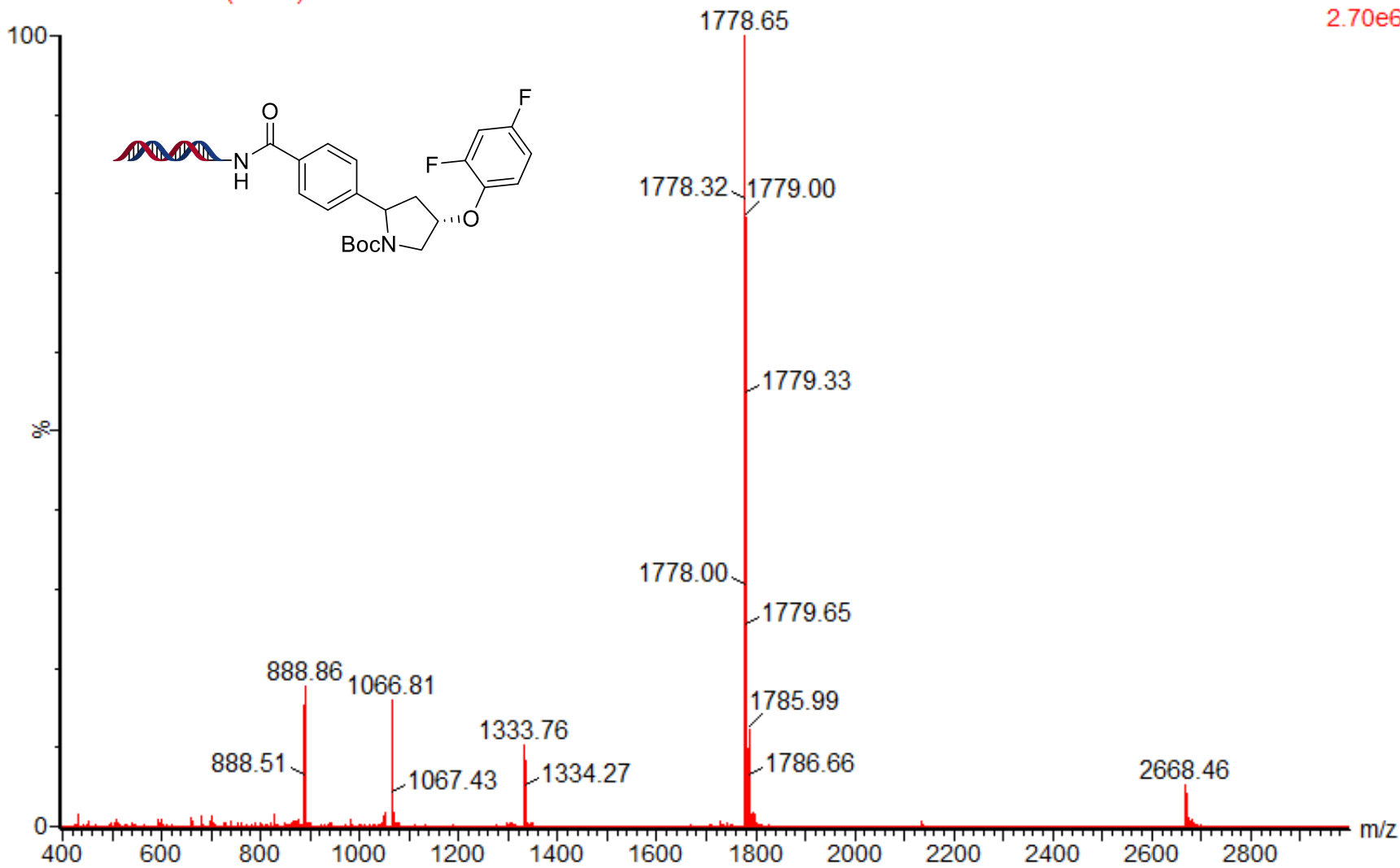

Figure S163. Mass spectrum of Table 2, entry 18.

\section{6-0763-0011:17}

DKoelmel344-1 860 (6.095)
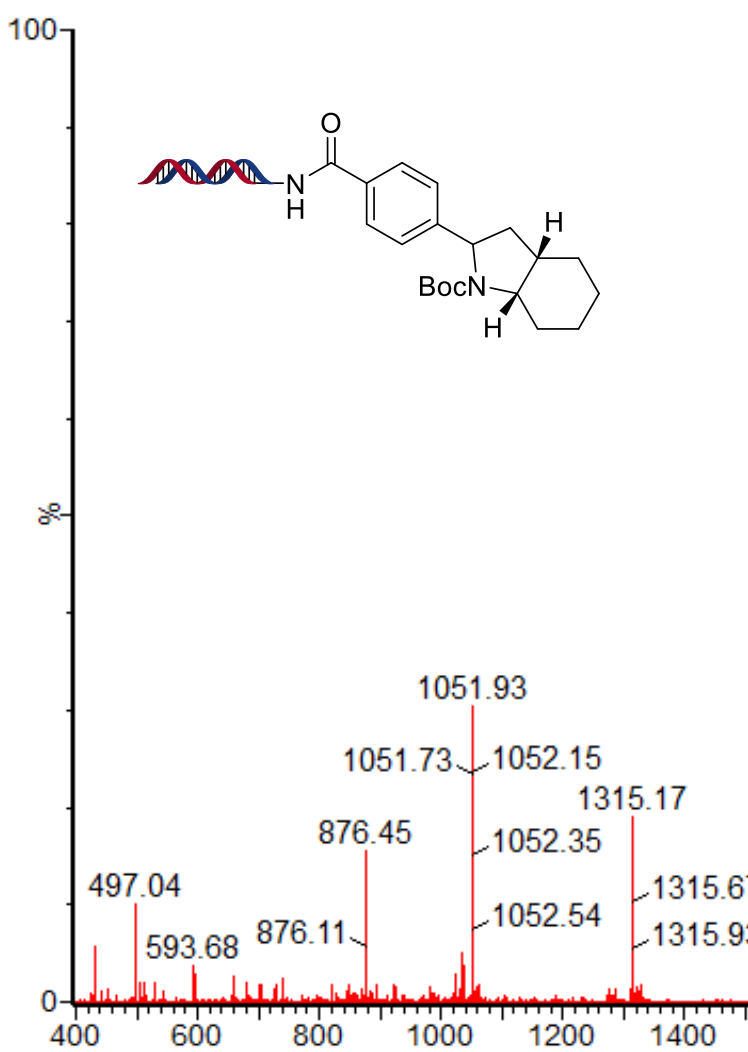

1753.88

1753.54

1754.22

1753.21

1754.87

1761.21

1761.56

1761.88

1772.87
1: TOF MS ES-

$1.02 \mathrm{e} 6$

Figure S164. Mass spectrum of Table 2, entry 19. 


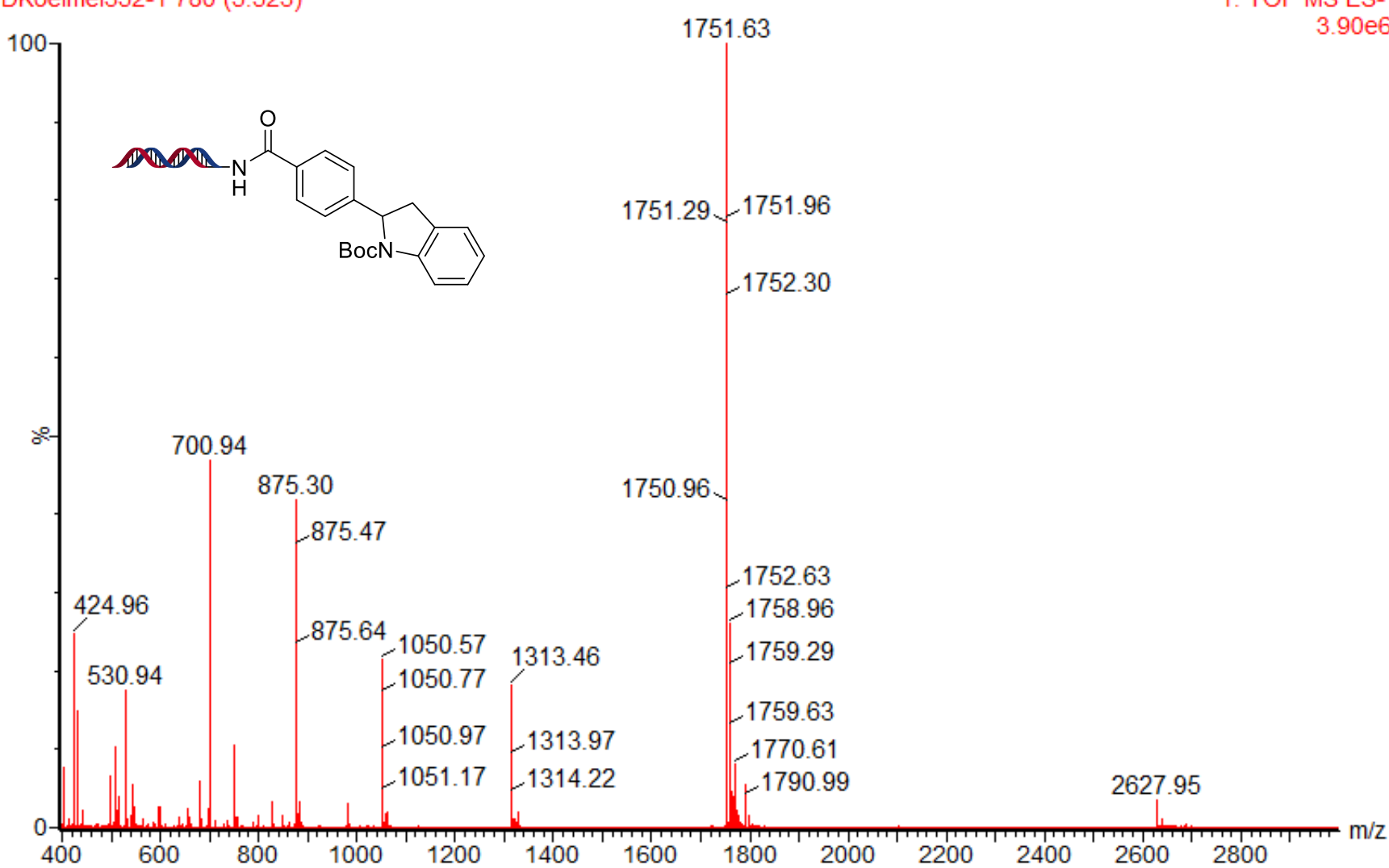

Figure S165. Mass spectrum of Table 2, entry 20.

00712256-0633-00100712256-0633-001

DKoelmel251-3 739 (5.240)
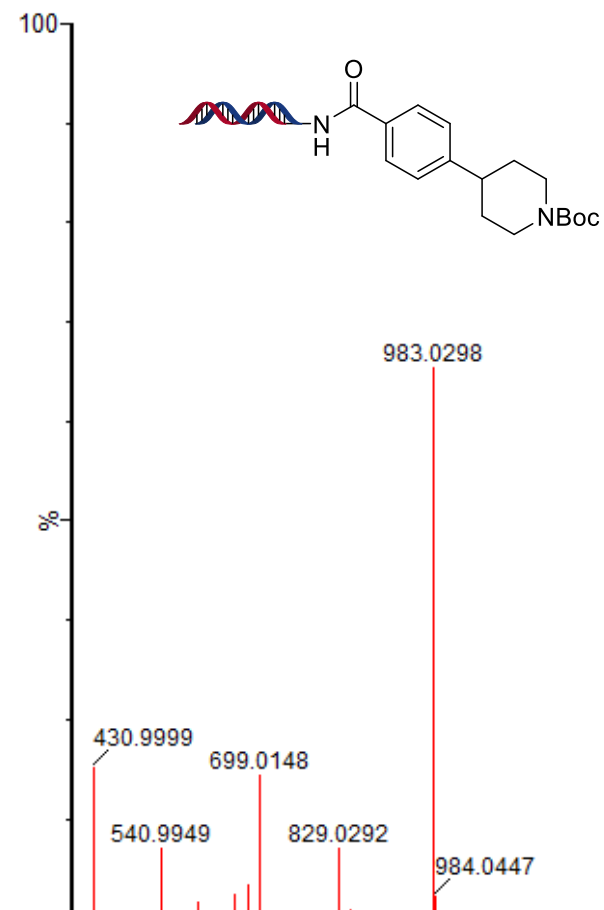

40.5063

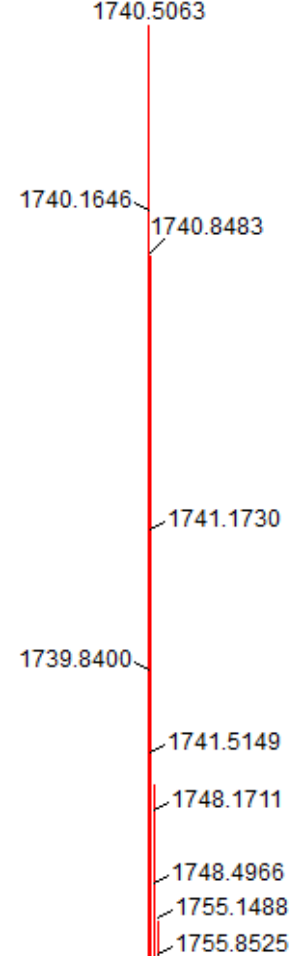

15-May-2018 19:06:49 1: TOF MS ES-

$7.94 \mathrm{e} 4$ 


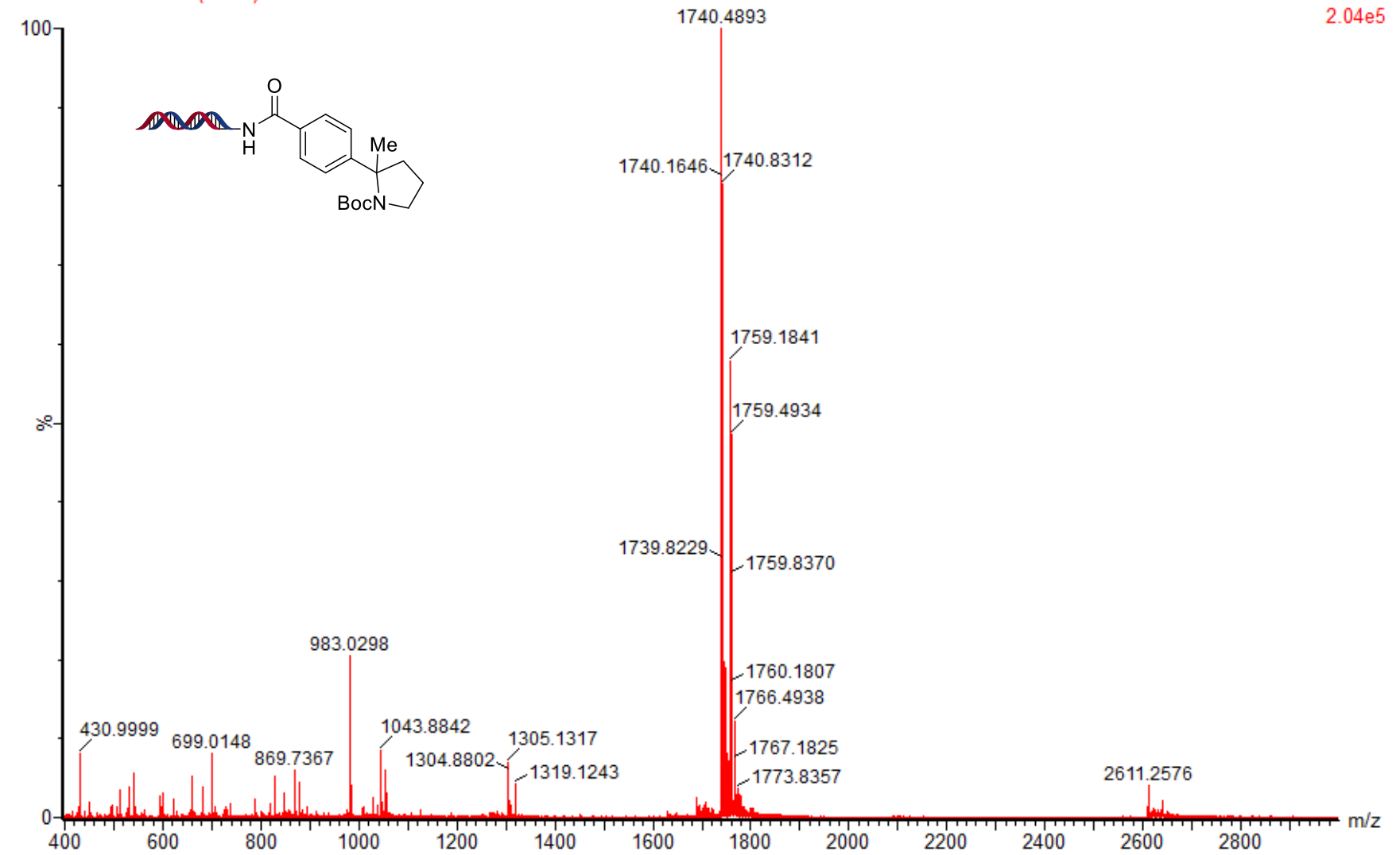

Figure S167. Mass spectrum of Table 2, entry 22.

00712256-0635-00100712256-0635-001

DKoelmel252-1 664 (4.702)

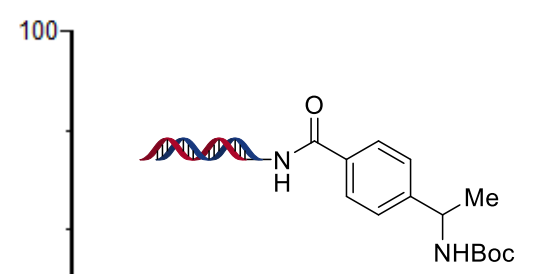

16-May-2018 12:07:33

1: TOF MS ES-

$5.04 \mathrm{e} 5$ 


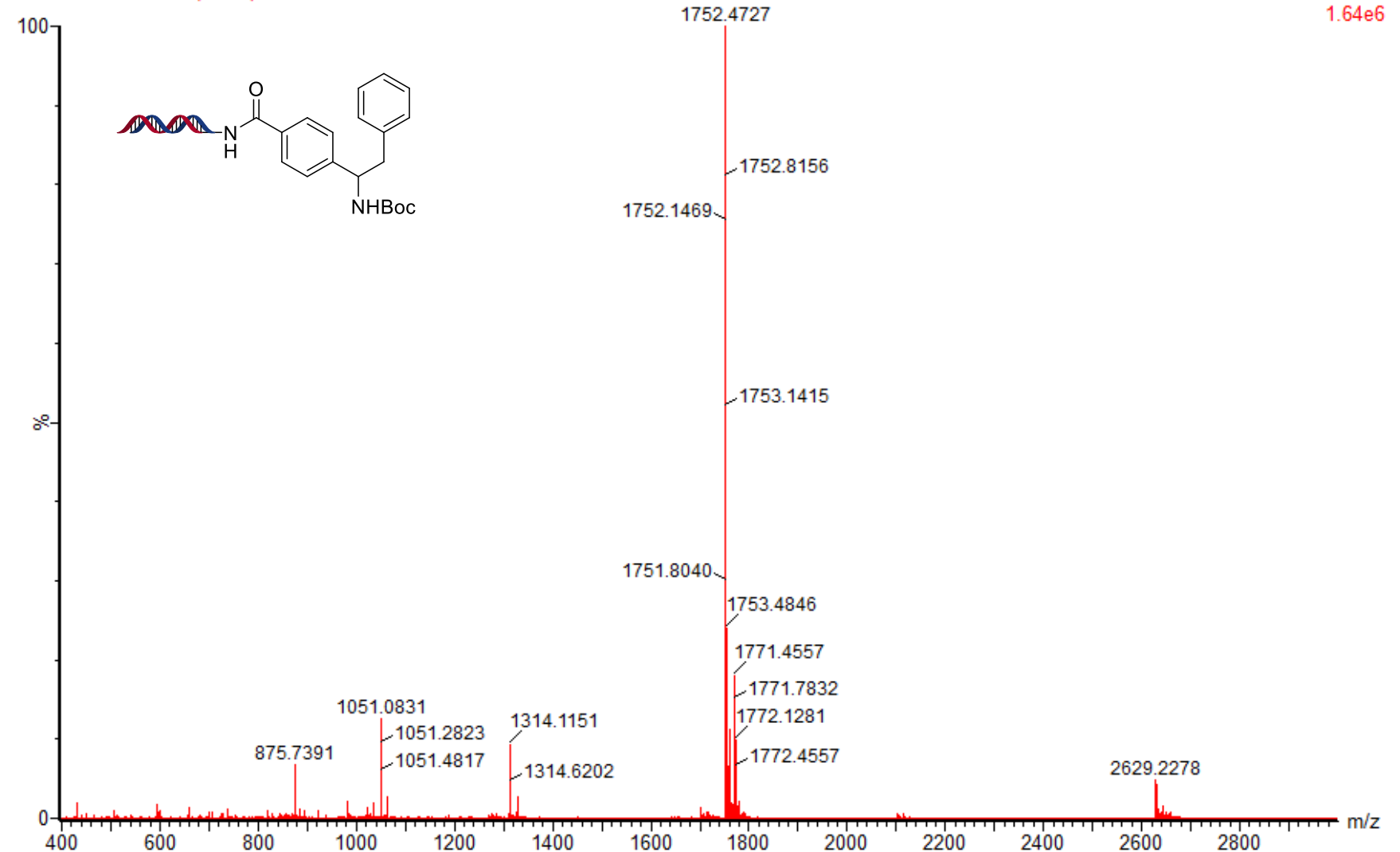

Figure S169. Mass spectrum of Table 2, entry 24.

\section{6-0795-0011:46}

DKoelmel358-2 639 (4.530)

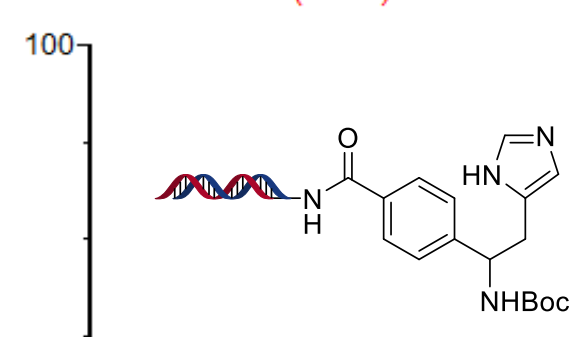

1: TOF MS ES-

$3.72 \mathrm{e} 6$

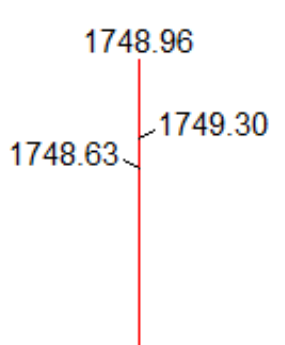

1749.63

1748.29

1749.97

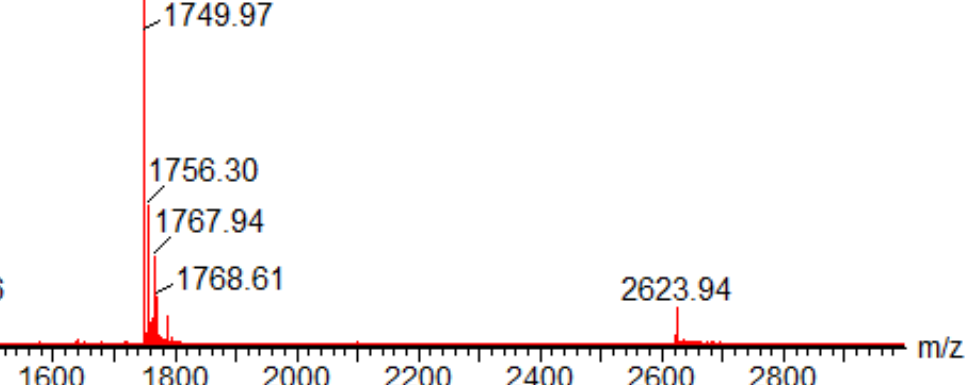

Figure S170. Mass spectrum of Table 2, entry 25. 


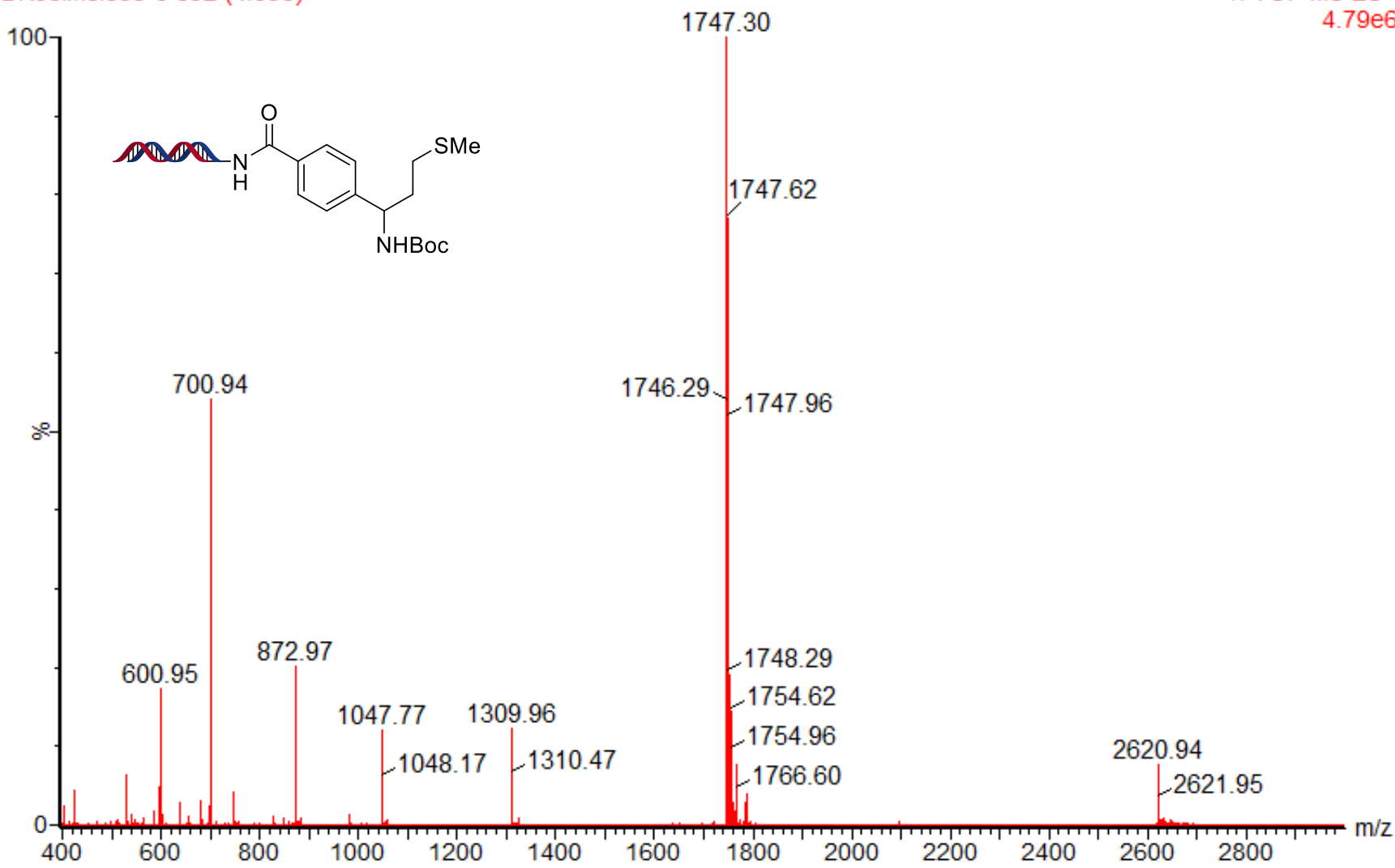

Figure S171. Mass spectrum of Table 2, entry 26.

\section{6-0826-0011:27}

DKoelmel364-1 690 (4.882)

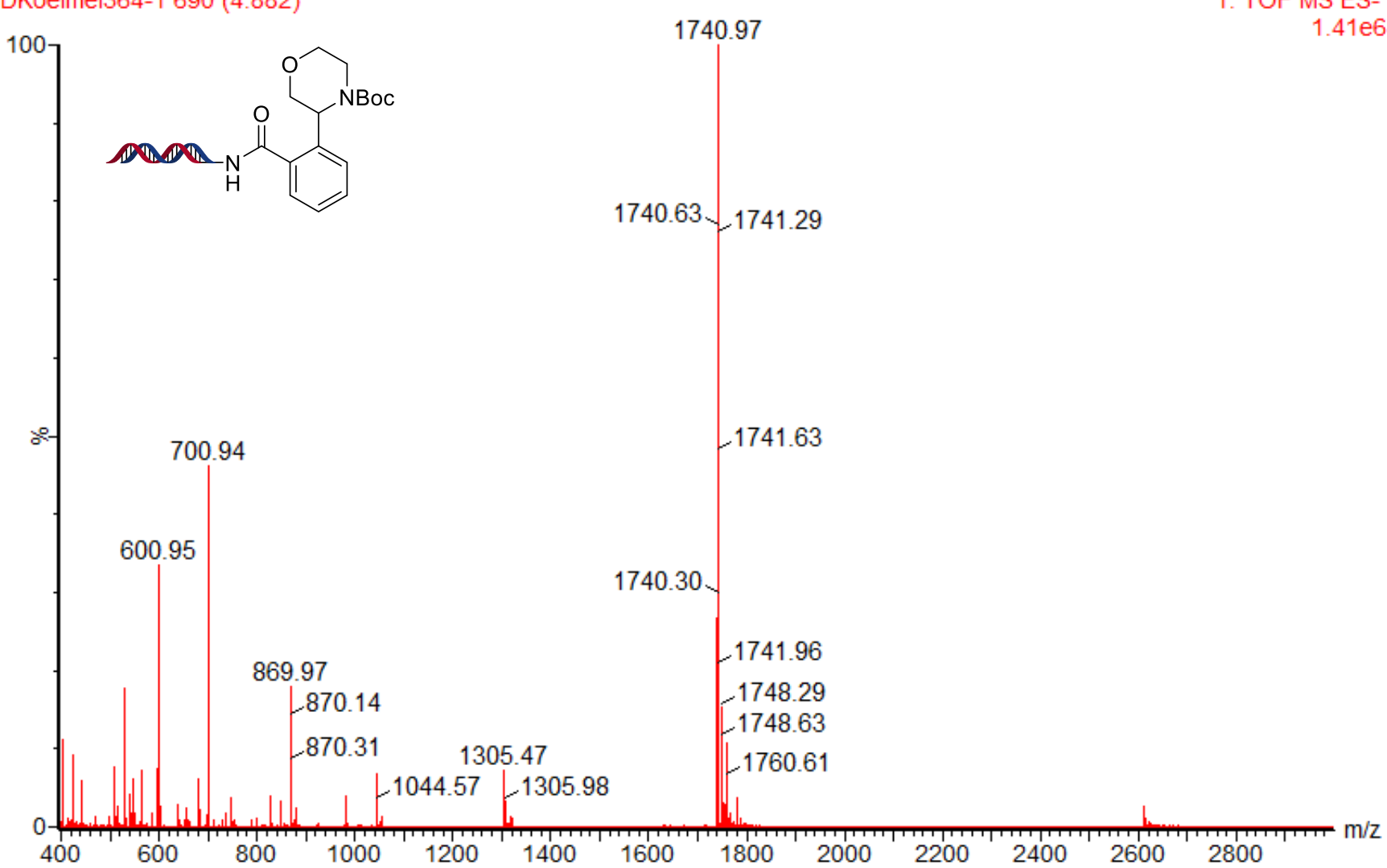

Figure S172. Mass spectrum of Table 3, entry 1 . 


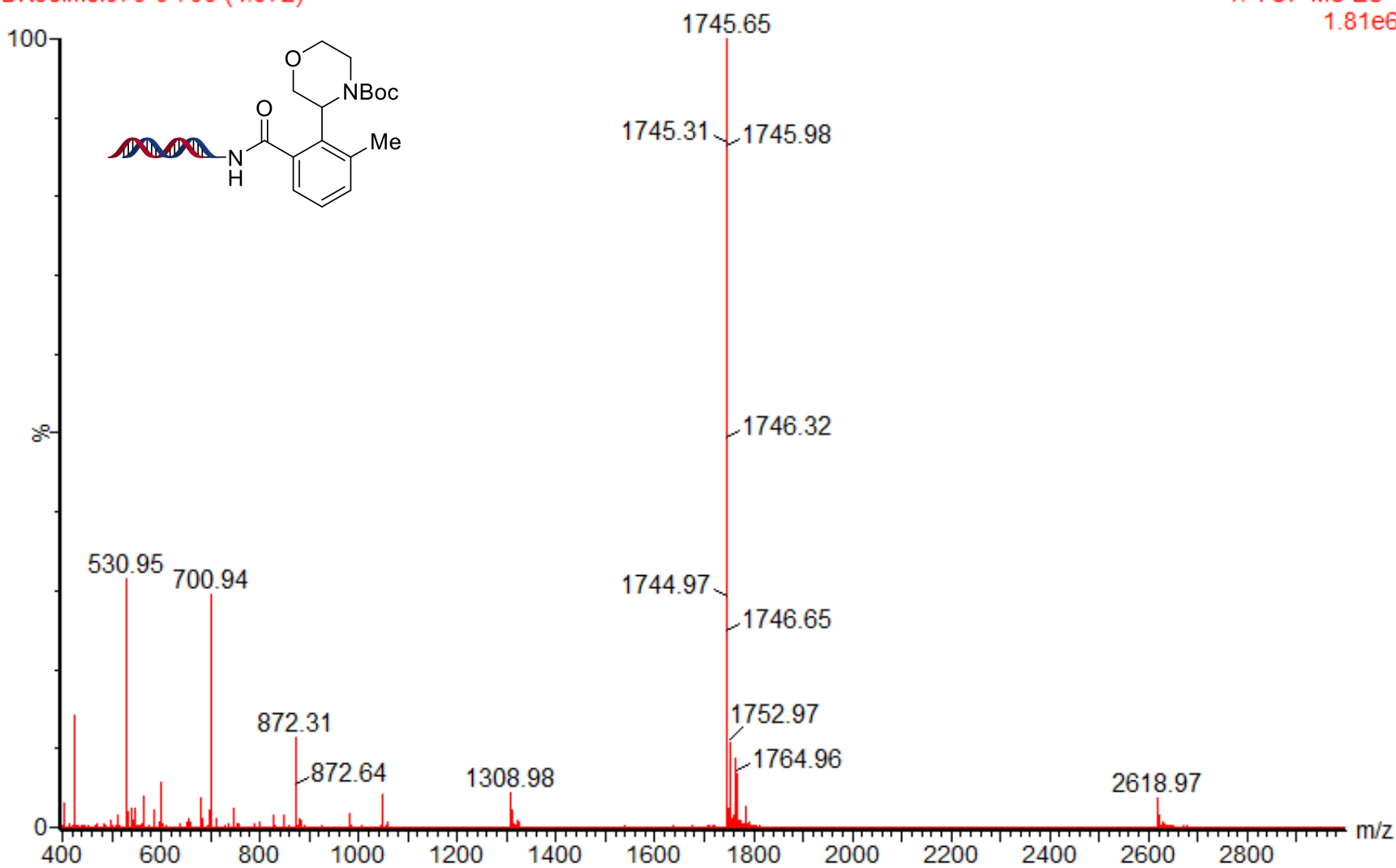

Figure S173. Mass spectrum of Table 3, entry 2.

\section{6-0835-0011:1}

DKoelmel372-1 680 (4.813)<smiles>O=C(O)Oc1ccc(NC(=O)c2ccc3c(c2C2COCCN2C(=O)O)OCO3)cc1</smiles>

1: TOF MS ES-

$1.45 \mathrm{e} 6$

700.95

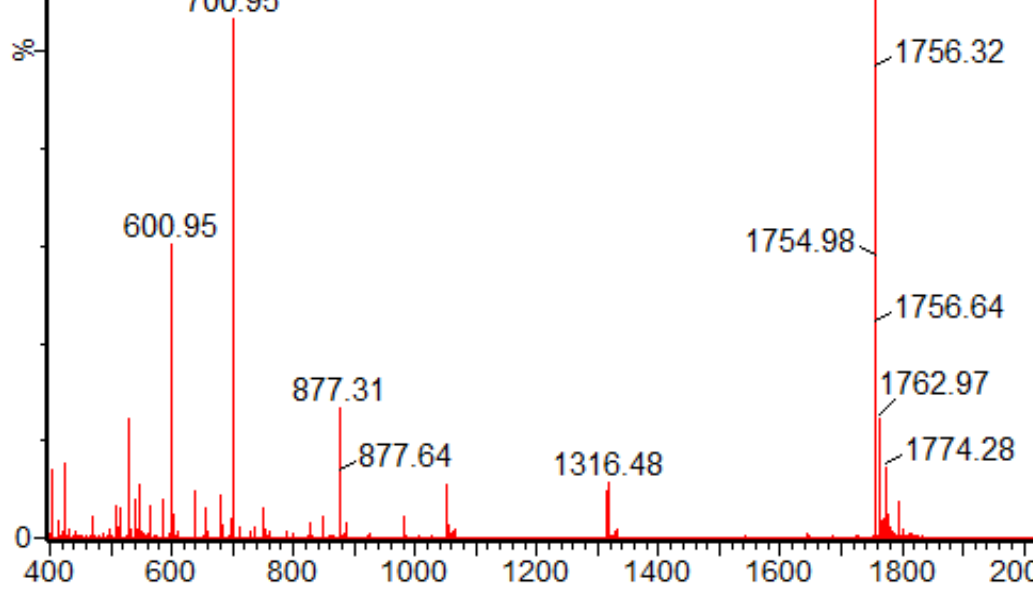

1755.65

1755.97

1755.30

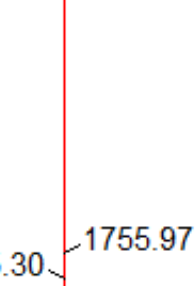

Figure S174. Mass spectrum of Table 3, entry 3. 


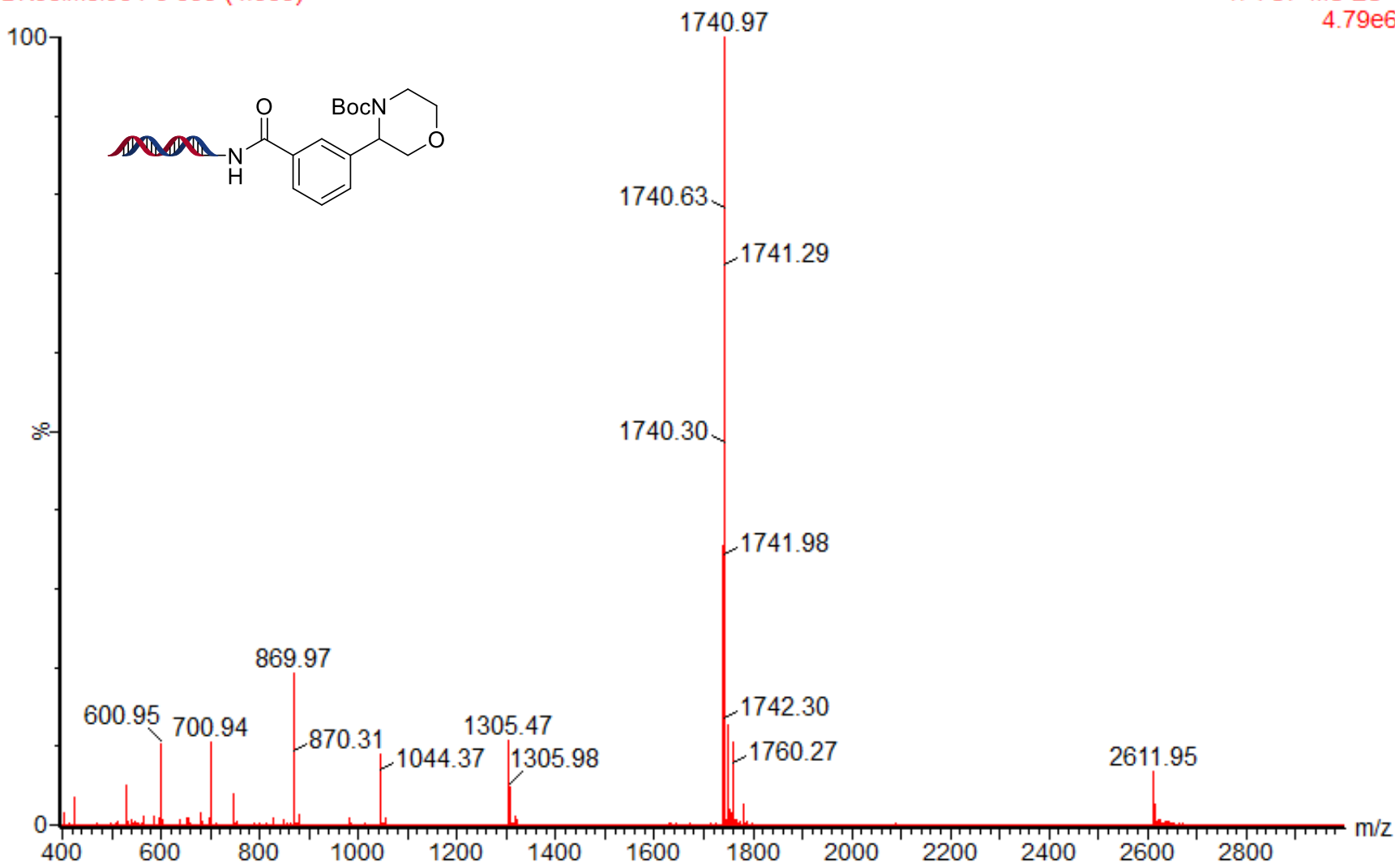

Figure S175. Mass spectrum of Table 3, entry 4.

\section{6-0833-0011:1}

DKoelmel371-1 718 (5.095)

100<smiles>CC(C)(C)OC(=O)c1cc(Br)cc(C(=O)Nc2ccccc2)c1</smiles>

1767.25

$\therefore$

$\left.530.94^{700.94}\right|_{883.46} ^{883.11}$
1767.60

1766.60

67.60

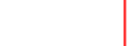

1767.92

$1766.25 \sqrt{1768.59}$

1325.19 1059.94

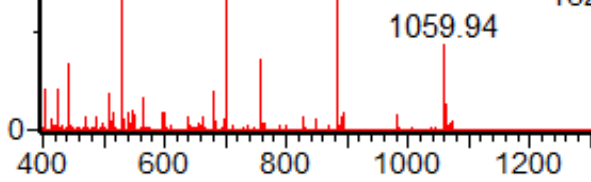
1325.70

1775.25

1786.57

1: TOF MS ES-

$3.14 \mathrm{e} 6$

Figure S176. Mass spectrum of Table 3, entry 5. 


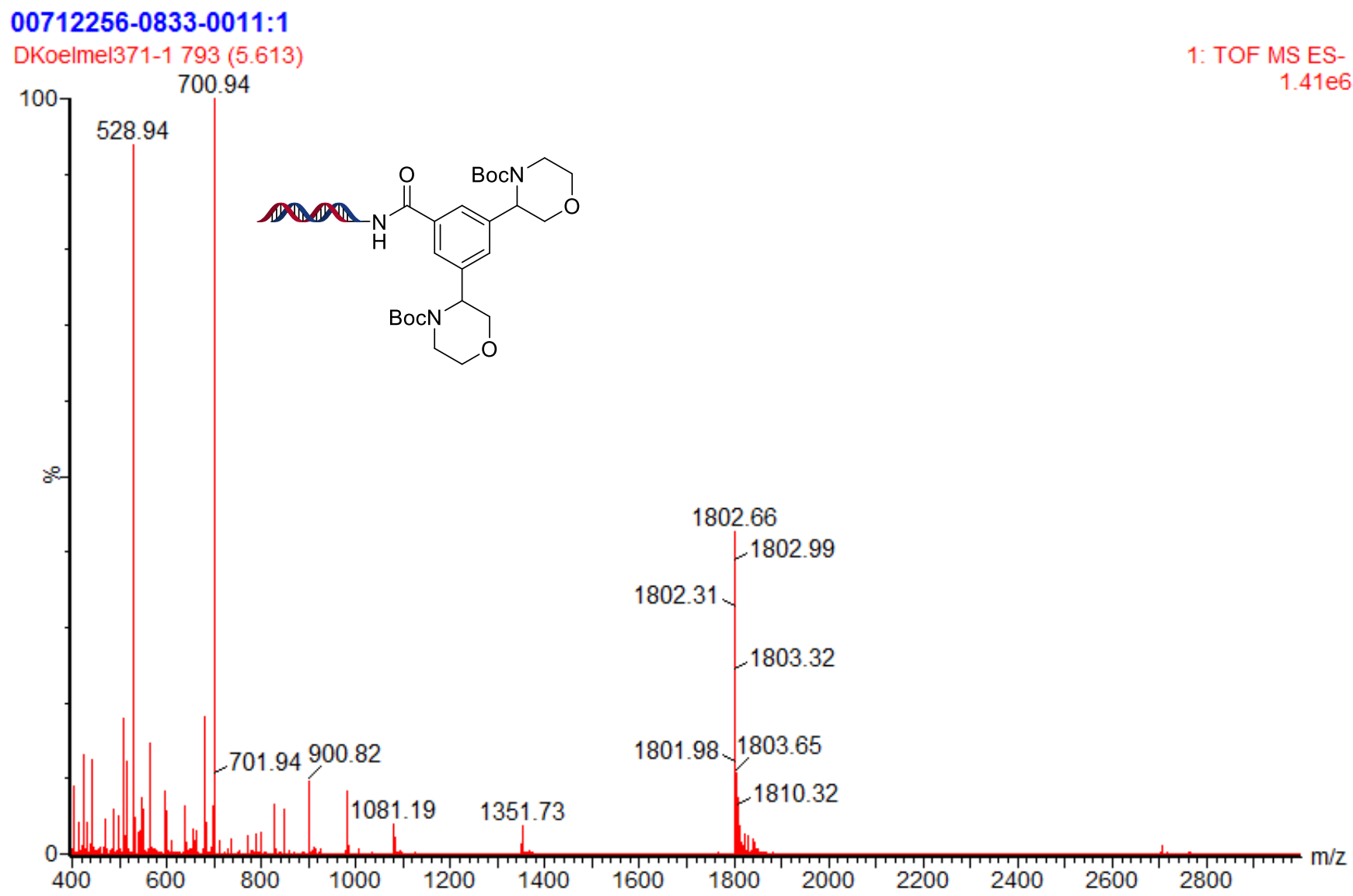

Figure S177. Mass spectrum of Table 3, entry 5 (dialkylated side product).

\section{6-0879-0011:2}

DKoelmel396-3 714 (5.048)

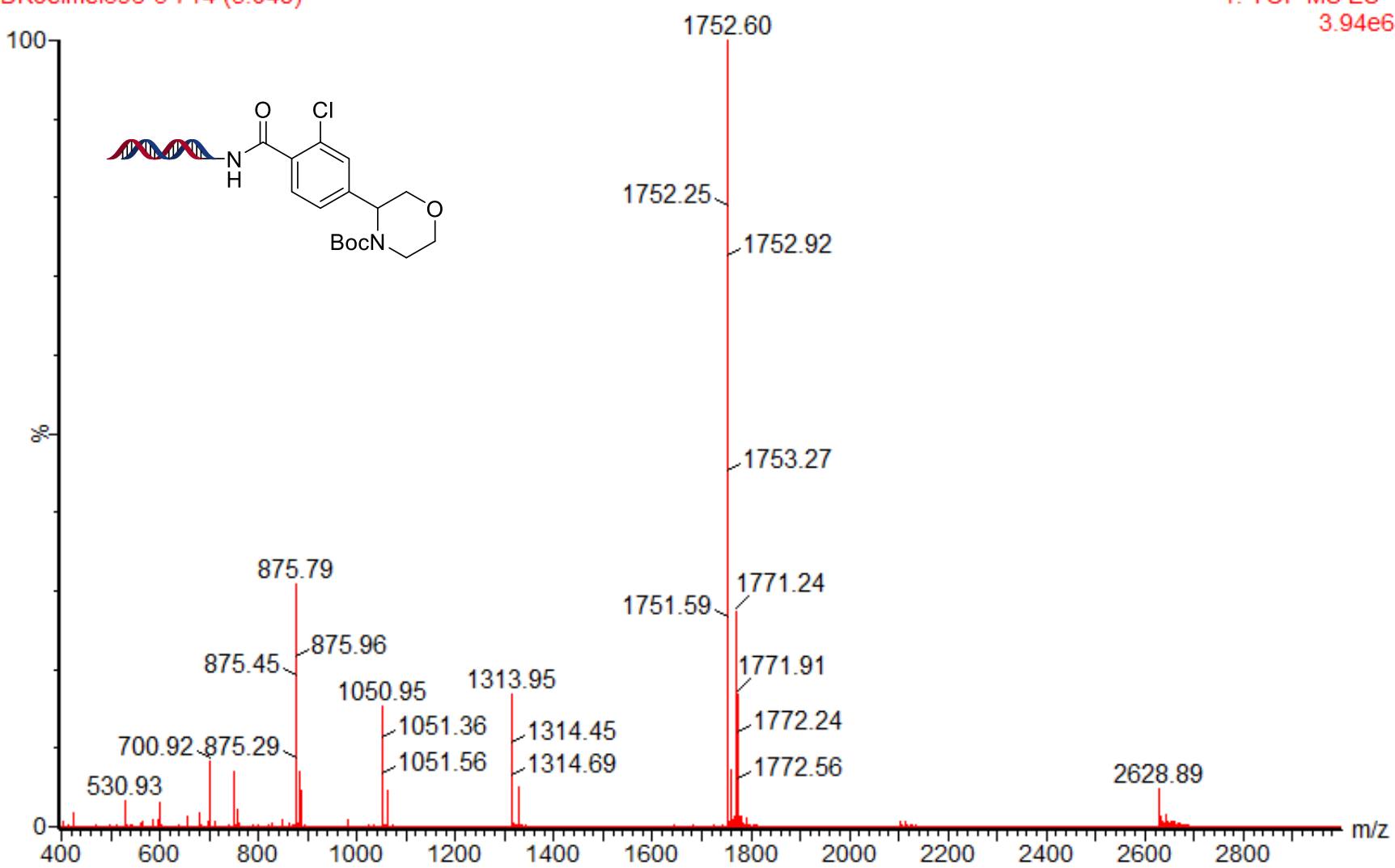

Figure S178. Mass spectrum of Table 3, entry 6. 


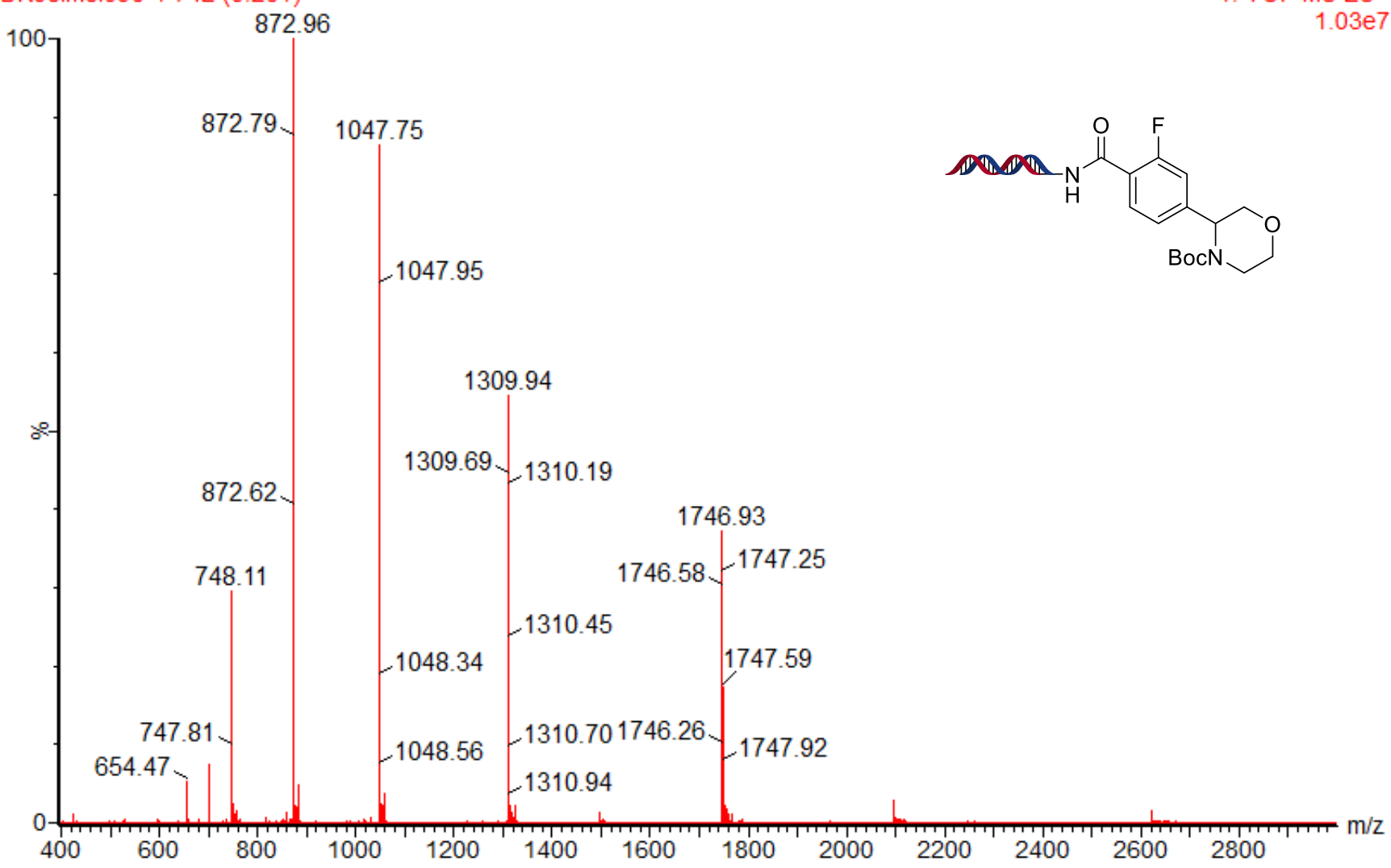

Figure S179. Mass spectrum of Table 3, entry 7.

\section{6-0888-001-Repeat1:7}

DKoelmel399-2 725 (5.143)<smiles>O=C(Nc1ccc(C(=O)OCc2ccccc2)cc1)c1ccc(C(F)(F)F)cc1</smiles>

881.30

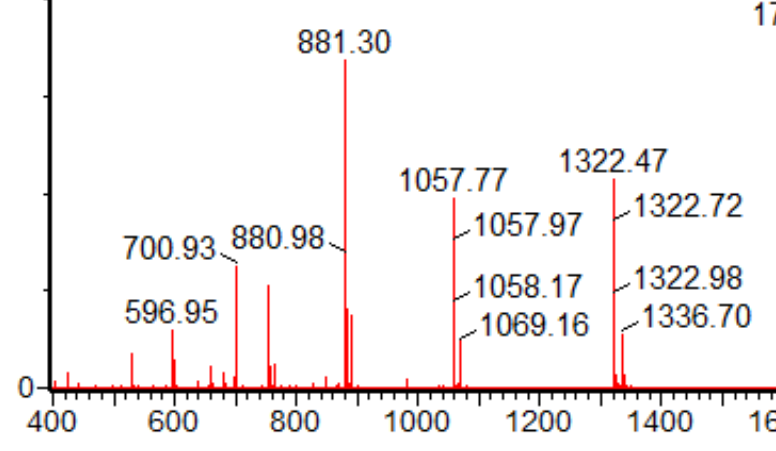

1763.30

1: TOF MS ES-

$3.78 \mathrm{e} 6$

1762.95

1764.64

2645.95

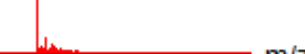

Figure S180. Mass spectrum of Table 3, entry 8. 


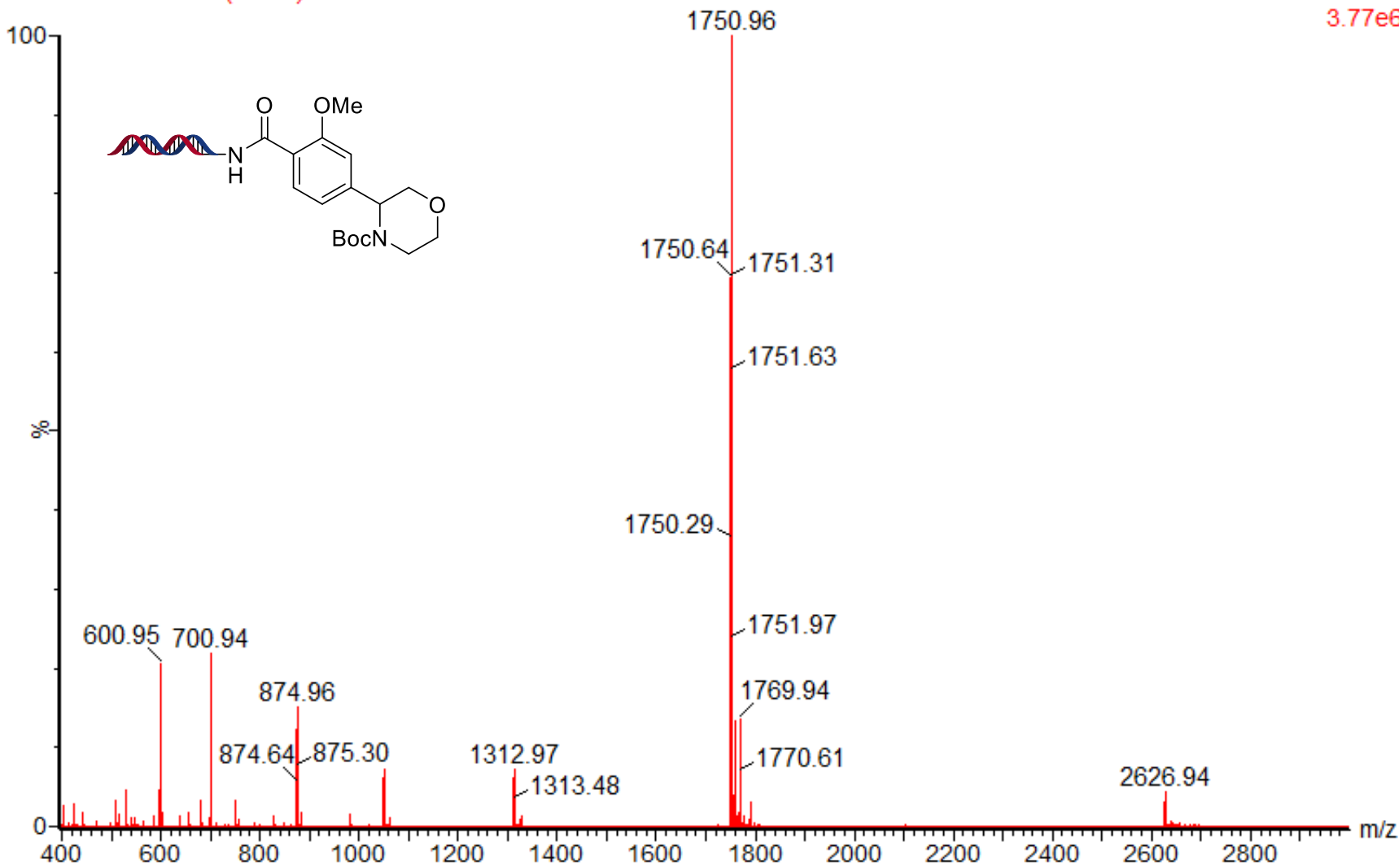

Figure S181. Mass spectrum of Table 3, entry 9.

\section{6-0837-0011:3}

DKoelmel373-1 702 (4.965)

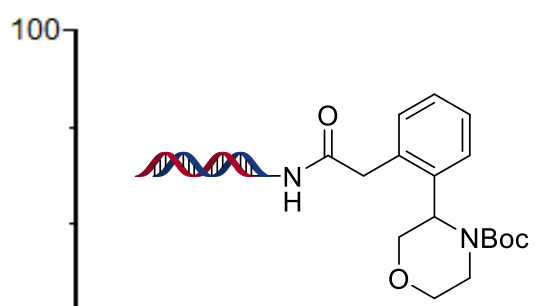

700.94

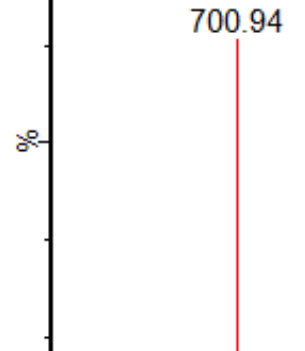

530.96

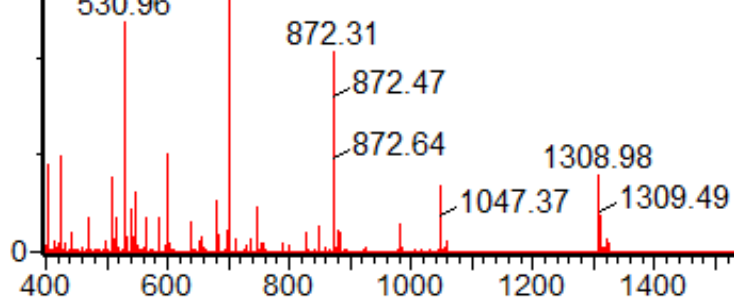

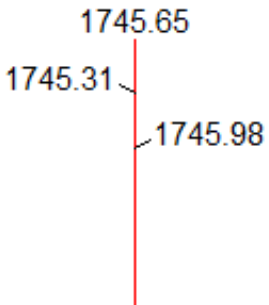

1746.32

1744.97

1746.65

1752.97

1753.31

1764.96

Figure S182. Mass spectrum of Table 3, entry 10. 


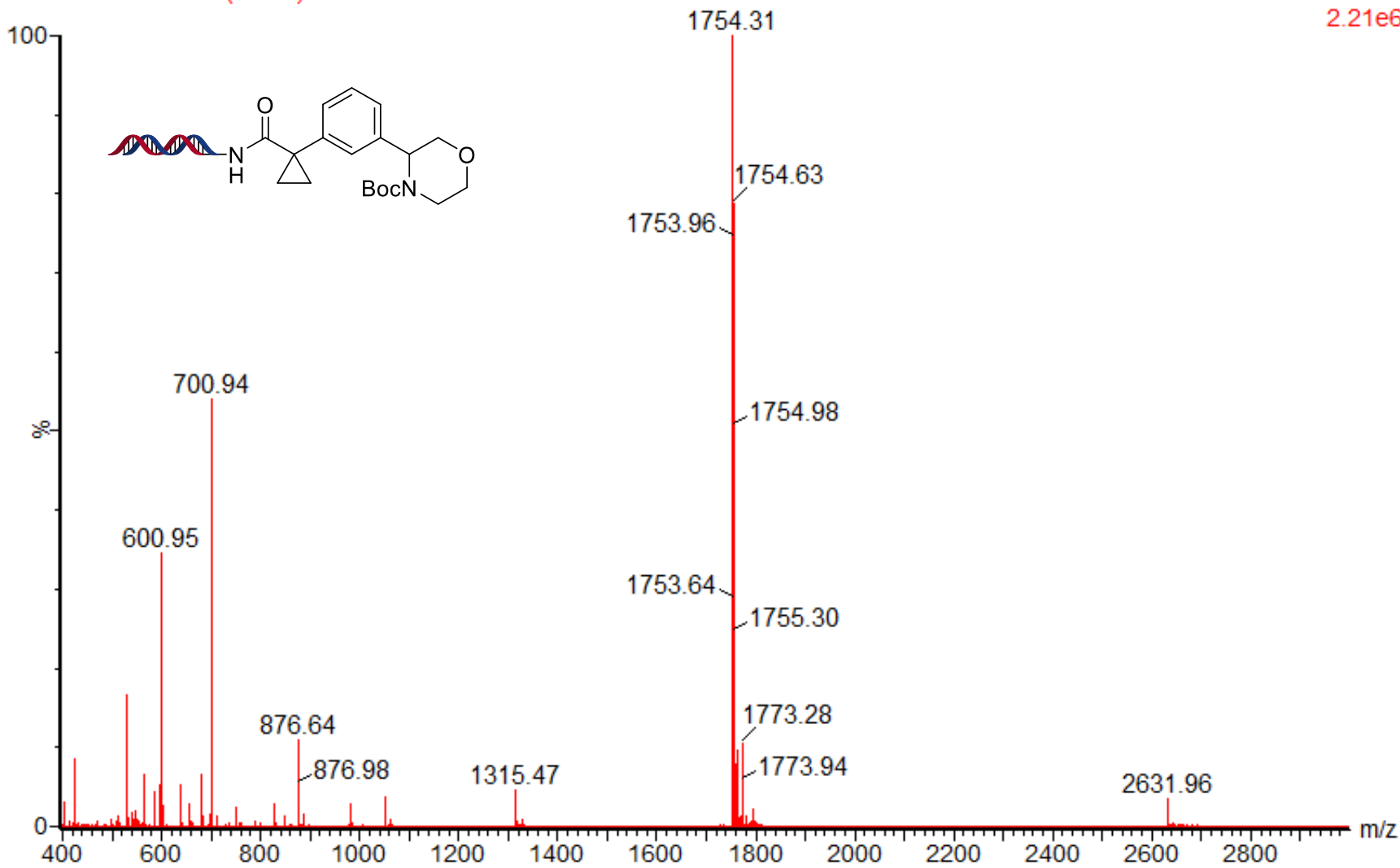

Figure S183. Mass spectrum of Table 3, entry 11.

\section{6-0861-001-Repeat1:12}

DKoelmel383-2 695 (4.916)

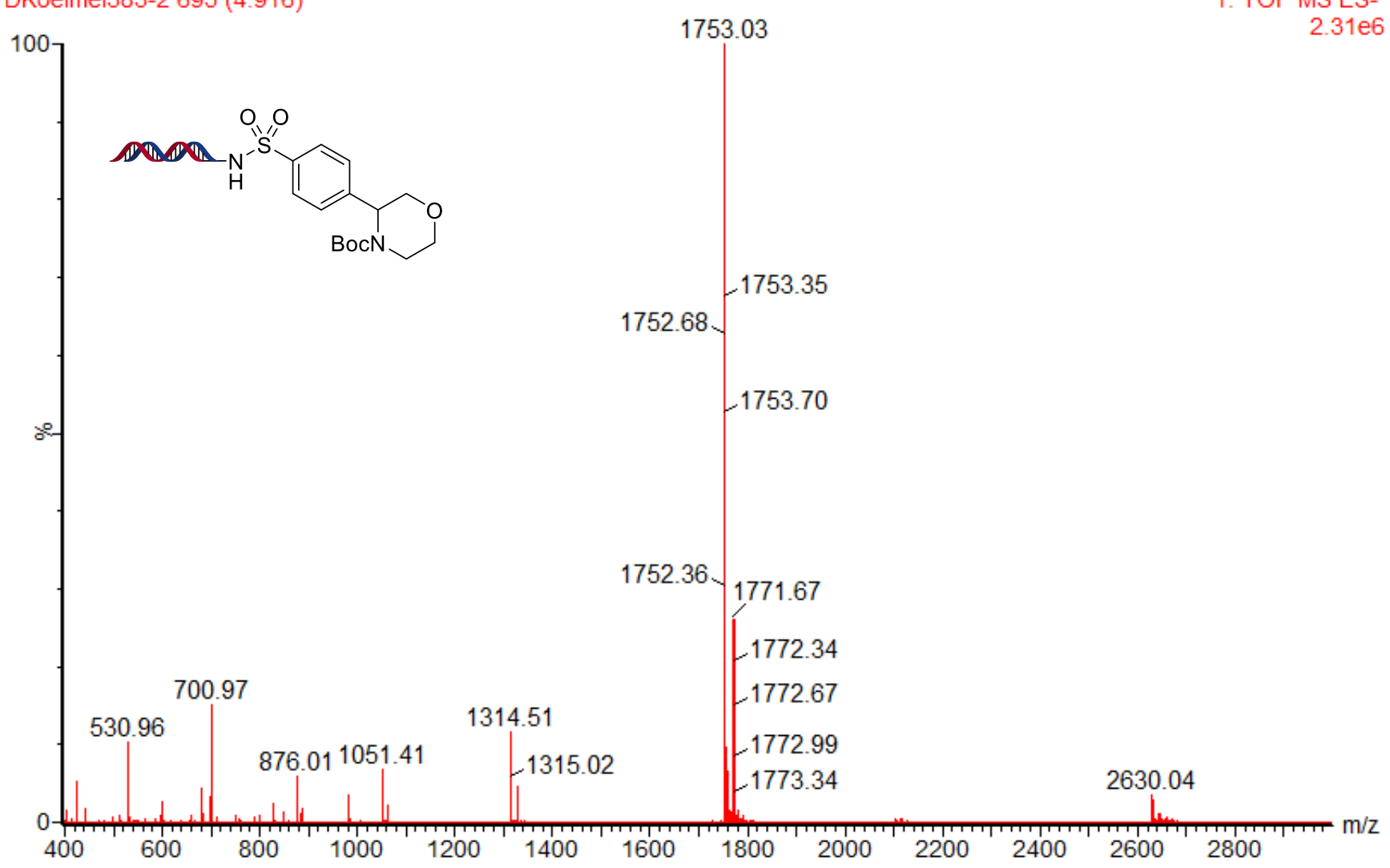

Figure S184. Mass spectrum of Table 3, entry 12 (from aryl iodide S12). 


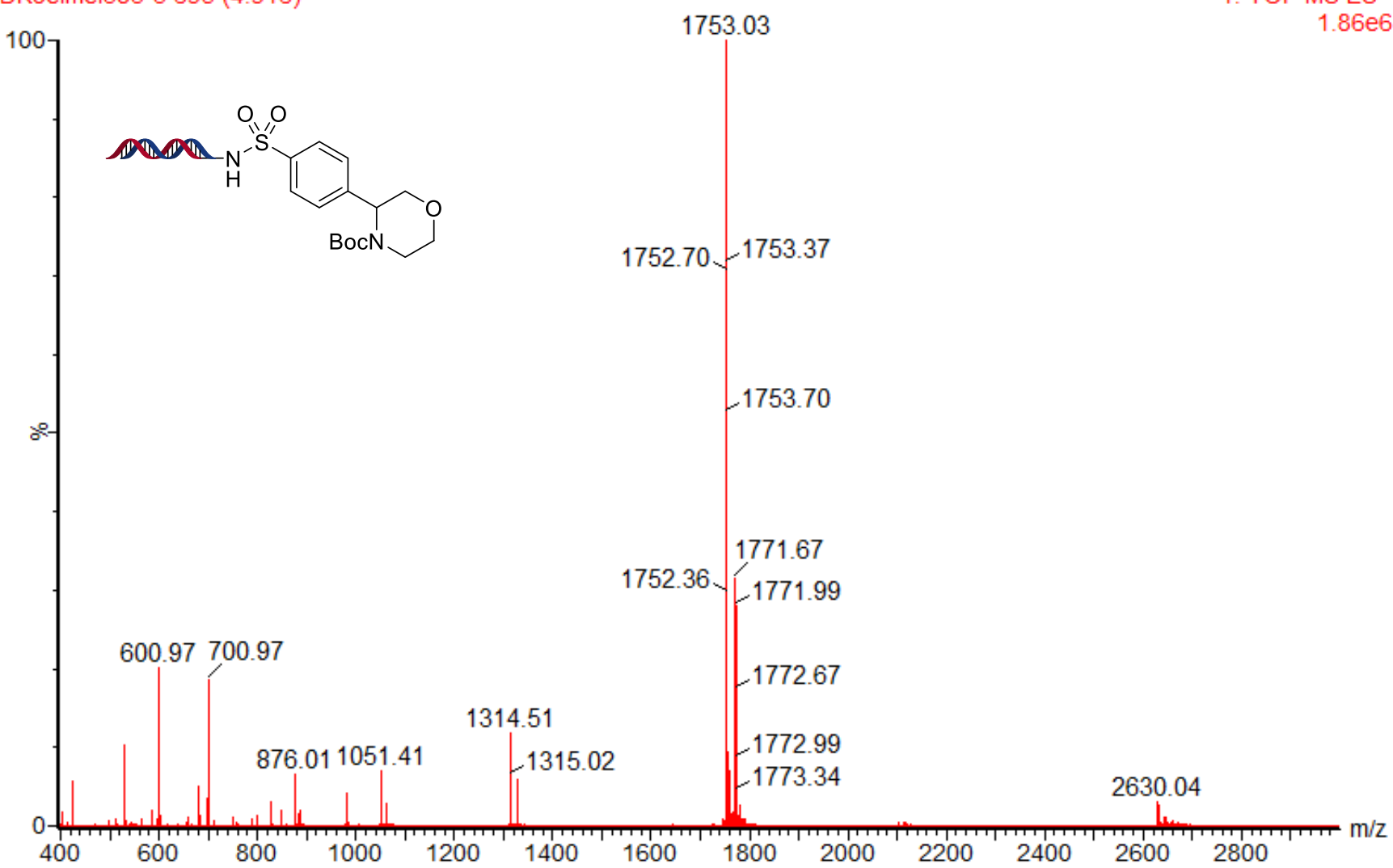

Figure S185. Mass spectrum of Table 3, entry 12 (from aryl bromide S13).

\section{6-0849-0011:2}

DKoelmel377-3 680 (4.813)<smiles>N#Cc1cc(C(=O)Nc2ccc(OC(=O)OCc3ccccc3)cc2)ccc1C1COCCN1C(=O)O</smiles>

874.17

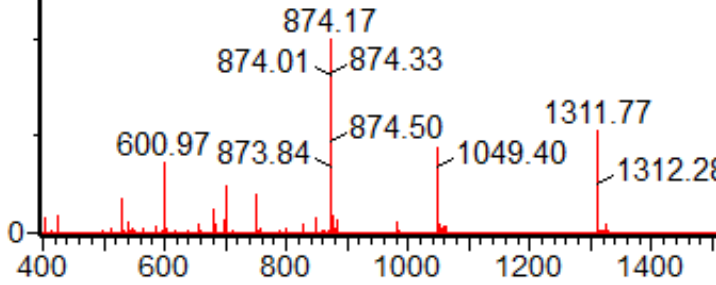

1749.37

1: TOF MS ES-

$3.77 \mathrm{e} 6$

Figure S186. Mass spectrum of Table 3, entry 13. 


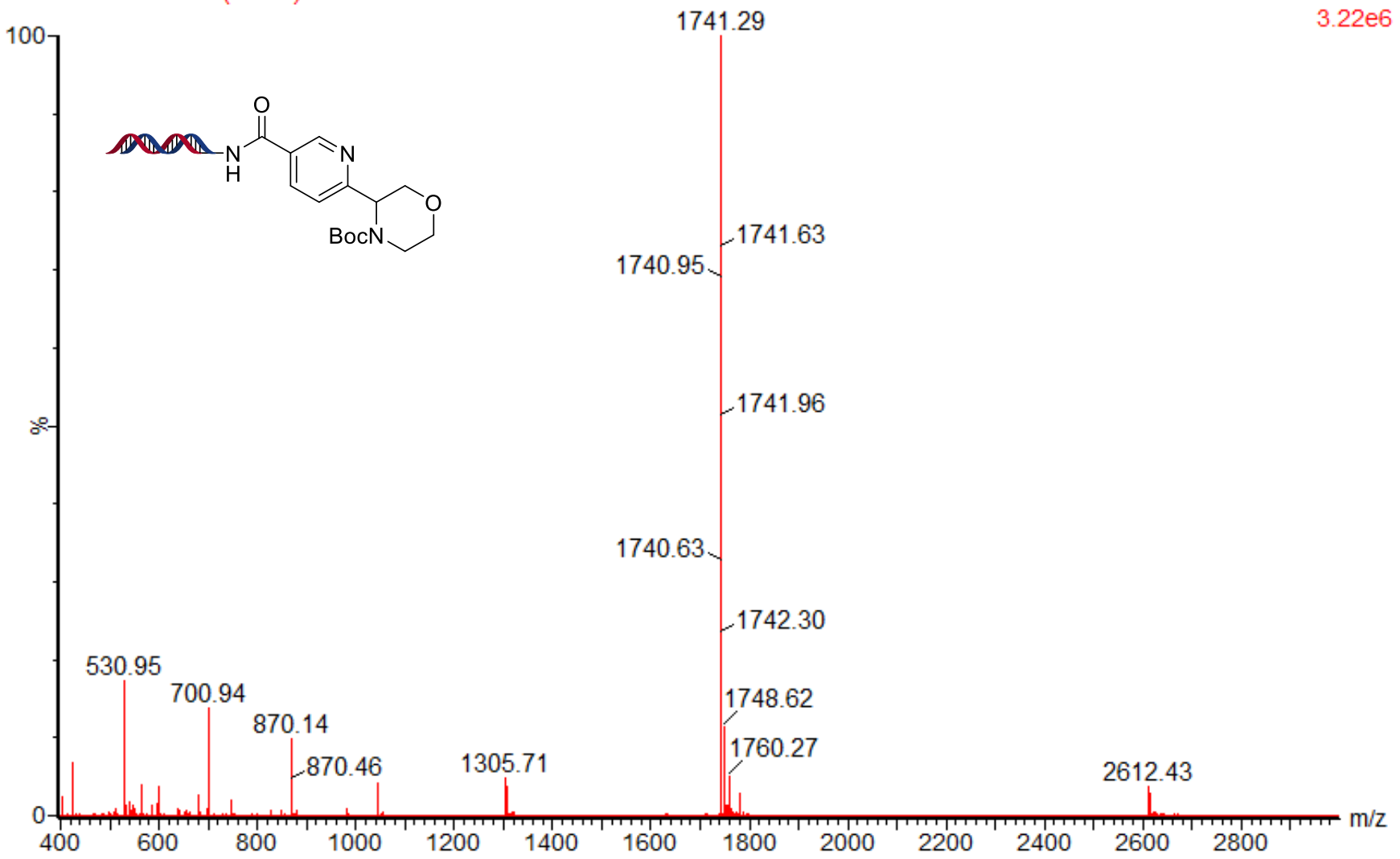

Figure S187. Mass spectrum of Table 3, entry 14 (from aryl iodide S15).

\section{6-0824-001-Repeat1:25}

DKoelmel363-2 668 (4.730)

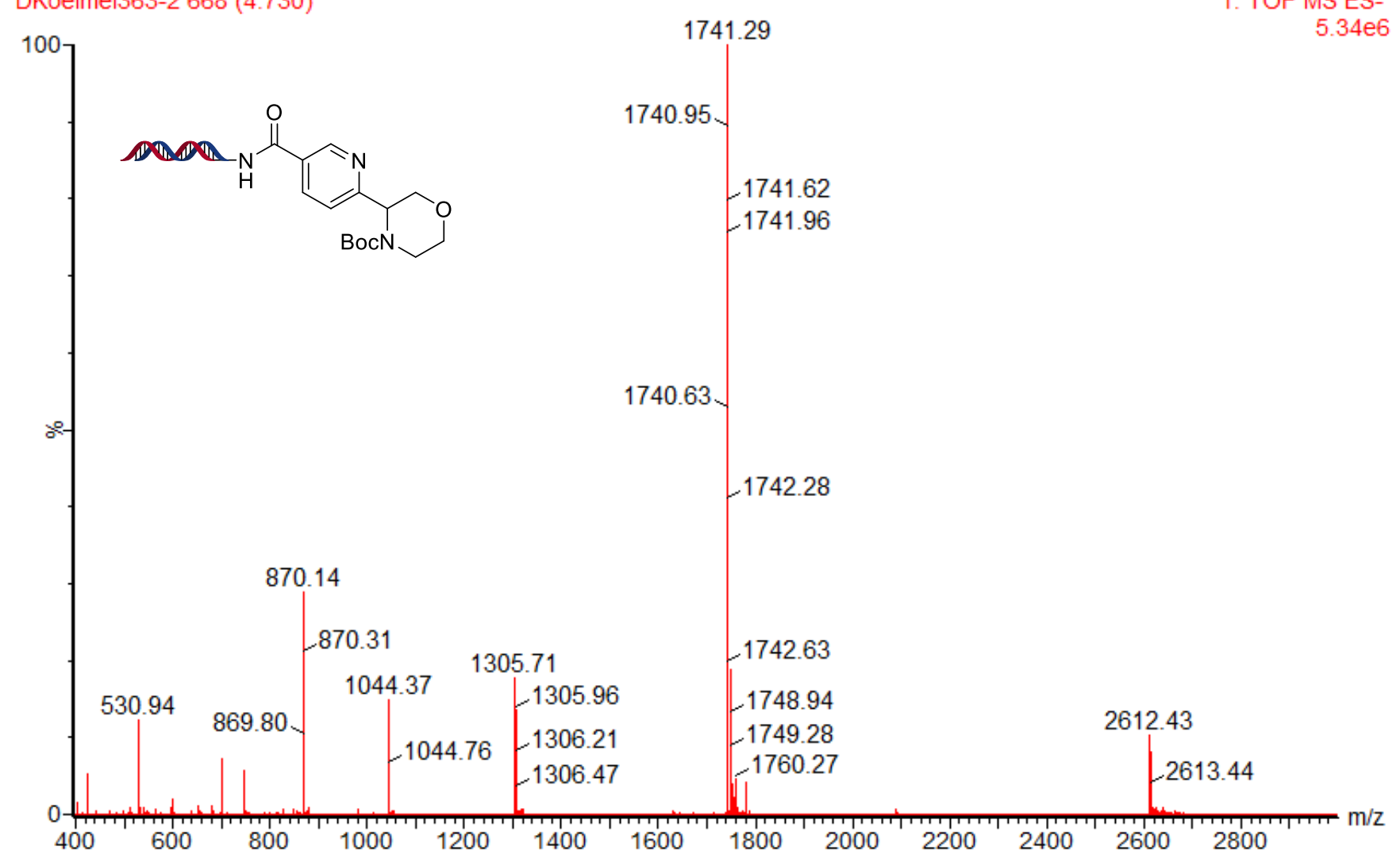

Figure S188. Mass spectrum of Table 3, entry 14 (from aryl bromide S16). 


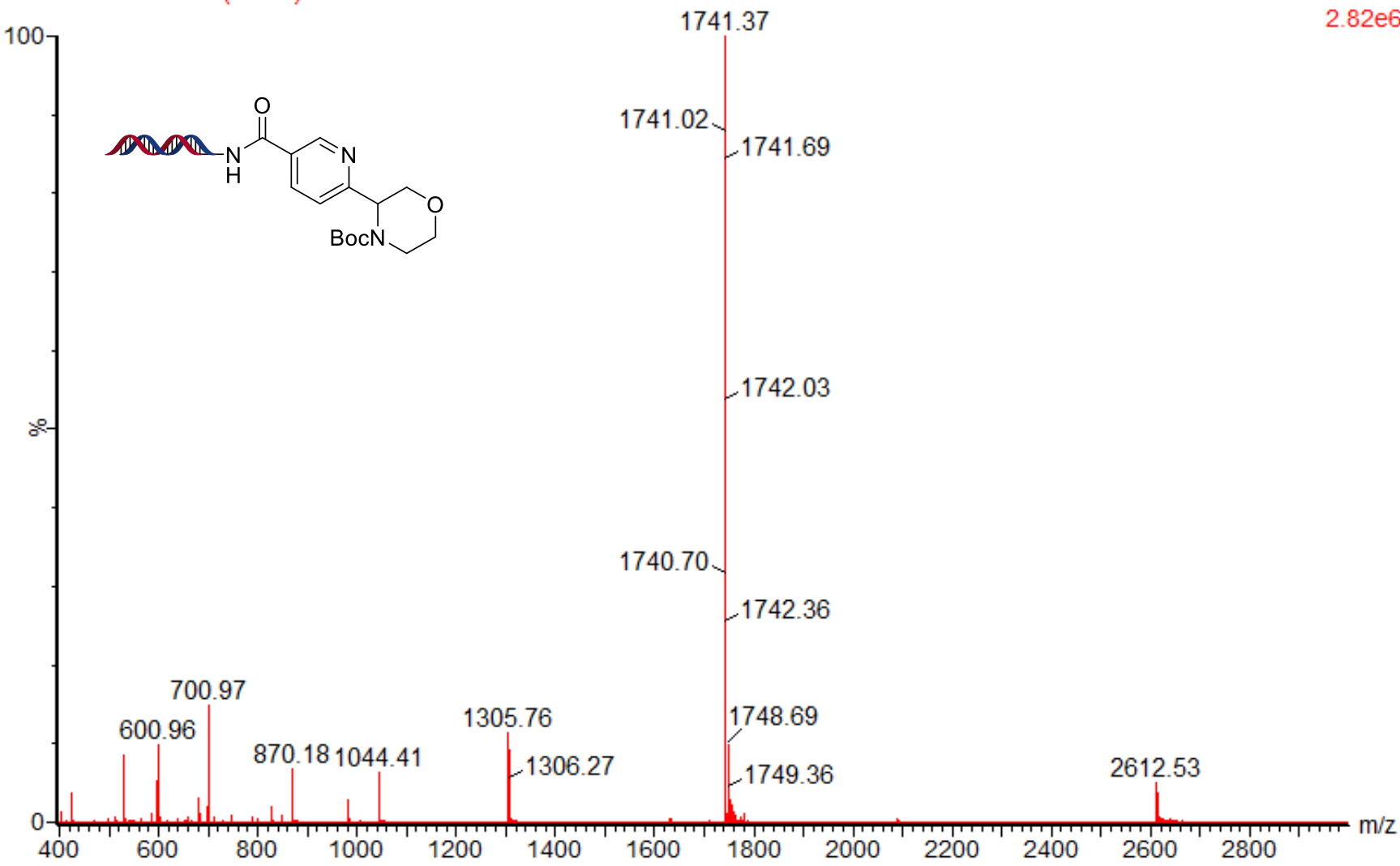

Figure S189. Mass spectrum of Table 3, entry 14 (from aryl chloride S17).

\section{6-0860-0011:8}

DKoelmel381-2 702 (4.965)

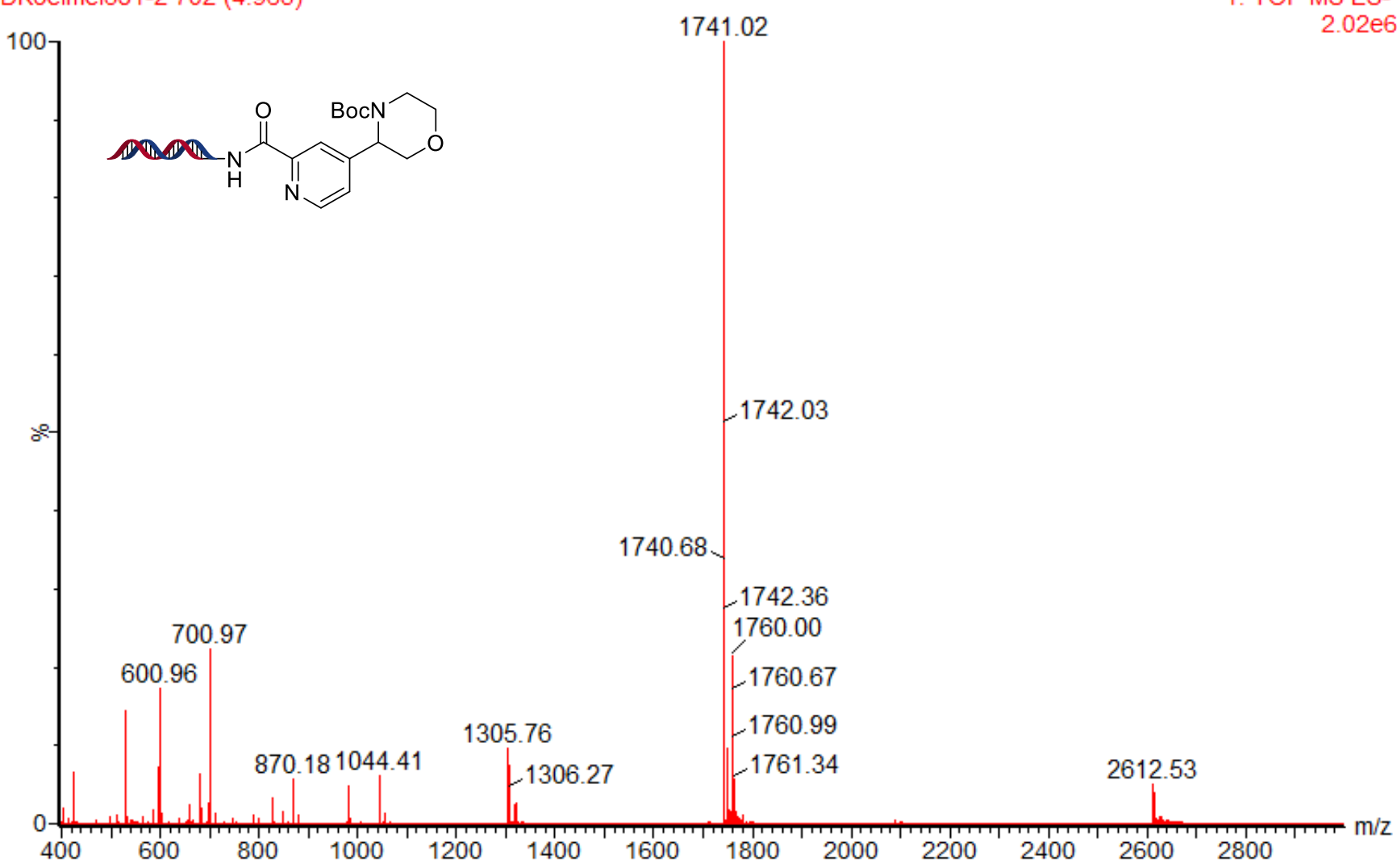

Figure S190. Mass spectrum of Table 3, entry 15. 


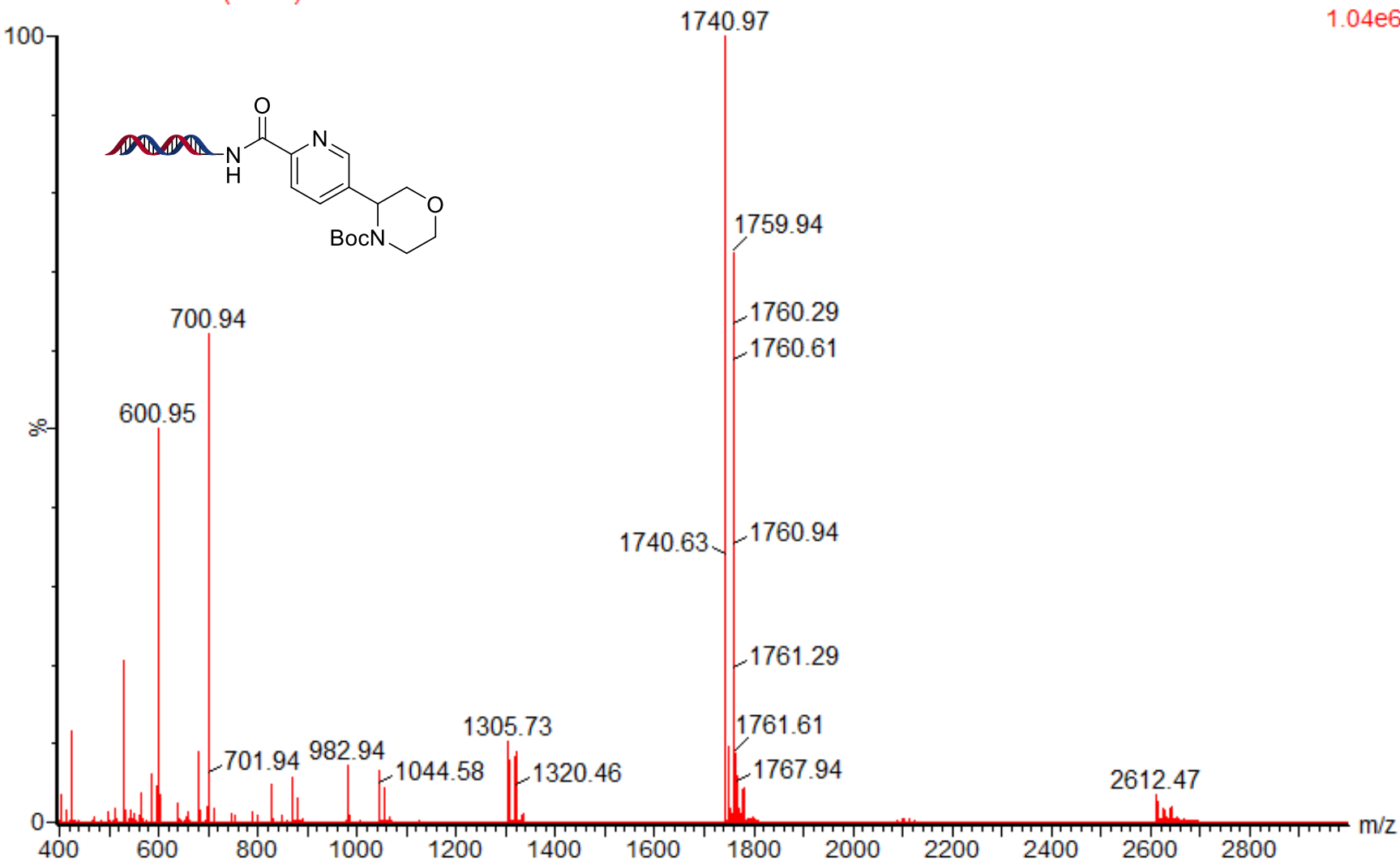

Figure S191. Mass spectrum of Table 3, entry 16.

\section{6-0863-0011:19}

DKoelmel385-1 769 (5.447)

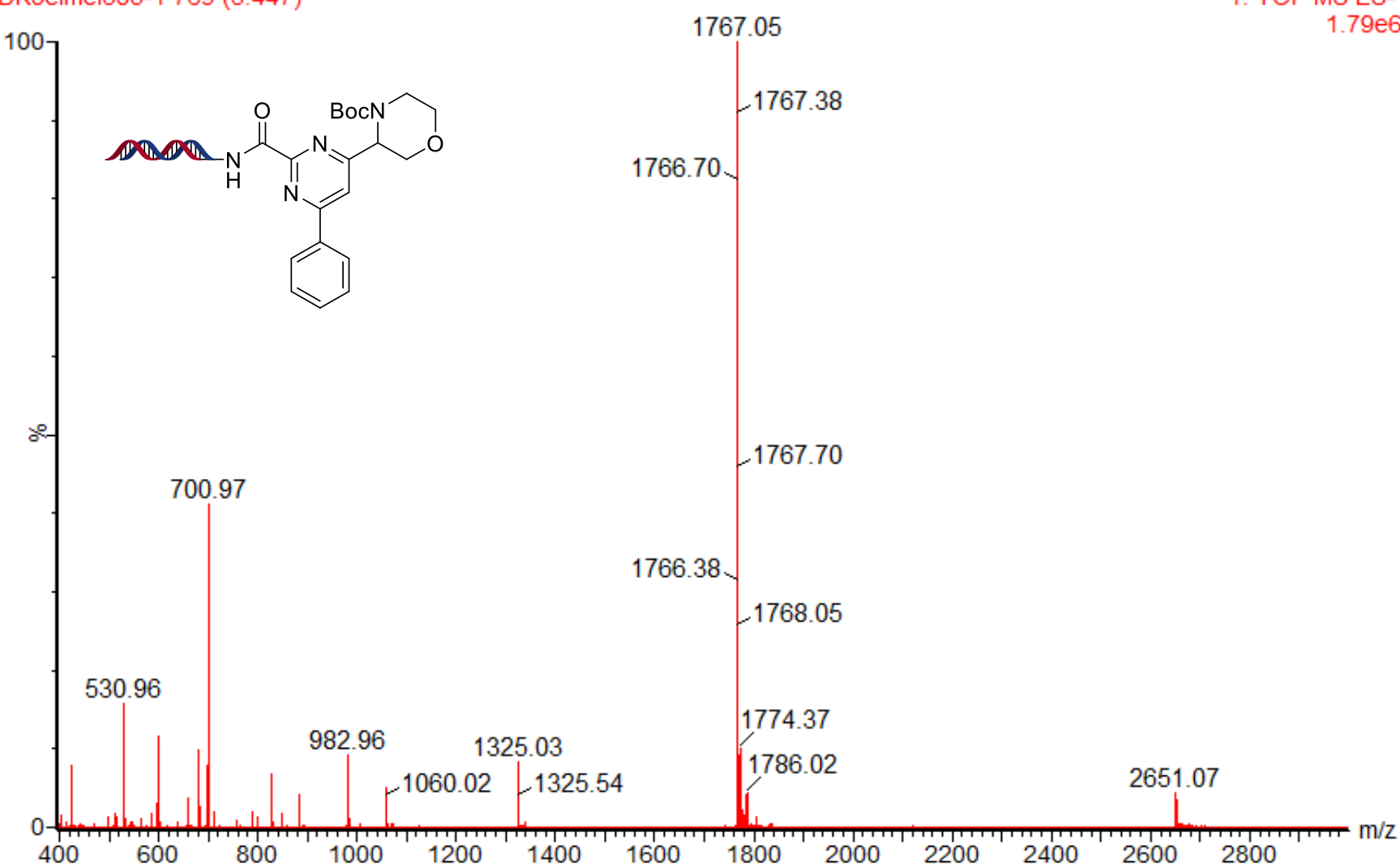

Figure S192. Mass spectrum of Table 3, entry 17. 


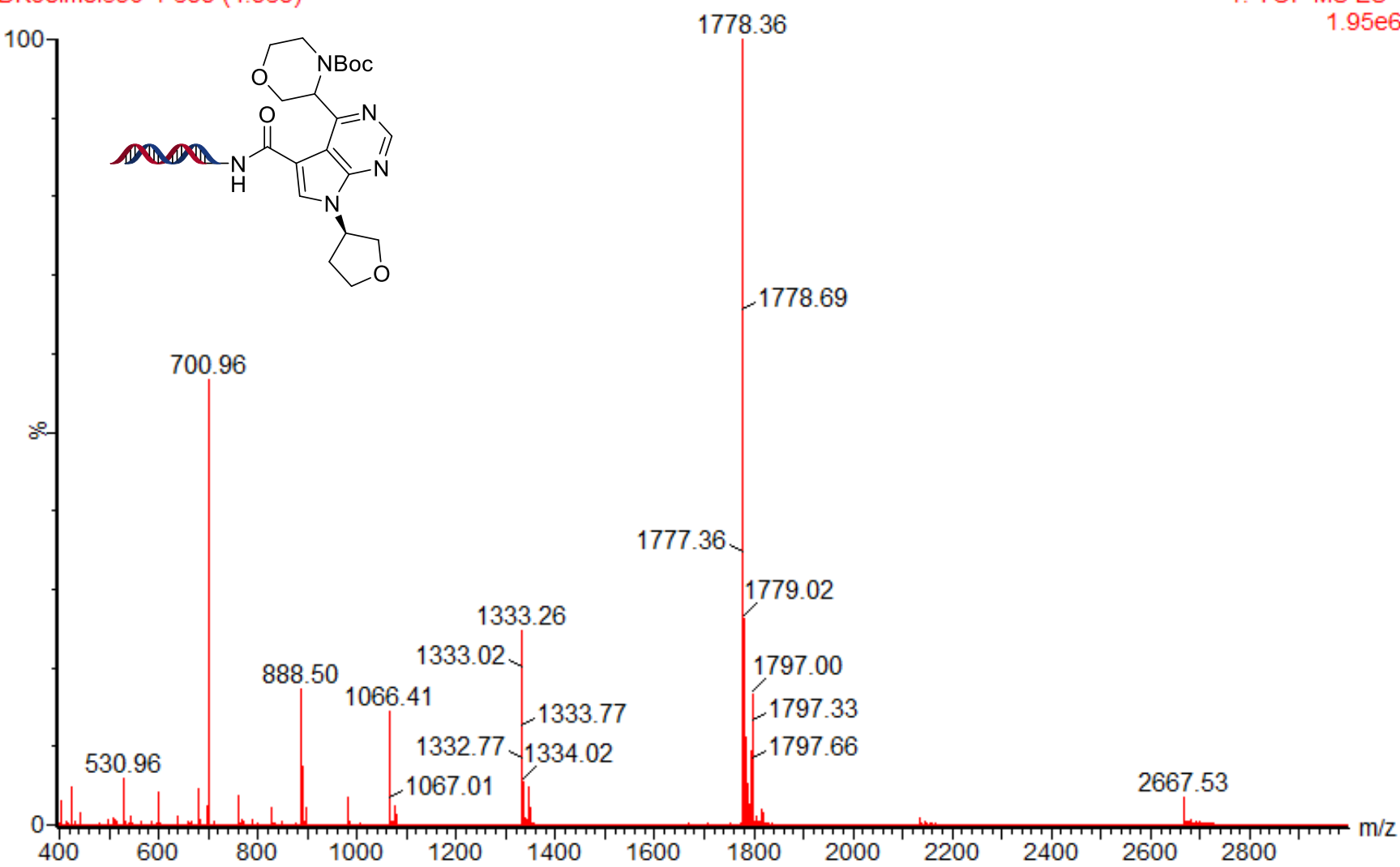

Figure S193. Mass spectrum of Table 3, entry 18.

\section{6-0896-001-C3-Repeat1:23}

DKoelmel406-02 725 (5.143)

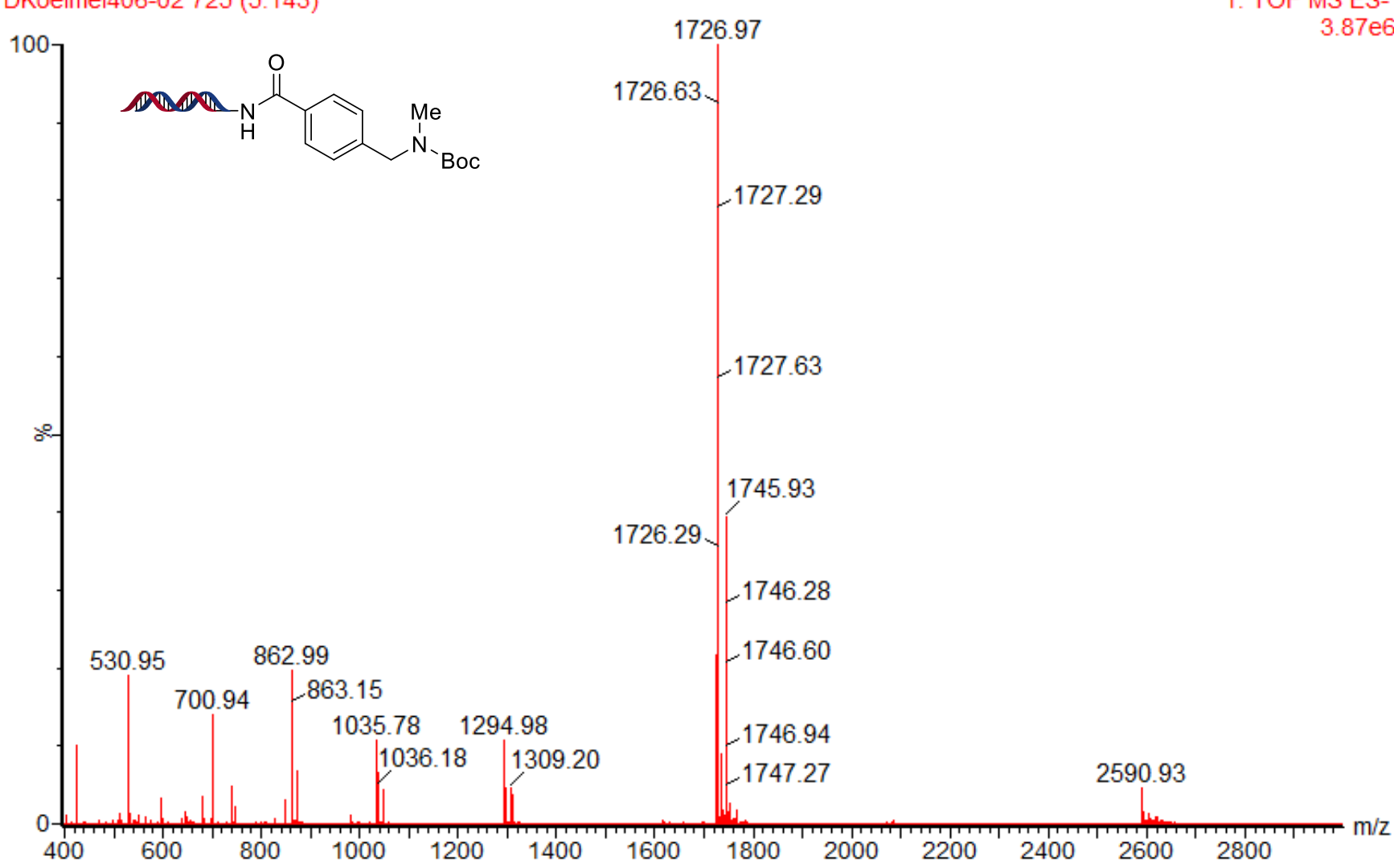

Figure S194. Mass spectrum of Table S1, entry 1 (96-well plate). 


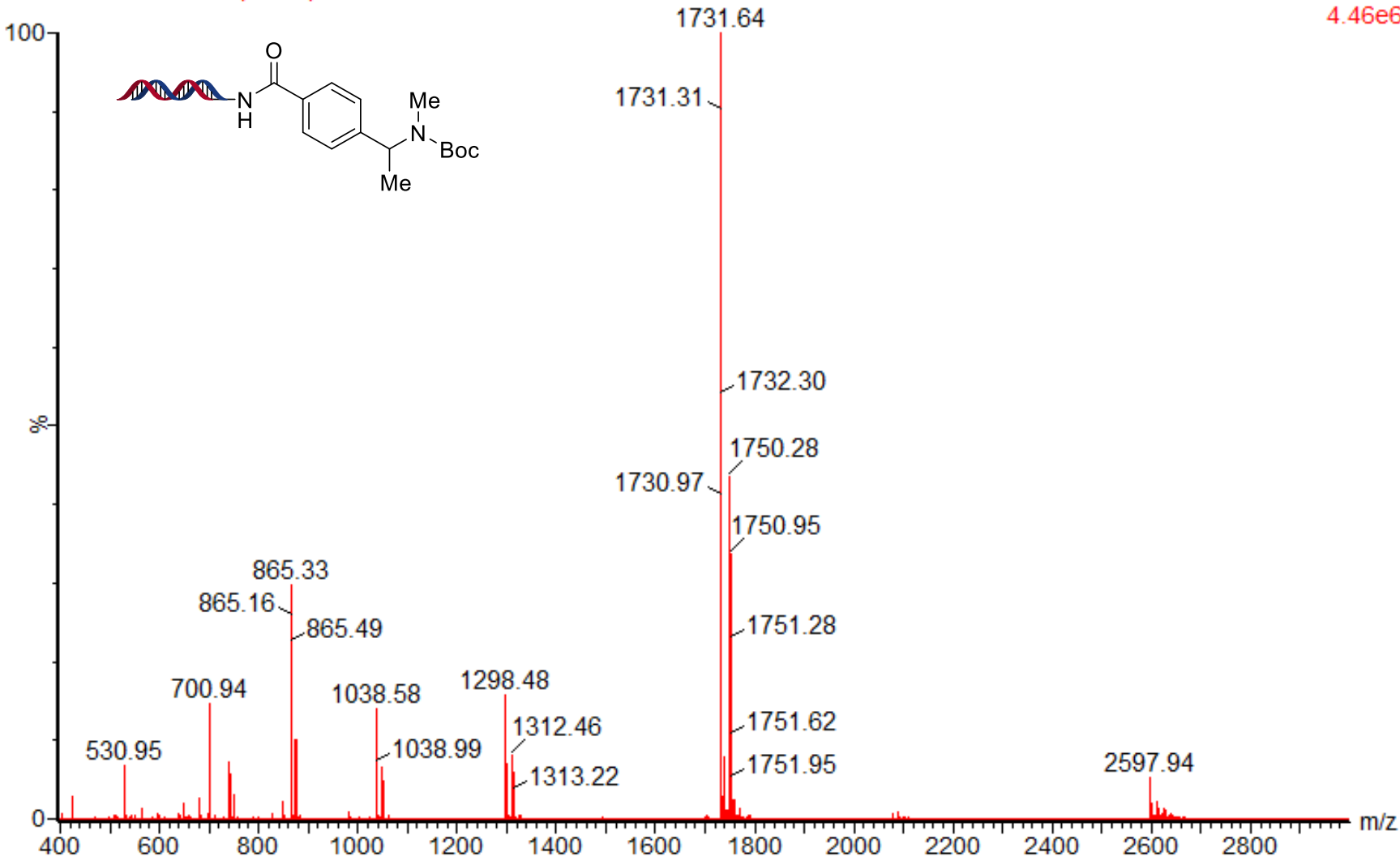

Figure S195. Mass spectrum of Table S1, entry 2 (96-well plate).

00712256-0896-001-C101:26

DKoelmel406-05 812 (5.744)

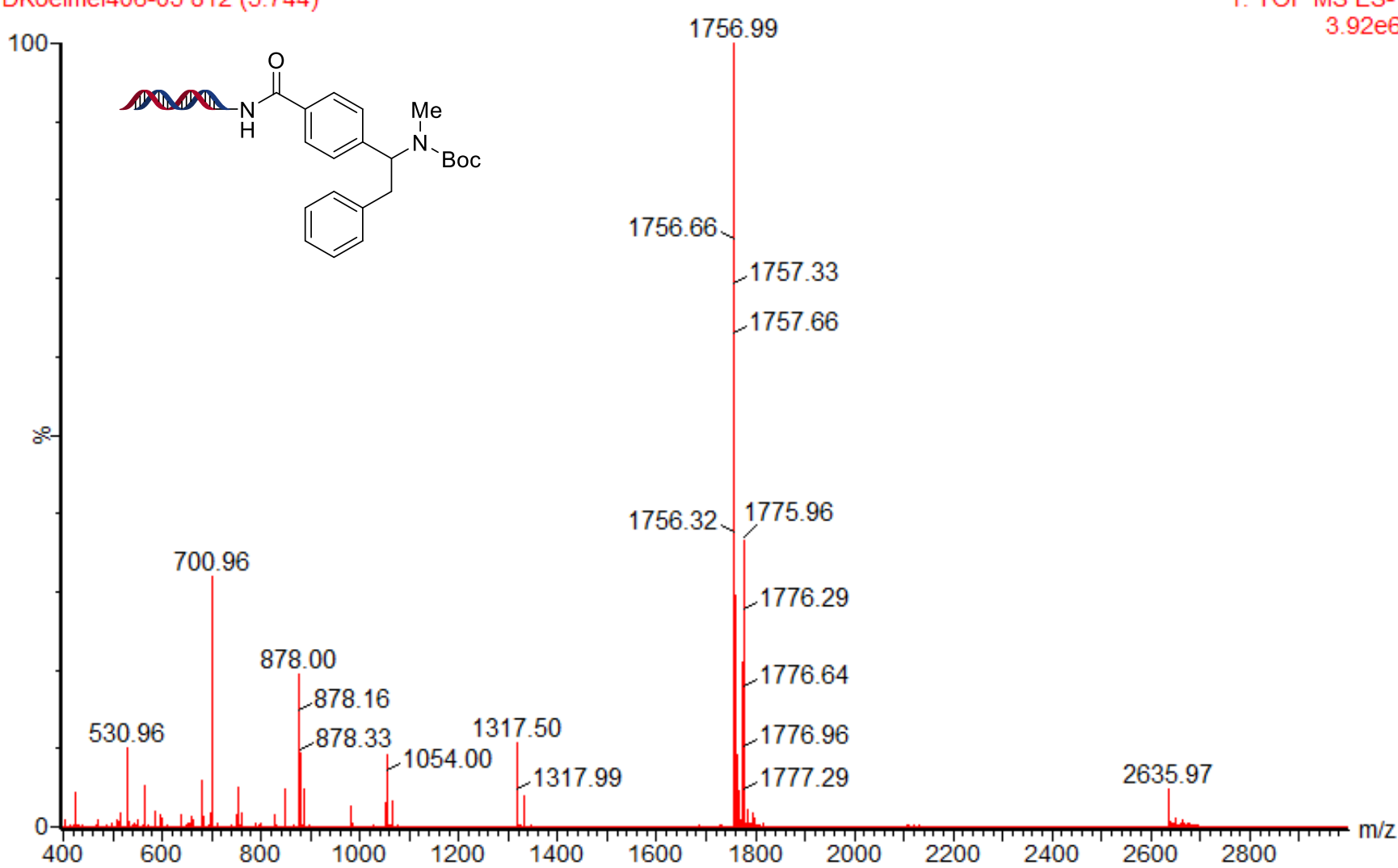

Figure S196. Mass spectrum of Table S1, entry 3 (96-well plate). 


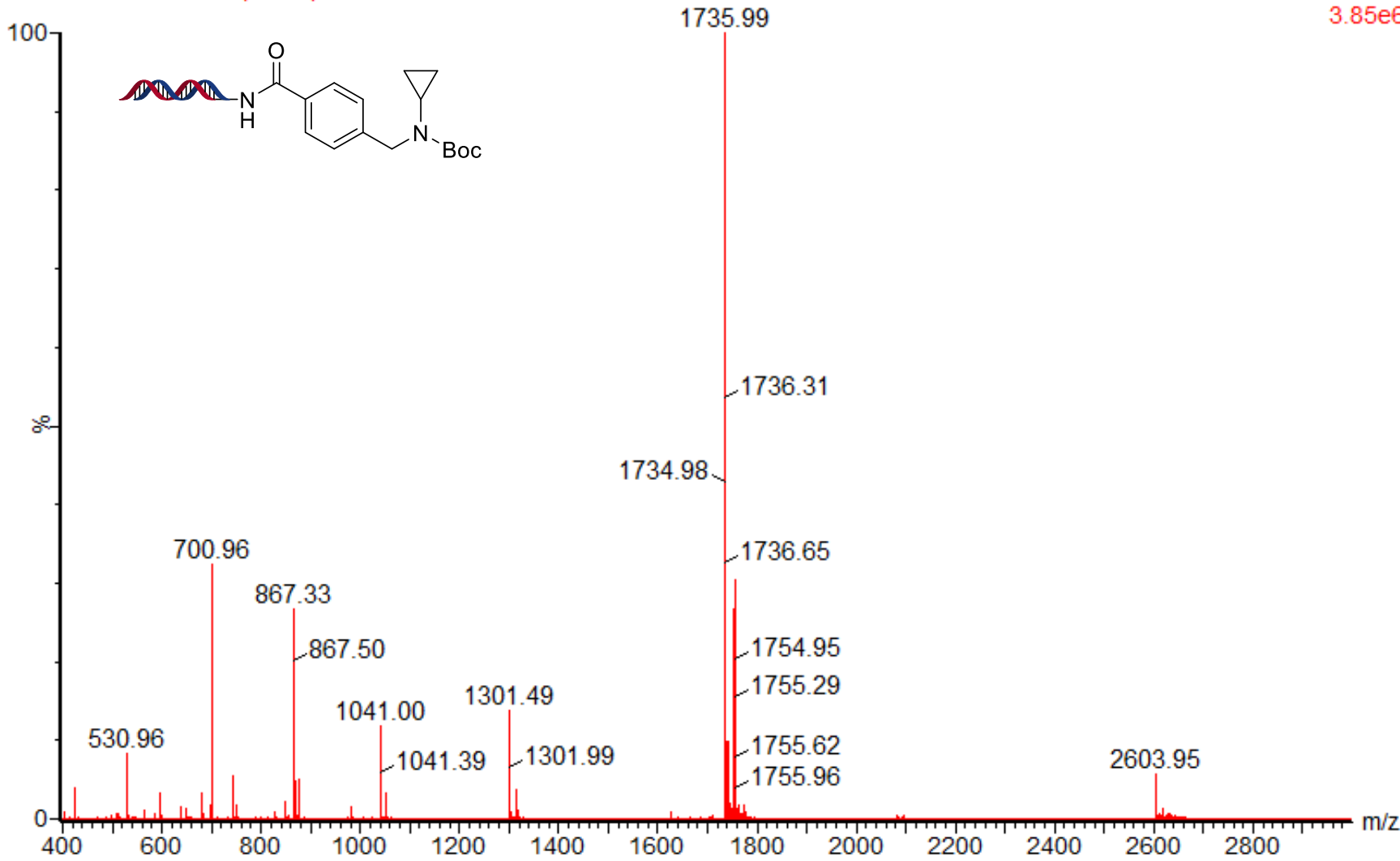

Figure S197. Mass spectrum of Table S1, entry 4 (96-well plate).

00712256-0896-001-C51:24

DKoelmel406-03 740 (5.247)

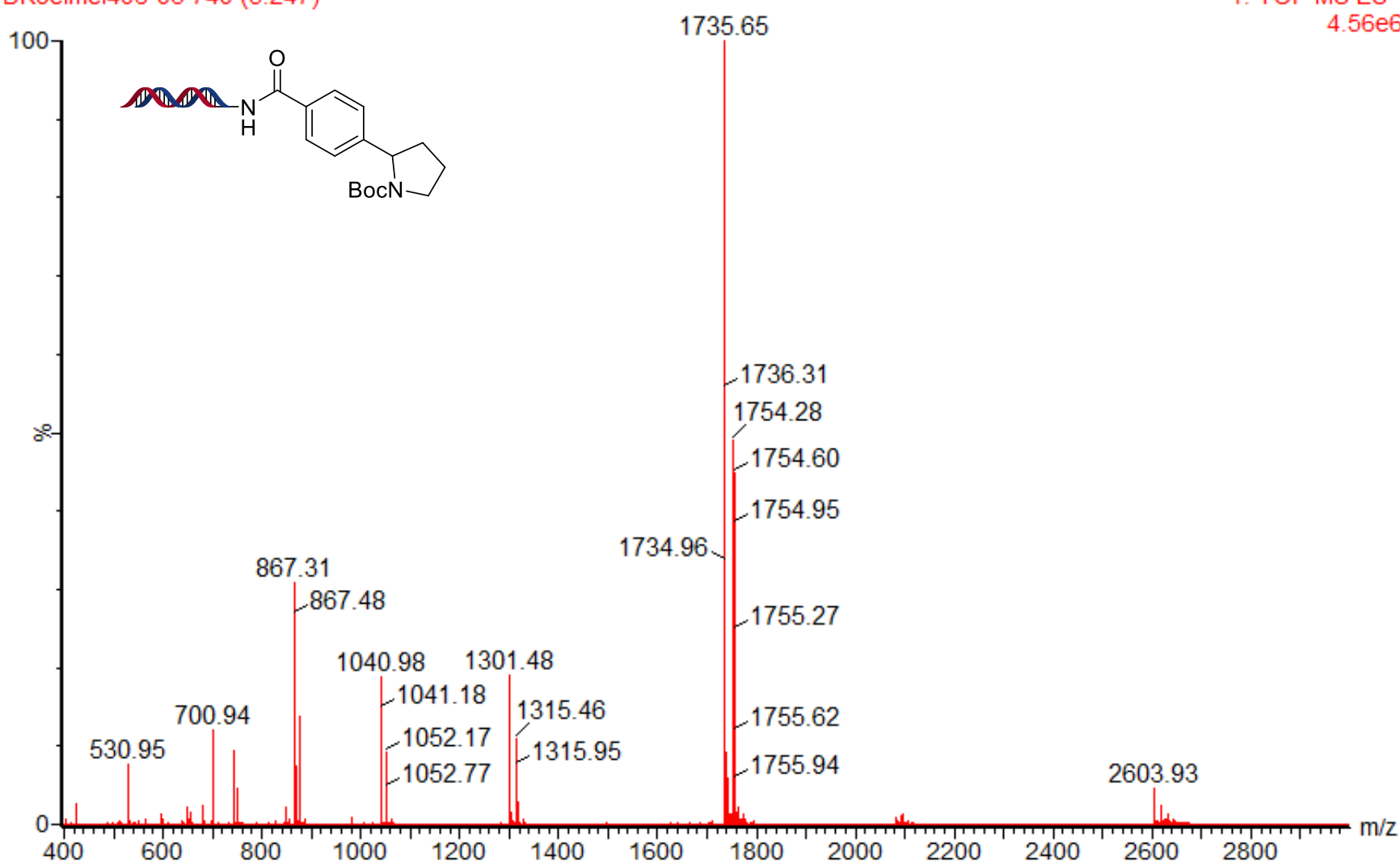

Figure S198. Mass spectrum of Table S1, entry 5 (96-well plate). 


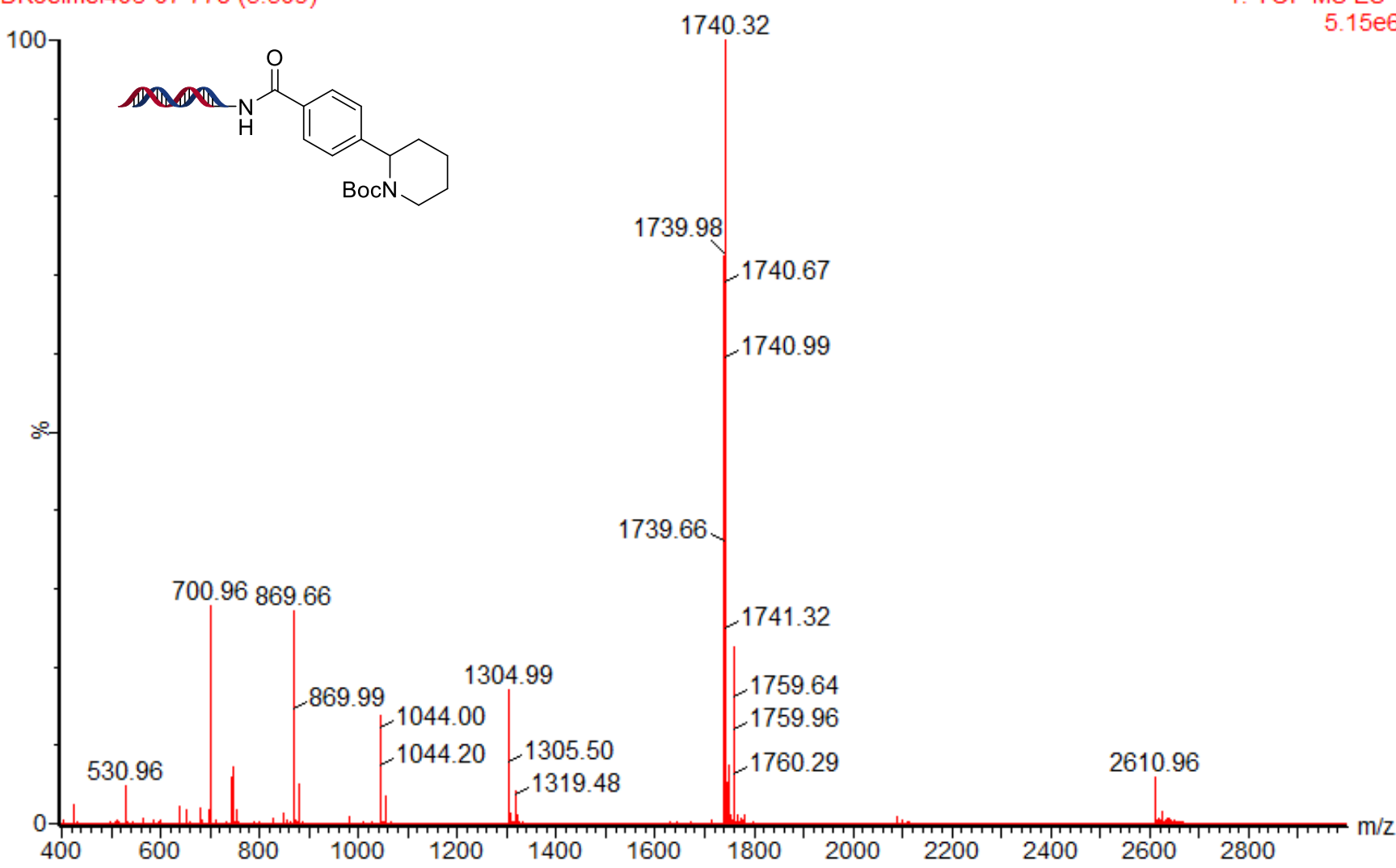

Figure S199. Mass spectrum of Table S1, entry 6 ( 96 -well plate).

\section{6-0896-001-E81:29}

DKoelmel406-08 796 (5.634)

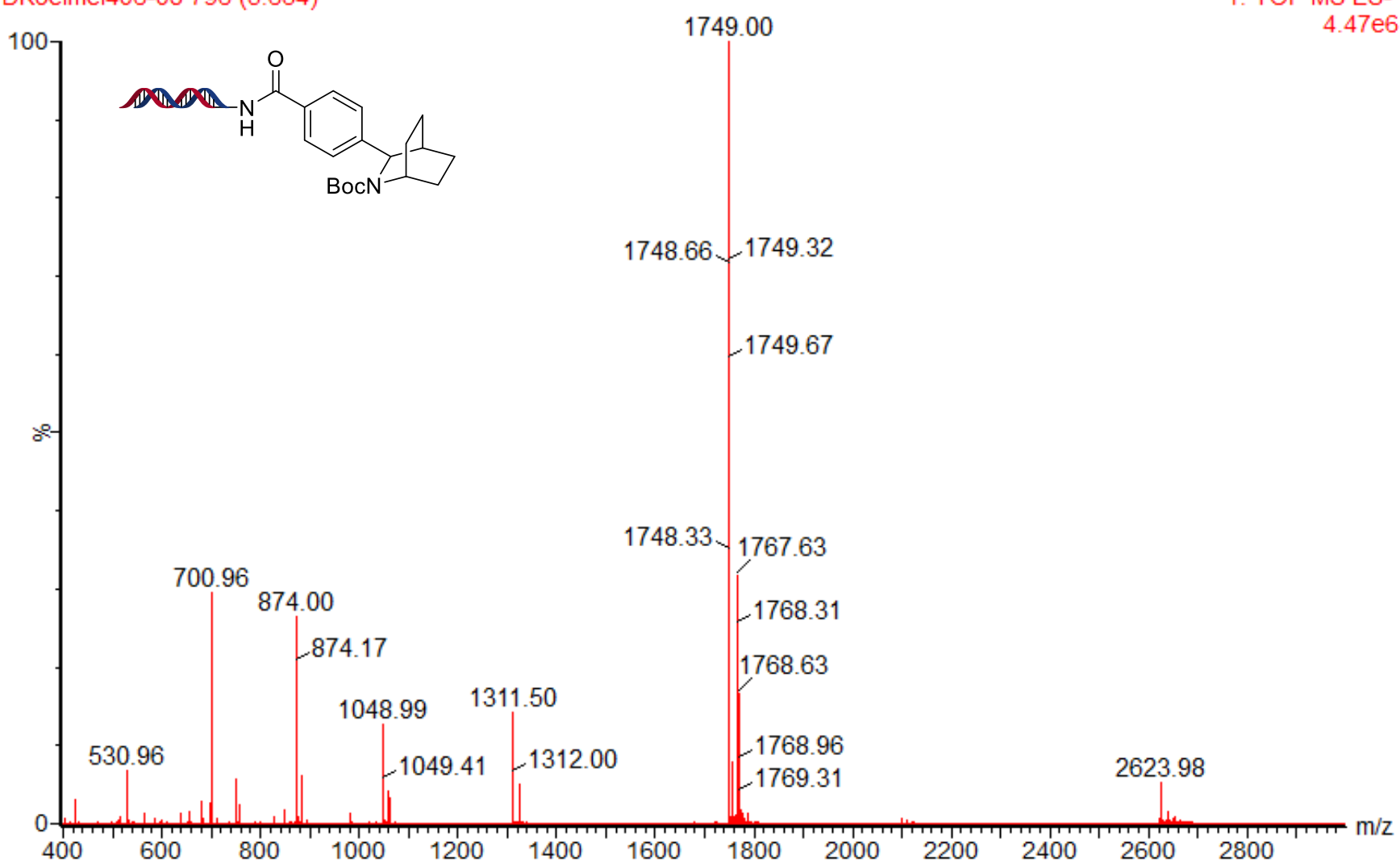

Figure S200. Mass spectrum of Table S1, entry 7 (96-well plate). 


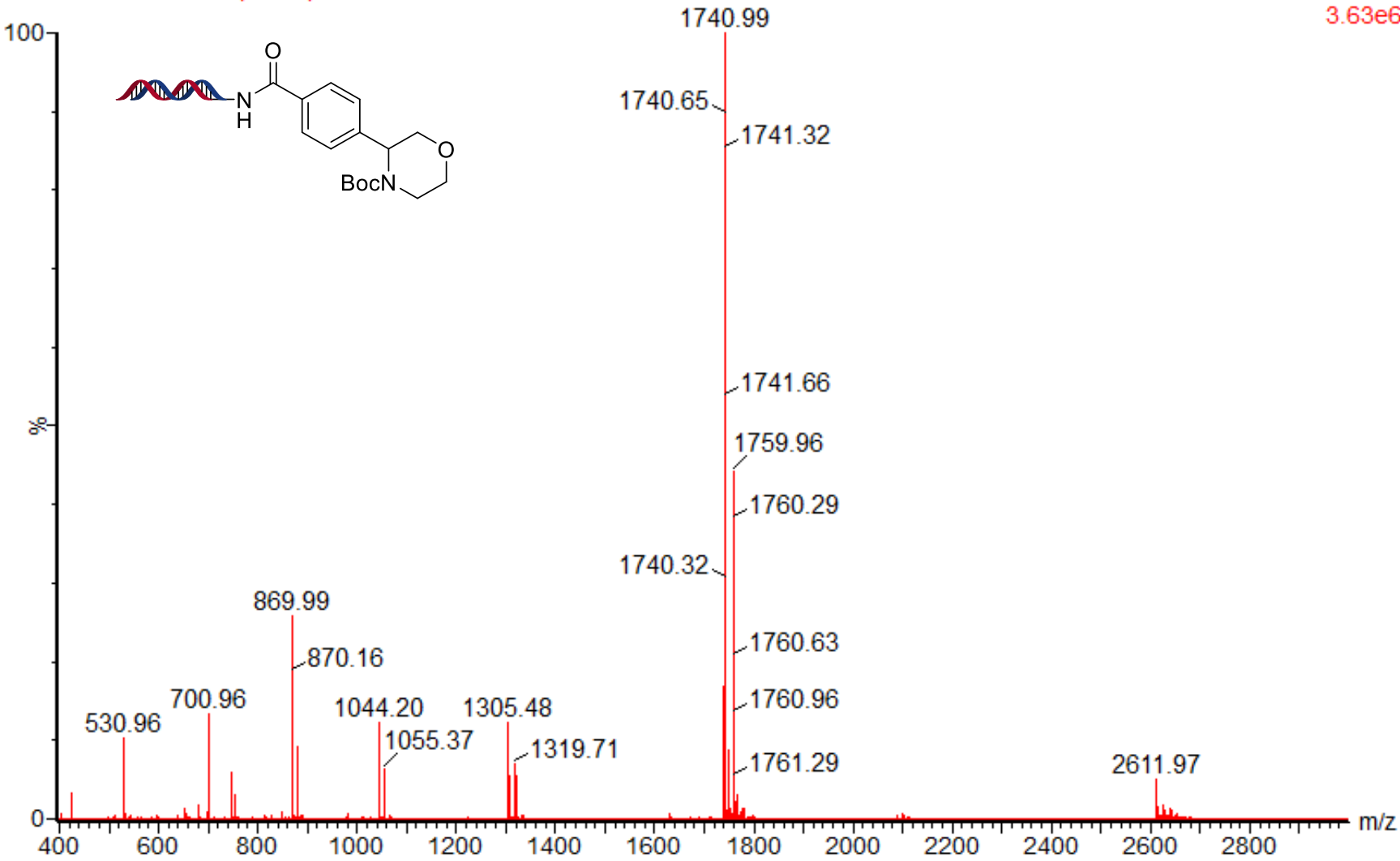

Figure S201. Mass spectrum of Table S1, entry 8 (96-well plate).

00712256-0896-001-G51:32

DKoelmel406-11 761 (5.392)

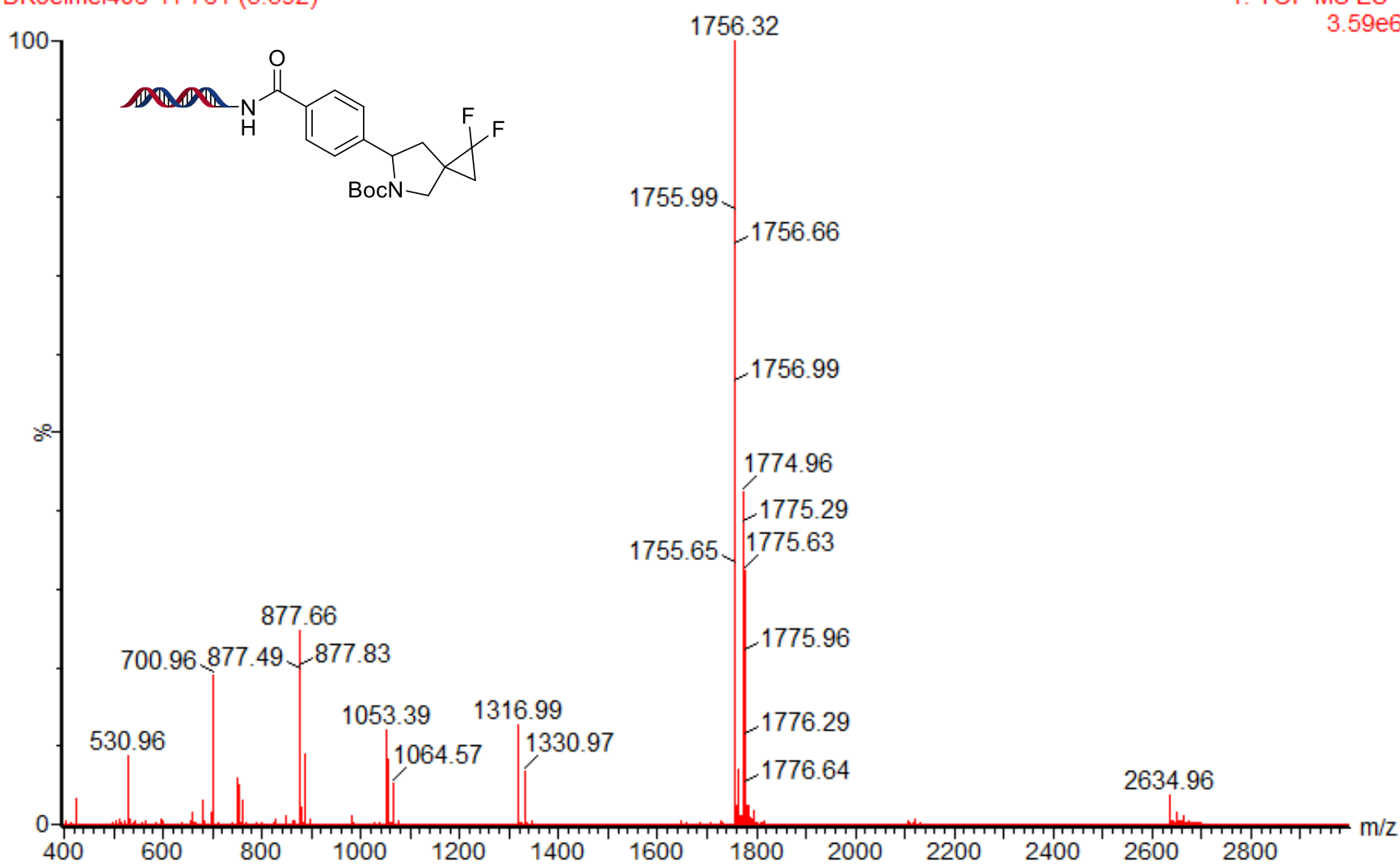

Figure S202. Mass spectrum of Table S1, entry 9 ( 96 -well plate). 


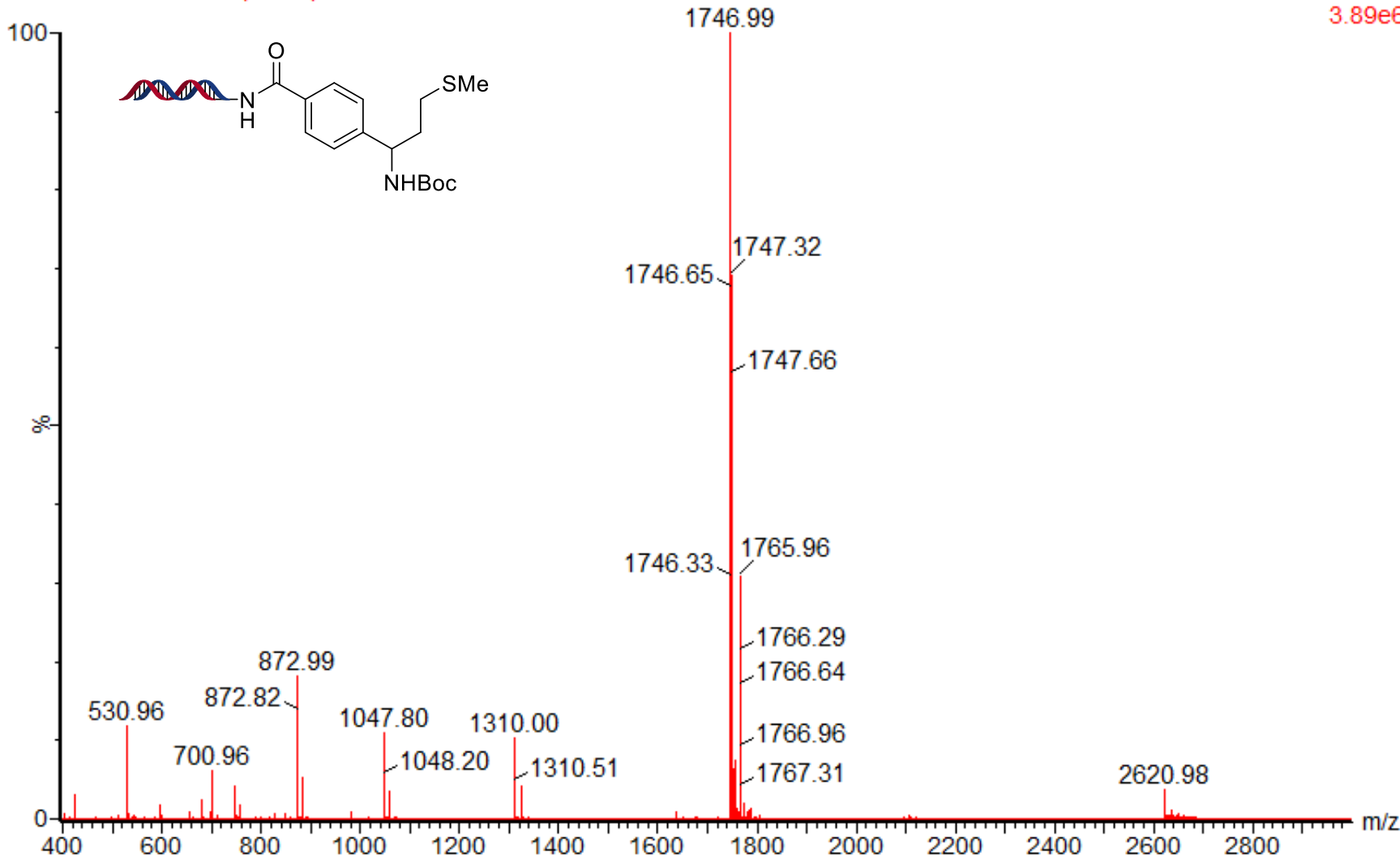

Figure S203. Mass spectrum of Table S1, entry 10 (96-well plate).

00712256-0655-00100712256-0655-001 DKoelmel261-1 741 (5.254)

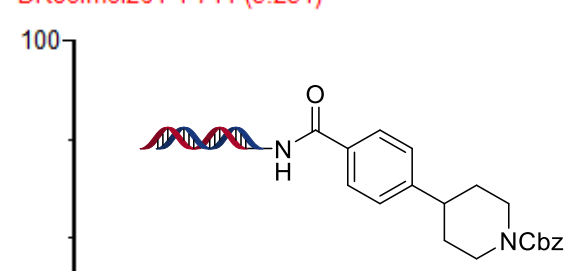

21-May-2018 13:22:17 1: TOF MS ES-

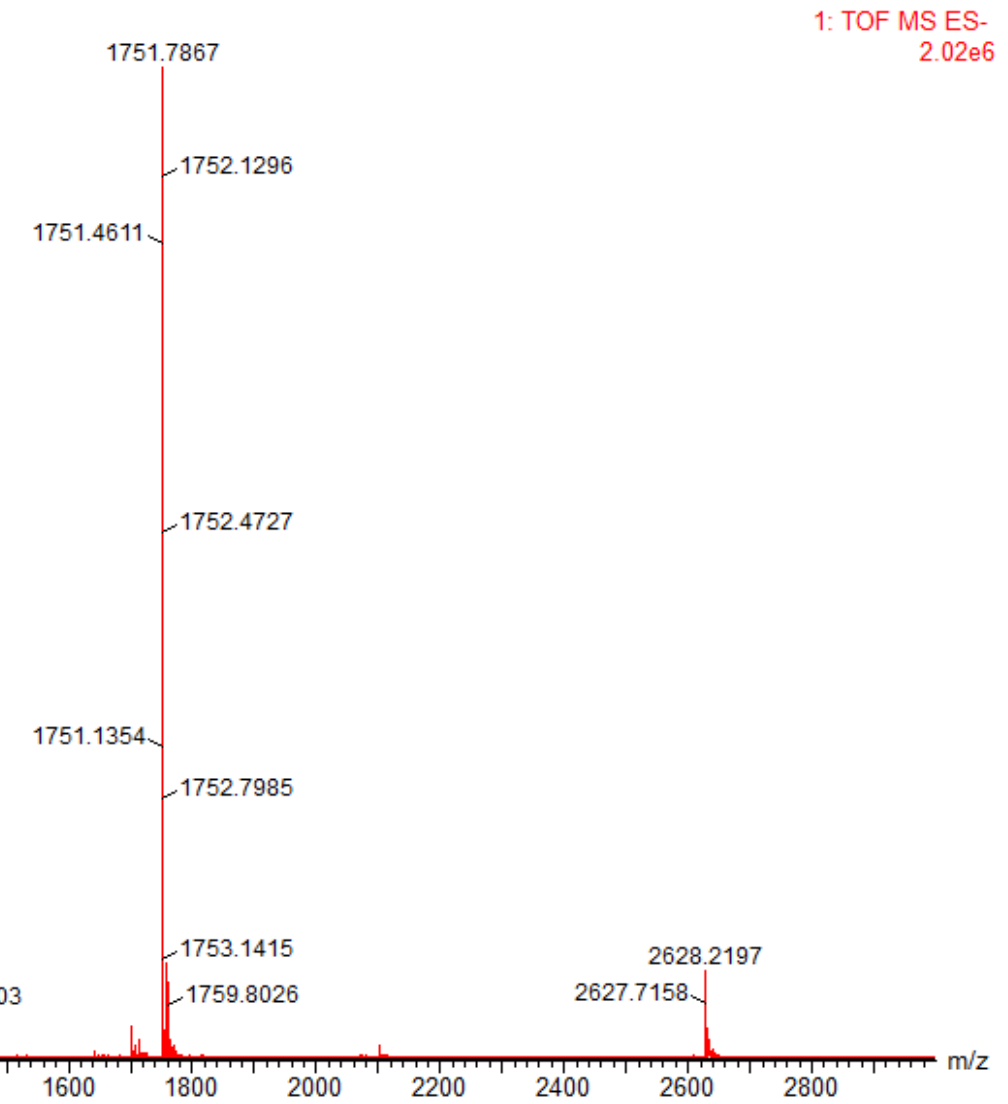

Figure S204. Mass spectrum of compound 26. 


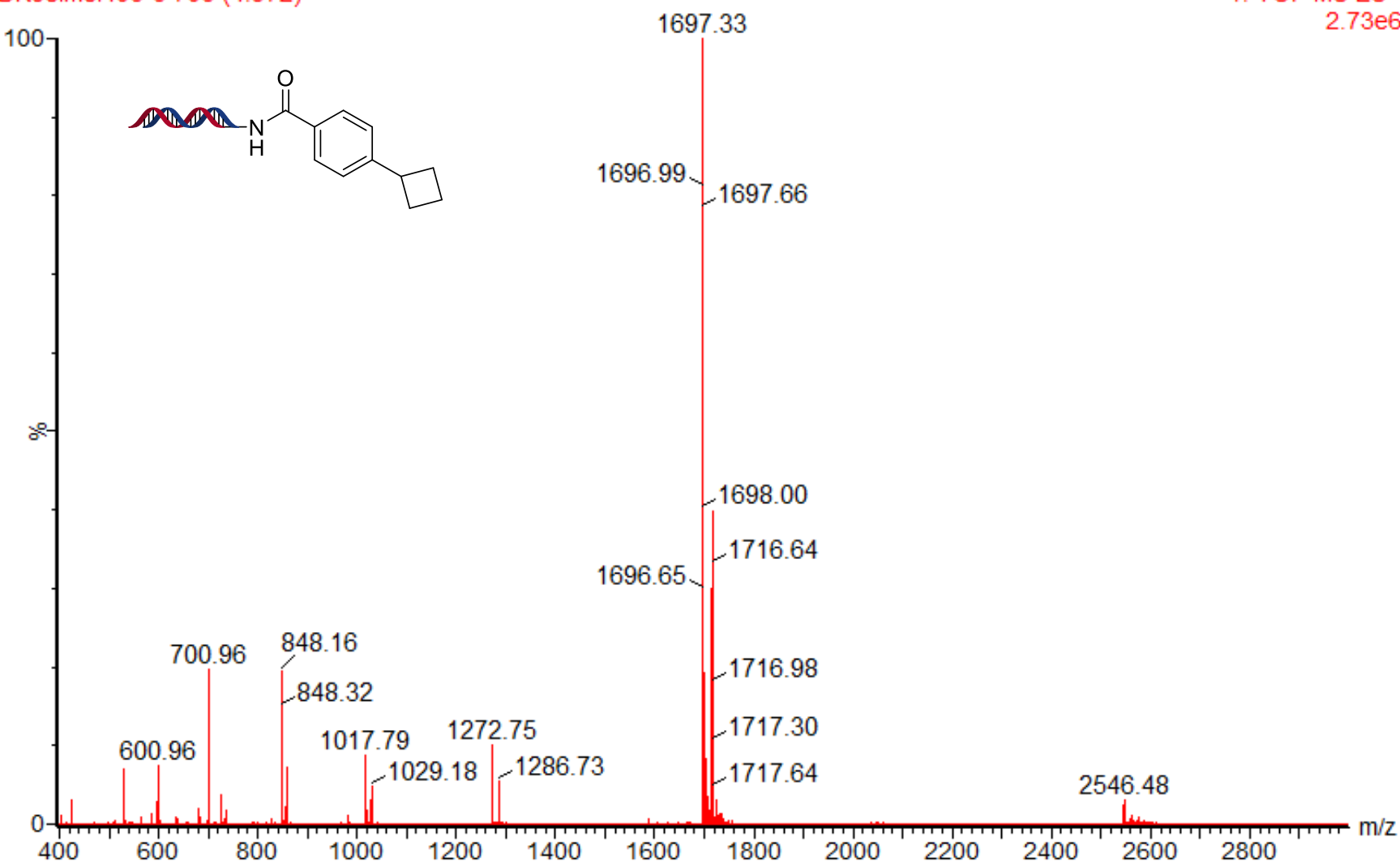

Figure S205. Mass spectrum of compound 27.

\section{6-0893-0011:20}

DKoelmel404-3 764 (5.413)

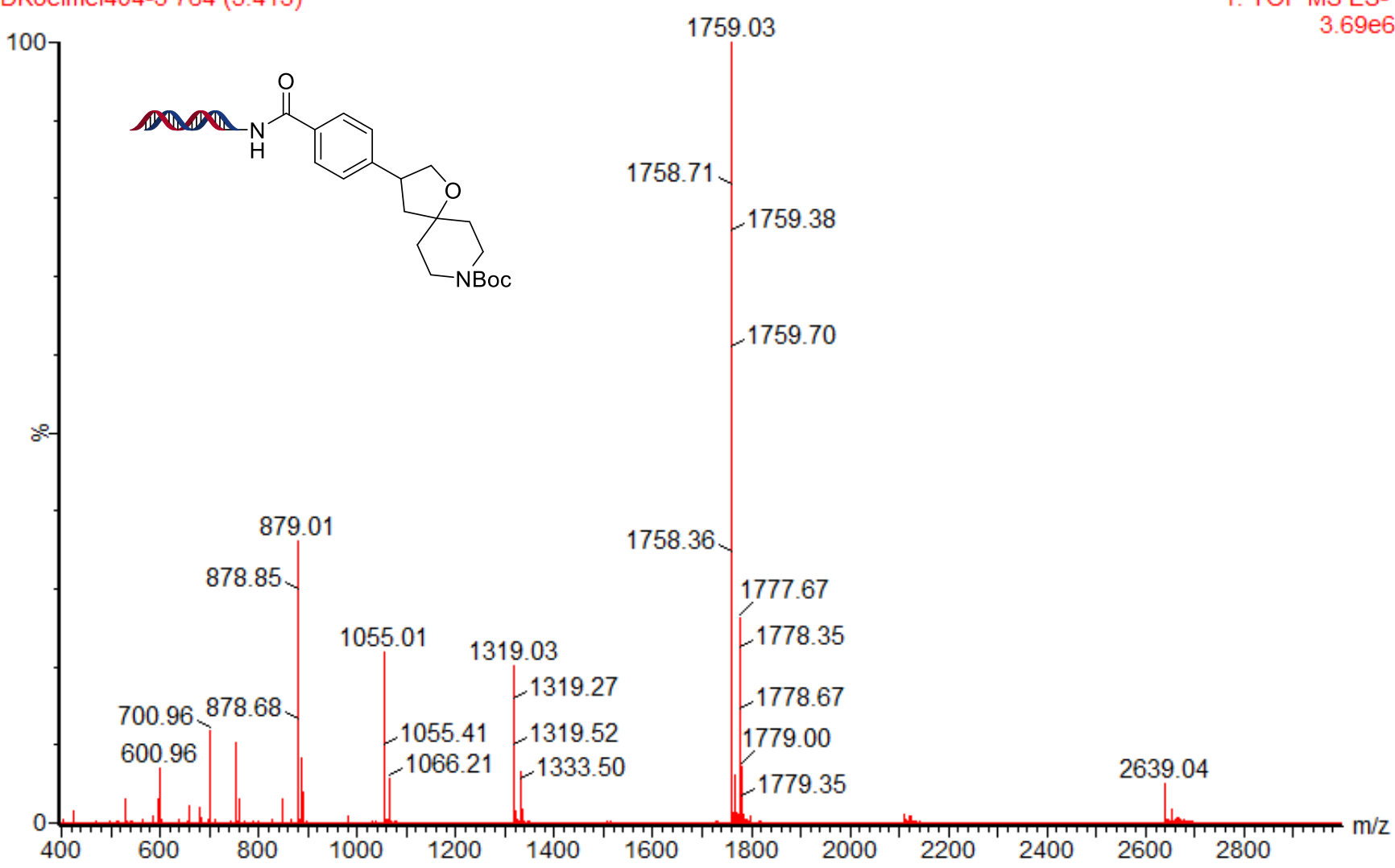

Figure S206. Mass spectrum of compound 28. 
00712256-1194-001-21:7

DKoelmel621-1 500 (3.629)

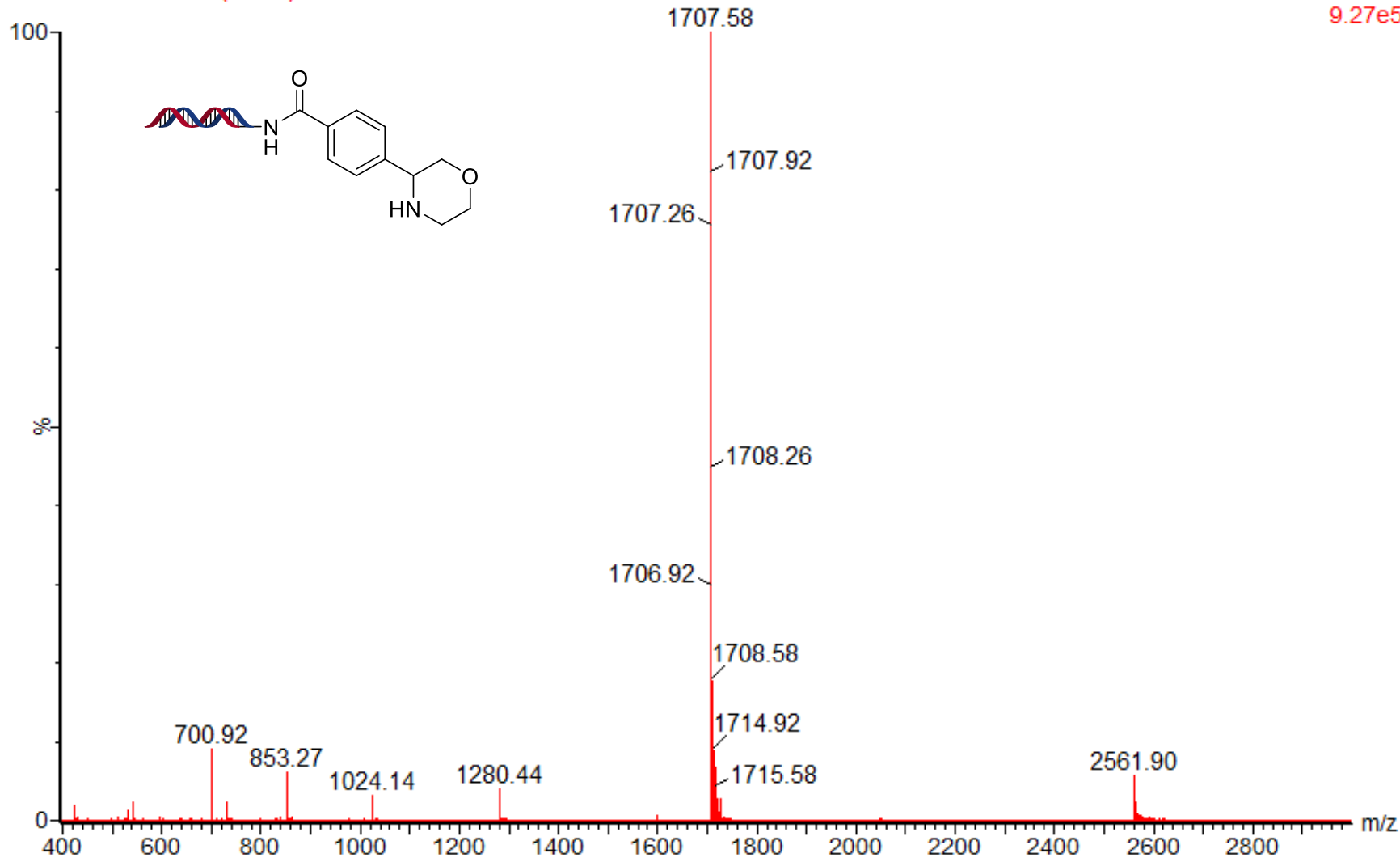

Figure S207. Mass spectrum of compound S22. 


\section{5) DNA Damage Evaluation}

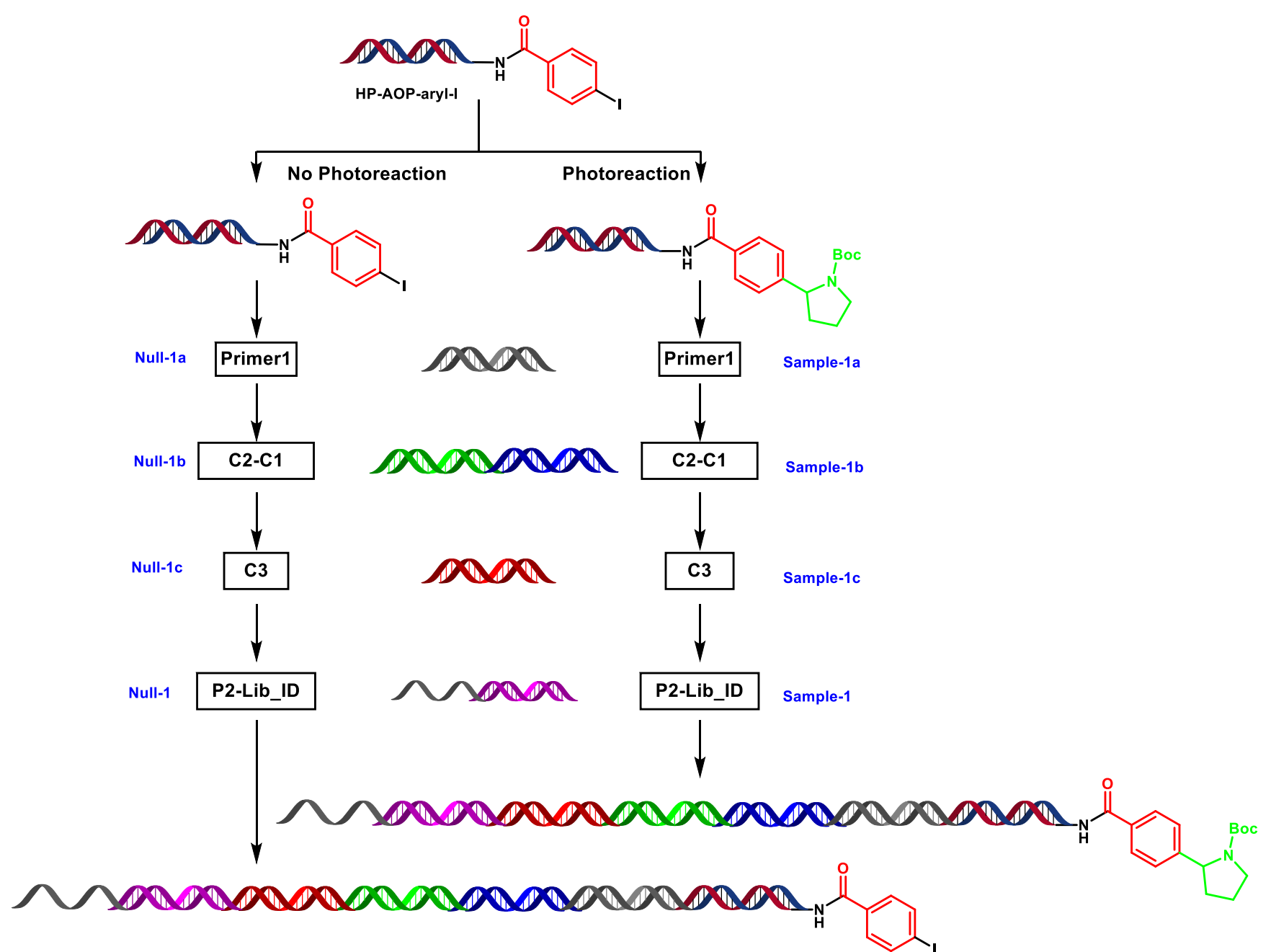

Figure S208. Synthetic outline for the preparation of Null-1 and Sample-1 from DNA headpiece.

\section{DNA sequences}

\section{Primer 1}

5'-GACCGAAGGTTG-3'

$3^{\prime}$-GGCTGGCTTCCA $\overline{-5}$

\section{Code 1}

\section{5'-CTTAGGCAGTCAG-3' \\ 3'-ACGAATCCGTCAG -5'}

\section{Code 2}

\section{5' -ACACCGACACT GT $-3^{\prime}$ \\ $3^{\prime}-$ TCTGTGGCTGTGA $\overline{-5}$}

\section{Code 3}

5' -GGTATTGGAGCGA-3' 3' - CACCATAACCTCG -5 '

Lib ID-P2

5' -AGGTGCTATNNNNNNNNNNNNNA GATCTGATGGCGCGAGGG -3' $3^{\prime}$ - CTTCCACGATA $-5^{\prime}$ 


\section{Preparation of Starting materials}

The DNA-tagged aryl halide (see Figure S208) was prepared according to the general procedure II from AOP-headpiece DNA (AOP = 15-amino-4,7,10,13-tetraoxapentadecanoic acid). The photoredoxcatalyzed decarboxylative arylation material was prepared according to the photoredox-catalyzed decarboxylative arylation procedure in a 96-well plate.

\section{Ligation of Primer 1 to the DNA substrate}

To the solution of DNA-tagged aryl halide $\left(450.0 \mathrm{nmol}\right.$ in $450 \mathrm{uL} \mathrm{H} \mathrm{H}_{2} \mathrm{O}, 1$ equiv.) was added Primer 1 (P1, $500 \mathrm{nmol}$ in $\mathrm{H}_{2} \mathrm{O}, 1.11$ equiv.), 10x ligation buffer $(200 \mu \mathrm{L})$, T4 DNA ligase $(21.29 \mu \mathrm{L}, 11.74 \mu \mathrm{g} / \mu \mathrm{L})$ and nuclease-free water $1162 \mathrm{uL}$ (total reaction volume: $1383.3 \mu \mathrm{L}$ ). After thoroughly vortexing, the reaction mixture was incubated at $20^{\circ} \mathrm{C}$ overnight and monitored by UPLC. After reaction, the crude material was purified by standard ethanol precipitation and preparative HPLC to remove the excess Primer 1.

Null-1a: $m / z=919.9[\mathrm{M}-14 \mathrm{H}]^{14-}$

The same procedure was used for the ligation of Primer 1 to the DNA substrate that underwent metallaphotoredox-catalyzed modification.

Sample-1a: $m / z=922.6[\mathrm{M}-14 \mathrm{H}]^{14-}$

\section{C1 and $\mathrm{C} 2$ ligation (C1-C2)}

To the solution of Code 1 ( $1 \mu \mathrm{mol}$ in $\mathrm{H}_{2} \mathrm{O}, 1$ equiv.) was added Code $2\left(1 \mu \mathrm{mol}\right.$ in $\mathrm{H}_{2} \mathrm{O}, 1$ equiv.), $10 \mathrm{x}$ ligation buffer $(400 \mu \mathrm{L})$, T4 DNA ligase $(42.59 \mu \mathrm{L}, 11.74 \mu \mathrm{g} / \mu \mathrm{L})$ and nuclease-free water $1557.4 \mathrm{uL}$ (total reaction volume: $4000 \mu \mathrm{L}$ ). After thoroughly vortexing, the reaction mixture was incubated at $20{ }^{\circ} \mathrm{C}$ overnight and monitored by UPLC. After reaction, the crude material was purified by standard ethanol precipitation and used in the next step without further purification.

\section{Ligation to pre-assembled C1-C2 (Null-1b and Sample-1 b)}

To the solution of either Null-1a or Sample-1a $\left(50.0 \mathrm{nmol}\right.$ in $80.7 \mathrm{uL} \mathrm{H} \mathrm{H}_{2} \mathrm{O}, 1.0$ equiv.) was added C1-C2 (60 nmol, $25 \mathrm{uL}, 1.2$ equiv.),10x ligation buffer $(20 \mu \mathrm{L})$, T4 DNA ligase $(2.71 \mu \mathrm{L}, 14.74 \mu \mathrm{g} / \mu \mathrm{L})$ and nuclease-free water $71.64 \mathrm{uL}$ (total reaction volume: $94.35 \mu \mathrm{L}$ ). After thoroughly vortexing, the reaction mixture was incubated at $20^{\circ} \mathrm{C}$ overnight and monitored by UPLC. After reaction, the crude material was purified by standard ethanol precipitation and used in the next step without further purification.

Null-1b: $m / z=1071.7[\mathrm{M}-27 \mathrm{H}]^{27-}$

Sample-1b: $m / z=1034.4[\mathrm{M}-28 \mathrm{H}]^{28-}$

\section{Ligation to C3 (Null-1c and Sample-1c)}

To the solution of either Null-1b or Sample- $1 \mathrm{~b}\left(50.0 \mathrm{nmol}\right.$ in $50 \mathrm{uL} \mathrm{H} \mathrm{H}_{2} \mathrm{O}, 1$ equiv.) was added Code 3 (C3, $70 \mathrm{nmol}$ in $70 \mathrm{uL} \mathrm{H}_{2} \mathrm{O}, 1.4$ equiv.), $10 x$ ligation buffer $(40 \mu \mathrm{L})$, T4 DNA ligase (2.71 $\left.\mu \mathrm{L}, 14.74 \mu \mathrm{g} / \mu \mathrm{L}\right)$ and nuclease-free water $37.3 \mathrm{uL}$ (total reaction volume: $80 \mu \mathrm{L}$ ). After thoroughly vortexing, the reaction mixture was incubated at $20{ }^{\circ} \mathrm{C}$ overnight before performing gel analysis. After reaction, the crude material was purified by standard ethanol precipitation and used in the next step without further purification.

Null-1c: $m / z=1192.7[\mathrm{M}-31 \mathrm{H}]^{31-}$; ligation yield $=92 \%$

Sample-1c: $m / z=1194.1[\mathrm{M}-31 \mathrm{H}]^{31-}$; ligation yield $=91 \%$

\section{Ligation to Lib ID-P2 (Null-1 and Sample 1)}

To the solution of either Null-1c or Sample-1c (25.0 nmol in $20 \mathrm{uL} \mathrm{H} \mathrm{H}_{2} \mathrm{O}, 1.0$ equiv.) was added Lib ID-P2 (50 nmol, 2 equiv.), 10x ligation buffer $(20 \mu \mathrm{L})$, T4 DNA ligase $(1.7 \mu \mathrm{L}, 14.74 \mu \mathrm{g} / \mu \mathrm{L})$ and nuclease -free water $8.3 \mathrm{uL}$ (total reaction volume: $100 \mu \mathrm{L}$ ). After thoroughly vortexing, the reaction mixture was 
incubated at $20{ }^{\circ} \mathrm{C}$ overnight before performing gel analysis. After reaction, the crude material was purified by standard ethanol precipitation and used in the next step without further purification.

Null-1: ligation yield $=97.2 \%$

Sample-1: ligation yield $=96.5 \%$

\section{DNA gel electrophoresis}

Ligation reactions were inspected by gel electrophoresis on $3 \%$ agarose gel in $0.5 x$ TBE buffer ( $40 \mathrm{mM}$ Tris-Cl, $45 \mathrm{mM}$ boric acid, $1 \mathrm{mM}$ EDTA, pH 8.3) system referenced by a 20 bp DNA ladder (Takara, Japan). Before gel loading, the DNA samples were mixed with 0.20 volumes of the $6 x$ gel-loading buffer (Takara, Japan) containing $0.2 \%$ GelRed nucleic acid gel stain (Biotium, USA). Then, 30 pmol of treated DNA samples were loaded on gel and the gel was run at $135 \mathrm{~V}$ for 35-40 min. DNA fragments were visualized and analyzed by Bio-Rad ChemiDoc XRS+ Imaging system (Bio-Rad, CA, USA).

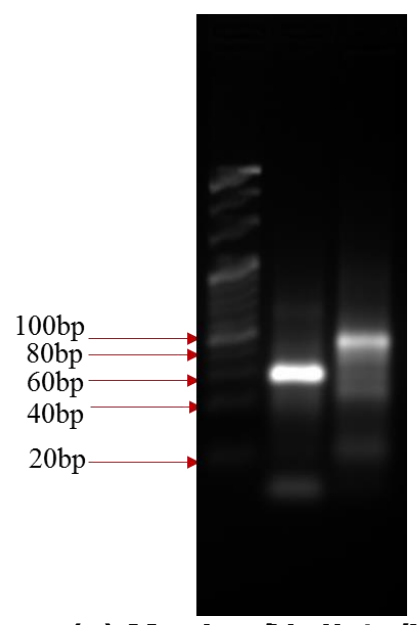

(a) Marker/Null-1c/Null-1

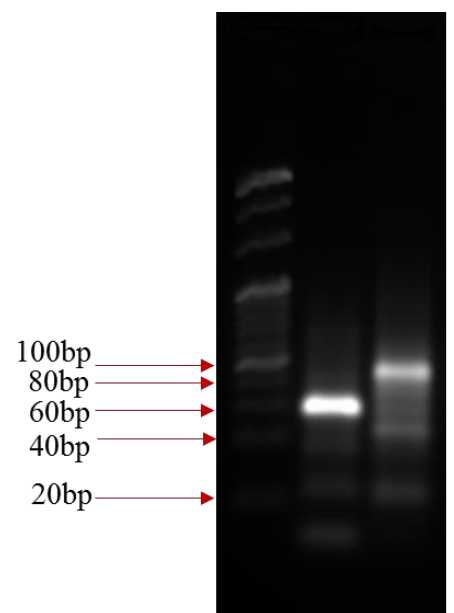

(b) Marker/Sample-1c/Sample-1

Figure S209. Gel image of Null-1c/1 and Sample-1c/1 (before and after ligation to Lib-ID-P2).

\section{Magnetic beads purification of Null-1 and Sample-1}

The final products were purified using Axygen MAGN-DNA-SS-250 kit (Corning, USA). Following the manufacturer's instructions, samples were pre-diluted to $2.1 \mu \mathrm{g} / \mu \mathrm{L}$ with Tris buffer $(10 \mathrm{mM} \mathrm{Tris,} \mathrm{pH}=$ 8.0) and purified by the beads ratio of $1.4 \mathrm{X}$ volume. The eluted products were concentrated by ultrafiltration using $30 \mathrm{KD}$ Amicon filter (Millipore, USA).

\section{Total DNA quantification via Qubit}

The purified final products Null-1 and Sample-1 were quantified using Qubit dsDNA HS Assay Kit (Q32854, Thermo Fisher, MA, USA) and the Qubit 3.0 fluorometer (Thermo Fisher, MA, USA). Following the manufacturer's instructions, samples are pre-diluted to a range of $0.2-20 \mathrm{ng} / \mu$ l concentration (estimated by DNA input amount) with Tris buffer $(10 \mathrm{mM}, \mathrm{pH} 8.0)$ for hte quantification. Concentrations provided by Qubit were used to calculate the molarity of the initial sample corrected by the dilution factor.

\section{DNA purity test}

The purity of the purified final products Null-1 and Sample-1 was analyzed using Agilent DNA 1000 Reagents Kit and Agilent Bioanalyzer 2100 (Agilent, CA, USA). Following the manufacturer's guidelines, $\sim 10 \mathrm{ng}$ DNA sample was loaded to each well of the chip for analysis. The target DNA fragment purity was represented by the area ratio of target DNA fragment to that of the total DNA.

\section{qPCR}

The beads purified final products Null-1 and Sample-1 were quantified by qPCR using a SYBR Green Master Mix kit (1804053, Life technologies, USA) and a StepOnePlus ${ }^{\text {TM }}$ Real-Time PCR System (Thermo Sci., USA). Following the manufacturer's guidelines, dilution series were made for all samples 
and run in parallel with an in-house made dsDNA standards (a series of pre-made dilutions of a 137bp dsDNA fragment). All samples and standards were run in duplicates and subjected to PCR cycles as follows: $95^{\circ} \mathrm{C}$ heat activation for $10 \mathrm{~min}$ followed by 30 cycles of $95^{\circ} \mathrm{C}$ denaturation for 10 seconds, $55^{\circ} \mathrm{C}$ annealing for 10 seconds and extension at $72^{\circ} \mathrm{C}$ for 10 seconds. The standard curve was used to calculate the PCR efficiency and subsequently the molarity of the libraries after correction.

Table S2. qPCR measurement and DNA damage evaluation.

\begin{tabular}{ccccc}
\hline Sample & $\begin{array}{c}\text { Agilent 2100 result (after beads } \\
\text { purification) }\end{array}$ & $\begin{array}{c}\text { Input DNA } \\
\text { (mM, Qubit) }\end{array}$ & $\begin{array}{c}\text { Input DNA } \\
(\mathrm{mM}, \mathrm{qPCR})\end{array}$ & $\begin{array}{c}\text { Amplifiable DNA } \\
\text { Ratio }\end{array}$ \\
\hline Null-1 & $64.4 \%$ & 0.1 & 0.06 & $60.2 \%$ \\
Sample-1 & $64.8 \%$ & 0.1 & 0.07 & $71.9 \%$
\end{tabular}

\section{UPLC-MS results}

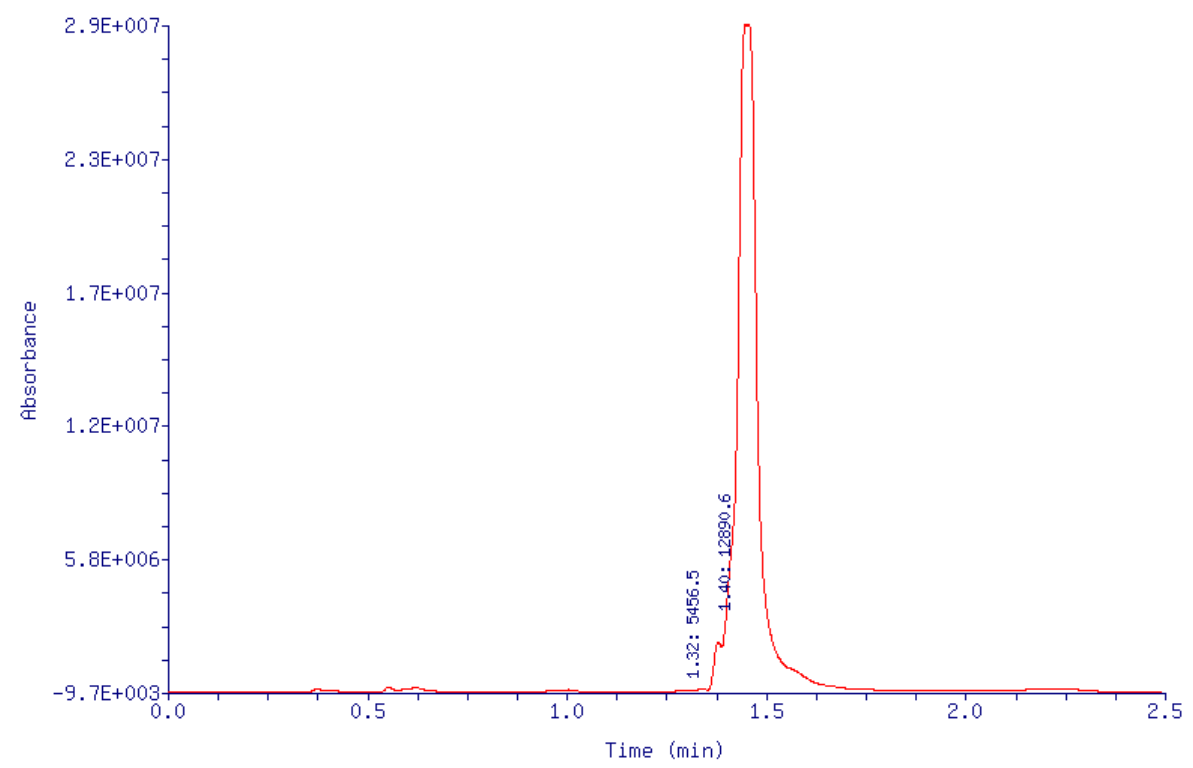

Figure S210. UPLC trace of Null-1a. 


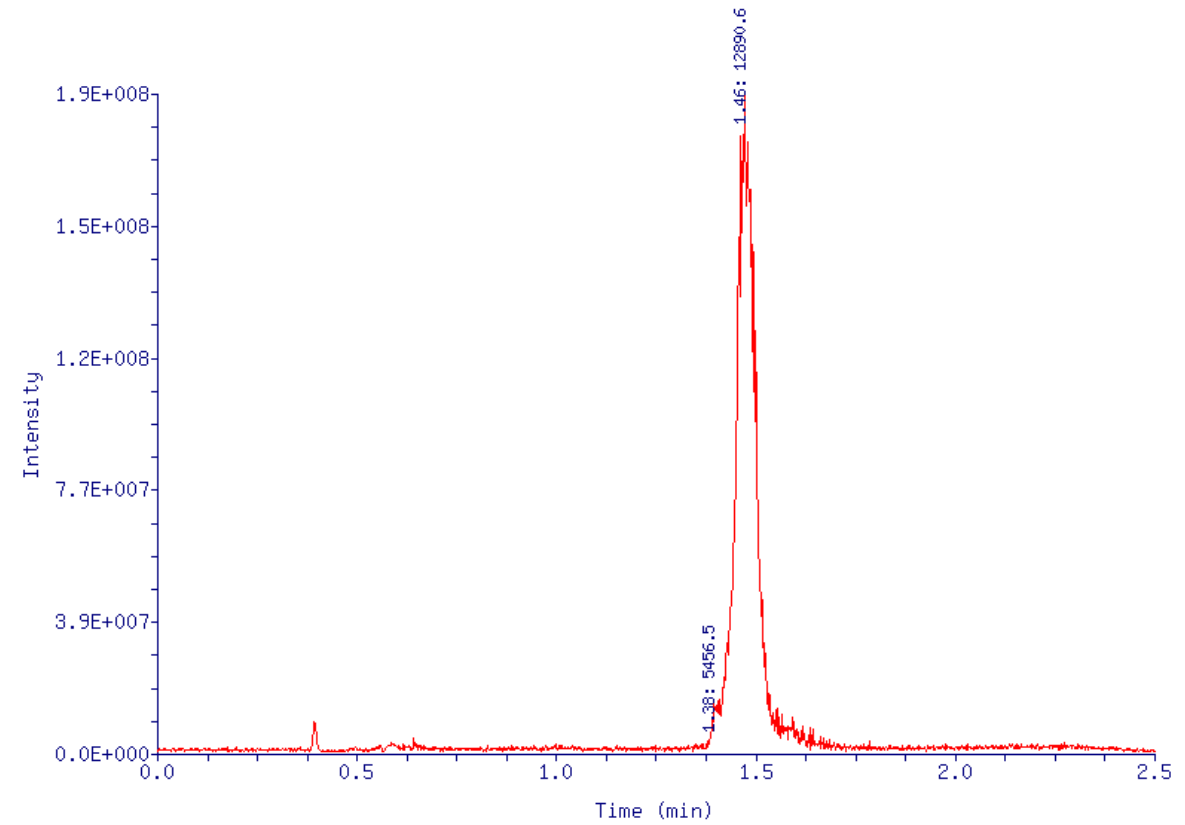

Figure S211. TIC trace of Null-1a.

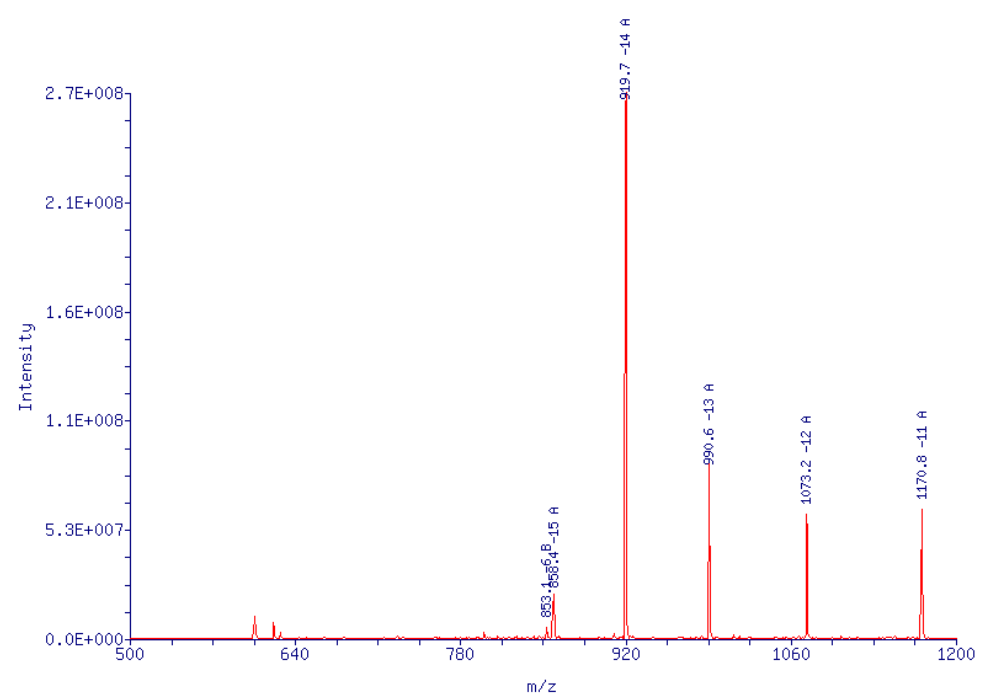

Figure S212. Mass spectrum Null-1a. 


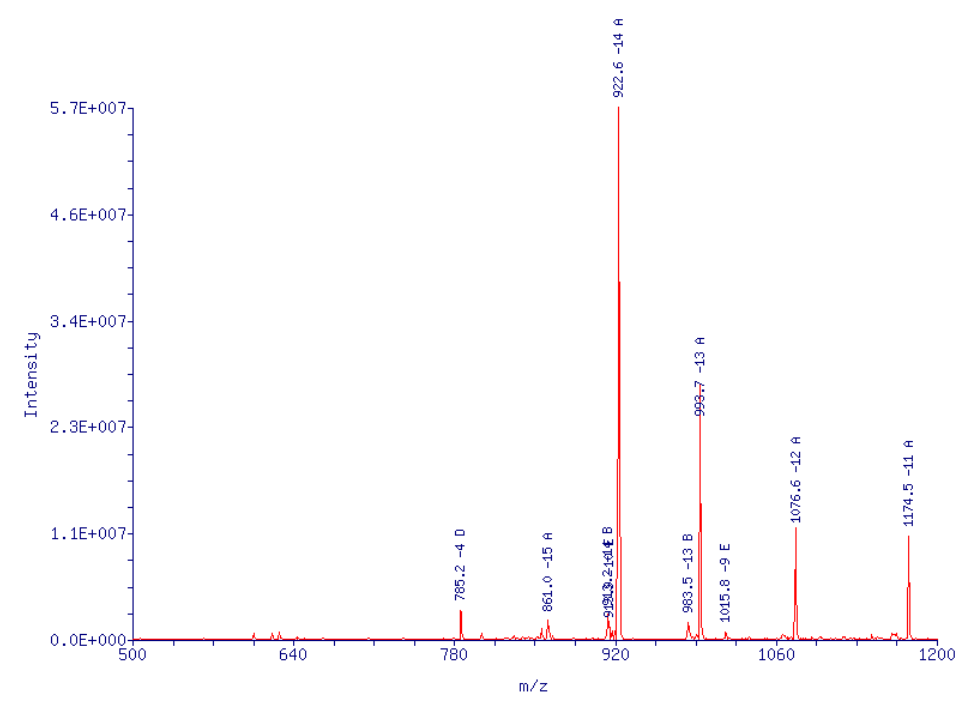

Figure S213. Mass spectrum Sample-1a.

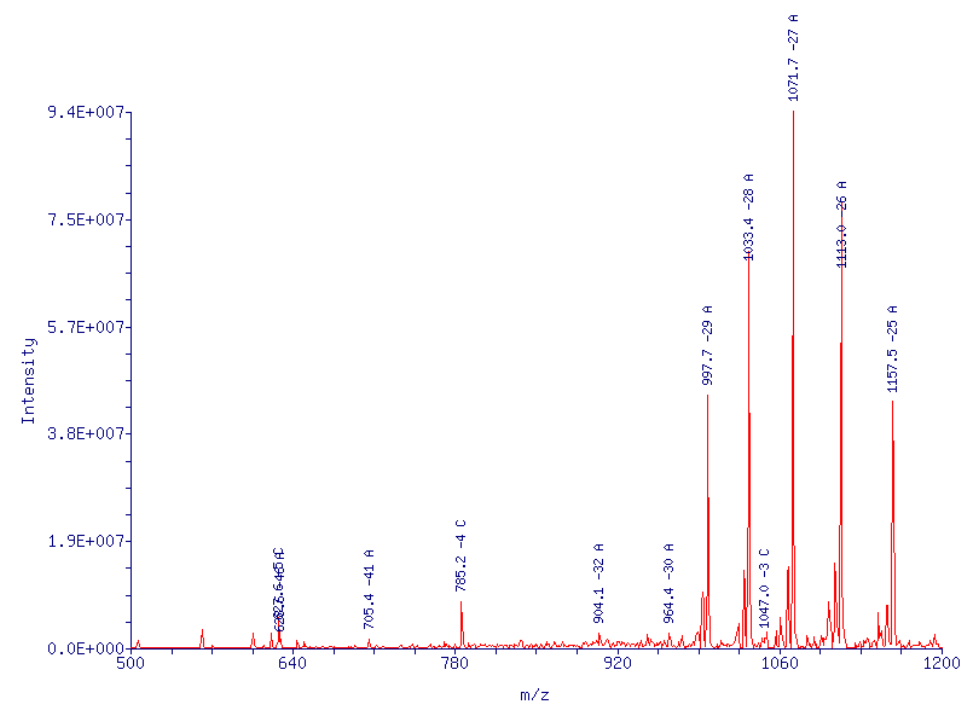

Figure S214. Mass spectrum Null-1b.

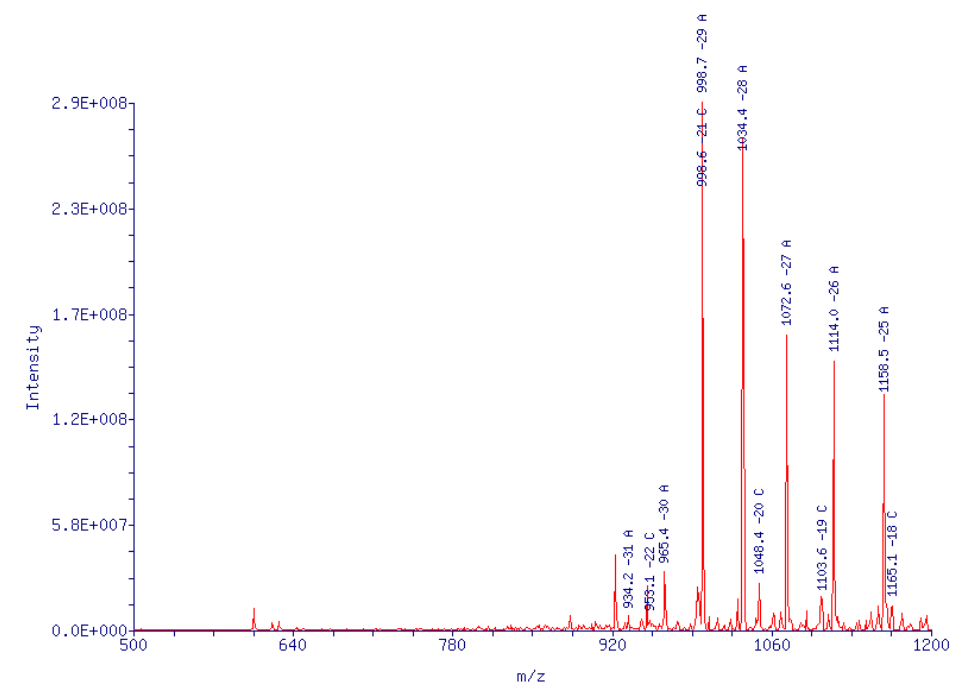

Figure S215. Mass spectrum Sample-1b. 


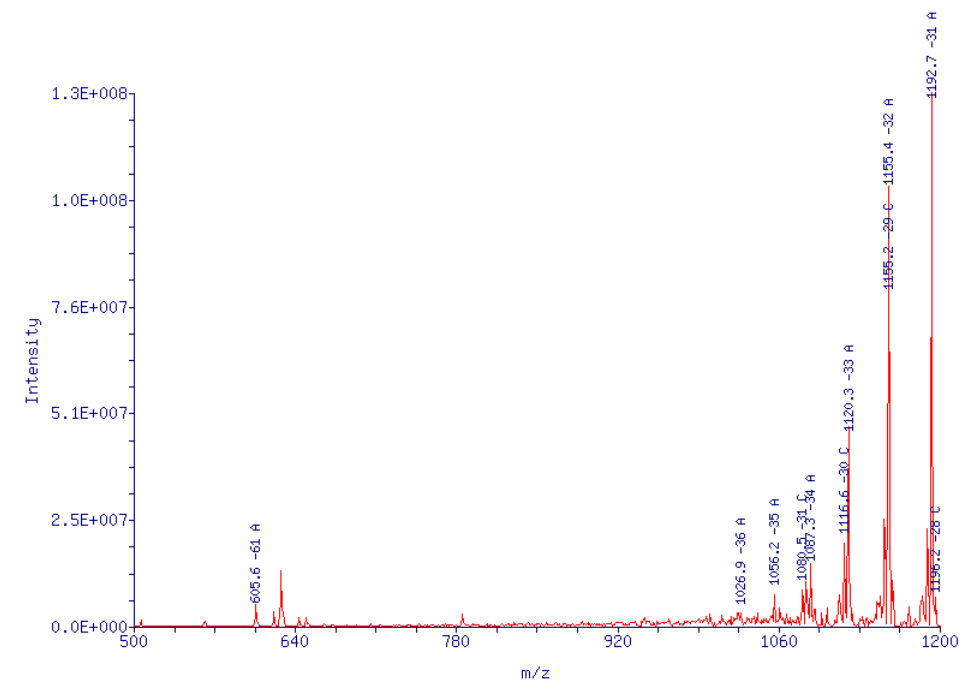

Figure S216. Mass spectrum Null-1c.

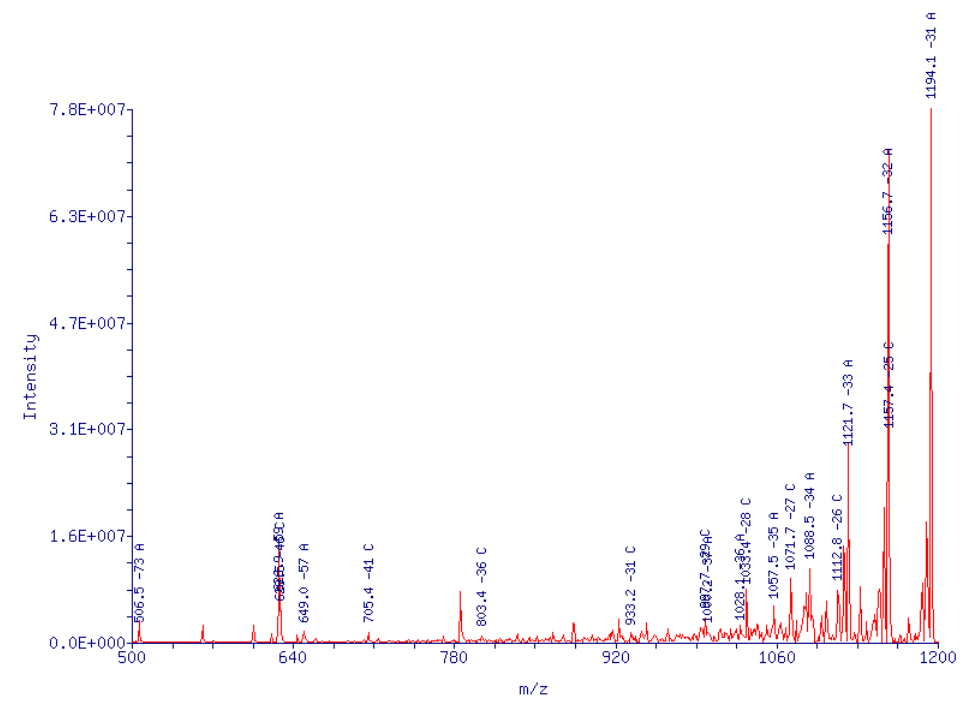

Figure S217. Mass spectrum Sample-1c. 


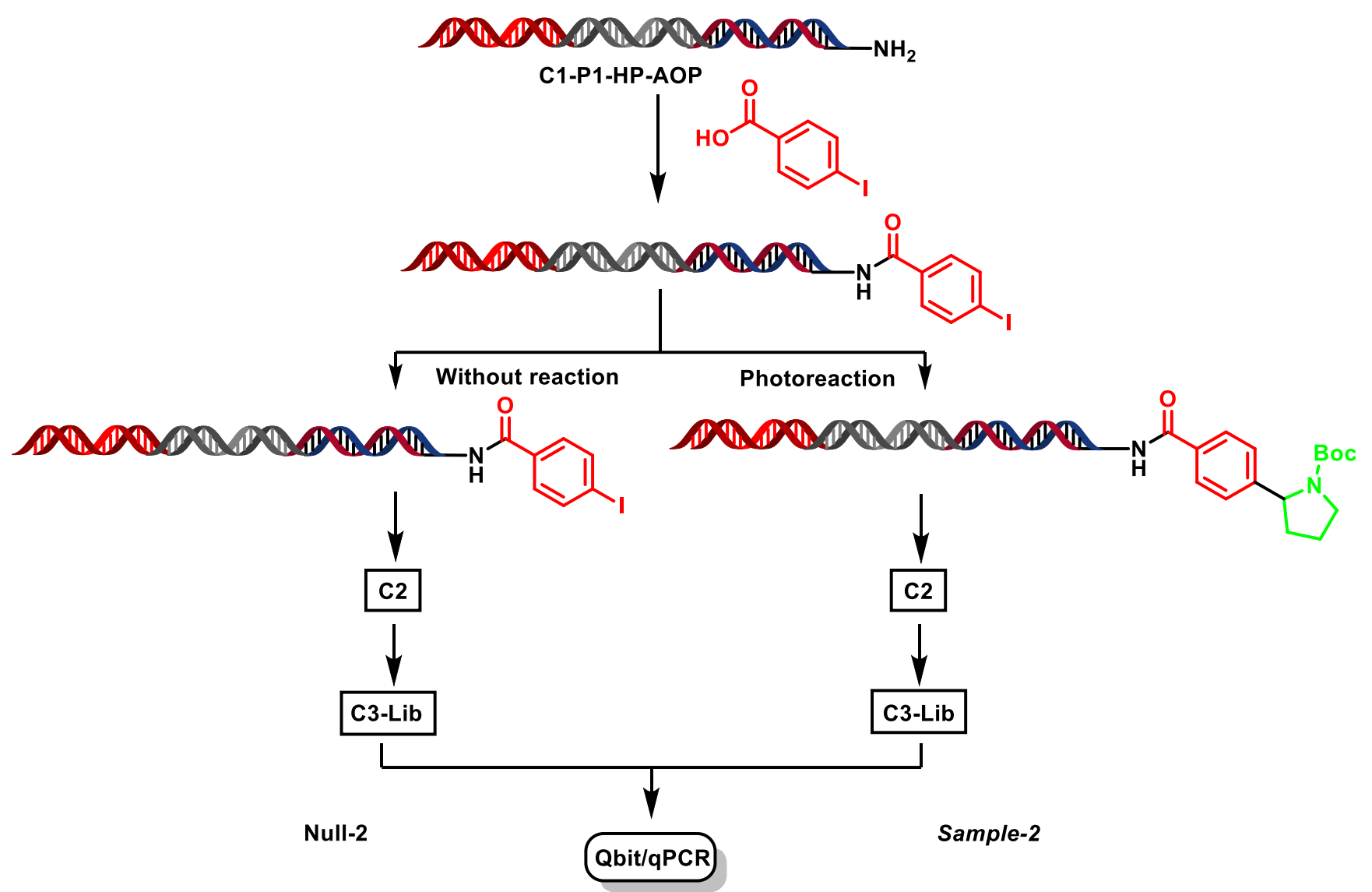

Figure S218. Synthetic outline for the preparation of Null-2 and Sample-2 from C1-P1-headpiece-AOP conjugate. The samples were prepared as described above.

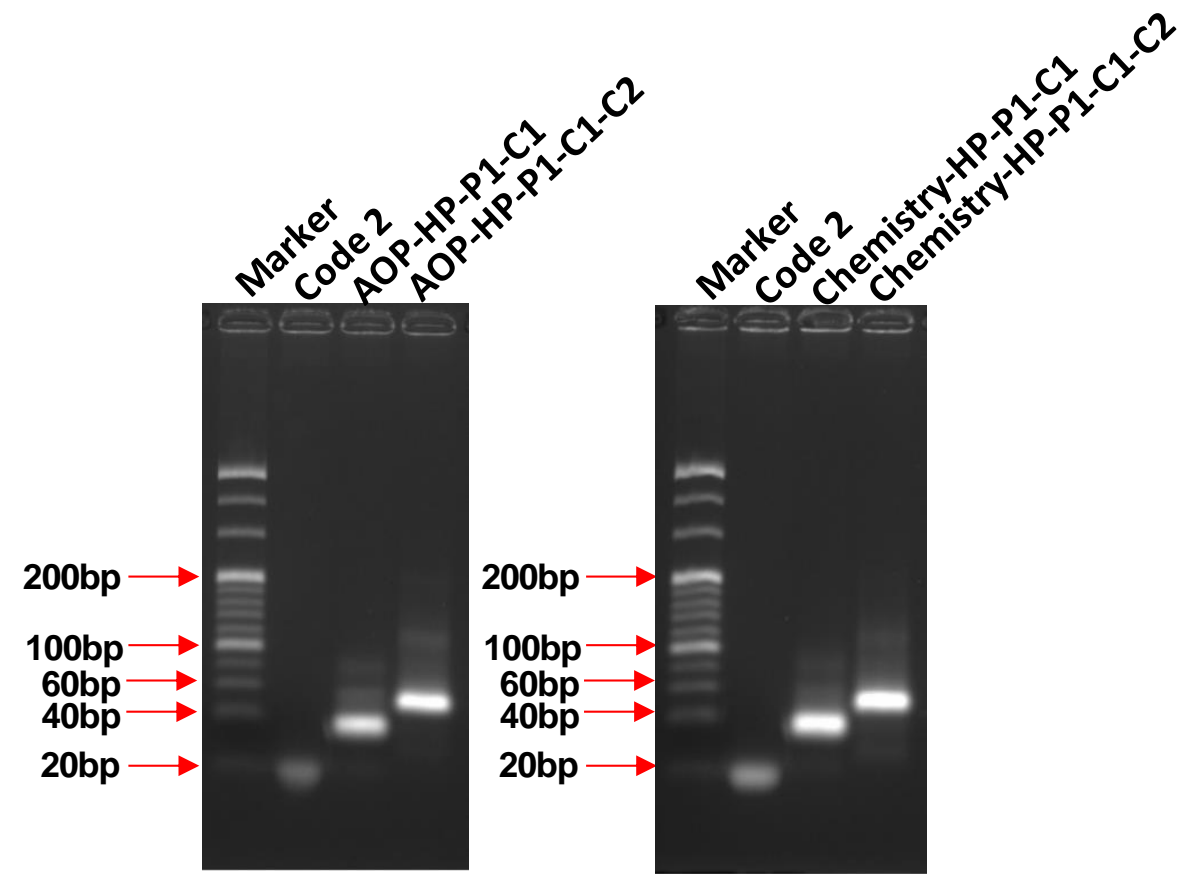

Figure S219. Gel image of Null-2 (left side) and Sample-2 (right side) before and after C2 ligation. 


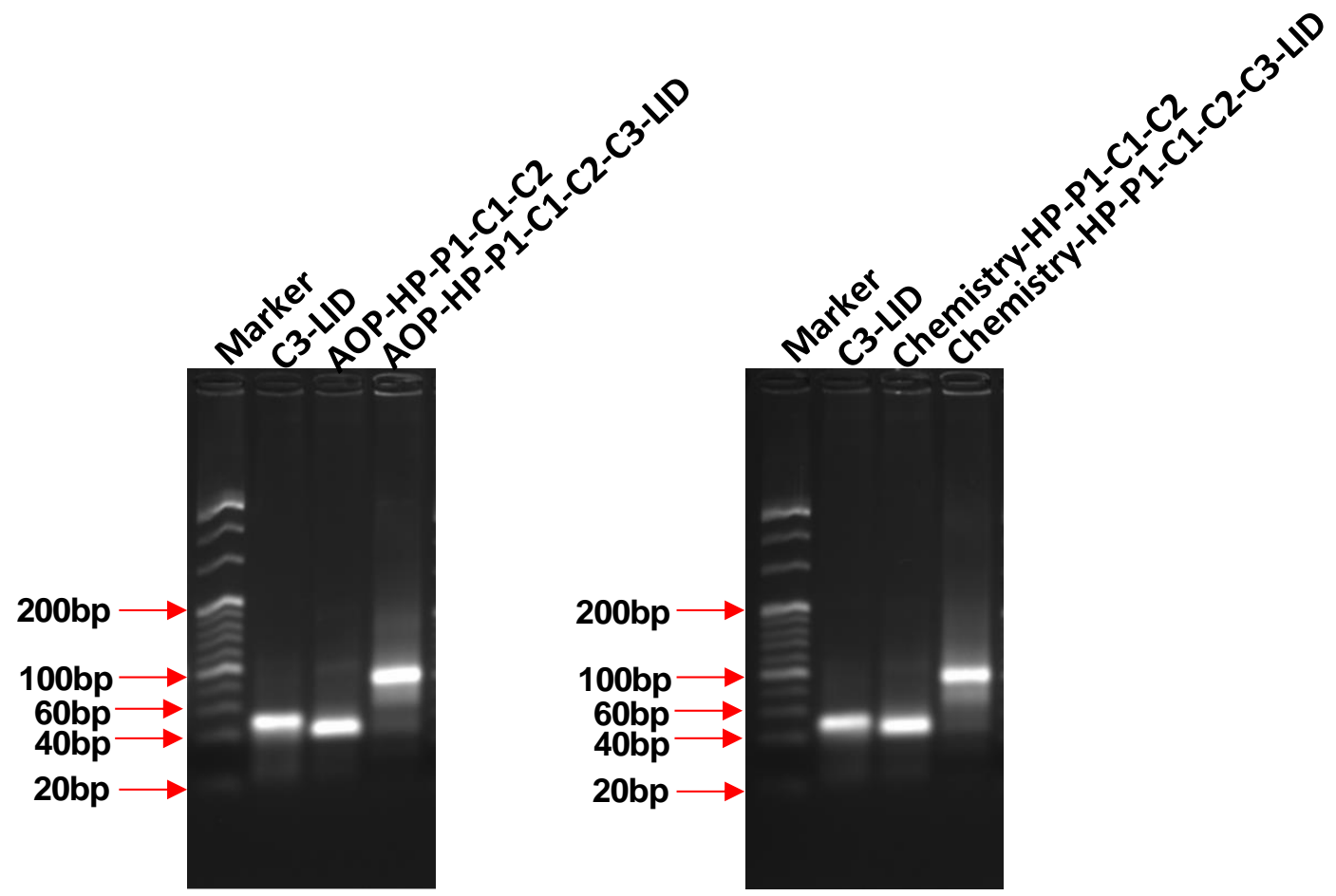

Figure S220. Gelimage of Null-2 (left side) and Sample-2 (right side) before and after C3-Lib-ID ligation.

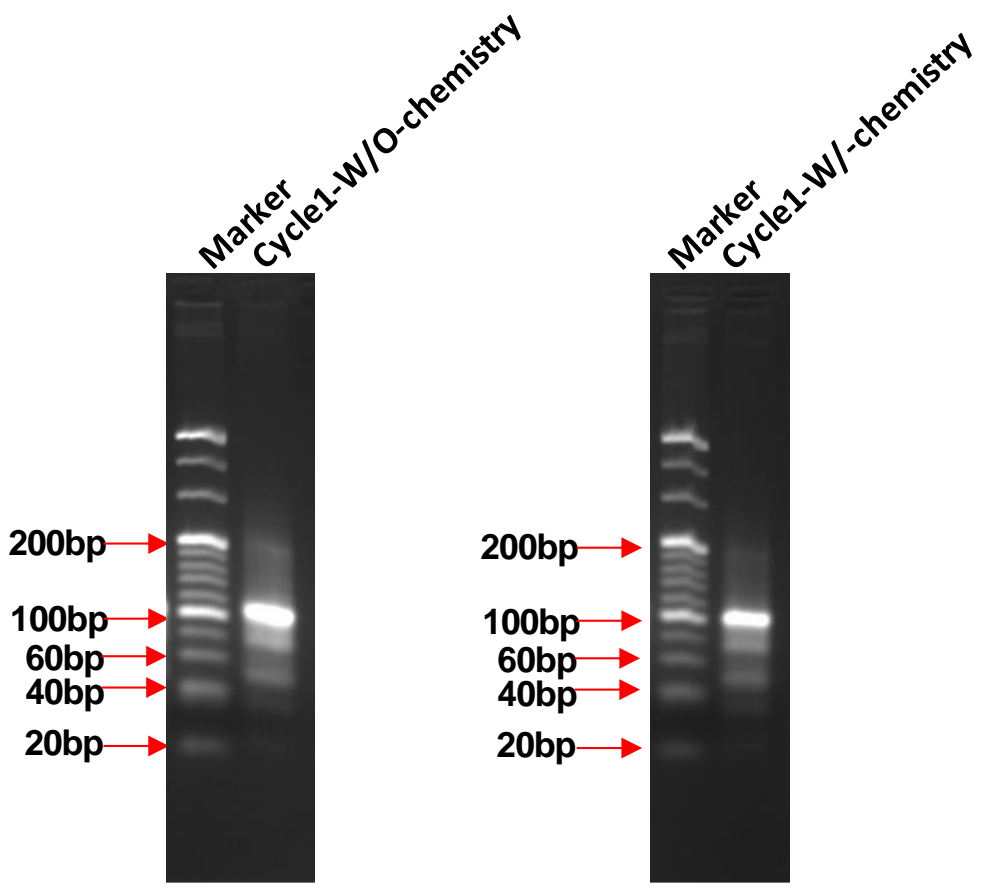

Figure S221. Gel image of Null-2 (left side) and Sample-2 (right side) after magnetic beads purification. 
Table S3. qPCR measurement and DNA damage evaluation.

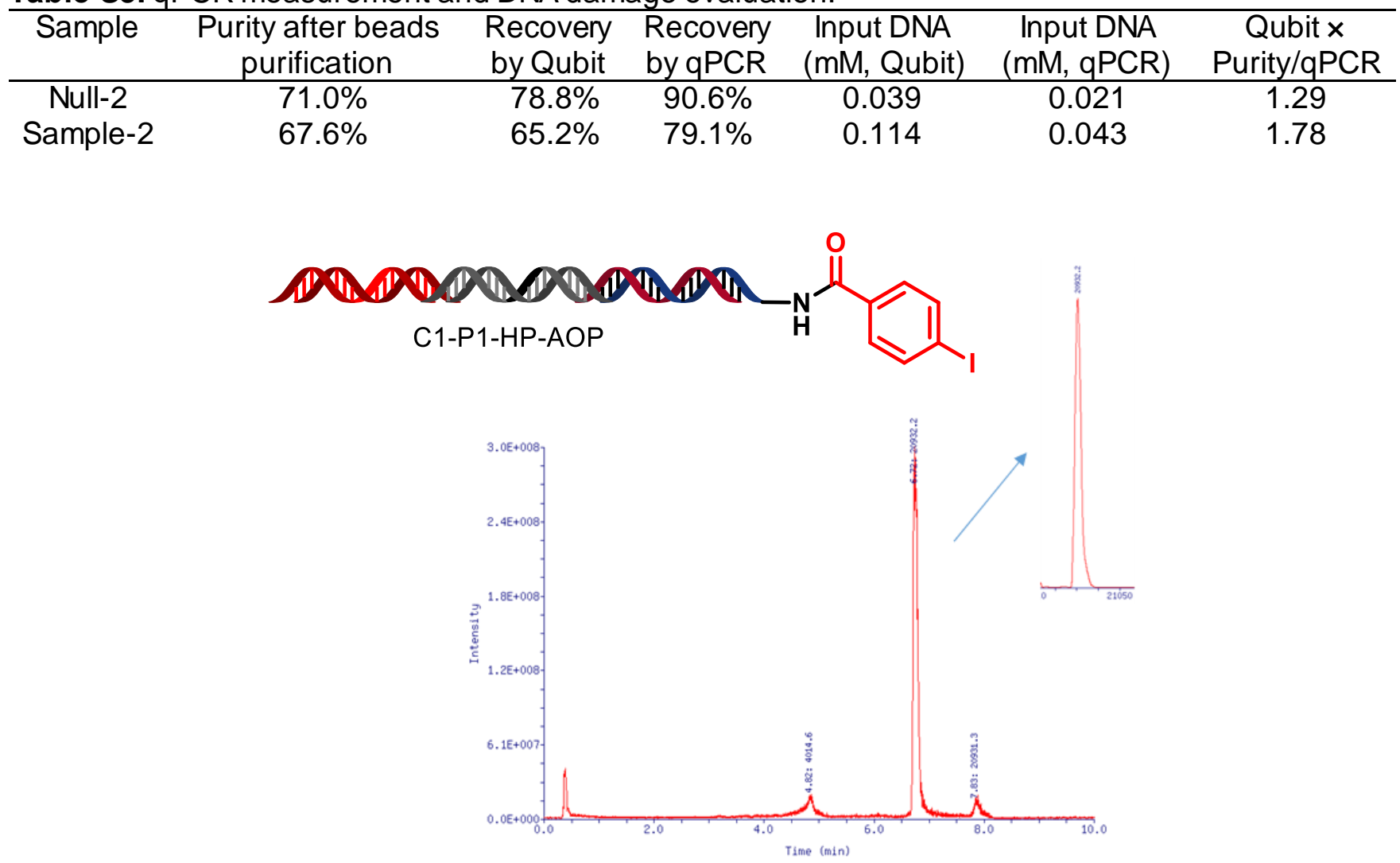

Figure S222. TIC trace and mass spectrum of C1-P1-headpiece-AOP aryl iodide before decarboxylative coupling; $m / z$ (starting material $)=20932$.

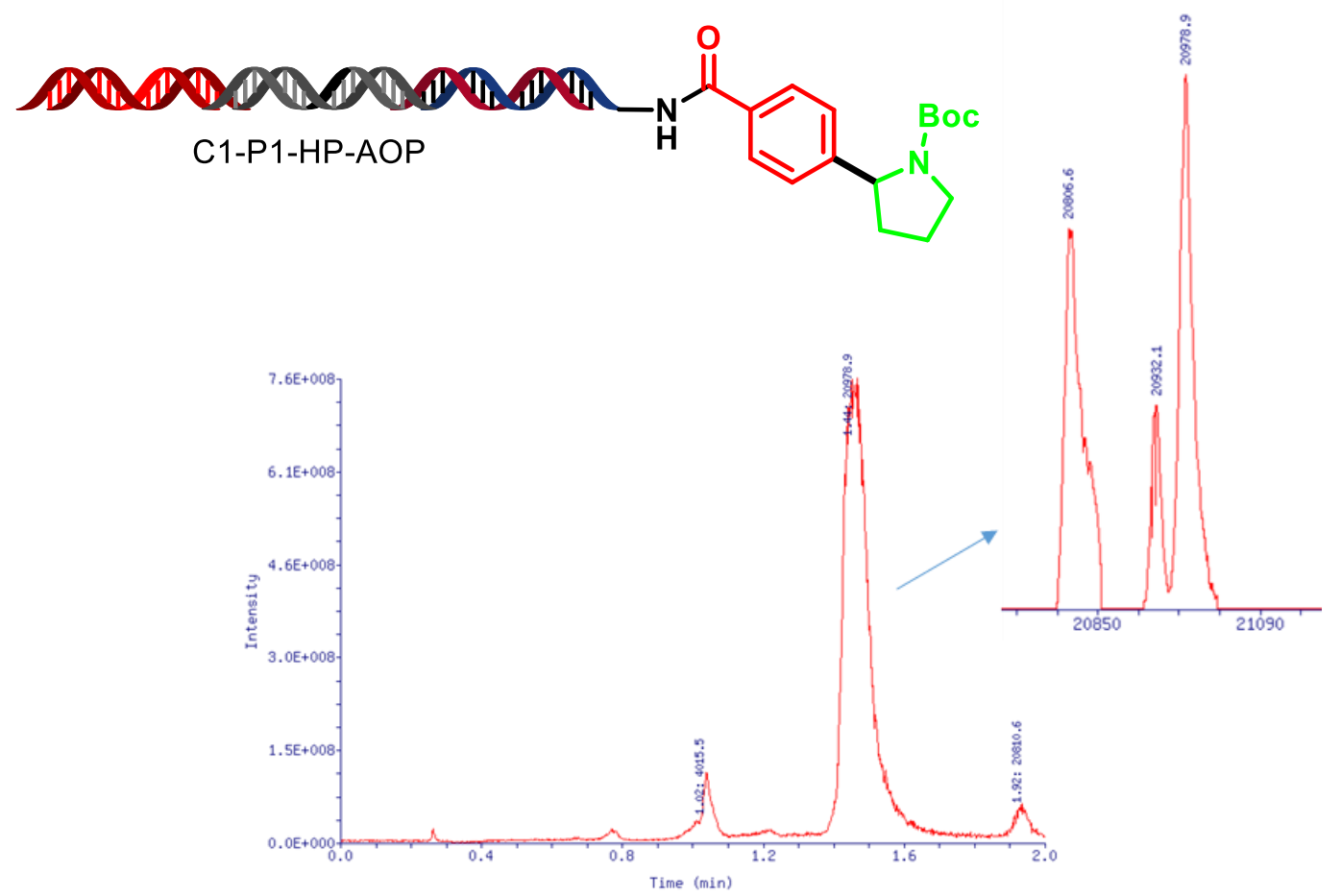

Figure S223. TIC trace and mass spectrum of C1-P1-headpiece-AOP aryl iodide after decarboxylative coupling; $m / z($ product $)=20979, m / z($ starting material $)=20932, m / z($ dehalogenated side product $)=$ 20807. 